\title{
Allene cyclization chemistry: Application to the syntheses of helical polycyclic aromatic hydrocarbons and the ABCD ring core of the camptothecin family of alkaloids
}

\author{
Weixiang Dai \\ West Virginia University
}

Follow this and additional works at: https://researchrepository.wvu.edu/etd

\section{Recommended Citation}

Dai, Weixiang, "Allene cyclization chemistry: Application to the syntheses of helical polycyclic aromatic hydrocarbons and the ABCD ring core of the camptothecin family of alkaloids" (2006). Graduate Theses, Dissertations, and Problem Reports. 4221.

https://researchrepository.wvu.edu/etd/4221

This Dissertation is protected by copyright and/or related rights. It has been brought to you by the The Research Repository @ WVU with permission from the rights-holder(s). You are free to use this Dissertation in any way that is permitted by the copyright and related rights legislation that applies to your use. For other uses you must obtain permission from the rights-holder(s) directly, unless additional rights are indicated by a Creative Commons license in the record and/ or on the work itself. This Dissertation has been accepted for inclusion in WVU Graduate Theses, Dissertations, and Problem Reports collection by an authorized administrator of The Research Repository @ WVU.

For more information, please contact researchrepository@mail.wvu.edu. 
Allene Cyclization Chemistry: Application to the Syntheses of Helical Polycyclic Aromatic Hydrocarbons and the ABCD Ring Core of the Camptothecin Family of Alkaloids

\title{
Weixiang Dai
}

\author{
Dissertation submitted to the \\ Eberly College of Arts and Sciences \\ at West Virginia University \\ in partial fulfillment of the requirements \\ for the degree of
}

Doctor of Philosophy
In
Organic Chemistry

Kung K. Wang, Ph.D., Chair

Peter M. Gannett, Ph.D.

George A. O'Doherty, Ph.D.

Jeffrey L. Petersen, Ph.D.

Björn C. Söderberg, Ph.D.

C. Eugene Bennett Department of Chemistry

Morgantown, West Virginia

2006

Keywords: Enyne-Allene, enallene-isonitrile, allene-nitrile, camptothecin

Copyright 2006 Weixiang Dai 


\section{ABSTRACT \\ Allene Cyclization Chemistry: Application to the Syntheses of Helical Polycyclic Aromatic Hydrocarbons and the ABCD Ring Core of the Camptothecin Family of Alkaloids}

\section{Weixiang Dai}

Thermolysis of the benzannulated enyne-allenes provides an efficient pathway to a variety of novel helical polycyclic aromatic hydrocarbons, which are represented by a remarkably beautiful diindenophenanthrene with four congested phenyl substituents. For example, its X-ray structure shows that the four phenyl substituents are essentially parallel to one another but are virtually perpendicular to the helical axis of the diindenophenanthrene ring system. Viewing from the direction perpendicular to the helical axis, the structure resembles that of a segment of a spiral staircase having four parallel steps.

The Wagner-Meerwein rearrangement was successfully applied to $11 H$-benzo[b]fluorene11-methanols and related fluorene derivatives leading to highly conjugated aromatic systems, which are prone to protonation for subsequent intramolecular electrophilic aromatic substitution reactions, leading to polycyclic aromatic hydrocarbons with novel architectures not easily attainable by other synthetic methods. Resolution of fluorenylmethanols derived from 15, 16-diaryl-diindeno[2,1- $b: 1$ ',2'- $h$ ]phenanthrenes was successfully achieved by using Mosher's reagent, providing a good opportunity to obtain the pure enantiomers of the corresponding helical polycyclic aromatic hydrocarbons.

Thermolysis of the benzannulated enyne-allenes bearing a heteroaromatic substituent at the allenic terminus produced a variety of indeno-fused heteroaromatic ring systems, which are of interest as potential candidates for pharmacological applications. The simplicity of this synthetic method encouraged us to explore the corresponding enallene-isonitrile cyclizations.

Thermolysis of the pyridodiynes provides an excellent synthetic pathway to the analogs of the $\mathrm{ABCD}$ ring core of the camptothecin family of alkloids. The facile thermal cyclization of the pyridodiynes compared with the corresponding benzodiynes encouraged us to explore the corresponding pyridoannulated nitrile-allene cyclizations.

Thermolysis of the pyridoannulated nitrile-allenes provides a very efficient synthetic pathway to the parent and substituted ABCD ring cores of the camptothecin family of alkaloids. This metal-free, base-catalyzed cyclization method may provide insight for new cyclization pathways and could be suitable for large scale synthesis and it represents the first successful allenic nitrile cyclization. 


\section{DEDICATED TO}

My wife, Chunrong Cheng, and my parents 


\section{ACKNOWLEDGEMENT}

I would like to express my sincere gratitude to my advisor, Dr. Kung K. Wang, for his support, patience, and encouragement throughout my graduate studies. His mentorship was essential to the completion of this dissertation.

My thanks also go to the research committee members, Dr. Peter M. Gannett, Dr. George A. O’Doherty, Dr. Jeffrey L. Petersen, and Dr. Björn C. Söderberg for their valuable comments that improved the contents of this dissertation.

My special thanks go to Dr. Jeffrey L. Petersen for his help with the X-ray structure analyses of many compounds, including a spiral staircase which was highlighted in the science magazine.

I would also like to thank the former and present group members, Dr. Hongbin Li, Dr. Xiaoling Lu, Dr. Yonghong Yang, Dr. Yanzhong Zhang, Dr. Hua Yang, Josh Bailey, Lily Wang, Daehwan Kim, Elbin Parbin, Bo Wen, and Ruoxin Zhang for their help and company and the entire faculty, staff, and graduate students for their friendship and help in a variety of ways.

Financial support from the C. Eugene Bennett Department of Chemistry at West Virginia University, the National Science Foundation, and the Petroleum Research Fund, administered by the American Chemical Society, are gratefully acknowledged.

Finally, and most importantly, I would like to thank my wife Chunrong for her understanding and love during the past few years. Her support and encouragement was in the end what made this dissertation possible. My parents receive my deepest gratitude and love for their dedication and the many years of support for my education. 
Title Page

\section{TABLE OF CONTENTS}

Abstract $\quad$ ii

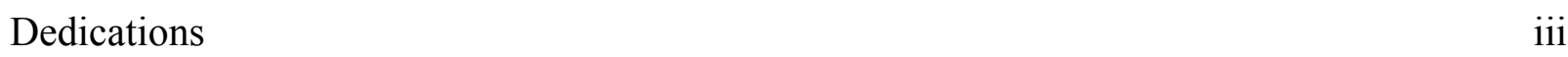

Acknowledgement $\quad$ iv

Table of Contents $\quad$ v

List of Figures $\quad$ viii

List of ${ }^{1} \mathrm{H}$ and ${ }^{13} \mathrm{C}$ NMR Spectra $\quad$ ix

\section{CHAPTER I}

\section{Prelude}

I-1. Introduction 1

I-2. Enyne-allene cyclizations 1

I-2.1. Earlier studies of Myers-Saito cyclizations 2

I-2.2. Earlier studies of Schmittel cyclizations 2

I-3. Application of enyne-allene Schmittel cyclization in the synthesis of helical polycyclic aromatic hydrocarbons 3

I-4. Application of enyne-heteroallene (enyne-carbodiimide) Schmittel cyclization in the synthesis of heterocycles structurally related to naturally occurring alkaloids $\quad 4$

I-5. The goal of this dissertation $\quad 5$

\section{CHAPTER II}

\section{Synthesis of helical polycyclic aromatic hydrocarbons}

II-1. Synthesis and structural characterization of a helical diindenophenanthrene compound that exhibits a structure resembling a molecular spiral staircase 
$\begin{array}{ll}\text { II-1.1. Introduction } & 7\end{array}$

II-1.2. Results and discussion 7

II-1.3. Conclusion 12

II-2 Synthesis and structural characterization of a helical 9-ring system that also exhibits a very interesting twist X-ray structure

II-2.1. Introduction 14

II-2.2. Results and discussion $\quad 15$

$\begin{array}{lr}\text { II-2.3. Conclusion } & 18\end{array}$

II-3 Synthesis and structural characterization of novel binaphthol derivatives

II-3.1. Introduction 19

II-3.2. Results and discussion 19

II-3.3. Conclusion 23

II-4 Ring expansion of polycyclic hydrocarbons by Wagner-Meerwein rearrangement

II-4.1. Introduction 24

$\begin{array}{ll}\text { II-4.2. Results and discussion } & 24\end{array}$

II-4.3. Conclusion 26

II-5 Resolution of polycyclic hydrocarbons

II-5.1. Introduction 28

II-5.2. Results and discussion 29

II-5.3. Conclusion 31

CHAPTER III

Synthesis of ABCD ring core of the camptothecin family of alkaloids

III-1. Retrosynthetic analysis

III-1.1.Introduction 
III-1.2. Representative strategies for construction of the ABCD ring core

III-1.3. Potential routes employing our allene cyclization chemistry 38

III-1.4. Challenges for enallene-isonitrile approach 39

$\begin{array}{ll}\text { III-1.5. Challenges for allene-nitrile approach } & 40\end{array}$

III-2. Preparation for enallene-isonitrile approach: Synthesis of indeno-fused derivatives of quinolizinium salts, imidazo[1,2-a]pyridine, pyrido[1,2-a]indole, and 4H-quinolizin-4-one via benzannulated enyne-allenes

$\begin{array}{ll}\text { III-2.1. Introduction } & 42\end{array}$

III-2.2. Results and Discussion $\quad 43$

III-2.3. Conclusions 49

III-3. Enallene-isonitrile approach

III-3.1. Introduction $\quad 51$

III-3.2. Results and Discussion $\quad 51$

III-3.3. Conclusions 53

III-4. Preparation for allene-nitrile approach

$\begin{array}{ll}\text { III-4.1. Introduction } & 55\end{array}$

$\begin{array}{ll}\text { III-4.2. Results and Discussion } & 56\end{array}$

$\begin{array}{ll}\text { III-4.3. Conclusions } & 58\end{array}$

III-5. Allene-nitrile approach

$\begin{array}{ll}\text { III-5.1. Introduction } & 60\end{array}$

$\begin{array}{ll}\text { III-5.2. Results and Discussion } & 60\end{array}$

$\begin{array}{ll}\text { III-5.3. Conclusions } & 64\end{array}$ 


\section{CHAPTER IV}

\section{Experimental Section}

Instrumentation, Materials and Manipulation $\quad 65$

$\begin{array}{ll}\text { References } & 114\end{array}$

$\begin{array}{ll}\text { Appendix } & 124\end{array}$

Highlight of the spiral staircase in science magazine 286

$\begin{array}{ll}\text { Publications \& Presentations } & 287\end{array}$

Approval of Examining Committee

\section{List of Figures}

Figure II-1. Molecular structure of II-8 10

Figure II-2. ORTEP drawing of the crystal structure of II-22 16

Figure II-3. ORTEP drawings of the crystal structures of diastereomer $1 \& 2$ of II-37 21

Figure II-4. ORTEP drawing of the crystal structure of diastereomer 1 of II-36 22

Figure II-5. ORTEP drawing of the crystal structure of II-49 30

Figure 6. ORTEP drawing of the crystal structure of II-8 124

Figure 7. ORTEP drawing of the crystal structure of II-16 124

Figure 8. ORTEP drawing of the crystal structure of II-20 125

Figure 9. ORTEP drawing of the crystal structure of II-28 125

Figure 10. ORTEP drawing of the crystal structure of II-44 126

Figure 11. ORTEP drawing of the crystal structure of II-46 127

Figure 12. ORTEP drawing of the crystal structure of III-67a 127

Figure 13. ORTEP drawing of the crystal structure of III-67b $\quad 128$ 
Figure 14. ORTEP drawing of the crystal structure of III-67c

Figure 15. ORTEP drawing of the crystal structure of III-73a

Figure 16. ORTEP drawing of the crystal structure of III-76

Figure 17. ORTEP drawing of the crystal structure of III-87

Figure 18. ORTEP drawing of the crystal structure of III-98

Figure 19. ORTEP drawing of the crystal structure of III-106

Figure 20. ORTEP drawing of the crystal structure of III-107

Figure 21. ORTEP drawing of the crystal structure of III-109

Figure 22. ORTEP drawing of the crystal structure of III-110

Figure 23. ORTEP drawing of the crystal structure of III-112

Figure 24. ORTEP drawing of the crystal structure of III-40

Figure 25. ORTEP drawing of the crystal structure of III-129

Figure 26. ORTEP drawing of the crystal structure of III-136

Figure 27. ORTEP drawing of the crystal structure of a substituted ABCD ring core

Figure 28. ORTEP drawing of the crystal structure of a substituted ABCD ring core

Figure 29. ORTEP drawing of the crystal structure of a polycyclic hydrocarbon

\section{List of ${ }^{1} \mathrm{H}$ and ${ }^{13} \mathrm{C}$ NMR Spectra}

\footnotetext{
${ }^{1} \mathrm{H}$ and ${ }^{13} \mathrm{C}$ NMR Spectra of Triflate II-3

${ }^{1} \mathrm{H}$ and ${ }^{13} \mathrm{C}$ NMR Spectra of Aldehyde II-4

${ }^{1} \mathrm{H}$ and ${ }^{13} \mathrm{C}$ NMR Spectra of Benzannulated Enediyne II-5
} 
${ }^{1} \mathrm{H}$ and ${ }^{13} \mathrm{C}$ NMR Spectra of Diastereomer 1 of Propargylic Diol II-6

${ }^{1} \mathrm{H}$ and ${ }^{13} \mathrm{C}$ NMR Spectra of Diastereomer 2 of Propargylic Diol II-6

${ }^{1} \mathrm{H}$ and ${ }^{13} \mathrm{C}$ NMR Spectra of Benzannulated Enediyne II-7

147-148

${ }^{1} \mathrm{H}$ and ${ }^{13} \mathrm{C}$ NMR Spectra of Spiral Staircase II-8

149-150

${ }^{1} \mathrm{H}$ and ${ }^{13} \mathrm{C}$ NMR Spectra of Propargylic Alcohol II-9

${ }^{1} \mathrm{H}$ and ${ }^{13} \mathrm{C}$ NMR Spectra of Benzannulated Enediyne II-10

153-154

${ }^{1} \mathrm{H}$ and ${ }^{13} \mathrm{C}$ NMR Spectra of Polycyclic Compound II-14

155-156

${ }^{1} \mathrm{H}$ NMR Spectrum of Polycyclic Compound II-15

${ }^{1} \mathrm{H}$ and ${ }^{13} \mathrm{C}$ NMR Spectra of Polycyclic Compound II-16

158-159

${ }^{1} \mathrm{H}$ and ${ }^{13} \mathrm{C}$ NMR Spectra of Aldehyde II-18

160-161

${ }^{1} \mathrm{H}$ and ${ }^{13} \mathrm{C}$ NMR Spectra of Benzannulated Enediyne II-19

162-163

${ }^{1}$ H NMR Spectrum of Diastereomer 1 of Propargylic Diol II-20

${ }^{1} \mathrm{H}$ and ${ }^{13} \mathrm{C}$ NMR Spectra of Diastereomer 2 Propargylic Diol II-20

165-166

${ }^{1} \mathrm{H}$ and ${ }^{13} \mathrm{C}$ NMR Spectra of Benzannulated Enediyne II-21

167-168

${ }^{1}$ H NMR Spectrum of Polycyclic Compound II-22

${ }^{1} \mathrm{H}$ and ${ }^{13} \mathrm{C}$ NMR Spectra of Propargylic Alcohol II-23

170-171

${ }^{1} \mathrm{H}$ and ${ }^{13} \mathrm{C}$ NMR Spectra of Benzannulated Enediyne II-24

172-173

${ }^{1} \mathrm{H}$ and ${ }^{13} \mathrm{C}$ NMR Spectra of Polycyclic Compound II-28

174-175

${ }^{1} \mathrm{H}$ and ${ }^{13} \mathrm{C}$ NMR Spectra of Substituted Phenanthrene II-29

176-177

${ }^{1} \mathrm{H}$ and ${ }^{13} \mathrm{C}$ NMR Spectra of Substituted Phenanthrene II-30

178-179

${ }^{1} \mathrm{H}$ and ${ }^{13} \mathrm{C}$ NMR Spectra of Benzannulated Enediyne II-35

180-181

${ }^{1} \mathrm{H}$ and ${ }^{13} \mathrm{C}$ NMR Spectra of Diastereomer 1 of Polycyclic Compound II-36

182-183 
${ }^{1} \mathrm{H}$ and ${ }^{13} \mathrm{C}$ NMR Spectra of Mixture of Diastereomer 2 and Diastereomer 3 of Polycyclic Compound II-36 184-185

${ }^{1}$ H NMR Spectrum of Diastereomer 1 of Polycyclic Compound II-37 186

${ }^{1} \mathrm{H}$ NMR Spectrum of Diastereomer 2 of Polycyclic Compound II-37 187

${ }^{1} \mathrm{H}$ and ${ }^{13} \mathrm{C}$ NMR Spectra of Fluorenylmethanol II-42 188-189

${ }^{1} \mathrm{H}$ and ${ }^{13} \mathrm{C}$ NMR Spectra of Anthracene II-43

190-192

${ }^{1} \mathrm{H}$ and ${ }^{13} \mathrm{C}$ NMR Spectra of Fluorenylmethanol II-44

193-194

${ }^{1} \mathrm{H}$ and ${ }^{13} \mathrm{C}$ NMR Spectra of Hydrocarbon II-46

195-196

${ }^{1} \mathrm{H}$ and ${ }^{13} \mathrm{C}$ NMR Spectra of Diol II-48a or II-48b

197-198

${ }^{1} \mathrm{H}$ and ${ }^{13} \mathrm{C}$ NMR Spectra of Diol II-48c

199-200

${ }^{1} \mathrm{H}$ and ${ }^{13} \mathrm{C}$ NMR Spectra of Mosher's Diester II-50a or II-50b

201-202

${ }^{1} \mathrm{H}$ and ${ }^{13} \mathrm{C}$ NMR Spectra of Mosher's Diester II-50c

203-204

${ }^{1} \mathrm{H}$ and ${ }^{13} \mathrm{C}$ NMR Spectra of Propargylic Alcohol III-60

205-206

${ }^{1} \mathrm{H}$ and ${ }^{13} \mathrm{C}$ NMR Spectra of Propargyl Methanesulfonate III-61

207-208

${ }^{1} \mathrm{H}$ and ${ }^{13} \mathrm{C}$ NMR Spectra of Pyridinium Methanesulfonate III-63a

209-210

${ }^{1} \mathrm{H}$ and ${ }^{13} \mathrm{C}$ NMR Spectra of Pyridinium Methanesulfonate III-63b

211-212

${ }^{1} \mathrm{H}$ and ${ }^{13} \mathrm{C}$ NMR Spectra of Pyridinium Methanesulfonate III-63c

213-214

${ }^{1} \mathrm{H}$ and ${ }^{13} \mathrm{C}$ NMR Spectra of Quinolizinium Salt III-67a

215-216

${ }^{1} \mathrm{H}$ and ${ }^{13} \mathrm{C}$ NMR Spectra of Quinolizinium Salt III-67b

217-218

${ }^{1} \mathrm{H}$ and ${ }^{13} \mathrm{C}$ NMR Spectra of Quinolizinium Salt III-67c

219-220

${ }^{1} \mathrm{H}$ and ${ }^{13} \mathrm{C}$ NMR Spectra of Propargylic Alcohol III-69a

221-222

${ }^{1} \mathrm{H}$ and ${ }^{13} \mathrm{C}$ NMR Spectra of Propargyl Methanesulfonate III-70a

223-224 
${ }^{1} \mathrm{H}$ and ${ }^{13} \mathrm{C}$ NMR Spectra of Propargyl Methanesulfonate III-70b

${ }^{1} \mathrm{H}$ and ${ }^{13} \mathrm{C}$ NMR Spectra of Pyridinium Methanesulfonate III-71a

$227-228$

${ }^{1} \mathrm{H}$ and ${ }^{13} \mathrm{C}$ NMR Spectra of Pyridinium Methanesulfonate III-71b

$229-230$

${ }^{1} \mathrm{H}$ and ${ }^{13} \mathrm{C}$ NMR Spectra of Quinolizinium Salt III-73a

$231-232$

${ }^{1} \mathrm{H}$ and ${ }^{13} \mathrm{C}$ NMR Spectra of Quinolizinium Salt III-73b

$233-234$

${ }^{1} \mathrm{H}$ and ${ }^{13} \mathrm{C}$ NMR Spectra of Imidazopyridine III-76

$235-236$

${ }^{1} \mathrm{H}$ and ${ }^{13} \mathrm{C}$ NMR Spectra of Imidazopyridine III-83

$237-238$

${ }^{1} \mathrm{H}$ and ${ }^{13} \mathrm{C}$ NMR Spectra of Pyridoindole III-84

$239-240$

${ }^{1} \mathrm{H}$ and ${ }^{13} \mathrm{C}$ NMR Spectra of Pyridinone III-86

$241-242$

${ }^{1} \mathrm{H}$ and ${ }^{13} \mathrm{C}$ NMR Spectra of Quinolizinone III-87

$243-244$

${ }^{1} \mathrm{H}$ and ${ }^{13} \mathrm{C}$ NMR Spectra of Formanilide III-42

$245-246$

${ }^{1}$ H NMR Spectrum of Compound III-98

${ }^{1} \mathrm{H}$ and ${ }^{13} \mathrm{C}$ NMR Spectra of Pyridine III-102

$248-249$

${ }^{1} \mathrm{H}$ and ${ }^{13} \mathrm{C}$ NMR Spectra of Pyridodiyne III-104

$250-251$

${ }^{1} \mathrm{H}$ and ${ }^{13} \mathrm{C}$ NMR Spectra of Pyridodiyne III-105

$252-253$

${ }^{1} \mathrm{H}$ and ${ }^{13} \mathrm{C}$ NMR Spectra of Polycyclic Heterocycle III-106

254-255

${ }^{1} \mathrm{H}$ and ${ }^{13} \mathrm{C}$ NMR Spectra of Polycyclic Heterocycle III-107

256-257

${ }^{1} \mathrm{H}$ and ${ }^{13} \mathrm{C}$ NMR Spectra of Pyridone III-44

258-259

${ }^{1} \mathrm{H}$ and ${ }^{13} \mathrm{C}$ NMR Spectra of ABCD Ring Core of Camptothecin III-40

260-261

${ }^{1} \mathrm{H}$ and ${ }^{13} \mathrm{C}$ NMR Spectra of Pyridone III-129

262-263

${ }^{1} \mathrm{H}$ and ${ }^{13} \mathrm{C}$ NMR Spectra of Pyridone III-130

264-265

${ }^{1} \mathrm{H}$ and ${ }^{13} \mathrm{C}$ NMR Spectra of Pyridone III-131

266-267 
${ }^{1} \mathrm{H}$ and ${ }^{13} \mathrm{C}$ NMR Spectra of Pyridone III-132

${ }^{1} \mathrm{H}$ and ${ }^{13} \mathrm{C}$ NMR Spectra of ABCD Ring Core of Camptothecin III-133

270-271

${ }^{1} \mathrm{H}$ and ${ }^{13} \mathrm{C}$ NMR Spectra of ABCD Ring Core of Camptothecin III-134

272-273

${ }^{1} \mathrm{H}$ and ${ }^{13} \mathrm{C}$ NMR Spectra of ABCD Ring Core of Camptothecin III-135

274-275

${ }^{1} \mathrm{H}$ and ${ }^{13} \mathrm{C}$ NMR Spectra of ABCD Ring Core of Camptothecin III-136

276-277

${ }^{1} \mathrm{H}$ and ${ }^{13} \mathrm{C}$ NMR Spectra of ABCD Ring Core of Camptothecin III-137

278-279

${ }^{1} \mathrm{H}$ and ${ }^{13} \mathrm{C}$ NMR Spectra of Propargyl Bromide III-143

280-281

${ }^{1} \mathrm{H}$ and ${ }^{13} \mathrm{C}$ NMR Spectra of Propargylic Alcohol III-144

282-283

${ }^{1} \mathrm{H}$ and ${ }^{13} \mathrm{C}$ NMR Spectra of Propargyl Bromide III-143

284-285 


\section{CHAPTER 1}

\section{Prelude}

\section{I-1. Introduction}

Allenes, two carbon-carbon double bonds connected directly, were once thought as reactive intermediates and not good materials for organic synthesis. The development of allene chemistry benefited greatly from the development of IR and Raman spectroscopy. ${ }^{1}$ Recently, allenes have been widely used in various types of reactions including stereoselective reactions taking advantage of their substituents and axial chirality. ${ }^{2}$ With the continued interest in allene chemistry, it is believed that many more new allene reactions will be discovered.

\section{I-2. Enyne-allene cyclizations}

In this dissertation, only a small branch of the allene chemistry, the enyne-allene type cyclizations, will be discussed. Enyne-allenes can undergo either Myers-Saito cyclizations ${ }^{3}\left(C^{2}-C^{7}\right)$ or Schmittel cyclizations ${ }^{4}\left(C^{2}-C^{6}\right)$. In a simple system such as I-1, the cyclization pathway depends on the alkynyl terminus substituent R (Scheme $\mathrm{I}-1)$. When $\mathrm{R}$ is a proton group or a $1^{\circ}$ alkyl group, such as the methyl group or the ethyl group, the enyne-allene favors the Myers-Saito cyclization pathway to produce the a,3-didehydrotoluene/naphthalene biradical $\mathbf{I - 2}$; when $\mathrm{R}$ is an aryl group or a sterically demanding group, such as the tert-butyl group or the trimethylsilyl group, the enyne-allene favors the Schmittel cyclization pathway to produce the fulvene/benzofulvene biradical I-3. 
Scheme I-1.

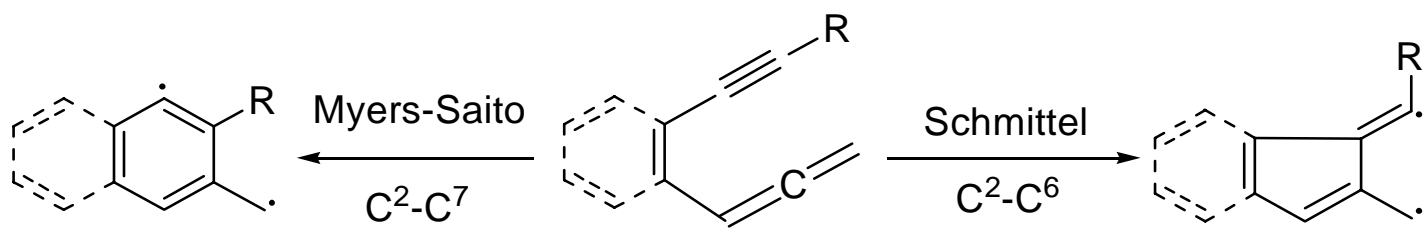

I-2

I-1

I-3

\section{I-2.1. Earlier studies of Myers-Saito cyclizations}

Our group reported Myers-Saito cyclizations of (Z)-1,2,4-heptatrien-6-ynes I-4 (Scheme I-2). ${ }^{5}$ When compared to the parent (Z)-1,2,4-heptatrien-6-yne, the rate of cycloaromatization of I-4a is increased because of the formation of a more stable tertiary benzylic radical center in $\mathbf{I - 5 a}$; but the rate of cycloaromatization of $\mathbf{I}-\mathbf{4} \mathbf{b}$ is not significantly affected because the formation of a more stable tertiary benzylic radical center in $\mathbf{I - 5} \mathbf{b}$ partially compensates for the increased steric interactions.

\section{Scheme I-2.}

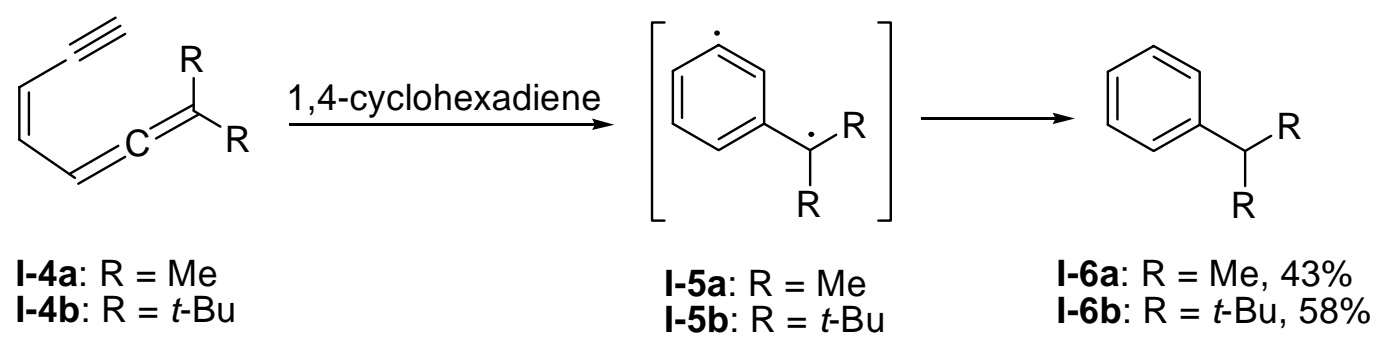

\section{I-2.2. Earlier studies of Schmittel cyclizations}

Our group reported the Schmittel cyclizations of I-7 with a benzene tether connecting the alkyne and the allene moiety to produce the benzofulvene biradicals I-8 (Scheme I-3). ${ }^{6}$ The aryl groups at the allenic terminus of the enyne-allene system could further 
participate in an intramolecular radical-radical coupling to form the formal Diels-Alder adducts I-9, after tautomerization, the tetracyclic hydrocarbons I-10.

\section{Scheme I-3.}

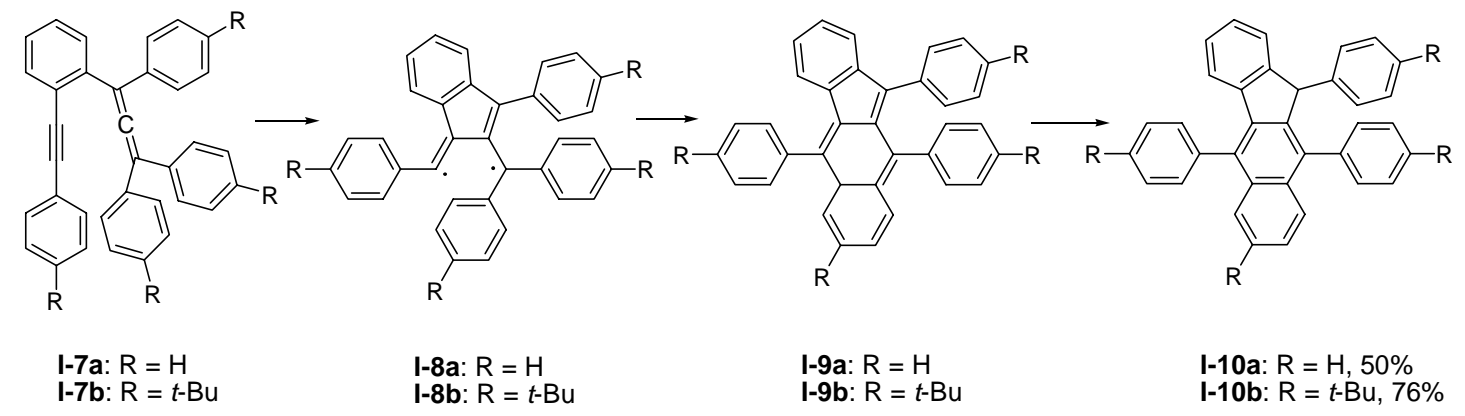

\section{I-3. Application of enyne-allene Schmittel cyclization in the synthesis of helical polycyclic aromatic hydrocarbons}

Our group reported a novel synthetic pathway to the 4,5-diaryldiindenophenanthrenes I-19 having a helical twist in their structures (Scheme I-4). ${ }^{7}$ The synthetic sequence involves condensation of the $p$-dipivaloylbenzene with 2 equiv of the lithium acetylide derived from the diacetylenes $\mathbf{I - 1 1}$ followed by protonation to produce the propargylic alcohols I-12. Reduction of I-12 with triethylsilane in the presence of trifluoroacetic acid furnished the tetraacetylenic hydrocarbons $\mathbf{I - 1 3}$ in nearly quantitative yields. Treatment of $\mathbf{I}-\mathbf{1 3}$ with potassium tert-butoxide under refluxing toluene at $110{ }^{\circ} \mathrm{C}$ for up to $10 \mathrm{~h}$ then furnished the 4,5-diaryldiindenophenanthrenes I-19. Apparently, the transformation from I-13 to I-19 involves initial prototropic isomerizations to form the benzannulated enyne-allenes I-14. Two subsequent formal intramolecular Diels-Alder reactions via the biradicals I-15 and I-17 derived from the 
$\mathrm{C}^{2}-\mathrm{C}^{6}$ cyclizations then led to $\mathbf{I}-\mathbf{1 8}$, which in turn underwent tautomerizations to give I-19.

\section{Scheme I-4.}
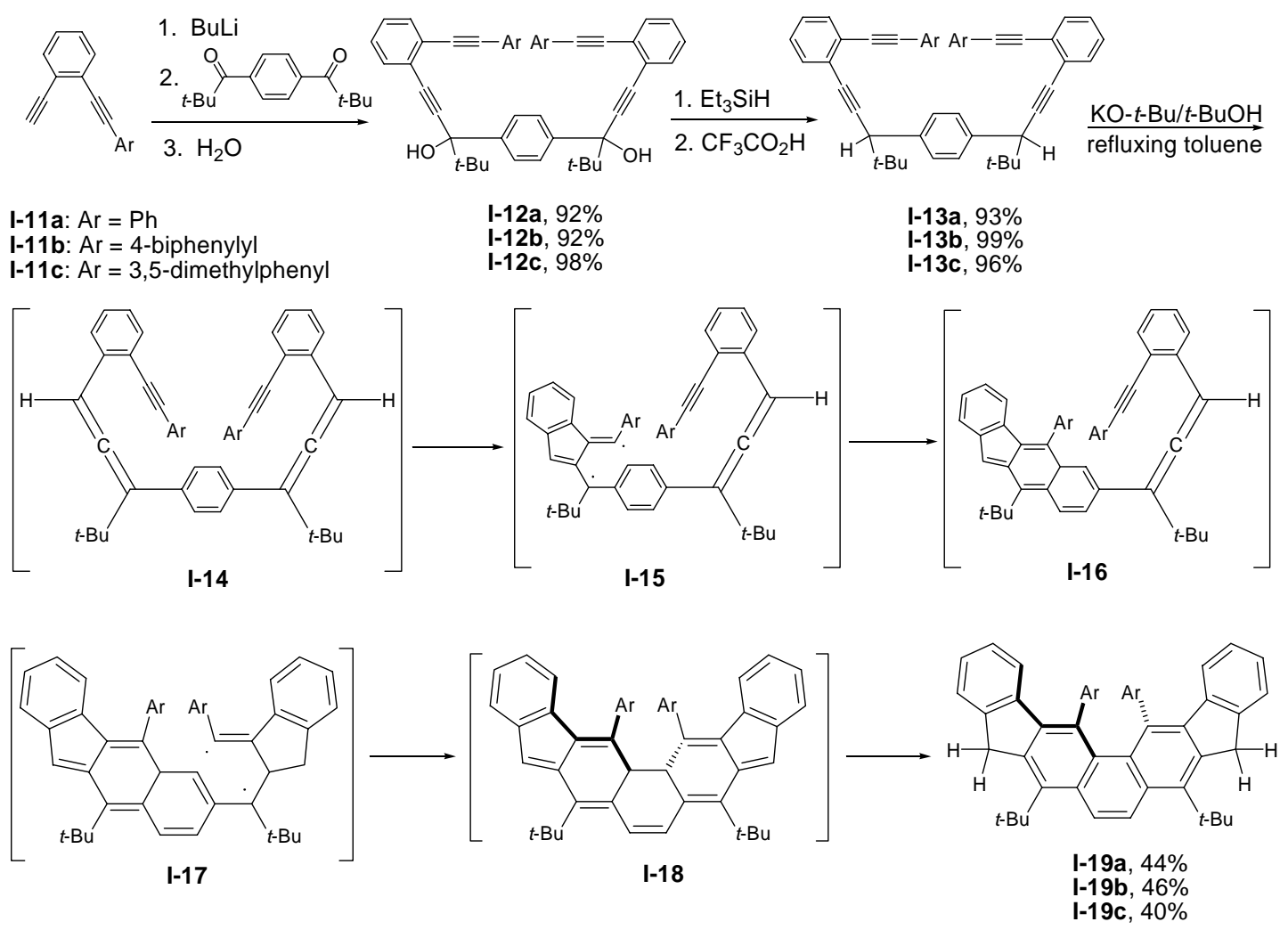

\section{I-4. Application of enyne-heteroallene (enyne-carbodiimide) Schmittel}

cyclization in the synthesis of heterocycles structurally related to naturally occurring alkaloids

Ellipticine I-20, a naturally occurring alkaloid isolated from the leaves of Ochrosia elliptica Labill (family Apocynaceae), ${ }^{8}$ and many of its derivatives were found to exhibit potent antitumor activities. ${ }^{9}$ The 9 -azaellipticines $\mathbf{I - 2 1}$ and $\mathbf{I - 2 2}$ are active on topoisomerase II and initiate the cleavage of DNA, ${ }^{9 b, k, 1}$ and $\mathbf{I - 2 2}$ has undergone 
clinical trials. $^{9 \mathrm{~b}, \mathrm{c}}$<smiles>Cc1c2ccncc2c(C)c2c1[nH]c1ccccc12</smiles>

$\mathbf{I}-20$<smiles>Cc1c2cnccc2c(C)c2c1[nH]c1ccncc12</smiles>

I-21<smiles>CCN(C)CCNc1nccc2cc3c(cc12)[nH]c1ccncc13</smiles>

I-22

Our group successfully synthesized 5-azaellipticines and 5,9-diazaellipticines I-28 by thermolysis of benzannulated and pyridannulated enyne-carbodiimides (Scheme I-5) ${ }^{10}$ It is interesting to note that the cyclizations of the enyne-carbodiimides favor the $\mathrm{C}^{2}-\mathrm{C}^{6}$ pathway (Schmittel cyclization) even when R are methyl and propyl groups.

\section{Scheme I-5.}

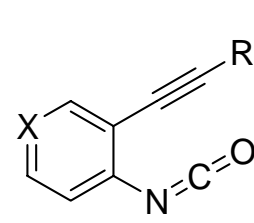

I-23a: $X=\mathrm{CH}$ I-23b: $X=N$<smiles>P=Nc1ccncc1</smiles><smiles>[R]C#Cc1ccccc1N=C=Nc1ccncc1</smiles>

I-25<smiles>[R]C=C1C(N([R6])c2ccncc2)=Nc2ccc(CC)cc21</smiles>

\section{I-5. The goal of this dissertation}

Thermolysis of the enyne-allenes (including hetero enyne-allenes) provides efficient synthetic pathways to a variety of polycyclic aromatic hydrocarbons and heterocycles. The simplicity of preparing diverse enyne-allene (including hetero enyne-allene) 
intermediates, the efficient subsequent cycloaromatization, the novel structures of the hydrocarbons and the potential pharmacological applications of the heterocycles make this method especially attractive. The research efforts of this dissertation are aimed at further application of this very interesting method to the syntheses of novel helical polycyclic aromatic hydrocarbons and naturally occurring, biologically important heterocycles. 


\section{CHAPTER 2}

\section{Synthesis of helical polycyclic aromatic hydrocarbons}

\section{II-1. Synthesis and structural characterization of a helical diindenophenanthrene compound that exhibits a structure resembling a molecular spiral staircase.}

\section{II-1.1. Introduction}

The distorted structure of 4,5-disubstituted phenanthrenes ${ }^{7,11}$ and related compounds ${ }^{12}$ has long been a subject of interest. The nonbonded steric interactions between the two substituents at the $\mathrm{C} 4$ and $\mathrm{C} 5$ positions cause them to bend away from the mean plane of the aromatic system and exert a torsional force that produces a helical twist of the aromatic framework. The X-ray crystallographic structure of 4,5-dimethylphenanthrene (II-1) shows a $28^{\circ}$ twist between the mean planes of the two outer aromatic rings (planes $1-2-3-4-4 a-10 a$ and $4 b-5-6-7-8-8 a) .{ }^{11 b}$ The twist of the corresponding aromatic rings of I-19a (rings $\mathrm{B}$ and $\mathrm{C}$ ), a diindeno-fused 4,5-diphenylphenanthrene, was more pronounced at $46^{\circ} .^{7}$ In addition, the two phenyl substituents are oriented essentially parallel to each other (within $1.3^{\circ}$ ), but are at a $53.1^{\circ}$ angle from the diindenophenanthrene system as indicated by X-ray structure analysis. The presence of a helical twist in I-19a could also be discerned from its ${ }^{1} \mathrm{H}$ NMR spectrum with a set of $A B$ quartet signals $(\mathrm{J}=21.0 \mathrm{~Hz})$ from the diastereotopic methylene hydrogens on the five-membered rings.

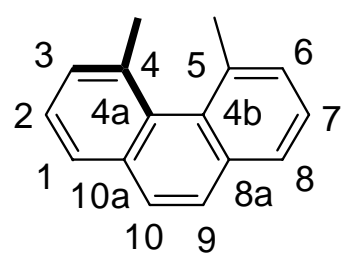

II-1

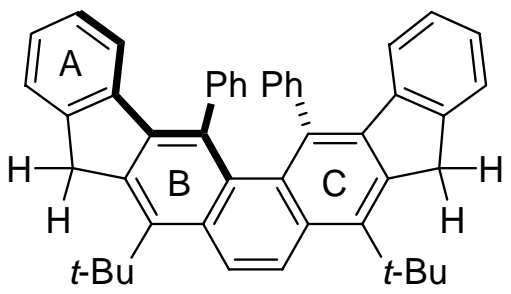

I-19a

\section{II-1.2. Results and discussion}

Our continued interest in nonplanar polycyclic aromatic compounds led us to apply 
the synthetic sequence developed for I-19a to the construction of II-8 having two additional phenyl substituents at the two outermost aromatic rings (Scheme II-1). Conversion of II-2, ${ }^{13}$ prepared from 1,1'-biphenyl-2-ol, to triflate II-3 followed by coupling with phenylacetylene produced II-4, which was then treated with dimethyl (1-diazo-2-oxopropyl)phosphonate and $\mathrm{K}_{2} \mathrm{CO}_{3}{ }^{14}$ to afford diyne II-5. The transformations from II-5 to II-8 are similar to what were reported previously for I-19a. Condensation between 2 equiv of II-5 and $p$-dipivaloylbenzene produced II-6, which was then reduced to furnish II-7. Treatment of II-7 with potassium $t$-butoxide under refluxing $p$-xylene then produced II-8 in a single operation. The transformation from II-7 to II-8 presumably involved two prototropic acetylene to allene rearrangements of the two internal acetylenic moieties followed by two formal intramolecular Diels-Alder reactions and subsequent prototropic rearrangements of the resulting Diels-Alder adduct as described previously for I-19a.

The X-ray structure of II-8 (Figure II-1) shows that the four phenyl substituents are essentially parallel to one another but are virtually perpendicular to the helical axis of the diindenophenanthrene system. Because the perpendicular distances of ca. $3.1 \AA$ between the neighboring phenyl substituents are shorter than the optimum $\pi$-system van der Waals contact distance of ca. $3.4 \AA \AA^{15}$ the phenyl substituents are not directly on top of one another but are in a skew conformation. Sighting along the line joining $\mathrm{C} 1$ and $\mathrm{C} 16$, the dihedral angle between the bonds attaching the two phenyl substituents to $\mathrm{C} 1$ and $\mathrm{C} 16$ is $53.6^{\circ}$, whereas viewing along the $\mathrm{C} 15-\mathrm{C} 16$ line the dihedral angle between the bonds connecting the two inner phenyl groups to C15 and $\mathrm{C} 16$ is even more pronounced at $63.5^{\circ}$. As a result, the two outer phenyl substituents are pointed essentially in opposite directions. Viewing along the $\mathrm{C} 1-\mathrm{C} 14$ line and following the direction of rotation of the helical twist, the bond connecting a phenyl 
substituent to $\mathrm{C} 14$ is rotated $184.3^{\circ}$ from the bond connecting a phenyl substituent to C1. The diindenophenanthrene system is also severely distorted with a $29^{\circ}$ twist angle between the mean planes of rings $\mathrm{A}$ and $\mathrm{B}$ and a more pronounced $59^{\circ}$ twist angle between the mean planes of rings $\mathrm{B}$ and $\mathrm{C}$, which is substantially larger than that of I-19a at $46^{\circ}$. Viewing from the direction perpendicular to the helical axis of the diindenophenanthrene ring system, the structure of $\mathbf{I I - 8}$ resembles that of a segment of a spiral staircase having four parallel steps or that of a portion of a single strand DNA containing four bases. ${ }^{16}$

\section{Scheme II-1.}
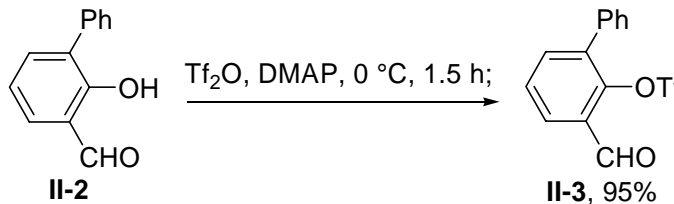

phenylacetylene, $\mathrm{Pd}\left(\mathrm{PPh}_{3}\right)_{2} \mathrm{Cl}_{2}$ (3 $\mathrm{mol} \%$ ), Cul, $\mathrm{Et}_{3} \mathrm{~N}, 85^{\circ} \mathrm{C}, 12 \mathrm{~h}$;

II-3, 95\%

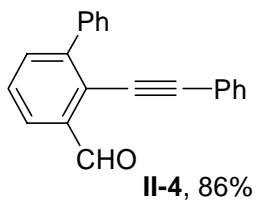

$\operatorname{MeCOC}\left(\mathrm{N}_{2}\right) \mathrm{P}(\mathrm{O})(\mathrm{OMe})_{2}$, $\mathrm{K}_{2} \mathrm{CO}_{3}$, rt, $12 \mathrm{~h}$

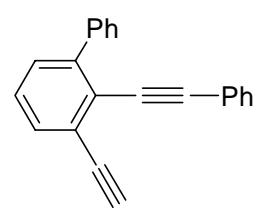

1. BuLi
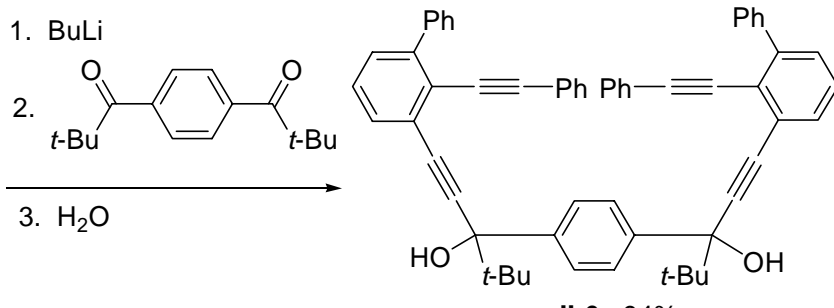

II-5, $81 \%$ 3. $\mathrm{H}_{2} \mathrm{O}$ II-6, 94\%

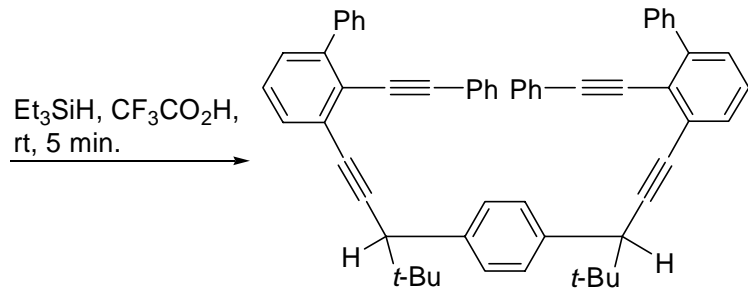

II-7, 94\%

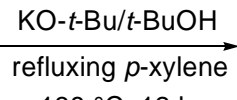

$138{ }^{\circ} \mathrm{C}, 12 \mathrm{~h}$

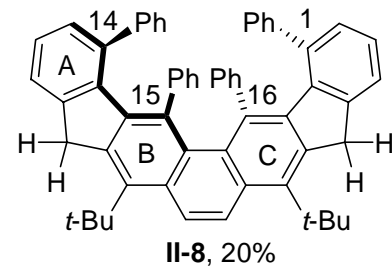

X-ray 


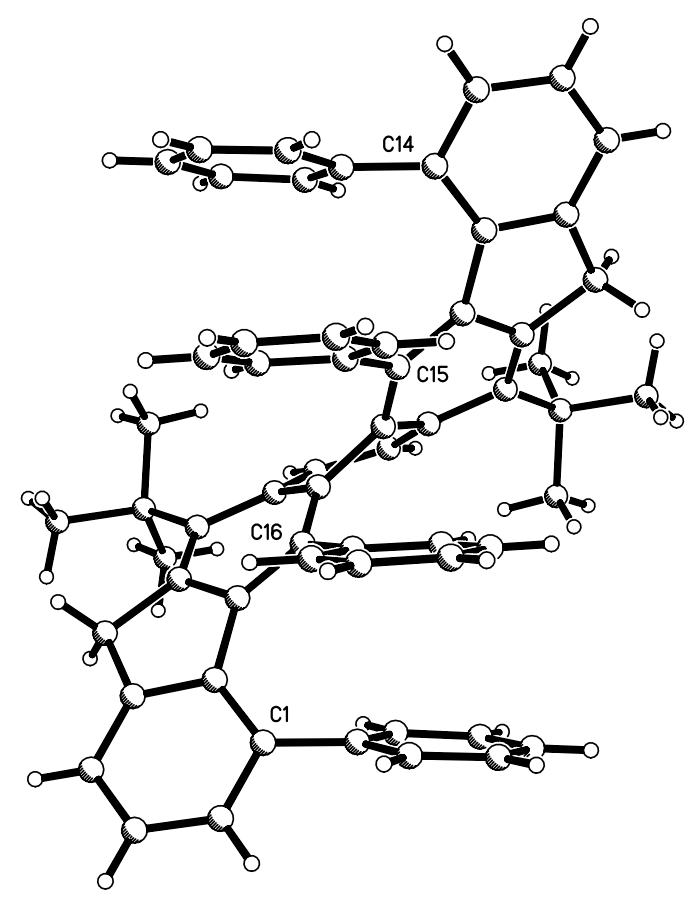

Figure II-1. Molecular structure of II-8. Its solid structure is constrained by a crystallographic two-fold rotation axis.

Due to additional buttressing effect, the rate of racemization of II-8 could be expected to be even slower than that of I-19a, which is most likely to be conformationally stable at $25{ }^{\circ} \mathrm{C} .{ }^{1 \mathrm{c}}$ The ${ }^{1} \mathrm{H}$ NMR spectrum $(600 \mathrm{MHz})$ of $\mathbf{I I - 8}$ in $\mathrm{CDCl}_{3}$ also exhibited a set of $\mathrm{AB}$ quartet at $\delta 4.34$ and $4.39(J=21.0 \mathrm{~Hz})$ from the diastereotopic methylene hydrogens, manifesting the presence of a helical twist.

The two most upfield signals (doublet) of the aromatic hydrogens at $\delta 5.34$ and 5.68 are attributable to the ortho hydrogens of the two inner phenyl substituents connected to $\mathrm{C} 15$ and $\mathrm{C} 16$. The fact that two distinct signals were observed for these ortho hydrogens suggests that the rate of rotation of the two inner phenyl groups is relatively slow on the NMR time scale at $25{ }^{\circ} \mathrm{C}$. Two distinct signals attributable to the meta hydrogens were also observed at $\delta 6.03$ and 6.24. This is in sharp contrast to the ${ }^{1} \mathrm{H}$ NMR spectrum (600 MHz) of I-19a at $25{ }^{\circ} \mathrm{C}$, which showed only one signal 
(doublet) at $\delta 6.52$ for the ortho hydrogens and one signal (triplet) at $\delta 7.00$ for the meta hydrogens. However, temperature-dependent NMR study of I-19a showed that at $-40{ }^{\circ} \mathrm{C}$ two doublets at $\delta 6.46$ and 6.51 for the ortho hydrogens and two triplets at $\delta$ 6.93 and 7.05 for the meta hydrogens appeared, and the coalescence temperatures were determined to be -22 and $-10{ }^{\circ} \mathrm{C}$, respectively, corresponding to rotational barriers of 12.5 and $12.6 \mathrm{kcal} / \mathrm{mol}$ at these two temperatures.

Interestingly, signals from the ortho and meta hydrogens of the two outer phenyl substituents connected to $\mathrm{C} 1$ and $\mathrm{C} 14$ of II-8 were conspicuously missing. Instead, broad humps could be discerned on the baseline due to restricted rotation of the phenyl groups. On lowering the temperature from 25 to $-20{ }^{\circ} \mathrm{C}$, additional peaks started to appear, and at $-20{ }^{\circ} \mathrm{C}$ two doublets at $\delta 6.21$ and 6.36 attributable to the ortho hydrogens and two triplets at $\delta 6.46$ and 6.73 attributable to the meta hydrogens could be identified. The coalescence temperatures for the ortho and meta hydrogens are $25^{\circ} \mathrm{C}$ and $30^{\circ} \mathrm{C}$, respectively, corresponding to rotational barriers of 14.3 and $14.2 \mathrm{kcal} / \mathrm{mol}$ at these two temperatures. At $55^{\circ} \mathrm{C}$ on a $270 \mathrm{MHz}$ NMR spectrometer, a single doublet at $\delta 6.29$ for the ortho hydrogens and a single triplet at $\delta 6.58$ for the meta hydrogens could be clearly discerned.

Compared to the synthesis of I-19a, the use of diyne II-5 bearing a phenyl substituent on the central benzene ring resulted in a lower yield for II-8. A model study with II-10 revealed that the expected benzo[b]fluorene II-14 was produced via a sequence of reactions involving a prototropic rearrangement to form the benzannulated enyne-allene II-11 followed by a Schmittel cyclization reaction ${ }^{4}$ to form biradical II-12, which in turn underwent an intramolecular radical-radical coupling and a prototropic rearrangement (Scheme II-2). However, two additional adducts, II-15 and II-16, were also produced. A competing intramolecular [2+2] cycloaddition reaction 
of II-11 could account for II-15. The generation of biradical II-13 from the Myers-Saito cyclization reaction ${ }^{3}$ of II-11 followed by trapping the aryl radical center with the phenyl substituent and a prototropic rearrangement could furnish II-16. Presumably, the emergence of nonbonded steric interactions between the two phenyl substituents along the pathway toward II-14 could be responsible for an increase of its activation energy, allowing a minor portion of II-11 to undergo the Myers-Saito cyclization reaction. ${ }^{17}$ On the other hand, the use of the diyne without a phenyl substituent on the central benzene ring produced the corresponding benzo[ $[b]$ fluorene exclusively in $90 \%$ yield. $^{18}$

\section{Scheme II-2.}
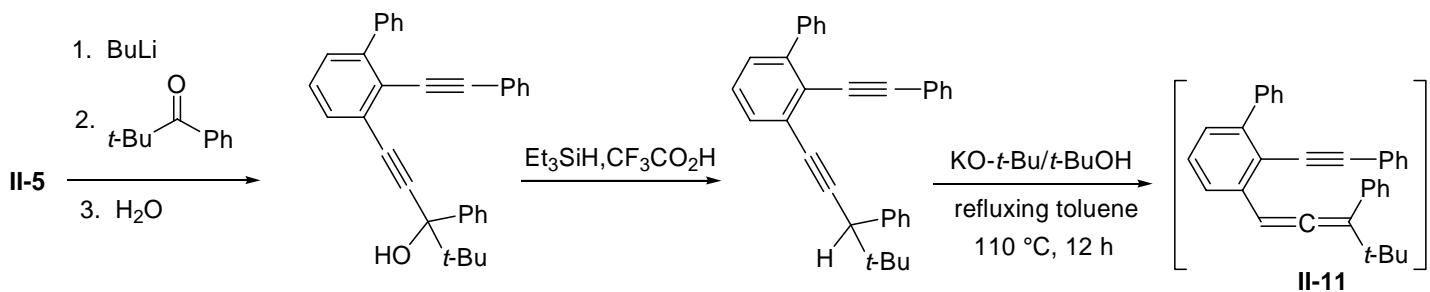

II-9, $86 \%$

$$
\text { II-10, 88\% }
$$
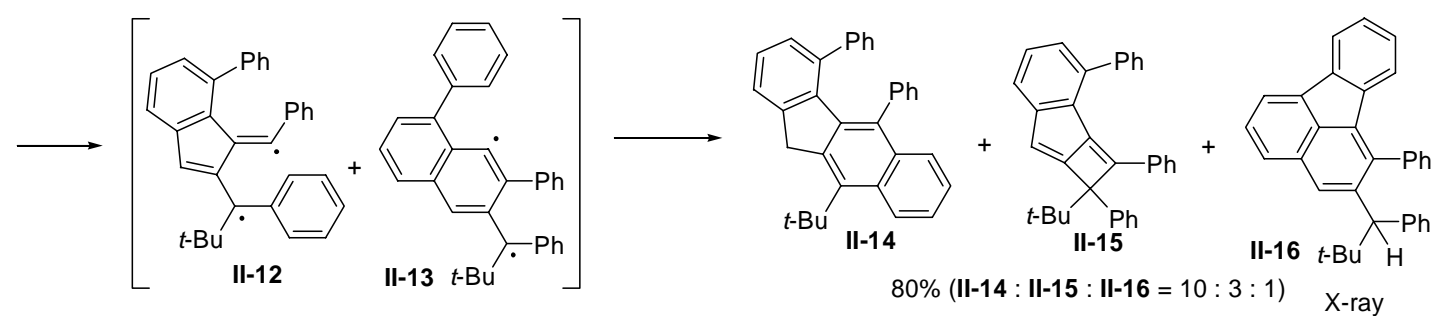

\section{II-1.3. Conclusion}

A synthetic pathway to 6,9-bis(1,1-dimethylethyl)-5,10-dihydro-1,14,15,16-tetraphenyldiindeno[2,1-b:1',2'-h]phenanthrene II-8, a 4,5-diphenylphenanthrene derivative, using two consecutive Schmittel cyclization reactions of a precursor bearing two benzannulated enyne-allene moieties was developed. The four phenyl substituents are in close proximity to one another and suffer from severe nonbonded steric interactions, which exert a torsional force causing a helical twist of the 
diindenophenanthrene framework. The X-ray structure shows that the four phenyl substituents are essentially parallel to one another but are virtually perpendicular to the helical axis of the diindenophenanthrene system. Viewing from the direction perpendicular to the helical axis, the structure resembles that of a segment of a spiral staircase having four parallel steps or that of a portion of one strand of DNA containing four bases. 


\section{II-2 Synthesis and structural characterization of a helical 9-ring system that also exhibits a very interesting twist $\mathrm{X}$-ray structure. ${ }^{7,19}$}

\section{II-2.1. Introduction}

We have successfully synthesized novel structures of substituted diindenophenanthrenes by using two consecutive Schmittel cyclization reactions of precursors bearing two benzannulated enyne-allene moieties. Because of the nonbonded steric interactions, the aromatic diindenophenanthrene framework exhibits a helical twist. The X-ray crystallographic structure of I-19a, a diindeno-fused 4,5-diphenylphenanthrene, shows a $46^{\circ}$ twist angle between the mean planes of the rings $\mathrm{B}$ and $\mathrm{C}$ and the two phenyl substituents are oriented essentially parallel to each other (within $1.3^{\circ}$ ), but are at a $53.1^{\circ}$ angle from the diindenophenanthrene system. The X-ray crystallographic structure of II-8, a 1,14,15,16-tetraphenyldiindenophenanthrene, shows a more pronounced $59^{\circ}$ twist angle between the mean planes of the rings B and $\mathrm{C}$ and a $29^{\circ}$ twist angle between the mean planes of the rings $\mathrm{A}$ and $\mathrm{B}$ and the four phenyl substituents are oriented essentially parallel to one another but are virtually perpendicular to the helical axis of the diindenophenanthrene system. The structure of II-8 resembles that of a segment of a spiral staircase having four parallel steps or that of a portion of a single strand DNA containing four bases.

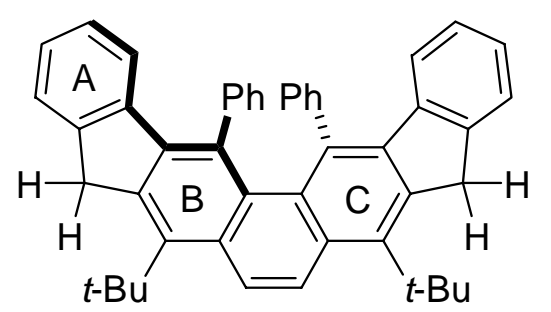

$\mathrm{I}-19 \mathrm{a}$

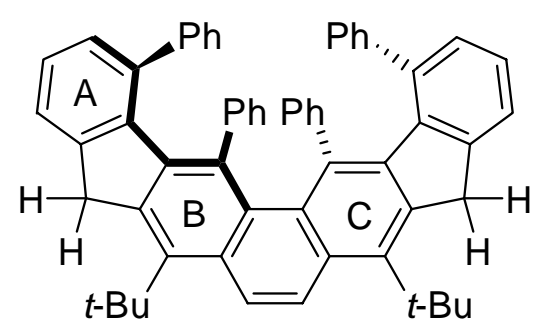

II-8 


\section{II-2.2. Results and discussion}

By placing two additional phenyl substituents at the two outermost aromatic rings, the diindenophenanthrene framework of II-8 shows a more pronounced twist than that of I-19a. Our continued interest in nonplanar polycyclic aromatic compounds led us to apply the synthetic sequence developed for I-19a and II-8 to the construction of II-22 having two additional phenyl rings connecting to the two outermost aromatic rings of diindenophenanthrene framework (Scheme II-3). The benzannulated enediyne II-19 was readily prepared by the Sonogashira reaction between phenylacetylene and II-17 to form II-18 followed by treatment of II-18 with dimethyl(1-diazo-2-oxopropyl)phosphonate. The transformations from II-19 to II-22 are similar to what were reported previously for I-19a and II-8. Condensation between 2 equiv of II-19 and p-dipivaloylbenzene produced II-20, which was then reduced to furnish II-21. Treatment of II-21 with potassium $t$-butoxide under refluxing toluene then produced II-22 in a single operation. The transformation from II-21 to II-22 presumably involved two prototropic acetylene to allene rearrangements of the two internal acetylenic moieties followed by two formal intramolecular Diels-Alder reactions and subsequent prototropic rearrangements of the resulting Diels-Alder adduct as described previously for I-19a and II-8.

The structure of II-22 was unequivocally established by the X-ray structure analysis. It is interesting to note that the crystal structure of II-22 does not contain a crystallographic 2-fold rotation axis. As a result, the twist angles between mean planes of rings $\mathrm{A}$ and $\mathrm{B}$ and rings $\mathrm{C}$ and $\mathrm{D}$ are slightly different, at $22^{\circ}$ and $23^{\circ}$ respectively, which are substantially larger than that of I-19a at $14^{\circ}$ and smaller than that of II-8 at $29^{\circ}$. The twist angle between B and C at $56^{\circ}$ is also significantly larger 
than that of I-19a at $46^{\circ}$ and smaller than that of II-8 at $59^{\circ}$. The two phenyl substituents are bent away from each other with the dihedral angle between bonds attaching phenyl substituents to the polycyclic ring system at $67.2^{\circ}$, which is substantially smaller that of I-19a at $84.0^{\circ}$ and larger than that of II-8 at $63.5^{\circ}$. The two phenyl substituents are oriented essentially parallel to each other and the perpendicular distance between the planes of them is ca. $2.9 \AA$ much shorter than the optimum $\pi$-system van der Waals contact distance of ca. $3.4 \AA$ and same as that of I-19a and shorter than that of II-8 at $3.1 \AA$.

\section{Scheme II-3.}

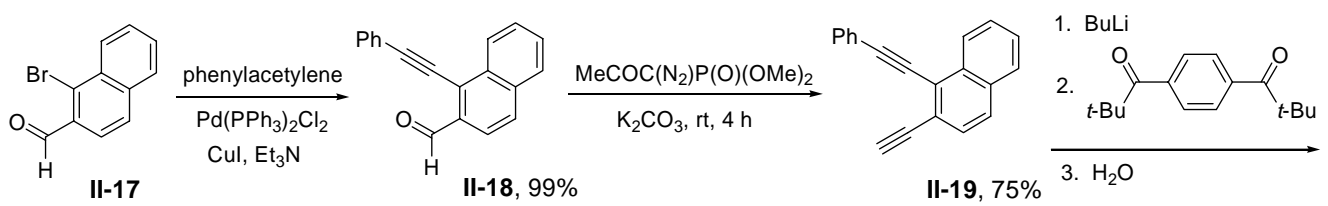

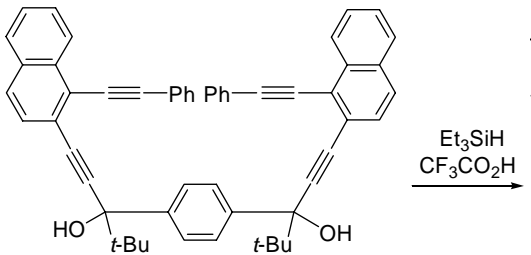

II-20, 78\% $\mathrm{X}$-ray of diastereomer 1

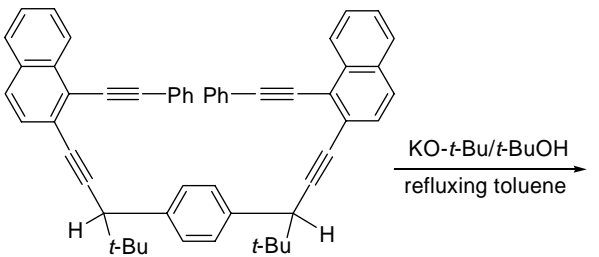

II-21, 69\%

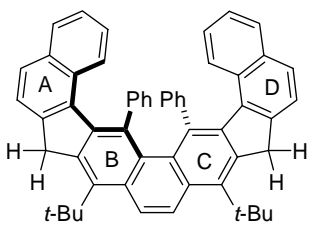

II-22, $40 \%$ X-ray

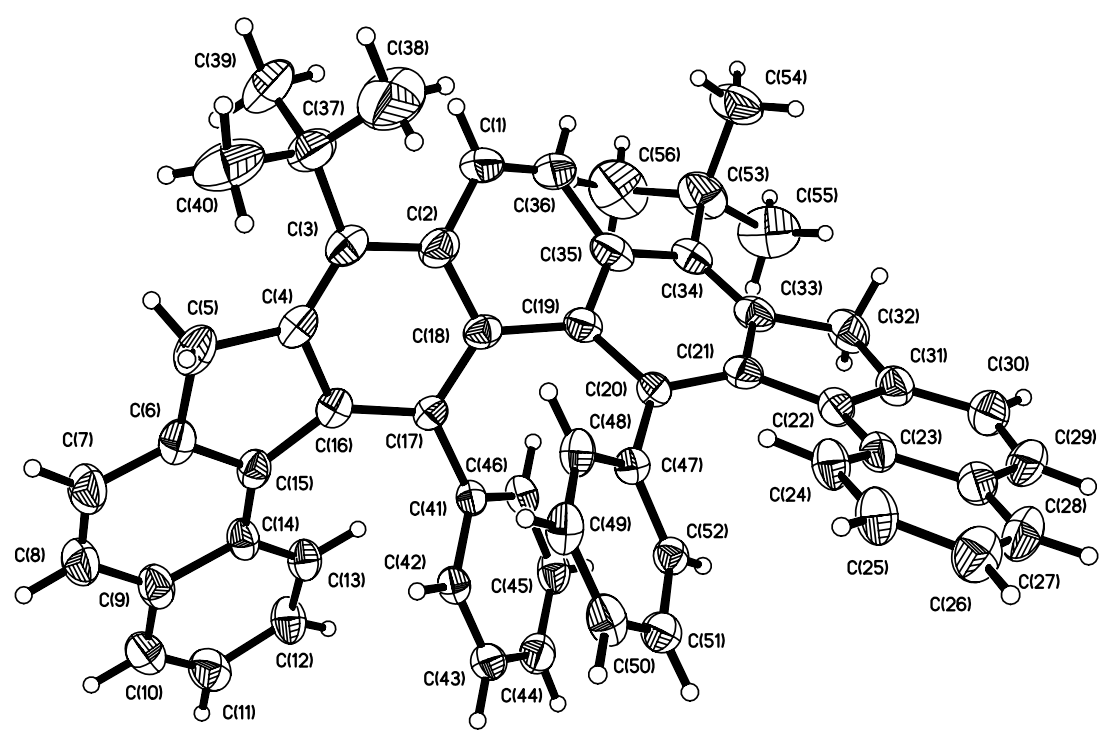


Figure II-2. ORTEP drawing of the crystal structure of II-22

Due to additional buttressing effect, the rate of racemization of II-22 could be expected to be even slower than that of I-19a, which is most likely to be conformationally stable at $25{ }^{\circ} \mathrm{C}$. The ${ }^{1} \mathrm{H}$ NMR spectrum $(270 \mathrm{MHz})$ of II-22 in $\mathrm{CDCl}_{3}$ also exhibited a set of $\mathrm{AB}$ quartet at $\delta 4.38$ and $4.57(J=21.6 \mathrm{~Hz})$ from the diastereotopic methylene hydrogens, manifesting the presence of a helical twist.

Signals from the ortho and meta hydrogens of the two phenyl substituents in II-22 were conspicuously missing. Instead, four broad humps at $\delta 5.8,6.2,6.6$ and 6.9 could be discerned on the baseline due to restricted rotation of the phenyl groups. The rotation of the two phenyl groups in I-19a is relatively quick because only two peaks at $\delta 6.52$ and 7.00 are contributed to the ortho and meta hydrogens of the two phenyl substituents respectively.

Compared to the synthesis of I-19a and II-8, the use of diyne II-19 produced a yield for II-22 similar to the yield for I-19a and higher than the yield for II-8. Similarly, the benzannulated enediynyl propargylic alcohol II-23 was synthesized by condensation between 2,2-dimethylpropiophenone and the benzannulated enediyne II-19. Reduction of II-23 followed by treatment of the resulting II-24 with potassium tert-butoxide in refluxing toluene then afforded 8-(1,1-dimethylethyl)-13-phenyl -7H-dibenzo[b,g]fluorene (II-28) in $80 \%$ yield along with two minor adducts II-29 and II-30. Presumably, a 1,3-prototropic rearrangement of II-24 gave the benzannulated enyne-allene II-25, which could undergo either a Schmittel cyclization reaction to give biradical II-26 leading to II-28 or a Myers-Saito cyclization reaction to form biradical II-27 leading to II-29 and II-30. On the other hand, the use of the diyne I-11 a without a phenyl substituent on the central benzene ring and diyne II-5 with a phenyl substituent on the central benzene ring produced the corresponding 
benzo[b]fluorene in $90 \%$ and $56 \%$ yield respectively.

Scheme II-4.

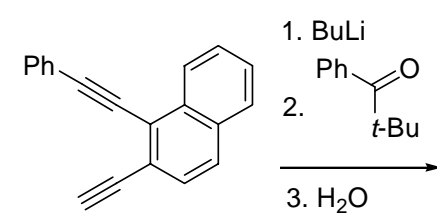

II-19

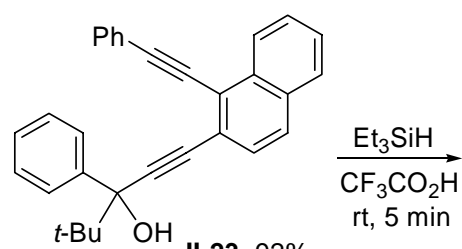

II-23, 92\%

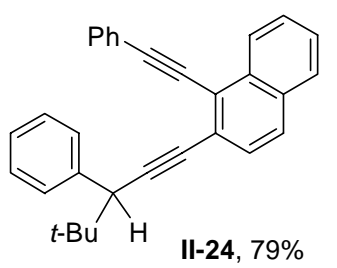

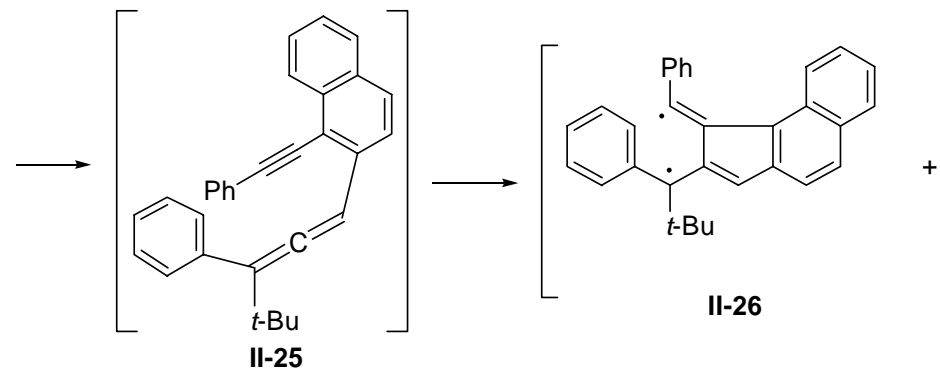<smiles>CC(C)(C)[C@H](c1ccccc1)c1cc2ccc3ccccc3c2cc1CCc1ccccc1</smiles>

II-27<smiles>CC(C)(C)c1ccccc1Cc1ccc(C(c2cc3ccc4ccccc4c3cc2-c2ccccc2)C(C)(C)C)cc1</smiles>

II-29, 5\%

II-30, $5 \%$

II-28, 80\%

X-ray

\section{II-2.3. Conclusion}

The synthetic pathway developed for the synthesis of I-19a and II-8 was successfully employed to synthesize the 9-ring system of II-22. The synthesis of II-22 further confirmed the power of the new synthetic route to the helical polycyclic aromatic system including a 4,5-diarylphenanthrene subunit. 


\section{II-3 Synthesis and structural characterization of novel binaphthol derivatives.}

\section{II-3.1. Introduction}

We recently developed an efficient transformation of the acetylenes I-11, II-5 and II-19 to the helical polycyclic aromatic hydrocarbons. ${ }^{7,19}$ The synthetic route includes only three simple steps. 1: Condensation between 2 equiv of the acetylenes I-11, II-5 and II-19 and $p$-dipivaloylbenzene to the corresponding diols I-12, II-6 and II-20; 2 : Reduction of diols I-12, II-6 and II-20 to the corresponding tetraacetylenic hydrocarbons I-13, II-7 and II-21; 3: Treatment of tetraacetylenic hydrocarbons I-13, II-7 and II-21 with potassium $t$-butoxide under refluxing toluene or $p$-xylene to the helical polycyclic aromatic hydrocarbons I-19, II-8 and II-22 in a single operation. The transformation from the tetraacetylenic hydrocarbons I-13, II-7 and II-21 to the helical polycyclic aromatic hydrocarbons $\quad$ I-19, II-8 and II-22 presumably involved two prototropic acetylene to allene rearrangements of the two internal acetylenic moieties followed by two formal intramolecular Diels-Alder reactions and subsequent prototropic rearrangements of the resulting Diels-Alder adducts. Our interest in enantiopure helical compounds let us replace $p$-dipivaloylbenzene with a binaphthol derivative, the diketone II-33 taking advantage of easy availability of enantiopure binaphthol derivatives and easy resolution of binaphthol derivatives. ${ }^{20}$ It is also worth noting that binaphthol itself is a very useful asymmetric catalyst, ${ }^{21}$ the resulting binaphthol derivatives could also be good asymmetric catalysts.

\section{II-3.2. Results and discussion}

The synthetic sequence outlined in Scheme II-5 provides an efficient route to benzannulated enediyne II-35. Compound II-31 was prepared according to the reported procedure. ${ }^{22}$ Alkylation of II-31 with 2 equiv ethyl bromide in boiling 
acetone and potassium carbonate as a base produced $\mathbf{I I - 3 2}$ in excellent yield. ${ }^{23}$ Treatment of II-32 with 4.4 equiv butyllithium followed by dry-ice then afforded a diacid, ${ }^{23}$ which was transformed to II-33 directly by treated with thionyl chloride followed by $t$-butyllithium. ${ }^{24}$ Condensation between II-33 and 2 equiv of I-11a produced II-34, which was then reduced to furnish II-35. Treatment of II-35 with potassium $t$-butoxide under refluxing toluene then produced II-36 and II-37. Compound II-36 contains three pairs of diastereomers because it has two chiral carbons, a binaphthol axial chirality and a potential C2 symmetry; Compound II-37 includes two pairs of diastereomers because it only has one chiral carbon and a binaphthol axial chirality. The structures of one diastereomer of II-36 and both diastereomers of II-37 were established by X-ray structure analysis.

\section{Scheme II-5.}
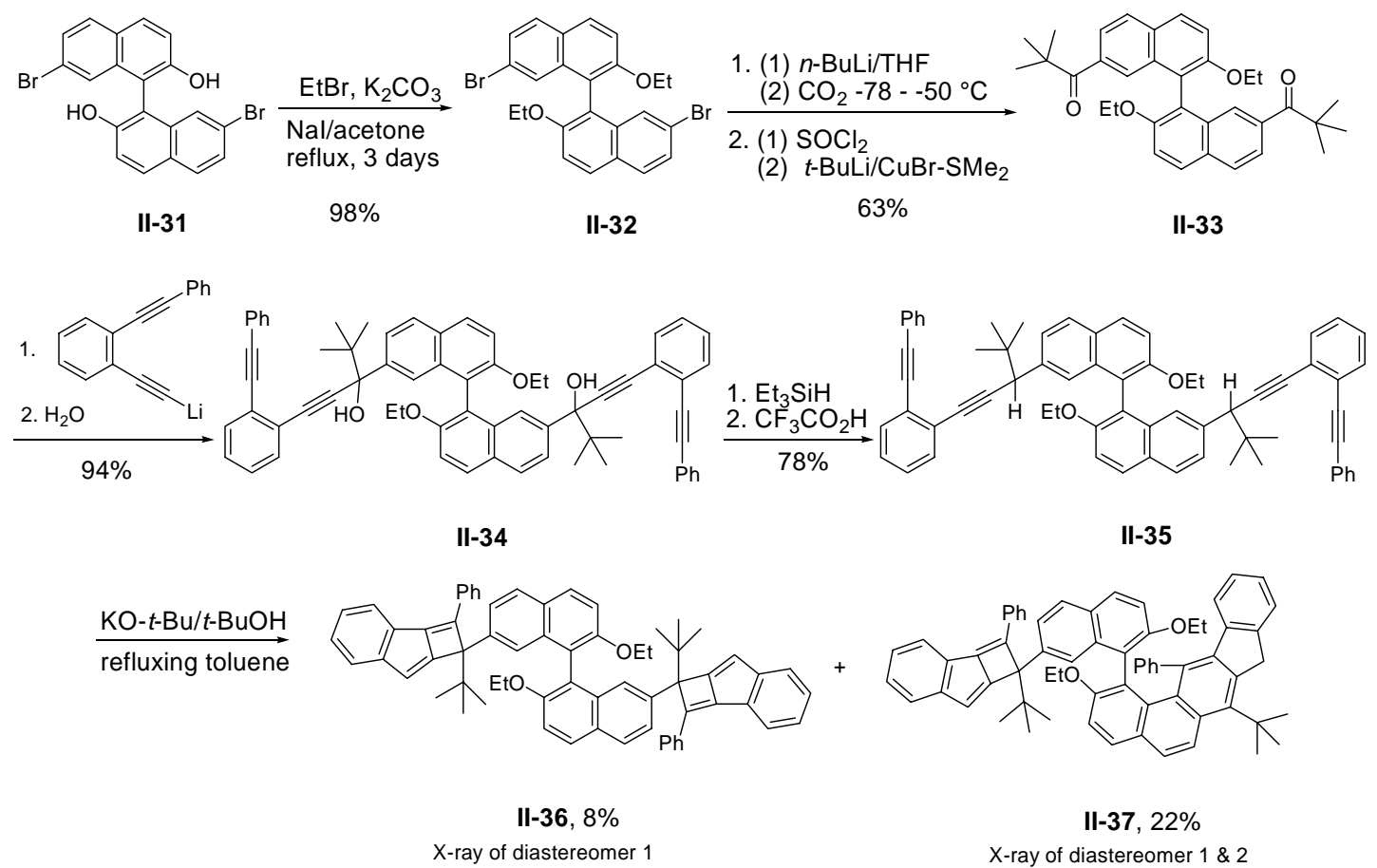

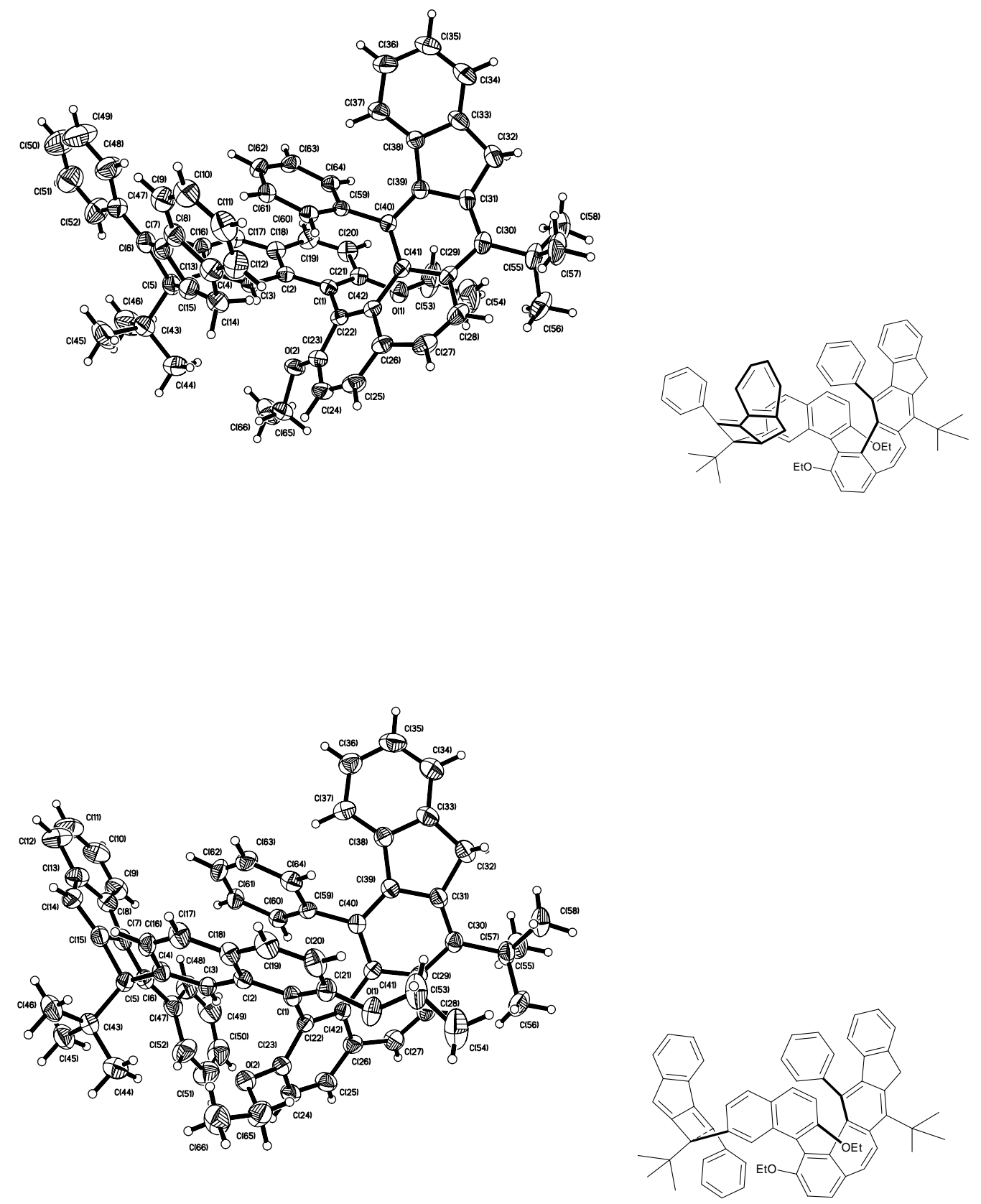

Figure II-3. ORTEP drawing of the crystal structures of diastereomer 1 (top) and diastereomer 2 (bottom) of II-37 

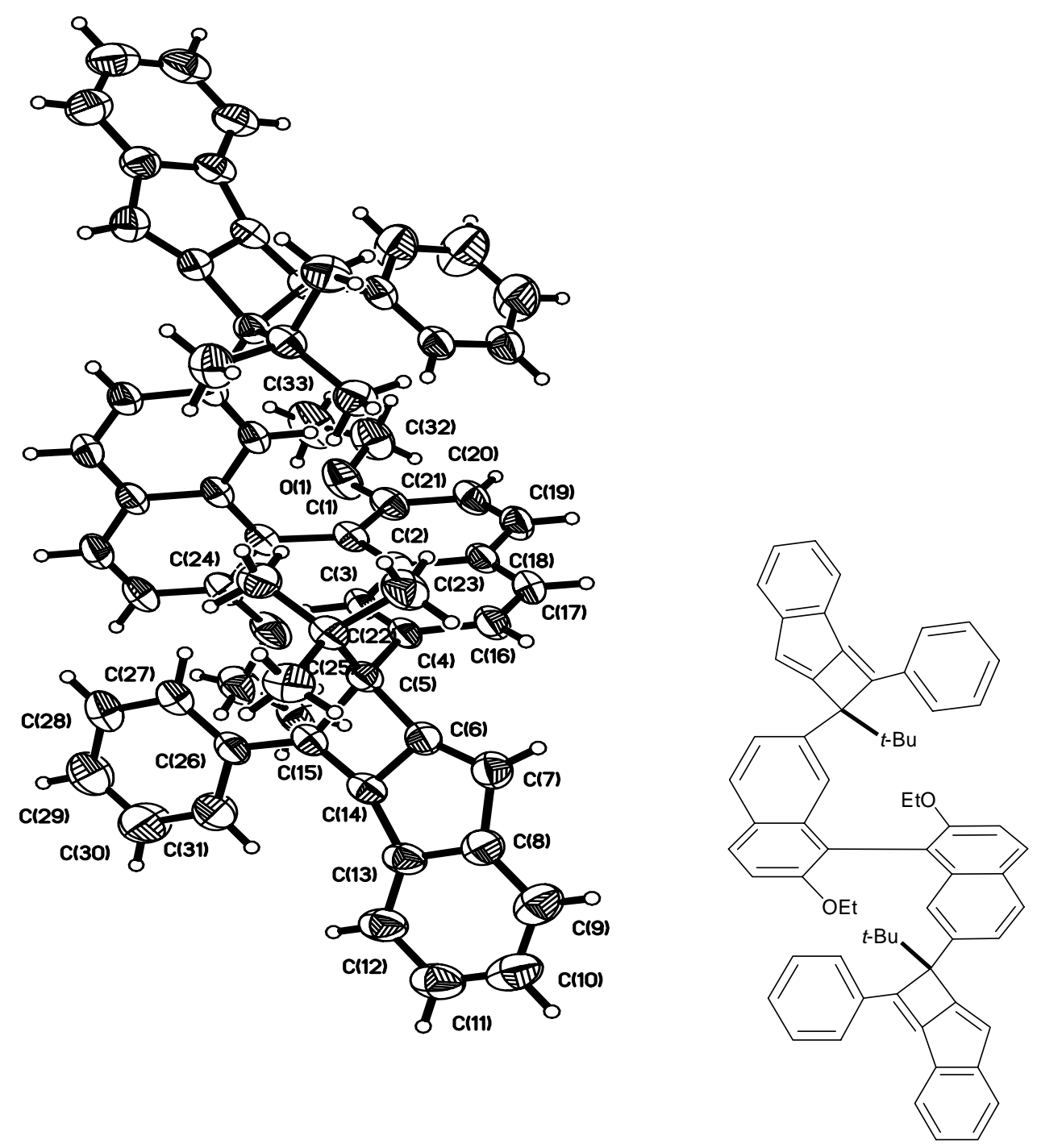

Figure II-4. ORTEP drawing of the crystal structure of diastereomer 1 of II-36

Supposedly, the transformation from II-35 to II-36 and II-37 involved initial prototropic isomerizations of II-35 to form the benzannulated enyne-allene II-38 (Scheme II-6). Two subsequent $\mathrm{C}^{2}-\mathrm{C}^{6}$ cyclization reactions generated the biradical II-39, which in turn underwent an intramolecular radical-radical coupling to give II-40 and II-41. Intermediate II-40 underwent either a direct radical-radical coupling to give II-36, which could also be considered resulting from [2+2] cyclizations of both enyne-allene moieties in II-38 or an intramolecular radical-radical coupling involving a double bond of the naphthol ring, after tautomerization, to give II-37, 
which could also be considered resulting from [4+2] cyclization of one enyne-allene moieties and [2+2] cyclization of the other enyne-allene moieties in II-38. Intermediate II-41 underwent the direct radical-radical coupling to give II-37.

\section{Scheme II-6.}
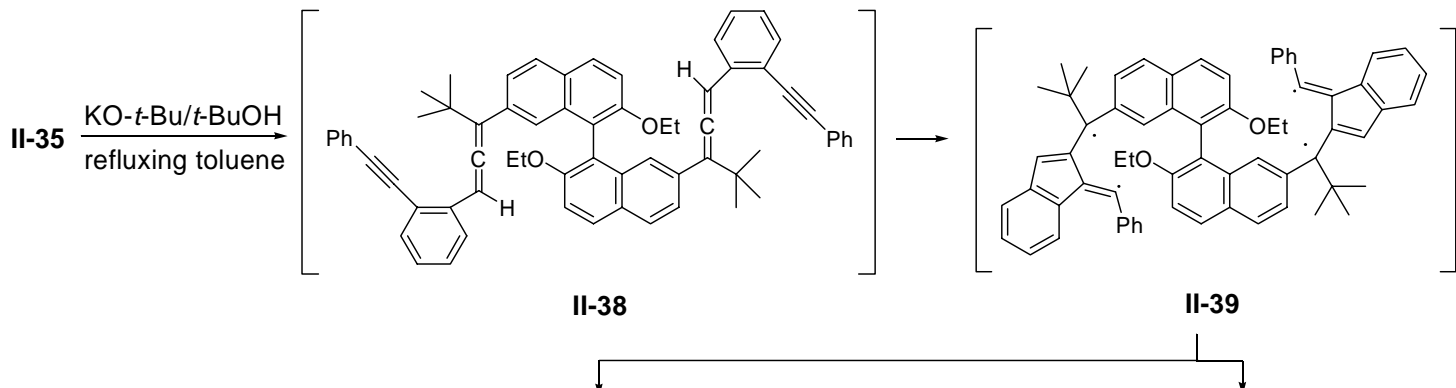
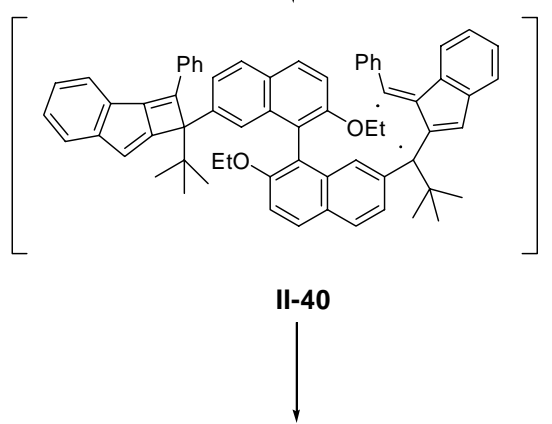

$11-36+11-37$

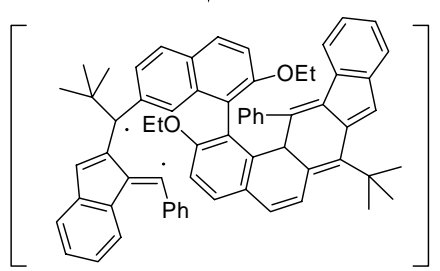

II-41

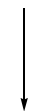

II-37

\section{II-3.3. Conclusion}

In summary, a binaphthol derivative, the diketone II-33 has been used to replace $p$-dipivaloylbenzene to involve in the efficient pathway to the helical polycyclic aromatic hydrocarbons. Because of steric hindrance, thermolysis of II-35 led to II-36, [2+2] cyclizations of both enyne-allene moieties in II-38, and II-37, [2+2] cyclization of one enyne-allene moiety and [4+2] cyclization of the other enyne-allene moiety in II-38. [4+2] cyclizations of both enyne-allene moieties in II-38 either did not occur or occurred in very small amount because the corresponding product was not observed. 


\section{II-4 Ring expansion of polycyclic hydrocarbons by Wagner-Meerwein rearrangement.}

\section{II-4.1. Introduction}

The Wagner-Meerwein rearrangement of 9-fluorenylmethanols and related fluorene derivatives provides an efficient pathway for ring expansion to form phenanthrenes. ${ }^{25}$ Specifically, the phosphorous pentoxide-induced rearrangement of the parent 9-fluorenylmethanol occurs in refluxing xylene to produce phenanthrene in excellent yield (eq II- 1$){ }^{25 b}$ We recently reported the synthesis of a variety of $11 H$-benzo[b]fluorenes and related derivatives via the benzannulated enediynyl propargylic alcohols. ${ }^{6,7,18,19,26}$ We now report the use of these benzofluorenyl derivatives to prepare $11 H$-benzo[b]fluorene-11-methanols for the subsequent Wagner-Meerwein rearrangement leading to phenanthrenes having extended conjugation and bearing one or two aryl substituents at the sterically most hindered positions. The presence of these aryl substituents also allows intramolecular electrophilic aromatic substitution reactions to occur, producing polycyclic aromatic hydrocarbons with novel architectures.

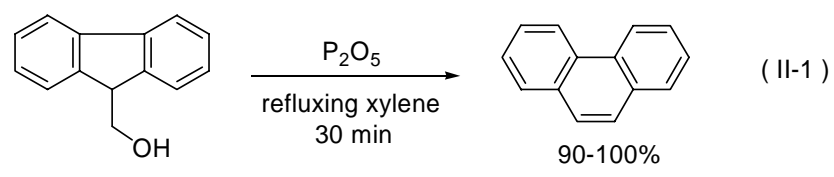

\section{II-4.2. Results and discussion}

Treatment of II-28 with LDA followed by paraformaldehyde then produced II-42 for the subsequent Wagner-Meerwein rearrangement to furnish 14-phenylnaphth[1,2-a]anthracene (II-43) with the phenyl substituent at one of the most sterically hindered positions in $74 \%$ yield. Because of steric hindrance, the rotation of the carboncarbon bond attaching the phenyl substituent to the naphth[1,2-a]anthracene system is restricted. As a result, the ${ }^{1} \mathrm{H}$ NMR signals $(600 \mathrm{MHz})$ of the ortho and meta 
hydrogens of the phenyl substituent appeared as broad humps at $\delta 8.2,7.5,6.7$, and 6.1 at $25{ }^{\circ} \mathrm{C}$. However, at $-20{ }^{\circ} \mathrm{C}$ two doublets at $\delta 8.24 / 6.14$ for the ortho hydrogens and two triplets at $\delta 7.49 / 6.67$ for the meta hydrogens could be clearly discerned. The coalescence temperatures were determined to be at $50{ }^{\circ} \mathrm{C}$ for the ortho hydrogens and at $40{ }^{\circ} \mathrm{C}$ for the meta hydrogens on a $270 \mathrm{MHz}$ spectrometer, corresponding to rotational barriers of $14.4 \mathrm{kcal} / \mathrm{mol}$ and $14.5 \mathrm{kcal} / \mathrm{mol}$ at these two temperatures, which are slightly higher than those of 1-phenylbenzo[ $[a]$ phenanthrenes $\left(\Delta G^{\ddagger}\right.$ rot $=$ ca. $\left.13 \mathrm{kcal} / \mathrm{mol}\right)$ reported earlier. ${ }^{27}$

\section{Scheme II-7.}<smiles>CC(C)(C)c1c2c(c(-c3ccccc3)c3ccccc13)-c1c(ccc3ccccc13)C2</smiles>

II-28
1. LDA 2. $\left.\underset{-}{-} \mathrm{CH}_{2} \mathrm{O}\right)_{\mathrm{n}}$<smiles>CC(C)(C)c1c2c(c(-c3ccccc3)c3ccccc13)-c1c(ccc3ccccc13)C2CO</smiles>

II-42, 80\%

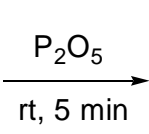<smiles></smiles>

II-43, 74\%

The benzo[b]fluorene derivative II-14 ${ }^{19}$ was also successfully employed to produce

II-44 (Scheme II-8). However, attempts to promote the Wagner-Meerwein rearrangement to give II-45 resulted in the formation of II-46 even under mild reaction conditions $\left(\mathrm{P}_{2} \mathrm{O}_{5}, 25{ }^{\circ} \mathrm{C}, 5 \mathrm{~min}\right)$. The structure of II-46 was established by X-ray structure analysis. Apparently, protonation of the initially formed II-45 and the subsequent intramolecular electrophilic aromatic substitution reaction are very facile under the reaction condition, preventing II-45 from being isolated. The reaction sequence of protonation followed by an intramolecular electrophilic aromatic substitution reaction is reminiscent of what was reported previously in the 
transformation of 1-phenylbenzo[ $a]$ anthracene to dibenzo[a,l]pyrene (Scheme II-9) ${ }^{28}$ However, the resulting II-46 is resistant to further transformation to II-47 on heating in refluxing $p$-xylene at $138{ }^{\circ} \mathrm{C}$ for $12 \mathrm{~h}$. Apparently, it is difficult to protonate the naphthalene moiety of II-46 for the subsequent intramolecular electrophilic aromatic substitution reaction.

\section{Scheme II-8.}

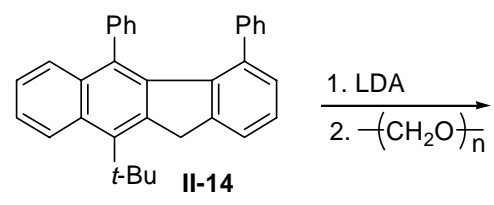

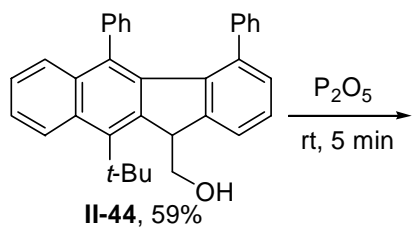<smiles>C1=CC2=CC=Cc3cccc(c3=C1)=C2c1cccc2ccccc12</smiles>

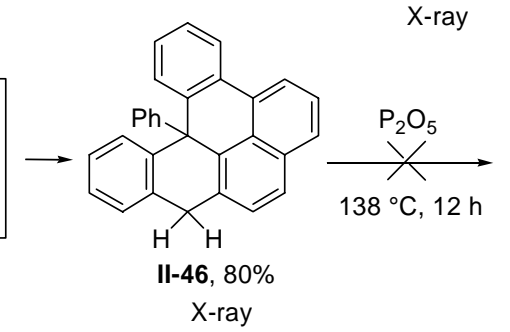

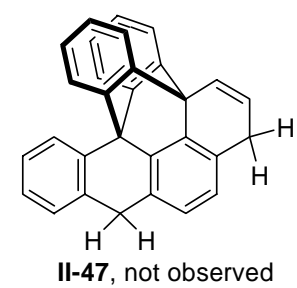

\section{Scheme II-9.}<smiles>c1ccc(-c2cccc3ccc4cc5ccccc5cc4c23)cc1</smiles><smiles></smiles><smiles>c1ccc2c(c1)cc1ccc3cccc4c5ccccc5c2c1c34</smiles>

\section{II-4.3. Conclusion}

The Wagner-Meerwein rearrangement was successfully applied to 11H-benzo[b]fluorene-11-methanols II-42 and II-44 leading to highly conjugated aromatic systems bearing one or two phenyl substituents at the most sterically hindered positions. These sterically congested aromatic systems are prone to 
protonation for subsequent intramolecular electrophilic aromatic substitution reactions, leading to polycyclic aromatic hydrocarbons with novel architectures not easily attainable by other synthetic methods. The synthetic sequence is simple and straightforward, making it easily adoptable for the synthesis of other polycyclic aromatic compounds. 


\section{II-5 Resolution of polycyclic hydrocarbons.}

\section{II-5.1. Introduction}

Our group successfully expanded the two five-membered rings of I-19a to benzene rings by the Wagner-Meerwein rearrangement (Scheme II-10). ${ }^{29}$ Treatment of I-19a with two equiv of LDA followed by paraformaldehyde produced II-48a-c as a mixture of three diastereomers in a 63 (II-48a or II-48b) : 34 (II-48c) : 3 (II-48a or II-48b) ratio in $76 \%$ combined yield. The use of a mixture of II-48a-c containing all three diastereomers for two consecutive Wagner-Meerwein rearrangements, promoted by $\mathrm{P}_{2} \mathrm{O}_{5}$ in $p$-xylene at $110{ }^{\circ} \mathrm{C}$ for $15 \mathrm{~min}$, was also successful, giving rise to 17,18-diphenyldibenzo[a,o]pentaphene (II-49) with the two phenyl substituents at the most sterically congested $\mathrm{C} 17$ and $\mathrm{C} 18$ positions.

\section{Scheme II-10.}

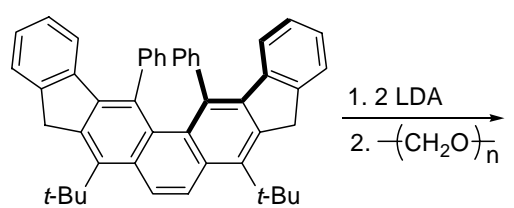

I-19a

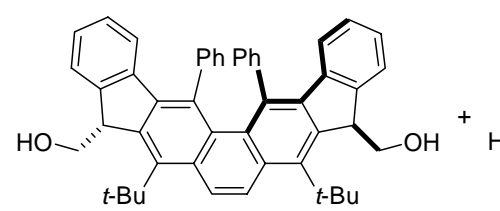

II-48a

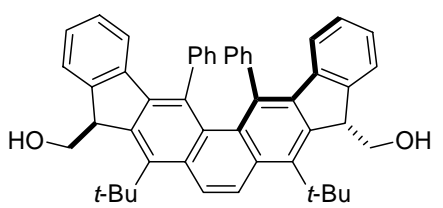

II-48b

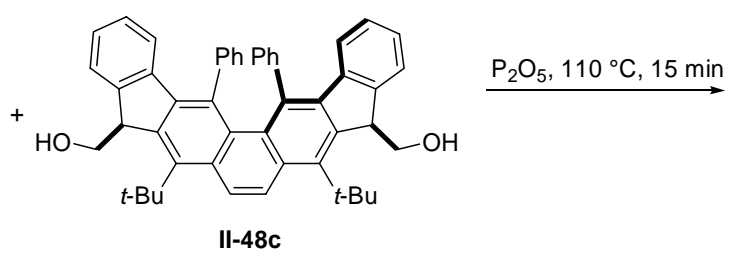

II-48a + II-48b + II-48c $=76 \%$

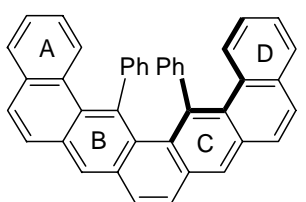

II-49, 73\%

X-ray

The novel helical structures of I-19a, II-8, II-22 and II-49 might possess unique properties associated with their inherent chirality. ${ }^{30}$ In order to exploit the potential properties of these novel compounds, resolution of them is first needed. Resolution of hydrocarbons without any functional group is not easy. Since two hydroxyl groups have been introduced during the ring expansion processes, the resolution of the corresponding diols could be much easier. 


\section{II-5.2. Results and discussion}

Separation of the mixture of II-48a-c afforded two pure diastereomers, II-48a or II-48b having $C_{2}$ symmetry and II-48c without $C_{2}$ symmetry. The strategy to resolve the enantiomers of II-48a or II-48b and II-48c is to make diastereomers from them. Treatment of II-48a or II-48b and II-48c with Mosher's reagent afforded the corresponding Mosher's diesters II-50a or II-50b and II-50c in excellent yield (Scheme II-11). These Mosher's diesters could be separated by recrystallization using the mixed solvents of ethanol and methylene chloride. In each case, we could get one pure diastereomer which was crystallized first from the solvent mixture. The two diastereomers crystallized out first happened to have different type of helices which were indicated by the opposite optical rotations. Efforts trying to do ring expansion of the Mosher's diesters were not successful. Deprotection of Mosher's diesters was achieved by using excess amount lithium aluminum hydride. The use of DME as the solvent was critical; the deprotection reaction did not work when either ethyl ether or THF was used as the solvent

\section{Scheme II-11.}

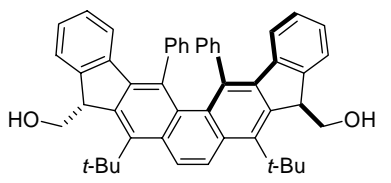

II-48a or II-48b 2.2 eq. Mosher's reagent

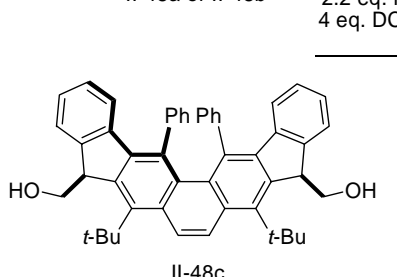

$1-48 c$

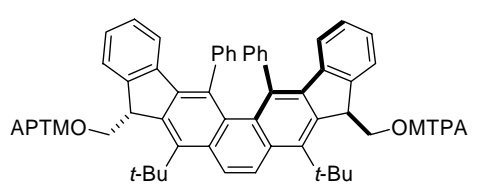

II-50a or II-50b

1). recrystallization 1). recrystallization

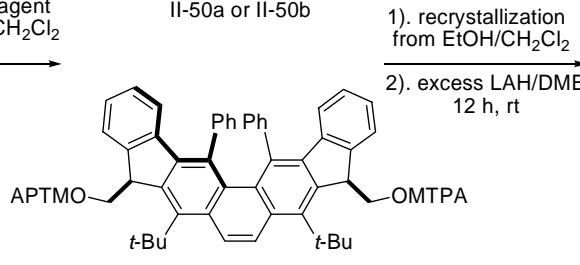

II-50c

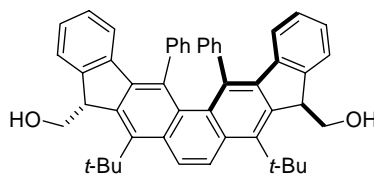

one enantiomer from II-48a or II-48b

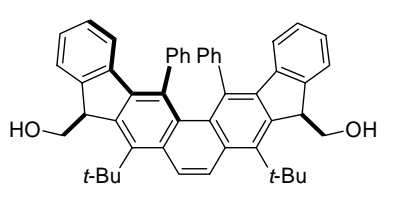

one enantiomer from II-48c 


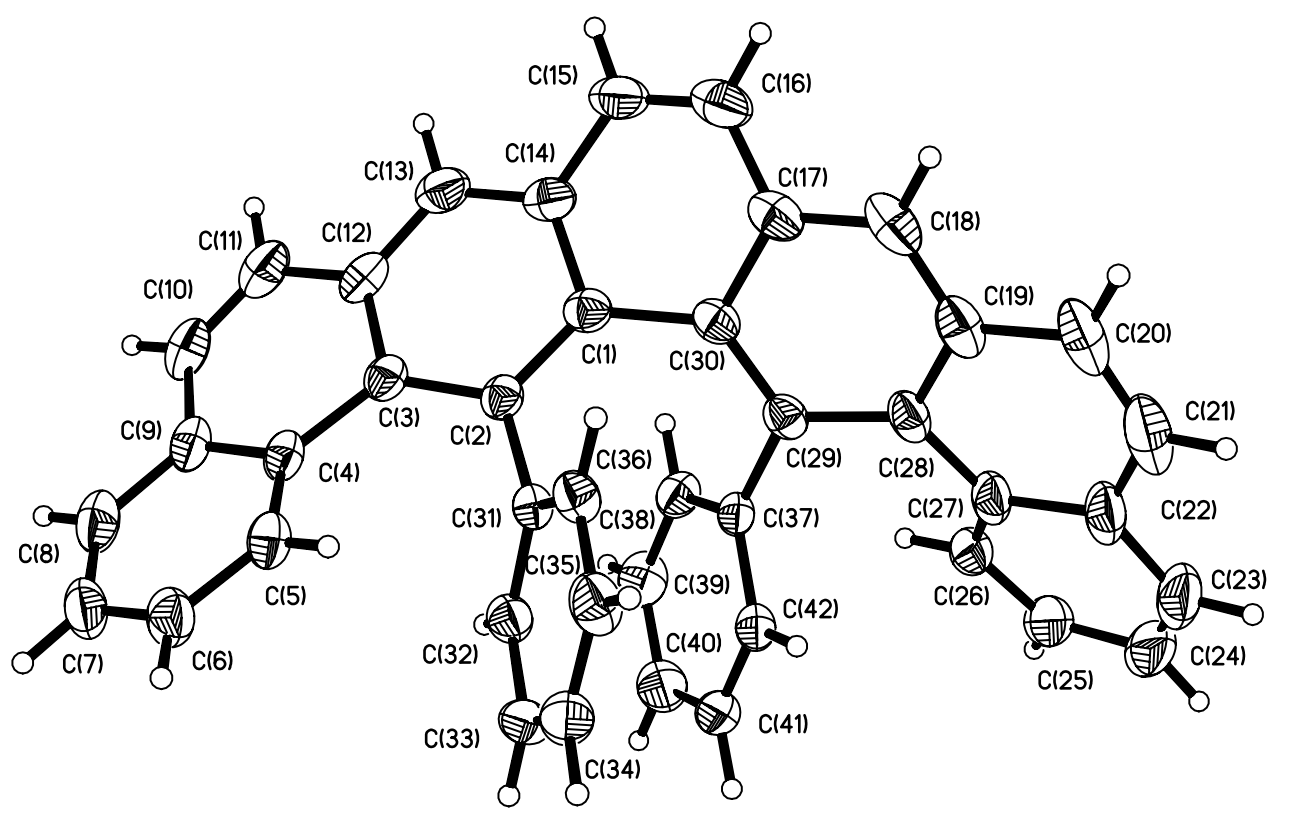

Figure II-5. ORTEP drawing of the crystal structure of II-49

The X-ray structure of II-49 shows that the two phenyl groups are oriented essentially parallel to each other with the dihedral angle between bonds attaching phenyl groups to the polycyclic ring system at $68.6^{\circ}$. The perpendicular distance between the planes of the two nearly parallel phenyl groups is ca. $2.6 \AA$ much shorter than the optimum $\pi$-system van der Walls contact distance of ca. $3.4 \AA$. It is interesting to note that the crystal structure of II-49 does not contain a crystallographic 2-fold rotation axis. The full aromatic 7-ring system is also severely distorted with a $31^{\circ}$ twist angle between the mean planes of rings $\mathrm{A}$ and $\mathrm{B}$ and a $27^{\circ}$ twist angle between the mean planes of rings $\mathrm{C}$ and $\mathrm{D}$ and a more pronounced $43^{\circ}$ twist angle between the mean planes of rings $\mathrm{B}$ and $\mathrm{C}$. 


\section{II-5.3. Conclusion}

Resolution of the diols from I-19a using the enantiopure Mosher's reagent provides an efficient chemical method to get pure enantiomers of these novel structures.

Table II-1. Comparison of X-ray structures of II-1, I-19a, II-8, II-22 and II-49

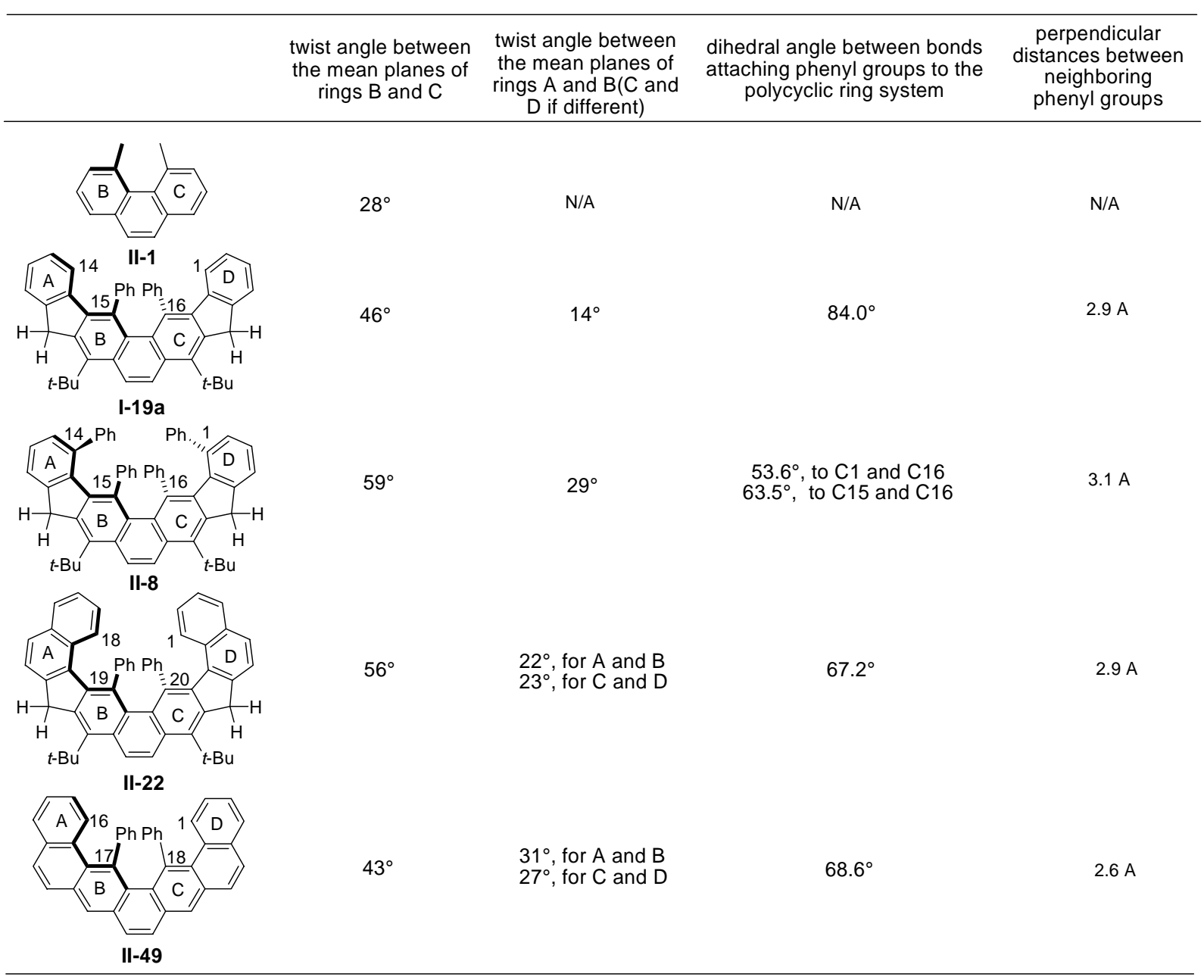




\section{CHAPTER 3}

\section{Synthesis of ABCD ring core of the camptothecin family of alkaloids}

\section{III-1. Retrosynthetic analysis}

\section{III-1.1. Introduction}

The potent antitumor and antibiotic activities of the camptothecin family of alkaloids have stimulated intense interest in developing synthetic methods for the parent (20S)-camptothecin (III-1a) and related analogues. ${ }^{31}$ Diverse approaches to the assembly of the pentacyclic ring structure have been reported. ${ }^{31 \mathrm{e}}$ The efforts have borne fruits with the approval of topotecan (III-1b) by the FDA for the treatment of ovarian cancer and small-lung cancer ${ }^{32}$ and irinotecan (III-1c) for refractory colorectal cancer. ${ }^{33}$ Several other camptothecin analogues are also in various stages of clinical trials.

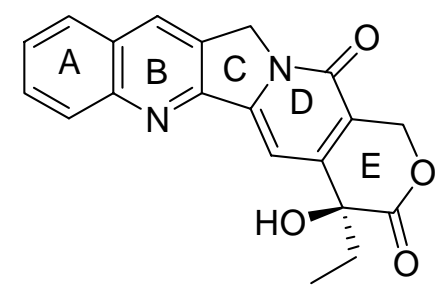

III-1a: S-(+)-Camptothecin<smiles>CC[C@@]1(O)C(=O)OCc2c1cc1n(c2=O)Cc2cc3c(CN(C)C)c(O)ccc3nc2-1</smiles>

III-1b: topotecan<smiles>CCc1c2c(nc3ccc(OC(=O)N4CCC(N5CCCCC5)CC4)cc13)-c1cc3c(c(=O)n1C2)COC(=O)[C@@]3(O)CC</smiles>

While the lactone $\mathrm{E}$ ring of camptothecins is essential in targeting DNA topoisomerase $\mathrm{I}^{34}$ the $\mathrm{ABCD}$ ring core can be modified with substituents to promote DNA binding. ${ }^{34,35}$ Alkaloids structurally related to camptothecin but without the E 
ring such as mappicine (III-2a) and mappicine ketone (III-2b) are also biologically important compounds. ${ }^{36}$<smiles>CC[C@H](O)c1cc2n(c(=O)c1C)Cc1cc3ccccc3nc1-2</smiles>

III-2a: Mappicine<smiles>CCC(=O)c1cc2n(c(=O)c1C)Cc1cc3ccccc3nc1-2</smiles>

III-2b: Mappicine ketone

\section{III-1.2. Representative strategies for construction of the $A B C D$ ring core}

The major synthetic strategies for the construction of the ABCD ring core include (i) the C-ring construction approach; ${ }^{37}$ (ii) the cascade radical cyclization approach; ${ }^{38}$ (iii) the Friedlander condensation approach; ${ }^{39}$ (iv) the Michael addition approach ${ }^{40}$ and (v) the Diels-Alder reaction approach. ${ }^{41}$

(i) the C-ring construction approach:

Connection of the $\mathrm{AB}$ - and $\mathrm{D} / \mathrm{E}$ fragments via an $N$-alkylation followed by a $\mathrm{sp}^{2}-\mathrm{sp}^{2}$ carbon-carbon bond formation is straightforward. This approach is represented by the Comin's asymmetric synthesis of III-1a (scheme III-1). ${ }^{37 \mathrm{~d}}$

The $\mathrm{AB}$ ring fragment III-3 was synthesized from the commercially available 2-chloro-3-formyl quinoline by treatment of TMSI and triethylsilane. Lithiation of 2-methoxy pyridine followed by trapping with a formamide gave an intermediate, which was subsequently quenched with $\mathrm{I}_{2}$, after reduction by $\mathrm{NaBH}_{4}$, to produce the pyridine III-4. Deprotection of the methyl ether in III-4 and subsequent protection of the two hydroxyl groups were conducted in one pot under TMSI/paraformaldehyde conditions to give III-5. Lithiation of III-5, addition to a keto ester, subsequent 
deprotection and simultaneous lactonization were achieved in one pot to give the lactone III-6. Alkylation of III-6 with III-3 afforded III-7, which then underwent a Heck coupling reaction to give III-1a.

\section{Scheme III-1.}

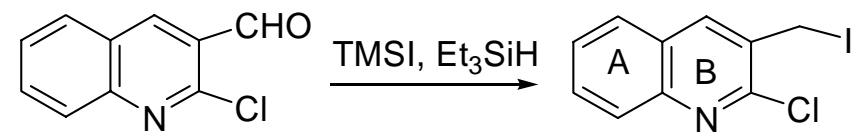

III-3
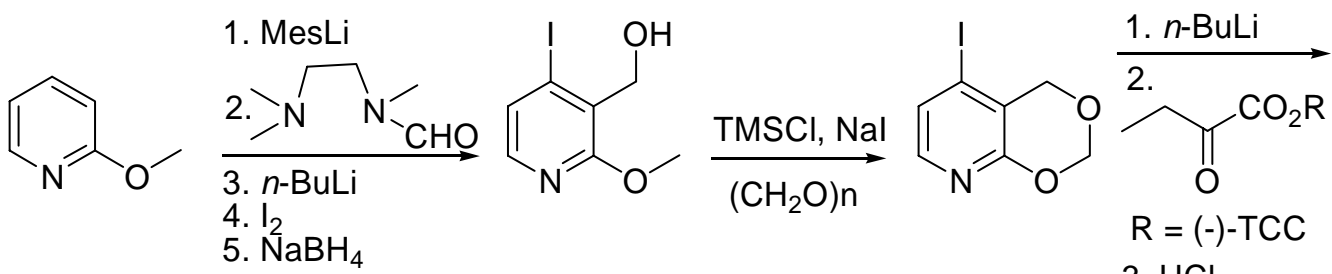

III-4, 46\%

III-5, 87\%

3. $\mathrm{HCl}$<smiles>CC[C@]1(O)C(=O)OCc2c1cc[nH]c2=O</smiles>

III-6, $60 \%$

III-7, 81\%

(ii) the cascade radical cyclization approach:

The $\mathrm{A}$ and $\mathrm{D} / \mathrm{E}$ fragments involved in a cascade free-radical cyclization leading to the formation of the B and C rings. This approach is represented by Curran's elegant synthesis of III-1a (scheme III-2). ${ }^{38 \mathrm{e}}$

Treatment of 2,6-dibromopyridine with sodium methoxide, $\mathrm{BuLi} / \mathrm{TMSCl}$ produced III-8, which was sequentially subjected to $t$ - BuLi, a formamide, $\mathrm{BuLi}$, and $\mathrm{I}_{2}$ to give pyridine III-9. Reductive etherification of III-9 under $\mathrm{Et}_{3} \mathrm{SiH} / \mathrm{TFA}$ produced ether III-10, which then underwent a Heck reaction to give vinyl ether III-11. Sharpless asymmetric dihydroxylation followed by oxidation under $\mathrm{CaCO}_{3} / \mathrm{I}_{2}$ of III-11 
produced lactone III-12, which was then treated with ICl to give III-13. Deprotection of the methyl ether of III-13, followed by a selective $N$-alkylation and a radical annulation with phenyl isonitrile then produced III-1a.

\section{Scheme III-2.}<smiles>CN(O)c1ccc(Br)nc1Br</smiles><smiles>COc1cccc(N(CCN(C)C=O)CCN(C)C(C)(C)C)n1</smiles>

III-8

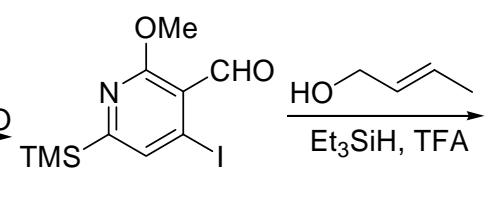

III-9, 49\%

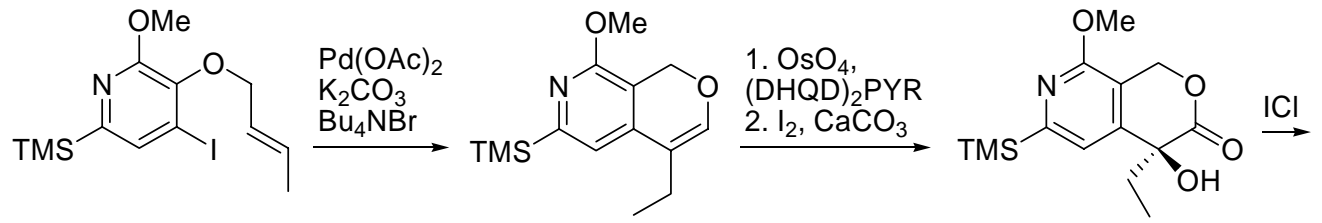

III-10, 63\%

III-11, 69\%

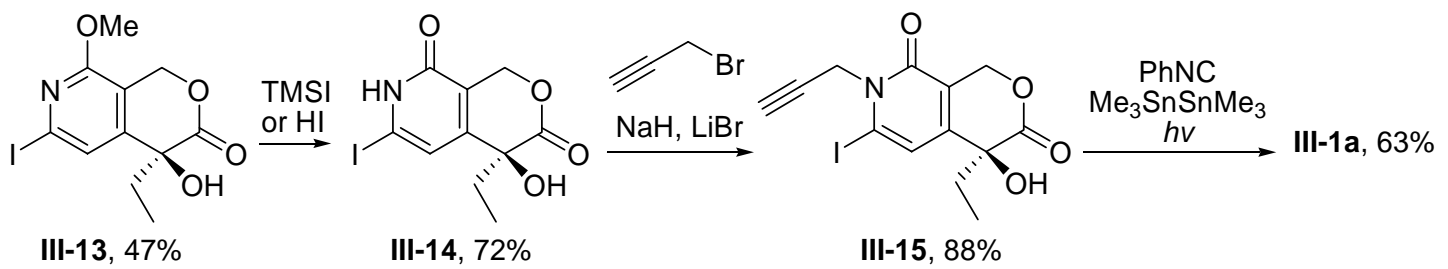

(iii) the Friedlander condensation approach:

Condensation of the $\mathrm{A}$ and the $\mathrm{CD} / \mathrm{E}$ ring fragments offered a reliable approach to prepare camptothecin analogs. This approach is represented by the following asymmetric total synthesis of III-1a (scheme III-3). ${ }^{39}$

Reduction of lactone III-16 with DIBAL-H followed by mesylation and elimination produced vinyl ether III-18, which was then subjected to a sharpless asymmetric dihydroxylation, a subsequent oxidation and an acidic condition for the removal of the acetal protective group to give lactone III-20. Frieldlander condensation of III-20 
with an acetal protected amino aldehyde then produced III-1a.

\section{Scheme III-3.}

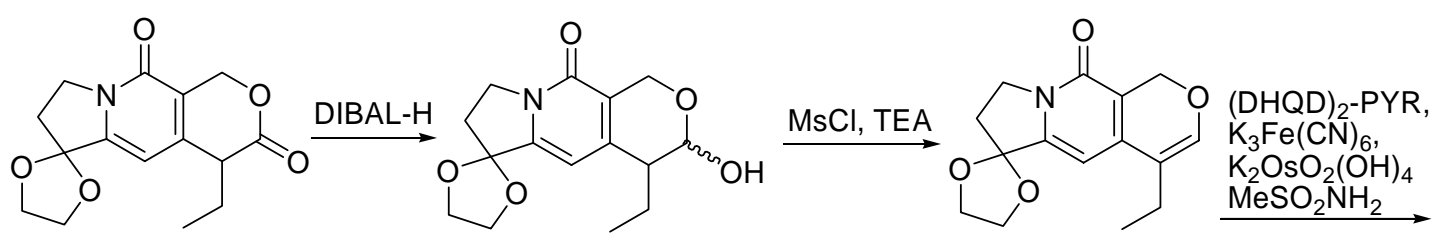

III-16

III-17, 94\%

III-18, 96\%<smiles>CC[C@]1(O)c2cc3n(c(=O)c2CO[C@H]1O)CCC31OCCO1</smiles>

III-19, 74\%<smiles>CC[C@]1(O)C(=O)OCc2c1cc1n(c2=O)CCC1=O</smiles>

III-20, 84\%<smiles>Nc1ccccc1C1OCCO1</smiles>

III-1a, $69 \%$

(iv) the Michael addition approach:

Michael addition reactions have been applied to the construction of the pyridone D ring of camptothecin. This approach is represented by Ciufolini's asymmetric total synthesis of III-1a (scheme III-4). ${ }^{40 a}$

Enzymatic resolution of III-21, followed by diethyl amidization and reduction with DIBAL-H then afforded the aldehyde III-23. Treatment of III-24 with a lithium phosphate produced III-25, which was condensed with III-23 to give enone III-26. Intermolecular Michael addition of the potassium enolate of 2-cyanoacetamide to III-26 produced III-27, which was then treated with $\mathrm{SeO}_{2}$ and $t$ - $\mathrm{BuOOH}$ to form the pyridone ring and subsequently with acid to give the pyridine lactone III-28. Reduction of the lactone of III-28 followed by treatment with acid then gave III-1a. 


\section{Scheme III-4.}

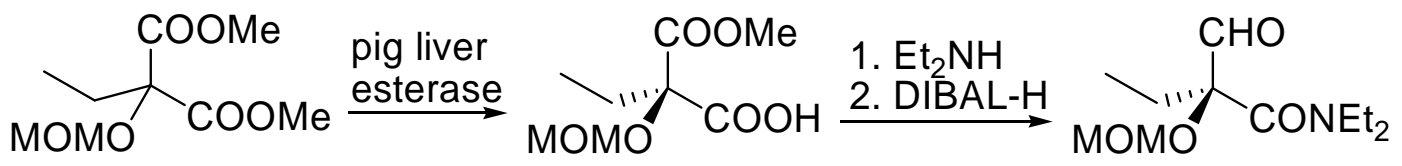

III-21

III-22, 90\% $>98 \%$ ee

III-23, 90\%

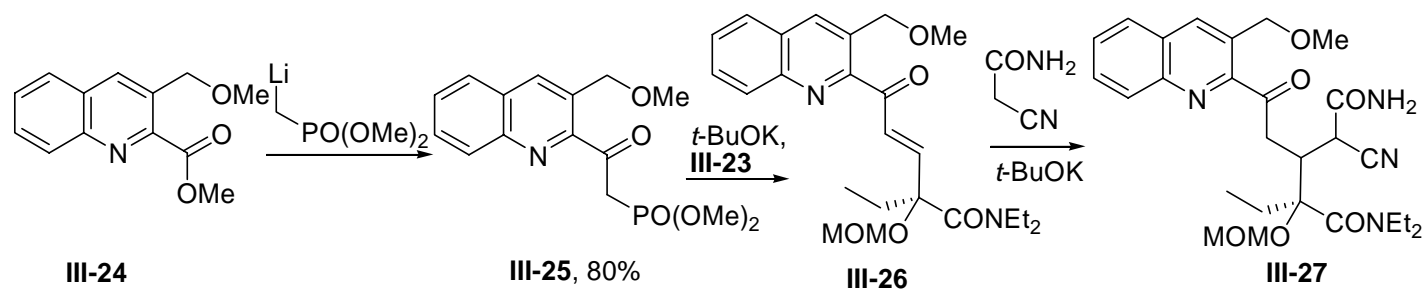

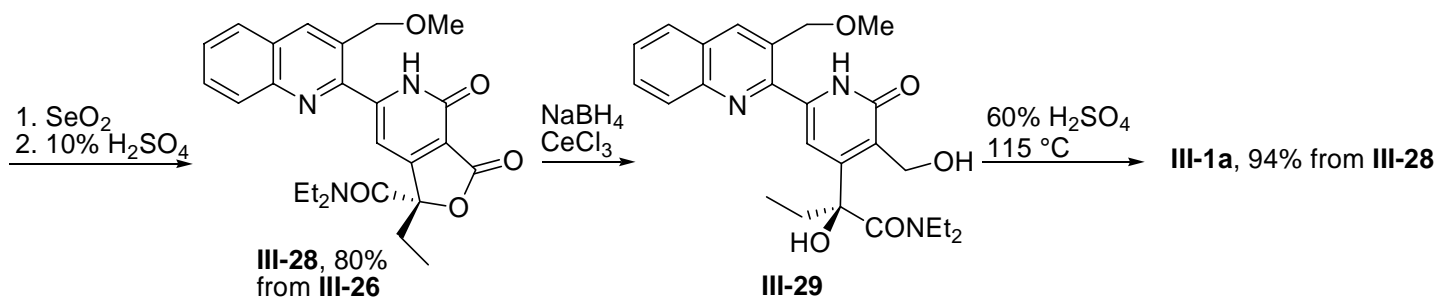

(v) the Diels-Alder reaction approach

Diels-Alder reactions have been applied to the construction of the pyridine B ring and pyridone D ring of camptothecin. This approach is represented by Fortunak's asymmetric total synthesis of III-1b (scheme III-5). ${ }^{41 \mathrm{~b}}$

Michael addition between III-30 and III-31 followed by hydrogenolysis gave acid III-33. An intramolecular Diels-Alder reaction of III-34 afforded III-35, which was deprotected with HBr to give amine III-36. Coupling of amine III-36 with acid III-33 produced III-37, which was then treated with TFA followed by DDQ to give III-38. Reduction of the ester and subsequent lactonization afforded III-39, which underwent deprotection of the methyl ether and a Mannich reaction to give III-1b. 


\section{Scheme III-5.}
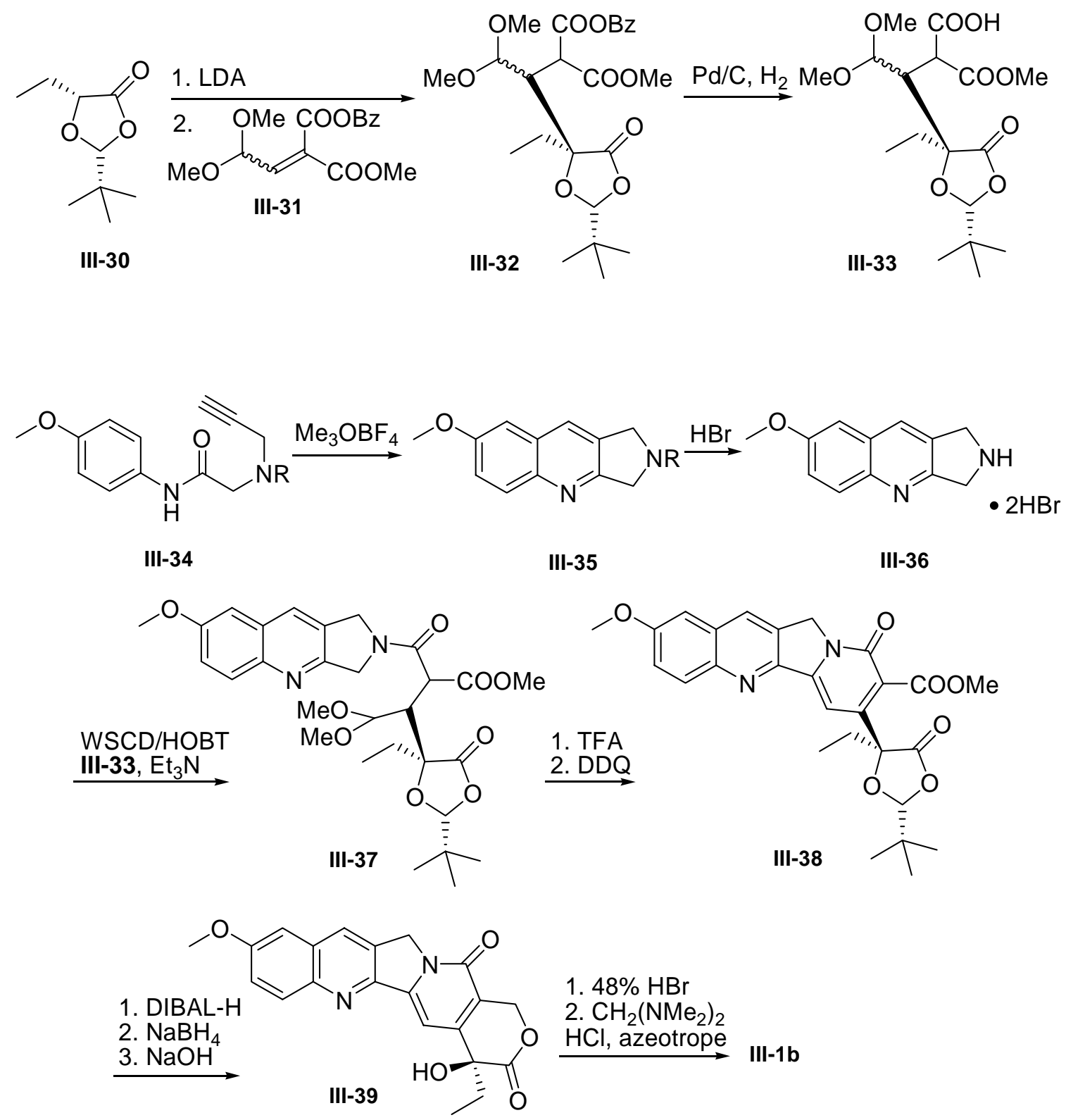

\section{III-1.3. Potential routes employing our allene cyclization chemistry}

We have applied the $C^{2}-C^{6}$ allene (heteroallene) cyclization chemistry in synthesizing a variety of 6-5-6-6 tetracyclic aromatics including those structurally related to ellipticine. ${ }^{10,42}$ Our continued interest in allene cyclization chemistry prompted us to 
apply it to the construction of the skeleton of the potent antitumor and antibiotic camptothecin family of alkaloids.

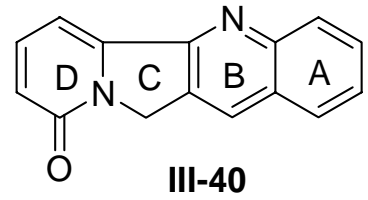

There are two potential routes to synthesize the ABCD ring core III-40 employing our allene cyclization chemistry.

(i) the retrosynthetic enallene-isonitrile approach:

The $\mathrm{ABCD}$ ring core III-40 could be generated from the enallene-isonitrile intermediate III-41, which is envisioned to be made from the formanilide III-42.

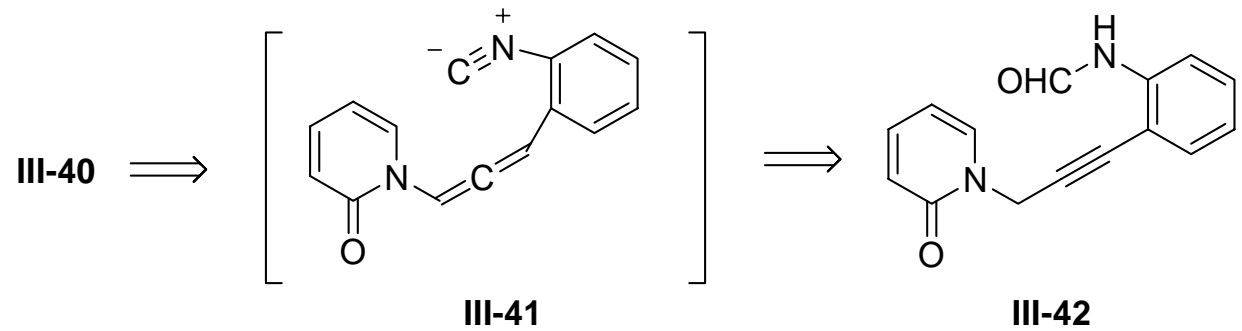

(ii) the retrosynthetic allene-nitrile approach:

The allene-nitrile intermediate III-43 might have a chance to undergo [4+2] cycloaddition leading to the ABCD ring core III-40.<smiles>COCCOCCO</smiles><smiles>C1=CCCCC1</smiles>

|| $\mid-43$<smiles>N#Cc1cccc(=O)n1CC#Cc1ccccc1</smiles>

III-44

\section{III-1.4. Challenges for enallene-isonitrile approach}

We envision that the enallene-isonitrile intermediate III-41 will be prepared from the 2-alkynylformanilide III-42. The challenges are that we need to generate the two active functionalities, the allene and the isonitrile, at the same time. Otherwise: 
(i) if the isonitrile is generated first:

Benzannulated enyne-isonitriles could undergo nucleophile-induced cyclization under mild conditions to give the 2,3-disubstituted quinolines, ${ }^{43}$ which will be very difficult to avoid.<smiles>[R]C#Cc1ccccc1N=[C-][R6]c1cc2nc(OC)c([R])cc2cc1OC</smiles>

III-45

III-46<smiles>[R]C#Cc1ccccc1[N+]#[C-]</smiles>

$\mathrm{R}=t-\mathrm{Bu}, c-\mathrm{Hex}, \mathrm{CH}_{2} \mathrm{OCH}_{3}$ and $\mathrm{Ph}$

(ii) if the allene is generated first:

Compounds III-49 will be easy to undergo intramolecular cyclization to form compounds III-50 under mild conditions, ${ }^{44}$ which also will be difficult to avoid.<smiles>[R]C=C=Cc1ccccc1N</smiles>

III-49<smiles>[R]Cc1cc2ccccc2[nH]1</smiles>

III-50

\section{III-1.5. Challenges for allene-nitrile approach}

Enediynes, enyne-allenes (including heteroallenes) and enyne-isonitriles have found success in organic synthesis, but the use of the isoelectronic nitrile group as a substitute for the alkynyl group was less successful. (Z)-2,4,5-Hexatrienenitriles III-51 showed remarkable thermal stability at 150 to $260{ }^{\circ} \mathrm{C}^{5}$ and the related compound III-52 polymerized at $150{ }^{\circ} \mathrm{C} .{ }^{45}$ 
<smiles>[R]C([R])=C=CC=CC#N</smiles>

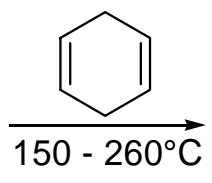

unchanged or unidentified products

III-51, $\mathrm{R}=\mathrm{Me}$ or $t-\mathrm{Bu}$<smiles>C=C=Cc1ccccc1C#N</smiles>

III-52

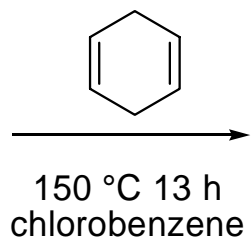
chlorobenzene polymeric material 
III-2. Preparation for enallene-isonitrile approach: Synthesis of indeno-fused derivatives of quinolizinium salts, imidazo[1,2-a]pyridine, pyrido[1,2-a]indole, and 4H-quinolizin-4-one via benzannulated enyne-allenes

\section{III-2.1. Introduction}

Benzannulated enyne-allenes bearing an aryl substituent at the alkynyl terminus have been shown to undergo the Schmittel cyclization reaction to produce the corresponding benzofulvene biradicals under mild thermal conditions. ${ }^{4}$ One such example involves a potassium $t$-butoxide-promoted 1,3-prototropic rearrangement of the benzannulated enediyne III-53 to produce in situ enyne-allene III-54 for the subsequent Schmittel cyclization reaction to generate biradical III-55 (Scheme III-6). ${ }^{18}$ The presence of a second phenyl substituent at the allenic terminus of III-54 permits an intramolecular radical-radical coupling to furnish the formal Diels-Alder adduct III-56, which in turn undergoes a prototropic rearrangement to afford III-57 as a benzo[b]fluorene derivative. Several other synthetic methods have also been reported to furnish enyne-allenes for similar cascade transformations to a variety of benzo[b]fluorenes and related polycyclic aromatic compounds. ${ }^{46}$ 


\section{Scheme III-6.}
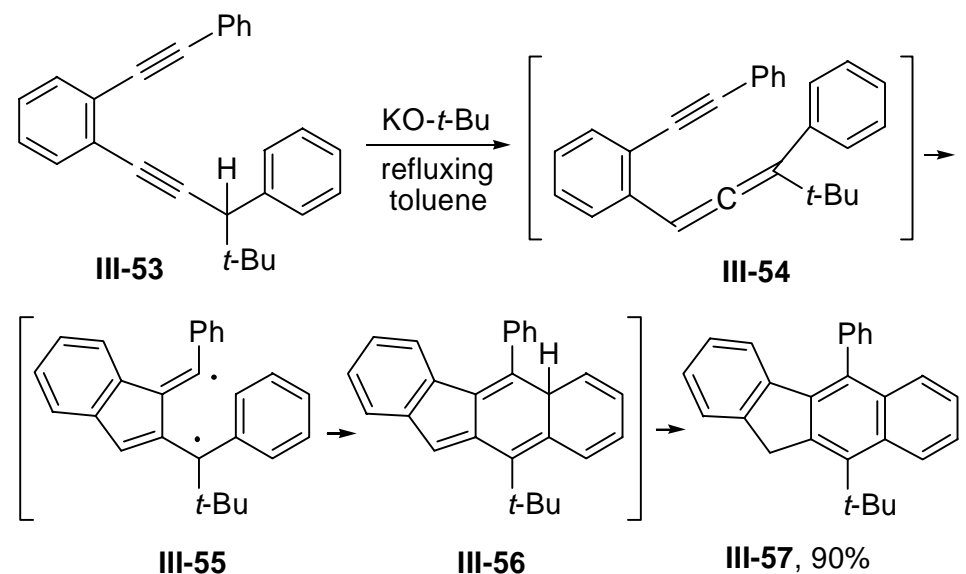

By placing a heteroaromatic substituent at the allenic terminus of the enyne-allene system, the cascade reaction sequence has been reported to lead to the derivatives of $10 H$-indeno[1,2-g]quinoline, $9 H$-fluoreno[2,3-b]furan, $9 H$-fluoreno[2,3-b]thiophene, and $5 H$ - and $6 H$-indeno[2,1-f]indolizines. ${ }^{4 \mathrm{~b}, 47}$ A similar strategy also finds success in the enyne-carbodiimide ${ }^{10,42 \mathrm{~d}}$ and enallene-isonitrile systems, ${ }^{48}$ producing a variety of novel heteroaromatic compounds. We have further applied this synthetic strategy to the preparation of the indeno-fused derivatives of quinolizinium salts, imidazo[1,2-a]pyridine, pyrido[1,2- $a]$ indole, and 4H-quinolizin-4-one, taking advantage of the facile 1,3-prototropic rearrangements of the corresponding benzannulated enediynes to furnish the requisite enyne-allenes for subsequent cascade transformations to heteroaromatic ring systems.

\section{III-2.2. Results and Discussion}

The synthetic sequence outlined in Scheme III-7 provides an efficient route to benzannulated enediynes III-63a-c. The palladium-catalyzed Sonogashira reaction between 1-bromo-2-iodobenzene and phenylacetylene produced III-58 as reported previously. ${ }^{7}$ Treatment of III-58 with butyllithium followed by iodine then afforded 
III-59, which was used for a second palladium-catalyzed coupling with propargyl alcohol to give III-60 and subsequently, after treatment with methanesulfonyl chloride and triethylamine, mesylate III-61. Upon exposure of III-61 to 4-aminopyridine, 4-(dimethylamino)pyridine, and 4-methoxypyridine, the benzannulated enediynes III-63a-c were obtained in essentially quantitative yield. ${ }^{49}$ Efficient transformations of III-63a-c to the indeno-fused quinolizinium methanesulfonates III-67a-c were achieved also in essentially quantitative yield with triethylamine in ethanol. The products III-67a-c appeared to be free of other byproducts as judged by ${ }^{1} \mathrm{H}$ NMR spectra without the need for purification by column chromatography. The structures of III-67a-c were established by X-ray structure analyses. Presumably, a 1,3-prototropic rearrangement of III-63 occurred to give the corresponding benzannulated enyne-allenes III-64, which then underwent either a concerted Diels-Alder reaction or a two-step process involving a Schmittel cyclization reaction to form biradical III-65 followed by an intramolecular radical-radical coupling to afford III-66. A subsequent prototropic rearrangement then produced the indeno-fused quinolizinium methanesulfonates III-67. It is worth noting that several 2-amino-substituted quinolizinium salts and related compounds were reported to exhibit interesting biological activities and pronounced DNA-binding properties. ${ }^{50}$ 
Scheme III-7.

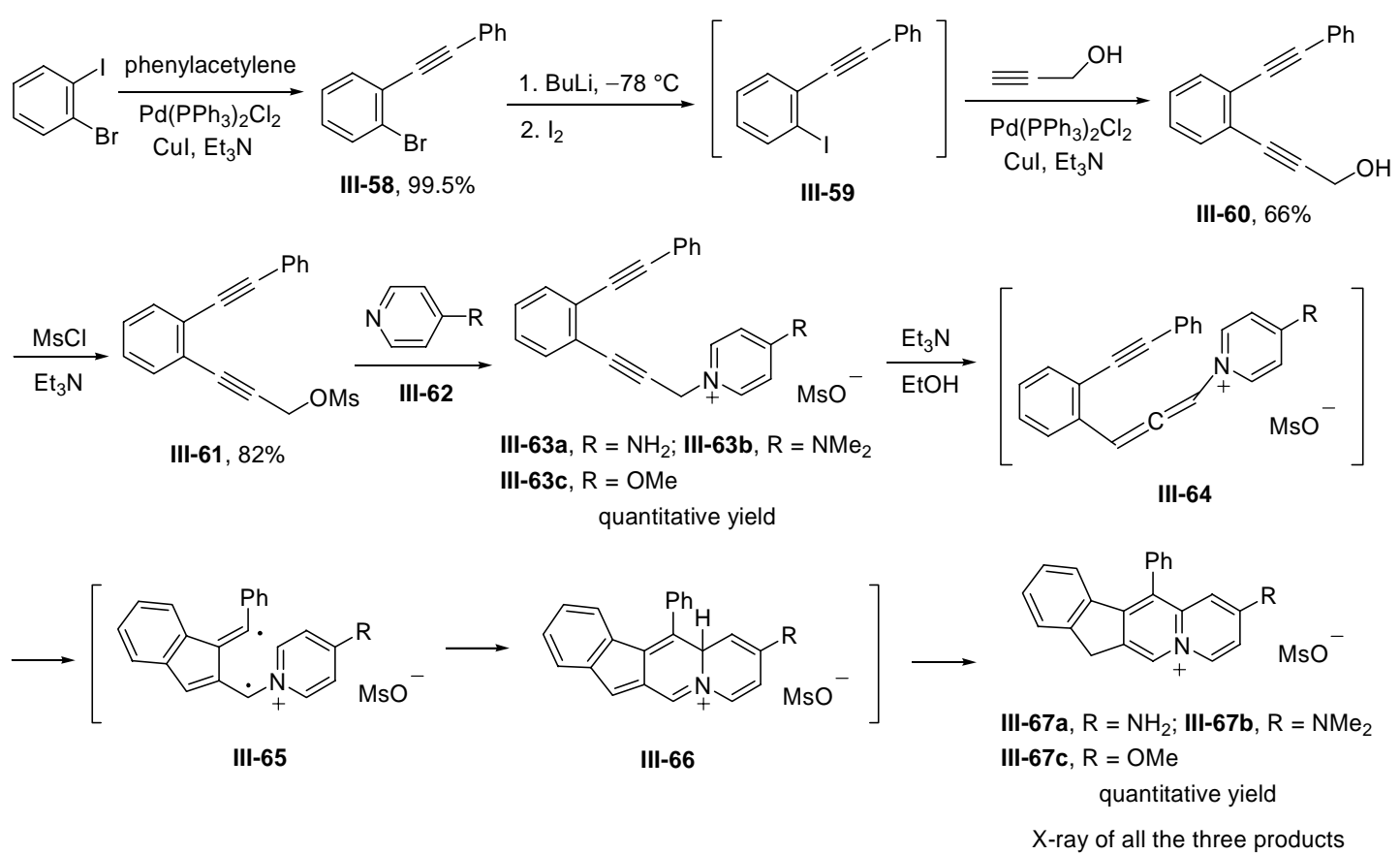

It was reported earlier that placing a sterically demanding substituent, such as $t$-butyl or trimethylsilyl, at the alkynyl terminus of the enyne-allene system also directed the biradical-forming reaction toward the Schmittel cyclization pathway. ${ }^{4 \mathrm{~d}}$ We have thus synthesized the benzannulated enediynes III-71a and III-71b bearing a $t$-butyl group and a trimethylsilyl group at the alkynyl terminus, respectively, as outlined in Scheme III-8. The starting iodide III-68 was prepared by the palladium-catalyzed Sonogashira reaction between 1,2-diiodobenzene and propargyl alcohol as described previously. ${ }^{51}$ Unlike III-63b, which underwent cyclization on exposure to triethylamine at room temperature to form III-67b, it was necessary to heat the reaction mixtures of III-71a and III-71b under refluxing ethanol to produce III-72a and III-72b. It was also necessary to purify the resulting products by column chromatography because significant amounts of unidentified byproducts were present 
as indicated by ${ }^{1} \mathrm{H}$ NMR spectra. Purification by column chromatography on neutral alumina resulted in an exchange of the mesylate anion by chloride to produce quinolizinium chlorides III-73a and III-73b in relatively low yields. The structure of III-73a was established by X-ray structure analysis.

\section{Scheme III-8.}
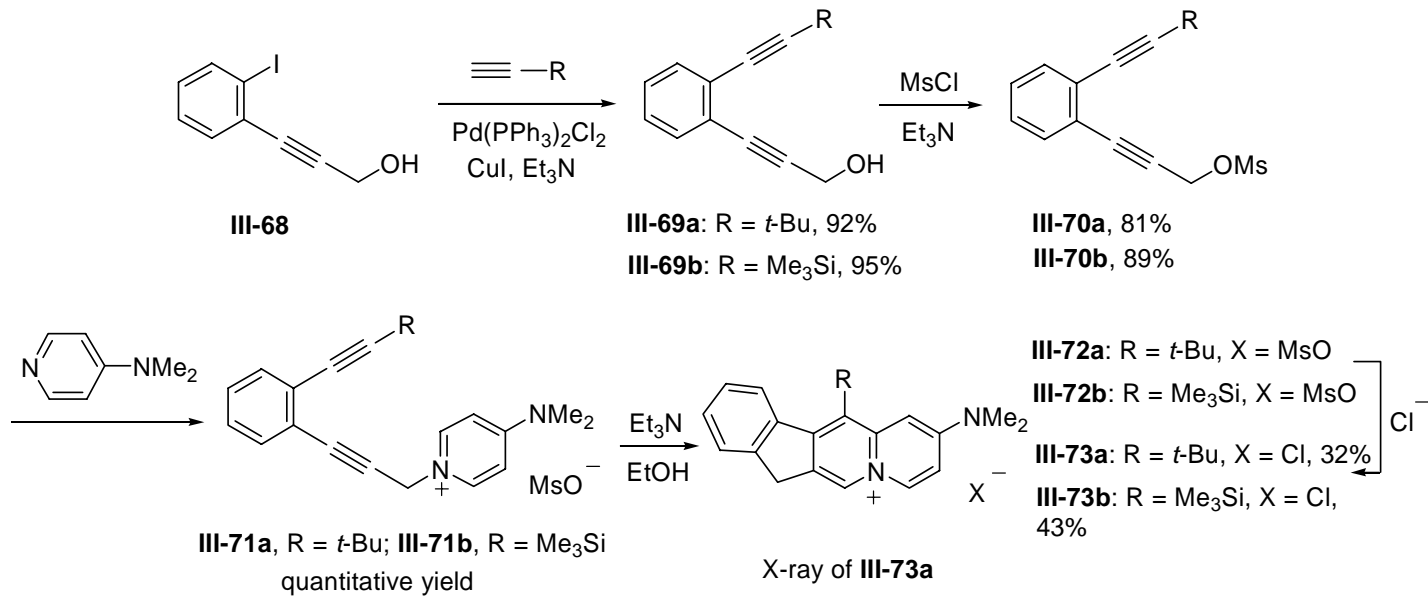

An attempt to alkylate imidazole with III-61 in a mixture containing sodium hydroxide and tetrabutylammonium iodide to produce III-74 resulted in the formation of the indeno-fused imidazo[1,2-a]pyridine III-76 directly albeit in relatively low yield (Scheme III-9). Presumably III-74 was formed initially, which then underwent a sodium hydroxide-promoted 1,3-prototropic rearrangement to the corresponding benzannulated enyne-allene III-75 for the subsequent cascade reaction sequence to yield III-76. Alternatively, the palladium-catalyzed Sonogashira reaction between III-59 and 1-(2-propynyl)-1H-imidazole (III-77) ${ }^{52}$ was employed to produce III-74. Under the reaction condition, a mixture of the benzannulated enediyne III-74 and the cyclized adduct III-76 (III-74:III-76 = 1:4) was produced in 94\% combined yield (Scheme III-10). Upon treatment of the mixture with potassium $t$-butoxide, III-74 
was converted to III-76 in essentially quantitative yield. The structure of III-76 was established by X-ray structure analysis. A variety of imidazo[1,2- $a$ ]pyridine derivatives were also reported to exhibit useful pharmacological activities. ${ }^{53}$

\section{Scheme III-9.}

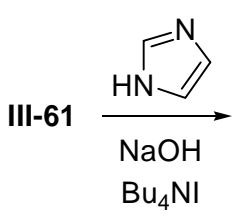

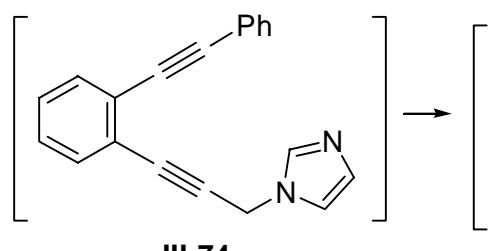

III-74<smiles>C(=Cc1ccccc1C#Cc1ccccc1)=Cn1ccnc1</smiles>

III-75

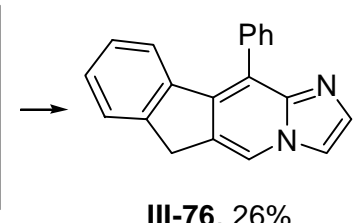

X-ray

Scheme III-10.

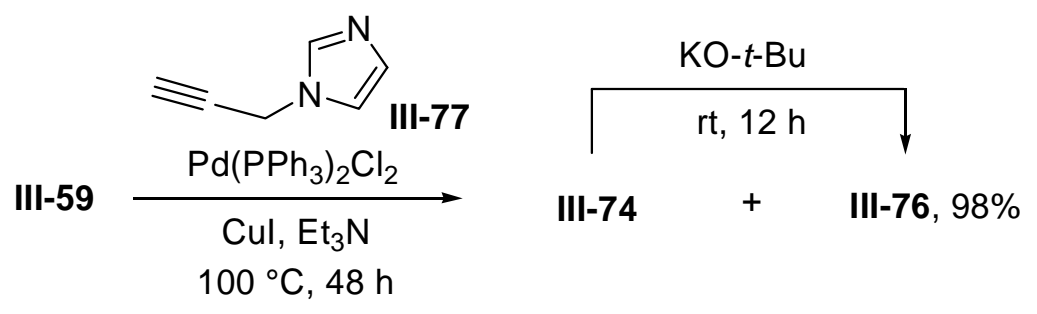

Unlike biradicals III-65, a direct intramolecular radical-radical coupling involving a $\pi$ bond of the imidazole substituent of biradical III-78 could not be achieved (Scheme III-11). Instead, a 6-exo-trig radical cyclization reaction involving the carbon-nitrogen double bond to form biradical III-79 occurred and, after a prototropic rearrangement, produced III-76. This is reminiscent of what had been observed previously in a benzannulated enyne-allene system bearing a 1-pyrrolyl substituent at the allenic terminus. ${ }^{47}$ It is also worth noting that because III-81 was not observed the radical cyclization reaction did not appear to occur with the carbon-carbon double bond of the imidazole ring to give biradical III-80. 


\section{Scheme III-11.}

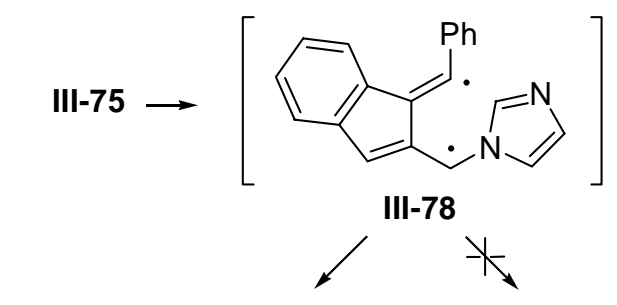

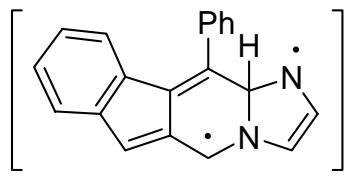

III-79

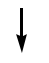

III-76

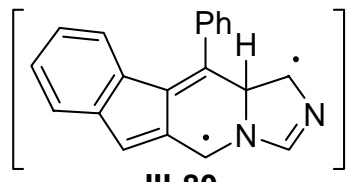

III-80

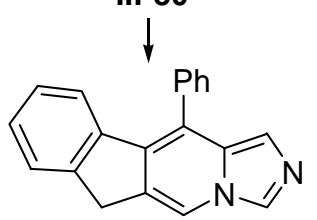

III-81, not observed

The palladium-catalyzed Sonogashira reaction between III-59 and 1-(2-propynyl)- $1 H$-indole (III-82) ${ }^{54}$ was successful in producing $\mathbf{I I I - 8 3}$ in excellent yield (Scheme III-12). Treatment of III-83 with potassium $t$-butoxide at room temperature for 48 hours produced the indeno-fused pyrido[1,2- $a]$ indole III-84 in $98 \%$ yield. It was reported that some pyrido[1,2- $a$ ]indole derivatives were unstable on exposure to air and decomposed to tarry materials in chloroform and methylene chloride solutions. ${ }^{55}$ The ${ }^{1} \mathrm{H}$ NMR spectrum of III-84 in $\mathrm{CDCl}_{3}$, taken immediately after the solution was prepared, was found to be relatively clean. However, the solution gradually turned dark on standing at room temperature. Attempts to purify III-84 by silica gel column chromatography also appeared to cause some decomposition. 


\section{Scheme III-12.}
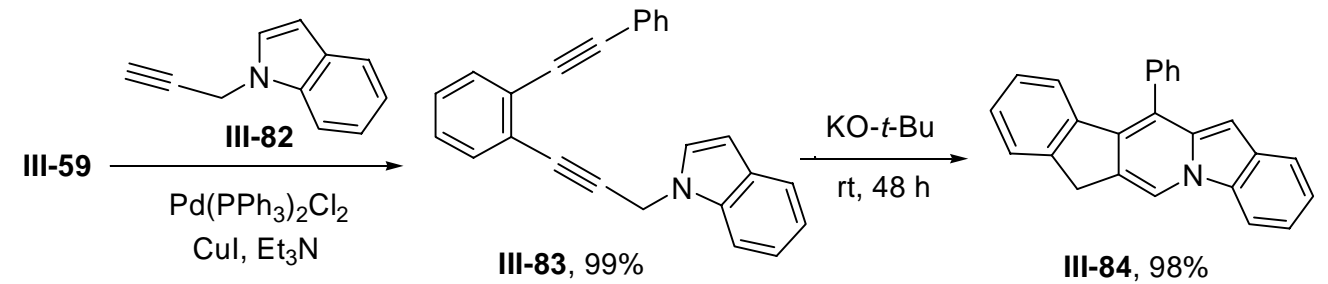

Similarly, III-86 was produced from coupling between III-59 and 1-(2-propynyl)-2(1H)-pyridinone (III-85) ${ }^{52}$ (Scheme III-13). Treatment of III-86 with potassium $t$-butoxide under refluxing toluene for twelve hours produced the indeno-fused $4 H$-quinolizin-4-one III-87 in 58\% yield. The structure of III-87 was established by X-ray structure analysis. Development of new synthetic pathways to $4 H$-quinolizin-4-ones is an area of interest because these heteroaromatic compounds could serve as precursors to naturally occurring alkaloids possessing interesting biological activities. $^{56}$

\section{Scheme III-13.}
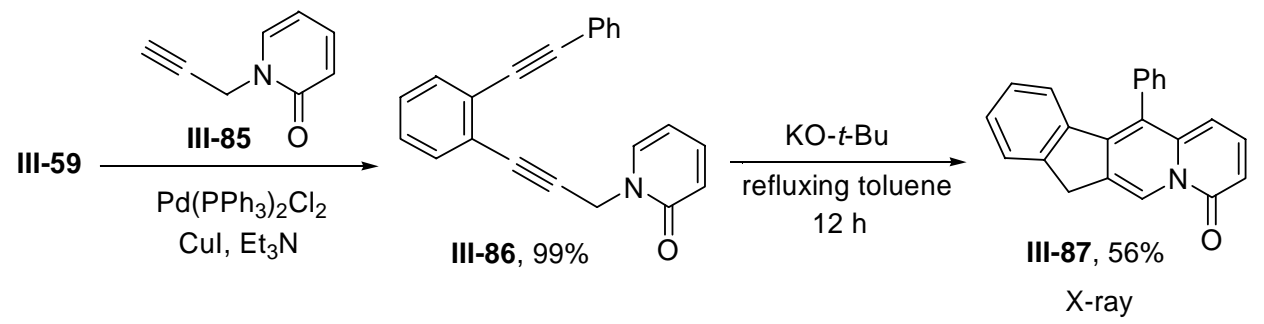

\section{III-2.3. Conclusions}

Benzannulated enyne-allenes bearing a heteroaromatic substituent at the allenic terminus are excellent precursors of a variety of indeno-fused heteroaromatic ring systems. The use of the 1,3-prototropic rearrangement of the corresponding benzannulated enediynes to furnish enyne-allenes is especially attractive because of 
simplicity of the procedure and ready availability of enediynes with diverse structural features. The resulting heteroaromatic compounds are of interest as potential candidates for pharmacological applications. 


\section{III-3. Enallene-isonitrile approach.}

\section{III-3.1. Introduction}

Compounds III-63 and III-86 have successfully been the precursors to the tetracyclic III-67 and III-87. ${ }^{57}$ The transformations from III-63 and III-86 to III-67 and III-87 presumably involved the benzannulated enyne-allenes. Although the feasibility of generating biradicals by thermolysis of enyne-isonitriles did not appear to have been explored, the isonitrile group has been recognized as a synthon of geminal radical precursor and acceptor in radical chemistry. ${ }^{58}$ We envisioned that replacing the enyne moieties with the reactive isonitrile, the resulting benzannulated enallene-isonitrile system might have excellent opportunities to generate biradicals under mild conditions, leading to the core heteroaromatic ring system of the camptothecin family of alkaloids.

\section{III-3.2. Results and Discussion}

Dr. Xiaoling Lu synthesized compound III-88, which upon exposure to $\mathrm{POCl}_{3}$ for dehydration afforded III-91 having the core heteroaromatic ring system of the camptothecin family of alkaloids (Scheme III-14). ${ }^{48}$ Presumably, dehydration followed by the 1,3-prototropic rearrangement of the propargylic pyridinium salt as observed previously produced in situ III-89, which then underwent a sequence of reactions, including cycloaromatization, intramolecular radical-radical coupling, to III-91.

Dr. Xiaoling Lu also synthesized compound III-92, which upon exposure to $\mathrm{POCl}_{3}$ 
afforded the 2-substituted indole III-95 in essentially quantitative yield (Scheme III-15). ${ }^{48}$ One of the pathways that could be used to account for the formation of III-95 involves a rapid 1,3-prototropic rearrangement to produce the putative intermediate III-93 before dehydration to form the isonitrile could occur. A subsequent intramolecular attack of the central carbon of the allenic moiety by the nitrogen of the formanilide or of the corresponding formimino phosphate could give III-94 or a related phosphate derivative leading to III-95.

\section{Scheme III-14.}<smiles>C=[N+]c1ccccc1C=C=C[n+]1ccc(N(C)C)cc1</smiles>

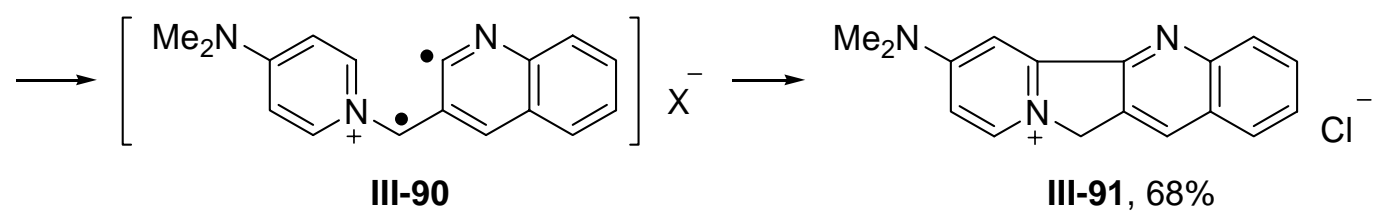

\section{Scheme III-15.}<smiles>[3H][PH+]([O-])c1ccc(NCc2ccccc2NC=O)c(C#CC[n+]2ccc(OC)cc2)c1</smiles>

$$
\mathrm{MsO}^{-} \quad \mathrm{III}-92
$$

III-93
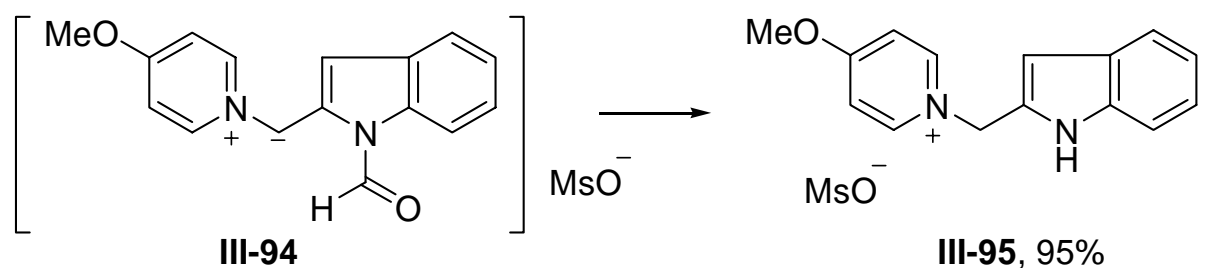

Compound III-42 was prepared by the palladium-catalyzed cross-coupling between

2-iodoformanilide and III-85 (Scheme III-16). Efforts to transfer III-42 into III-40 
were not successful. Presumably, the intermediate III-41 was not formed, which might have chance to lead to III-40 as the allene intermediates in synthesizing III-67, III-87 and III-91 did. .8,57 $^{\text {III }}$

\section{Scheme III-16.}

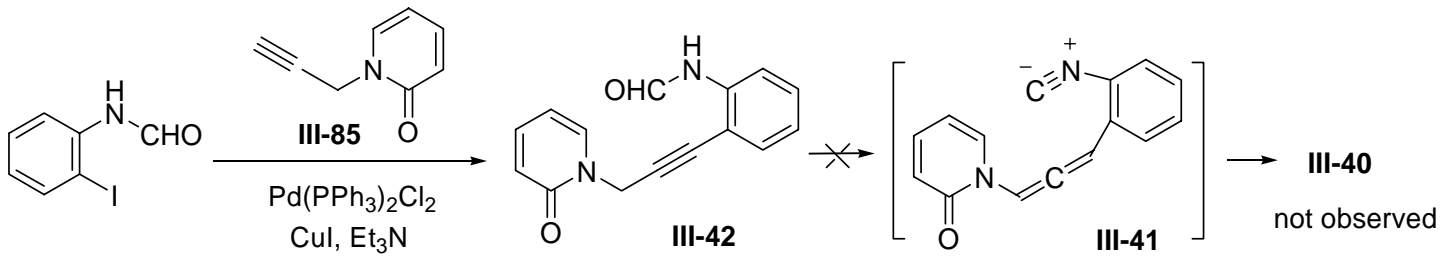

Exposure of the mixture of the palladium-catalyzed cross-coupling solution between

2-iodoformanilide and III-85 to air for a long time afforded III-98 in essentially quantitative yield (Scheme III-17). Presumably, a rapid 1,3-prototropic rearrangement produced III-96, which then underwent an intramolecular cyclization leading to III-97 as III-93 leading to III-95 or an intramolecular cyclization involving palladium catalyst produced III-97 directly. III-97 could then be oxidized to III-98.

\section{Scheme III-17.}
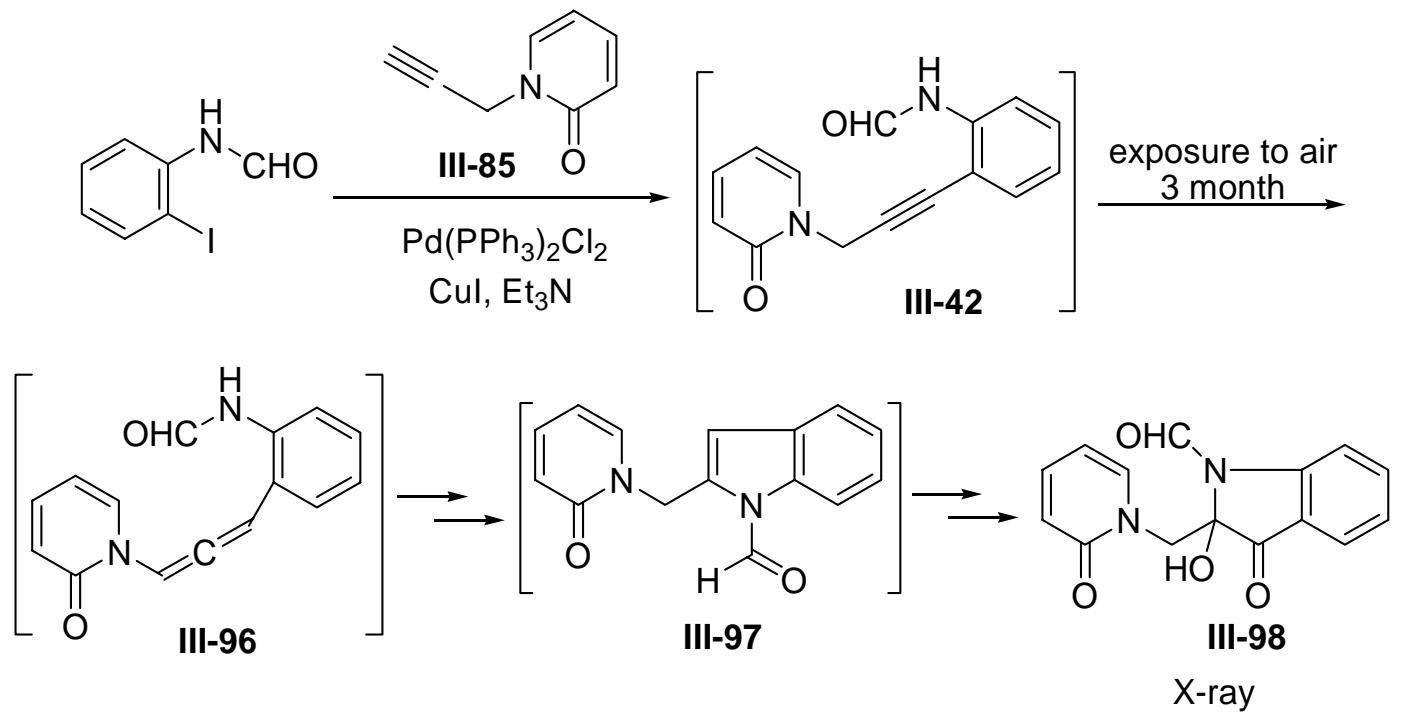

\section{III-3.3. Conclusions}

A new synthetic pathway involving the benzannulated enyne-isonitriles to 
$11 H$-indolizino[1,2-b]quinoline and related compounds was established. The successful cyclization of III-88 to III-91 via the benzannulated enallene-isonitrile intermediate III-89 demonstrated that the isonitrile group could serve as a synthon of geminal radical in the bidiradical cyclizations. The failure of cyclizations of III-42 and III-92 to the corresponding tetracyclic heterocycles was probably because the corresponding benzannulated enallene-isonitriles were not formed. 


\section{III-4. Preparation for allene-nitrile approach.}

\section{III-4.1. Introduction}

In the model reaction of synthesizing the $\mathrm{ABCD}$ ring core of camptothecin family of alkaloids, compound III-86 only gave moderate yield of III-87 (Scheme III-18). ${ }^{57}$ Presumably, the transformations involved the formation of benzannulated enyne-allene intermediate III-99, which then underwent the $C^{2}-C^{6}$ cycloaddition, after tautomerization, to produce III-87. The pyridone ring substituent at the allenic terminus of benzannulated enyne-allene intermediate III-99 could be responsible for the medium yield because the vinyl radical at III-100 could then attack either carbon atom which is neighboring to the nitrogen atom on the pyridone ring.

\section{Scheme III-18.}
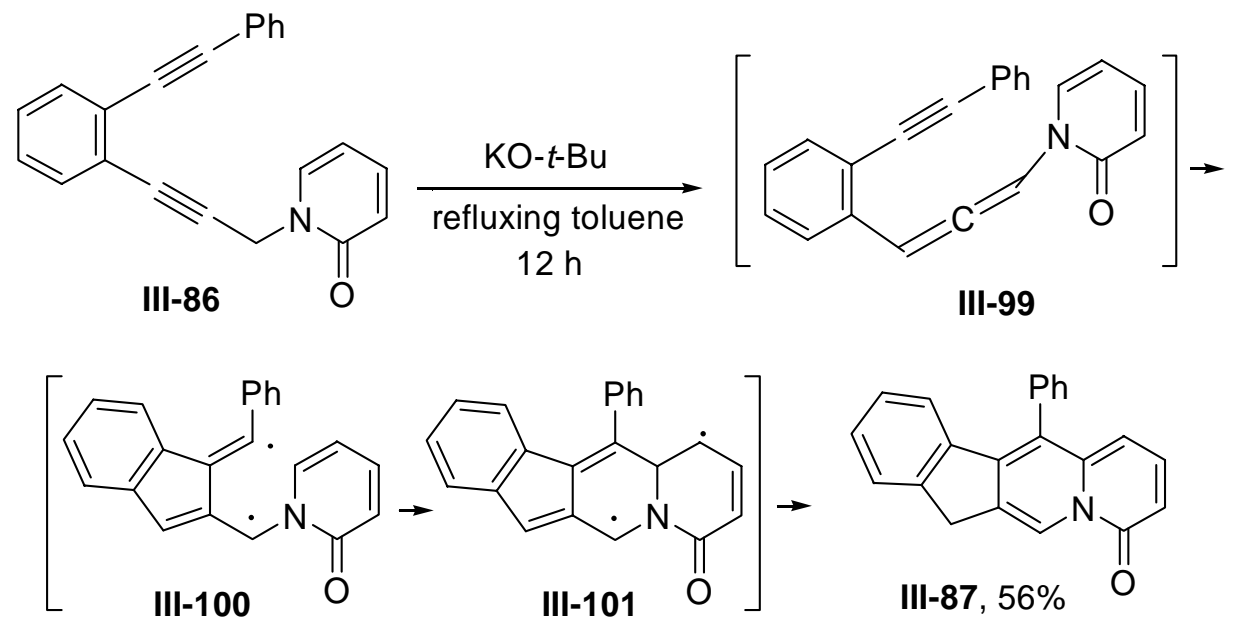

In order to avoid the possible loss of yield because the pyridone ring substituent is at the allenic terminus, a new system with the pyridone ring tether connecting the enyne and the possible allene moieties is needed to synthesize the polycyclic 
heteroaromatics with a pyridone ring subunit.

\section{III-4.2. Results and Discussion}

Compound III-102 was prepared by the palladium-catalyzed Sonogashira reaction between 2-bromo-6-methoxypyridine and phenylacetylene (Scheme III-19). Deprotection of the methyl ether in III-102, ${ }^{38 \mathrm{k}}$ followed by an $\mathrm{N}$-alkylation with the propargyl bromide afforded the pyridodiyne III-104, ${ }^{52}$ which then underwent another palladium-catalyzed Sonogashira reaction with iodobenzene to produce pyridodiyne III-105. Thermolysis of III-105 without any base under refluxing ethyl ethanol produced a mixture of III-106 and III-107. It was worth noting that III-105 in chloroform underwent slow cyclization reaction even at room temperature. It seemed that the cyclization reaction of III-105 did not require the initial formation of the allene intermediate.

Scheme III-19.

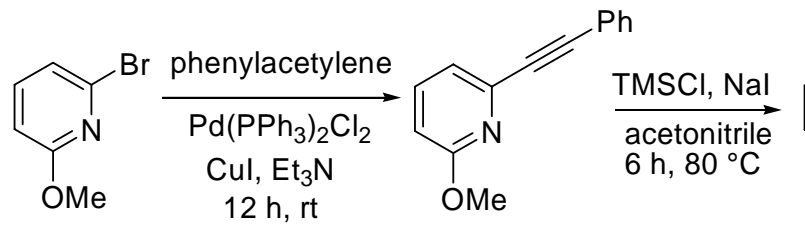

III-102, 96\%<smiles></smiles>

III-103

III-104,44\%

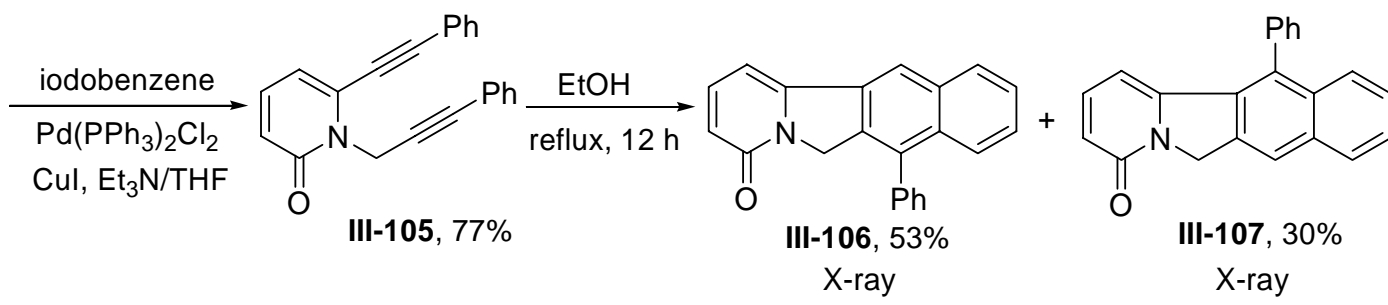

Compound III-108 was prepared by the palladium-catalyzed Sonogashira reaction between III-104 and 2-bromopyridine (Scheme III-20). Thermolysis of III-108 produced a mixture of III-109 and III-110. It was interesting to note that the cycloaddition of III-108 did not involve the carbon-nitrogen bond on the pyridyl ring. 
If the corresponding allene intermediate was formed first, the cyclization would prefer to involve the carbon-nitrogen bond on the pyridyl ring. ${ }^{42 \mathrm{~d}}$

Scheme III-20.

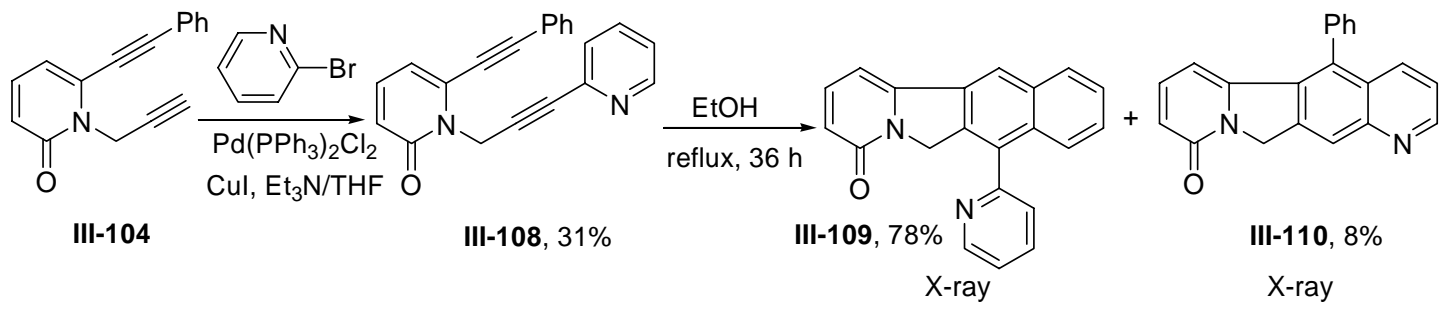

It was interesting that thermolysis of III-104 under refluxing $p$-xylene produced a mixture of III-112 and III-116 (Scheme III-21). Presumably, a direct [4+2] cycloaddition produced the cyclic allene intermediate III-111. ${ }^{59}$ In the solvent of p-xylene, the aromatizing isomerization of III-111 to III-112 was slow so that a portion of III-111 could undergo a six-electron electrocyclic opening to produce III-113, which was isomerized to III-114. [1,6]-electrocyclization of III-114 produced the new cyclic allene intermediate III-115, which then underwent aromatizing isomerization to III-116. 


\section{Scheme III-21.}<smiles>C#CCn1c(C#Cc2ccccc2)cccc1=O</smiles>

III-104

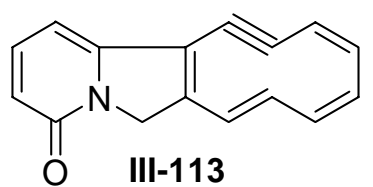<smiles>C=CC1C=Cc2cc3c(cc2C1)CC=CC=C3</smiles>

III-111<smiles>O=c1cccc2n1Cc1cc3ccccc3cc1-2</smiles>

X-ray<smiles></smiles><smiles>CCCCCn1c2ccccc2c2ccccc21</smiles>

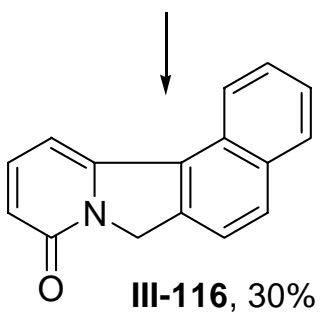

It was very encouraging to find that the thermal cyclization of the pyridodiynes

III-104 and III-105 was easier compared with that of the corresponding benzodiynes III-117, III-120, III-123 and III-125 (Table III-1). ${ }^{59 a}$ Thermal cyclization of III-105 happened under refluxing ethyl ethanol $\left(78^{\circ} \mathrm{C}\right)$, but III-117 and III-120 required 100 ${ }^{\circ} \mathrm{C}$ and $170{ }^{\circ} \mathrm{C}$ respectively; thermal cyclization of III-104 happened under refluxing $p$-xylene $\left(138^{\circ} \mathrm{C}\right)$, but thermal cyclization of III-123 required $150{ }^{\circ} \mathrm{C}$ and III-125 did not undergo cyclization even under $170^{\circ} \mathrm{C}$.

\section{III-4.3. Conclusions}

Pyridodiynes could undergo thermal cyclizations without requiring the initial formation of the corresponding allene intermediates. It provides an excellent new synthetic pathway to the analogs of the ABCD ring core of the camptothecin family of alkaloids. 
Table III-1. Comparison of Thermal Cyclization of Benzodiynes and Pyridodiynes

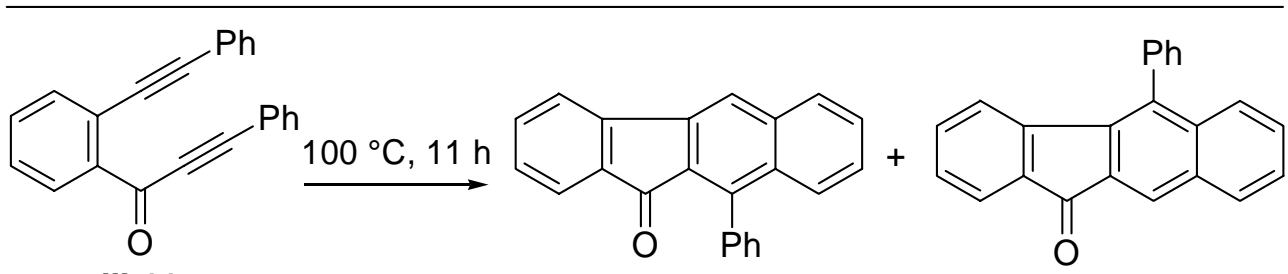

III-117

III-118, $72 \%$

III-119,24\%

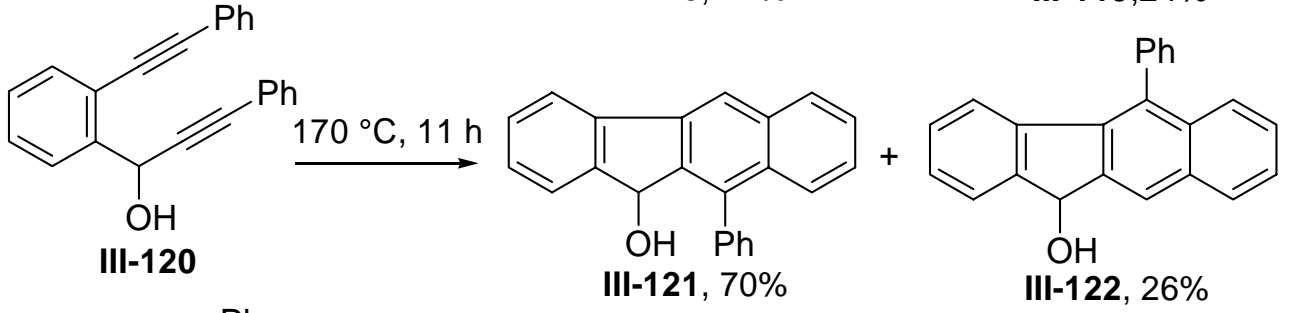<smiles>CC#CCn1c(C#CC)cccc1=O</smiles>

III-105<smiles>CCOCc1ccc2n(c1=O)Cc1c-2ccc2cc3ccccc3c(-c3ccccc3)c12</smiles>

III-106, 53\%<smiles>O=c1cccc2n1Cc1cc3ccccc3c(-c3ccccc3)c1-2</smiles>

III-107, 30\%<smiles>C#CC(=O)c1ccccc1C#Cc1ccccc1</smiles>

III-123<smiles>O=C1c2ccccc2-c2cc3ccccc3cc21</smiles>

III-124, 74\%

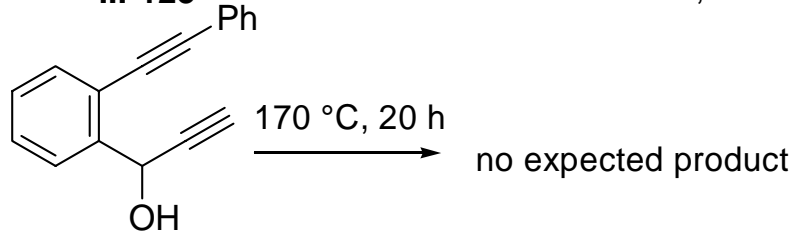

III-125

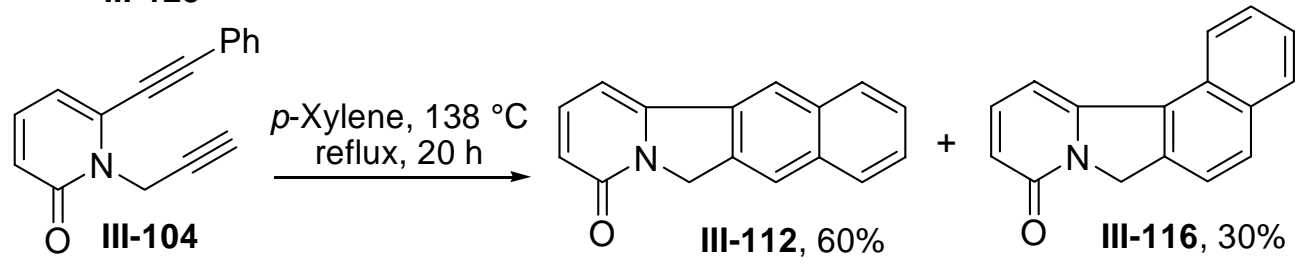




\section{III-5. Allene-nitrile approach.}

\section{III-5.1. Introduction}

The use of nitrile group as a substitute of alkynyl group in the thermolysis of enediynes, enyne-allenes was less successful. Diels-Alder reactions involving unactivated nitriles proceed only under harsh conditions to produce pyridine exclusively. ${ }^{60}$ But, compounds III-104 and III-105 are much easier to undergo the [4+2] cycloaddition compared with the corresponding benzene ring tether analogs. We envision that compound III-43 with a pyridone ring tether connecting the nitrile and the allene moieties and with a phenyl group at the allenic terminus might have a chance to undergo either a $\mathrm{C}^{2}-\mathrm{C}^{6}$ biradical cyclization or a formal [4+2] Diels-Alder reaction. The reasons are the potential ability of the pyridone ring to activate the nitrile and the regain of the aromaticity after the cyclization reaction.<smiles>N#Cc1cccc(=O)n1C=C=Cc1ccccc1</smiles>

III-43

\section{III-5.2. Results and Discussion}

The synthetic sequence outlined in Scheme III-22 involved the $N$-alkylation of III-126 with 3-bromo-1-phenylpropyne to produce III-44 in 86\% yield using Curran's protocol. ${ }^{61}$ Treatment of III-44 with DBU produced III-40 in essentially quantitative yield. Without DBU, III-44 was recovered. Presumably, the transformation from III-44 to III-40 involved an initial 1,3-prototropic rearrangement to form the 
corresponding allenic intermediate III-43, which underwent either a one step Diels-Alder reaction to the tetracyclic intermediate III-128 or a $\mathrm{C}^{2}-\mathrm{C}^{6}$ cyclization to the biradical intermediate III-127 and a subsequent intramolecular radical-radical coupling to III-128 followed by a second prototropic rearrangement to regain aromaticity to give III-40.

\section{Scheme III-22.}<smiles>N#Cc1cccc(=O)[nH]1</smiles>

III-126
III-43<smiles>Cc1ccc2n3cc(Cc4cccc(CC5=Cn6c(cccc6=O)C5=N)c4)cccc-3c(=O)n1Cc1cc3ccccc3nc1-2</smiles>

III-127

III-128

III-40, quantitative yield X-ray

We next demonstrated the feasibility to incorporate substituents on the A ring. All $N$-alkylations with the methoxyl group at different positions gave excellent yields (table 1). Cyclization of III-129 produced the only possible product III-133 in essentially quantitative yield. Cyclization of III-130 did not occur at the carbon connect to the methoxyl group, giving the only product III-134 in essentially quantitative yield. Cyclization of III-131 afforded a mixture of III-135 and III-136 ( $3: 4)$ in essentially quantitative yield. The product III-135 with the methoxyl group on the 10-position of the $\mathrm{ABCD}$ ring core is especially interesting. ${ }^{32,33}$ Compound III-132 with methoxyl group on both orth and meta positions produced the only 
product III-137 having a methoxyl group on the 10-position of the ABCD ring core in essentially quantitative yield.

Table III-2. $\quad N$-alkylation and Cyclization with substituted A ring

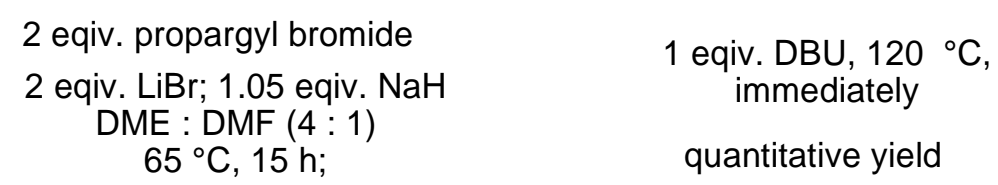<smiles>COc1ccc(C#CCn2c(C#N)cccc2=O)cc1</smiles><smiles>COc1ccc2cc3c(nc2c1)-c1cccc(=O)n1C3</smiles><smiles>COc1ccccc1C#CCn1c(C#N)cccc1=O</smiles><smiles>COc1cccc2nc3c(cc12)Cn1c-3cccc1=O</smiles><smiles>COc1cccc(C#CCn2c(C#N)cccc2=O)c1</smiles><smiles>COc1ccc2nc3c(cc2c1)Cn1c-3cccc1=O</smiles><smiles></smiles><smiles>COc1cccc(C#CCn2c([14CH3])cccc2=O)c1OC</smiles>

III-135: III-136 (3:4)<smiles>COc1ccc2nc3c(cc2c1OC)Cn1c-3cccc1=O</smiles>

Nitrile group has been employed for the construction of the ABCD ring core III-40 by Bowman and Coworkers (Scheme III-23). ${ }^{38 k}$ Treatment of III-138 with hexamethylditin produced III-40 via one pot cascade radical reactions in 73\% yield. One of the proposed mechanism was that the vinyl radical III-139 was initiated by the trimethyltin radical first, followed by a 5-exo cyclization onto the nitrile group to the iminyl radical intermediate $\mathbf{I I I - 1 4 0}$, then a 6-endo cyclization onto the carbon-carbon 
double bond of the benzene ring to the tetracyclic $\pi$-radical intermediate III-141, after losing a hydrogen, to the $\mathrm{ABCD}$ ring core III-40. Our approach to the $\mathrm{ABCD}$ ring cores is in a way similar to this. If the allenic nitrile intermediates could generate the biradical intermediates, the iminyl radical of which should be more prone to attack the carbon-carbon double bond of the benzene ring and the resulting tetracyclic intermediates should also be easier to regain the aromaticity to the ABCD ring cores. But the use of the isoelectronic nitrile group as a substitute for the alkynyl group of enyne-allene systems was less successful and there is no reported $C^{2}-C^{6}$ allenic nitile cyclization so far.

\section{Scheme III-23.}
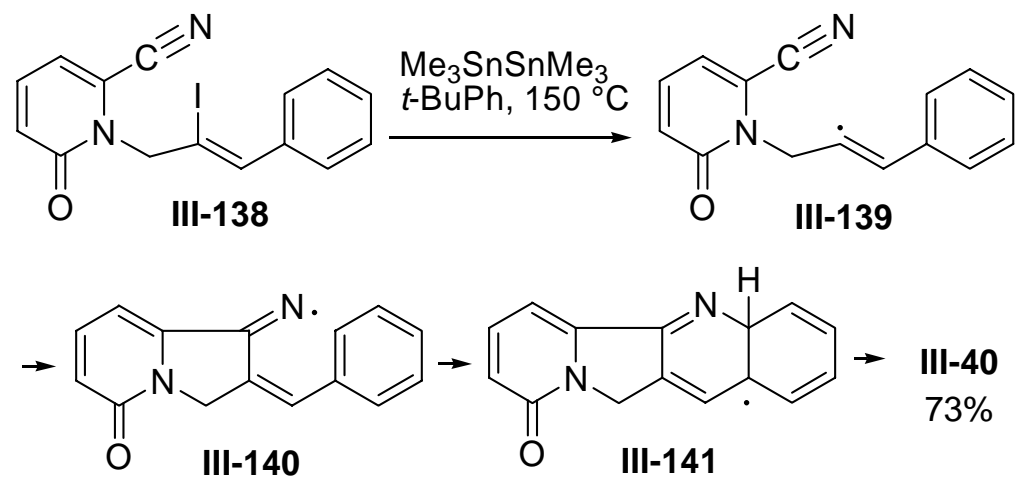

Heating compound III-138 without hexamethylditin also produced the ABCD ring core III-40 albeit in trace amount (eq III-1), which might indicate the mechanism involving a Diels-Alder cycloaddition to the tetracyclic intermediate III-142 followed by 1,4-conjugate elimination of HI. This could be appropriate to account for the mechanism of our approach to the ABCD ring cores. The Diels-Alder cycloaddition of unactivated nitrile group is still a challenge in organic synthesis, but the pyridone ring could activate the nitrile group. The ease to regain the aromaticity of the Diels-Alder adducts could be the driving force for the cyclization. 


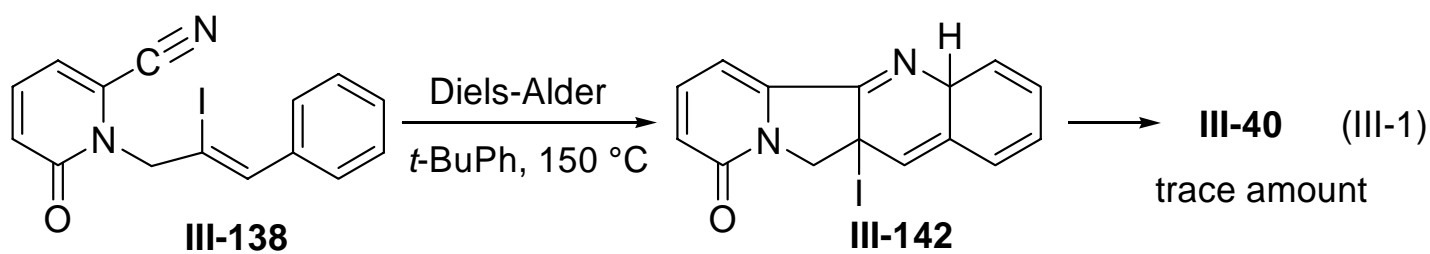

The bromide III-143 was prepared by treatment of 3-(2-methoxyphenyl)-2-propyn1-ol ${ }^{62}$ with methanesulfonyl chloride and triethylamine, then lithium bromide. The palladium-catalyzed Sonogashira reaction between 1-iodo-2,3-dimethoxybenzene and propargyl alcohol produced III-144, which was then treated with methanesulfonyl chloride and triethylamine, followed by lithium bromide to produce the bromide III-145 (Scheme III-24).

Scheme III-24.
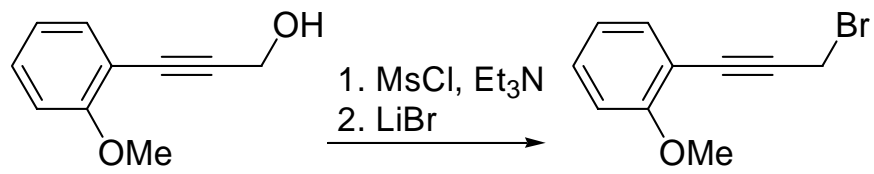

III-143, 89\%

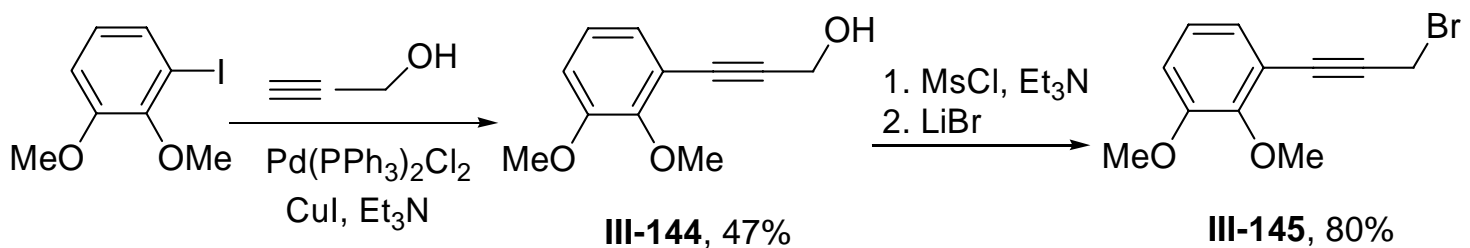

\section{III-5.3. Conclusions}

In conclusion, a new synthetic pathway to the parent and substituted $\mathrm{ABCD}$ ring cores of the camptothecin family of alkaloids has been developed. This metal-free, base-catalyzed cyclization method may provide insight for new cyclization pathways and could be suitable for large scale synthesis and it represents the first successful allenic nitrile cyclization. 


\section{Chapter 4}

\section{Experimental Section}

\section{General Experimental Methods}

All reactions were conducted in oven-dried $\left(120^{\circ} \mathrm{C}\right)$ glassware under a nitrogen atmosphere. Diethyl ether and tetrahydrofuran (THF) were distilled from benzophenone ketyl and triethylamine was distilled over $\mathrm{CaH}_{2}$ prior to use. Melting points were uncorrected. ${ }^{1} \mathrm{H}(270 \mathrm{MHz})$ and ${ }^{13} \mathrm{C}(67.9 \mathrm{MHz})$ NMR spectra were recorded in $\mathrm{CDCl}_{3}$ using $\mathrm{CHCl}_{3}\left({ }^{1} \mathrm{H} \delta\right.$ 7.26) and $\mathrm{CDCl}_{3}\left({ }^{13} \mathrm{C} \delta\right.$ 77.00) as internal standards unless otherwise indicated.

\section{Experimental Section of Chapter 2.1}

4-(Dimethylamino)pyridine, trifluoromethanesulfonic anhydride, phenylacetylene, $\operatorname{Pd}\left(\mathrm{PPh}_{3}\right)_{2} \mathrm{Cl}_{2}$, copper(I) iodide, dimethyl (2-oxopropyl)phosphonate, triethylsilane, trifluoroacetic acid, $2.5 \mathrm{M}$ solution of butyllithium in hexanes, $1.0 \mathrm{M}$ solution of potassium $t$-butoxide in THF, $p$-xylene (anhydrous), toluene (anhydrous), and 2,2-dimethylpropiophenone were purchased from chemical suppliers and were used as received. 2-Hydroxy-[1,1'-biphenyl]-3-carboxaldehyde (II-2) was prepared from 1,1'-biphenyl-2-ol according to the reported procedure. ${ }^{13}$ Dimethyl(1-diazo-2-oxopropyl)phosphonate ${ }^{14}$ was prepared from dimethyl(2-oxopropyl)phosphonate and $p$-dipivaloylbenzene ${ }^{7}$ was prepared from terephthaloyl chloride as reported previously.

Triflate II-3. To a mixture of II-2 (560 mg, $2.83 \mathrm{mmol})$, 4-(dimethylamino)pyridine (17 $\mathrm{mg}, 0.14 \mathrm{mmol}, 5 \mathrm{~mol} \%$ ) in $7 \mathrm{~mL}$ of methylene chloride and $7 \mathrm{~mL}$ of pyridine 
under a nitrogen atmosphere at $0 \quad{ }^{\circ} \mathrm{C}$ was added dropwise $0.95 \mathrm{~mL}$ of trifluoromethanesulfonic anhydride $(5.65 \mathrm{mmol})$. After $1.5 \mathrm{~h}$ of stirring at $0{ }^{\circ} \mathrm{C}, 20 \mathrm{~mL}$ of water was added. The resulting mixture was then extracted with diethyl ether $(3 \times$ $30 \mathrm{ml}$ ), and the combined organic layers were washed with $1 \mathrm{M} \mathrm{HCl}$ and brine, dried over sodium sulfate, and concentrated. Purification by flash column chromatography (silica gel/hexanes) gave II-3 (880 mg, 95\% yield) as a colorless liquid: IR 1712, $1698,1213,1138,882,766,700 \mathrm{~cm}^{-1} ;{ }^{1} \mathrm{H} \delta 10.32(1 \mathrm{H}, \mathrm{s}), 8.00(1 \mathrm{H}, \mathrm{dd}, J=7.6,1.8$ $\mathrm{Hz}), 7.75(1 \mathrm{H}, \mathrm{dd}, J=7.6,1.8 \mathrm{~Hz}), 7.61(1 \mathrm{H}, \mathrm{t}, J=7.6 \mathrm{~Hz}), 7.48(5 \mathrm{H}, \mathrm{s}) ;{ }^{13} \mathrm{C} \delta$ $186.9,146.6,137.7,137.2,134.7,129.9,129.7,129.5,128.9,128.7,118.0$ (quartet, $J$ $=320.4 \mathrm{~Hz}) ; \mathrm{MS} m / z 330\left(\mathrm{M}^{+}\right), 169$.

Aldehyde II-4. To a mixture of II-3 (375 mg, $1.14 \mathrm{mmol}), \mathrm{Pd}\left(\mathrm{PPh}_{3}\right)_{2} \mathrm{Cl}_{2}(24 \mathrm{mg}$, $0.034 \mathrm{mmol})$ and copper(I) iodide $(11 \mathrm{mg}, 0.057 \mathrm{mmol})$ in $10 \mathrm{~mL}$ of triethylamine was added $140 \mathrm{mg}$ of phenylacetylene $(1.37 \mathrm{mmol})$. After $12 \mathrm{~h}$ of stirring at $85^{\circ} \mathrm{C}, 10$ $\mathrm{mL}$ of a saturated aqueous ammonium chloride solution and $20 \mathrm{~mL}$ of diethyl ether were added. The organic layer was separated, and the aqueous layer was back extracted with diethyl ether. The combined organic layers were washed with brine and water, dried over sodium sulfate, and concentrated. Purification of the residue by flash column chromatography (silica gel/hexanes) afforded $276 \mathrm{mg}$ of II-4 (0.98 mmol, $86 \%$ yield) as a pale yellow solid: $\mathrm{mp} 105-106^{\circ} \mathrm{C}$; IR 2211, 1694, 1239, 756, 690 $\mathrm{cm}^{-1} ;{ }^{1} \mathrm{H} \delta 10.80(1 \mathrm{H}, \mathrm{s}), 7.98(1 \mathrm{H}, \mathrm{dd}, J=7.6,1.3 \mathrm{~Hz}), 7.70-7.62(3 \mathrm{H}, \mathrm{m})$, 7.56-7.42 (4 H, m), $7.32(5 \mathrm{H}, \mathrm{s}) ;{ }^{13} \mathrm{C} \delta 192.3,145.5,139.4,136.1,134.8,131.4$, $129.4,128.9,128.4,128.3,128.00,127.95,126.0,125.2,122.4,99.7,84.4 ; \mathrm{MS} \mathrm{m} / z$ 
$282\left(\mathrm{M}^{+}\right), 281,253,252$.

Benzannulated Enediyne II-5. To a mixture of $458 \mathrm{mg}(1.62 \mathrm{mmol})$ of II-4 and $450 \mathrm{mg}(3.24 \mathrm{mmol})$ of potassium carbonate in $20 \mathrm{~mL}$ of anhydrous methanol was added $373 \mathrm{mg}$ (1.94 mmol) of dimethyl (1-diazo-2-oxopropyl)phosphonate at room temperature. After $12 \mathrm{~h}$ of stirring, $40 \mathrm{~mL}$ of diethyl ether was added, and the reaction mixture was washed with a 5\% aqueous sodium bicarbonate solution, dried over magnesium sulfate, and concentrated. Purification of the residue by flash column chromatography (silica gel/ hexanes) afforded $367 \mathrm{mg}$ of II-5 (1.32 mmol, 81\% yield) as a pale yellow solid: $\mathrm{mp} 76-77^{\circ} \mathrm{C}$; IR $3290,2214,1490,1456,758,689 \mathrm{~cm}^{-1} ;{ }^{1} \mathrm{H} \delta$ 7.72-7.64 (2 H, m), $7.58(1 \mathrm{H}, \mathrm{dd}, J=7.6,1.6 \mathrm{~Hz}), 7.54-7.27(10 \mathrm{H}, \mathrm{m}), 3.43(1 \mathrm{H}, \mathrm{s})$; ${ }^{13} \mathrm{C} \delta 144.3,140.1,131.5,131.4,129.8,129.3,128.3,128.2,127.9,127.8,127.7$, 125.5, 124.6, 123.3, 96.7, 87.7, 82.6, 81.0; MS $m / z 278\left(\mathrm{M}^{+}\right)$; HRMS calcd for $\mathrm{C}_{22} \mathrm{H}_{14}$ 278.1096, found 278.1085.

Propargylic Diol II-6. To a solution of $489 \mathrm{mg}$ of II-5 $(1.76 \mathrm{mmol})$ in $20 \mathrm{~mL}$ of THF under a nitrogen atmosphere at $0{ }^{\circ} \mathrm{C}$ was added $0.70 \mathrm{~mL}$ of a $2.5 \mathrm{M}$ solution of butyllithium (1.76 mmol) in hexanes. After $30 \mathrm{~min}$ of stirring, a solution of $195 \mathrm{mg}$ (0.79 mmol) of $p$-dipivaloylbenzene in $20 \mathrm{~mL}$ of THF was introduced via cannula, and the reaction mixture was allowed to warm to room temperature. After an additional $2 \mathrm{~h}, 30 \mathrm{~mL}$ of water was introduced, and the reaction mixture was extracted with diethyl ether. The combined organic extracts were dried over sodium sulfate and concentrated. The residue was purified by flash column chromatography (silica gel $/ 20 \%$ diethyl ether in hexanes) to provide $590 \mathrm{mg}(0.74 \mathrm{mmol}, 94 \%$ yield, $1: 1$ 
mixture of diastereomers) of II-6 as a white solid. Some fractions were found to contain only one of the two diastereomers. Diastereomer $1\left(R_{f}=0.1\right): \operatorname{mp} 218-220{ }^{\circ} \mathrm{C}$; IR 3563, 3454, $2211 \mathrm{~cm}^{-1} ;{ }^{1} \mathrm{H} \delta 7.70-7.60(8 \mathrm{H}, \mathrm{m}), 7.53-7.31(12 \mathrm{H}, \mathrm{m}), 7.22(10 \mathrm{H}$, m), $2.41(2 \mathrm{H}, \mathrm{s}), 1.09(18 \mathrm{H}, \mathrm{s}) ;{ }^{13} \mathrm{C} \delta 144.8,141.0,140.3,131.4,131.2,129.3$, $128.21,128.17,127.9,127.6,126.5,125.8,123.9,123.2,96.5,96.1,88.2,85.0,79.5$, 39.8, 25.6; MS m/z $825\left(\mathrm{MNa}^{+}\right), 728,666$; HRMS calcd for $\mathrm{C}_{60} \mathrm{H}_{50} \mathrm{O}_{2} \mathrm{Na}\left(\mathrm{MNa}^{+}\right)$ 825.3703, found 825.3740. Diastereomer $2\left(R_{f}=0.2\right)$ : $\mathrm{mp} 90-92{ }^{\circ} \mathrm{C}$; IR 3567,3462 , $2212 \mathrm{~cm}^{-1} ;{ }^{1} \mathrm{H} \delta 7.67-7.62(8 \mathrm{H}, \mathrm{m}), 7.55-7.31(12 \mathrm{H}, \mathrm{m}), 7.17(10 \mathrm{H}, \mathrm{s}), 2.29(2 \mathrm{H}$, s), $1.09(18 \mathrm{H}, \mathrm{s}) ;{ }^{13} \mathrm{C} \delta 144.8,141.1,140.3,131.4,131.0,129.4,128.2,127.9,127.6$, $126.6,125.9,124.1,123.2,96.5,96.2,88.2,85.0,79.5,39.7,25.6$.

Benzannulated Enediyne II-7. To a mixture of II-6 (590 mg, $0.74 \mathrm{mmol})$ and triethylsilane (262 mg, $2.21 \mathrm{mmol})$ in $20 \mathrm{~mL}$ of methylene chloride was added 0.45 $\mathrm{mL}$ of trifluoroacetic acid $(673 \mathrm{mg}, 5.91 \mathrm{mmol})$. After $5 \mathrm{~min}$ of stirring at room temperature, $315 \mathrm{mg}$ of sodium carbonate $(2.96 \mathrm{mmol})$ was added followed by $10 \mathrm{~mL}$ of water and $50 \mathrm{~mL}$ of diethyl ether. The organic layer was separated, dried over sodium sulfate, and concentrated. Purification by flash column chromatography (silica gel $/ 5 \%$ diethyl ether in hexanes) provided $536 \mathrm{mg}(0.70 \mathrm{mmol}, 94 \%$ yield, $1: 1$ mixture of diastereomers) of II-7 as a white solid: $\operatorname{mp} 105-107^{\circ} \mathrm{C}$; IR $2228,757,690$ $\mathrm{cm}^{-1} ;{ }^{1} \mathrm{H}(1: 1 \mathrm{mixture}) \delta 7.69-7.60(4 \mathrm{H}, \mathrm{m}), 7.52-7.38(8 \mathrm{H}, \mathrm{m}), 7.37-7.28(8 \mathrm{H}, \mathrm{m})$, $7.22(10 \mathrm{H}, \mathrm{s}), 3.71$ and $3.69(2 \mathrm{H}$, two singlets, $1: 1$ ratio $), 1.06(18 \mathrm{H}, \mathrm{s}) ;{ }^{13} \mathrm{C}(1: 1$ mixture) $\delta 144.6,140.5,137.45,137.41,131.4,131.2,131.1,129.4,129.0,128.6$, $128.1,128.0,127.8,127.7,127.5,127.1,127.0,123.9,123.8,123.4,123.3,96.2,96.1$, 
$95.72,95.66,88.6,88.5,82.82,82.79,50.3,35.6,35.5,27.8$.

\section{6,9-Bis(1,1-dimethylethyl)-5,10-dihydro-1,14,15,16-tetraphenyldiindeno[2,1-b:1',}

2'-h]phenanthrene (II-8). To a solution of $150 \mathrm{mg}$ of II-7 $(0.195 \mathrm{mmol})$ in $10 \mathrm{~mL}$ of anhydrous $p$-xylene under a nitrogen atmosphere was added $0.40 \mathrm{~mL}$ of a $1.0 \mathrm{M}$ solution of potassium $t$-butoxide in THF $(0.40 \mathrm{mmol})$ and $0.4 \mathrm{~mL}$ of $t$-butyl alcohol. The reaction mixture was heated under reflux for $12 \mathrm{~h}$. After the reaction mixture was allowed to cool to room temperature, $10 \mathrm{~mL}$ of water and $40 \mathrm{~mL}$ of methylene chloride were introduced, and the organic layer was separated, dried over sodium sulfate, and concentrated. Recrystallization of the residue from methylene chloride/ethanol afforded $30 \mathrm{mg}$ of II-8 (0.039 mmol, 20\% yield) as a yellow solid: Compound turns black without melting at $280{ }^{\circ} \mathrm{C}$; IR 1464, 755, $694 \mathrm{~cm}^{-1} ;{ }^{1} \mathrm{H}(600$ MHz) $\delta 7.76(2 \mathrm{H}, \mathrm{s}), 7.34(2 \mathrm{H}, \mathrm{d}, J=7.2 \mathrm{~Hz}), 7.09(2 \mathrm{H}, \mathrm{t}, J=7.2 \mathrm{~Hz}), 6.71(2 \mathrm{H}, \mathrm{t}$, $J=7.2 \mathrm{~Hz}), 6.7$ and $6.5(4 \mathrm{H}$, very broad $), 6.68(2 \mathrm{H}, \mathrm{d}, J=7.2 \mathrm{~Hz}), 6.40(2 \mathrm{H}, \mathrm{t}, J=$ $7.2 \mathrm{~Hz}), 6.3(4 \mathrm{H}$, very broad), $6.24(2 \mathrm{H}, \mathrm{t}, J=7.2 \mathrm{~Hz}), 6.03(2 \mathrm{H}, \mathrm{t}, J=7.2 \mathrm{~Hz}), 5.68$ $(2 \mathrm{H}, \mathrm{d}, J=7.2 \mathrm{~Hz}), 5.34(2 \mathrm{H}, \mathrm{d}, J=7.2 \mathrm{~Hz}), 4.39(2 \mathrm{H}, \mathrm{d}, J=21.0 \mathrm{~Hz}), 4.34(2 \mathrm{H}, \mathrm{d}$, $J=21.0 \mathrm{~Hz}), 1.84(18 \mathrm{H}, \mathrm{s})$. The decoupling experiments showed that the doublet at $\delta$ 5.34 is coupled to the triplet at $\delta 6.03$, whereas the doublet at $\delta 5.68$ is coupled to the triplet at $\delta 6.24$. The triplets at $\delta 6.40$ and 6.71 are assigned to the para hydrogens of the two inner phenyl substituents and the para hydrogens of the two outer phenyl substituents, respectively. The signals at $\delta 7.34,7.09$, and 6.68 are assigned to the hydrogens on $\mathrm{C} 4 / \mathrm{C} 11, \mathrm{C} 3 / \mathrm{C} 12$, and $\mathrm{C} 2 / \mathrm{C} 13$, respectively.; ${ }^{13} \mathrm{C}(150 \mathrm{MHz}) \delta 144.8$, $142.1,138.53,138.50,137.98,137.95,136.9,136.0,134.2,132.1,131.6,130.7,129.9$ 
$129.4,128.3,127.7$ (broad) 126.9, 125.8, 125.0, 124.6, 121.8, 121.6, 40.3, 37.9, 33.8;

MS $m / z$ 772, 771, $770\left(\mathrm{M}^{+}\right), 747,746,745,731$; HRMS calcd for $\mathrm{C}_{60} \mathrm{H}_{50}$ 770.3907, found 770.3905. The structure of II-8 was established by X-ray structure analysis.

Calculation of rotational barriers of the ortho and meta hydrogens of the two outer phenyl substituents connected to $\mathrm{C} 1$ and $\mathrm{C} 14$ of II-8:

Calculated with the formula: $\mathrm{K}_{\mathrm{e}}=\pi(\delta \Delta) / 2^{0.5}$

$$
\Delta \mathrm{G}^{*}=4.57 \mathrm{~T}_{\mathrm{c}}\left(10.32+\log \mathrm{T}_{\mathrm{c}} / \mathrm{K}_{\mathrm{e}}\right)
$$

$\mathrm{K}_{\mathrm{e}}$ : exchange rate; $\delta \Delta$ : difference of chemical shift $(\mathrm{Hz}) ; \mathrm{T}_{\mathrm{c}}$ : coalescence temperature. For the ortho hydrogens:

$\delta \Delta=(6.36-6.21) * 600=90 \mathrm{~Hz} ; \mathrm{T}_{\mathrm{c}}=298.15 \mathrm{~K} ; \Delta \mathrm{G}^{*}=14.3 \mathrm{kcal} / \mathrm{mol}$

For the meta hydrogens:

$\delta \Delta=(6.73-6.46) * 600=162 \mathrm{~Hz} ; \mathrm{T}_{\mathrm{c}}=303.15 \mathrm{~K} ; \Delta \mathrm{G}^{*}=14.2 \mathrm{kcal} / \mathrm{mol}$

Propargylic Alcohol II-9. To a solution of $367 \mathrm{mg}$ of II-5 $(1.32 \mathrm{mmol})$ in $15 \mathrm{~mL}$ of THF under a nitrogen atmosphere at $0{ }^{\circ} \mathrm{C}$ was added $0.53 \mathrm{~mL}$ of a $2.5 \mathrm{M}$ solution of butyllithium $(1.32 \mathrm{mmol})$ in hexanes. After $30 \mathrm{~min}$ of stirring, $193 \mathrm{mg}(1.19 \mathrm{mmol})$ of 2,2-dimethylpropiophenone in $10 \mathrm{~mL}$ of THF was introduced via cannula, and the reaction mixture was allowed to warm to room temperature. After an additional $2 \mathrm{~h}$, $30 \mathrm{~mL}$ of water was introduced, and the reaction mixture was extracted with diethyl ether. The combined organic extracts were dried over sodium sulfate and concentrated. The residue was purified by flash column chromatography (silica gel/hexanes:diethyl ether $=1: 1)$ to provide $449 \mathrm{mg}(1.02 \mathrm{mmol}, 86 \%$ yield $)$ of II-9 as a viscous liquid: IR 3564, 2212, 756, $701 \mathrm{~cm}^{-1} ;{ }^{1} \mathrm{H} \delta 7.88-7.78$ (2 H, m), 7.72-7.63 (2 H, m), 7.60-7.16 
(14 H, m), 2.54 (1 H, br s), $1.16(9 \mathrm{H}, \mathrm{s}) ;{ }^{13} \mathrm{C} \delta 144.7,142.1,140.3,131.4,131.1$, $129.3,128.2,128.1,127.9,127.8,127.6,127.3,127.1,125.8,124.0,123.1,96.5,96.2$, 88.2, 84.9, 79.6, 39.7, 25.6; MS $m / z 463\left(\mathrm{MNa}^{+}\right), 423,383$; HRMS calcd for $\mathrm{C}_{33} \mathrm{H}_{28} \mathrm{ONa}\left(\mathrm{MNa}^{+}\right)$463.2038, found 463.2054.

Benzannulated Enediyne II-10. To a mixture of II-9 (367 mg, $0.835 \mathrm{mmol})$ and triethylsilane $(146 \mathrm{mg}, 1.25 \mathrm{mmol})$ in $10 \mathrm{~mL}$ of methylene chloride was added 0.26 $\mathrm{mL}$ of trifluoroacetic acid $(388 \mathrm{mg}, 3.39 \mathrm{mmol})$. After $5 \mathrm{~min}$ of stirring at room temperature, $359 \mathrm{mg}$ of sodium carbonate $(3.39 \mathrm{mmol})$ was added followed by $10 \mathrm{~mL}$ of water and $40 \mathrm{~mL}$ of diethyl ether. The organic layer was separated, dried over sodium sulfate, and concentrated. Purification by flash column chromatography (silica gel/1\% diethyl ether in hexanes) provided $307 \mathrm{mg}(0.724 \mathrm{mmol}, 88 \%$ yield $)$ of II-10 as a yellow liquid: IR 2225, 758, $700 \mathrm{~cm}^{-1} ;{ }^{1} \mathrm{H} \delta 7.74-7.66(2 \mathrm{H}, \mathrm{m}), 7.61-7.42(6 \mathrm{H}$, m), 7.40-7.16 (10 H, m), $3.81(1 \mathrm{H}, \mathrm{s}), 1.16(9 \mathrm{H}, \mathrm{s}) ;{ }^{13} \mathrm{C} \delta 144.6,140.5,139.2,131.4$, $131.1,129.8,129.4,128.7,128.0,127.8,127.6,127.5,127.0,126.6,123.8,123.4$ $96.1,95.6,88.5,82.8,50.7,35.5,27.8$.

Compounds II-14, II-15, and II-16. To a solution of $204 \mathrm{mg}$ of II-10 (0.481 mmol) in $10 \mathrm{~mL}$ of anhydrous toluene under a nitrogen atmosphere was added $0.50 \mathrm{~mL}$ of a 1.0 $\mathrm{M}$ solution of potassium $t$-butoxide in THF $(0.50 \mathrm{mmol})$ and $0.5 \mathrm{~mL}$ of $t$-butyl alcohol. The reaction mixture was heated under reflux for $12 \mathrm{~h}$. After the reaction mixture was allowed to cool to room temperature, $10 \mathrm{~mL}$ of water and $40 \mathrm{~mL}$ of diethyl ether were introduced, and the organic layer was separated, dried over sodium sulfate, and concentrated. Purification by flash column chromatography (silica 
gel/hexanes) provided $116 \mathrm{mg}(0.273 \mathrm{mmol}, 57 \%$ yield $)$ of II-14 as a pale yellow solid, II-15 (17\% yield based on the ${ }^{1} \mathrm{H}$ NMR integration of the crude product before purification) as a pale yellow solid, and II-16 (6\% yield based on the ${ }^{1} \mathrm{H}$ NMR integration of the crude product before purification) as a colorless solid. Small portions of relatively pure samples of II-15 and II-16 were isolated for structural elucidation. II-14: $\mathrm{mp} 103-106{ }^{\circ} \mathrm{C}$; IR 914, 753, $699 \mathrm{~cm}^{-1} ;{ }^{1} \mathrm{H} \delta 8.60(1 \mathrm{H}, \mathrm{d}, J=8.7$ Hz), $7.71(1 \mathrm{H}, \mathrm{dd}, J=8.7,1.6 \mathrm{~Hz}), 7.49-7.32(2 \mathrm{H}, \mathrm{m}), 7.31-7.11(2 \mathrm{H}, \mathrm{m})$, 7.10-6.85 (7 H, m), 6.66-6.78 (4 H, m), $4.62(2 \mathrm{H}, \mathrm{s}), 1.93(9 \mathrm{H}, \mathrm{s}) ;{ }^{13} \mathrm{C} \delta 145.3$, $143.1,140.1,139.4,139.0,138.9,138.0,137.4,133.7,131.6,131.2,130.1,129.1$, $129.0,128.3,127.8,127.7,127.5,127.0,126.9,125.7,125.6,41.1,38.9,34.3 ; \mathrm{MS}$ $m / z 424\left(\mathrm{M}^{+}\right), 367,289 . \quad$ II-15: ${ }^{1} \mathrm{H} \delta 7.38-7.33(4 \mathrm{H}, \mathrm{m}), 7.24-7.09(8 \mathrm{H}, \mathrm{m})$, 7.03-6.95 (4 H, m), $6.88(2 \mathrm{H}, \mathrm{t}, J=7.6 \mathrm{~Hz}), 6.45(1 \mathrm{H}, \mathrm{s}), 1.19(9 \mathrm{H}, \mathrm{s})$. The ${ }^{1} \mathrm{H}$ NMR signal at $\delta 6.45$ is attributable to the alkenyl hydrogen on the five-membered ring as observed previously in a related system. ${ }^{1 \mathrm{c}}$ II-16: $\mathrm{mp} 212-215{ }^{\circ} \mathrm{C}$; IR 752,701 $\mathrm{cm}^{-1} ;{ }^{1} \mathrm{H} \delta 8.43(1 \mathrm{H}, \mathrm{s}), 7.96-7.90(2 \mathrm{H}, \mathrm{m}), 7.84(1 \mathrm{H}, \mathrm{d}, J=7.4 \mathrm{~Hz}), 7.72-6.88(13$ H, m), $6.33(1 \mathrm{H}, \mathrm{d}, J=7.6 \mathrm{~Hz}), 4.05(1 \mathrm{H}, \mathrm{s}), 1.05(9 \mathrm{H}, \mathrm{s}) ;{ }^{13} \mathrm{C} \delta 142.9,142.0,139.7$, $139.5,136.4,134.5,130.6,129.9,129.5,128.8,128.4,128.3,127.7,127.6,127.5$, $127.2,126.9,126.4,125.8,125.7,123.4,121.1,119.5,57.5,35.8,29.7$. The structure of II-16 was established by X-ray structure analysis.

\section{Experimental Section of Chapter 2.2}

1-bromo-2-naphthalenecarboxaldehyde (II-17) was purchased from chemical supplier and was used as received. 
1-(Phenylethynyl)-2-naphthaldehyde (II-18). To a mixture of II-17 (1.00 g, 4.26 $\mathrm{mmol}), \mathrm{Pd}\left(\mathrm{PPh}_{3}\right)_{2} \mathrm{Cl}_{2}(0.091 \mathrm{~g}, 0.13 \mathrm{mmol})$, and copper(I) iodide $(0.025 \mathrm{~g}, 0.13 \mathrm{mmol})$ in $20 \mathrm{~mL}$ of triethylamine was added $0.478 \mathrm{~g}$ of phenylacetylene $(4.69 \mathrm{mmol})$. After $12 \mathrm{~h}$ of stirring at room temperature, $20 \mathrm{~mL}$ of a saturated aqueous ammonium chloride solution and $40 \mathrm{~mL}$ of diethyl ether were added. The organic layer was separated, and the aqueous layer was back extracted with diethyl ether. The combined organic layers were washed with brine and water, dried over sodium sulfate, and concentrated. Purification of the residue by flash column chromatography (silica gel/2\% diethyl ether in hexanes) afforded $1.08 \mathrm{~g}$ of II-18 (4.22 mmol, 99\%) as a pale yellow solid: $\mathrm{mp} 122-123{ }^{\circ} \mathrm{C}$; IR $1675,758 \mathrm{~cm}^{-1} ;{ }^{1} \mathrm{H} \delta 10.90(1 \mathrm{H}, \mathrm{s}), 8.67-8.58(1 \mathrm{H}$, s), $8.00(1 \mathrm{H}, \mathrm{d}, J=8.5 \mathrm{~Hz}), 7.95-7.86(2 \mathrm{H}, \mathrm{m}), 7.75-7.64(4 \mathrm{H}, \mathrm{m}), 7.49-7.42(3 \mathrm{H}$, $\mathrm{m}) ;{ }^{13} \mathrm{C} \delta 192.2,135.8,134.2,133.1,131.8,129.4,128.9,128.7,128.5,127.7,127.5$, $127.2,122.3,122.1,102.3,82.9$.

2-Ethynyl-1-(phenylethynyl)naphthalene (II-19). To a mixture of $0.540 \mathrm{~g}$ (2.11 mmol) of II-18 and $0.582 \mathrm{~g}(4.22 \mathrm{mmol})$ of potassium carbonate in $20 \mathrm{~mL}$ of anhydrous methanol was added $0.486 \mathrm{~g} \quad(2.53 \mathrm{mmol})$ of dimethyl (1-diazo-2-oxopropyl)phosphonate ${ }^{7}$ at room temperature. After 4 h of stirring, $40 \mathrm{~mL}$ of diethyl ether was added, and the reaction mixture was washed with a $5 \%$ aqueous sodium bicarbonate solution, dried over magnesium sulfate, and concentrated. Purification of the residue by flash column chromatography (silica gel/hexanes) afforded $0.398 \mathrm{~g}$ of II-19 (1.58 mmol, 75\%) as a pale yellow liquid: IR 3286, 819, $753 \mathrm{~cm}^{-1} ;{ }^{1} \mathrm{H} \delta 8.45(1 \mathrm{H}, \mathrm{d}, J=8.4 \mathrm{~Hz}), 7.84(1 \mathrm{H}, \mathrm{d}, J=7.6 \mathrm{~Hz}), 7.77(1 \mathrm{H}, \mathrm{d}, J=$ 
8.4 Hz), 7.73-7.67 (2 H, m), 7.66-7.51 (3 H, m), 7.46-7.36 (3 H, m), 3.49 (1 H, s);

${ }^{13} \mathrm{C} \delta 132.9,132.7,131.8,128.7,128.5,128.4,128.16,128.13,127.4,127.2,126.6$, $124.7,123.3,123.0,99.1,86.2,83.1,81.9$.

Propargylic Diol II-20. To a solution of $206 \mathrm{mg}$ of II-19 $(0.82 \mathrm{mmol})$ in $10 \mathrm{~mL}$ of THF under a nitrogen atmosphere at $0{ }^{\circ} \mathrm{C}$ was added $0.33 \mathrm{~mL}$ of a $2.5 \mathrm{M}$ solution of butyllithium $(0.82 \mathrm{mmol})$ in hexanes. After $30 \mathrm{~min}$ of stirring, a solution of $91 \mathrm{mg}$ (0.37 mmol) of $p$-dipivaloylbenzene in $5 \mathrm{~mL}$ of THF was introduced via cannula, and the reaction mixture was allowed to warm to room temperature. After an additional 2 $\mathrm{h}, 10 \mathrm{~mL}$ of water was introduced, and the reaction mixture was extracted with diethyl ether. The combined organic extracts were dried over sodium sulfate and concentrated. The residue was purified by flash column chromatography (silica gel/20\% diethyl ether in hexanes) to provide $218 \mathrm{mg}(0.29 \mathrm{mmol}, 78 \%$ yield, $1: 1$ mixture of diastereomers) of II-20 as a white solid. Some fractions were found to contain only one of the two diastereomers. The more polar diastereomer $1:{ }^{1} \mathrm{H} \delta 8.43(2 \mathrm{H}, \mathrm{d}, J=$ $8.2 \mathrm{~Hz}), 7.83(2 \mathrm{H}, \mathrm{d}, J=7.4 \mathrm{~Hz}), 7.76(2 \mathrm{H}, \mathrm{d}, J=8.7 \mathrm{~Hz}), 7.65(4 \mathrm{H}, \mathrm{s}), 7.64-7.49$ (12 H, m), 7.35-7.28 (4 H, m), $2.42(2 \mathrm{H}, \mathrm{s}), 1.09(18 \mathrm{H}, \mathrm{s})$; The structure of the more polar diastereomer of II-20 was established by X-ray structure analysis. The less polar diastereomer 2: ${ }^{1} \mathrm{H} \delta 8.45(2 \mathrm{H}, \mathrm{d}, J=8.2 \mathrm{~Hz}), 7.83(2 \mathrm{H}, \mathrm{d}, J=7.9 \mathrm{~Hz}), 7.76(2 \mathrm{H}, \mathrm{d}$, $J=8.7 \mathrm{~Hz}), 7.69(4 \mathrm{H}, \mathrm{s}), 7.66-7.49(10 \mathrm{H}, \mathrm{m}), 7.36-7.17(6 \mathrm{H}, \mathrm{m}), 2.41(2 \mathrm{H}, \mathrm{s}), 1.11$ $(18 \mathrm{H}, \mathrm{s}) ;{ }^{13} \mathrm{C} \delta 141.1,133.2,132.5,131.7,128.5,128.3,128.2,127.4,127.0,126.6$, $126.4,123.8,123.6,123.1,98.8,97.2,86.6,85.6,79.5,39.8,25.6$.

Benzannulated Enediyne II-21. To a mixture of II-20 (48 mg, $0.064 \mathrm{mmol}$ ) and 
triethylsilane $(23 \mathrm{mg}, 0.19 \mathrm{mmol})$ in $5 \mathrm{~mL}$ of methylene chloride was added $58 \mathrm{mg}$ of trifluoroacetic acid $(0.51 \mathrm{mmol})$. After $5 \mathrm{~min}$ of stirring at room temperature, $28 \mathrm{mg}$ of sodium carbonate $(0.26 \mathrm{mmol})$ was added followed by $2 \mathrm{~mL}$ of water and $5 \mathrm{~mL}$ of diethyl ether. The organic layer was separated, dried over sodium sulfate, and concentrated. Purification by flash column chromatography (silica gel/5\% diethyl ether in hexanes) provided $32 \mathrm{mg}(0.045 \mathrm{mmol}, 69 \%$ yield, 1:1 mixture of diastereomers) of $\mathbf{I I - 2 1}$ as a white solid; ${ }^{1} \mathrm{H}(1: 1$ mixture $) \delta 8.43(2 \mathrm{H}, \mathrm{dd}, J=7.6,2.4$ Hz), $7.82(2 \mathrm{H}, \mathrm{dd}, J=7.6,4.7 \mathrm{~Hz}), 7.74(2 \mathrm{H}, \mathrm{t}, J=8.2 \mathrm{~Hz}), 7.66-7.46(10 \mathrm{H}, \mathrm{m})$, 7.38-7.28 $(10 \mathrm{H}, \mathrm{m}), 3.72$ and $3.70(2 \mathrm{H}$, two singlets, $1: 1$ ratio $), 1.06(18 \mathrm{H}, \mathrm{s}) ;{ }^{13} \mathrm{C}$ (1:1 mixture) $\delta 137.5,137.4,133.3,132.2,131.7,129.0,128.81,128.77,128.4,128.3$, $128.1,128.0,127.22,127.20,126.6,126.4,124.9,123.4,123.35,123.29,123.21$, $98.39,98.35,96.91,96.86,86.91,86.85,83.47,83.44,50.4,35.61,35.57,27.9$.

Compound II-22. To a solution of $50 \mathrm{mg}$ of II-21 $(0.07 \mathrm{mmol})$ in $5 \mathrm{~mL}$ of anhydrous toluene under a nitrogen atmosphere was added $0.07 \mathrm{~mL}$ of a $1.0 \mathrm{M}$ solution of potassium $t$-butoxide in THF $(0.07 \mathrm{mmol})$ and $0.1 \mathrm{~mL}$ of $t$-butyl alcohol. The reaction mixture was heated under reflux for $12 \mathrm{~h}$. After the reaction mixture was allowed to cool to room temperature, $2 \mathrm{~mL}$ of water and $10 \mathrm{~mL}$ of methylene chloride were introduced, and the organic layer was separated, dried over sodium sulfate, and concentrated. Purification by flash column chromatography (silica gel/10\% methylene chloride in hexanes) provided $20 \mathrm{mg}$ of II-22 $(0.028 \mathrm{mmol}, 40 \%$ yield $)$ as a pale yellow solid; ${ }^{1} \mathrm{H} \delta 7.89(2 \mathrm{H}, \mathrm{s}), 7.64(2 \mathrm{H}, \mathrm{d}, J=8.2 \mathrm{~Hz}), 7.57(2 \mathrm{H}, \mathrm{d}, J=8.2$ Hz), 7.03-6.93 (2H, m), 6.9 (2 H, very broad), 6.69 (2 H, t, $J=7.4 \mathrm{~Hz}), 6.6(2 \mathrm{H}$, very 
broad), 6.44-6.35 (4 H, m), 6.2 and 5.8 (4 H, very broad), 4.57 (2 H, d, J=21.6 Hz), $4.38(2 \mathrm{H}, \mathrm{d}, J=21.6 \mathrm{~Hz}), 1.91(18 \mathrm{H}, \mathrm{s})$. The structure of II-22 was established by $\mathrm{X}$-ray structure analysis.

Propargylic Alcohol II-23. To a solution of $0.289 \mathrm{~g}$ of II-19 $(1.15 \mathrm{mmol})$ in $15 \mathrm{~mL}$ of THF under a nitrogen atmosphere at $0{ }^{\circ} \mathrm{C}$ was added $0.46 \mathrm{~mL}$ of a $2.5 \mathrm{M}$ solution of $n$-butyllithium $(1.15 \mathrm{mmol})$ in hexanes. After $30 \mathrm{~min}$ of stirring, $0.187 \mathrm{~g}(1.15 \mathrm{mmol})$ of 2,2-dimethylpropiophenone in $10 \mathrm{~mL}$ of THF was introduced via cannula, and the reaction mixture was allowed to warm to room temperature. After an additional $2 \mathrm{~h}$, $30 \mathrm{~mL}$ of water was introduced, and the reaction mixture was extracted with diethyl ether. The combined organic extracts were dried over sodium sulfate and concentrated. The residue was purified by flash column chromatography (silica gel/hexanes:diethyl ether $=9: 1)$ to provide $0.436 \mathrm{~g}(1.05 \mathrm{mmol}, 92 \%)$ of $\mathbf{I I - 2 3}$ as a viscous liquid: IR $3457,753,689 \mathrm{~cm}^{-1} ;{ }^{1} \mathrm{H} \delta 8.44(1 \mathrm{H}, \mathrm{d}, J=8.2 \mathrm{~Hz}), 7.86-7.73(4 \mathrm{H}, \mathrm{m}), 7.64-7.49(5$ $\mathrm{H}, \mathrm{m}), 7.41-7.31(3 \mathrm{H}, \mathrm{m}), 7.30-7.20(3 \mathrm{H}, \mathrm{m}), 2.47(1 \mathrm{H}, \mathrm{OH}), 1.13(9 \mathrm{H}, \mathrm{s}) ;{ }^{13} \mathrm{C} \delta$ $142.1,133.2,132.5,131.8,128.6,128.43,128.36,128.2,127.8,127.4,127.3,127.1$, $127.0,126.4,123.8,123.5,123.2,98.8,97.2,86.6,85.5,79.7,39.8,25.6$.

Benzannulated Enediyne II-24. To a mixture of II-23 (0.391 g, $0.944 \mathrm{mmol})$ and triethylsilane $(0.165 \mathrm{~g}, 1.41 \mathrm{mmol})$ in $10 \mathrm{~mL}$ of methylene chloride was added 0.29 $\mathrm{mL}$ of trifluoroacetic acid $(0.438 \mathrm{~g}, 3.83 \mathrm{mmol})$. After $5 \mathrm{~min}$ of stirring at room temperature, $0.406 \mathrm{~g}$ of sodium carbonate $(3.83 \mathrm{mmol})$ was added followed by $10 \mathrm{~mL}$ of water and $40 \mathrm{~mL}$ of diethyl ether. The organic layer was separated, dried over sodium sulfate, and concentrated. The residue was purified by flash column 
chromatography (silica gel/hexanes) to provide $0.298 \mathrm{~g}(0.749 \mathrm{mmol}, 79 \%)$ of II-24 as a colorless liquid: IR 817, 752, 702, $689 \mathrm{~cm}^{-1} ;{ }^{1} \mathrm{H} \delta 8.43(1 \mathrm{H}, \mathrm{d}, J=8.5 \mathrm{~Hz}), 7.82$ $(1 \mathrm{H}, \mathrm{d}, J=7.4 \mathrm{~Hz}), 7.74(1 \mathrm{H}, \mathrm{d}, J=8.7 \mathrm{~Hz}), 7.64-7.44(7 \mathrm{H}, \mathrm{m}), 7.41-7.32(3 \mathrm{H}, \mathrm{m})$, 7.29-7.20 (3 H, m), $3.77(1 \mathrm{H}, \mathrm{s}), 1.09(9 \mathrm{H}, \mathrm{s}) ;{ }^{13} \mathrm{C} \delta 139.2,133.2,132.2,131.8$, $129.8,128.7,128.35,128.28,128.1,128.0,127.6,127.2,126.65,126.62,126.3,124.8$ $123.4,123.2,98.3,96.7,86.9,83.4,50.8,35.6,27.8$.

\section{8-(1,1-Dimethylethyl)-13-phenyl-7H-dibenzo $[b, g]$ fluorine II-28 and Compounds}

II-29 and II-30. To a solution of $0.242 \mathrm{~g}$ of II-24 $(0.608 \mathrm{mmol})$ in $10 \mathrm{~mL}$ of anhydrous toluene under a nitrogen atmosphere was added $0.61 \mathrm{~mL}$ of a $1.0 \mathrm{M}$ solution of potassium tert-butoxide in THF $(0.61 \mathrm{mmol})$ and $0.61 \mathrm{~mL}$ of tert-butyl alcohol. The reaction mixture was heated under reflux for $12 \mathrm{~h}$. After the reaction mixture was allowed to cool to room temperature, $10 \mathrm{~mL}$ of water and $40 \mathrm{~mL}$ of diethyl ether were introduced, and the organic layer was separated, dried over sodium sulfate, and concentrated. The residue was purified by flash column chromatography (silica gel/hexanes) to provide $0.194 \mathrm{~g}(0.487 \mathrm{mmol}, 80 \%)$ of $\mathbf{I I - 2 8}$ as a pale green solid, II-29 (5\% yield based on the ${ }^{1} \mathrm{H}$ NMR integration of the crude product before purification) as a pale yellow solid, and II-30 (5\% yield based on the ${ }^{1} \mathrm{H}$ NMR integration of the crude product before purification) as a pale yellow solid. Small portions of relatively pure samples of II-29 and II-30 were isolated for structural elucidation. II-28: $\mathrm{mp} 233-235{ }^{\circ} \mathrm{C}$; IR $803,765,701 \mathrm{~cm}^{-1} ;{ }^{1} \mathrm{H} \delta 8.65(1 \mathrm{H}, \mathrm{d}, J=8.4$ $\mathrm{Hz}), 8.03(1 \mathrm{H}, \mathrm{d}, J=8.5 \mathrm{~Hz}), 7.78(1 \mathrm{H}, \mathrm{d}, J=7.9 \mathrm{~Hz}), 7.73(1 \mathrm{H}, \mathrm{d}, J=7.9 \mathrm{~Hz})$, $7.60(1 \mathrm{H}, \mathrm{d}, J=8.2 \mathrm{~Hz}), 7.52-7.31(7 \mathrm{H}, \mathrm{m}), 7.26-7.14(2 \mathrm{H}, \mathrm{m}), 6.75(1 \mathrm{H}, \mathrm{t}, J=$ 
$7.8 \mathrm{~Hz}), 4.62(2 \mathrm{H}, \mathrm{s}), 1.96(9 \mathrm{H}, \mathrm{s}) ;{ }^{13} \mathrm{C} \delta 143.6,141.3,140.6,140.3,138.3,135.6$, $134.1,133.3,132.6,132.2,131.1,129.4,128.5,127.86,127.80,127.76,127.3,125.8$, 124.1, 123.8, 123.4, 122.0, 41.4, 39.0, 34.4. Recrystallization of II-28 from a mixture of $\mathrm{CH}_{2} \mathrm{Cl}_{2} /$ hexanes produced a single crystal suitable for X-ray structure analysis. II-29: ${ }^{1} \mathrm{H} \delta 8.62-8.53(1 \mathrm{H}, \mathrm{m}), 8.44(2 \mathrm{H}, \mathrm{d}, J=4.0 \mathrm{~Hz}), 7.93-7.81(2 \mathrm{H}$, m), $7.76(1 \mathrm{H}, \mathrm{d}, J=9.0 \mathrm{~Hz}), 7.62-7.53(2 \mathrm{H}, \mathrm{m}), 7.45(3 \mathrm{H}, \mathrm{broad}), 7.39-7.00(7 \mathrm{H}$, $\mathrm{m}), 4.11(1 \mathrm{H}, \mathrm{s}), 0.97(9 \mathrm{H}, \mathrm{s}) ;{ }^{13} \mathrm{C} \delta 142.93,142.85,142.3,140.2,132.0,131.0$, $130.4,130.0,128.5,128.0,127.9,127.7,127.0,126.8,126.5,126.4,125.9,124.2$ 122.6, 57.4, 36.0, 29.4; MS m/z $400\left(\mathrm{M}^{+}\right)$, 343, 265; HRMS calcd for $\mathrm{C}_{31} \mathrm{H}_{28}$ 400.2191, found 400.2185. II-30: ${ }^{1} \mathrm{H} \delta 8.62-8.53(1 \mathrm{H}, \mathrm{m}), 8.42(2 \mathrm{H}, \mathrm{d}, J=10.5$ Hz), 7.91-7.86 (1 H, m), $7.83(1 \mathrm{H}, \mathrm{d}, J=9.0 \mathrm{~Hz}), 7.75(1 \mathrm{H}, \mathrm{d}, J=8.7 \mathrm{~Hz})$, 7.63-7.53 (2 H, m), 7.43 (4 H, broad), 7.32-7.23 (4 H, m), 7.22-7.14 (4 H, m), 7.07

$(2 \mathrm{H}, \mathrm{d}, J=8.2 \mathrm{~Hz}), 4.08(1 \mathrm{H}, \mathrm{s}), 3.94(2 \mathrm{H}, \mathrm{s}), 0.95(9 \mathrm{H}, \mathrm{s}) ;{ }^{13} \mathrm{C} \delta 142.9,141.2$, $140.3,140.1,138.5,132.0,131.0,130.4,130.0,129.0,128.5,128.36,128.28,128.0$ $127.9,127.0,126.9,126.8,126.5,126.4,126.0,124.2,122.5,56.9,41.4,36.0,29.4$ MS $m / z 490\left(\mathrm{M}^{+}\right), 433,265$; HRMS calcd for $\mathrm{C}_{38} \mathrm{H}_{34}$ 490.2661, found 490.2663.

\section{Experimental Section of Chapter 2.3}

Ethyl bromide, thionyl chloride, tert-butyllithium $(1.7 \mathrm{M})$ in pentane, $\mathrm{CuBr} \cdot \mathrm{SMe}_{2}$ and 1.0 $\mathrm{M}$ solution of potassium $t$-butoxide in $t$-butyl alcohol were purchased from chemical suppliers and were used as received. 1,2-Bis[(2-ethynylphenyl)ethynyl]benzene $^{7}$ and 7,7'-dibromo-1,1'-binaphthalene-2,2'-diol (II-31) ${ }^{22}$ were prepared as reported previously. 
II-32 A mixture of $1.72 \mathrm{~g}$ of II-31 $(3.87 \mathrm{mmol}), 2.70 \mathrm{~g}$ of bromoethane (24.8 mol), $2.3 \mathrm{~g}$ of dry potassium carbonate, and a catalytic amount of $\mathrm{NaI}(0.2 \mathrm{~g})$ in $10 \mathrm{~mL}$ of dry acetone was stirred and refluxed under anhydrous conditions $\left(\mathrm{CaCl}_{2}\right.$ tube) for three days. After cooling to room temperature, the reaction mixture was poured into water and extracted with methylene chloride. The combined organic layers were dried over magnesium sulfate, and the solvent was removed in vacuo after filtration. The residue was purified by flash column chromatography (silica gel/50\% $\mathrm{CH}_{2} \mathrm{Cl}_{2}$ in hexanes) to provide $1.90 \mathrm{~g}$ (3.79 mmol, 98\%) of II-32 as a white solid: $\mathrm{mp}$ 204-205 ${ }^{\circ} \mathrm{C} ;{ }^{1} \mathrm{H} \delta 7.91(2 \mathrm{H}, \mathrm{d}, J=9.2 \mathrm{~Hz}), 7.72(2 \mathrm{H}, \mathrm{d}, J=8.7 \mathrm{~Hz}), 7.41(2 \mathrm{H}, \mathrm{d}, J=9.0 \mathrm{~Hz})$, $7.39(2 \mathrm{H}, \mathrm{dd}, J=8.7,2.3 \mathrm{~Hz}), 7.26(2 \mathrm{H}, \mathrm{s}), 4.07(4 \mathrm{H}, \mathrm{q}, J=6.9 \mathrm{~Hz}), 1.06(6 \mathrm{H}, \mathrm{t}, J$ $=6.9 \mathrm{~Hz})$.

II-33 A solution of $1.61 \mathrm{~g}$ of II-32 $(3.22 \mathrm{mmol})$ in $40 \mathrm{~mL}$ of dry THF was cooled to $-78{ }^{\circ} \mathrm{C}$ and $5.67 \mathrm{~mL}$ of $n$-BuLi in $n$-hexane $(2.5 \mathrm{M})(14.2 \mathrm{mmol})$ was added at such a rate in order not to allow the temperature to exceed $-70{ }^{\circ} \mathrm{C}$. After $5 \mathrm{~h}$ of stirring at this temperature, $937 \mathrm{~g}$ dry ice $(21.3 \mathrm{mmol})$ was added so that the temperature remained below $-50{ }^{\circ} \mathrm{C}$. After stirring for $1 \mathrm{~h}$ at this temperature, $1 \mathrm{~N} \mathrm{HCl}$ was added to the reaction solution until it is acidic as indicated by the $\mathrm{pH}$ paper. The solution was filtrated and the solid was washed by water and ethyl ether and dried. $\mathrm{mp}>350{ }^{\circ} \mathrm{C}$; The diacid was transferred into $10 \mathrm{~mL}$ of thionyl chloride and was heated under ca 80 ${ }^{\circ} \mathrm{C}$ for $6 \mathrm{~h}$. The thionyl chloride was then removed in vacuo and the diacetyl chloride was dissolved in $10 \mathrm{~mL}$ of THF. To a suspension of $1.59 \mathrm{~g}$ of $\mathrm{CuBr} \cdot \mathrm{SMe} 2(7.73 \mathrm{mmol})$ in $40 \mathrm{~mL}$ of THF was added $4.5 \mathrm{~mL}$ of a $1.7 \mathrm{M}$ solution of tert-butyllithium $(7.73$ 
mmol) in pentane at $-50{ }^{\circ} \mathrm{C}$. After 30 min of stirring, the solution of the diacetyl chloride in $10 \mathrm{~mL}$ of THF was introduced dropwise via cannula. After an additional 4 $\mathrm{h}$ at $-50{ }^{\circ} \mathrm{C}$, the reaction mixture was allowed to warm to room temperature and treated with $20 \mathrm{~mL}$ of a saturated aqueous ammonium chloride solution. The organic layer was separated, and the aqueous layer was back extracted with diethyl ether. The combined organic layers were washed with brine and water, dried over sodium sulfate, and concentrated. Purification by flash column chromatography (silica gel/30\% methylene chloride in hexanes) afforded $1.04 \mathrm{~g}$ of II-33 (2.03 mmol, 63\%) as a white solid: $\mathrm{mp} 190-191{ }^{\circ} \mathrm{C}$; IR 2979, 1670, 1238, 1174, 1122, $838 \mathrm{~cm}^{-1} ;{ }^{1} \mathrm{H} \delta 7.96(2 \mathrm{H}, \mathrm{d}$, $J=9.0 \mathrm{~Hz}), 7.87(2 \mathrm{H}, \mathrm{d}, J=8.4 \mathrm{~Hz}), 7.61(2 \mathrm{H}, \mathrm{dd}, J=8.4,1.8 \mathrm{~Hz}), 7.54(2 \mathrm{H}, \mathrm{s})$, $7.50(2 \mathrm{H}, \mathrm{d}, J=9.0 \mathrm{~Hz}), 4.16-3.98(4 \mathrm{H}, \mathrm{m}), 1.07(6 \mathrm{H}, \mathrm{t}, J=6.8 \mathrm{~Hz}), 1.04(18 \mathrm{H}, \mathrm{s})$. II-34 To a solution of $636 \mathrm{mg}$ of I-11a (3.15 mmol) in $20 \mathrm{~mL}$ of THF under a nitrogen atmosphere at $0{ }^{\circ} \mathrm{C}$ was added $1.26 \mathrm{~mL}$ of a $2.5 \mathrm{M}$ solution of butyllithium $(3.15$ $\mathrm{mmol})$ in hexanes. After $30 \mathrm{~min}$ of stirring, a solution of $320 \mathrm{mg}(0.63 \mathrm{mmol})$ of II-33 in $20 \mathrm{~mL}$ of THF was introduced via cannula, and the reaction mixture was allowed to warm to room temperature. After an additional $2 \mathrm{~h}, 30 \mathrm{~mL}$ of water was introduced, and the reaction mixture was extracted with diethyl ether. The combined organic extracts were dried over sodium sulfate and concentrated. The residue was purified by flash column chromatography (silica gel/40\% diethyl ether in hexanes) to provide 539 mg (0.59 mmol, 94\% yield) of II-34 as a pale yellow solid.

II-35 To a mixture of II-34 (539 mg, $0.59 \mathrm{mmol})$ and triethylsilane (209 mg, 1.76 mmol) in $20 \mathrm{~mL}$ of methylene chloride was added $0.36 \mathrm{~mL}$ of trifluoroacetic acid 
(536 mg, $4.71 \mathrm{mmol}$ ). After $5 \mathrm{~min}$ of stirring at room temperature, $251 \mathrm{mg}$ of sodium carbonate $(2.36 \mathrm{mmol})$ was added followed by $10 \mathrm{~mL}$ of water and $50 \mathrm{~mL}$ of diethyl ether. The organic layer was separated, dried over sodium sulfate, and concentrated. Purification by flash column chromatography (silica gel/20\% methylene chloride in hexanes) provided $406 \mathrm{mg}$ ( $0.46 \mathrm{mmol}, 78 \%$ yield $)$ of II-35 as a pale yellow solid; ${ }^{1} \mathrm{H}$ (mixture of diastereomers) $\delta 7.92-6.83(28 \mathrm{H}, \mathrm{m}), 4.10-3.78(4 \mathrm{H}, \mathrm{m}), 3.56-3.35(2 \mathrm{H}$, $\mathrm{m}), 1.10-0.75(24 \mathrm{H}, \mathrm{m}) ;{ }^{13} \mathrm{C}$ (mixture of diastereomers) $\delta 154.53,154.47,154.3$, $154.2,137.1,137.0,136.8,133.9,133.7,133.6,132.1,132.0,131.9,131.7,131.6$, $128.67,128.62,128.3,128.2,128.1,128.0,127.9,127.7,127.15,127.06,126.8,126.4$, $126.23,126.17,126.0,125.4,125.30,125.26,123.2,120.6,120.5,120.3,115.6,115.3$, $115.1,95.84,95.76,95.6,95.5,92.71,92.67,92.6,88.6,88.5,82.4,82.3,65.2,65.0$, $64.9,35.5,35.4,15.00,14.96$.

II-36 and II-37 To a solution of $135 \mathrm{mg}$ of II-35 $(0.153 \mathrm{mmol})$ in $10 \mathrm{~mL}$ of anhydrous toluene under a nitrogen atmosphere was added $0.67 \mathrm{~mL}$ of a $1.0 \mathrm{M}$ solution of potassium $t$-butoxide in $t$-butyl alcohol $(0.67 \mathrm{mmol})$. The reaction mixture was heated under reflux for $12 \mathrm{~h}$. After the reaction mixture was allowed to cool to room temperature, $10 \mathrm{~mL}$ of water and $40 \mathrm{~mL}$ of methylene chloride were introduced, and the organic layer was separated, dried over sodium sulfate, and concentrated. Purification by flash column chromatography (silica gel/30\% methylene chloride in hexanes) provided $10.8 \mathrm{mg}(0.012 \mathrm{mmol}, 8 \%$ yield $)$ of II-36 as an orange solid and $30.0 \mathrm{mg}(0.034 \mathrm{mmol}, 22 \%$ yield $)$ of II-37 as a pale yellow solid. Small amounts of the pure diastereomer 1 of II-36 and the mixture of diastereomer 2 and 3 of II-36 and 
the pure diastereomer 1 and 2 of II-37 were separated for structure analyses. Diastereomer 1 of II-36: $\mathrm{mp} 274-275{ }^{\circ} \mathrm{C}$; IR 1622, 1504, 1231, 755, $690 \mathrm{~cm}^{-1} ;{ }^{1} \mathrm{H}$ $(270 \mathrm{MHz}) \delta 7.82(2 \mathrm{H}, \mathrm{d}, J=16.3 \mathrm{~Hz}), 7.79(2 \mathrm{H}, \mathrm{d}, J=16.1 \mathrm{~Hz}), 7.51-7.57(6 \mathrm{H}, \mathrm{m})$, $7.47(1 \mathrm{H}, \mathrm{d}, J=1.6 \mathrm{~Hz}), 7.44(1 \mathrm{H}, \mathrm{d}, J=1.6 \mathrm{~Hz}), 7.28-7.32(2 \mathrm{H}, \mathrm{m}), 7.16-7.23(12$ H, m), 7.11 (4 H, d, J=9.0 Hz), 6.97-7.04 (2 H, m), $5.82(2 \mathrm{H}, \mathrm{s}), 3.65-3.77(2 \mathrm{H}, \mathrm{m})$, 3.42-3.54 (2 H, m), $0.75(18 \mathrm{H}, \mathrm{s}), 0.72(6 \mathrm{H}, \mathrm{t}, J=7.1 \mathrm{~Hz}) ;{ }^{13} \mathrm{C}(67.9 \mathrm{MHz}) \delta 154.35$, $154.32,154.24,154.17,152.3,150.9,147.7,140.4,135.0,134.7,133.7,129.1,128.9$, $128.8,128.7,128.6,128.2,127.8,126.2,125.3,125.2,123.7,123.3,121.6,121.1$, $116.3,111.2,75.7,65.3,36.6,28.3,14.8$. The structure of diastereomer 1 of II-36 was established by X-ray structure analysis. Diastereomer 2 and 3 (1:1) of II-36: mp $153-155^{\circ} \mathrm{C}$; IR 1623, 1504, 1231, 755, $690 \mathrm{~cm}^{-1} ;{ }^{1} \mathrm{H}(270 \mathrm{MHz}) \delta 7.79-7.86(6 \mathrm{H}, \mathrm{m})$, 7.50-7.59 (8 H, m), 7.42-7.47 (4 H, m), 7.27-7.36 (12 H, m), 6.94-7.25 (26 H, m), $6.17(2 \mathrm{H}, \mathrm{s}), 6.10(2 \mathrm{H}, \mathrm{s}), 3.83-4.05(2 \mathrm{H}, \mathrm{m}), 3.49-3.61(2 \mathrm{H}, \mathrm{m}), 3.17-3.30(2 \mathrm{H}, \mathrm{m})$, $0.98(18 \mathrm{H}, \mathrm{s}), 0.94(6 \mathrm{H}, \mathrm{t}, J=7.1 \mathrm{~Hz}), 0.63(18 \mathrm{H}, \mathrm{s}), 0.57(6 \mathrm{H}, \mathrm{t}, J=7.1 \mathrm{~Hz}) ;{ }^{13} \mathrm{C}$ $(67.9 \mathrm{MHz}) \delta 154.5,154.4,154.3,154.2,152.25,152.20,151.02,150.96,147.5$, $147.4,140.5,140.2,134.7,134.4,133.7,133.4,129.2,129.0,128.74,128.70,128.66$, $128.58,128.54,128.46,128.37,128.26,127.7,127.6,126.4,126.3,125.6,125.3$, $124.9,124.6,123.9,123.6,123.315,123.307,121.4,121.1,120.9,116.6,115.4$, $111.15,111.09,75.7,65.33,65.31,36.9,36.6,28.5,28.2,15.0,14.7$. Diastereomer 1 of II-37: ${ }^{1} \mathrm{H}(600 \mathrm{MHz}) \delta 8.09(2 \mathrm{H}, \mathrm{d}, J=8.4 \mathrm{~Hz}), 7.85(1 \mathrm{H}, \mathrm{d}, J=8.4 \mathrm{~Hz}), 7.84(1$ $\mathrm{H}, \mathrm{d}, J=9.0 \mathrm{~Hz}), 7.72(1 \mathrm{H}, \mathrm{d}, J=7.8 \mathrm{~Hz}), 7.59(2 \mathrm{H}, \mathrm{t}, J=7.8 \mathrm{~Hz}), 7.56(1 \mathrm{H}, \mathrm{d}, J=$ 9.6 Hz), 7.45-7.50 (1 H, m), 7.35-7.42 (3 H, m), 7.31-7.33 (1 H, m), 7.27-7.30 (1 H, 
m), 7.21-7.25 (5 H, m), $7.18(1 \mathrm{H}, \mathrm{t}, J=7.8 \mathrm{~Hz}), 7.05(2 \mathrm{H}, \mathrm{t}, J=7.8 \mathrm{~Hz}), 6.90(1 \mathrm{H}, \mathrm{d}$, $J=8.4 \mathrm{~Hz}), 6.89(1 \mathrm{H}, \mathrm{t}, J=7.8 \mathrm{~Hz}), 6.45(1 \mathrm{H}, \mathrm{t}, J=7.8 \mathrm{~Hz}), 5.97(1 \mathrm{H}, \mathrm{t}, J=7.8$ Hz), $5.90(1 \mathrm{H}, \mathrm{s}), 5.01(1 \mathrm{H}, \mathrm{d}, J=8.4 \mathrm{~Hz}), 4.24(1 \mathrm{H}, \mathrm{d}, J=21.0 \mathrm{~Hz}), 4.11(1 \mathrm{H}, \mathrm{d}, J$ $=20.4 \mathrm{~Hz}), 3.58-3.64(1 \mathrm{H}, \mathrm{m}), 3.33-3.40(1 \mathrm{H}, \mathrm{m}), 3.18-3.26(2 \mathrm{H}, \mathrm{m}), 1.77(9 \mathrm{H}, \mathrm{s})$, $1.18(9 \mathrm{H}, \mathrm{s}), 0.67(3 \mathrm{H}, \mathrm{t}, J=6.6 \mathrm{~Hz}), 0.48(3 \mathrm{H}, \mathrm{t}, J=6.6 \mathrm{~Hz})$. The structure of diastereomer 1 of II-37 was established by X-ray structure analysis. Diastereomer 2 of II-37: ${ }^{1} \mathrm{H}(600 \mathrm{MHz}) \delta 7.95(2 \mathrm{H}, \mathrm{d}, J=8.4 \mathrm{~Hz}), 7.91(1 \mathrm{H}, \mathrm{d}, J=8.4 \mathrm{~Hz}), 7.84(1$ H, d, $J=9.6 \mathrm{~Hz}), 7.81(1 \mathrm{H}, \mathrm{d}, J=7.8 \mathrm{~Hz}), 7.59(1 \mathrm{H}, \mathrm{d}, J=9.0 \mathrm{~Hz}), 7.49(1 \mathrm{H}, \mathrm{d}, J=$ $7.8 \mathrm{~Hz}), 7.41(2 \mathrm{H}, \mathrm{t}, J=7.8 \mathrm{~Hz}), 7.36(4 \mathrm{H}, \mathrm{d}, J=9.0 \mathrm{~Hz}), 7.31(2 \mathrm{H}, \mathrm{d}, J=7.8 \mathrm{~Hz})$, $7.28(2 \mathrm{H}, \mathrm{d}, J=7.8 \mathrm{~Hz}), 7.25(1 \mathrm{H}, \mathrm{t}, J=9.0 \mathrm{~Hz}), 7.22(1 \mathrm{H}, \mathrm{t}, J=8.4 \mathrm{~Hz}), 7.13(1 \mathrm{H}$, t, $J=7.8 \mathrm{~Hz}), 6.90(1 \mathrm{H}, \mathrm{d}, J=9.6 \mathrm{~Hz}), 6.87(1 \mathrm{H}, \mathrm{t}, J=7.8 \mathrm{~Hz}), 6.41(1 \mathrm{H}, \mathrm{t}, J=7.8$ Hz), 6.40 (1 H, s), 5.73 (1 H, bump), $5.63(1 \mathrm{H}, \mathrm{t}, J=7.8 \mathrm{~Hz}), 4.86(1 \mathrm{H}, \mathrm{d}, J=7.8$ Hz), $4.22(1 \mathrm{H}, \mathrm{d}, J=21.6 \mathrm{~Hz}), 4.08(1 \mathrm{H}, \mathrm{d}, J=21.0 \mathrm{~Hz}), 3.58-3.64 \quad(1 \mathrm{H}, \mathrm{m})$, 3.32-3.38 (1 H, m), 3.20-3.27 (2 H, m), $1.76(9 \mathrm{H}, \mathrm{s}), 1.14(9 \mathrm{H}, \mathrm{s}), 0.64(3 \mathrm{H}, \mathrm{t}, J=$ $7.8 \mathrm{~Hz}), 0.50(3 \mathrm{H}, \mathrm{t}, J=7.8 \mathrm{~Hz})$. The structure of diastereomer 2 of II-37 was established by X-ray structure analysis.

\section{Experimental Section of Chapter 2.4}

Lithium diisopropylamide (LDA, $2.0 \mathrm{M}$ ) in heptane/THF/ethylbenzene and phosphorus pentoxide were purchased from chemical suppliers and were used as received.

\section{8-(1,1-Dimethylethyl)-13-phenyl-7H-dibenzo[b,g]fluorene-7-methanol}

(II-42).

To a solution of $0.066 \mathrm{~g}(0.16 \mathrm{mmol})$ of II-28 in $5 \mathrm{~mL}$ of THF under a nitrogen 
atmosphere at $0{ }^{\circ} \mathrm{C}$ was added $0.10 \mathrm{~mL}$ of a $2.0 \mathrm{M}$ solution of LDA $(0.20 \mathrm{mmol})$ in heptane/tetrahydrofuran/ethylbenzene. After $10 \mathrm{~min}$ at $0{ }^{\circ} \mathrm{C}, 0.006 \mathrm{~g}(0.2 \mathrm{mmol})$ of paraformaldehyde was introduced via a $120^{\circ}$ angle glass tubing fitted with ground joints at both ends. The reaction mixture was then allowed to warm to room temperature. After an additional $15 \mathrm{~min}, 2 \mathrm{~mL}$ of a saturated sodium bicarbonate solution was introduced, and the reaction mixture was extracted with diethyl ether. The combined organic extracts were washed with brine and water, dried over magnesium sulfate, and concentrated. The residue was purified by flash column chromatography (silica gel $/ 20 \%$ diethyl ether in hexanes) to afford $0.057 \mathrm{~g}$ of II-42 (0.13 mmol, 80\%) as a white solid: $\mathrm{mp} 180-182{ }^{\circ} \mathrm{C}$; IR 3413, 756, $703 \mathrm{~cm}^{-1}$; ${ }^{1} \mathrm{H} \delta$ $8.64(1 \mathrm{H}, \mathrm{d}, J=8.7 \mathrm{~Hz}), 8.01(1 \mathrm{H}, \mathrm{d}, J=8.4 \mathrm{~Hz}), 7.83(1 \mathrm{H}, \mathrm{d}, J=8.2 \mathrm{~Hz}), 7.76(1$ $\mathrm{H}, \mathrm{d}, J=8.2 \mathrm{~Hz}), 7.74(1 \mathrm{H}, \mathrm{d}, J=8.2 \mathrm{~Hz}), 7.68(1 \mathrm{H}$, very broad $), 7.50(1 \mathrm{H}, \mathrm{t}, J=$ 7.1 Hz), 7.42-7.30 (2 H, m), 7.24-7.15 (2 H, m), 7.04 (3 H, very broad), $6.78(1 \mathrm{H}, \mathrm{t}$, $J=7.1 \mathrm{~Hz}), 5.20(1 \mathrm{H}, \mathrm{dd}, J=7.1,4.2 \mathrm{~Hz}), 4.30(1 \mathrm{H}, \mathrm{m}), 3.61(1 \mathrm{H}, \mathrm{m}), 1.95(9 \mathrm{H}, \mathrm{s})$, $1.48(1 \mathrm{H}, \mathrm{OH}) ;{ }^{13} \mathrm{C} \delta 144.2,141.03,140.98,139.4,136.4,134.5,133.7,133.0,132.2$ $131.9,129.8,128.8$ (br), 128.3, 128.0, 127.8, 127.4, 125.8, 124.3, 124.2, 123.9, 121.9, $68.3,52.6,38.7,34.3$.

14-Phenylnaphth[1,2-a]anthracene (II-43). To a flask containing $0.040 \mathrm{~g}(0.093$ mmol $)$ of II-42 were added $0.20 \mathrm{~g}(1.4 \mathrm{mmol})$ of phosphorus pentoxide and $10 \mathrm{~mL}$ of benzene. After $5 \mathrm{~min}$ at room temperature, $10 \mathrm{~mL}$ of a saturated sodium bicarbonate solution was introduced, and the organic layer was separated. The aqueous layer was back extracted with diethyl ether. The combined organic extracts were washed with 
water, dried over magnesium sulfate, and concentrated. The residue was purified by flash column chromatography (silica gel/10\% methylene chloride in hexanes) to provide $0.027 \mathrm{~g}$ of a pale yellow solid containing ca. $90 \%$ of II-43 (0.068 mmol, 74\% yield) and ca. $10 \%$ of adducts retaining a tert-butyl group most likely at C5 to C9 positions. II-43: ${ }^{1} \mathrm{H} \delta\left(600 \mathrm{MHz}\right.$ at $\left.-20{ }^{\circ} \mathrm{C}\right) 8.53(1 \mathrm{H}, \mathrm{s}), 8.34(1 \mathrm{H}, \mathrm{d}, J=9.0 \mathrm{~Hz})$, $8.24(1 \mathrm{H}, \mathrm{d}, J=7.2 \mathrm{~Hz}), 8.17(1 \mathrm{H}, \mathrm{d}, J=7.8 \mathrm{~Hz}), 7.92(1 \mathrm{H}, \mathrm{d}, J=8.4 \mathrm{~Hz}), 7.89(1$ $\mathrm{H}, \mathrm{d}, J=8.4 \mathrm{~Hz}), 7.85(1 \mathrm{H}, \mathrm{d}, J=8.4 \mathrm{~Hz}), 7.76(1 \mathrm{H}, \mathrm{d}, J=8.4 \mathrm{~Hz}), 7.67(1 \mathrm{H}, \mathrm{d}, J=$ $5.4 \mathrm{~Hz}), 7.66(1 \mathrm{H}, \mathrm{d}, J=8.4 \mathrm{~Hz}), 7.61(1 \mathrm{H}, \mathrm{t}, J=7.2 \mathrm{~Hz}), 7.52(1 \mathrm{H}, \mathrm{t}, J=7.8 \mathrm{~Hz})$, $7.49(1 \mathrm{H}, \mathrm{t}, J=7.2 \mathrm{~Hz}), 7.20(1 \mathrm{H}, \mathrm{t}, J=7.2 \mathrm{~Hz}), 7.02-6.98(2 \mathrm{H}, \mathrm{m}), 6.67(1 \mathrm{H}, \mathrm{t}, J$ $=7.2 \mathrm{~Hz}), 6.14(1 \mathrm{H}, \mathrm{d}, J=7.8 \mathrm{~Hz}) ;{ }^{13} \mathrm{C} \delta 140.6,138.3,132.3,132.07,132.03,131.4$, $130.4,130.0,129.7,128.4,128.0,127.6,127.5,127.31,127.27,126.5,126.4,126.2$ $126.0,125.5,125.3,124.60,124.58$.

\section{0-(1,1-Dimethylethyl)-4,5-diphenyl-11H-benzo[b]fluorene-11-methanol (II-44).}

To a solution of $0.065 \mathrm{~g}(0.15 \mathrm{mmol})$ of II-14 in $5 \mathrm{~mL}$ of THF under a nitrogen atmosphere at $0{ }^{\circ} \mathrm{C}$ was added $0.10 \mathrm{~mL}$ of a $2.0 \mathrm{M}$ solution of LDA $(0.20 \mathrm{mmol})$ in heptane/tetrahydrofuran/ethylbenzene. After $10 \mathrm{~min}$ at $0{ }^{\circ} \mathrm{C}, 0.006 \mathrm{~g}(0.2 \mathrm{mmol})$ of paraformaldehyde was introduced via a $120^{\circ}$ angle glass tubing fitted with ground joints at both ends. The reaction mixture was then allowed to warm to room temperature. After an additional $15 \mathrm{~min}, 2 \mathrm{~mL}$ of a saturated sodium bicarbonate solution was introduced, and the reaction mixture was extracted with diethyl ether. The combined organic extracts were washed with brine and water, dried over magnesium sulfate, and concentrated. The residue was purified by flash column 
chromatography (silica gel/30\% diethyl ether in hexanes) to afford $0.041 \mathrm{~g}$ of II-44 (0.090 mmol, 59\%) as a white solid: mp 214-215 ${ }^{\circ} \mathrm{C}$; IR 3384 (br), $1048 \mathrm{~cm}^{-1} ;{ }^{1} \mathrm{H} \delta$ $8.60(1 \mathrm{H}, \mathrm{d}, J=9.0 \mathrm{~Hz}), 7.66(1 \mathrm{H}, \mathrm{dd}, J=8.4,1.3 \mathrm{~Hz}), 7.58(1 \mathrm{H}, \mathrm{d}, J=7.4 \mathrm{~Hz})$, $7.42(1 \mathrm{H}, \mathrm{ddd}, J=8.2,6.6,1.3 \mathrm{~Hz}), 7.32(1 \mathrm{H}, \mathrm{d}, J=7.6 \mathrm{~Hz}), 7.27(1 \mathrm{H}, \mathrm{d}, J=7.6$ Hz), $7.22(1 \mathrm{H}, \mathrm{ddd}, J=8.2,6.6,1.1 \mathrm{~Hz}), 7.12-6.72(8 \mathrm{H}, \mathrm{m}), 6.58(2 \mathrm{H}, \mathrm{d}, J=6.6$ Hz), 5.20 (1 H, dd, $J=7.4,4.2 \mathrm{~Hz}), 4.19(1 \mathrm{H}$, broad), $3.45(1 \mathrm{H}, \mathrm{t}, J=7.9 \mathrm{~Hz}), 1.94$ $(9 \mathrm{H}, \mathrm{s}), 1.56(1 \mathrm{H}, \mathrm{OH}) ;{ }^{13} \mathrm{C} \delta 145.7,142.7,140.9,140.4,139.5,138.8,138.0$, $137.8,134.1,132.22,132.15,130.9,130.3,129.4,128.4,127.84,127.77,127.4,127.3$,

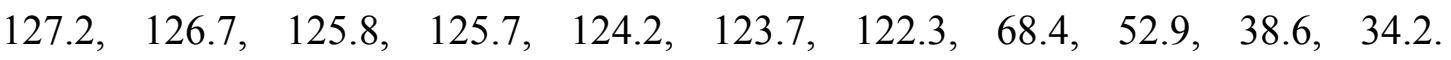
Recrystallization of II-44 from a mixture of $\mathrm{CH}_{2} \mathrm{Cl}_{2} /$ hexanes produced a single crystal suitable for X-ray structure analysis.

Hydrocarbon II-46. To a flask containing $0.030 \mathrm{~g}$ (0.066 mmol) of II-44 were added $0.20 \mathrm{~g}(1.4 \mathrm{mmol})$ of phosphorus pentoxide and $10 \mathrm{~mL}$ of benzene. After $5 \mathrm{~min}$ at room temperature, $10 \mathrm{~mL}$ of a saturated sodium bicarbonate solution was introduced, and the organic layer was separated. The aqueous layer was back extracted with diethyl ether. The combined organic extracts were washed with water, dried over magnesium sulfate, and concentrated. The residue was purified by flash column chromatography (silica gel $/ 5 \%$ methylene chloride in hexanes) to provide $0.020 \mathrm{~g}$ of II-46 (0.053 mmol, 80\%) as a colorless solid: $\mathrm{mp} 211-216{ }^{\circ} \mathrm{C} ;{ }^{1} \mathrm{H} \delta 8.27(1 \mathrm{H}, \mathrm{dd}, J=$ 7.8, $1.4 \mathrm{~Hz}), 8.17(1 \mathrm{H}, \mathrm{d}, J=7.1 \mathrm{~Hz}), 7.81(1 \mathrm{H}, \mathrm{d}, J=8.2 \mathrm{~Hz}), 7.70(1 \mathrm{H}, \mathrm{d}, J=8.2$ Hz), 7.65-7.57 (1 H, m), $7.52(1 \mathrm{H}, \mathrm{t}, J=7.8 \mathrm{~Hz}), 7.48-7.39 \quad(3 \mathrm{H}, \mathrm{m}), 7.38-7.17(4$ H, m), 7.16-6.82 (4 H, m), 6.66 (1 H, broad), $3.75(1 \mathrm{H}, \mathrm{d}, J=16.9 \mathrm{~Hz}), 3.47$ (1 H, d, 
$J=16.9 \mathrm{~Hz}) ;{ }^{13} \mathrm{C} \delta 148.5,144.4,139.1,138.4,137.9,137.1,134.3,132.0,130.9$, $128.7,128.1,127.9,127.25,127.20,126.8,126.7,126.2,125.8,125.7,125.39,125.35$, 123.3, 119.2, 54.5, 38.8. Recrystallization of II-46 from a mixture of $\mathrm{CH}_{2} \mathrm{Cl}_{2} /$ hexanes produced a single crystal suitable for X-ray structure analysis.

\section{Experimental Section of Chapter 2.5}

(+)-Mosher's reagent, DCC, lithium aluminum hydride and DME were purchased from chemical suppliers and were used as received.

Diols II-48a-c. To a solution of $0.344 \mathrm{~g}(0.557 \mathrm{mmol})$ of I-19a in $60 \mathrm{~mL}$ of benzene and $50 \mathrm{~mL}$ of THF under a nitrogen atmosphere at $0{ }^{\circ} \mathrm{C}$ was added $1.80 \mathrm{~mL}$ of a 2.0 M solution of LDA (3.60 mmol) in heptane/tetrahydrofuran/ethylbenzene. After 20 min at $0{ }^{\circ} \mathrm{C}, 0.220 \mathrm{~g}(7.33 \mathrm{mmol})$ of paraformaldehyde was transferred into the reaction mixture via a $120^{\circ}$ angle glass tubing fitted with ground joints at both ends. The reaction mixture was allowed to warm to room temperature. After an additional $30 \mathrm{~min}, 10 \mathrm{~mL}$ of a saturated sodium bicarbonate solution was introduced, and the reaction mixture was extracted with diethyl ether. The combined organic extracts were washed with brine and water, dried over magnesium sulfate, and concentrated. The residue was purified by flash column chromatography (silica gel/50\% diethyl ether in hexanes) to afford $0.287 \mathrm{~g}$ of II-48a-c $(0.423 \mathrm{mmol}, 76 \%$, a mixture of three isomers, isomer ratio $=63: 34: 3)$ as a pale yellow solid. The ${ }^{1} \mathrm{H}$ NMR spectrum suggests that all three diastereomers, II-48a and II-48b having a $C_{2}$ symmetry (63\% and 3\% not necessarily respectively) and II-48c without a $C_{2}$ symmetry (34\%), were produced. The major isomer (II-48a or II-48b) and II-48c were further separated by 
column chromatography on a silica gel column. II-48a-c: $m p \quad 221-225{ }^{\circ} \mathrm{C}$; IR 3412 (br), 1052, $704 \mathrm{~cm}^{-1} ;{ }^{1} \mathrm{H}(\mathbf{I I}-48 \mathbf{a}$ or II-48b) $\delta 7.81(2 \mathrm{H}, \mathrm{s}), 7.49(2 \mathrm{H}, \mathrm{d}, J=7.5 \mathrm{~Hz})$, $7.13(2 \mathrm{H}, \mathrm{tm}, J=7.5,1 \mathrm{~Hz}), 7.10(2 \mathrm{H}, \mathrm{tm}, J=7.5,1 \mathrm{~Hz}), 6.99(4 \mathrm{H}, \mathrm{t}, J=7.5 \mathrm{~Hz})$, $6.78(2 \mathrm{H}, \mathrm{t}, J=7.2 \mathrm{~Hz}), 6.46(4 \mathrm{H}, \mathrm{d}, J=6.9 \mathrm{~Hz}), 6.22(2 \mathrm{H}, \mathrm{d}, J=7.9 \mathrm{~Hz}), 4.70(2 \mathrm{H}$, $\mathrm{dd}, J=5.9,3.0 \mathrm{~Hz}), 4.47(2 \mathrm{H}, \mathrm{m}), 3.82(2 \mathrm{H}, \mathrm{m}), 1.82(18 \mathrm{H}, \mathrm{s}), 1.13(2 \mathrm{H}, \mathrm{OH}) ;{ }^{13} \mathrm{C}$ (II-48a or II-48b) $\delta 146.6,140.7,140.6,138.7,137.4,135.1,134.9,132.1,131.2$, $128.2,126.56,126.51,126.0,123.8,122.9,121.9,67.0,50.7,37.7,34.3 ;{ }^{1} \mathrm{H}(\mathbf{I I}-48 \mathrm{c}) \delta$ $7.97(1 \mathrm{H}, \mathrm{d}, J=9.7 \mathrm{~Hz}), 7.88(1 \mathrm{H}, \mathrm{d}, J=9.3 \mathrm{~Hz}), 7.50(1 \mathrm{H}, \mathrm{d}, J=7.5 \mathrm{~Hz}), 7.45(1$ $\mathrm{H}, \mathrm{d}, J=7.1 \mathrm{~Hz}), 7.19-6.91(8 \mathrm{H}, \mathrm{m}), 6.83-6.74(2 \mathrm{H}, \mathrm{m}), 6.47(4 \mathrm{H}, \mathrm{t}, J=8.1 \mathrm{~Hz})$, $6.32(2 \mathrm{H}, \mathrm{t}, J=6.9 \mathrm{~Hz}), 4.85(1 \mathrm{H}, \mathrm{dd}, J=7.7,3.8 \mathrm{~Hz}), 4.73(1 \mathrm{H}, \mathrm{dd}, J=6.1,3.2$ Hz), $4.47(1 \mathrm{H}, \mathrm{m}), 4.36(1 \mathrm{H}, \mathrm{m}), 3.74(1 \mathrm{H}, \mathrm{m}), 3.47(1 \mathrm{H}, \mathrm{t}, J=8 \mathrm{~Hz}), 1.86(9 \mathrm{H}, \mathrm{s})$, $1.85(9 \mathrm{H}, \mathrm{s}), 1.64(1 \mathrm{H}, \mathrm{OH}), 1.17(1 \mathrm{H}, \mathrm{OH}) ;{ }^{13} \mathrm{C}(\mathbf{I I}-48 \mathrm{c}) \delta 146.7,146.6,140.8$, $140.5,140.4,139.0,138.9,138.5,138.4,137.3,135.9,134.9,134.6,133.3,133.0$, $132.5,132.2,127.7,126.9,126.6,126.1,123.8,123.5,123.3,123.0,122.8,122.1$, 69.6, 67.2, 52.2, 50.7, 38.3, 37.8, 34.5, 34.2; The ${ }^{1} \mathrm{H}$ NMR signals attributable to the minor isomer having a $C_{2}$ symmetry (II-48a or II-48b) were observed at $\delta 8.05(2 \mathrm{H}$, s) and $1.90(18 \mathrm{H}, \mathrm{s})$; MS m/z $678\left(\mathrm{M}^{+}\right), 664,647,605$; HRMS calcd for $\mathrm{C}_{50} \mathrm{H}_{46} \mathrm{O}_{2}$ 678.3492, found 678.3496 .

General procedure for Mosher's diester: A mixture of one equivalent of the diol, 2.2 equivalent of Mosher's reagent, 4 equivalent of DCC and catalytic amount of DMAP in methylene chloride was stirred at room temperature for $12 \mathrm{~h}$. The solvent was removed and the residue was purified by flash column chromatography (silica 
gel $/ 20 \%$ ethyl ether in hexanes) to give the corresponding Mosher's diester.

Crystallization for Mosher's diester: The corresponding Mosher's diester from one diol was dissolved in small amount of methylene chloride and ethyl alcohol was added until precipitate appeared. Methylene chloride was added again to dissolve the precipitate. Slowly evaporating the solvent, the first precipitate contained most of one diastereomer of the Mosher's diester (depending on the evaporation speed). Crystallization again using the first precipitate might be needed.

Deprotection of the Mosher's diester: the Mosher's diester was dissolved in DME solvent, excess amount of LAH was added. After stirring at room temperature for $12 \mathrm{~h}$, saturated sodium bicarbonate solution was introduced, and the reaction mixture was extracted with diethyl ether then following the separation procedure for diols II-48a-c.

Pure enantiomer of II-50a or II-50b $[a]^{25}{ }_{\mathrm{D}}=-948^{\circ}{ }^{1} \mathrm{H}(600 \mathrm{MHz}) \delta 7.78(2 \mathrm{H}, \mathrm{s})$, 7.28-7.23 (4 H, m), $7.18(2 \mathrm{H}, \mathrm{d}, J=7.2 \mathrm{~Hz}), 7.16-7.07(8 \mathrm{H}, \mathrm{m}), 6.97(4 \mathrm{H}, \mathrm{t}, J=7.2$ Hz), $6.94(2 \mathrm{H}, \mathrm{t}, J=7.2 \mathrm{~Hz}), 6.72(2 \mathrm{H}, \mathrm{t}, J=7.8 \mathrm{~Hz}), 6.40(4 \mathrm{H}, \mathrm{d}, J=7.8 \mathrm{~Hz}), 6.10$ $(2 \mathrm{H}, \mathrm{d}, J=8.4 \mathrm{~Hz}), 5.15(2 \mathrm{H}, \mathrm{dd}, J=10.8,1.8 \mathrm{~Hz}), 4.83(2 \mathrm{H}, \mathrm{d}, J=4.8 \mathrm{~Hz}), 4.43(2$ $\mathrm{H}, \mathrm{dd}, J=10.8,6.6 \mathrm{~Hz}), 3.22(6 \mathrm{H}, \mathrm{s}), 1.81(18 \mathrm{H}, \mathrm{s}) ;{ }^{13} \mathrm{C}(150 \mathrm{MHz}) \delta 166.3,145.6$, $140.7,140.4,138.7,138.0,137.3,135.2,135.1,131.7,131.3,129.2,128.19,128.16$, $127.1,126.60,126.56,126.1,123.5,123.2,121.8,70.3,55.1,47.0,37.6,34.2$.

Pure enantiomer of II-50c $[a]^{25}{ }_{\mathrm{D}}=+992^{\circ}{ }^{1} \mathrm{H}(600 \mathrm{MHz}) \delta 7.98(1 \mathrm{H}, \mathrm{d}, J=9.6 \mathrm{~Hz})$, $7.89(1 \mathrm{H}, \mathrm{d}, J=9.0 \mathrm{~Hz}), 7.60(2 \mathrm{H}, \mathrm{d}, J=6.6 \mathrm{~Hz}), 7.50-7.42(4 \mathrm{H}, \mathrm{m}), 7.34-7.26(1 \mathrm{H}$, m), 7.24-7.16 (6 H, m), 7.11 (1 H, t, $J=6.6 \mathrm{~Hz}), 7.06-6.92(5 \mathrm{H}, \mathrm{m}), 6.82(1 \mathrm{H}, \mathrm{dt}, J=$ 7.2, $2.4 \mathrm{~Hz}), 6.76-6.68(2 \mathrm{H}, \mathrm{m}), 6.48(2 \mathrm{H}, \mathrm{d}, J=6.6 \mathrm{~Hz}), 6.39(2 \mathrm{H}, \mathrm{d}, J=6.6 \mathrm{~Hz})$, 
$6.23(1 \mathrm{H}, \mathrm{d}, J=7.8 \mathrm{~Hz}), 6.20(1 \mathrm{H}, \mathrm{d}, J=8.4 \mathrm{~Hz}), 5.26(1 \mathrm{H}, \mathrm{d}, J=10.8 \mathrm{~Hz}), 5.07(1$ H, d, $J=10.2 \mathrm{~Hz}), 4.91(1 \mathrm{H}, \mathrm{d}, J=10.2 \mathrm{~Hz}), 4.82(1 \mathrm{H}, \mathrm{d}, J=7.2 \mathrm{~Hz}), 4.17(1 \mathrm{H}, \mathrm{t}, J$ $=8.4 \mathrm{~Hz}), 3.88(1 \mathrm{H}, \mathrm{t}, J=10.2 \mathrm{~Hz}), 3.63(3 \mathrm{H}, \mathrm{s}), 3.20(3 \mathrm{H}, \mathrm{s}), 1.88(9 \mathrm{H}, \mathrm{s}), 1.85(9$ $\mathrm{H}, \mathrm{s}) ;{ }^{13} \mathrm{C}(150 \mathrm{MHz}) \delta 166.3,145.6,140.7,140.4,138.7,138.0,137.3,135.2,135.1$, $131.7,131.3,129.2,128.19,128.16,127.1,126.60,126.56,126.1,123.5,123.2,121.8$ $70.3,55.1,47.0,37.6,34.2$.

\section{Experimental Section of Chapter 3.2}

Compounds III-58, ${ }^{7}$ III-68, ${ }^{51}$ III-69b, ${ }^{51}$ III-77, ${ }^{52}$ III-82, ${ }^{52}$ and III-85 $^{52}$ were prepared according to the reported procedures. 4-Aminopyridine, 4-(dimethylamino)pyridine, 4-methoxypyridine, propargyl alcohol, methanesulfonyl chloride, 3,3-dimethyl-1-butyne, (trimethylsilyl)ethyne, imidazole, tetrabutylammonium iodide were purchased from chemical suppliers and were used as received.

Propargylic Alcohol III-60. To a solution of III-58 (480 mg, $1.87 \mathrm{mmol})$ in $20 \mathrm{~mL}$ of anhydrous diethyl ether at $-78{ }^{\circ} \mathrm{C}$ was added dropwise $0.9 \mathrm{~mL}$ of a $2.5 \mathrm{M}$ solution of $n$-butyllithium $(2.25 \mathrm{mmol})$ in hexanes. After one hour of stirring at $-78{ }^{\circ} \mathrm{C}$, a solution of $640 \mathrm{mg}$ of iodine $(2.52 \mathrm{mmol})$ in $30 \mathrm{~mL}$ of anhydrous diethyl ether was added dropwise via cannula. The reaction mixture was allowed to warm to room temperature before $15 \mathrm{~mL}$ of a $5 \%$ sodium thiosulfate solution was introduced. The organic layer was separated, washed with water, dried over sodium sulfate, and concentrated to give $477 \mathrm{mg}$ of III-59. To a mixture of $477 \mathrm{mg}$ of the crude iodide III-59, $55 \mathrm{mg}(0.078$ mmol) of $\mathrm{Pd}\left(\mathrm{PPh}_{3}\right)_{2} \mathrm{Cl}_{2}$, and $29 \mathrm{mg}(0.15 \mathrm{mmol})$ of copper(I) iodide in $25 \mathrm{~mL}$ of 
triethylamine under a nitrogen atmosphere was added dropwise via cannula a solution of $240 \mathrm{mg}$ of propargyl alcohol $(4.29 \mathrm{mmol})$ in $5 \mathrm{~mL}$ of triethylamine. The reaction mixture was stirred vigorously at $75^{\circ} \mathrm{C}$ for $12 \mathrm{~h}$ before it was allowed to cool to room temperature. Then $50 \mathrm{~mL}$ of a saturated $\mathrm{NH}_{4} \mathrm{Cl}$ solution and $50 \mathrm{~mL}$ of diethyl ether were introduced. The organic layer was separated, and the aqueous layer was back extracted with diethyl ether. The combined organic layers were washed with water, dried over $\mathrm{MgSO}_{4}$, and concentrated. The residue was purified by column chromatography (silica gel/diethyl ether:hexanes $=3: 7)$ to give $286 \mathrm{mg}(1.23 \mathrm{mmol}$, $66 \%$ overall yield) of III-60 as a colorless liquid: IR 3334, 2217, 755, $690 \mathrm{~cm}^{-1} ;{ }^{1} \mathrm{H} \delta$ 7.45-7.60 (4 H, m), 7.23-7.40 (5 H, m), $4.57(2 \mathrm{H}, \mathrm{d}, J=5.9 \mathrm{~Hz}), 1.75(1 \mathrm{H}, \mathrm{t}, J=6.2$ $\mathrm{Hz}) ;{ }^{13} \mathrm{C} \delta 131.9,131.7,128.5,128.4,128.2,127.9,125.8,125.0,123.1,93.5,91.3$, 88.0, 84.5, 51.8; MS $m / z 232\left(\mathrm{M}^{+}\right), 231,202,101$.

Propargyl Methanesulfonate III-61. To a solution of III-60 (322 mg, $1.39 \mathrm{mmol})$ and triethylamine $(211 \mathrm{mg}, 2.01 \mathrm{mmol})$ in $10 \mathrm{~mL}$ of methylene chloride at $-50{ }^{\circ} \mathrm{C}$ under a nitrogen atmosphere was added dropwise methanesulfonyl chloride (207 mg, $1.81 \mathrm{mmol})$. The reaction mixture was allowed to warm to room temperature and stirred for $1 \mathrm{~h}$ before $5 \mathrm{~mL}$ of water was introduced. The organic layer was separated, and the aqueous layer was back extracted with methylene chloride. The combined organic layers were washed with water, dried over $\mathrm{MgSO}_{4}$, and concentrated. The residue was purified by column chromatography (silica gel/diethyl ether:hexanes = 3:7) to give $353 \mathrm{mg}(1.14 \mathrm{mmol}, 82 \%)$ of III-61 as a colorless liquid: IR 2217, 1360 $\mathrm{cm}^{-1} ;{ }^{1} \mathrm{H} \delta$ 7.48-7.61 (4 H, m), 7.28-7.42 (5 H, m), $5.18(2 \mathrm{H}, \mathrm{s}), 3.12(3 \mathrm{H}, \mathrm{s}) ;{ }^{13} \mathrm{C} \delta$ 
$132.3,132.0,131.7,129.2,128.8,128.5,128.1,126.2,123.5,122.7,93.9,88.1,87.5$, $84.6,58.5,39.2$.

Pyridinium Methanesulfonate III-63a. To a solution of III-61 (186 mg, $0.600 \mathrm{mmol})$ in $5 \mathrm{~mL}$ of methylene chloride was added dropwise a solution of 4-aminopyridine (56 $\mathrm{mg}, 0.60 \mathrm{mmol}$ ) in $5 \mathrm{~mL}$ of methylene chloride. The reaction mixture was stirred at room temperature for $24 \mathrm{~h}$ and concentrated. The residue was washed with diethyl ether to give $242 \mathrm{mg}(0.599 \mathrm{mmol}, 100 \%)$ of III-63a as a colorless solid: mp 189-190 ${ }^{\circ} \mathrm{C}$; IR 3330, 3120, $1197 \mathrm{~cm}^{-1} ;{ }^{1} \mathrm{H} \delta 8.11(2 \mathrm{H}, \mathrm{s}), 7.97(2 \mathrm{H}, \mathrm{d}, J=6.9 \mathrm{~Hz}), 7.22-7.52$ $(9 \mathrm{H}, \mathrm{m}), 6.96(2 \mathrm{H}, \mathrm{d}, J=6.9 \mathrm{~Hz}), 5.23(2 \mathrm{H}, \mathrm{s}), 2.79(3 \mathrm{H}, \mathrm{s}) ;{ }^{13} \mathrm{C} \delta 159.7,140.9$, $132.2,132.0,131.5,129.2,129.0,128.6,128.2,126.0,123.3,122.4,93.7,88.0,87.4$ 83.6, 47.6, 39.7.

Pyridinium Methanesulfonate III-63b. To a solution of III-61 (186 mg, $0.600 \mathrm{mmol})$ in $5 \mathrm{~mL}$ of methylene chloride was added dropwise a solution of 4-(dimethylamino)pyridine $(73 \mathrm{mg}, 0.60 \mathrm{mmol})$ in $5 \mathrm{~mL}$ of methylene chloride. The reaction mixture was stirred at room temperature for $24 \mathrm{~h}$ and concentrated. The residue was washed with diethyl ether to give $259 \mathrm{mg}(0.600 \mathrm{mmol}, 100 \%)$ of III-63b as a viscous liquid: IR 1651, 1192, $765 \mathrm{~cm}^{-1} ;{ }^{1} \mathrm{H} \delta 8.64(2 \mathrm{H}, \mathrm{d}, J=7.9 \mathrm{~Hz})$, 7.46-7.57 (4 H, m), 7.29-7.42 (5 H, m), $6.51(2 \mathrm{H}, \mathrm{d}, J=7.9 \mathrm{~Hz}), 5.53(2 \mathrm{H}, \mathrm{s}), 3.07$ (6 H, s), $2.81(3 \mathrm{H}, \mathrm{s}) ;{ }^{13} \mathrm{C} \delta 156.2,141.6,131.8,131.7,129.0,128.7,128.5,128.3$, $125.5,123.5,122.6,107.7,93.0,88.4,87.9,83.7,47.5,40.1,39.5$.

Pyridinium Methanesulfonate III-63c. To a solution of III-61 (30 mg, $0.097 \mathrm{mmol})$ in $5 \mathrm{~mL}$ of methylene chloride was added dropwise a solution of 4-methoxypyridine 
(11 mg, $0.101 \mathrm{mmol}$ ) in $5 \mathrm{~mL}$ of methylene chloride. The reaction mixture was stirred at room temperature for $24 \mathrm{~h}$ and concentrated. The residue was washed with diethyl ether to give $41 \mathrm{mg}(0.097 \mathrm{mmol}, 100 \%)$ of III-63c as a colorless solid: $\mathrm{mp} \mathrm{133-134}$ ${ }^{\circ} \mathrm{C}$; IR 2216, 1192, $762 \mathrm{~cm}^{-1} ;{ }^{1} \mathrm{H} \delta 9.19(2 \mathrm{H}, \mathrm{d}, J=6.9 \mathrm{~Hz}), 7.31-7.55$ (9 H, m), 6.99

$(2 \mathrm{H}, \mathrm{d}, J=6.9 \mathrm{~Hz}), 5.86(2 \mathrm{H}, \mathrm{s}), 3.96(3 \mathrm{H}, \mathrm{s}), 2.78(3 \mathrm{H}, \mathrm{s}) ;{ }^{13} \mathrm{C} \delta 171.1,145.7$, $131.9,131.7,129.3,128.9,128.7,128.5,128.4,125.7,123.2,122.6,113.2,93.0,89.8$, $87.9,82.7,57.8,49.9,39.5$.

\section{2-Amino-12-phenyl-7H-indeno[1,2-b]quinolizin-5-ium}

Methanesulfonate

(III-67a). A solution of III-63a (45 mg, $0.11 \mathrm{mmol})$ and triethylamine (11 $\mathrm{mg}, 0.11$ mmol) in $10 \mathrm{~mL}$ of ethanol was heated under reflux for $12 \mathrm{~h}$. The solvent was removed and the residue was washed with diethyl ether to give $45 \mathrm{mg}(0.11 \mathrm{mmol}$, $100 \%$ ) of III-67a as a yellow solid: compound becomes black at $270{ }^{\circ} \mathrm{C}$ without melting; IR 3361, 1652, $1194 \mathrm{~cm}^{-1} ;{ }^{1} \mathrm{H} \delta 8.67(1 \mathrm{H}, \mathrm{d}, J=7.4 \mathrm{~Hz}), 8.63(1 \mathrm{H}, \mathrm{s})$, 7.60-7.62 (3 H, m), $7.52(1 \mathrm{H}, \mathrm{d}, J=7.6 \mathrm{~Hz}), 7.28-7.39(4 \mathrm{H}, \mathrm{m}), 7.05(1 \mathrm{H}, \mathrm{t}, J=7.6$ $\mathrm{Hz}), 6.33-6.43(2 \mathrm{H}, \mathrm{m}), 4.13(2 \mathrm{H}, \mathrm{s}), 2.99(2 \mathrm{H}, \mathrm{s}), 2.75(3 \mathrm{H}, \mathrm{s}),{ }^{13} \mathrm{C}\left(10 \% \mathrm{CD}_{3} \mathrm{OD}\right.$ in $\left.\mathrm{CDCl}_{3}\right) \delta 153.9,145.5,145.1,144.4,136.9,136.6,133.4,131.9,131.0,130.0$, $129.4, \quad 129.1, \quad 128.5, \quad 127.5, \quad 126.7, \quad 125.4, \quad 125.2, \quad 112.9, \quad 101.6, \quad 38.9, \quad 33.8$. Recrystallization of III-67a from a mixture of chloroform and methanol produced a crystal suitable for X-ray structure analysis.

\section{2-(Dimethylamino)-12-phenyl-7H-indeno[1,2-b]quinolizin-5-ium}

Methanesulfonate (III-67b). A solution of III-63b (51 mg, $0.12 \mathrm{mmol})$ and triethylamine $(12 \mathrm{mg}, 0.12 \mathrm{mmol})$ in $10 \mathrm{~mL}$ of ethanol was stirred at room 
temperature for $72 \mathrm{~h}$. The solvent was removed and the residue was washed with diethyl ether to give $51 \mathrm{mg}(0.12 \mathrm{mmol}, 100 \%)$ of III-67b as a yellow solid: compound becomes black at $228{ }^{\circ} \mathrm{C}$ without melting; IR $1647,1195 \mathrm{~cm}^{-1} ;{ }^{1} \mathrm{H} \delta 9.62$ $(1 \mathrm{H}, \mathrm{d}, J=7.6 \mathrm{~Hz}), 9.39(1 \mathrm{H}, \mathrm{s}), 7.61-7.71(3 \mathrm{H}, \mathrm{m}), 7.55(1 \mathrm{H}, \mathrm{d}, J=7.7 \mathrm{~Hz})$, 7.26-7.41 (4 H, m), 7.07 (1 H, t, $J=7.9 \mathrm{~Hz}), 6.43(1 \mathrm{H}, \mathrm{d}, J=8.2 \mathrm{~Hz}), 6.27(1 \mathrm{H}, \mathrm{d}, J$ $=2.9 \mathrm{~Hz}), 4.22(2 \mathrm{H}, \mathrm{s}), 3.04(6 \mathrm{H}, \mathrm{s}), 2.87(3 \mathrm{H}, \mathrm{s}) ;{ }^{13} \mathrm{C} \delta 152.0,146.3,145.7,143.8$, $138.8,136.8,133.9,132.4,131.0,130.3,130.1,129.7,129.2,127.4,126.6,125.6$ 125.3, 109.8, 99.6, 39.7, 39.6, 34.3. Recrystallization of III-67b from a mixture of dichloromethane and hexanes produced a crystal suitable for X-ray structure analysis.

2-Methoxy-12-phenyl-7H-indeno[1,2-b]quinolizin-5-ium

Methanesulfonate

(III-67c). A solution of III-63c (150 mg, $0.358 \mathrm{mmol})$ and triethylamine (36 mg, 0.36 $\mathrm{mmol}$ ) in $40 \mathrm{~mL}$ of ethanol was stirred at room temperature for $15 \mathrm{~h}$. The solvent was removed and the residue was washed with diethyl ether to give $150 \mathrm{mg}(0.358 \mathrm{mmol}$, $100 \%$ ) of III-67c as a yellow solid: compound becomes black at $228{ }^{\circ} \mathrm{C}$ without melting; IR 1644, $1193 \mathrm{~cm}^{-1}$; ${ }^{1} \mathrm{H} \delta 10.09(1 \mathrm{H}, \mathrm{s}), 9.99(1 \mathrm{H}, \mathrm{d}, J=7.7 \mathrm{~Hz}), 7.69-7.78$ (3 H, m), $7.64(1 \mathrm{H}, \mathrm{d}, J=7.9 \mathrm{~Hz}), 7.37-7.52(4 \mathrm{H}, \mathrm{m}), 7.14(1 \mathrm{H}, \mathrm{t}, J=7.8 \mathrm{~Hz}), 6.87$ $(1 \mathrm{H}, \mathrm{d}, J=3.0 \mathrm{~Hz}), 6.52(1 \mathrm{H}, \mathrm{d}, J=8.2 \mathrm{~Hz}), 4.39(2 \mathrm{H}, \mathrm{s}), 3.86(3 \mathrm{H}, \mathrm{s}), 2.92(3 \mathrm{H}$, s); ${ }^{13} \mathrm{C} \delta 163.8,148.0,146.9,144.5,140.3,136.4,136.2,133.1,132.3,131.9,130.5$, $130.1, \quad 129.2, \quad 127.9, \quad 127.7, \quad 125.8, \quad 125.6, \quad 114.4, \quad 103.2, \quad 56.6, \quad 39.6, \quad 34.8$ Recrystallization of III-67c from a mixture of dichloromethane and hexanes produced a crystal suitable for X-ray structure analysis.

Propargylic Alcohol III-69a. To a mixture of $269 \mathrm{mg}(1.04 \mathrm{mmol})$ of III-68, $22 \mathrm{mg}$ 
$(0.030 \mathrm{mmol})$ of $\mathrm{Pd}\left(\mathrm{PPh}_{3}\right)_{2} \mathrm{Cl}_{2}$, and $11 \mathrm{mg}(0.060 \mathrm{mmol})$ of copper(I) iodide in $20 \mathrm{~mL}$ of triethylamine under a nitrogen atmosphere was added dropwise via cannula a solution of $103 \mathrm{mg}$ of 3,3-dimethyl-1-butyne $(1.25 \mathrm{mmol})$ in $5 \mathrm{~mL}$ of triethylamine. The reaction mixture was stirred at room temperature for $12 \mathrm{~h}$ before $20 \mathrm{~mL}$ of a saturated $\mathrm{NH}_{4} \mathrm{Cl}$ solution and $50 \mathrm{~mL}$ of diethyl ether were introduced. The organic layer was separated, and the aqueous layer was back extracted with diethyl ether. The combined organic layers were washed with water, dried over $\mathrm{MgSO}_{4}$, and concentrated. The residue was purified by column chromatography (silica gel/diethyl ether:hexanes $=1: 2)$ to give $203 \mathrm{mg}(0.96 \mathrm{mmol}, 92 \%)$ of III-69a as a colorless liquid: IR 3331, 1025, $755 \mathrm{~cm}^{-1} ;{ }^{1} \mathrm{H} \delta$ 7.33-7.42 (2 H, m), 7.14-7.25 (2 H, m), $4.52(2 \mathrm{H}, \mathrm{s})$, $1.97(1 \mathrm{H}, \mathrm{br}), 1.33(9 \mathrm{H}, \mathrm{s}) ;{ }^{13} \mathrm{C} \delta 131.6,131.5,128.1,127.1,126.6,124.9,103.0$, 90.6, 84.6, 77.7, 51.6, 30.9, 28.1; MS m/z $212\left(\mathrm{M}^{+}\right), 197,178,165$.

Propargyl Methanesulfonate III-70a. To a solution of III-69a (68 mg, $0.32 \mathrm{mmol})$ and triethylamine (49 $\mathrm{mg}, 0.48 \mathrm{mmol}$ ) in $10 \mathrm{~mL}$ of methylene chloride at $-50{ }^{\circ} \mathrm{C}$ under a nitrogen atmosphere was added dropwise methanesulfonyl chloride (48 mg, 0.42 mmol). The reaction mixture was allowed to warm to room temperature and stirred for $1 \mathrm{~h}$ before $5 \mathrm{~mL}$ of water was introduced. The organic layer was separated, and the aqueous layer was back extracted with methylene chloride. The combined organic layers were washed with water, dried over $\mathrm{MgSO}_{4}$, and concentrated. The residue was purified by column chromatography ( $\mathrm{mg}(0.26 \mathrm{mmol}, 81 \%)$ of III-70a as a colorless liquid: IR 2239, 1362, $1179 \mathrm{~cm}^{-1} ;{ }^{1} \mathrm{H} \delta$ 7.35-7.44 (2 H, m), $7.28(1 \mathrm{H}, \mathrm{td}, J=7.6,1.6 \mathrm{~Hz}), 7.21(1 \mathrm{H}, \mathrm{td}, J=7.4,1.6 \mathrm{~Hz}), 5.11$ 
(2 H, s), $3.16(3 \mathrm{H}, \mathrm{s}), 1.34(9 \mathrm{H}, \mathrm{s}) ;{ }^{13} \mathrm{C} \delta 132.0,131.8,129.0,127.2,127.1,103.6$, $88.3,83.8,77.3,58.4,39.2,30.9,28.1$.

Propargyl Methanesulfonate III-70b. To a solution of III-69b (164 mg, $0.72 \mathrm{mmol})$ and triethylamine $(109 \mathrm{mg}, 1.08 \mathrm{mmol})$ in $10 \mathrm{~mL}$ of methylene chloride at $-50{ }^{\circ} \mathrm{C}$ under a nitrogen atmosphere was added dropwise methanesulfonyl chloride (108 mg, $0.94 \mathrm{mmol})$. The reaction mixture was allowed to warm to room temperature and stirred for $1 \mathrm{~h}$ before $5 \mathrm{~mL}$ of water was introduced. The organic layer was separated, and the aqueous layer was back extracted with methylene chloride. The combined organic layers were washed with water, dried over $\mathrm{MgSO}_{4}$, and concentrated. The residue was purified by column chromatography (silica gel/ethyl acetate:hexanes = 1:4) to give $196 \mathrm{mg}(0.64 \mathrm{mmol}, 89 \%)$ of III-70b as a colorless liquid: IR 2232, 2159, 1367, $1177 \mathrm{~cm}^{-1} ;{ }^{1} \mathrm{H} \delta 7.41-7.50(2 \mathrm{H}, \mathrm{m}), 7.25-7.35(2 \mathrm{H}, \mathrm{m}), 5.12(2 \mathrm{H}, \mathrm{s}), 3.17(3$ $\mathrm{H}, \mathrm{s}), 0.27(9 \mathrm{H}, \mathrm{s}) ;{ }^{13} \mathrm{C} \delta 132.4,132.2,129.1,128.3,126.1,124.0,102.7,99.4,87.9$, $84.4,58.4,39.3,-0.1$.

Pyridinium Methanesulfonate III-71a. To a solution of III-70a (26 mg, $0.090 \mathrm{mmol})$ in $5 \mathrm{~mL}$ of methylene chloride was added dropwise a solution of 4-(dimethylamino)pyridine $(11 \mathrm{mg}, 0.090 \mathrm{mmol})$ in $5 \mathrm{~mL}$ of methylene chloride. The reaction mixture was stirred at room temperature for $24 \mathrm{~h}$ and concentrated. The residue was washed with diethyl ether to give $36 \mathrm{mg}(0.087 \mathrm{mmol}, 97 \%)$ of III-71a as a colorless solid: $\mathrm{mp} 127-128{ }^{\circ} \mathrm{C}$; IR 2238, 1652, $1192 \mathrm{~cm}^{-1} ;{ }^{1} \mathrm{H} \delta 8.56(2 \mathrm{H}, \mathrm{d}, J=7.4$ Hz), 7.35-7.41 (2 H, m), 7.16-7.28 (2 H, m), 6.96 (2 H, d, J= 7.6 Hz), $5.44(2 \mathrm{H}, \mathrm{s})$, $3.22(6 \mathrm{H}, \mathrm{s}), 2.75(3 \mathrm{H}, \mathrm{s}), 1.25(9 \mathrm{H}, \mathrm{s}) ;{ }^{13} \mathrm{C} \delta 156.5,141.9,132.3,131.9,129.0$, 
$127.3,126.8,123.1,108.1,103.2,88.6,82.7,47.7,40.3,39.5,30.9,28.1$.

Pyridinium Methanesulfonate III-71b. To a solution of III-70b (26 mg, 0.085 mmol) in $5 \mathrm{~mL}$ of methylene chloride was added dropwise a solution of 4-(dimethylamino)pyridine $(10.4 \mathrm{mg}, 0.085 \mathrm{mmol})$ in $5 \mathrm{~mL}$ of methylene chloride. The reaction mixture was stirred at room temperature for $24 \mathrm{~h}$ and concentrated. The residue was washed with diethyl ether to give $36 \mathrm{mg}$ ( $0.084 \mathrm{mmol}, 99 \%)$ of III-71b as a colorless solid: compound becomes black at $162^{\circ} \mathrm{C}$ without melting; IR 2158, 1652 , $1194 \mathrm{~cm}^{-1} ;{ }^{1} \mathrm{H} \delta 8.61(2 \mathrm{H}, \mathrm{d}, J=7.4 \mathrm{~Hz}), 7.43-7.49(2 \mathrm{H}, \mathrm{m}), 7.28-7.34(2 \mathrm{H}, \mathrm{m})$, $6.97(2 \mathrm{H}, \mathrm{d}, J=7.7 \mathrm{~Hz}), 5.48(2 \mathrm{H}, \mathrm{s}), 3.25(6 \mathrm{H}, \mathrm{s}), 2.79(3 \mathrm{H}, \mathrm{s}), 0.21(9 \mathrm{H}, \mathrm{s}) ;{ }^{13} \mathrm{C} \delta$ $156.6,141.9,132.5,132.4,129.1,128.4,125.7,123.5,108.1,103.0,98.9,88.3,83.2$, $47.8,40.3,39.5,0.0$.

\section{2-(Dimethylamino)-12-(1,1-dimethylethyl)-7H-indeno[1,2-b]quinolizin-5-ium}

Chloride (III-73a). A solution of III-71a (26 mg, $0.063 \mathrm{mmol})$ and triethylamine (6 $\mathrm{mg}, 0.06 \mathrm{mmol}$ ) in $10 \mathrm{~mL}$ of ethanol was heated under reflux for $48 \mathrm{~h}$. The solvent was removed in vacuo, and the residue was purified by column chromatography (neutral alumina/ethanol:methylene chloride $=1: 10)$ to give $7 \mathrm{mg}(0.020 \mathrm{mmol}, 32 \%)$ of III-73a as a yellow solid: $\mathrm{mp}>360{ }^{\circ} \mathrm{C}$; IR 1646, 1236, $\mathrm{cm}^{-1} ;{ }^{1} \mathrm{H} \delta 10.14(1 \mathrm{H}, \mathrm{d}, J$ $=7.6 \mathrm{~Hz}), 9.52(1 \mathrm{H}, \mathrm{s}), 8.03(1 \mathrm{H}, \mathrm{dd}, J=6.9,2.1 \mathrm{~Hz}), 7.60(1 \mathrm{H}, \mathrm{d}, J=6.6 \mathrm{~Hz})$, 7.41-7.51 (2 H, m), $7.24(1 \mathrm{H}, \mathrm{dd}, J=7.6,2.9 \mathrm{~Hz}), 7.11(1 \mathrm{H}, \mathrm{d}, J=2.6 \mathrm{~Hz}), 4.17$ (2 $\mathrm{H}, \mathrm{s}), 3.27(6 \mathrm{H}, \mathrm{s}), 1.77(9 \mathrm{H}, \mathrm{s}) ;{ }^{13} \mathrm{C} \delta 150.4,148.1,146.3,143.5,139.1,138.6,136.2$, $133.7,130.4,129.7,127.1,126.7,125.7,109.1,101.8,40.1,37.1,34.7,31.8$. Recrystallization of III-73a from a mixture of dichloromethane and hexanes produced 
a crystal suitable for X-ray structure analysis.

\section{2-(Dimethylamino)-12-(trimethylsilyl)-7H-indeno[1,2-b]quinolizin-5-ium}

Chloride (III-73b). A solution of III-71b $(30 \mathrm{mg}, 0.070 \mathrm{mmol})$ and triethylamine (7 $\mathrm{mg}, 0.07 \mathrm{mmol}$ ) in $10 \mathrm{~mL}$ of ethanol was heated under reflux for $48 \mathrm{~h}$. The solvent was removed in vacuo, and the residue was purified by column chromatography (neutral alumina/ethanol:methylene chloride $=1: 10)$ to give $11 \mathrm{mg}(0.030 \mathrm{mmol}, 43 \%)$ of III-73b as a yellow solid: $\mathrm{mp}>360{ }^{\circ} \mathrm{C}$; IR 1646, $1235 \mathrm{~cm}^{-1} ;{ }^{1} \mathrm{H} \delta 10.16(1 \mathrm{H}, \mathrm{d}, J$ $=7.6 \mathrm{~Hz}), 9.70(1 \mathrm{H}, \mathrm{s}), 7.93(1 \mathrm{H}, \mathrm{d}, J=7.6 \mathrm{~Hz}), 7.62(1 \mathrm{H}, \mathrm{d}, J=7.6 \mathrm{~Hz}), 7.40-7.56$ (3 H, m), $7.21(1 \mathrm{H}, \mathrm{dd}, J=7.6,2.9 \mathrm{~Hz}), 6.98(1 \mathrm{H}, \mathrm{d}, J=2.6 \mathrm{~Hz}), 4.15(2 \mathrm{H}, \mathrm{s}), 3.26$ (6 H, s), $0.62(9 \mathrm{H}, \mathrm{s}) ;{ }^{13} \mathrm{C} \delta 157.1,151.4,147.0,146.6,139.2,138.2,132.6,131.2$, $130.5,127.7,126.7,125.9,125.3,109.2,103.2,40.1,34.5,2.6$.

11-Phenyl-6H-indeno[1,2-d]imidazo[1,2-a]pyridine (III-76). To a stirred mixture of imidazole (10 mg, $0.15 \mathrm{mmol})$, tetrabutylammonium iodide $(27 \mathrm{mg}, 0.073 \mathrm{mmol})$ and sodium hydroxide $(50 \%$ aqueous solution, $0.52 \mathrm{~mL})$ in toluene $(0.41 \mathrm{~mL})$ was added III-61 (47 mg, $0.15 \mathrm{mmol})$. After $15 \mathrm{~min}$ at room temperature, toluene $(0.5 \mathrm{~mL})$ and water $(0.5 \mathrm{~mL})$ were added. The organic layer was separated, washed with water, dried over $\mathrm{MgSO}_{4}$, and concentrated. The residue was purified by column chromatography (silica gel/diethyl ether:methanol $=100: 3)$ to give $11 \mathrm{mg}(0.039$ mmol, 26\%) of III-76 as a pale yellow solid.

Alternatively, III-76 was synthesized by treatment of a mixture of $15 \mathrm{mg}(0.021$ $\mathrm{mmol})$ of $\mathrm{Pd}\left(\mathrm{PPh}_{3}\right)_{2} \mathrm{Cl}_{2}, 7.5 \mathrm{mg}(0.039 \mathrm{mmol})$ of copper(I) iodide, and $200 \mathrm{mg}(0.658$ mmol) of III-59 under a nitrogen atmosphere with $5 \mathrm{~mL}$ of DMF, $2 \mathrm{~mL}$ of 
triethylamine, and a solution of $85 \mathrm{mg}(0.80 \mathrm{mmol})$ of III-77 in $5 \mathrm{~mL}$ of DMF. The reaction mixture was heated at $100{ }^{\circ} \mathrm{C}$ for $48 \mathrm{~h}$ before it was allowed to cool to room temperature. The reaction mixture was then poured into a flask containing $40 \mathrm{~mL}$ of ethyl acetate and $5 \mathrm{~mL}$ of a saturated $\mathrm{NH}_{4} \mathrm{Cl}$ solution. The organic layer was separated, washed with water, dried over $\mathrm{MgSO}_{4}$, and concentrated. The residue was purified by column chromatography ( (0.642 mmol, 98\%) of a mixture of III-74 and III-76 (1:4) as a pale yellow solid. The ${ }^{1} \mathrm{H}$ NMR spectrum of the mixture exhibited a singlet at $\delta 5.02$, attributable to the methylene hydrogens of III-74.

To a solution of $181 \mathrm{mg}(0.642 \mathrm{mmol})$ of a mixture of III-74 and III-76 (1:4) in $5 \mathrm{~mL}$ of $t$-butyl alcohol under a nitrogen atmosphere was added $0.64 \mathrm{~mL}$ of a $1.0 \mathrm{M}$ solution of potassium $t$-butoxide in $t$-butyl alcohol. The reaction mixture was stirred at room temperature for $12 \mathrm{~h}$ before $5 \mathrm{~mL}$ of water and $20 \mathrm{~mL}$ of ethyl acetate were introduced. The organic layer was separated, washed with water, dried over $\mathrm{MgSO}_{4}$, and concentrated. The residue was purified by column chromatography (silica gel/diethyl ether:methanol $=100: 3)$ to give $181 \mathrm{mg}(0.642 \mathrm{mmol}, 100 \%)$ of III-76 as a pale yellow solid: $\mathrm{mp} 217-218^{\circ} \mathrm{C}$; IR 1301, 1234, 727, $699 \mathrm{~cm}^{-1} ;{ }^{1} \mathrm{H} \delta 8.34(1 \mathrm{H}, \mathrm{s})$, $7.68(1 \mathrm{H}, \mathrm{d}, J=1.2 \mathrm{~Hz}), 7.47-7.64(7 \mathrm{H}, \mathrm{m}), 7.29(1 \mathrm{H}, \mathrm{td}, J=7.4,1.0 \mathrm{~Hz}), 7.08(1 \mathrm{H}$, t, $J=7.9 \mathrm{~Hz}), 6.87(1 \mathrm{H}, \mathrm{d}, J=7.9 \mathrm{~Hz}) 4.07(2 \mathrm{H}, \mathrm{s}) ;{ }^{13} \mathrm{C} \delta 145.7,144.0,139.3,137.2$, $134.9,133.8,129.6,129.1,128.6,128.4,128.1,126.9,125.1,123.9,120.0,112.3$, 33.6. Recrystallization of III-76 from a mixture of dichloromethane and hexanes produced a crystal suitable for X-ray structure analysis. 
Indole III-83. To a mixture of $7 \mathrm{mg}(0.010 \mathrm{mmol})$ of $\mathrm{Pd}\left(\mathrm{PPh}_{3}\right)_{2} \mathrm{Cl}_{2}, 4 \mathrm{mg}(0.020$ mmol) of copper(I) iodide, and $104 \mathrm{mg}(0.34 \mathrm{mmol})$ of III-59 under a nitrogen atmosphere was added in sequence $5 \mathrm{~mL}$ of $\mathrm{DMF}, 2 \mathrm{~mL}$ of triethylamine, and a solution of $58 \mathrm{mg}(0.38 \mathrm{mmol})$ of III-82 in $5 \mathrm{~mL}$ of DMF. After $4 \mathrm{~h}$ of stirring at room temperature, the reaction mixture was poured into a flask containing $40 \mathrm{~mL}$ of ethyl acetate and $5 \mathrm{~mL}$ of a saturated $\mathrm{NH}_{4} \mathrm{Cl}$ solution. The organic layer was separated, washed with water, dried over $\mathrm{MgSO}_{4}$, and concentrated. The residue was purified by column chromatography ( mg (0.335 mmol, 99\%) of III-83 as a white solid: $\mathrm{mp} 123-124{ }^{\circ} \mathrm{C}$; IR 2216, 1494 , 755, 742, $690 \mathrm{~cm}^{-1} ; \quad{ }^{1} \mathrm{H} \delta$ 7.67-7.71 (1 H, m), 7.48-7.58 (3 H, m), 7.39-7.46 (3 H, m), 7.28-7.38 (5 H, m), 7.14-7.26 (2 H, m), $6.52(1 \mathrm{H}, \mathrm{dd}, J=3.2,0.8 \mathrm{~Hz}), 5.19(2 \mathrm{H}, \mathrm{s})$; ${ }^{13} \mathrm{C} \delta 135.8,132.1,131.9,131.7,128.8,128.4,128.33,128.28,127.9,127.3,125.9$, $124.7,122.9,121.8,121.0,119.7,109.4,101.8,93.4,87.9,86.9,84.0,36.7$.

12-Phenyl-7H-indeno[ $\left[1^{\prime}, 2^{\prime}: 4,5\right]$ pyrido[1,2-a]indole (III-84). To a solution of $41 \mathrm{mg}$ $(0.12 \mathrm{mmol})$ of III-83 in $5 \mathrm{~mL}$ of anhydrous toluene under a nitrogen atmosphere was added $0.1 \mathrm{~mL}$ of a $1.0 \mathrm{M}$ solution of potassium $t$-butoxide in $t$-butyl alcohol. After 48 $\mathrm{h}$ of stirring at room temperature, $5 \mathrm{~mL}$ of water and $20 \mathrm{~mL}$ of ethyl acetate were introduced. The organic layer was separated, washed with water, dried over $\mathrm{MgSO}_{4}$, and concentrated. The residue was purified by column chromatography (silica gel/hexanes:methylene chloride $=95: 5)$ to give $40 \mathrm{mg}(0.12 \mathrm{mmol}, 98 \%)$ of III-84 as a pale yellow solid: $\mathrm{mp} 170-173{ }^{\circ} \mathrm{C}$; IR $1459,1323,762,724,700 \mathrm{~cm}^{-1} ;{ }^{1} \mathrm{H} \delta 8.44(1$ H, s), $7.90(1 \mathrm{H}, \mathrm{d}, J=7.6 \mathrm{~Hz}), 7.70(1 \mathrm{H}, \mathrm{d}, J=7.6 \mathrm{~Hz}), 7.50-7.65(5 \mathrm{H}, \mathrm{m}), 7.48(1$ 
$\mathrm{H}, \mathrm{d}, J=7.6 \mathrm{~Hz}), 7.22-7.35(3 \mathrm{H}, \mathrm{m}), 7.05(1 \mathrm{H}, \mathrm{t}, J=7.5 \mathrm{~Hz}), 6.79(1 \mathrm{H}, \mathrm{d}, J=7.9$ $\mathrm{Hz}), 6.31(1 \mathrm{H}, \mathrm{s}), 4.09(2 \mathrm{H}, \mathrm{s}) ;{ }^{13} \mathrm{C} \delta 144.4,139.5,138.5,137.0,134.5,129.5$, $129.1,128.2,127.8,126.7,125.2,123.9,123.7,122.4,120.3,119.4,118.1,110.0$, 91.9, 33.6.

2(1H)-Pyridinone III-86. To a mixture of $12 \mathrm{mg}(0.017 \mathrm{mmol})$ of $\mathrm{Pd}\left(\mathrm{PPh}_{3}\right)_{2} \mathrm{Cl}_{2}, 6.5$ $\mathrm{mg}(0.034 \mathrm{mmol})$ of copper(I) iodide, and $171 \mathrm{mg}(0.56 \mathrm{mmol})$ of III-59 under a nitrogen atmosphere was added in sequence $5 \mathrm{~mL}$ of DMF, $2 \mathrm{~mL}$ of triethylamine, and a solution of $82 \mathrm{mg}(0.62 \mathrm{mmol})$ of III-85 in $5 \mathrm{~mL}$ of DMF. After $1 \mathrm{~h}$ of stirring at room temperature, the reaction mixture was poured into a flask containing $40 \mathrm{~mL}$ of ethyl acetate and $10 \mathrm{~mL}$ of a saturated $\mathrm{NH}_{4} \mathrm{Cl}$ solution. The organic layer was separated, washed with water, dried over $\mathrm{MgSO}_{4}$, and concentrated. The residue was purified by column chromatography ( silica gel/hexanes:ethyl acetate $=1: 1$ ) to give $171 \mathrm{mg}(0.553 \mathrm{mmol}, 99 \%)$ of III-86 as a colorless solid: $\mathrm{mp} 76-78{ }^{\circ} \mathrm{C}$; IR 1660 , 1588, 1538, $757 \mathrm{~cm}^{-1} ; \quad{ }^{1} \mathrm{H} \delta 7.91(1 \mathrm{H}, \mathrm{dt}, J=6.9,0.9 \mathrm{~Hz}), 7.45-7.57(4 \mathrm{H}, \mathrm{m})$, 7.24-7.39 (6 H, m), $6.58(1 \mathrm{H}, \mathrm{dd}, J=9.2,0.5 \mathrm{~Hz}), 5.93(1 \mathrm{H}, \mathrm{dt}, J=6.7,0.8 \mathrm{~Hz})$, $5.07(2 \mathrm{H}, \mathrm{s}) ;{ }^{13} \mathrm{C} \delta 162.1,139.7,135.7,132.0,131.9,131.7,128.6,128.4,128.1$, $125.9,124.3,122.8,120.2,106.4,93.4,87.8,86.6,85.6,38.5$.

4,7-Dihydro-12-phenylindeno[2,1-g]quinolizin-4-one (III-87). To a solution of 155 $\mathrm{mg}(0.502 \mathrm{mmol})$ of III-86 in $30 \mathrm{~mL}$ of anhydrous toluene under nitrogen atmosphere was added $0.5 \mathrm{~mL}$ of a $1.0 \mathrm{M}$ solution of potassium $t$-butoxide in $t$-butyl alcohol. The reaction mixture was heated under reflux for $12 \mathrm{~h}$. After the reaction mixture was allowed to cool to room temperature, $20 \mathrm{~mL}$ of water and $50 \mathrm{~mL}$ of ethyl acetate were 
introduced. The organic layer was separated, washed with water, dried over $\mathrm{MgSO}_{4}$, and concentrated. The residue was purified by column chromatography (silica gel $/$ methanol:methylene chloride $=1: 100)$ to give $87 \mathrm{mg}(0.28 \mathrm{mmol}, 56 \%)$ of III-87 as a pale yellow solid: mp 205-207 ${ }^{\circ} \mathrm{C}$; IR 1659, $1482 \mathrm{~cm}^{-1} ;{ }^{1} \mathrm{H} \delta 9.44(1 \mathrm{H}, \mathrm{s})$, 7.59-7.72 (3 H, m), 7.50-7.59 (2 H, m), 7.32-7.43 (3 H, m), 7.08 (1 H, t, J= 7.9 Hz), $6.69(1 \mathrm{H}, \mathrm{d}, J=8.6 \mathrm{~Hz}), 6.46(1 \mathrm{H}, \mathrm{d}, J=7.9 \mathrm{~Hz}), 6.36(1 \mathrm{H}, \mathrm{d}, J=7.9 \mathrm{~Hz}), 4.18(2$ $\mathrm{H}, \mathrm{s}) ;{ }^{13} \mathrm{C} \delta 145.5,143.4,141.9,138.1,137.0,135.6,130.5,129.8,129.7,129.5,129.0$, 128.9, 127.3, 125.4, 124.8, 121.7, 107.4, 103.3, 34.4. Recrystallization of III-87 from a mixture of dichloromethane and hexanes under a nitrogen atmosphere produced a crystal suitable for X-ray structure analysis.

\section{Experimental Section of Chapter 3.3}

Compound III-42 To a mixture of $161 \mathrm{mg}(0.23 \mathrm{mmol})$ of $\mathrm{Pd}\left(\mathrm{PPh}_{3}\right)_{2} \mathrm{Cl}_{2}, 43.8 \mathrm{mg}$ (0.23 mmol) of copper(I) iodide, and $1906 \mathrm{mg}(7.72 \mathrm{mmol})$ of 2-iodoformanilide under a nitrogen atmosphere was added in sequence $10 \mathrm{~mL}$ of $\mathrm{DMF}, 5 \mathrm{~mL}$ of triethylamine, and a solution of $1232 \mathrm{mg}(9.26 \mathrm{mmol})$ of III-85 in $10 \mathrm{~mL}$ of DMF. After $12 \mathrm{~h}$ of stirring at room temperature, the reaction mixture was poured into a flask containing $100 \mathrm{~mL}$ of ethyl acetate and $20 \mathrm{~mL}$ of a saturated $\mathrm{NH}_{4} \mathrm{Cl}$ solution. The organic layer was separated, washed with water, dried over $\mathrm{MgSO}_{4}$, and concentrated. The residue was purified by column chromatography (silica gel/ethyl acetate:methanol $=50: 1)$ to give $1653 \mathrm{mg}(6.56 \mathrm{mmol}, 85 \%)$ of III-42 as a colorless solid: mp $106-107^{\circ} \mathrm{C}$.

Compound III-98 To a mixture of $32 \mathrm{mg}(0.046 \mathrm{mmol})$ of $\mathrm{Pd}\left(\mathrm{PPh}_{3}\right)_{2} \mathrm{Cl}_{2}, 8.8 \mathrm{mg}$ 
(0.046 mmol) of copper(I) iodide, and $379 \mathrm{mg}(1.53 \mathrm{mmol})$ of 2-iodoformanilide under a nitrogen atmosphere was added in sequence $5 \mathrm{~mL}$ of DMF, $2 \mathrm{~mL}$ of triethylamine, and a solution of $245 \mathrm{mg}(1.84 \mathrm{mmol})$ of III-85 in $10 \mathrm{~mL}$ of DMF. After $12 \mathrm{~h}$ of stirring at room temperature, the mixture was exposed to air for 3 months. The residue was dissolved in the mixture of $40 \mathrm{~mL}$ of ethyl acetate and 10 $\mathrm{mL}$ of a saturated $\mathrm{NH}_{4} \mathrm{Cl}$ solution. The organic layer was separated, washed with water, dried over $\mathrm{MgSO}_{4}$, and concentrated. The residue was purified by column chromatography (silica gel/ethyl acetate:methanol $=50: 1)$ to give $435 \mathrm{mg}(1.53 \mathrm{mmol}$, $100 \%$ ) of III-98 as a colorless solid: $164-165{ }^{\circ} \mathrm{C}$. The structure of III-98 was established by X-ray structure analysis.

\section{Experimental Section of Chapter 3.4}

2-bromo-6-methoxyl-pyridine, TMSCl, propargyl bromide, iodobenzene and 2-bromopyridine were purchased from chemical suppliers and were used as received.

Compound III-102 To a mixture of 2-bromo-6-methoxyl-pyridine (1.88 g, $10 \mathrm{mmol}$ ), $\mathrm{Pd}\left(\mathrm{PPh}_{3}\right)_{2} \mathrm{Cl}_{2}(0.21 \mathrm{~g}, 0.3 \mathrm{mmol})$ and copper(I) iodide $(0.057 \mathrm{~g}, 0.3 \mathrm{mmol})$ in $20 \mathrm{~mL}$ of triethylamine was added $1.22 \mathrm{~g}$ of phenylacetylene $(12 \mathrm{mmol})$. After $12 \mathrm{~h}$ of stirring at room temperature, $20 \mathrm{~mL}$ of a saturated aqueous ammonium chloride solution and $40 \mathrm{~mL}$ of diethyl ether were added. The organic layer was separated, and the aqueous layer was back extracted with diethyl ether. The combined organic layers were washed with brine and water, dried over sodium sulfate, and concentrated. Purification of the residue by flash column chromatography (silica gel/hexanes:ethyl ether $=10: 1)$ afforded $2.0 \mathrm{~g}$ of $\mathbf{I I - 1 0 2}(9.6 \mathrm{mmol}, 96 \%$ yield $) ;{ }^{1} \mathrm{H} \delta 7.65-7.49(3 \mathrm{H}, \mathrm{m})$, 
7.40-7.32 (3 H, m), $7.14(1 \mathrm{H}, \mathrm{dd}, J=7.3,0.6 \mathrm{~Hz}), 6.72(1 \mathrm{H}, \mathrm{dd}, J=8.3,0.6 \mathrm{~Hz})$, $3.99(3 \mathrm{H}, \mathrm{s}) ;{ }^{13} \mathrm{C} \delta 163.8,140.2,138.4,131.9,128.8,128.3,122.4,120.7,111.0,88.8$, $88.5,53.5$.

Compound III-104 Chlorotrimethylsilane $(2.0 \mathrm{~mL}, 15.4 \mathrm{mmol})$ was added slowly to a mixture of III-102 $(1.05 \mathrm{~g}, 5.02 \mathrm{mmol})$ and sodium iodide $(2.31 \mathrm{~g}, 15.4 \mathrm{mmol})$ in acetonitrile $(8 \mathrm{~mL})$ and stirred at $80{ }^{\circ} \mathrm{C}$ for $6 \mathrm{~h}$. The resultant solution was cooled to room temperature, poured into $5 \%$ aqueous $\mathrm{Na}_{2} \mathrm{~S}_{2} \mathrm{O}_{3}$ and brine and extracted with ethyl acetate. The combined organic layers were dried and concentrated. The residue was purified by column chromatography (silica gel/methylene chloride: ethyl acetate $=$ 1:1) to give $0.83 \mathrm{~g}$ of III-103 (Containing small amount impurities). To a mixture of $0.83 \mathrm{~g}$ of III-103 and potassium carbonate $(1.38 \mathrm{~g}, 10 \mathrm{mmol})$ in dry DME $(10 \mathrm{~mL})$ was added a solution of propargyl bromide ( $80 \%$ in toluene, $1.1 \mathrm{~g}, 7.5 \mathrm{mmol})$. The resulting mixture was stirred at $60{ }^{\circ} \mathrm{C}$ for $16 \mathrm{~h}$. The mixture was then filtered, the filtrate evaporated in vacuo and the residue dissolved in methylene chloride $(50 \mathrm{~mL})$ and washed with water. The organic layer was separated, dried (MgSO4), and concentrated. The residue was purified by column chromatography (silical gel, methylene chloride:ethyl acetate $=4: 1)$ to give $515 \mathrm{mg}(2.21 \mathrm{mmol}, 44 \%)$ of III-104 as a colorless solid: mp $110-114{ }^{\circ} \mathrm{C} ;{ }^{1} \mathrm{H}(600 \mathrm{MHz}) \delta$ 7.59-7.56 $(2 \mathrm{H}, \mathrm{m}), 7.45-7.37(3$ H, m), 7.31-7.25 (1 H, m), $6.63(1 \mathrm{H}, \mathrm{dd}, J=9.6,0.6 \mathrm{~Hz}), 6.54(1 \mathrm{H}, \mathrm{dd}, J=6.6,0.6$ $\mathrm{Hz}), 5.06(2 \mathrm{H}, \mathrm{d}, J=2.4 \mathrm{~Hz}), 2.28(1 \mathrm{H}, \mathrm{t}, J=2.4 \mathrm{~Hz}) ;{ }^{13} \mathrm{C}(150 \mathrm{MHz}) \delta 161.7,138.6$, $131.8,131.1,129.8,128.6,121.7,112.3,97.6,81.8,78.1,71.8,35.4$.

Compound III-105 To a mixture of iodobenzene (108 mg, $0.53 \mathrm{mmol}), \mathrm{Pd}\left(\mathrm{PPh}_{3}\right)_{2} \mathrm{Cl}_{2}$ 
(19 $\mathrm{mg}, 0.027 \mathrm{mmol})$ and copper(I) iodide $(5 \mathrm{mg}, 0.027 \mathrm{mmol})$ in $5 \mathrm{~mL}$ of triethylamine was added $123 \mathrm{mg}$ of III-104 $(0.53 \mathrm{mmol})$ in $2 \mathrm{~mL}$ of THF. After $1 \mathrm{~h}$ of stirring at room temperature, $5 \mathrm{~mL}$ of a saturated aqueous ammonium chloride solution and $20 \mathrm{~mL}$ of methylene chloride were added. The organic layer was separated, and the aqueous layer was back extracted with methylene chloride. The combined organic layers were washed with brine and water, dried over sodium sulfate, and concentrated. Purification of the residue by flash column chromatography (silica gel/ methylene chloride: ethyl acetate $=4: 1)$ afforded $127 \mathrm{mg}$ of III-105 $(0.41 \mathrm{mmol}$, $77 \%$ yield $)$ as a pale yellow solid: ${ }^{1} \mathrm{H}(600 \mathrm{MHz}) \delta 7.61-7.58(2 \mathrm{H}, \mathrm{m}), 7.43-7.36(5 \mathrm{H}$, m), 7.32-7.22 (4 H, m), $6.66(1 \mathrm{H}, \mathrm{dd}, J=9.0,0.6 \mathrm{~Hz}), 6.57(1 \mathrm{H}, \mathrm{dd}, J=7.2,0.6 \mathrm{~Hz})$, $5.30(2 \mathrm{H}, \mathrm{s}) ;{ }^{13} \mathrm{C}(150 \mathrm{MHz}) \delta 161.8,138.6,132.0,131.9,129.8,129.3,129.1,128.9$, $128.6,128.4,128.2,121.7,112.3,97.7,83.7,83.5,82.2,36.2$.

Compound III-106 and III-107 A solution of III-105 (50 mg, $0.16 \mathrm{mmol})$ in $5 \mathrm{~mL}$ of ethanol was heated under reflux for $12 \mathrm{~h}$. The solvent was removed in vacuo and the residue was purified by flash column chromatography (silica gel/ methylene chloride:ethyl acetate $=1: 2$ ) to give $26.5 \mathrm{mg}$ of III-106 and then (silica gel/ethyl acetate) to give $15 \mathrm{mg}$ of III-107. III-106: $\mathrm{mp}$ submit $>260{ }^{\circ} \mathrm{C}{ }^{1} \mathrm{H}(600 \mathrm{MHz}) \delta 8.27$ $(1 \mathrm{H}, \mathrm{s}), 8.01(1 \mathrm{H}, \mathrm{d}, J=8.4 \mathrm{~Hz}), 7.74(1 \mathrm{H}, \mathrm{d}, J=8.4 \mathrm{~Hz}), 7.62-7.47(6 \mathrm{H}, \mathrm{m})$, 7.40-7.37 (2 H, m), $6.93(1 \mathrm{H}, \mathrm{d}, J=6.6 \mathrm{~Hz}), 6.58(1 \mathrm{H}, \mathrm{d}, J=9.6 \mathrm{~Hz}), 5.05(2 \mathrm{H}, \mathrm{s})$; ${ }^{13} \mathrm{C}(150 \mathrm{MHz}) \delta 161.8,148.0,140.1,136.9,135.6,133.6,133.13,133.08,131.4$ $129.3,129.0,128.8,128.3,127.4,126.5,126.1,120.3,118.0,99.0,52.3$. The structure of III-106 was established by X-ray structure analysis. III-107: mp 243-244 ${ }^{\circ} \mathrm{C}{ }^{1} \mathrm{H}$ 
$(600 \mathrm{MHz}) \delta 8.07(1 \mathrm{H}, \mathrm{s}), 7.96(1 \mathrm{H}, \mathrm{d}, J=8.4 \mathrm{~Hz}), 7.64-7.55(5 \mathrm{H}, \mathrm{m}), 7.44(1 \mathrm{H}, \mathrm{td}$, $J=7.2,1.8 \mathrm{~Hz}), 7.39-7.35(2 \mathrm{H}, \mathrm{m}), 7.23(1 \mathrm{H}, \mathrm{td}, J=7.2,1.8 \mathrm{~Hz}), 6.49(1 \mathrm{H}, \mathrm{d}, J=$ $9.0 \mathrm{~Hz}), 5.46(1 \mathrm{H}, \mathrm{d}, J=7.2 \mathrm{~Hz}), 5.31(2 \mathrm{H}, \mathrm{s}) ;{ }^{13} \mathrm{C}(150 \mathrm{MHz}) \delta 161.8,147.6,140.0$, $136.7,136.4,134.1,134.0,132.8,129.6,129.2,128.5,128.0,127.3,126.9,126.5$, 121.8, 117.6, 102.6, 51.7. The structure of III-107 was established by X-ray structure analysis.

Compound III-108 To a mixture of 2-bromopyridine (79 $\mathrm{mg}, 0.50 \mathrm{mmol}$ ), $\mathrm{Pd}\left(\mathrm{PPh}_{3}\right)_{2} \mathrm{Cl}_{2}(12 \mathrm{mg}, 0.017 \mathrm{mmol})$ and copper(I) iodide $(3 \mathrm{mg}, 0.017 \mathrm{mmol})$ in $5 \mathrm{~mL}$ of triethylamine was added $78 \mathrm{mg}$ of III-104 $(0.33 \mathrm{mmol})$ in $2 \mathrm{~mL}$ of THF. After $12 \mathrm{~h}$ of stirring at room temperature, $5 \mathrm{~mL}$ of a saturated aqueous ammonium chloride solution and $20 \mathrm{~mL}$ of methylene chloride were added. The organic layer was separated, and the aqueous layer was back extracted with methylene chloride. The combined organic layers were washed with brine and water, dried over sodium sulfate, and concentrated. Purification of the residue by flash column chromatography (silica gel/ methylene chloride:ethyl acetate $=1: 1)$ afforded $32 \mathrm{mg}$ of III-108 $(0.10 \mathrm{mmol}$, $77 \%$ yield) as a pale yellow solid.

Compound III-109 and III-110 A solution of III-108 (25 mg, $0.08 \mathrm{mmol})$ in $5 \mathrm{~mL}$ of ethanol was heated under reflux for $36 \mathrm{~h}$. The solvent was removed in vacuo and the residue was purified by flash column chromatography (silica gel/ethyl acetate:methanol $=20: 1)$ to give $19.5 \mathrm{mg}$ of III-109 and $2.0 \mathrm{mg}$ of III-110. The structures of both III-109 and III-110 were established by X-ray structure analysis.

Compound III-112 and III-116 A solution of III-104 (68 $\mathrm{mg}, 0.29 \mathrm{mmol})$ in $5 \mathrm{~mL}$ of 
p-xylene was heated under reflux for $20 \mathrm{~h}$. The mixture was purified by flash column chromatography (silica gel/ methylene chloride:ethyl acetate $=3: 2$ ) to give a mixture of $61 \mathrm{mg}$ of III-112 and III-116 (ratio $=2: 1$ as indicated by the proton NMR). The structure of III-112 was established by X-ray structure analysis.

\section{Experimental Section of Chapter 3.5}

Sodium hydride, DMF, DBU and 1-iodo-2,3-dimethoxybenzene were purchased from chemical suppliers and were used as received.

Compound III-44 To a solution of 6-oxo-1,6-dihydropyridine-2-carbonitrile (120 mg, $1 \mathrm{mmol})$ in DME $(2.0 \mathrm{~mL})$ and DMF $(0.5 \mathrm{~mL})$ under nitrogen was added $60 \% \mathrm{NaH}$ (42 mg, $1.05 \mathrm{mmol})$ at $0{ }^{\circ} \mathrm{C}$. $\mathrm{LiBr}$ was added $(174 \mathrm{mg}, 2 \mathrm{mmol}) 10 \mathrm{~min}$ later. The mixture was stirred $15 \mathrm{~min}$ at room temperature, the phenyl propargyl bromide ${ }^{63}$ (390 mg, $2 \mathrm{mmol}$ ) was added, and the reaction was heated at $65{ }^{\circ} \mathrm{C}$ for $15 \mathrm{~h}$. After cooled to room temperature, the mixture was poured into brine $(50 \mathrm{~mL})$, extracted with AcOEt $(2 \times 50 \mathrm{~mL})$, and dried over sodium sulfate and concentrated. The residue was purified by column chromatography (silical gel, AcOEt) to give $201 \mathrm{mg}(0.86 \mathrm{mmol}$, $86 \%$ ) of III-44 as a colorless solid: $\mathrm{mp} 104-105{ }^{\circ} \mathrm{C}$; IR 2222, 1655, 1586, 1148, 815,

758, $686 \mathrm{~cm}^{-1} ;{ }^{1} \mathrm{H} \delta$ 7.48-7.38 (2 H, m), 7.36-7.21 (4 H, m), $6.84(1 \mathrm{H}, \mathrm{dd}, J=9.4,1.2$ $\mathrm{Hz}), 6.77(1 \mathrm{H}, \mathrm{dd}, J=6.9,1.5 \mathrm{~Hz}), 5.14(2 \mathrm{H}, \mathrm{s}) ;{ }^{13} \mathrm{C} \delta 160.1,137.6,132.0,128.8$, $128.2,127.4,121.8,120.7,116.2,112.3,85.3,81.7,36.7$.

Compound III-40 The mixture of III-44 (50 mg, $0.21 \mathrm{mmol})$, DBU (32 mg, 0.21 mmol) in $4 \mathrm{~mL} \mathrm{1,2-dichlorobenzene} \mathrm{was} \mathrm{heated} \mathrm{to} 120{ }^{\circ} \mathrm{C}$ under nitrogen. After cooled to room temperature, the mixture was purified by column chromatography 
(silical gel, AcOEt:MeOH = 6:1) to give $50 \mathrm{mg}(0.21 \mathrm{mmol}, 100 \%)$ of III-40 as a pale orange solid: $\mathrm{mp} 252-253{ }^{\circ} \mathrm{C}$; IR $1666,1599,803,784,757,730 \mathrm{~cm}^{-1} ;{ }^{1} \mathrm{H} \delta 8.31(1 \mathrm{H}$, s), $8.18(1 \mathrm{H}, \mathrm{d}, J=8.6 \mathrm{~Hz}), 7.87(1 \mathrm{H}, \mathrm{d}, J=8.2 \mathrm{~Hz}), 7.78(1 \mathrm{H}, \mathrm{td}, J=6.9,1.5 \mathrm{~Hz})$, 7.71-7.56 (2 H, m), $7.28(1 \mathrm{H}, \mathrm{d}, J=6.9 \mathrm{~Hz}), 6.71(1 \mathrm{H}, \mathrm{dd}, J=8.9,0.5 \mathrm{~Hz}), 5.22(2$ $\mathrm{H}, \mathrm{d}, J=0.5 \mathrm{~Hz}) ;{ }^{13} \mathrm{C} \delta 161.5,152.8,148.7,146.0,140.3,130.9,130.3,129.5,128.5$, 128.02, 127.97, 127.6, 120.5, 100.9, 49.9. The structure of III-40 was established by X-ray structure analysis.

Compound III-129 To a solution of 6-oxo-1,6-dihydropyridine-2-carbonitrile (120 mg, $1 \mathrm{mmol})$ in DME $(2.0 \mathrm{~mL})$ and DMF $(0.5 \mathrm{~mL})$ under nitrogen was added $60 \% \mathrm{NaH}$ (42 mg, $1.05 \mathrm{mmol})$ at $0{ }^{\circ} \mathrm{C}$. $\mathrm{LiBr}$ was added $(174 \mathrm{mg}, 2 \mathrm{mmol}) 10 \mathrm{~min}$ later. The mixture was stirred $15 \mathrm{~min}$ at room temperature, the 4-methoxyphenyl propargyl bromide (450 mg, $2 \mathrm{mmol}$ ) was added, and the reaction was heated at $65^{\circ} \mathrm{C}$ for $15 \mathrm{~h}$. After cooled to room temperature, the mixture was poured into brine $(50 \mathrm{~mL})$, extracted with AcOEt $(2 \times 50 \mathrm{~mL})$, and dried over sodium sulfate and concentrated. The residue was purified by column chromatography (silical gel, AcOEt) to give 243 mg (0.92 mmol, 92\%) of III-129 as a colorless solid: mp 130-131 ${ }^{\circ} \mathrm{C}$; IR 2221, 1656, $1583,1510,1245,1144,1032,836,800,725,663 \mathrm{~cm}^{-1} ;{ }^{1} \mathrm{H} \delta 7.42-7.25(3 \mathrm{H}, \mathrm{m})$, 6.89-6.73 (4 H, m), $5.13(2 \mathrm{H}, \mathrm{s}), 3.77(3 \mathrm{H}, \mathrm{s}) ;{ }^{13} \mathrm{C} \delta 160.1,160.0,137.6,133.5$, 127.4, 120.6, 116.2, 113.8, 112.3, 85.2, 80.3, 55.2, 36.8. The structure of III-129 was established by X-ray structure analysis.

Compound III-130 To a solution of 6-oxo-1,6-dihydropyridine-2-carbonitrile (120 mg, $1 \mathrm{mmol})$ in DME $(2.0 \mathrm{~mL})$ and DMF $(0.5 \mathrm{~mL})$ under nitrogen was added $60 \% \mathrm{NaH}$ 
(42 mg, $1.05 \mathrm{mmol})$ at $0{ }^{\circ} \mathrm{C} . \mathrm{LiBr}$ was added (174 mg, $\left.2 \mathrm{mmol}\right) 10 \mathrm{~min}$ later. The mixture was stirred $15 \mathrm{~min}$ at room temperature, the 2-methoxyphenyl propargyl bromide ${ }^{64}(450 \mathrm{mg}, 2 \mathrm{mmol})$ was added, and the reaction was heated at $65^{\circ} \mathrm{C}$ for $15 \mathrm{~h}$. After cooled to room temperature, the mixture was poured into brine $(50 \mathrm{~mL})$, extracted with AcOEt $(2 \times 50 \mathrm{~mL})$, and dried over sodium sulfate and concentrated. The residue was purified by column chromatography (silical gel, AcOEt) to give 227 mg (0.86 mmol, 86\%) of III-130 as a pale yellow solid: $\mathrm{mp} 136-137{ }^{\circ} \mathrm{C}$; IR 2234 , $1660,1581,1266,1024,822,756 \mathrm{~cm}^{-1} ;{ }^{1} \mathrm{H} \delta 7.41(1 \mathrm{H}, \mathrm{dd}, J=7.4,1.7 \mathrm{~Hz}), 7.38-7.24$ $(2 \mathrm{H}, \mathrm{m}), 6.92-6.81(3 \mathrm{H}, \mathrm{m}), 6.78(1 \mathrm{H}, \mathrm{dd}, J=6.7,1.2 \mathrm{~Hz}), 5.21(2 \mathrm{H}, \mathrm{s}), 3.85(3 \mathrm{H}$, s); ${ }^{13} \mathrm{C} \delta 160.4,160.1,137.6,134.0,130.3,127.4,120.8,120.3,116.2,112.3,111.0$ $110.6,85.6,81.9,55.7,36.9$.

Compound III-131 To a solution of 6-oxo-1,6-dihydropyridine-2-carbonitrile (120 mg, $1 \mathrm{mmol})$ in DME $(2.0 \mathrm{~mL})$ and DMF $(0.5 \mathrm{~mL})$ under nitrogen was added $60 \% \mathrm{NaH}$ (42 mg, $1.05 \mathrm{mmol})$ at $0{ }^{\circ} \mathrm{C}$. $\mathrm{LiBr}$ was added $(174 \mathrm{mg}, 2 \mathrm{mmol}) 10 \mathrm{~min}$ later. The mixture was stirred $15 \mathrm{~min}$ at room temperature, the 3-methoxyphenyl propargyl bromide (450 mg, $2 \mathrm{mmol}$ ) was added, and the reaction was heated at $65^{\circ} \mathrm{C}$ for $15 \mathrm{~h}$. After cooled to room temperature, the mixture was poured into brine $(50 \mathrm{~mL})$, extracted with AcOEt $(2 \times 50 \mathrm{~mL})$, and dried over sodium sulfate and concentrated. The residue was purified by column chromatography (silical gel, AcOEt) to give 222 mg (0.84 mmol, 84\%) of III-131 as a colorless solid: mp 95-96 ${ }^{\circ} \mathrm{C}$; IR 2224, 1668, 1593, 1149, 801, 774, $684 \mathrm{~cm}^{-1} ;{ }^{1} \mathrm{H} \delta 7.32(1 \mathrm{H}, \mathrm{dd}, J=9.4,6.7 \mathrm{~Hz}), 7.21-7.14(1 \mathrm{H}$, m), 7.07-6.99 (1 H, m), 6.98-6.93 (1 H, m), 6.90-6.81 (2 H, m), $6.77(1 \mathrm{H}, \mathrm{dd}, J=6.7$, 
$1.2 \mathrm{~Hz}), 5.14(2 \mathrm{H}, \mathrm{s}), 3.75(3 \mathrm{H}, \mathrm{s}) ;{ }^{13} \mathrm{C} \delta 160.0,159.1,137.7,129.2,127.4,124.4$, $122.6,120.6,116.5,116.2,115.5,112.3,85.1,81.4,55.2,36.6$.

Compound III-132 To a solution of 6-oxo-1,6-dihydropyridine-2-carbonitrile (48 mg, $0.4 \mathrm{mmol})$ in DME $(1.0 \mathrm{~mL})$ and DMF $(0.25 \mathrm{~mL})$ under nitrogen was added $60 \%$ $\mathrm{NaH}(17 \mathrm{mg}, 0.42 \mathrm{mmol})$ at $0{ }^{\circ} \mathrm{C}$. $\mathrm{LiBr}$ was added $(70 \mathrm{mg}, 0.8 \mathrm{mmol}) 10 \mathrm{~min}$ later. The mixture was stirred $15 \mathrm{~min}$ at room temperature, the 2,3-dimethoxyphenyl propargyl bromide ${ }^{65}(204 \mathrm{mg}, 0.8 \mathrm{mmol})$ was added, and the reaction was heated at $65{ }^{\circ} \mathrm{C}$ for $15 \mathrm{~h}$. After cooled to room temperature, the mixture was poured into brine $(20 \mathrm{~mL})$, extracted with AcOEt $(2 \times 20 \mathrm{~mL})$, and dried over sodium sulfate and concentrated. The residue was purified by column chromatography (silical gel, AcOEt) to give $89 \mathrm{mg}(0.3 \mathrm{mmol}, 76 \%)$ of III-132 as a colorless solid: $\mathrm{mp} 124-125{ }^{\circ} \mathrm{C}$; IR 2230, 1663, 1475, 1100, 997, 806, 787, $753 \mathrm{~cm}^{-1} ;{ }^{1} \mathrm{H} \delta 7.33(1 \mathrm{H}, \mathrm{dd}, J=9.4,6.7 \mathrm{~Hz})$, 7.03-6.82 (4 H, m), $6.78(1 \mathrm{H}, \mathrm{dd}, J=6.7,1.2 \mathrm{~Hz}), 5.19(2 \mathrm{H}, \mathrm{s}), 3.89$ (3 H, s), 3.82 (3 $\mathrm{H}, \mathrm{s}) ;{ }^{13} \mathrm{C} \delta 160.1,152.6,150.8,137.7,127.4,125.2,123.7,120.7,116.4,116.2,113.4$ $112.3,85.6,81.5,61.1,55.9,36.9$.

III-133 The mixture of III-129 (50 mg, $0.19 \mathrm{mmol})$, DBU (29 mg, $0.19 \mathrm{mmol})$ in 4 $\mathrm{mL}$ 1,2-dichlorobenzene was heated to $120{ }^{\circ} \mathrm{C}$ under nitrogen. After cooled to room temperature, the mixture was purified by column chromatography (silical gel, AcOEt:MeOH $=6: 1)$ to give $50 \mathrm{mg}(0.19 \mathrm{mmol}, 100 \%)$ of III-133 as a pale yellow solid: mp 250-251 ${ }^{\circ} \mathrm{C}$; IR 1666, 1618, 1597, 1224, 1130, 1023, 813, 767, 751, 725 $\mathrm{cm}^{-1} ;{ }^{1} \mathrm{H} \delta 8.27(1 \mathrm{H}, \mathrm{s}), 7.77(1 \mathrm{H}, \mathrm{d}, J=9.2 \mathrm{~Hz}), 7.66(1 \mathrm{H}, \mathrm{dd}, J=8.9,6.9 \mathrm{~Hz}), 7.51$ $(1 \mathrm{H}, \mathrm{s}), 7.34-7.24(2 \mathrm{H}, \mathrm{m}), 6.71(1 \mathrm{H}, \mathrm{d}, J=9.2 \mathrm{~Hz}), 5.21(2 \mathrm{H}, \mathrm{s}), 3.99(3 \mathrm{H}, \mathrm{s}) ;{ }^{13} \mathrm{C}$ 
$\delta 161.5,152.6,150.3,146.0,140.3,130.9,128.9,126.6,123.5,121.3,120.3,106.9$, $100.9,55.7,49.9$.

III-134 The mixture of III-130 (50 mg, $0.19 \mathrm{mmol})$, DBU (29 mg, $0.19 \mathrm{mmol})$ in 4 $\mathrm{mL}$ 1,2-dichlorobenzene was heated to $120{ }^{\circ} \mathrm{C}$ under nitrogen. After cooled to room temperature, the mixture was purified by column chromatography (silical gel, AcOEt:MeOH $=6: 1)$ to give $50 \mathrm{mg}(0.19 \mathrm{mmol}, 100 \%)$ of III-134 as a pale yellow solid: $\mathrm{mp} 270-271^{\circ} \mathrm{C}$; IR 1657, 1589, 1570, 1366, 1261, 1187, 1150, 1113, $806 \mathrm{~cm}^{-1}$; ${ }^{1} \mathrm{H} \delta 8.76(1 \mathrm{H}, \mathrm{s}), 7.77(1 \mathrm{H}, \mathrm{d}, J=8.4 \mathrm{~Hz}), 7.73-7.62(2 \mathrm{H}, \mathrm{m}), 7.28(1 \mathrm{H}, \mathrm{d}, J=6.5$ Hz), $6.92(1 \mathrm{H}, \mathrm{d}, J=6.9 \mathrm{~Hz}), 6.72(1 \mathrm{H}, \mathrm{dd}, J=9.2,1.0 \mathrm{~Hz}), 5.22(1 \mathrm{H}, \mathrm{d}, J=0.7$ $\mathrm{Hz}), 4.04(3 \mathrm{H}, \mathrm{s}) ;{ }^{13} \mathrm{C} \delta 161.5,155.1,152.9,149.4,146.1,140.2,130.3,127.6,125.8$, $121.4,120.5,120.4,105.1,100.9,55.8,50.0$.

III-135 and III-136 The mixture of III-131 (50 mg, $0.19 \mathrm{mmol})$, DBU (29 mg, 0.19 mmol) in $4 \mathrm{~mL}$ 1,2-dichlorobenzene was heated to $120{ }^{\circ} \mathrm{C}$ under nitrogen. After cooled to room temperature, the mixture was purified by column chromatography ( silical gel, AcOEt:MeOH = 6:1) to give $50 \mathrm{mg}(0.19 \mathrm{mmol}, 100 \%)$ of a mixture of III-135 and III-136 (3 : 4) as a pale yellow solid: III-135 ${ }^{1} \mathrm{H} \delta 8.28(1 \mathrm{H}, \mathrm{s}), 8.16(1$ H, d, $J=9.4 \mathrm{~Hz}), 7.68(1 \mathrm{H}, \mathrm{dd}, J=8.9,6.9 \mathrm{~Hz}), 7.47(1 \mathrm{H}, \mathrm{dd}, J=9.2,2.7 \mathrm{~Hz}), 7.33$ $(1 \mathrm{H}, \mathrm{d}, J=6.9 \mathrm{~Hz}), 7.17(1 \mathrm{H}, \mathrm{d}, J=2.7 \mathrm{~Hz}), 6.72(1 \mathrm{H}, \mathrm{d}, J=8.9 \mathrm{~Hz}), 5.27(2 \mathrm{H}, \mathrm{s})$, 3.98 (3 H, s); III-136 mp 281-283 ${ }^{\circ} \mathrm{C}$; IR 1656, 1591, 1259, 1239, 1155, 758, 712 $\mathrm{cm}^{-1} ;{ }^{1} \mathrm{H} \delta 8.35(1 \mathrm{H}, \mathrm{s}), 7.67(1 \mathrm{H}, \mathrm{dd}, J=8.9,6.9 \mathrm{~Hz}), 7.61-7.45(2 \mathrm{H}, \mathrm{m}), 7.40(1 \mathrm{H}$, $\mathrm{d}, J=6.9 \mathrm{~Hz}), 7.15(1 \mathrm{H}, \mathrm{dd}, J=7.7,1.2 \mathrm{~Hz}), 6.72(1 \mathrm{H}, \mathrm{d}, J=8.9 \mathrm{~Hz}), 5.27(2 \mathrm{H}, \mathrm{s})$, $4.14(3 \mathrm{H}, \mathrm{s}) ;{ }^{13} \mathrm{C} \delta 161.5,155.5,152.0,146.0,140.8,140.3,130.9,129.23,129.20$, 
128.0, 120.4, 120.0, 108.5, 101.5, 56.3, 49.9. The structure of III-136 was established by X-ray structure analysis.

III-137 The mixture of III-132 (50 mg, $0.17 \mathrm{mmol})$, DBU (26 mg, $0.17 \mathrm{mmol})$ in 4 $\mathrm{mL}$ 1,2-dichlorobenzene was heated to $120{ }^{\circ} \mathrm{C}$ under nitrogen. After cooled to room temperature, the mixture was purified by column chromatography (silical gel, AcOEt:MeOH $=6: 1)$ to give $50 \mathrm{mg}(0.17 \mathrm{mmol}, 100 \%)$ of III-137 as a pale yellow solid: $\operatorname{mp} 216-218{ }^{\circ} \mathrm{C}$; IR 1659, 1595, 1443, 1262, 1112, 1092, 1048, 988, 799, 736 $\mathrm{cm}^{-1} ;{ }^{1} \mathrm{H} \delta 8.61(1 \mathrm{H}, \mathrm{d}, J=0.7 \mathrm{~Hz}), 7.95(1 \mathrm{H}, \mathrm{d}, J=9.4 \mathrm{~Hz}), 7.64(1 \mathrm{H}, \mathrm{dd}, J=8.9$, $6.7 \mathrm{~Hz}), 7.57(1 \mathrm{H}, \mathrm{d}, J=9.4 \mathrm{~Hz}), 7.22(1 \mathrm{H}, \mathrm{d}, J=6.2 \mathrm{~Hz}), 6.69(1 \mathrm{H}, \mathrm{dd}, J=8.9,0.7$ Hz), $5.23(2 \mathrm{H}, \mathrm{d}, J=1.0 \mathrm{~Hz}), 4.04(3 \mathrm{H}, \mathrm{s}) ;{ }^{13} \mathrm{C} \delta 161.5,151.2,149.3,146.1,144.2$, $142.0,140.3,128.6,125.6,124.9,123.9,120.2,118.7,100.5,61.4,56.7,50.0$.

III-143 To a solution of 3-(2-methoxyphenyl)-2-Propyn-1-ol (648 mg, $4 \mathrm{mmol})$ and triethylamine $(607 \mathrm{mg}, 5.78 \mathrm{mmol})$ in $20 \mathrm{~mL}$ of methylene chloride at $-50{ }^{\circ} \mathrm{C}$ under a nitrogen atmosphere was added dropwise methanesulfonyl chloride (596 mg, 5.21 mmol). The reaction mixture was allowed to warm to room temperature and stirred for $1 \mathrm{~h}$ and $\mathrm{LiBr}(3.48 \mathrm{~g}, 40 \mathrm{mmol})$ in $20 \mathrm{~mL}$ of THF was then added. The mixture was stirred for $12 \mathrm{~h}$ at room temperature before $10 \mathrm{~mL}$ of water was introduced. The organic layer was separated, and the aqueous layer was back extracted with methylene chloride. The combined organic layers were washed with water, dried over $\mathrm{MgSO}_{4}$, and concentrated. The residue was purified by column chromatography (silical gel, diethyl ether:hexane $=1: 10)$ to give $801 \mathrm{mg}(3.56 \mathrm{mmol}, 89 \%)$ of III-143 as a colorless liquid: IR 2217, 1491, 1270, 1022, $749 \mathrm{~cm}^{-1} ;{ }^{1} \mathrm{H} \delta 7.42(1 \mathrm{H}, \mathrm{dd}, J=7.7,1.7$ 
Hz), $7.31(1 \mathrm{H}, \mathrm{td}, J=8.2,1.7 \mathrm{~Hz}), 6.96-6.82(2 \mathrm{H}, \mathrm{m}), 4.23(2 \mathrm{H}, \mathrm{s}), 3.87(3 \mathrm{H}, \mathrm{s})$;

${ }^{13} \mathrm{C} \delta 160.1,133.9,130.3,120.4,111.1,110.5,88.1,83.1,55.7,15.8$.

III-144 To a mixture of 1-Iodo-2,3-dimethoxybenzene (528 mg, $2 \mathrm{mmol}), 70 \mathrm{mg}(0.1$ mmol $)$ of $\mathrm{Pd}\left(\mathrm{PPh}_{3}\right)_{2} \mathrm{Cl}_{2}$, and $38 \mathrm{mg}(0.2 \mathrm{mmol})$ of copper(I) iodide in $25 \mathrm{~mL}$ of triethylamine under a nitrogen atmosphere was added dropwise via cannula a solution of $224 \mathrm{mg}$ of propargyl alcohol $(4 \mathrm{mmol})$ in $5 \mathrm{~mL}$ of triethylamine. The reaction mixture was stirred vigorously at $90{ }^{\circ} \mathrm{C}$ for $12 \mathrm{~h}$ before it was allowed to cool to room temperature. Then $50 \mathrm{~mL}$ of a saturated $\mathrm{NH}_{4} \mathrm{Cl}$ solution and $50 \mathrm{~mL}$ of diethyl ether were introduced. The organic layer was separated, and the aqueous layer was back extracted with diethyl ether. The combined organic layers were washed with water, dried over $\mathrm{MgSO}_{4}$, and concentrated. The residue was purified by column chromatography (silical gel, diethyl ether:hexanes $=1: 1)$ to give $180 \mathrm{mg}(0.94 \mathrm{mmol}$, 47\%) of III-144 as a pale yellow liquid: IR 3420, 2227, 1470, 1260, 1096, 1001, 784, $745 \mathrm{~cm}^{-1} ;{ }^{1} \mathrm{H} \delta$ 7.04-6.86 (3 H, m), $4.53(2 \mathrm{H}, \mathrm{s}), 3.92(3 \mathrm{H}, \mathrm{s}), 3.86(3 \mathrm{H}, \mathrm{s}), 1.80(1 \mathrm{H}$, s); ${ }^{13} \mathrm{C} \delta 152.6,150.4,125.1,123.9,117.2,113.1,91.2,81.7,61.0,55.9,51.8$.

III-145 To a solution of III-144 $(170 \mathrm{mg}, 0.89 \mathrm{mmol})$ and triethylamine (135 $\mathrm{mg}$, $1.29 \mathrm{mmol}$ ) in $10 \mathrm{~mL}$ of methylene chloride at $-50{ }^{\circ} \mathrm{C}$ under a nitrogen atmosphere was added dropwise methanesulfonyl chloride $(133 \mathrm{mg}, 1.16 \mathrm{mmol})$. The reaction mixture was allowed to warm to room temperature and stirred for $1 \mathrm{~h}$ and $\mathrm{LiBr}(783$ $\mathrm{mg}, 9 \mathrm{mmol}$ ) in $10 \mathrm{~mL}$ of THF was then added. The mixture was stirred for $12 \mathrm{~h}$ at room temperature before $5 \mathrm{~mL}$ of water was introduced. The organic layer was separated, and the aqueous layer was back extracted with methylene chloride. The 
combined organic layers were washed with water, dried over $\mathrm{MgSO}_{4}$, and concentrated. The residue was purified by column chromatography (silical gel, diethyl ether:hexane $=1: 10)$ to give $181 \mathrm{mg}(0.71 \mathrm{mmol}, 80 \%)$ of III-145 as a colorless liquid: IR 2229, 1470, 1262, 1102, 998, 783, $744 \mathrm{~cm}^{-1} ;{ }^{1} H \delta 7.03-6.86(3 \mathrm{H}, \mathrm{m}), 4.21$ (2 H, s), $3.93(3 \mathrm{H}, \mathrm{s}), 3.86(3 \mathrm{H}, \mathrm{s}) ;{ }^{13} \mathrm{C} \delta 152.6,150.7,125.2,123.8,116.8,113.4$, $88.0,82.9,61.2,55.9,15.5$.

\section{References:}

1 Hoffman-Roder, A.; Krause, N. Angew. Chem., Int. Ed. 2004, 43, 1196.

2 For reviews, see: (a) Zimmer, R.; Dinesh, C.; Nandanan, E.; Khan, F. Chem. Rev. 2000, 100, 3067. (b) Marshall, J. Chem. Rev. 2000, 100, 3163. (c) Hashmi, A. S. K. Angew. Chem., Int. Ed. 2000, 39, 3590. (d) Bates, R.; Satcharoen, V. Chem. Soc. Rev. 2002, 31, 12. (e) Ma, S. Handbook of Organopalladium Chemistry for Organic Synthesis; Negishi, E., Ed.; John Wiley \& Sons: New York, 2002; p 1491. (f) Sydnes, L. Chem. Rev. 2003, 103, 1133. (g) Ma, S. Acc. Chem. Res. 2003, 36, 701. (h) Brandsma, L.; Nedolya, N. A. Synthesis 2004, 735. (i) Tius, M. Acc. Chem. Res. 2003, 36, 284. (j) Wei, L.-L.; Xiong, H.; Hsung, R. P. Acc. Chem. Res. 2003, 36, 773. (k) Lu, X.; Zhang, C.; Xu, Z. Acc. Chem. Res. 2001, 34, 535. (1) Wang, K. K. Chem. Rev. 1996, 96, 207. (m) Pan, F.; Fu, C.; Ma, S. Chin. J. Org. Chem. 2004, 24, 1168. (n) Ma, S. Chem. Rev. 2005, 105, 2829.

3 (a) Myers, A. G.; Kuo, E. Y.; Finney, N. S. J. Am. Chem. Soc. 1989, 111, 8057-8059.

(b) Myers, A. G.; Dragovich, P. S. J. Am. Chem. Soc. 1989, 111, 9130-9132. (c) 
Nagata, R.; Yamanaka, H.; Okazaki, E.; Saito, I. Tetrahedron Lett. 1989, 30, 4995-4998. (d) Nagata, R.; Yamanaka, H.; Murahashi, E.; Saito, I. Tetrahedron Lett. 1990, 31, 2907-2910.

4 (a) Schmittel, M.; Strittmatter, M.; Kiau, S. Tetrahedron Lett. 1995, 36, 4975-4978.

(b) Schmittel, M.; Strittmatter, M.; Vollmann, K.; Kiau, S. Tetrahedron Lett. 1996, 37, 999-1002. (c) Schmittel, M.; Strittmatter, M.; Kiau, S. Angew. Chem., Int. Ed. Engl. 1996, 35, 1843-1845. (d) Schmittel, M.; Kiau, S.; Siebert, T.; Strittmatter, M. Tetrahedron Lett. 1996, 37, 7691-7694. (e) Schmittel, M.; Keller, M.; Kiau, S.; Strittmatter, M. Chem.-Eur. J. 1997, 3, 807-816. (f) Schmittel, M.; Steffen, J.-P.; Maywald, M.; Engels, B.; Helten, H.; Musch, P. J. Chem. Soc., Perkin Trans. 2 2001, 1331-1339.

5 Wang, K. K.; Wang, Z.; Sattsangi, P. D. J. Org. Chem. 1996, 61, 1516-1518.

6 Wang, K. K.; Zhang, H.-R.; Petersen, J. L. J. Org. Chem. 1999, 64, 1650-1656.

7 Li, H.; Petersen, J. L.; Wang, K. K. J. Org. Chem. 2001, 66, 7804-7810.

8 Goodwin S.; Smith, A. F.; Horning, E. C. J. Am. Chem. Soc. 1959, 81, 1903-1908.

9 (a) Dalton, L. K.; Demerac, S.; Elmes, B. C.; Loder, J. W.; Swan, J. M.; Teitei, T. Aust. J. Chem. 1967, 20, 2715-2727. (b) Gribble, G. W. In The Alkaloids; Brossi, A., Ed.; Academic Press: New York, 1990; Vol. 39, pp 239-351.(c) Suffness, M.; Cordell, G. A. In The Alkaloids; Brossi, A., Ed.; Academic Press: New York, 1985; Vol. 25, pp 89-142. (d) Kansal, V. K.; Potier, P. Tetrahedron 1986, 42, 2389-2408. (e) Gribble, G. W.; Saulnier, M. G.; Obaza-Nutaitis, J. A.; Ketcha, D. M. J. Org. Chem. 1992, 57, 5891-5899. (f) Ishikura, M.; Yaginuma, T.; Agata, I.; Miwa, Y.; Yanada, R.; Taga, T. 
Synlett 1997, 214-216. (g) Díaz, M. T.; Cobas, A.; Guitián, E.; Castedo, L. Synlett 1998, 157-158. (h) Ergün, Y.; Patir, S.; Okay, G. J. Heterocycl. Chem. 1998, 35, 1445-1447. (i) Ishikura, M.; Hino, A.; Yaginuma, T.; Agata, I.; Katagiri, N. Tetrahedron 2000, 56, 193-207. (j) Anderson, W. K.; Gopalsamy, A.; Reddy, P. S. J. Med. Chem. 1994, 37, 1955-1963. (k) Pierson, V.; Pierre, A.; Pommier, Y.; Gros, P. Cancer Res. 1988, 48, 1404-1409. (1) Vilarem, M. J.; Riou, J. F.; Multon, E.; Gros, M. P.; Larsen, C. J. Biochem. Pharmacol. 1986, 35, 2087-2095.

10 (a) Zhang, Q.; Shi, C.; Zhang, H.-R.; Wang, K. K. J. Org. Chem. 2000, 65, 7977-7983. (b) Lu, X.; Petersen, J. L.; Wang, K. K. J. Org. Chem. 2002, 67, 5412-5415.

11 (a) Newman, M. S.; Hussey, A. S. J. Am. Chem. Soc. 1947, 69, 3023-3027. (b) Armstrong, R. N.; Ammon, H. L.; Darnow, J. N. J. Am. Chem. Soc. 1987, 109, 2077-2082.

12 Tinnemans, A. H. A.; Laarhoven, W. H. Tetrahedron 1979, 35, 1537-1541.

13 Casiraghi, G.; Casnati, G.; Puglia, G.; Sartori, G.; Terenghi, G. J. Chem. Soc., Perkin Trans 1 1980, 1862-1865.

14 Müller, S.; Liepold, B.; Roth, G. J.; Bestmann, H. J. Synlett 1996, 521-522.

15 Robertson, J. M. Organic Crystals and Molecules; Cornell University Press: Ithaca, New York, 1953; pp 206-214.

16 Schmuck, C. Angew. Chem., Int. Ed. 2003, 42, 2448-2452 and references therein. 17 (a) Engels, B.; Lennartz, C.; Hanrath, M.; Schmittel, M.; Strittmatter, M. Angew.Chem., Int. Ed. 1998, 37, 1960-1963. (b) Engels, B.; Hanrath, M. J. Am. Chem. 
Soc. 1998, 120, 6356-6361. (c) Schreiner, P. R.; Prall, M. J. Am. Chem. Soc. 1999, 121, 8615-8627. (d) Wenthold, P. G.; Lipton, M. A. J. Am. Chem. Soc. 2000, 122, 9265-9270. (e) Cramer, C. J.; Kormos, B. L.; Seierstad, M.; Sherer, E. C.; Winget, P. Org. Lett. 2001, 3, 1881-1884.

18 Li, H.; Zhang, H.-R.; Petersen, J. L.; Wang, K. K. J. Org. Chem. 2001, 66, $6662-6668$.

19 Dai, W.; Petersen, J. L.; Wang, K. K. Org. Lett. 2004, 6, 4355-4357.

20 (a) Jacques, J.; Fouquey, C. Org. Synth., Coll. Vol. VIII 1993, 50; (b) Kazlauskas, R. J. Org. Synth., Coll. Vol. IX 1998, 77. (c) Cai, D.; Hughes, D. L.; Verhoeven, T. R.; Reider, P. J. Org. Synth., Coll. Vol. X 2004, 93.

21 (a) Noyori, R.; Tomino, I.; Tanimoto, Y. J. Am. Chem. Soc. 1979, 101, 3129. (b)

Noyori, R.; Tomino, I.; Tanimoto, Y. J. Am. Chem. Soc. 1979, 101, 5843. (c) Nishizawa, M.; Noyori, R. Tetrahedron Lett. 1980, 2821. (d) Noyori, R. Chem. Soc. Rev. 1989, 18, 187.

22 Lustenberger, P.; Diederich, F. Helv. Chim. Acta 2000, 83, 2865-2883.

23 Deussen, H.-J.; Hendrickx, E.; Boutton, C.; Krog, D.; Clays, K.; Bechgaard, K.; Persoons, A.; BjФrnholm, T. J. Am. Chem. Soc. 1996, 118, 6841-6852.

24 Bennett, G. B.; Nadelson, J.; Alden, L.; Jani, A. Org. Prep. Proced. Int. 1976, 8, $13-18$.

25 (a) Floyd, A. J.; Dyke, S. F.; Ward, S. E. Chem. Rev. 1976, 76, 509-562. (b) Brown, W. G.; Bluestein, B. J. Am. Chem. Soc. 1940, 62, 3256-3257.

26 (a) Zhang, H.-R.; Wang, K. K. J. Org. Chem. 1999, 64, 7996-7999. (b) Yang, Y.; 
Petersen, J. L.; Wang, K. K. J. Org. Chem. 2003, 68, 5832-5837. (c) Yang, Y.;

Petersen, J. L.; Wang, K. K. J. Org. Chem. 2003, 68, 8545-8549. (d) Han, X.; Zhang, Y.; Wang, K. K. J. Org. Chem. 2005, 70, 2406-2408.

27 Laarhoven, W. H.; Peters, W. H. M.; Tinnemans, A. H. A. Tetrahedron. 1978, 34, 769-777.

28 Vingiello, F. A.; Yanez, J.; Campbell, J. A. J. Org. Chem. 1971, 36, 2053-2056.

29 Yang, Y.; Dai, W.; Zhang, Y.; Petersen, J. L.; Wang, K. K. Tetrahedron in press

30 Janke, R. H.; Haufe, G.; Wurthwein, E.-U.; Borkent, J. H. J. Am. Chem. Soc. 1996, $118,6031-6035$.

31 (a) M.E. Wall and M.C. Wani. In: J.E. Saxton, Editor, The Monoterpenoid Indole Alkaloids, Wiley, London 1994; p. 689. (b) H. Takayama, M. Kitajima and N. Aimi. J. Synth. Org. Chem. 1999, 57, 181. (c) S. Baurle and U. Koert. In: H.-G. Schmalz, Editor, Organic Synthesis Highlights IV; 2000; p. 232. (d) Y. Kawato and H. Terasawa. Prog. Med. Chem. 1997, 34, 69. (e) Du, W. Tetrahedron 2003, 59, 8649-8687.

32 (a) Ormrod, D.; Spencer, C. M. Drugs 1999, 58, 533. (b) Herzog, T. J. Oncologist 2002, 7(Suppl. 5), 3.

33 Saltz, L. B. Colorectal Cancer; Saltz, L. B., Ed.; Humana Press Inc., Totowa, 2002, 513.

34 Redinbo, M. R.; Champoux, J. J.; Hol, W. G. J. Biochemistry 2000, 39, 6832-6840. 35 (a) Kerrigan, J. E.; Pilch, D. S. Biochemistry 2001, 40, 9792-9798. (b) Laco, G. S.; Collins, J. R.; Luke, B. T.; Kroth, H.; Sayer, J. M.; Jerina, D. M.; Pommier, Y. Biochemistry 2002, 41, 1428-1435. 
36 (a) Boger, D. L.; Hong, J. J. Am. Chem. Soc. 1998, 120, 1218. (b) Comins, D. L.; Saha, J. K. J. Org. Chem. 1996, 61, 9623. (c) Pendrak, I.; Barney, S.; Wittrock, R.; Lambert, D. M.; Kingsbury, W. D. J. Org. Chem. 1994, 59, 2623. (d) Pendrak, I.; Wittrock, R.; Kingsbury, W. D. J. Org. Chem. 1995, 60, 2912.

37 (a) D.L. Comins, M.F. Baevsky and H. Hong. J. Am. Chem. Soc. 1992, 114, 10971.

(b) D.L. Comins, H. Hong and J. Gao. Tetrahedron Lett. 1994, 30, 5331. (c) D.L. Comins, H. Hong, J.K. Saha and J. Gao. J. Org. Chem. 1994, 59, 5120. (d) D.L. Comins and J.M. Nolan. Org. Lett. 2001, 3, 4255. (e) D.L. Comins and J.K. Saha. J. Org. Chem. 1996, 61, 9623. (f) F.G. Fang, D.D. Bankston, E.M. Huie, R.M. Johnson, M.-C. Kang, C.S. LeHollier, G.C. Lewis, T.C. Lovelace, M.W. Lowery, D.L. McDouglad, C.A. Meerholz, J.J. Partridge, M.J. Sharp and S. Xie. Tetrahedron 1997, 53, 10953. (g) M.-L. Bennasar, C. Juan and J. Bosch. Chem. Commun. 2000, 2459. (h) M.-L. Bennasar, E. Zulaica, C. Juan, Y. Alonso and J. Bosch. J. Org. Chem. 2002, 67 , 7465. (i) N. Murata, T. Sugihara, Y. Kondo and T. Sakamoto. Synlett 1997, 298.

38 (a) D.P. Curran. J. Chin. Chem. Soc. (Taipei) 1993, 40, 1. (b) D.P. Curran, H. Josien, D. Bom, A.E. Gabarda and W. Du. Ann N.Y. Acad. Sci. 2000, 922, 112. (c) D.P. Curran and H. Liu. J. Am. Chem. Soc. 1992, 114, 5863. (d) H. Josien and D.P. Curran. Tetrahedron 1997, 53, 8881. (e) D.P. Curran, S.-B. Ko and H. Josien. Angew. Chem. Int. Ed. 1995, 34, 2683. (f) D.P. Curran, H. Liu, H. Josien and S.-B. Ko. Tetrahedron 1996, 52, 11385. (g) H. Josien, S.-B. Ko, D. Bom and D.P. Curran. Chem. Eur. J. 1998, 4, 67. (h) K. Yabu, S. Masumoto, S. Yamasaki, Y. Hamashima, M. Kanai, W. Du, D.P. Curran and M. Shibashaki. J. Am. Chem. Soc. 2001, 123, 9908. (i) D.P. Curran and W. 
Du. Org. Lett. 2002, 4, 3215. (j) W.R. Bowman, C.F. Bridge, P. Brookes, M.O. Cloonan and D.C. Leach. Synlett 2001, 6, 765. (k) W.R. Bowman, C.F. Bridge, P. Brookes, M.O. Cloonan and D.C. Leach. J. Chem. Soc., Perkin Trans. 1 2002, 58-68. 39 (a) M.E. Wall, M.C. Wani, S.M. Natschke and A.W. Nicholas. J. Med. Chem. 1986, 29, 1553 (b) M.C. Wani, A.W. Nicholas and M.E. Wall. J. Med. Chem. 1986, 29, 2358. (c) M.C. Wani, A.W. Nicholas, G. Manikumar and M.E. Wall. J. Med. Chem. 1987, 30, 1774. (d) M.C. Wani, A.W. Nicholas and M.E. Wall. J. Med. Chem. 1987, 30, 2317. (e) S.-S. Jew, K.-D. Ok, H.-J. Kim, M.G. Kim, J.M. Kim, J.M. Hah and Y.-S. Cho. Tetrahedron: Asymmetry 1995, 6, 1245. (f) K. Tagami, N. Nkazawa, S. Sano and Y. Nagao. Hetrocycles 2000, 53, 771. (g) W. Shen, C.A. Coburn, W.G. Bornmann and S.J. Danishefsky. J. Org. Chem. 1993, 58, 611. (h) K.E. Henegar, S.W. Ashford, T.A. Baughman, J.C. Sih and R.-L. Gu. J. Org. Chem. 1997, 62, 6588.

40 (a) M.A. Ciufolini and F. Roschangar. Angew. Chem. Int. Ed. 1990, 35, 1692. (b) M.A. Ciufolini and F. Roschangar. Tetrahedron 1997, 32, 11049. (c) M.A. Ciufolini and F. Roschangar. Targets Hetrocycl. Syst. 2000, 4, 25. (d) L. Carles, K. Narkunan, S. Penlou, L. Rousset, D. Bouchu and M.A. Ciufolini. J. Org. Chem. 2002, 67, 4304. (e) S.P. Chavan and M.S. Venkatraman. Tetrahedron Lett. 1998, 39, 6745. (f) K. Mekouar, Y. Genisson, S. Leue and A.E. Greene. J. Org. Chem. 2000, 65, 5212.

41 (a) J.M.D. Fortunak, A.R. Mastrocola, M. Mellinger, N.J. Sisti, J.L. Wood and Z.-P. Zhuang. Tetrahedron Lett. 1996, 37, 5679. (b) J.M.D. Fortunak, J. Kitteringham, A.R. Mastrocola, M. Mellinger, N.J. Sisti, J.L. Wood and Z.-P. Zhuang. Tetrahedron Lett. 1996, 37, 5683. (c) D.L. Boger and J. Hong. J. Am. Chem. Soc. 1998, 120, 
1218. (d) B.S.J. Blagg and D.L. Boger. Tetrahedron 2002, 58, 6343. (e) M. Toyota, C. Komori and M. Ihara. Hetrocycles 2000, 52, 591. (f) M. Toyota, C. Komori and M. Ihara. J. Org. Chem. 2000, 65, 7110. (g) J.H. Rigby and D.M. Danca. Tetrahedron Lett. 1997, 38, 4969.

42 (a) Shi, C.; Wang, K. K. J. Org. Chem. 1998, 63, 3517-3520. (b) Shi, C.; Wang, K. K. J. Org. Chem. 1999, 64, 925-932. (c) Zhang, Q.; Shi, C.; Zhang, H.-R.; Wang, K. K. J. Org. Chem. 2000, 65, 7977-7983. (d) Lu, X.; Petersen, J. L.; Wang, K. K. J. Org. Chem. 2002, 67, 7797-7801.

43 Suginome, M.; Fukuda, T.; Ito, Y. Org. Lett. 1999, 1, 1977-1979.

44 Katritzky, A. R.; Schwarz, O. A.; Rubio, O. Helv. Chim. Acta 1984, 67, 939-946. 45 Gillmann, T.; Heckhoff, S. Tetrahedron Lett. 1996, 37, 839-840.

46 Wang, K. K. In Modern Allene Chemistry; Krause, N., Hashmi, A. S. K., Eds.; Wiley-VCH: Weinheim, Germany, 2004; Vol. 2, pp 1091-1126.

47 Schmittel, M.; Steffen, J.-P.; Bohn, I. Heterocycl. Commun. 1997, 3, 443-447.

48 Lu, X.; Petersen, J. L.; Wang, K. K. Org. Lett. 2003, 5, 3277-3280.

49 Katritzky, A. R.; Schwarz, O. A.; Rubio, O.; Markees, D. G. Helv. Chim. Acta 1984, 67, 939-946.

50 (a) Alaimo, R. J.; Hatton, C. J.; Eckman, M. K. J. Med. Chem. 1970, 13, 554-556. (b) Alaimo, R. J.; Goldenberg, M. M. J. Med. Chem. 1975, 18, 1145-1147. (c) Marivingt-Mounir, C.; Norez, C.; Dérand, R.; Bulteau-Pignoux, L.; Nguyen-Huy, D.; Viossat, B.; Morgant, G.; Becq, F.; Vierfond, J.-M.; Mettey, Y. J. Med. Chem. 2004, 47, 962-972. (d) Ihmels, H.; Faulhaber, K.; Wissel, K.; Bringmann, G.; Messer, K.; Viola, 
G.; Vedaldi, D. Eur. J. Org. Chem. 2001, 1157-1161. (e) Pastor, J.; Siro, J. G.; García-Navío, J. L.; Vaquero, J. J.; Alvarez-Builla, J.; Gago, F.; de Pascual-Teresa, B.; Pastor, M.; Rodrigo, M. M. J. Org. Chem. 1997, 62, 5476-5483.

51 Grissom, J. W.; Klingberg, D.; Huang, D.; Slattery, B. J. J. Org. Chem. 1997, 62, 603-626.

52 Casaschi, A.; Grigg, R.; Sansano, J. M. Tetrahedron 2001, 57, 607-615.

53 (a) Knölker, H.-J.; Boese, R.; Hitzemann, R. Chem. Ber. 1990, 123, 327-339. (b)

Gueiffier, A.; Mavel, S.; Lhassani, M.; Elhakmaoui, A.; Snoeck, R.; Andrei, G.;

Chavignon, O.; Teulade, J.-C.; Witvrouw, M.; Balzarini, J.; De Clercq, E.; Chapat, J.-P. J. Med. Chem. 1998, 41, 5108-5112. (c) Kaminski, J. J.; Doweyko, A. M. J. Med. Chem. 1997, 40, 427-436. (d) Sanfilippo, P. J.; Urbanski, M.; Press, J. B.; Dubinsky, B.; Moore, J. B., Jr. J. Med. Chem. 1988, 31, 2221-2227. (e) Gueiffier, A.; Lhassani, M.; Elhakmaoui, A.; Snoeck, R.; Andrei, G.; Chavignon, O.; Teulade, J.-C.; Kerbal, A.; Essassi, E. M.; Debouzy, J.-C.; Witvrouw, M.; Blache, Y.; Balzarini, J.; De Clercq, E.; Chapat, J.-P. J. Med. Chem. 1996, 39, 2856-2859.

54 Galons, H.; Bergerat, I.; Combet-Farnoux, C.; Miocque, M.; Decodts, G.; Bram, G. J. Chem. Soc., Chem. Commun. 1985, 23, 1730-1731.

55 Ohsawa, A.; Kawaguchi, T.; Igeta, H. J. Org. Chem. 1982, 47, 3497-3503.

56 (a) Eberbach, W.; Maier, W. Tetrahedron Lett. 1989, 30, 5591-5594. (b) Forti, L.;

Gelmi, M. L.; Pocar, D.; Varallo, M. Heterocycles 1986, 24, 1401-1410. (c) Goldberg, S. I.; Lipkin, A. H. J. Org. Chem. 1970, 35, 242-244.

57 Dai, W.; Petersen, J. L.; Wang, K. K. J. Org. Chem. 2005, 70, 6647-6652. 
58 (a) Ryu, I.; Sonoda, N.; Curran, D. P. Chem. Rev. 1996, 96, 177. (b) Nanni, D. In Radicals in Organic Synthesis; $1^{\text {st }}$ ed.; Renaud, P., Sibi, M. P., Eds. Wiley-VCH: Weinheim 2001, vol. 2, p. 44.

59 (a) Rodriguez, D.; Navarro, A.; Castedo, L.; Dominguez, D.; Saa, C. Org. Lett. 2000, 2, 1497-1500. (b) Rodriguez, D.; Martinez-Esperon, M. F.; Navarro-Vazquez, A.; Castedo, L.; Dominguez, D.; Saa, C. J. Org. Chem. 2004, 69, 3842-3848.

60 Hammer, J. 1,4-Cycloaddition Reactions, the Diels-Alder Reaction in Heterocyclic Synthesis; Academic Press: New York, 1967.

61 Liu, H.; Ko, S.-B.; Josien, H.; Curran, D. P. Tetrahedron Lett. 1995, 36, 8917-8920.

62 Liron, F.; Garrec, P. L.; Alami, M. Synlett 1999, 246-248.

63 Zhao, L.; Lu, X.; Xu, W. J. Org. Chem. 2005, 70, 4059-4063.

64 Yi, X.-H.; Meng, Y.; Hua, X.-G.; Li, C.-J. J. Org. Chem. 1998, 63, 7472-7480.

65 Zhang, W.; Luo, Z.; Chen, C. H.-T.; Curran, D. P. J. Am. Chem. Soc. 2002, 124, 10443-10450. 


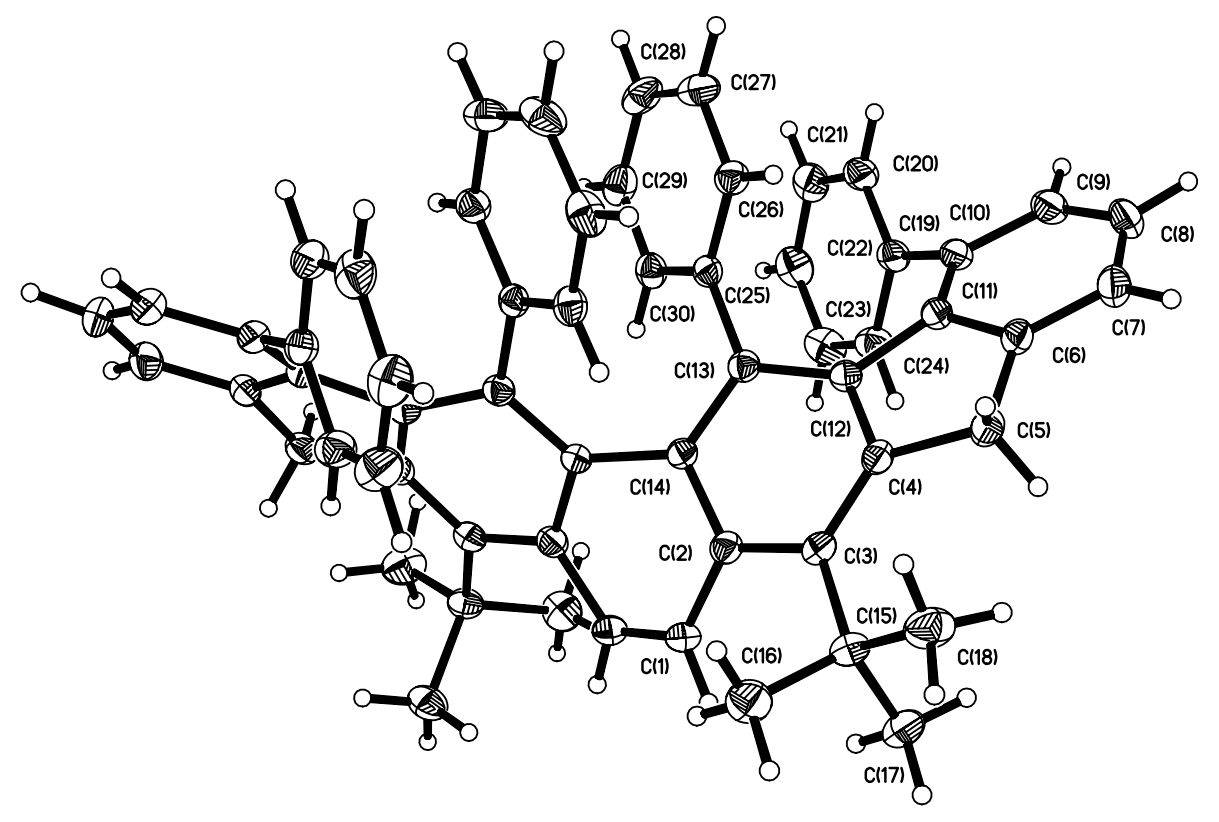

Figure 6. ORTEP drawing of the crystal structure of II-8

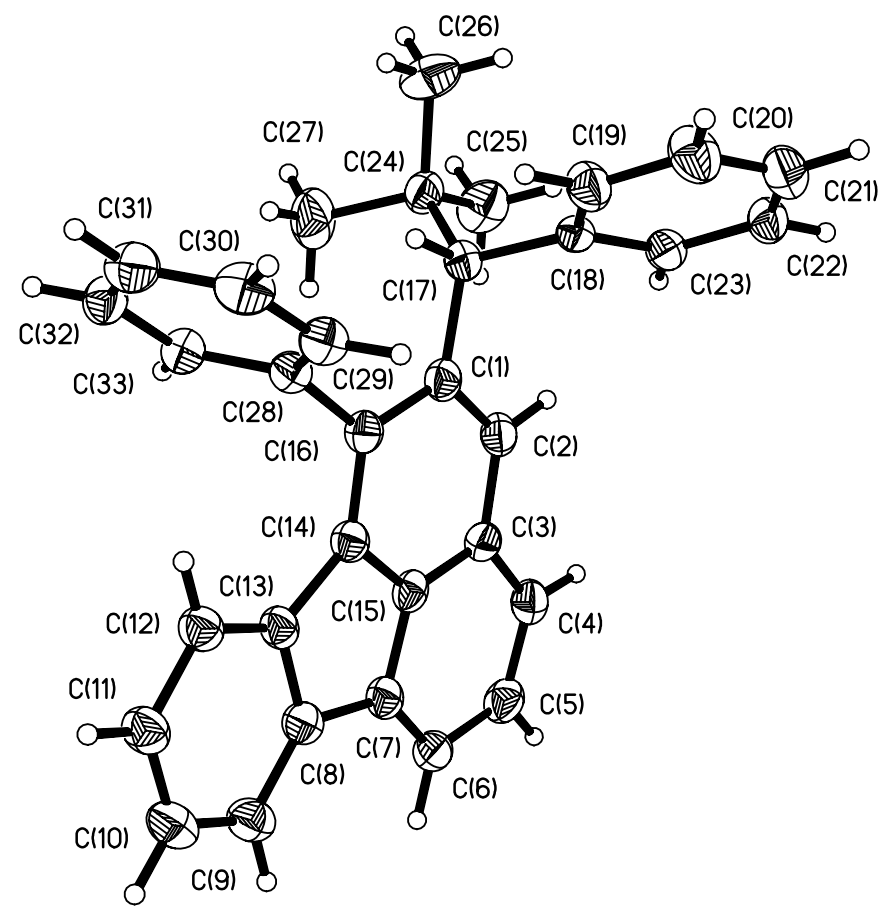

Figure 7. ORTEP drawing of the crystal structure of II-16 


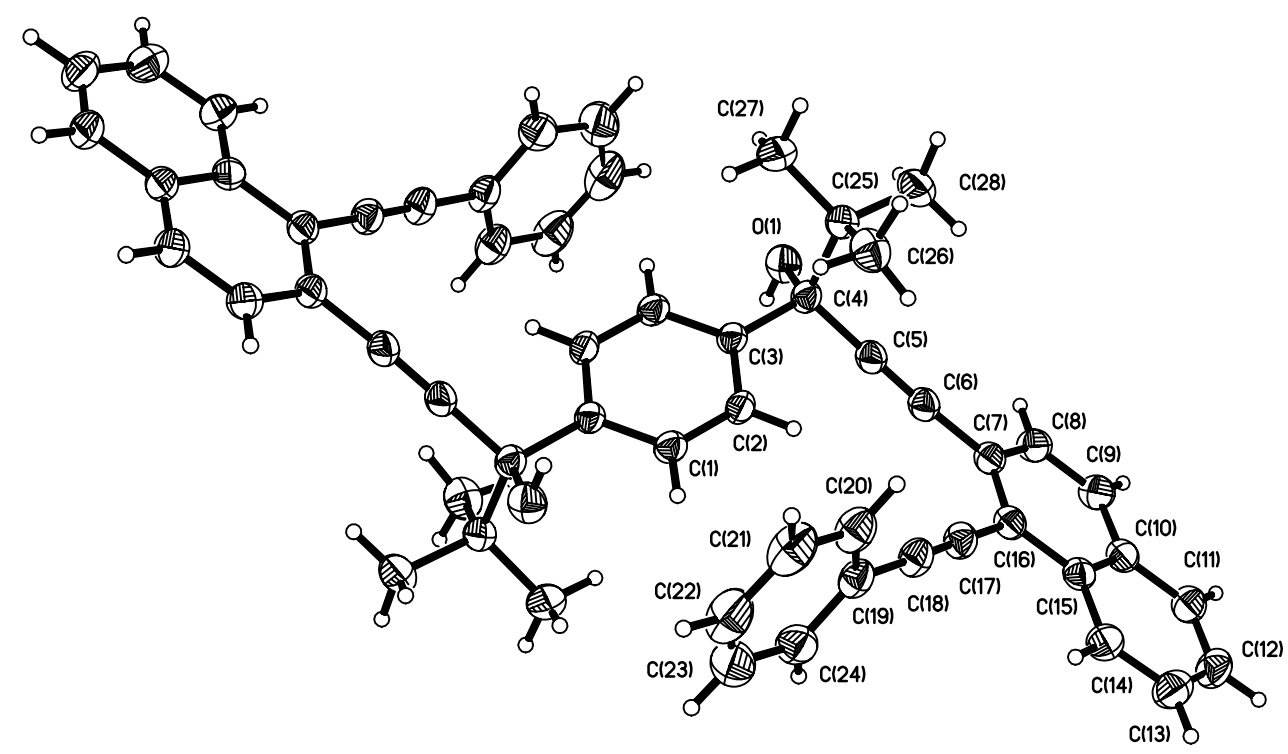

Figure 8. ORTEP drawing of the crystal structure of diasteromer 1 of II-20

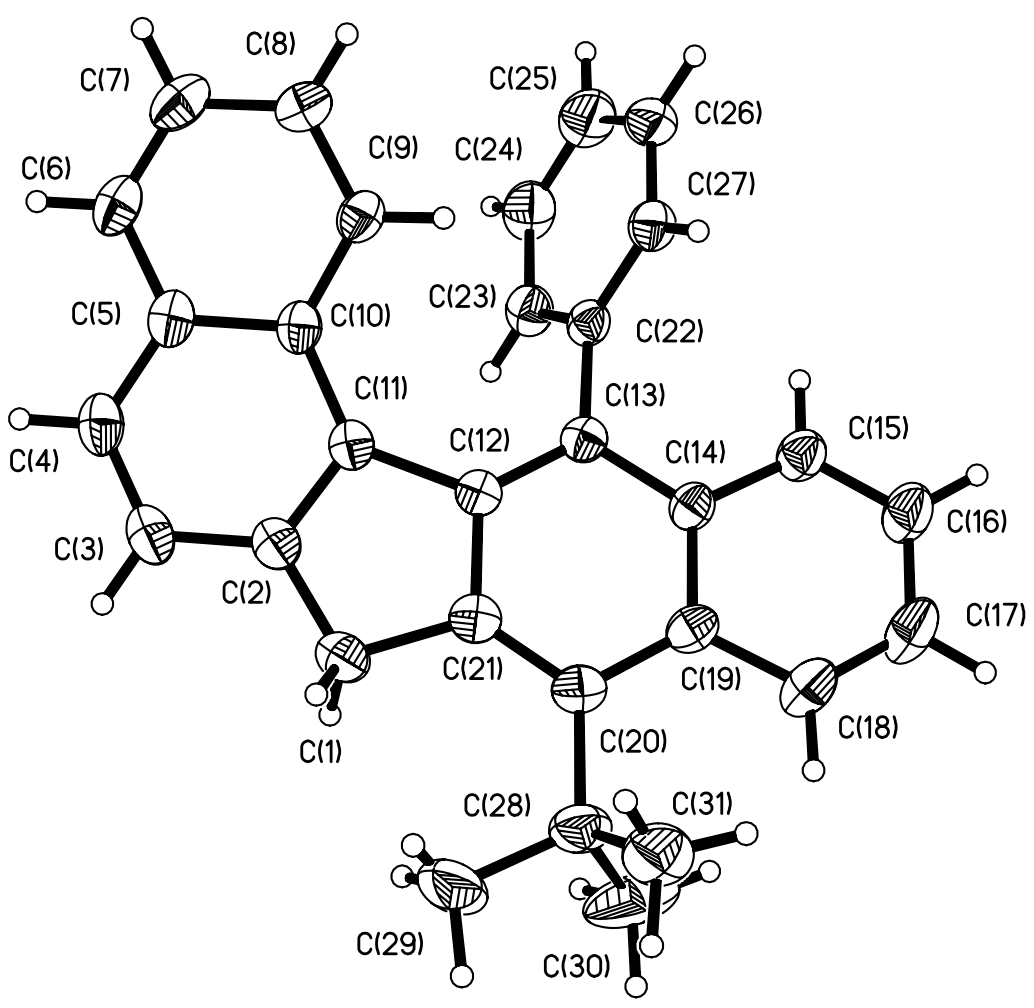

Figure 9. ORTEP drawing of the crystal structure of II-28 

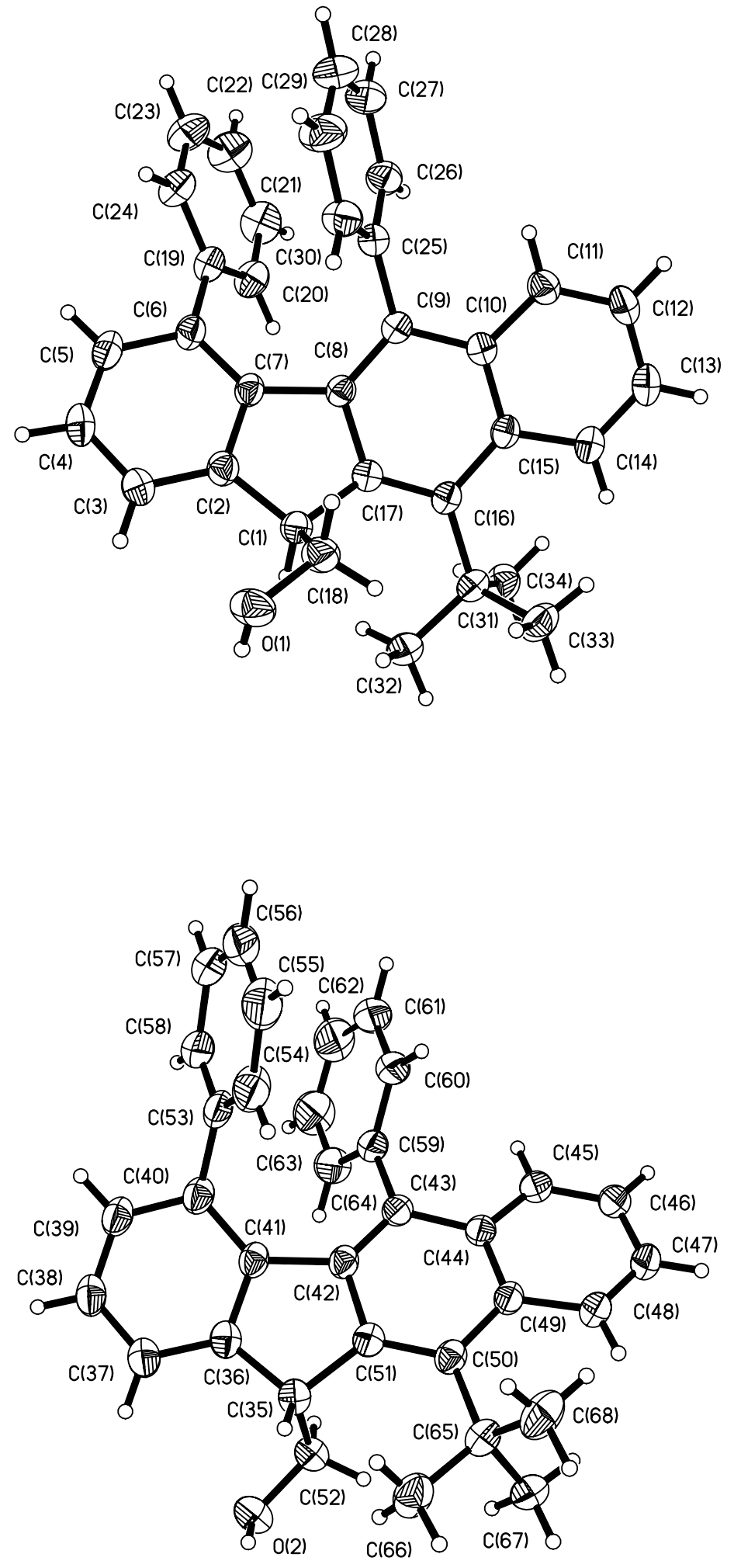

Figure 10. ORTEP drawing of the crystal structures of two independent molecules of II-44 


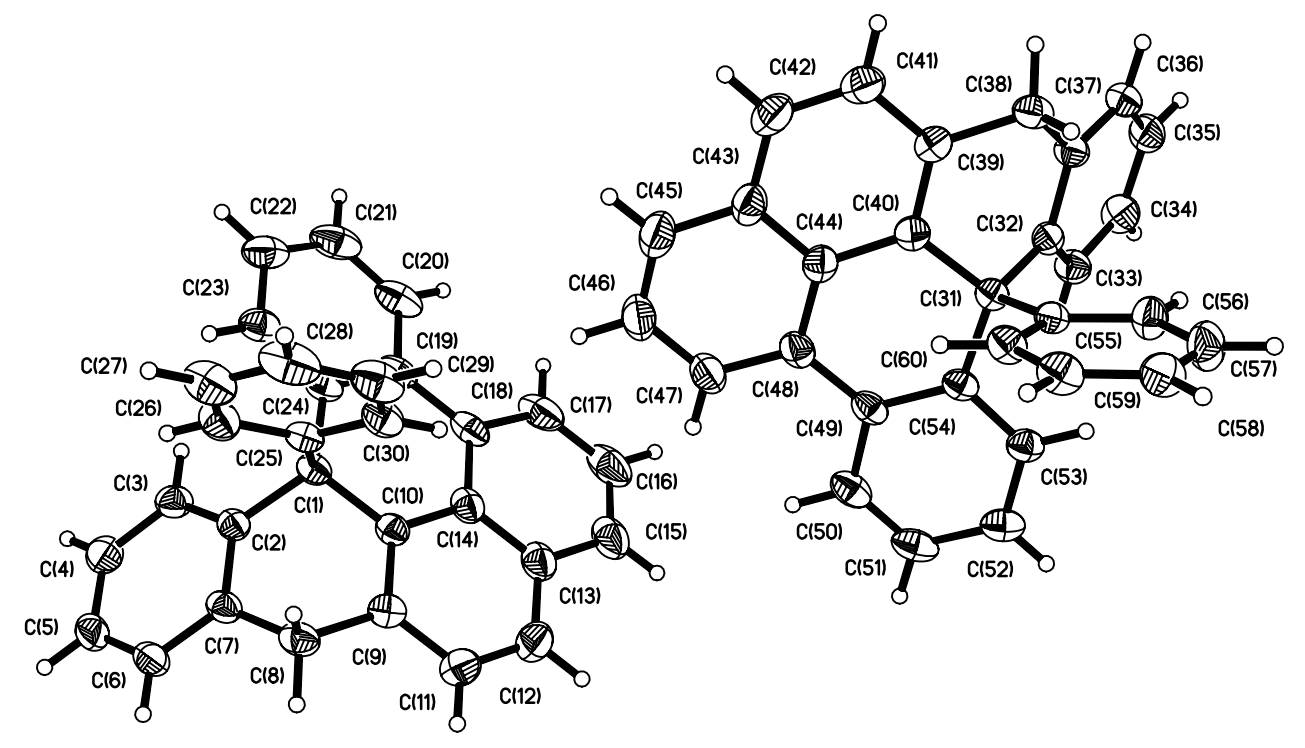

Figure 11. ORTEP drawing of the crystal structures of two independent molecules of II-46

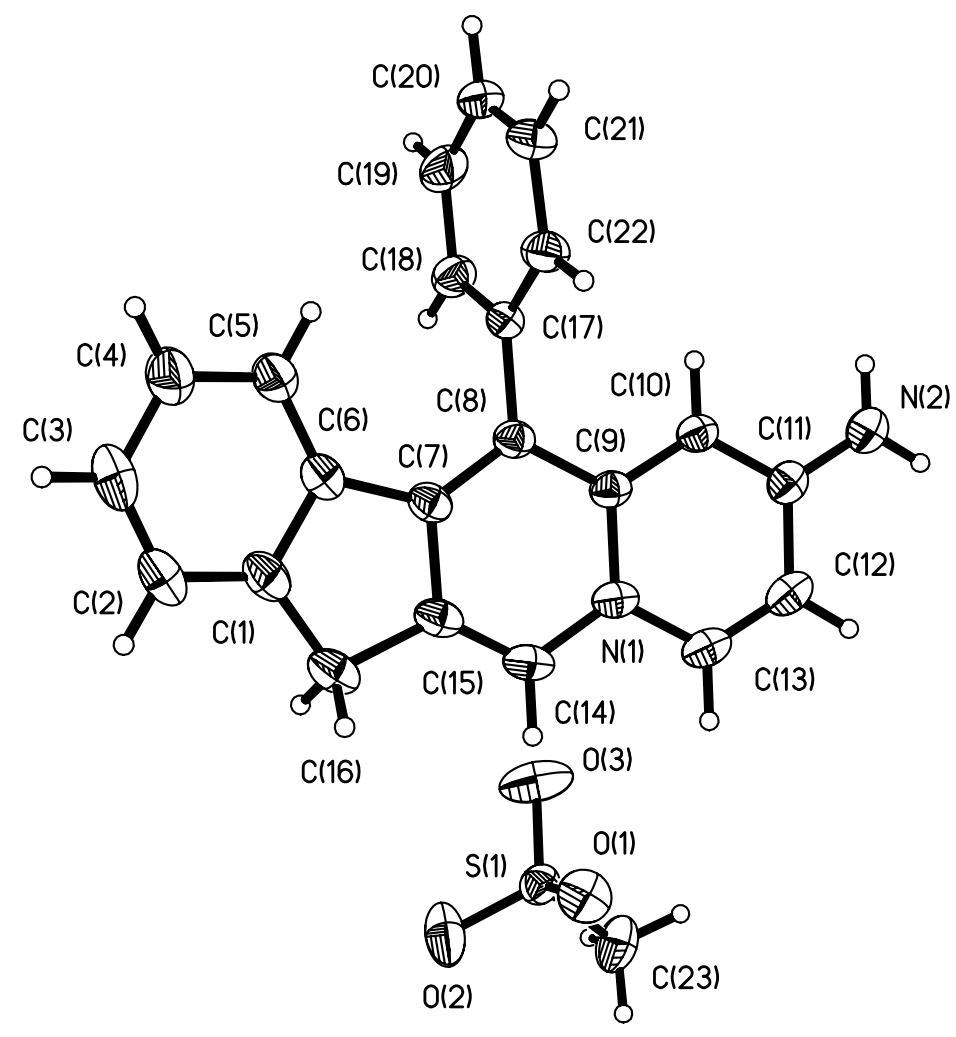

Figure 12. ORTEP drawing of the crystal structure of III-67a 


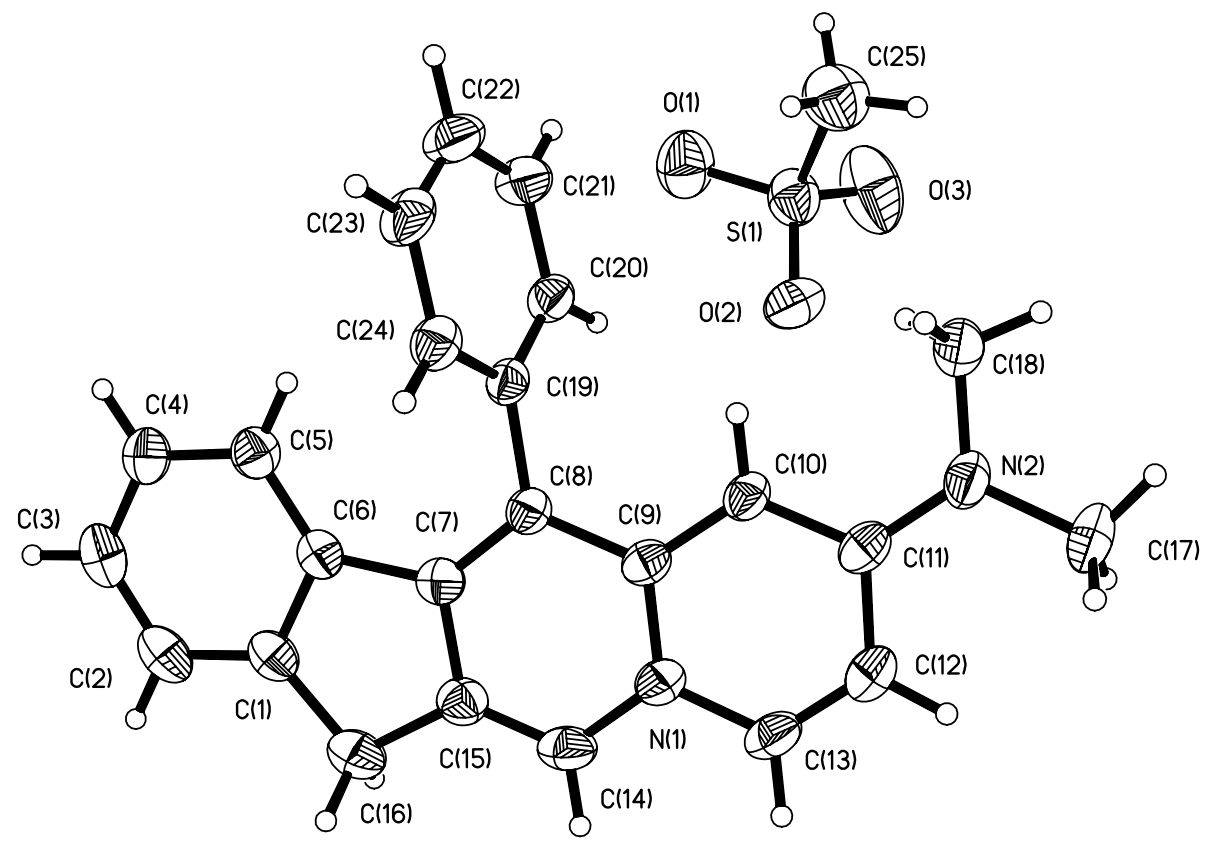

Figure 13. ORTEP drawing of the crystal structure of III-67b

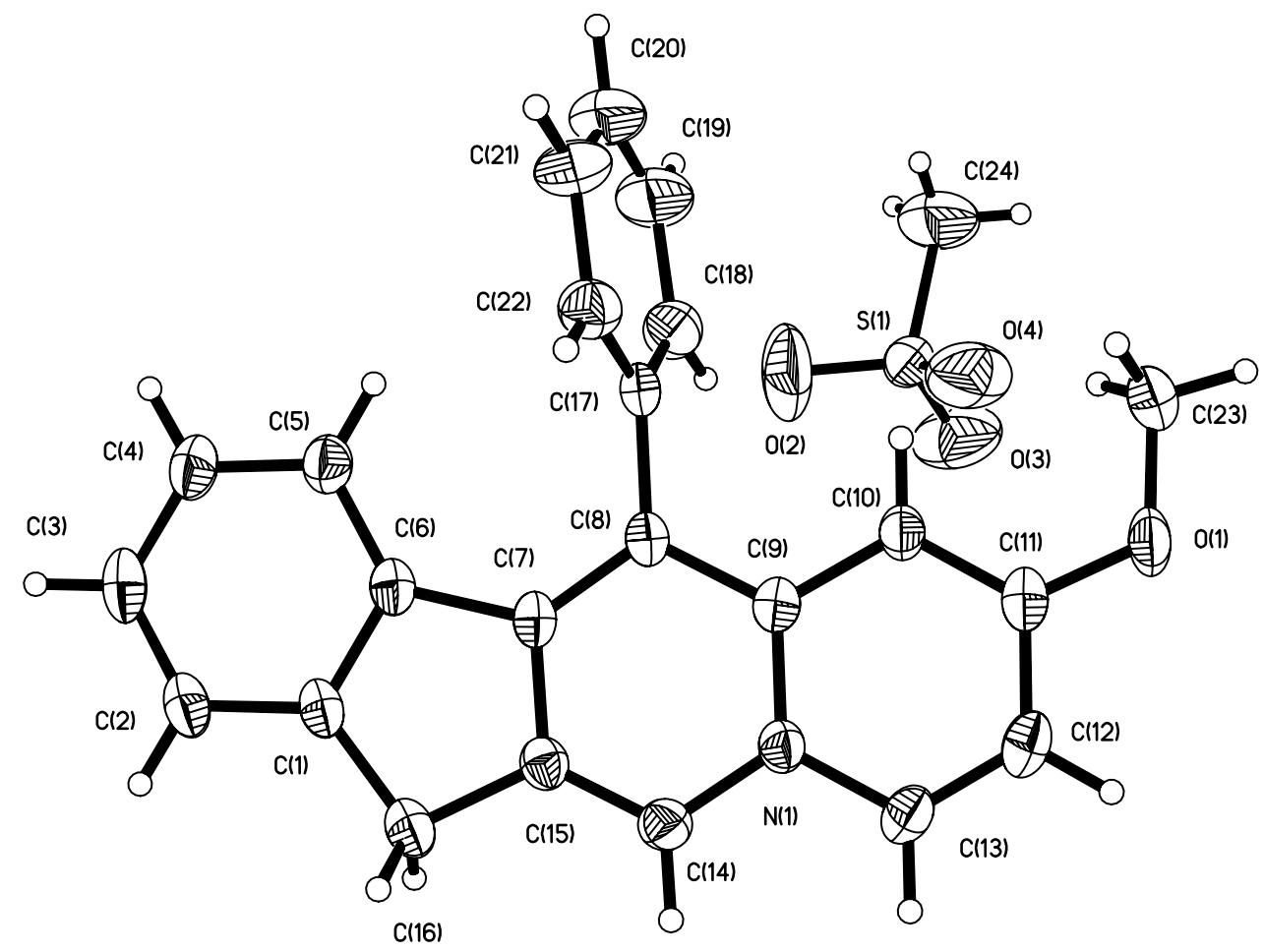

Figure 14. ORTEP drawing of the crystal structure of III-67c 


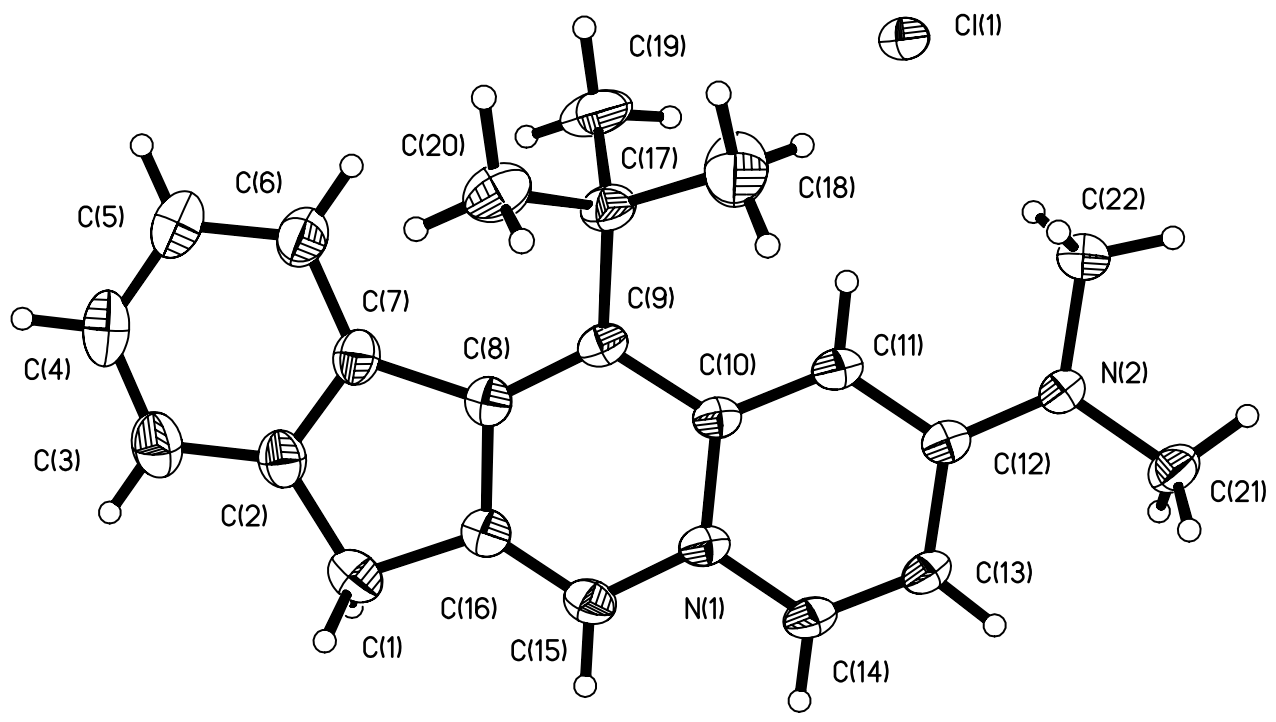

Figure 15. ORTEP drawing of the crystal structure of III-73a

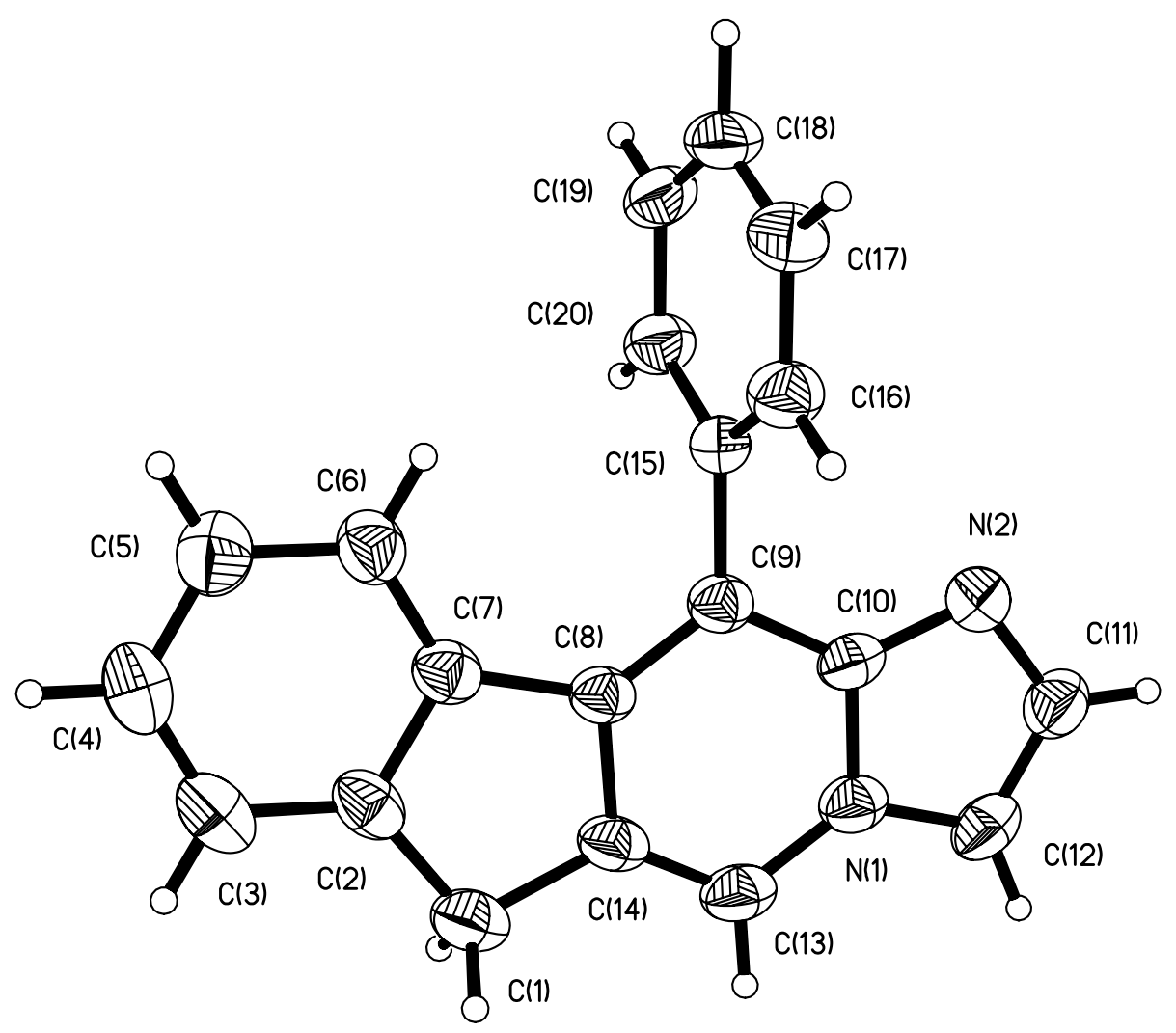

Figure 16. ORTEP drawing of the crystal structure of III-76 


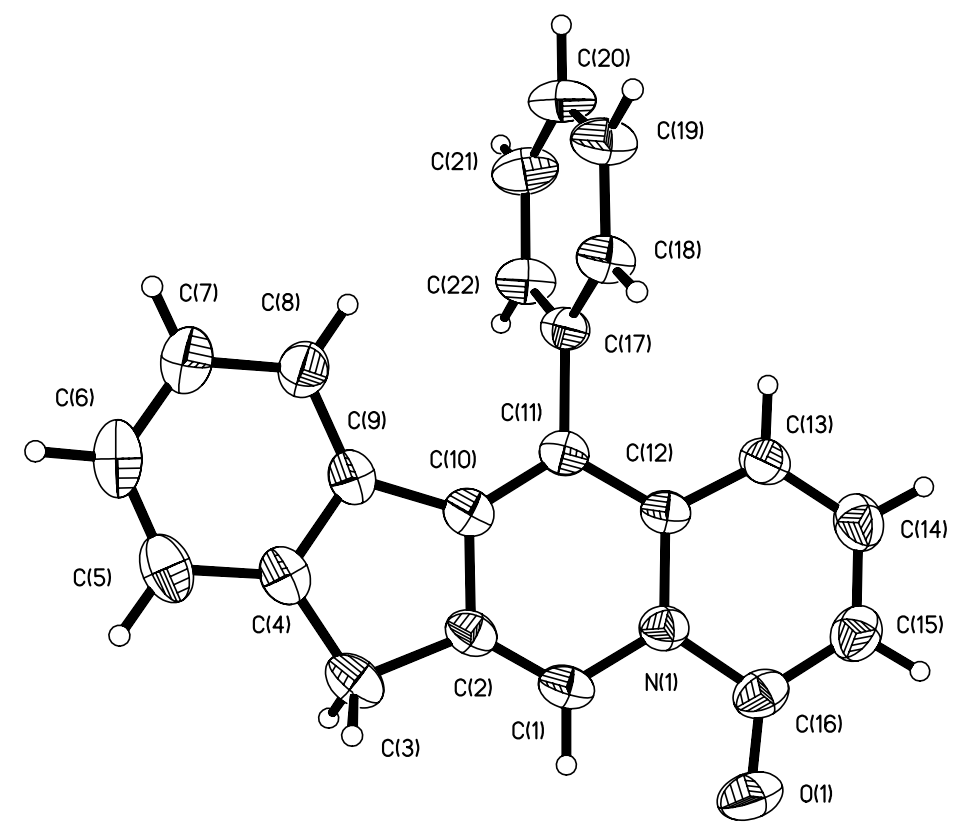

Figure 17. ORTEP drawing of the crystal structure of III-87

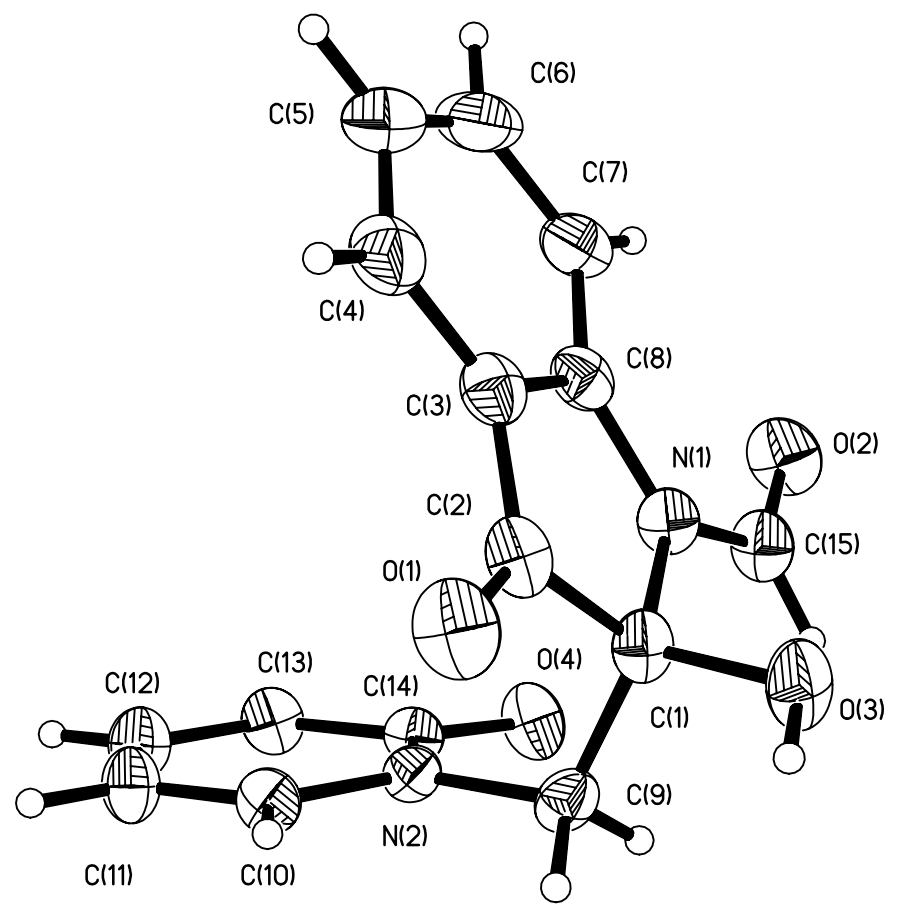

Figure 18. ORTEP drawing of the crystal structure of III-98 


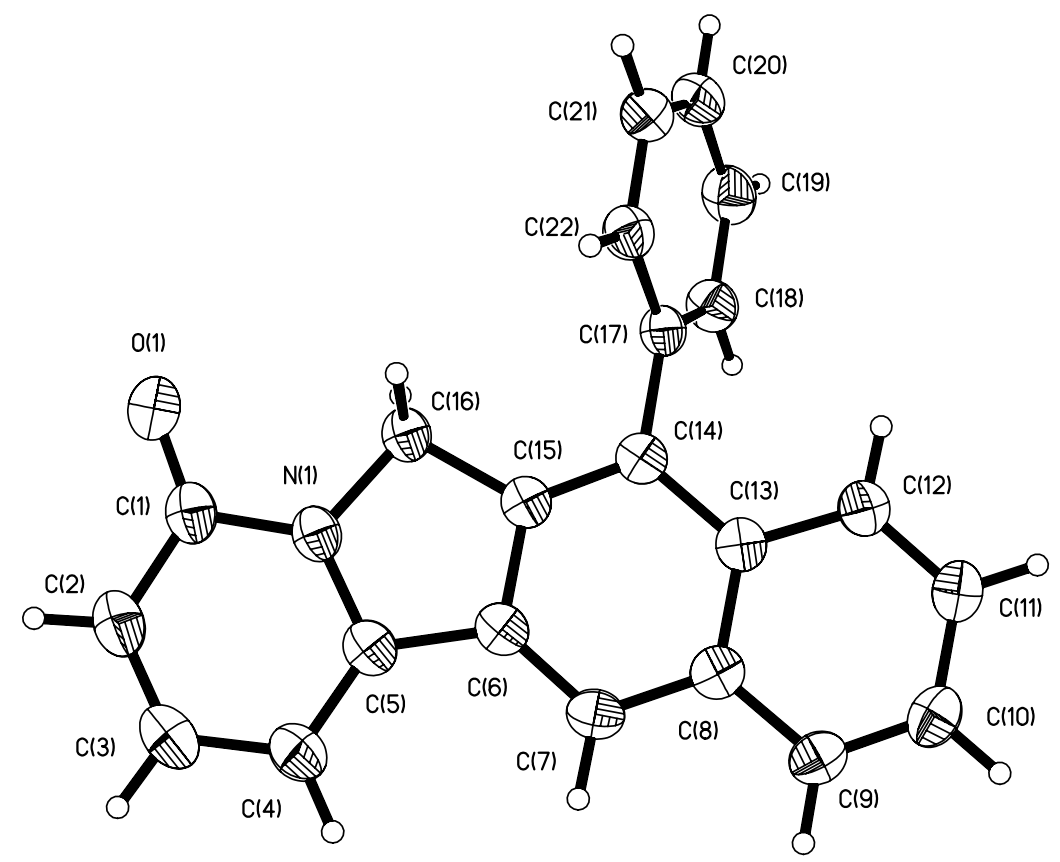

Figure 19. ORTEP drawing of the crystal structure of III-106

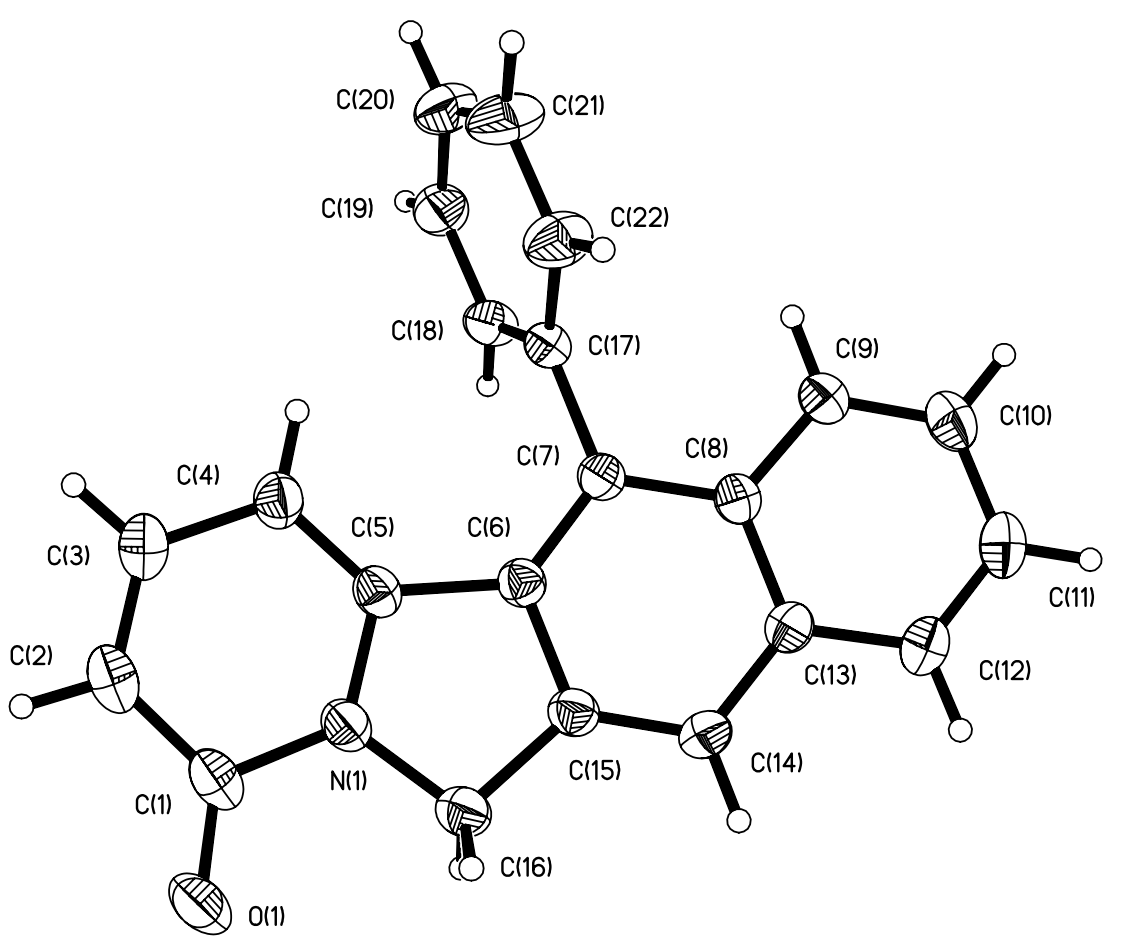

Figure 20. ORTEP drawing of the crystal structure of III-107 


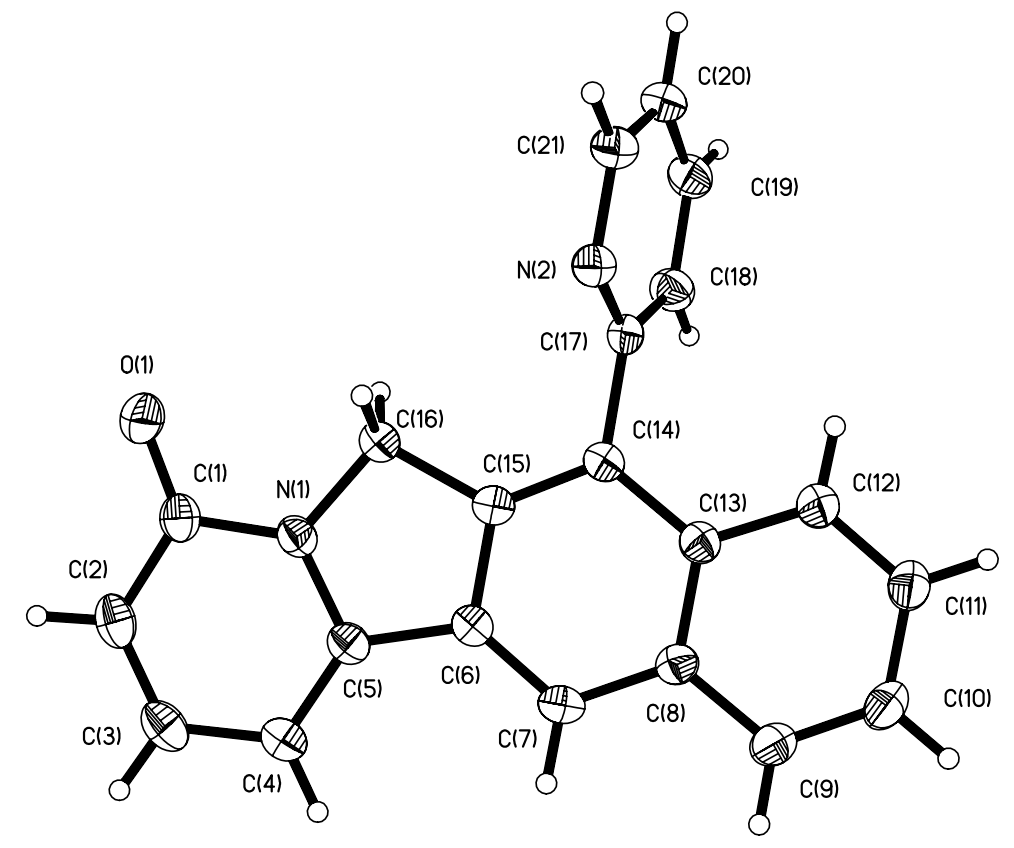

Figure 21. ORTEP drawing of the crystal structure of III-109

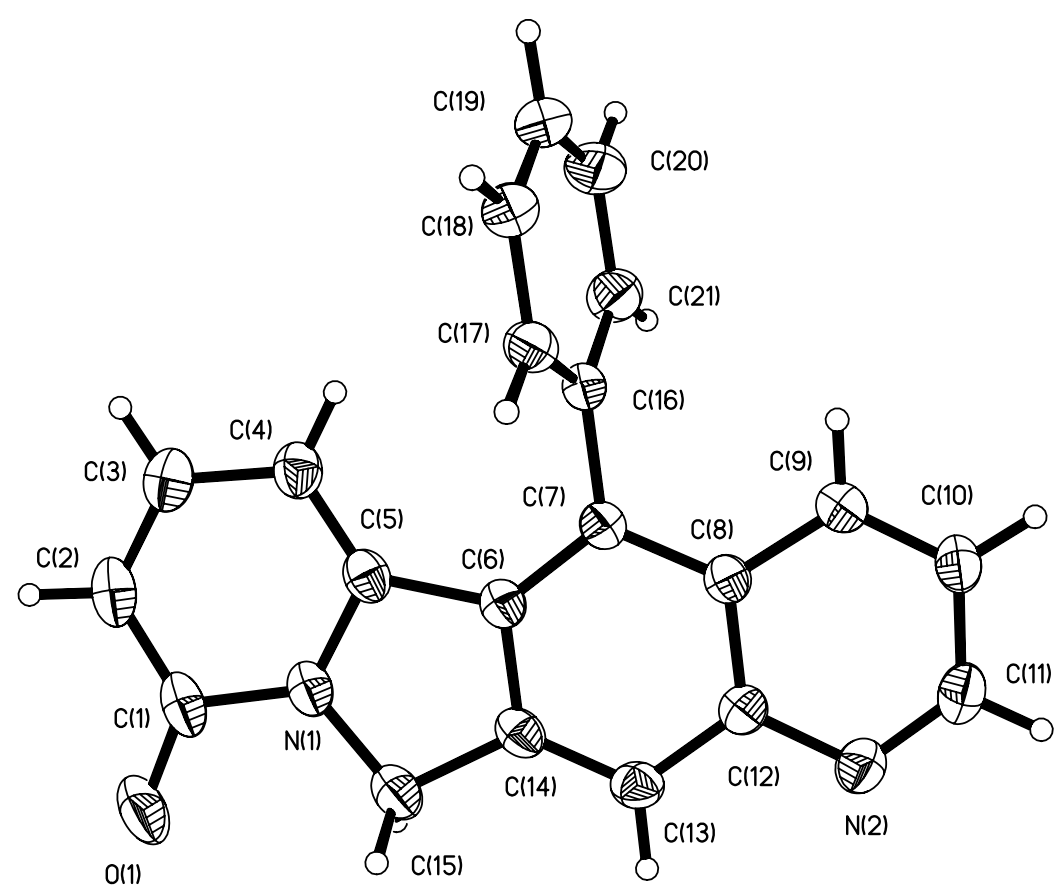

Figure 22. ORTEP drawing of the crystal structure of III-110 


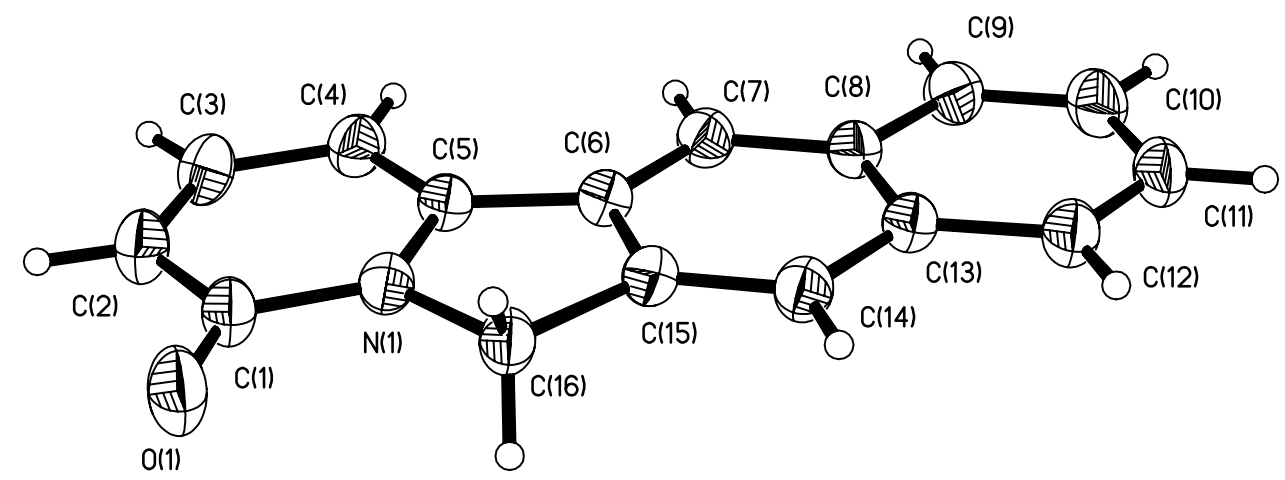

Figure 23. ORTEP drawing of the crystal structure of III-112

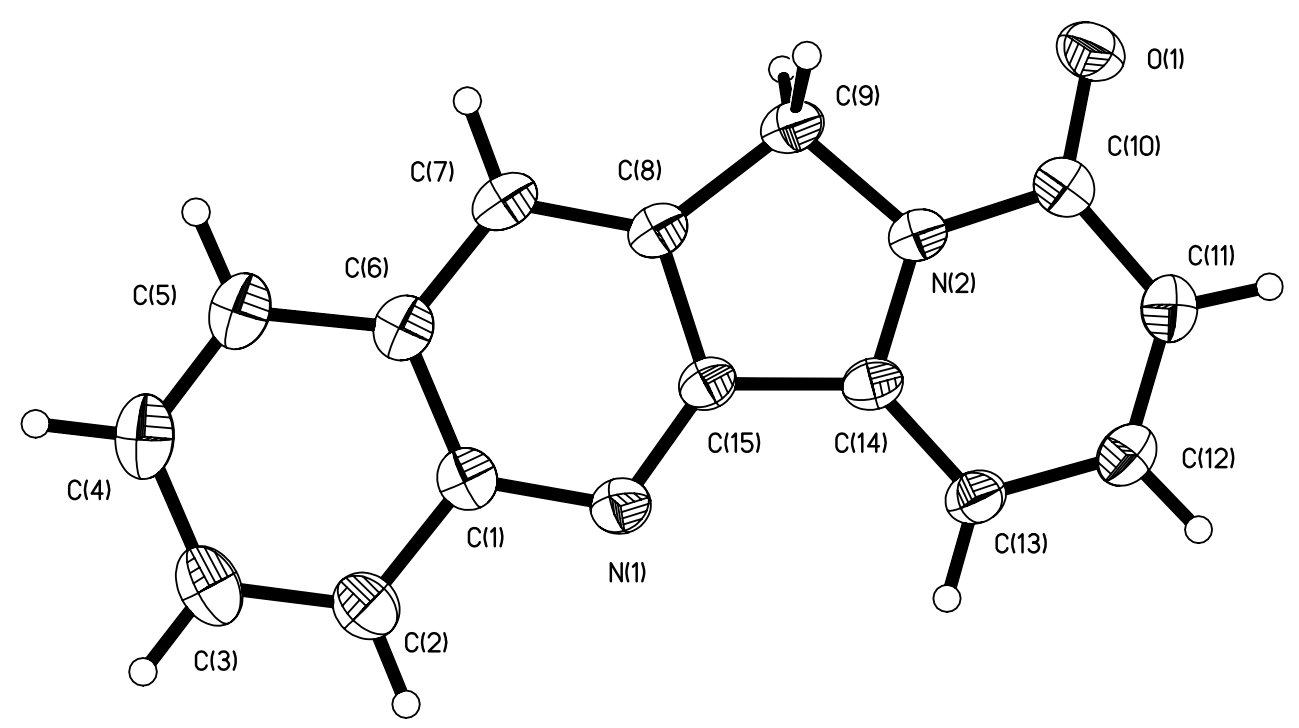

Figure 24. ORTEP drawing of the crystal structure of III-40 


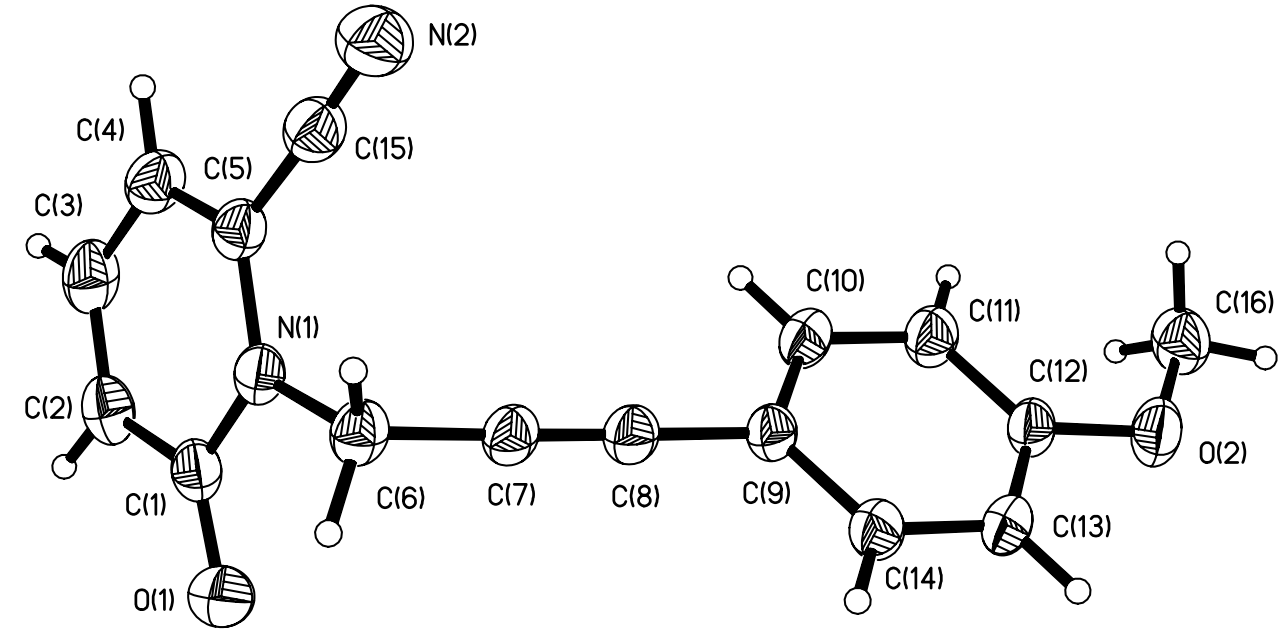

Figure 25. ORTEP drawing of the crystal structure of III-129

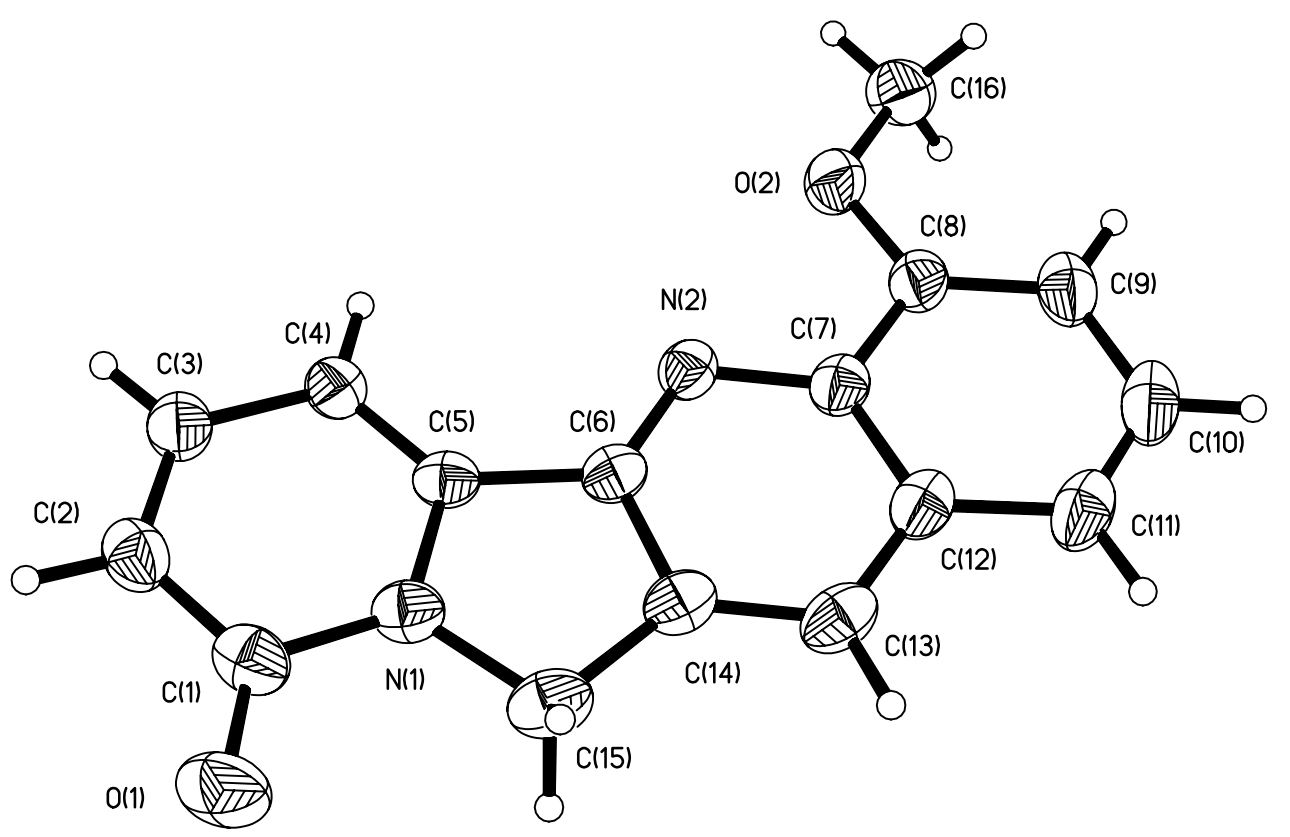

Figure 26. ORTEP drawing of the crystal structure of III-136 


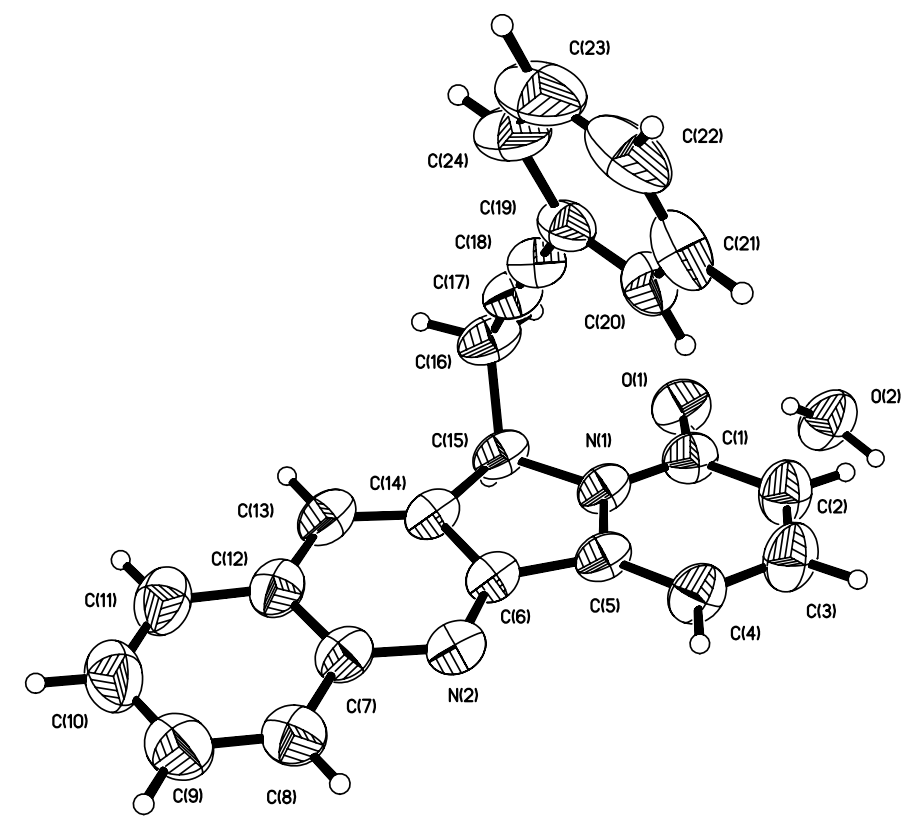

Figure 27. ORTEP drawing of the crystal structure of a substituted ABCD ring core

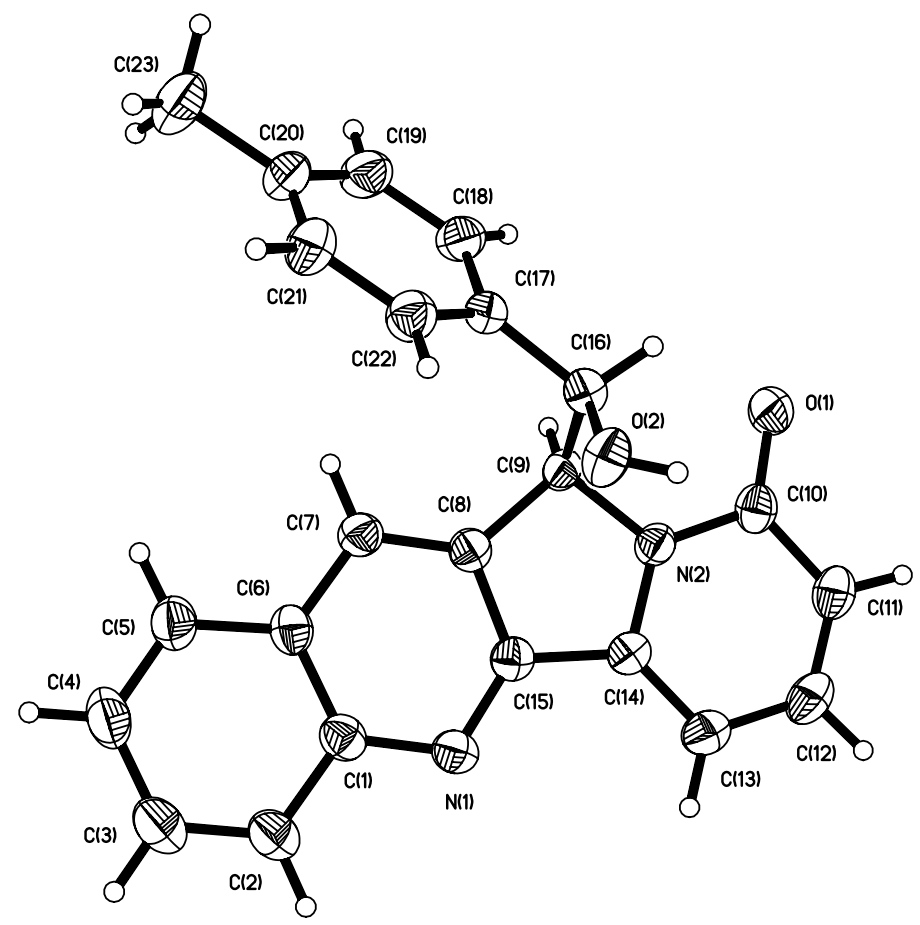

Figure 28. ORTEP drawing of the crystal structure of a substituted ABCD ring core 


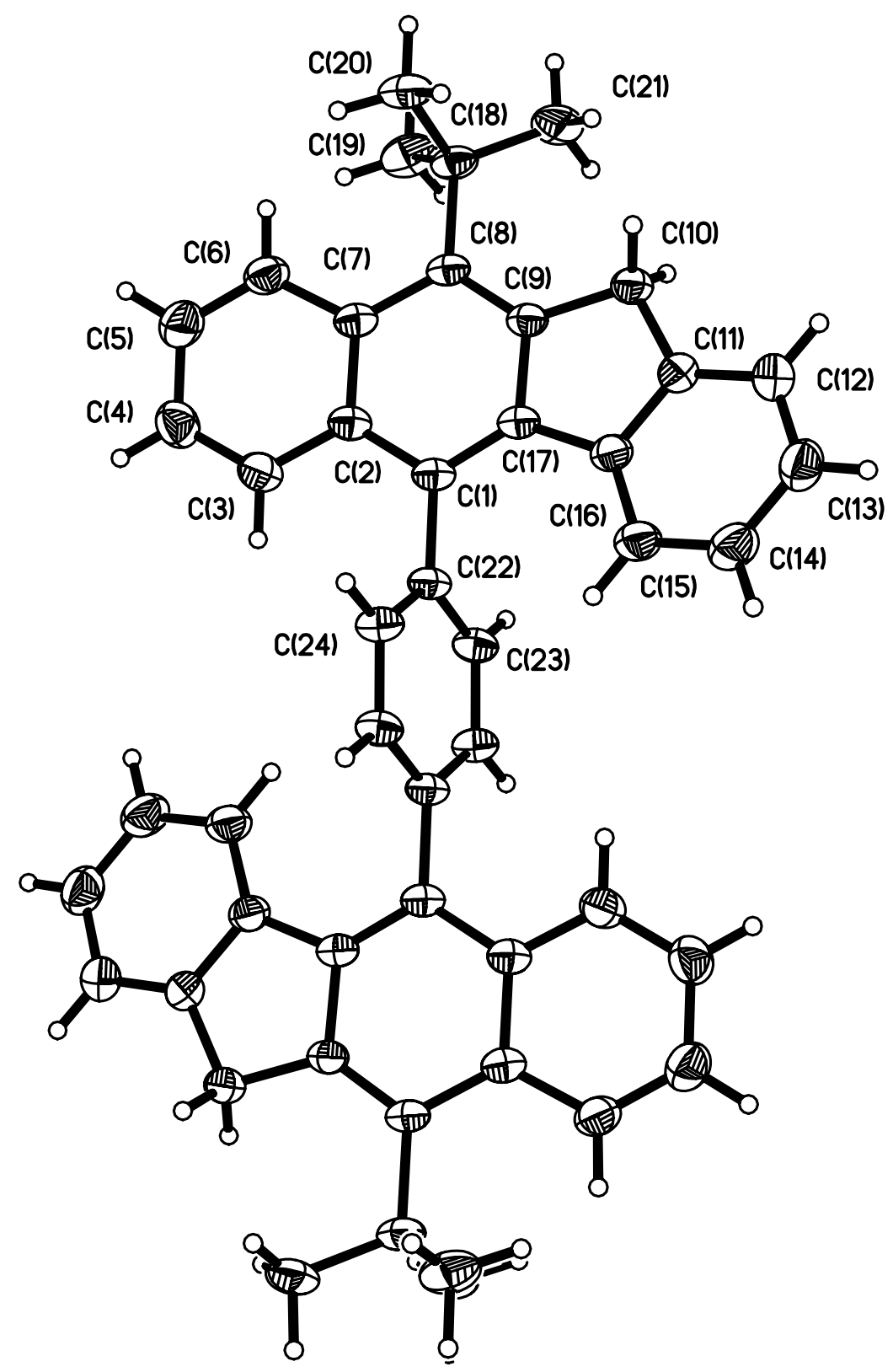

Figure 29. ORTEP drawing of the crystal structure of a polycyclic hydrocarbon 


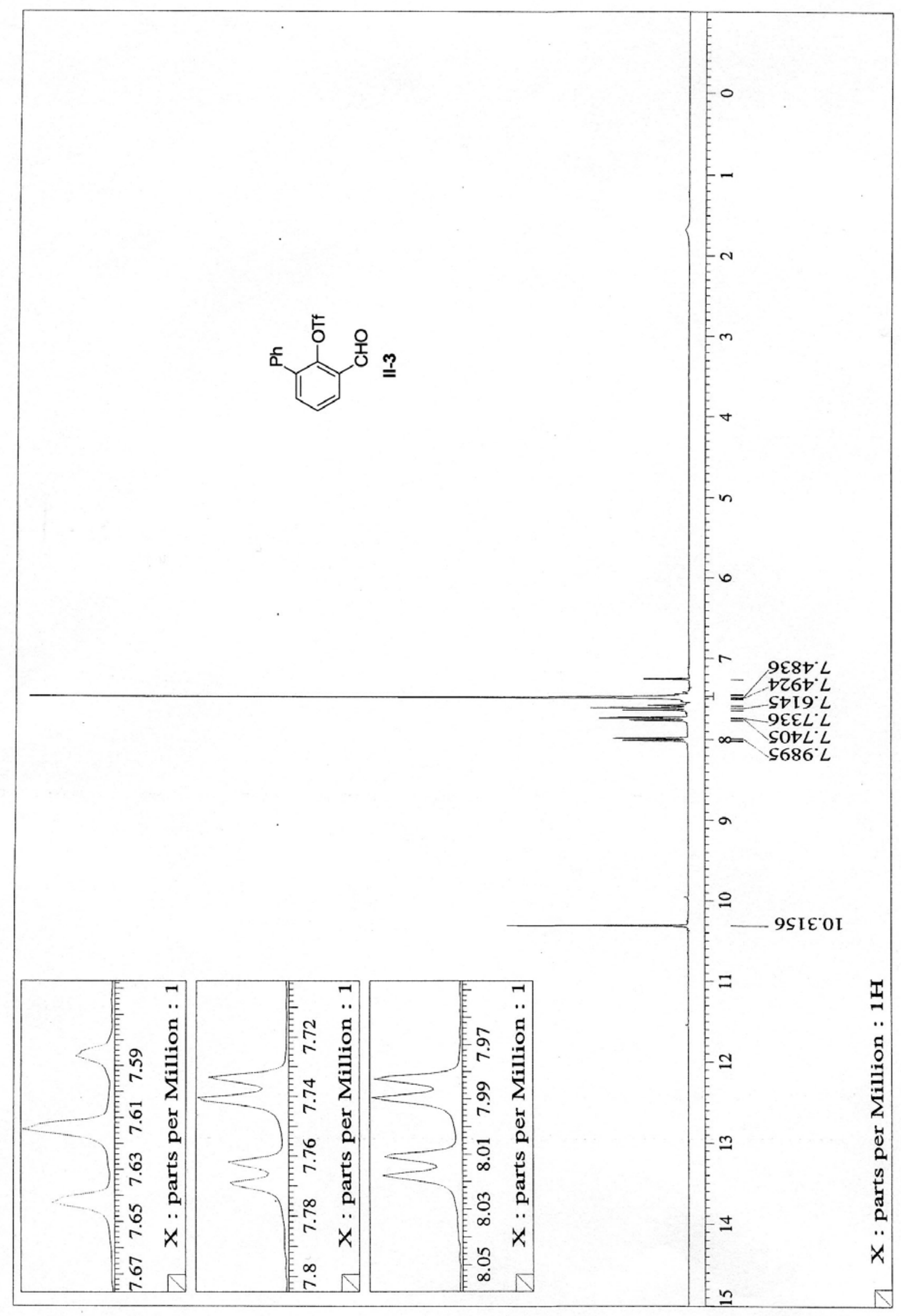




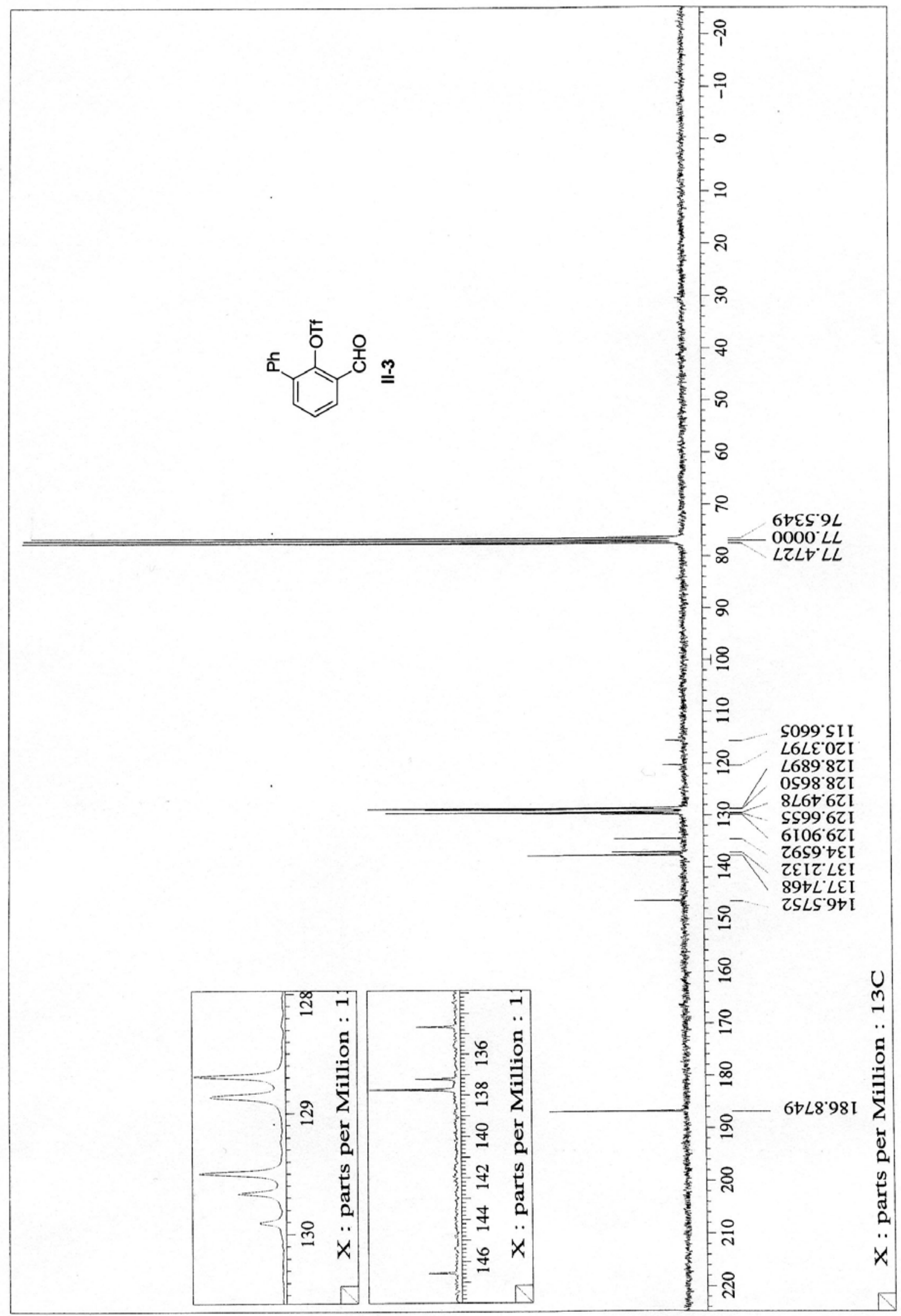




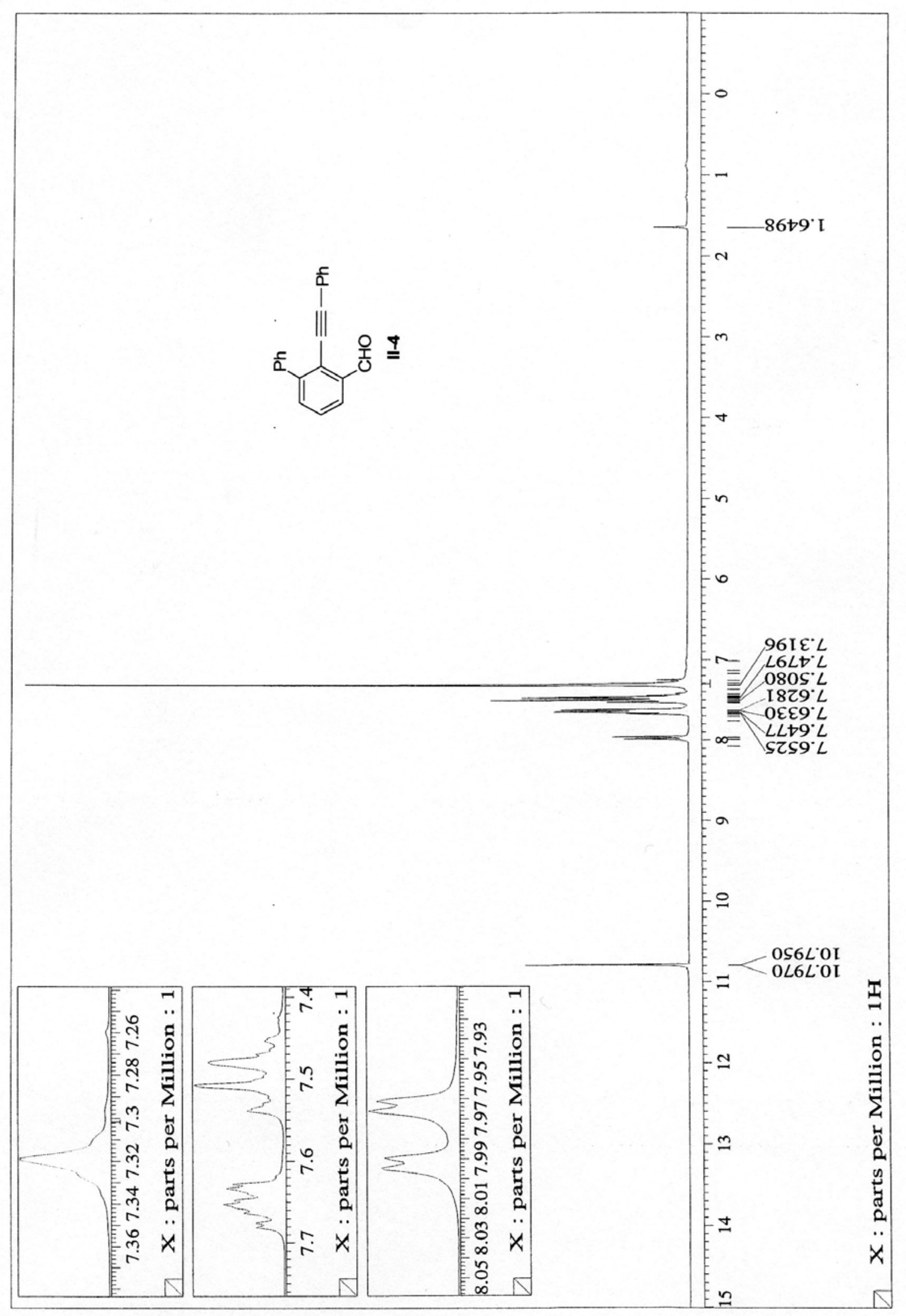




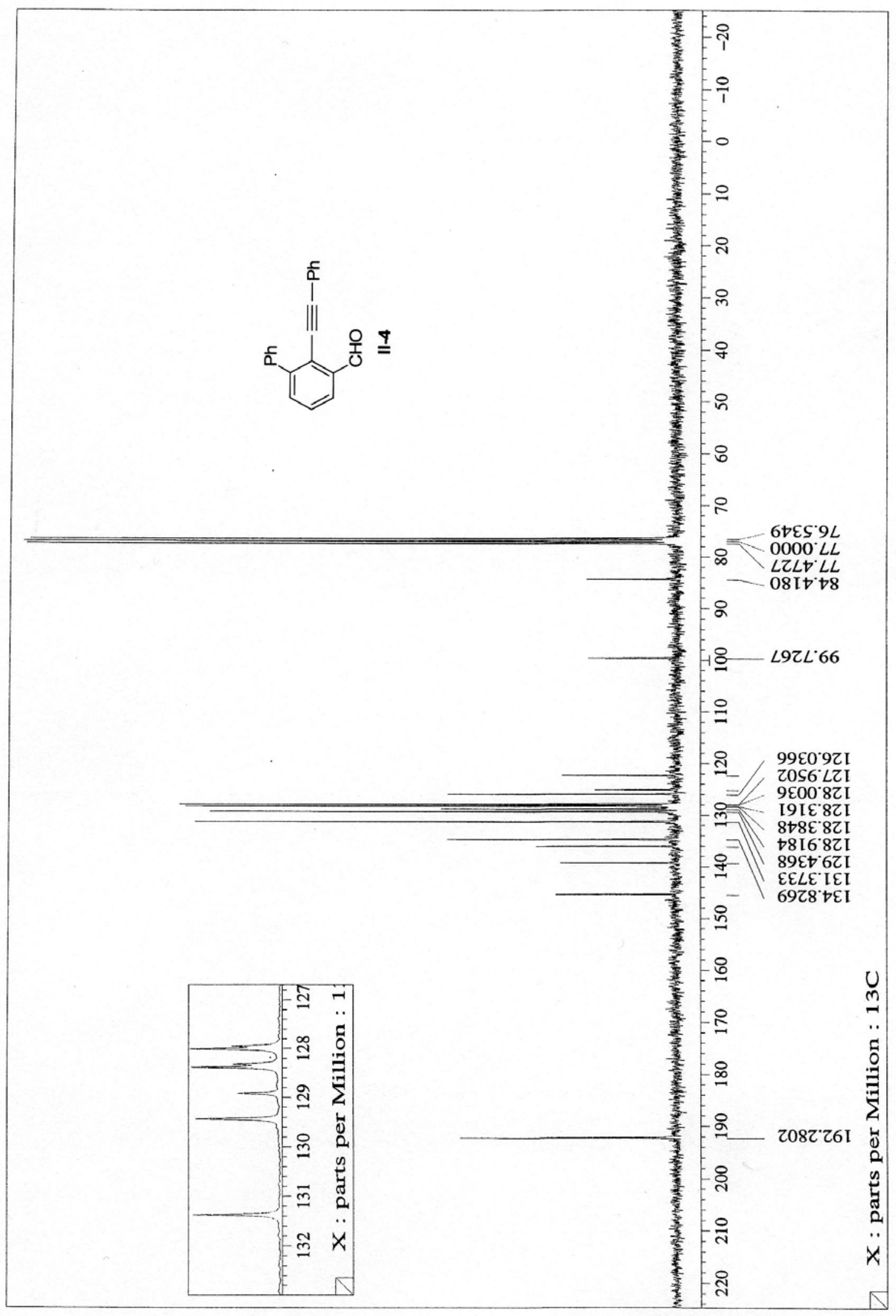




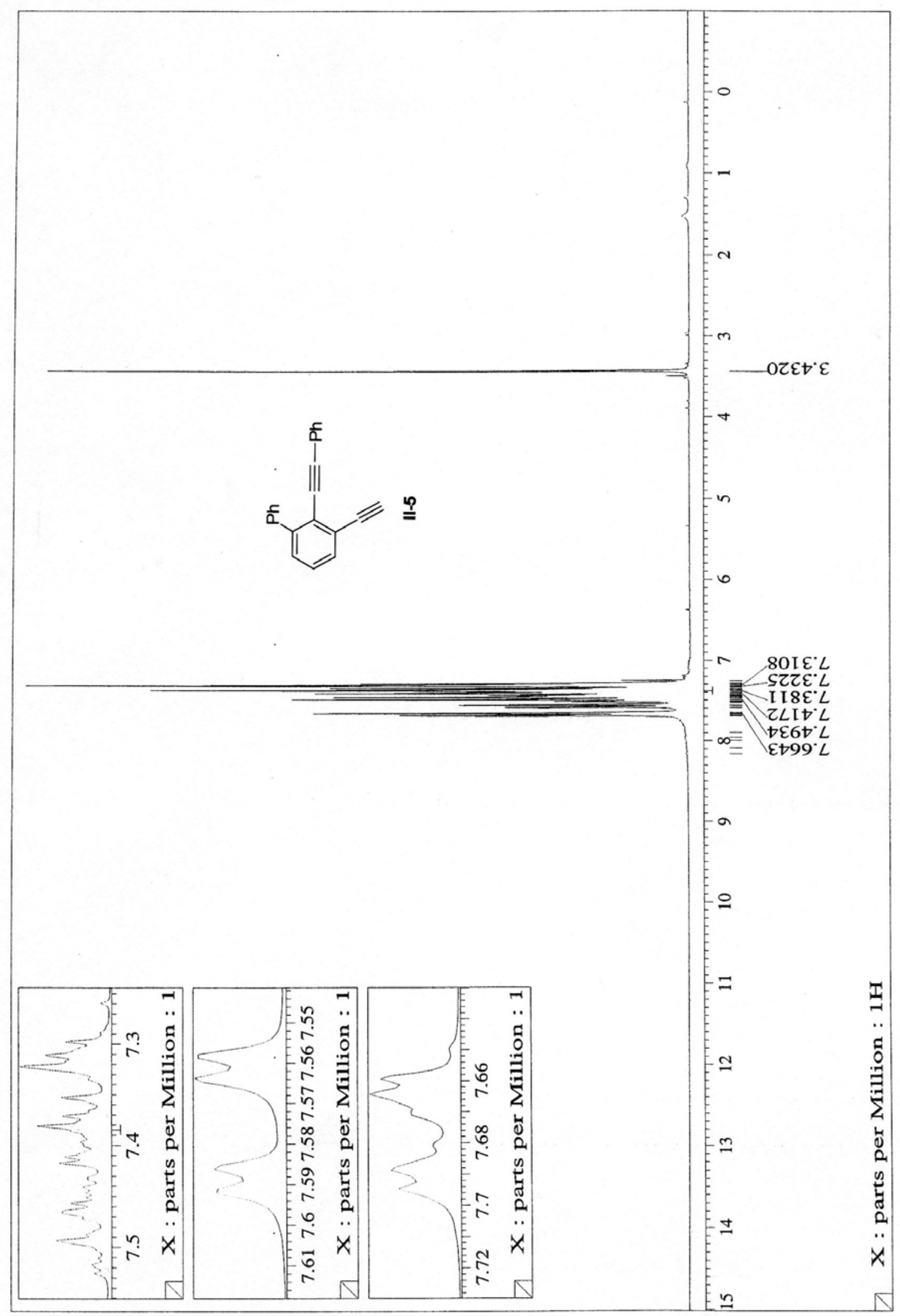




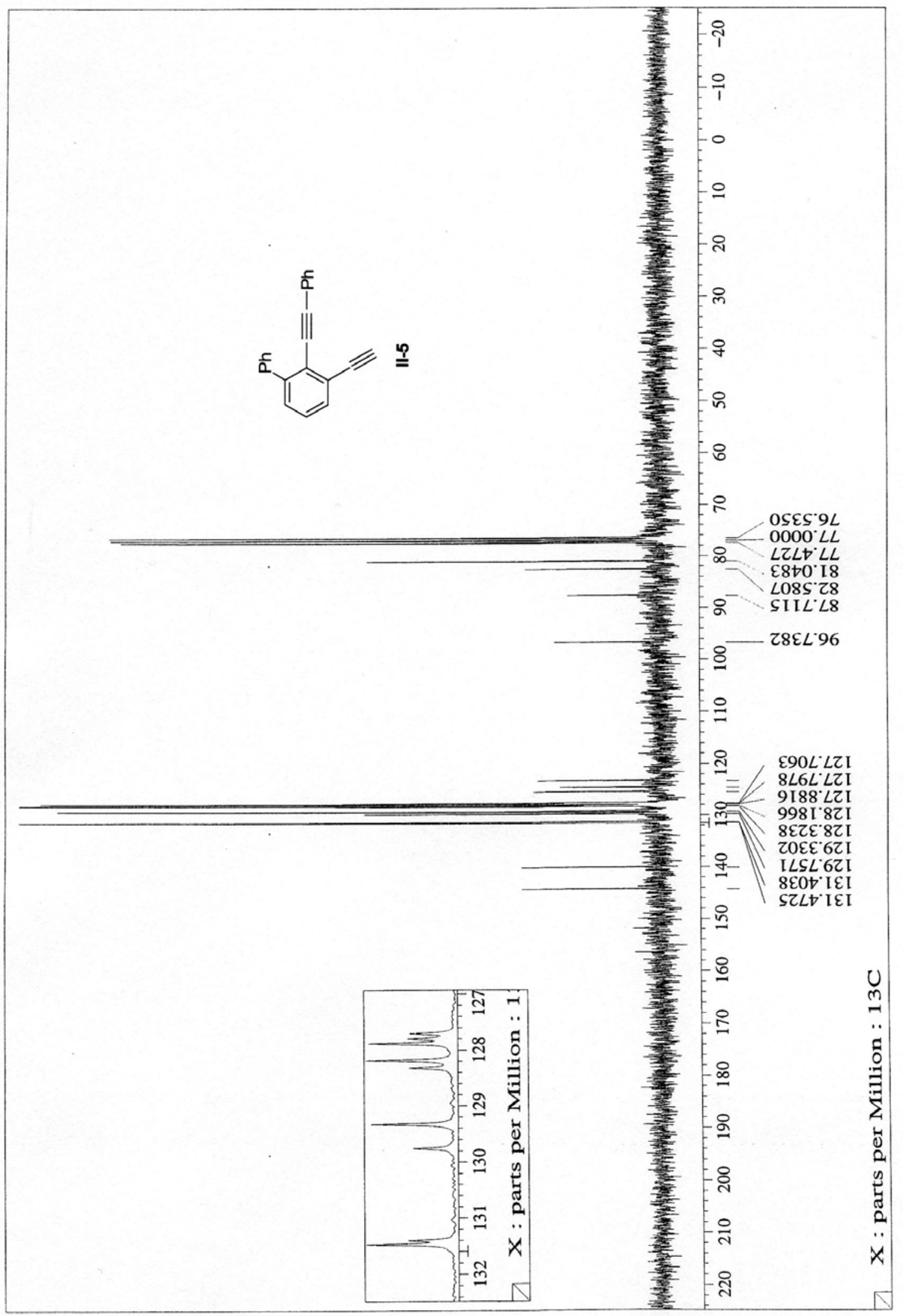




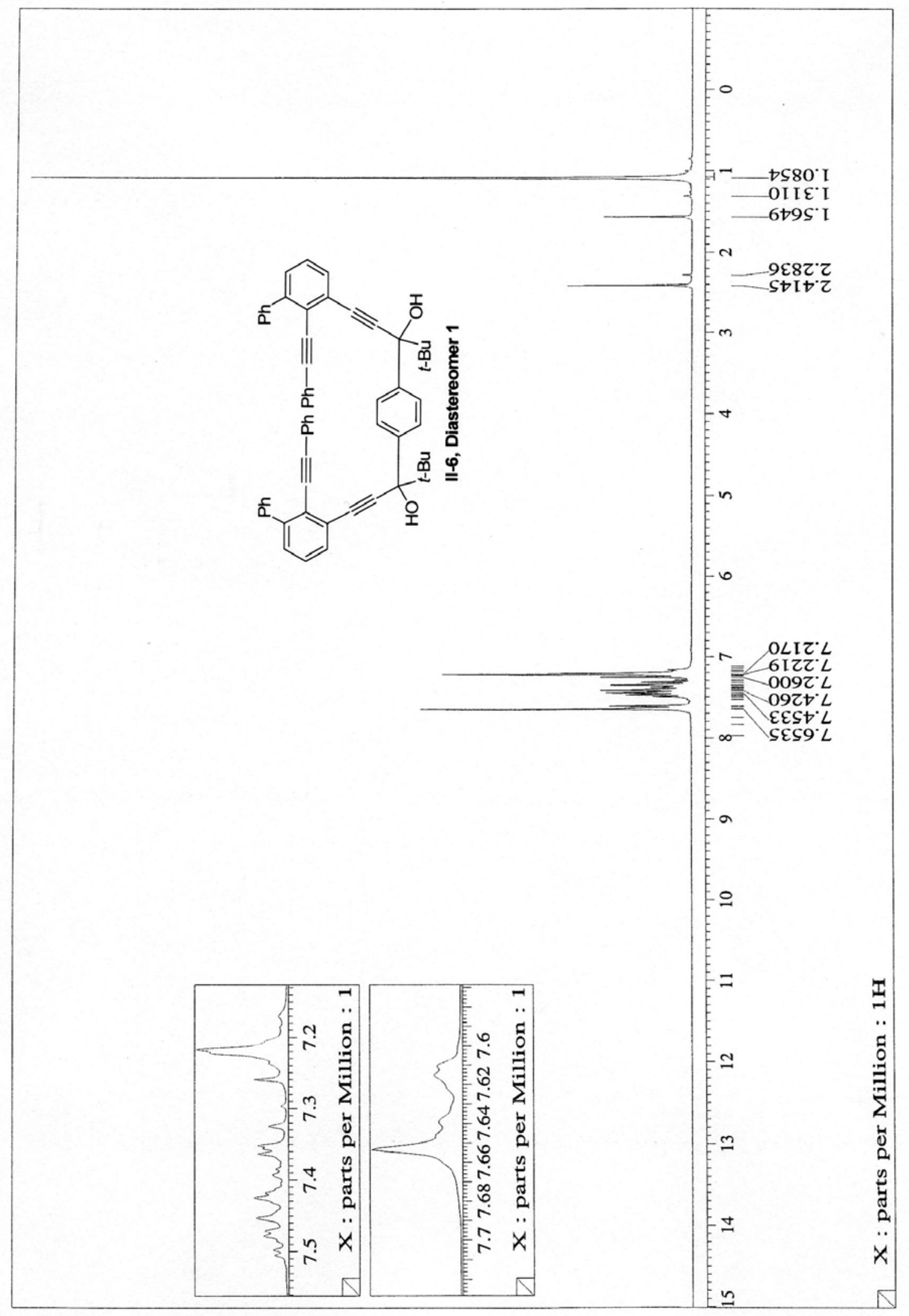




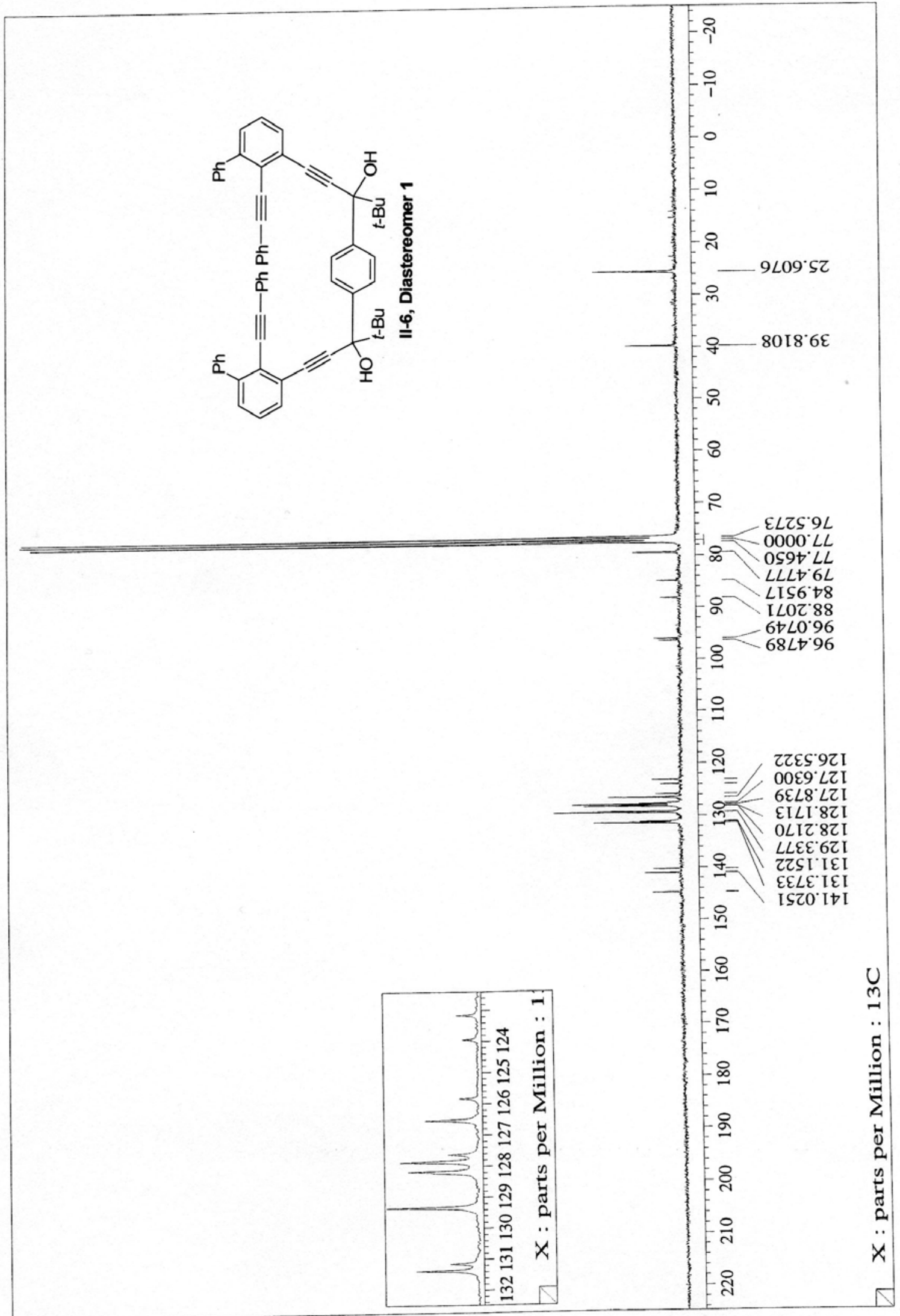




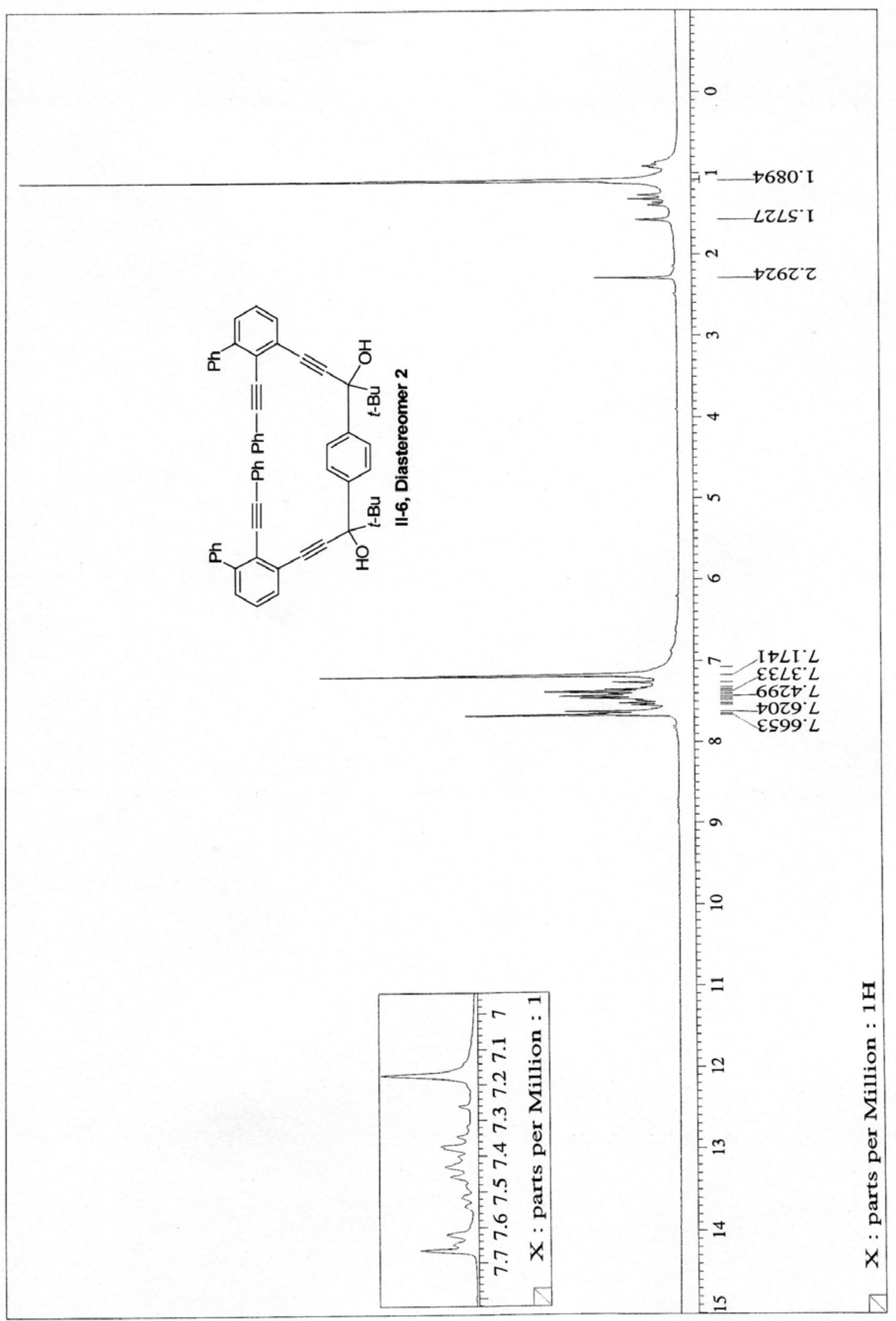




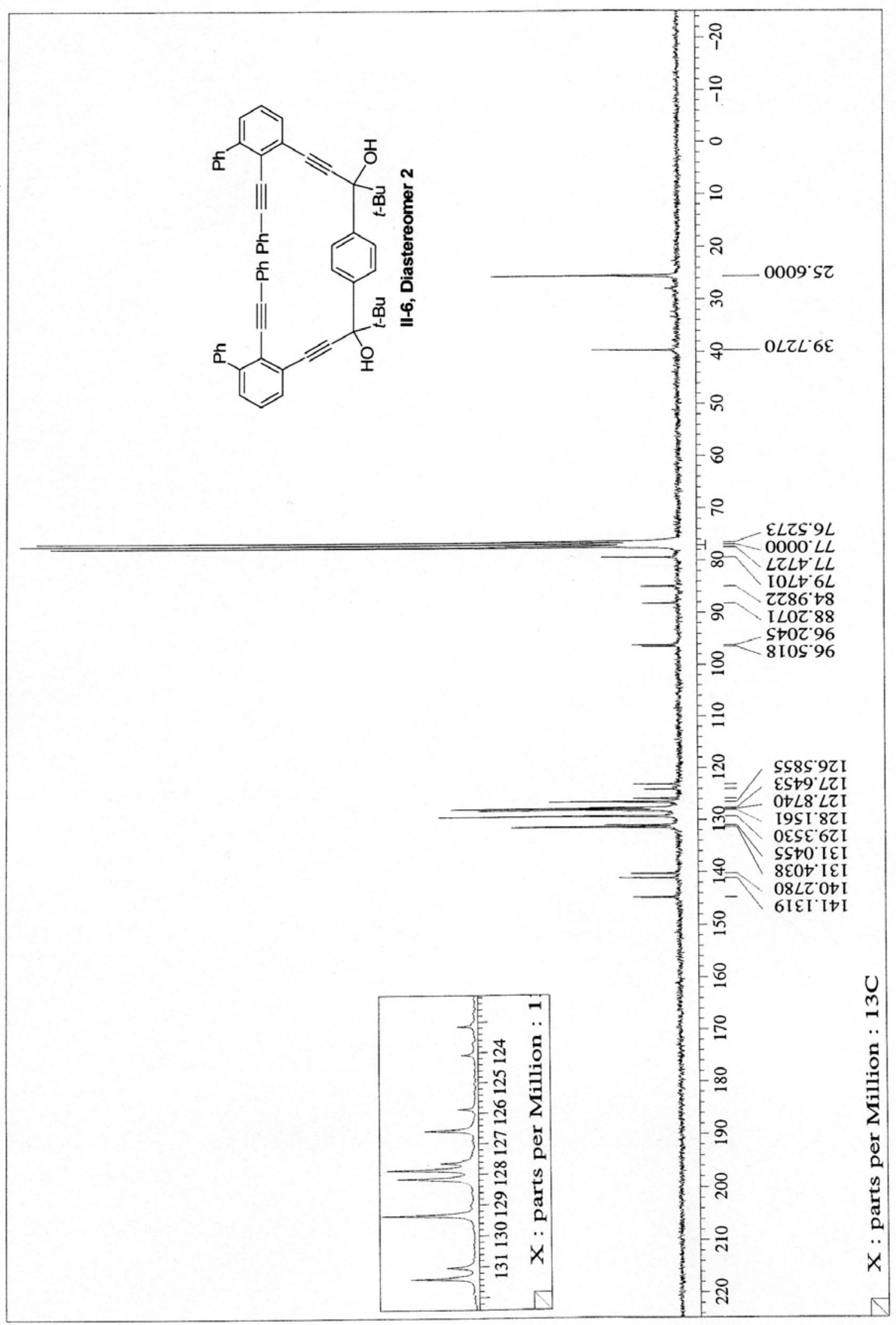




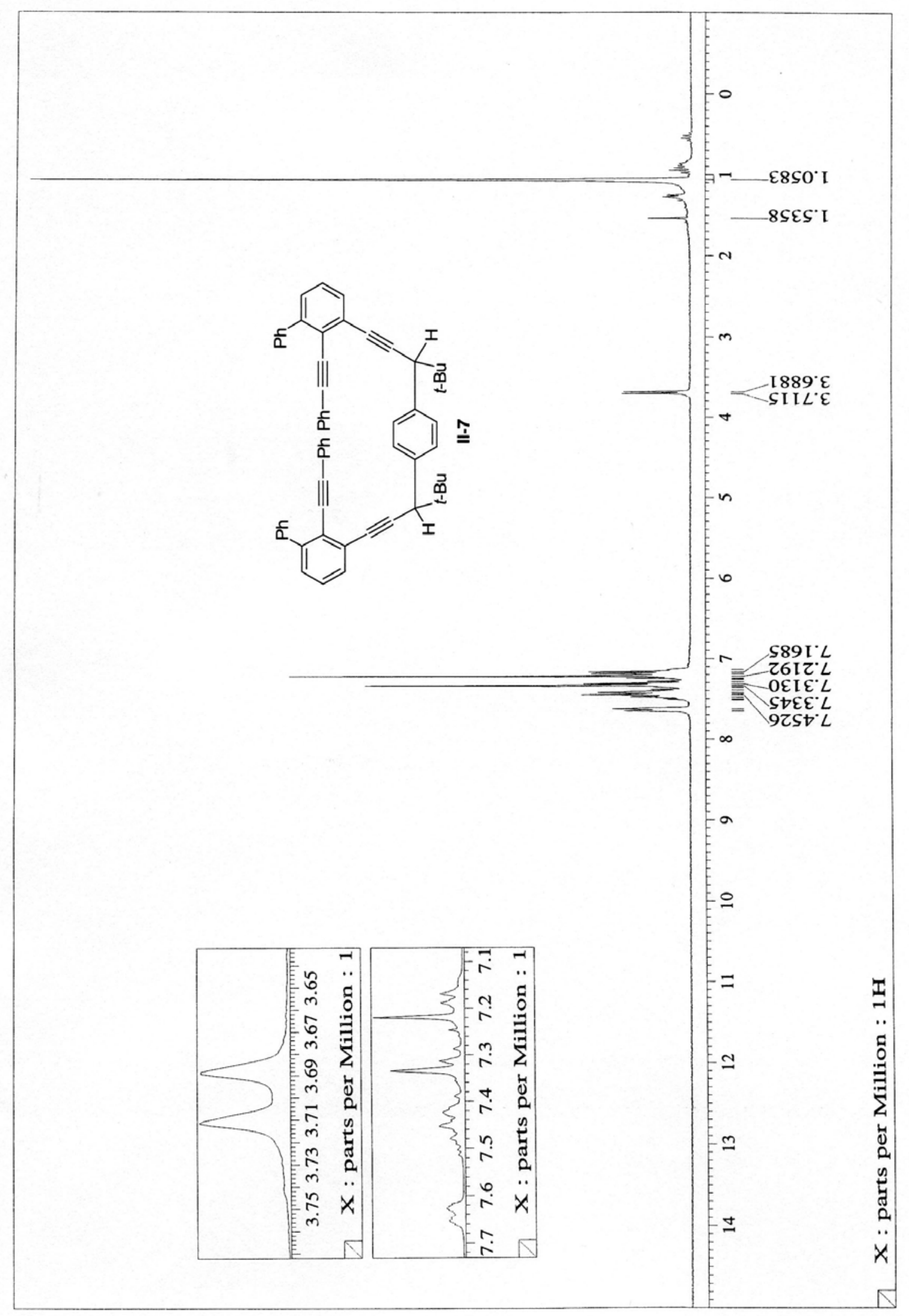




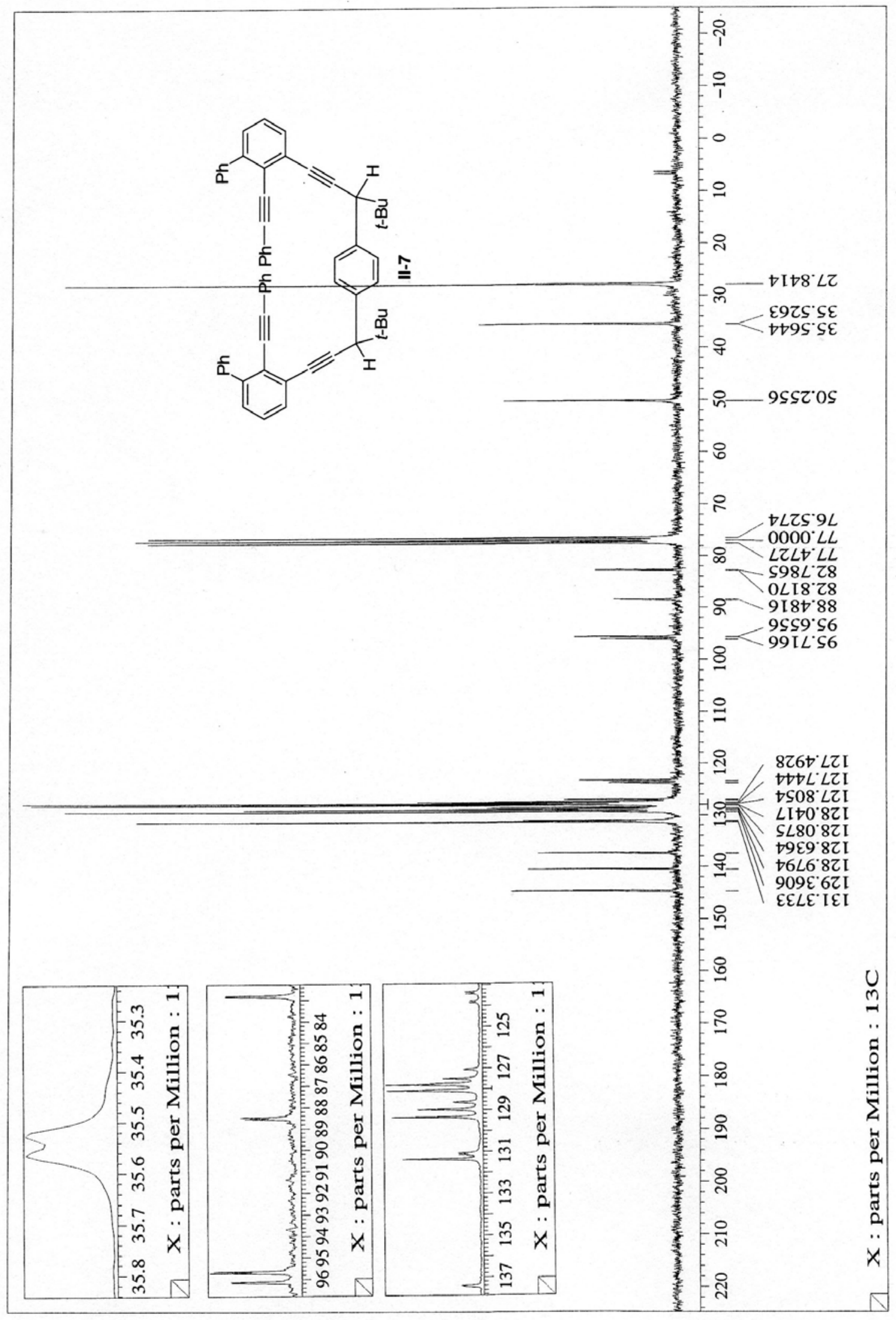



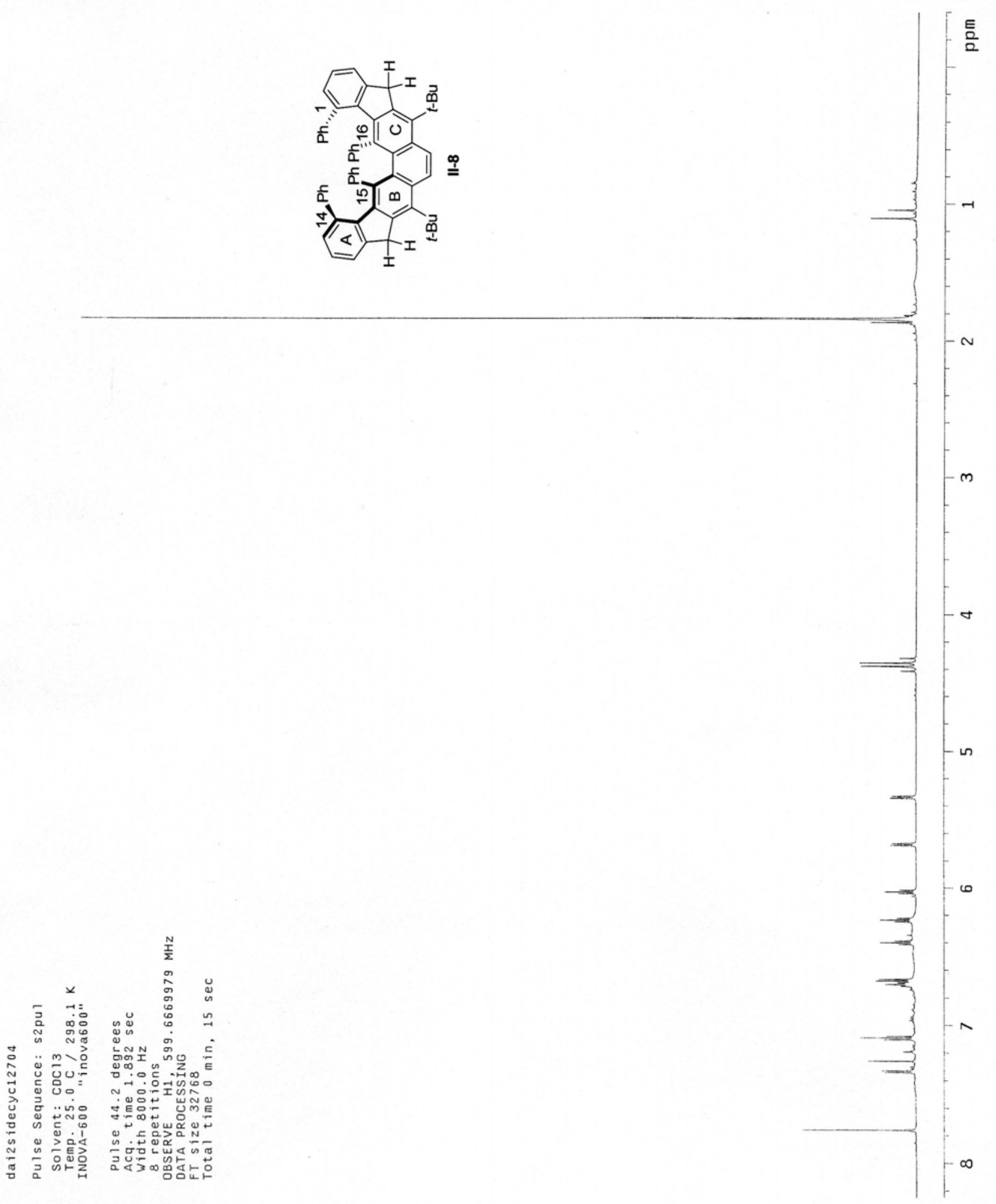

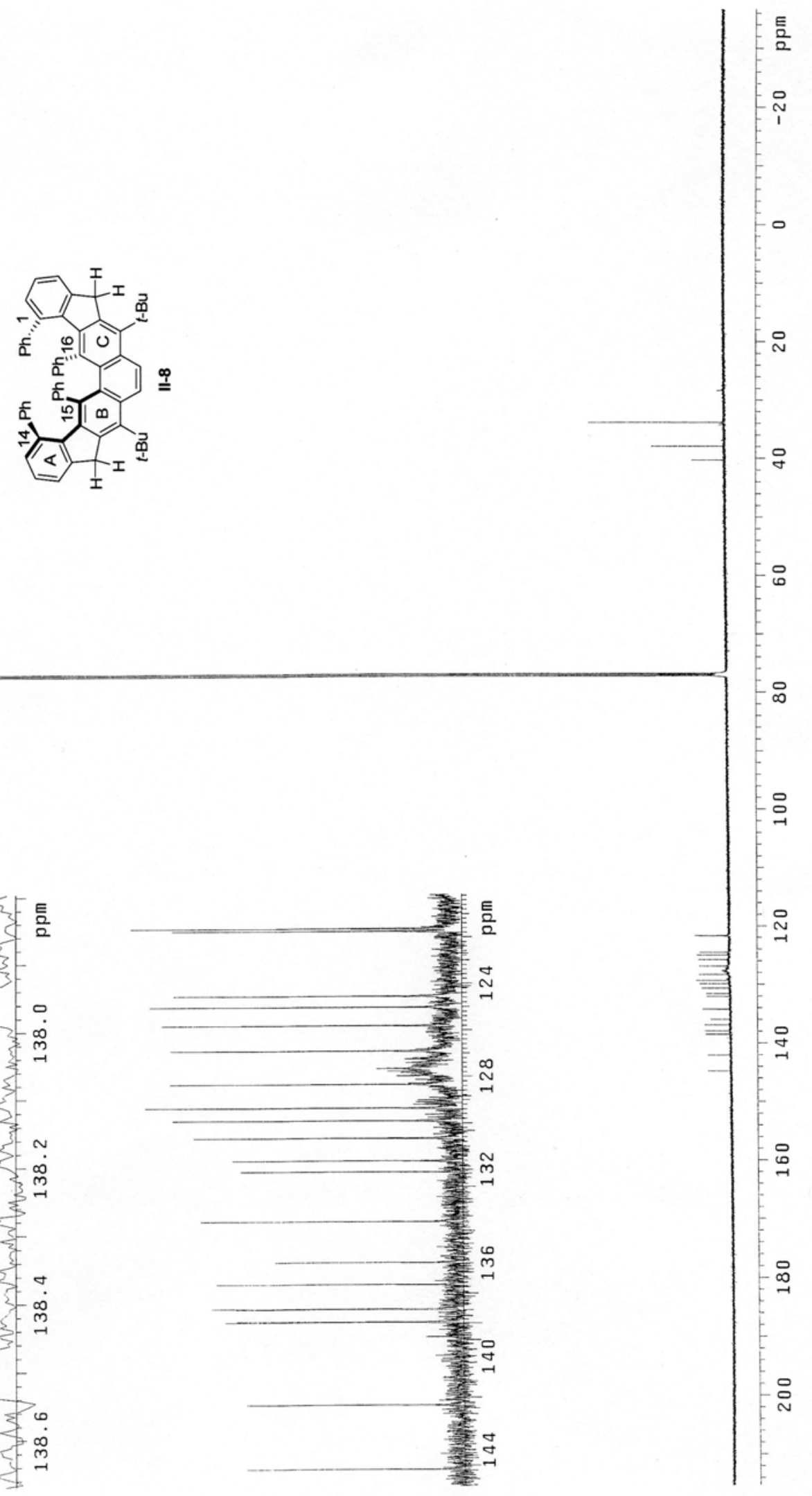


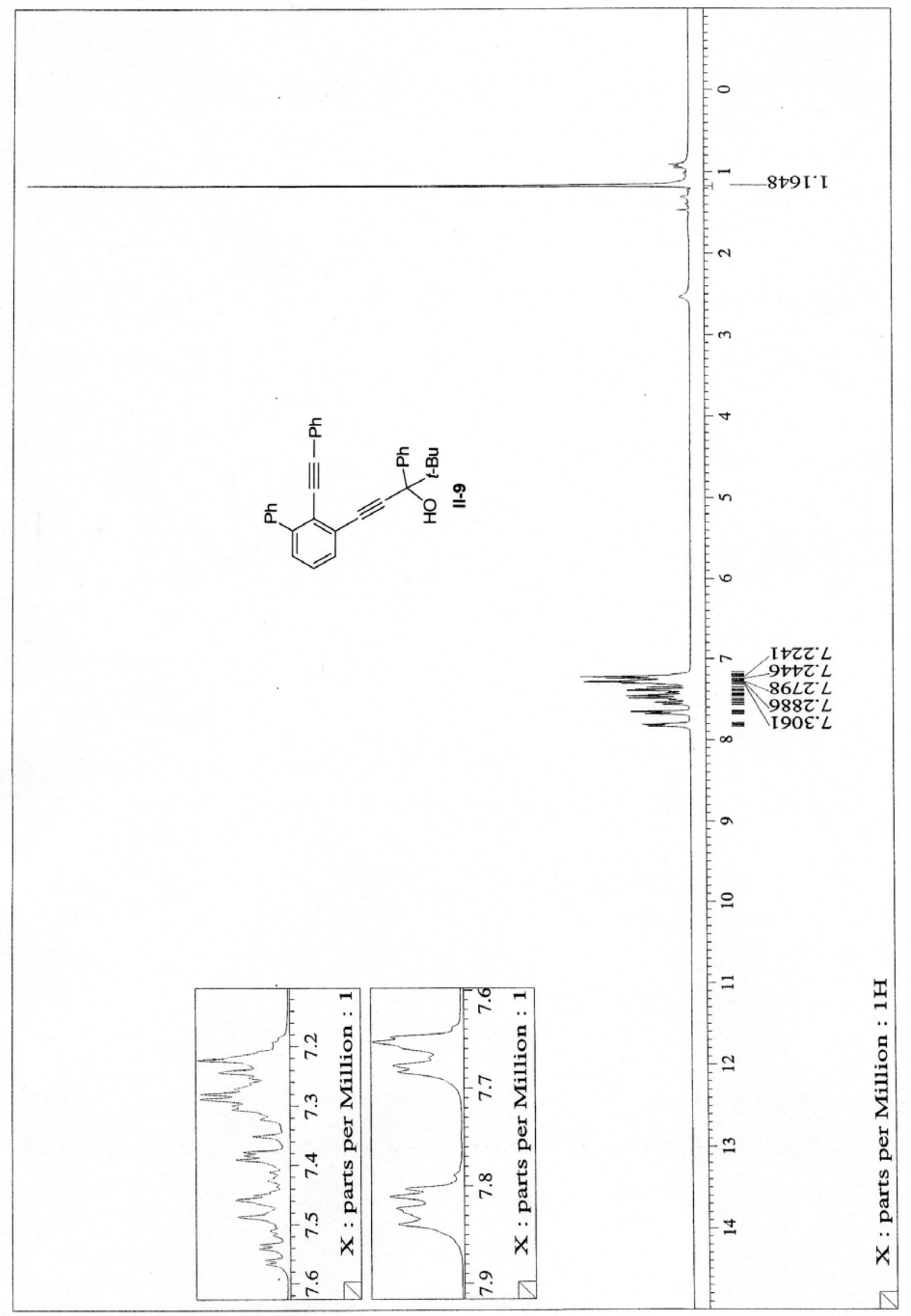




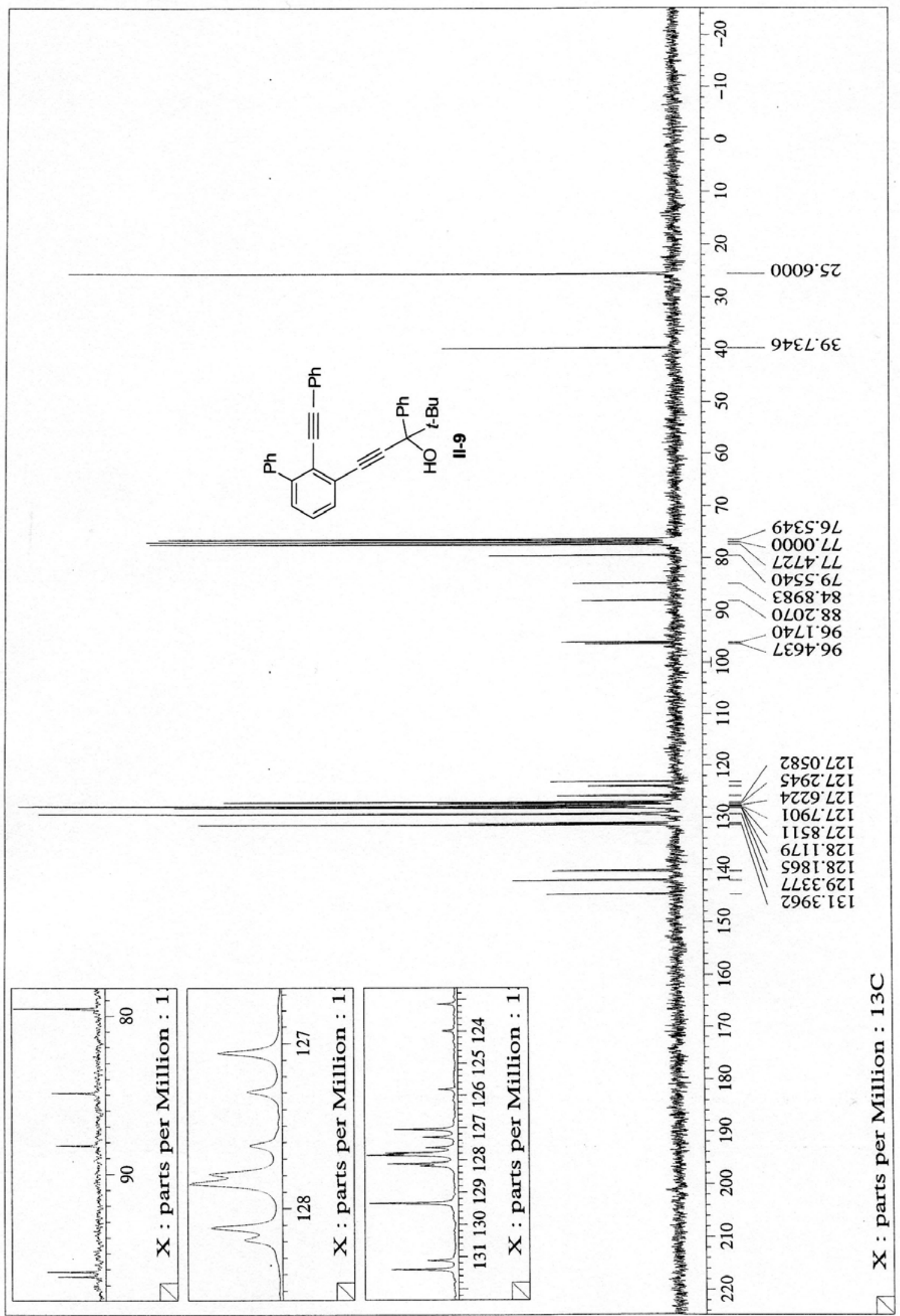




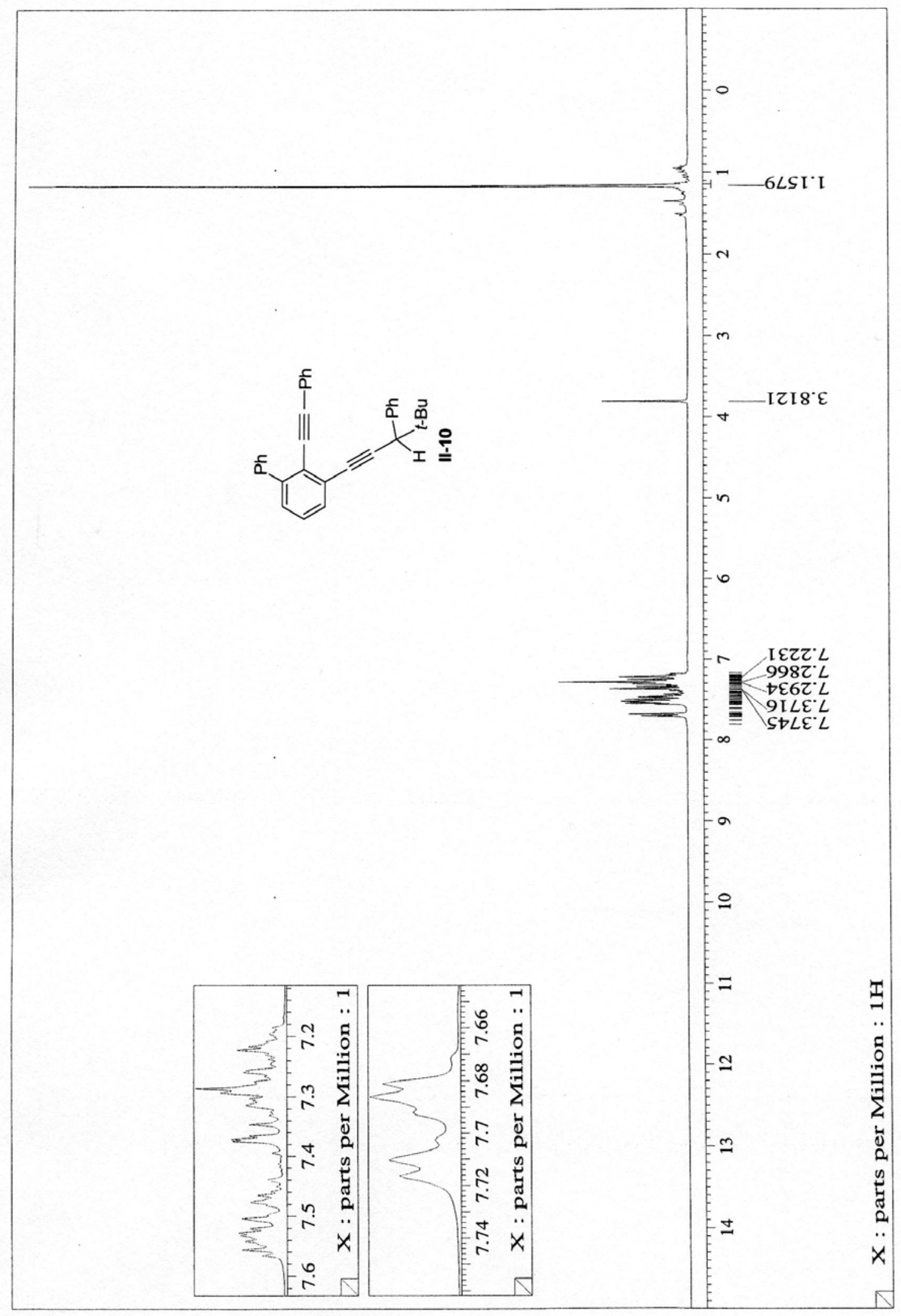




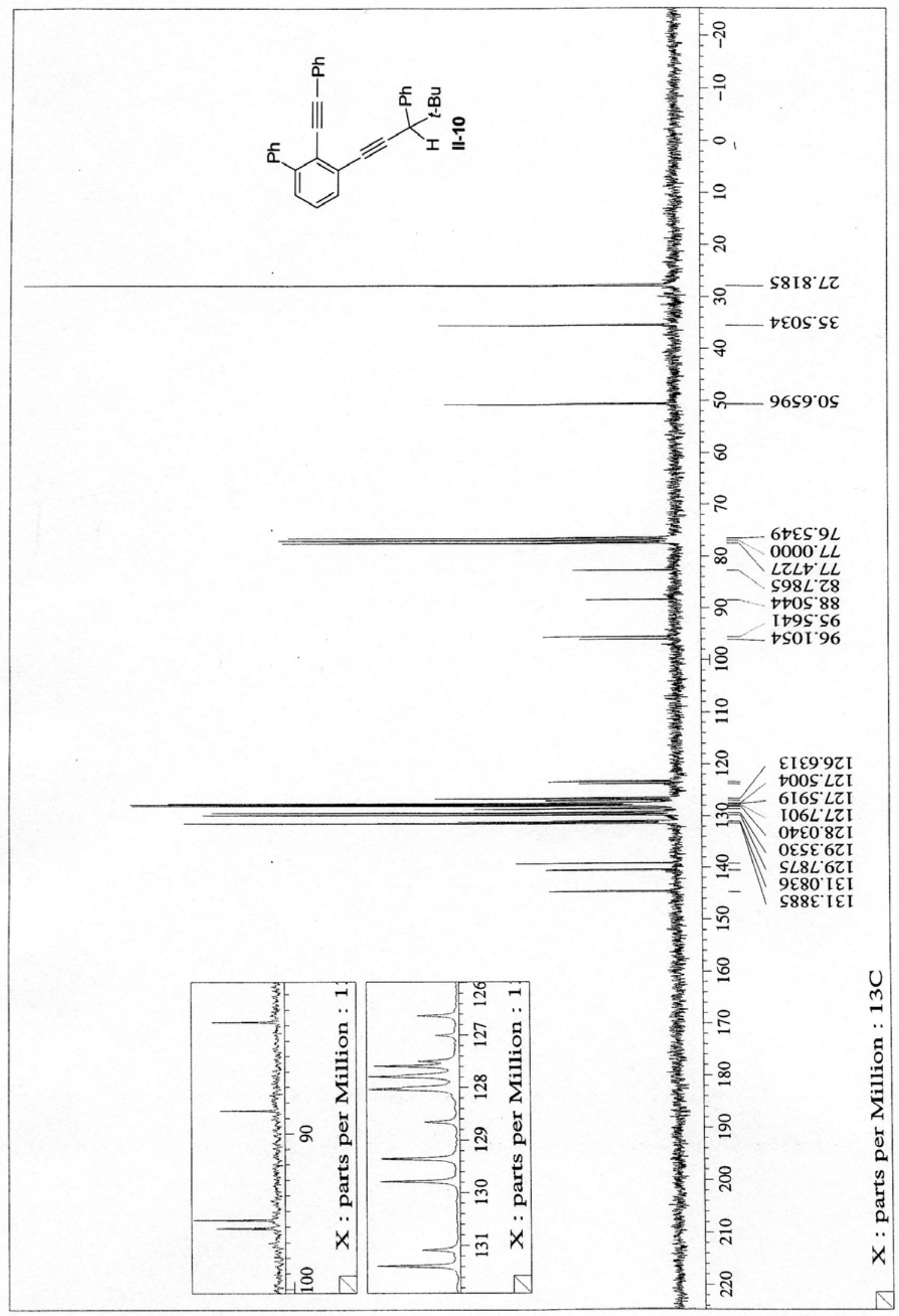




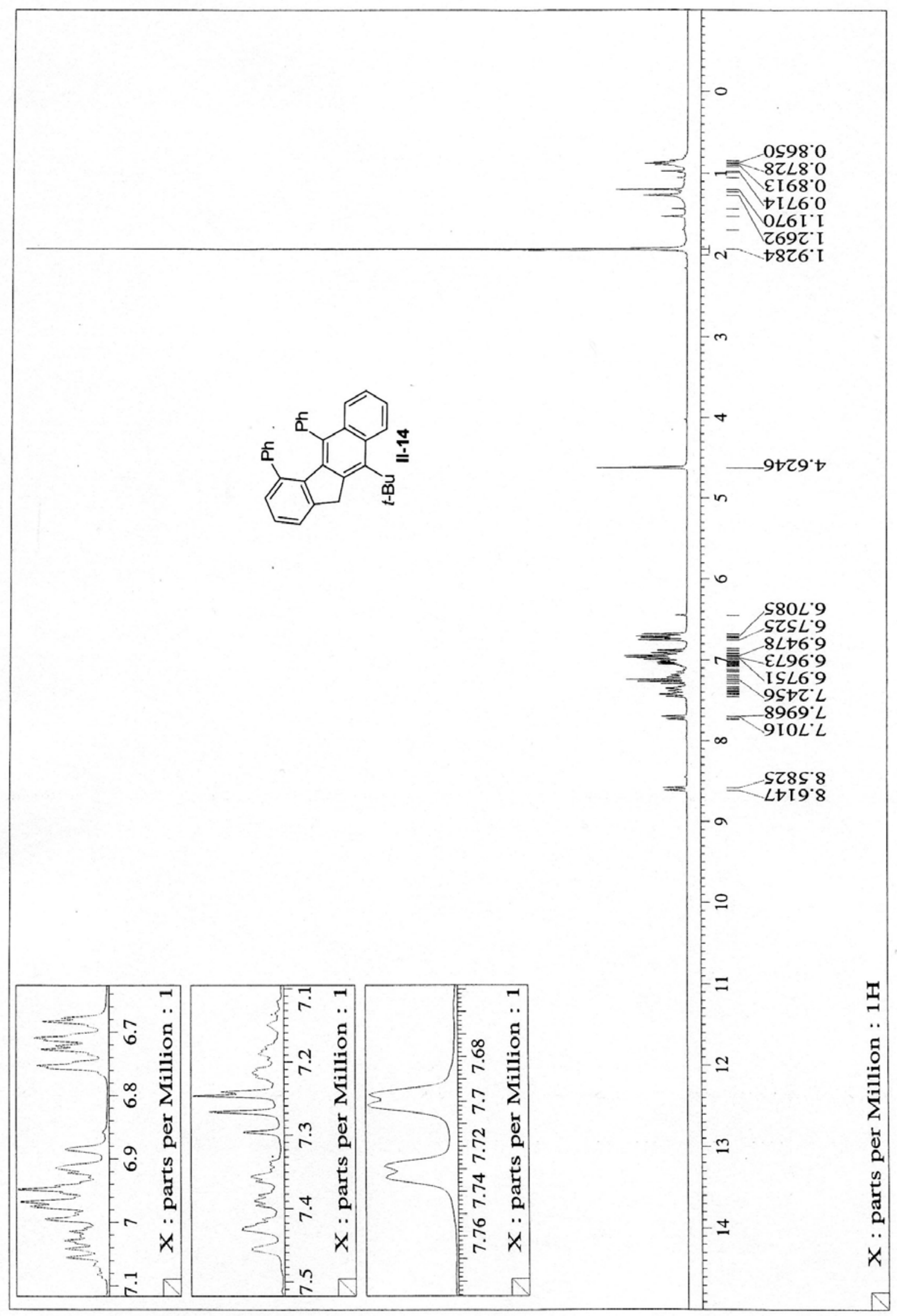




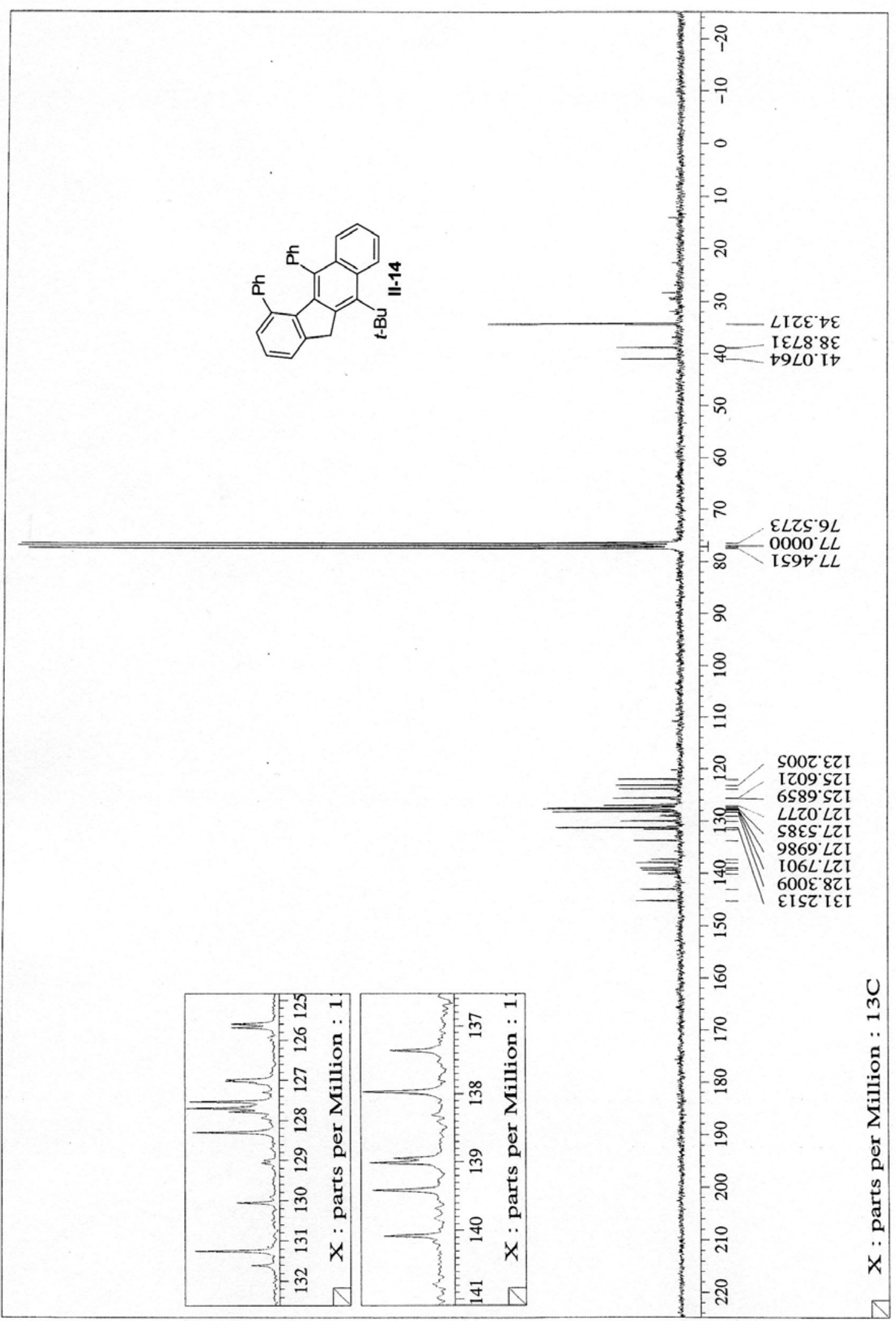




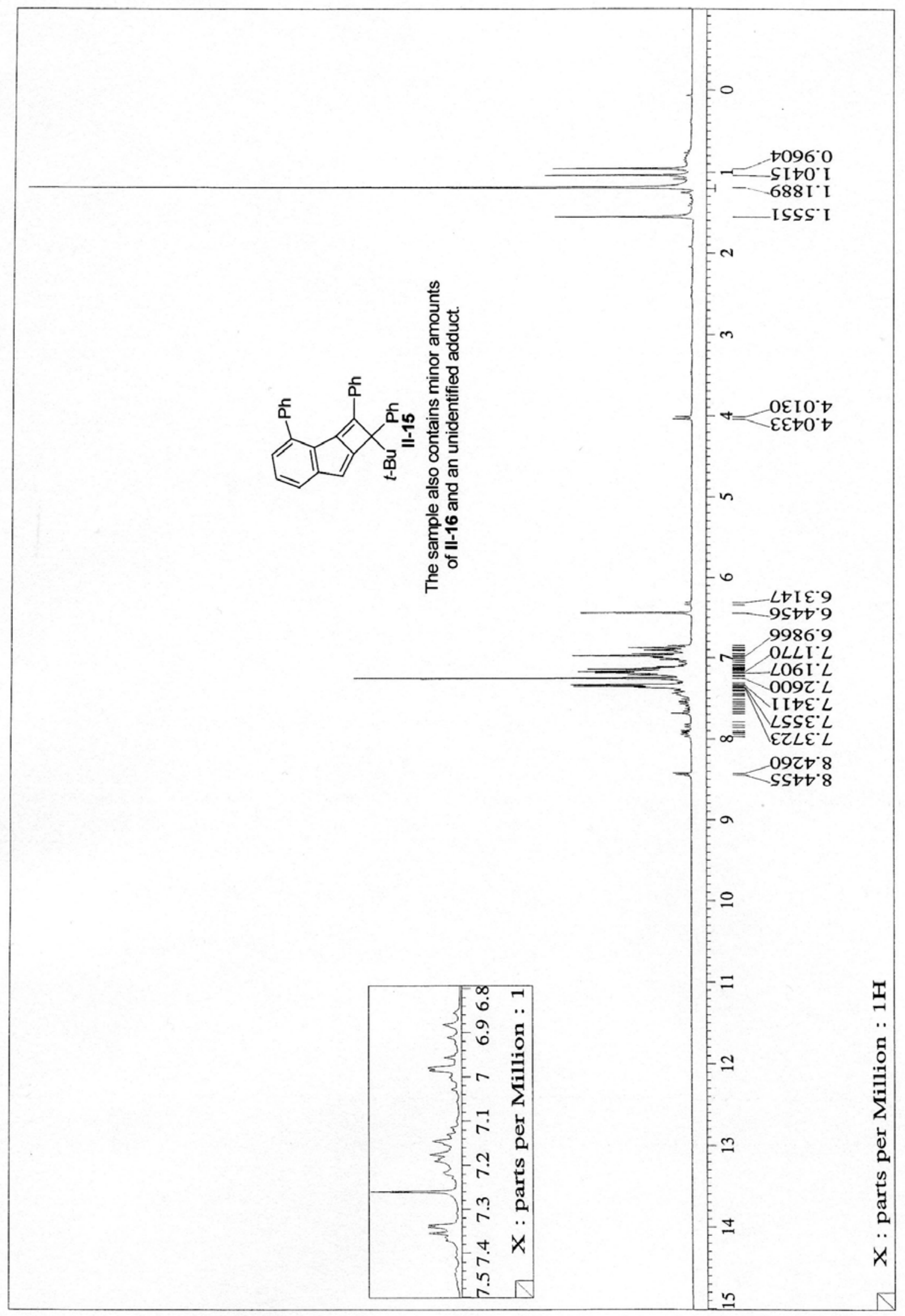




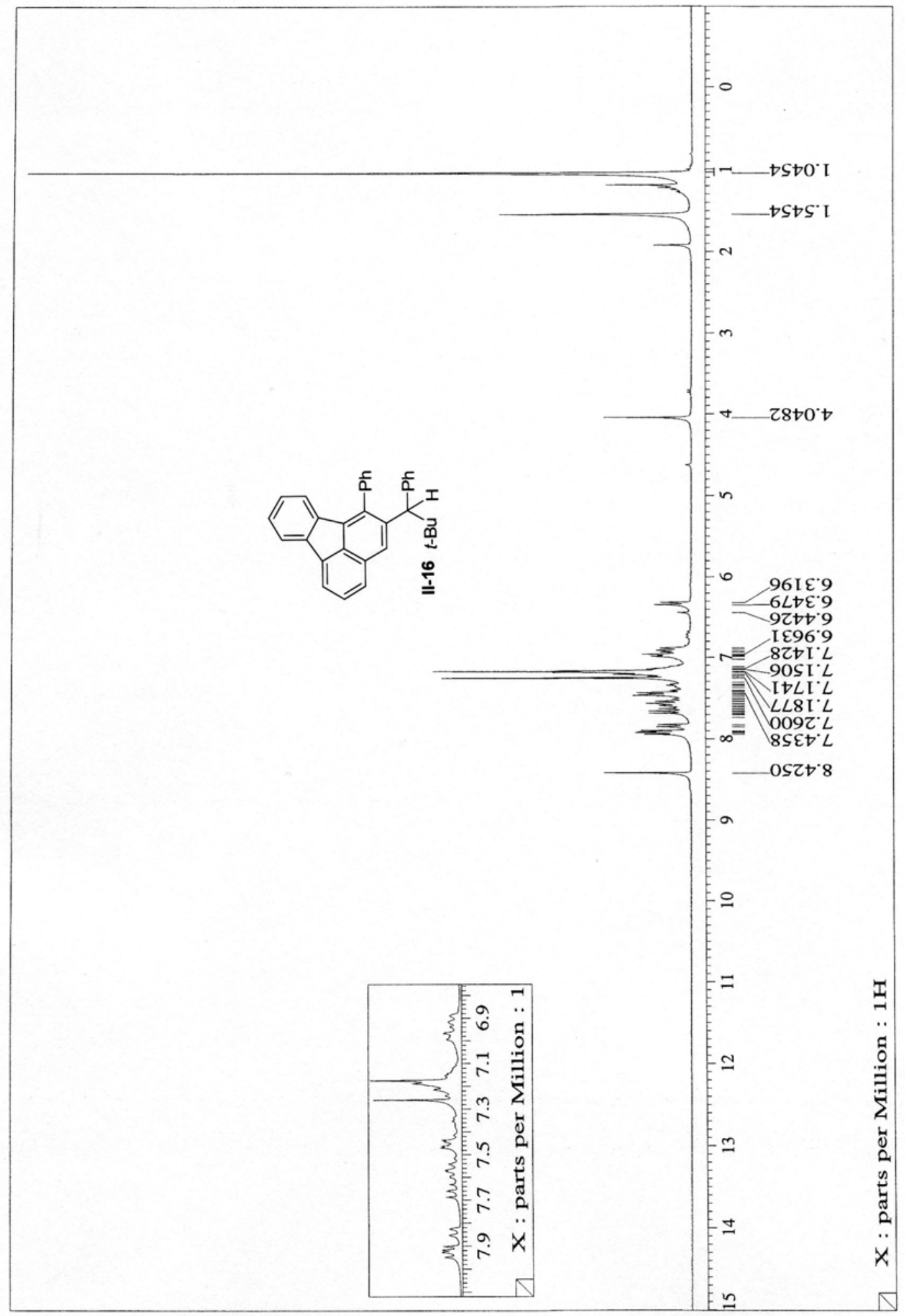




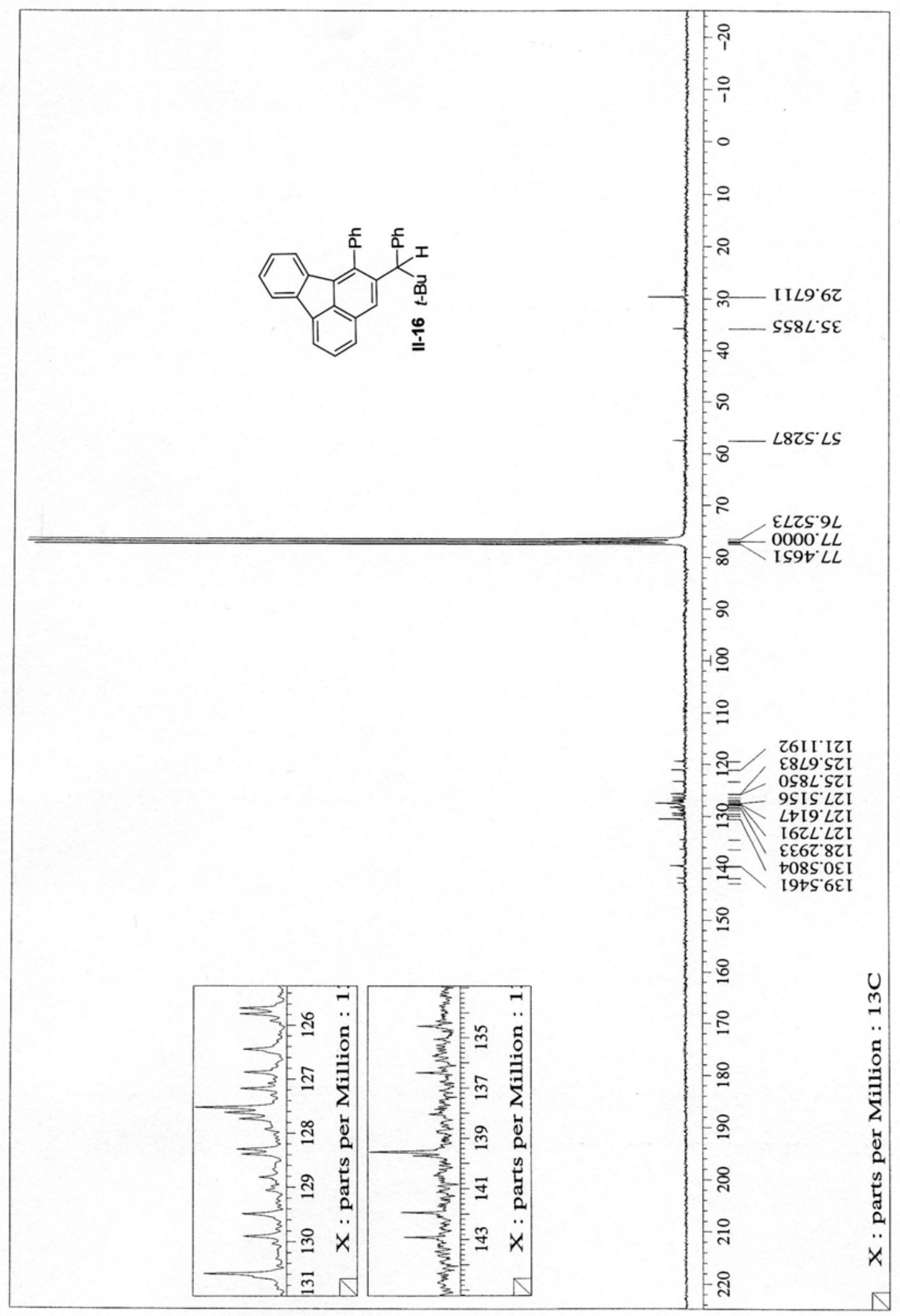




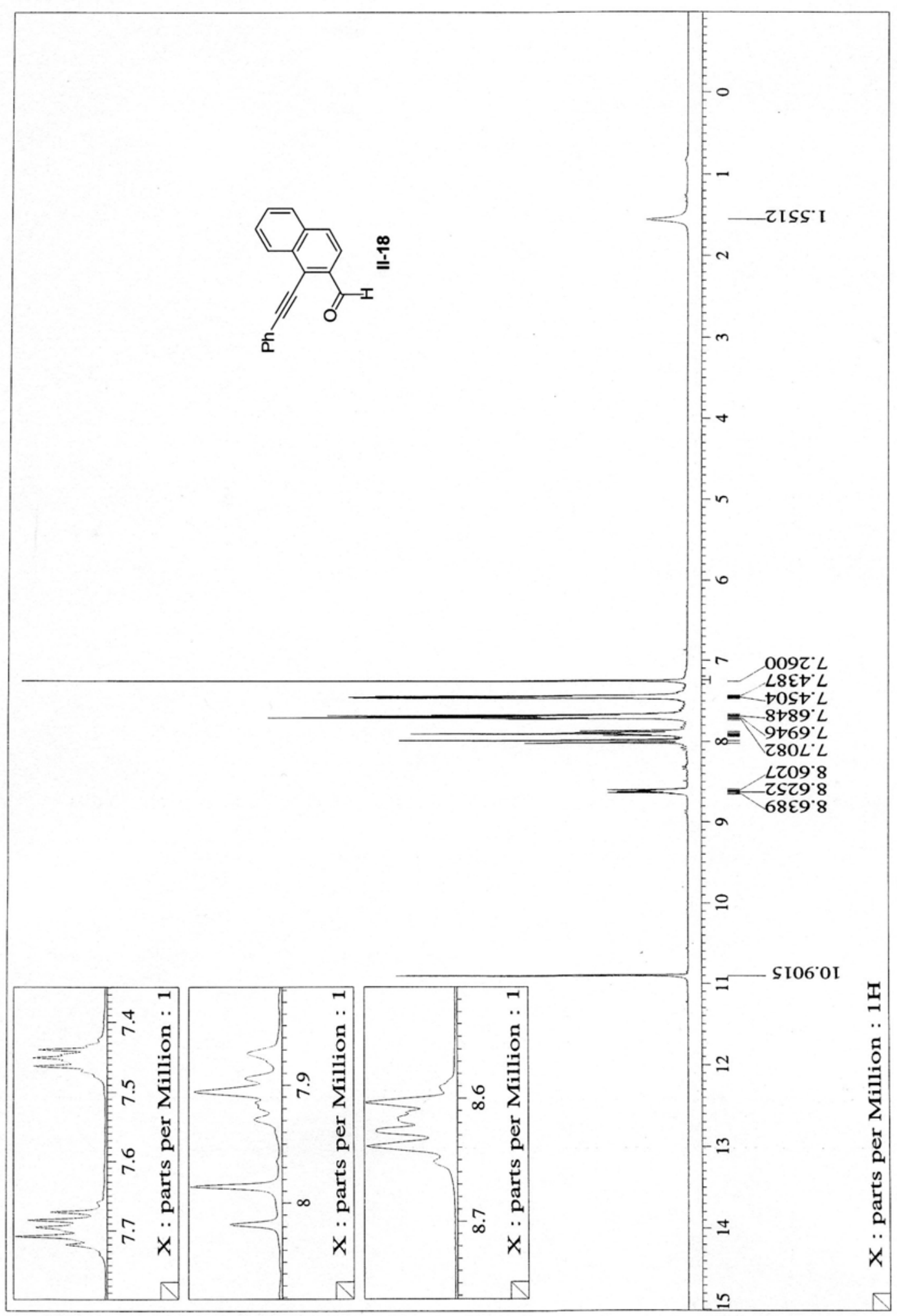




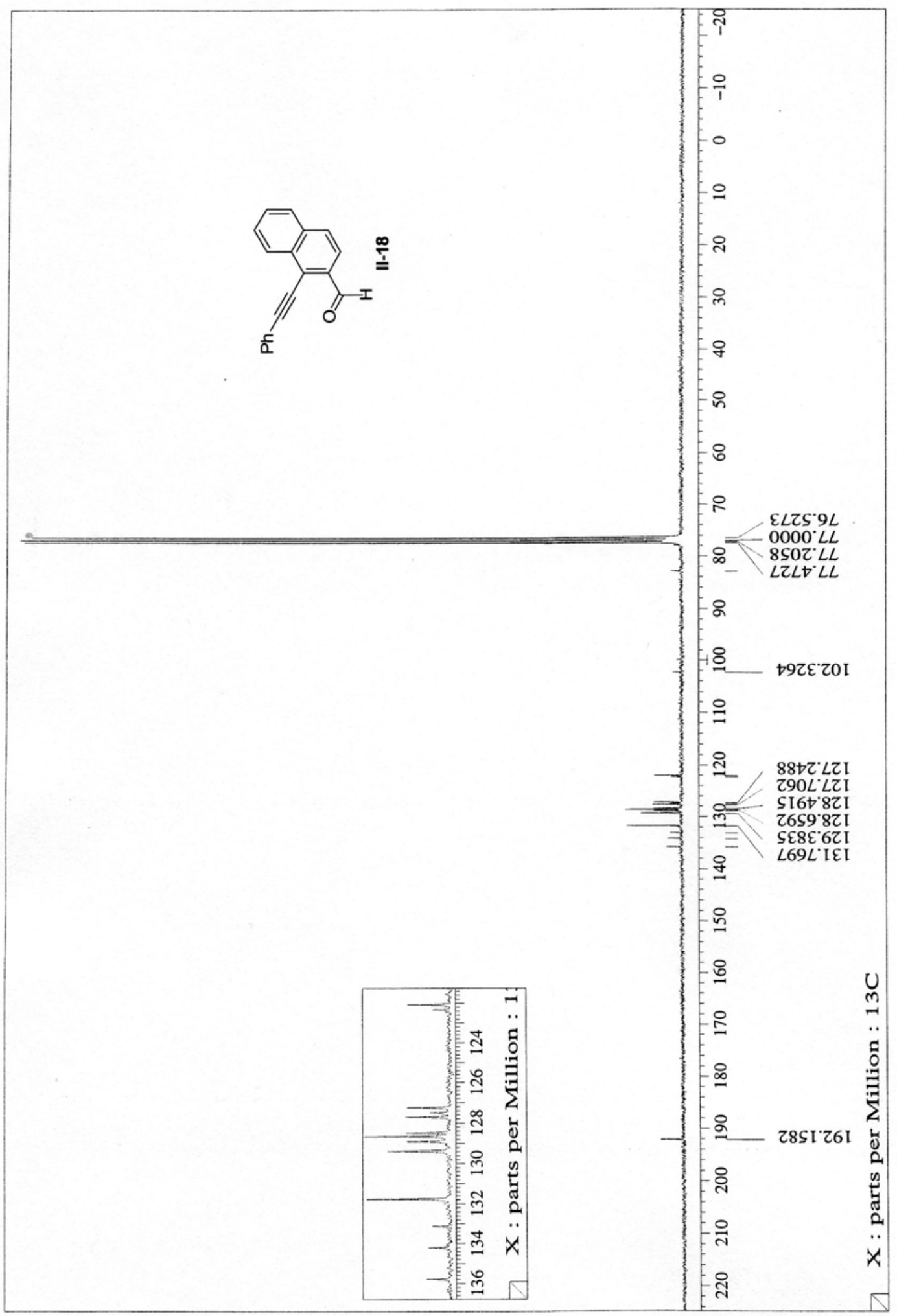




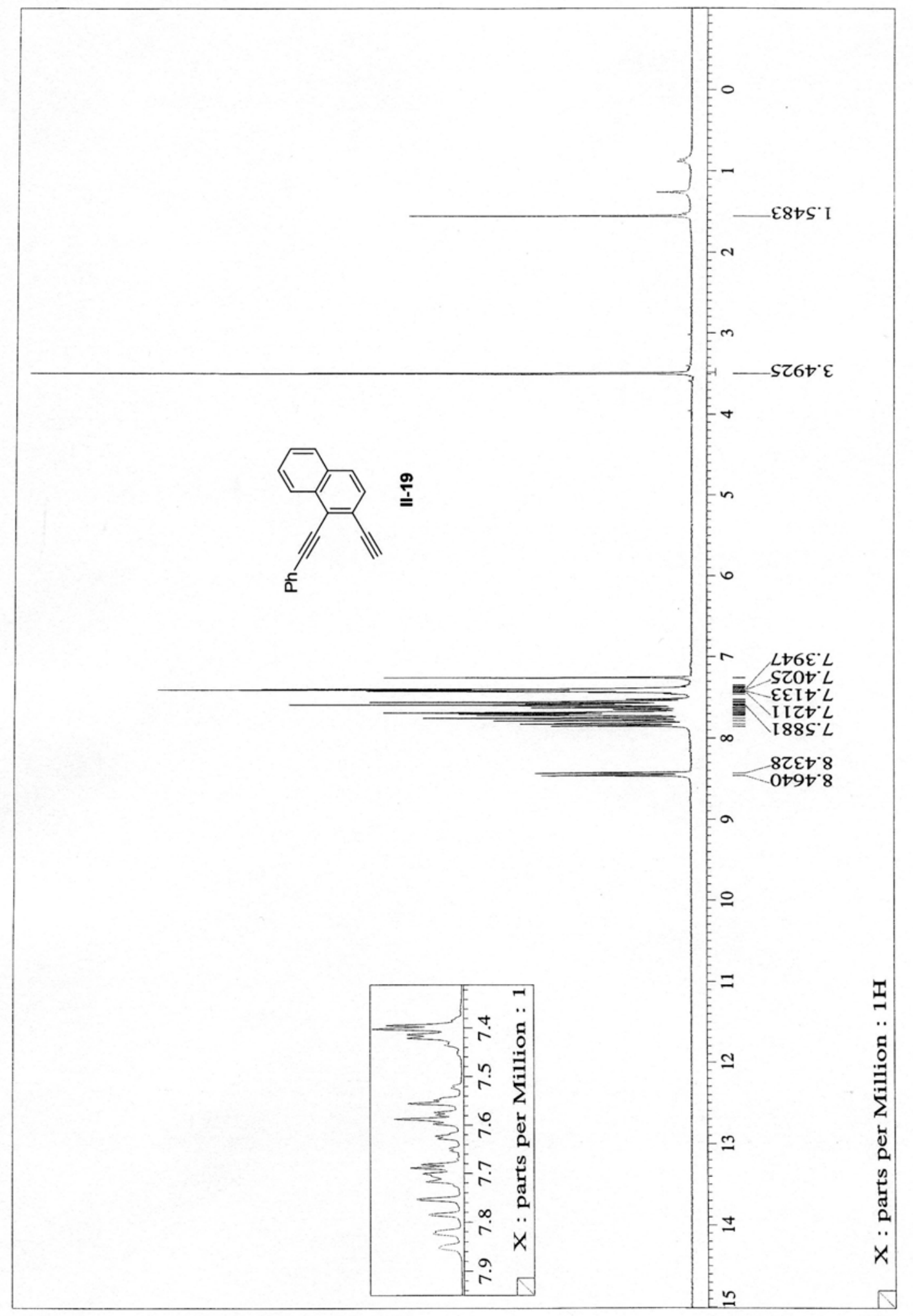




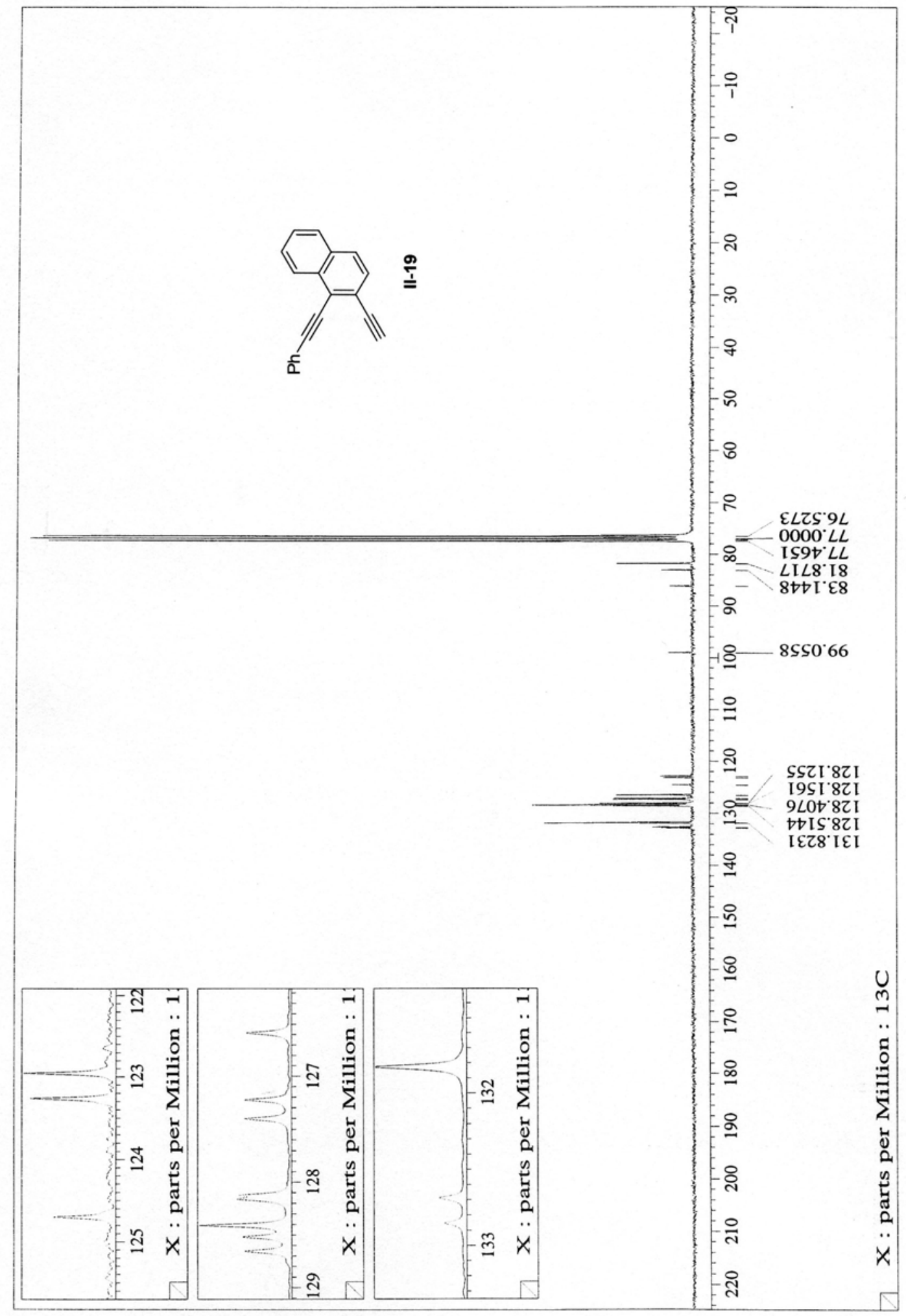




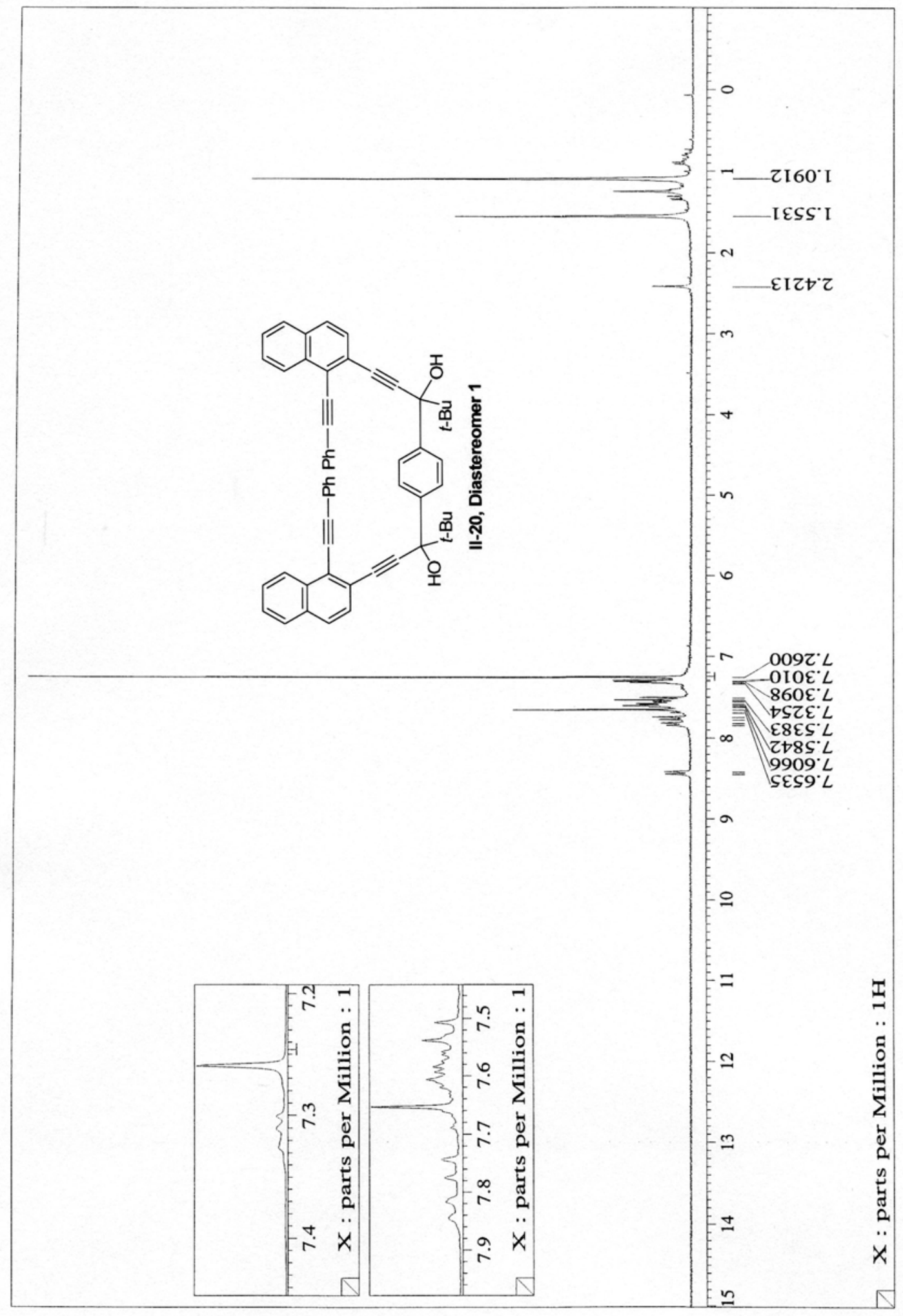




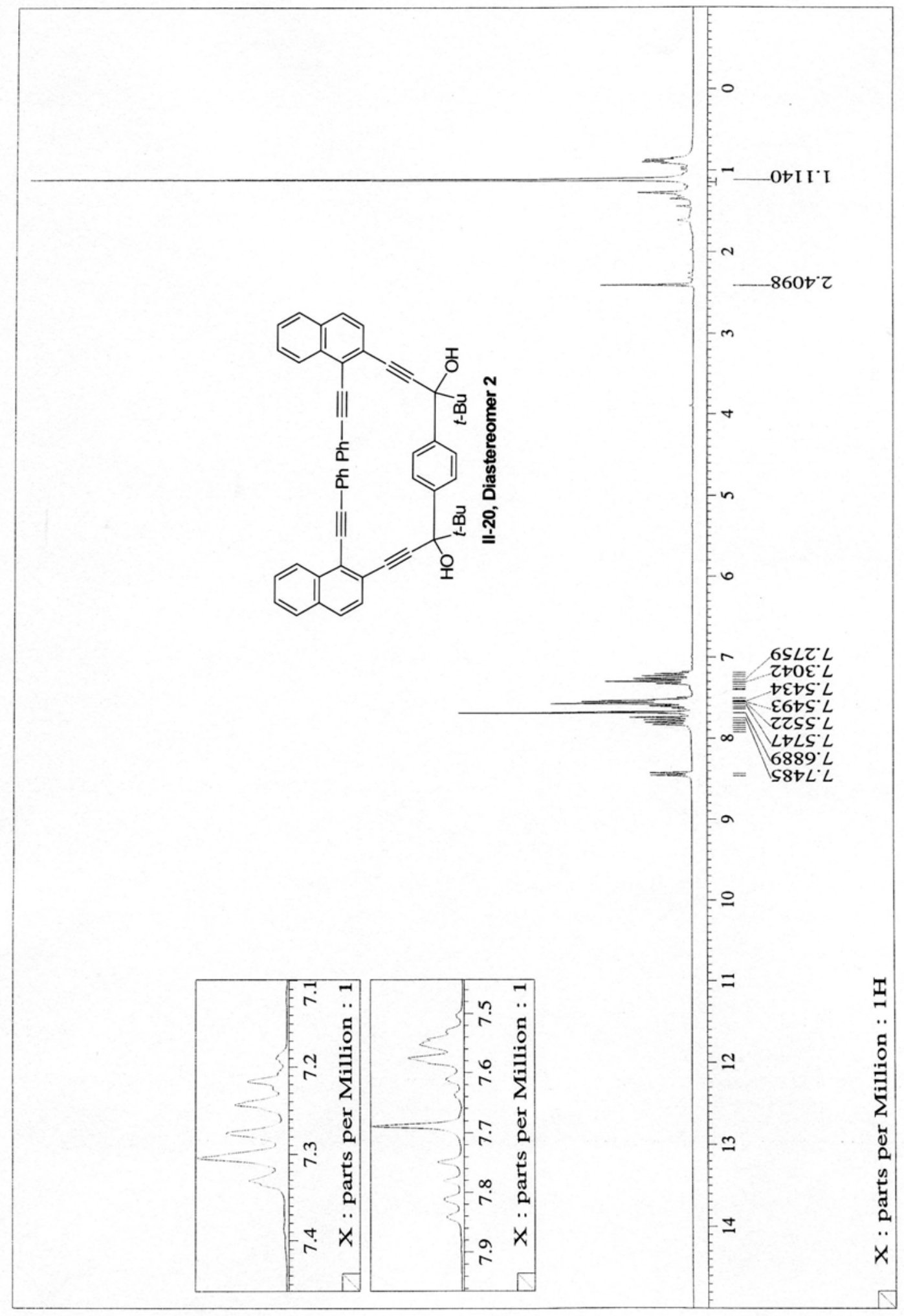




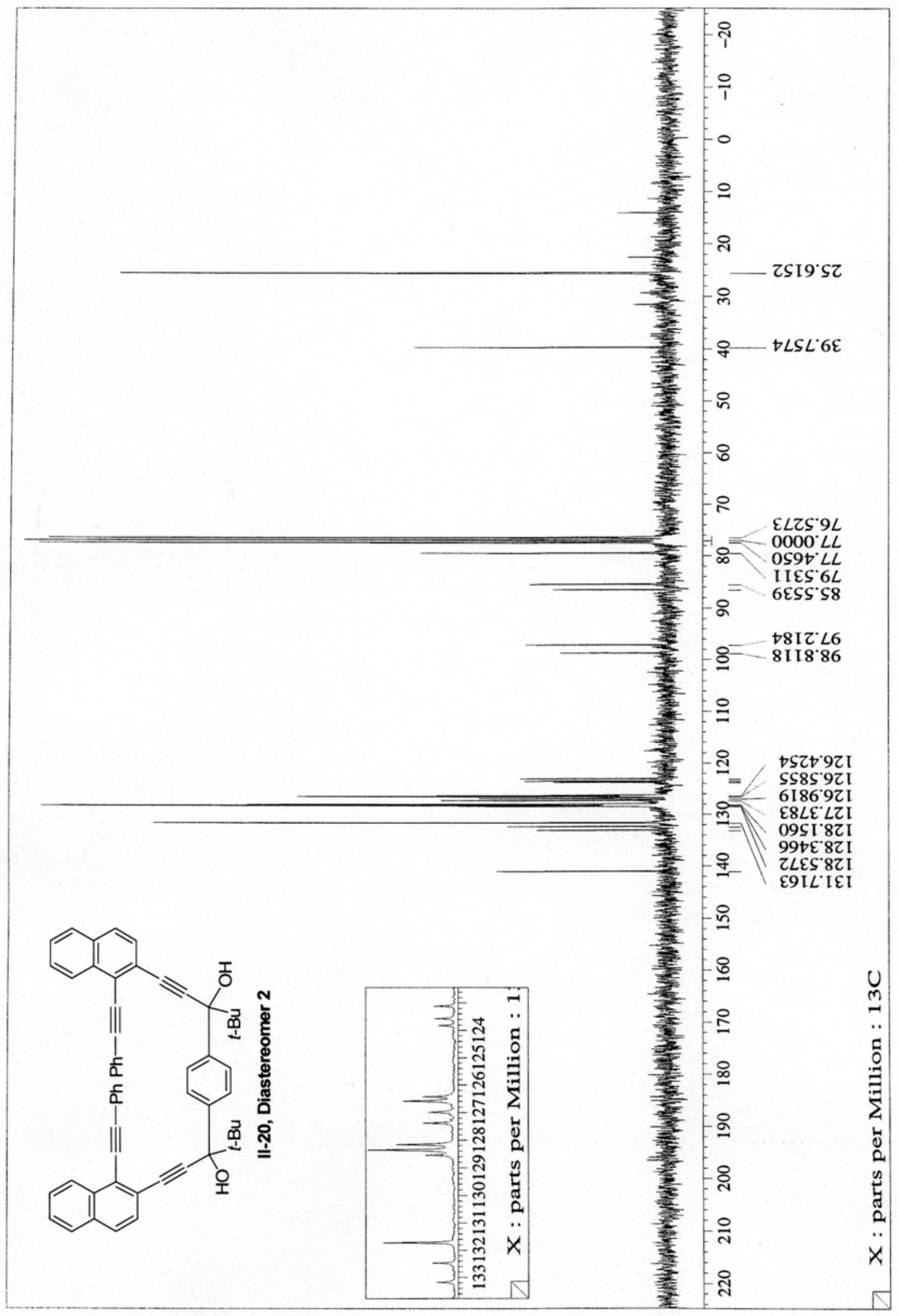




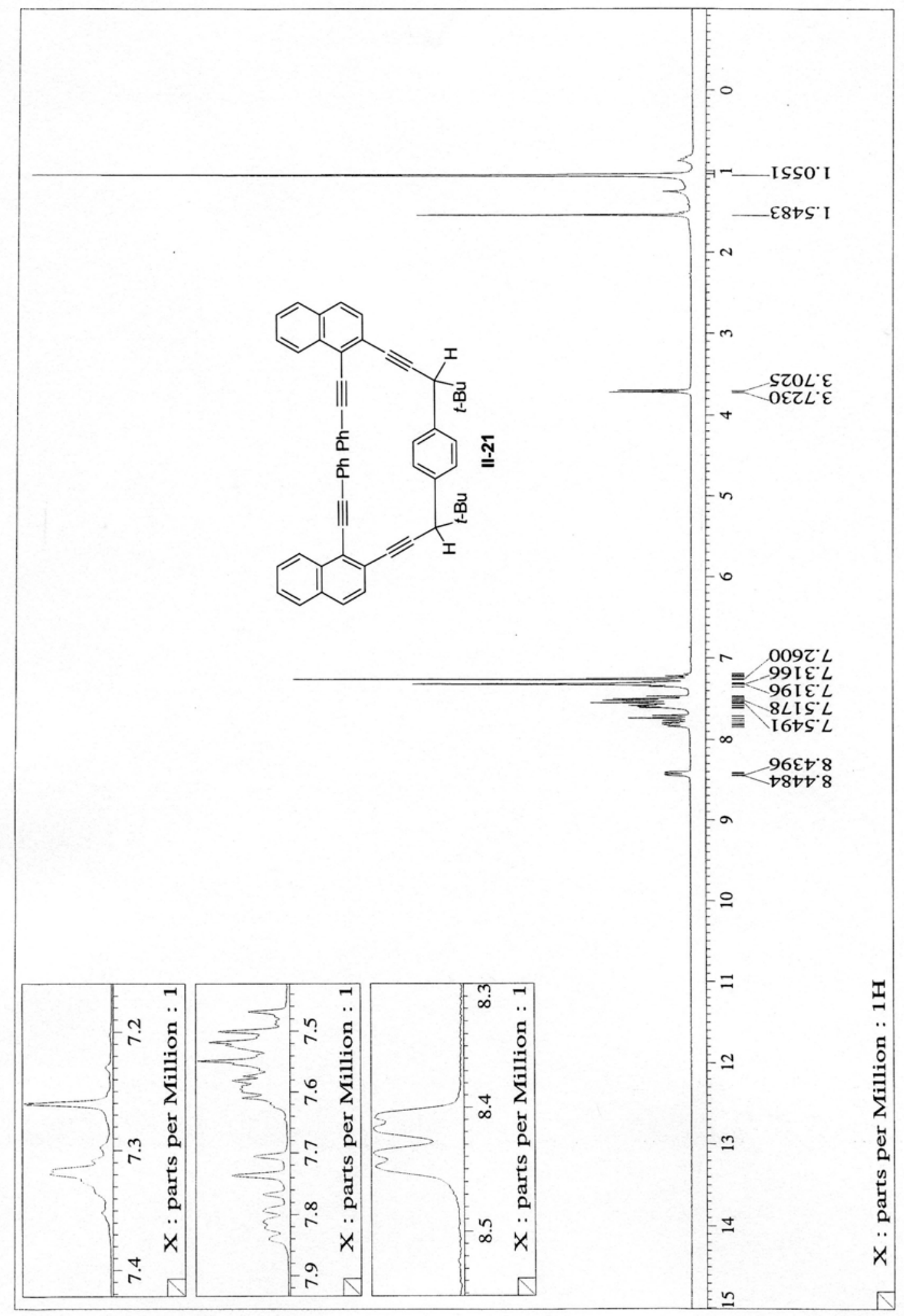




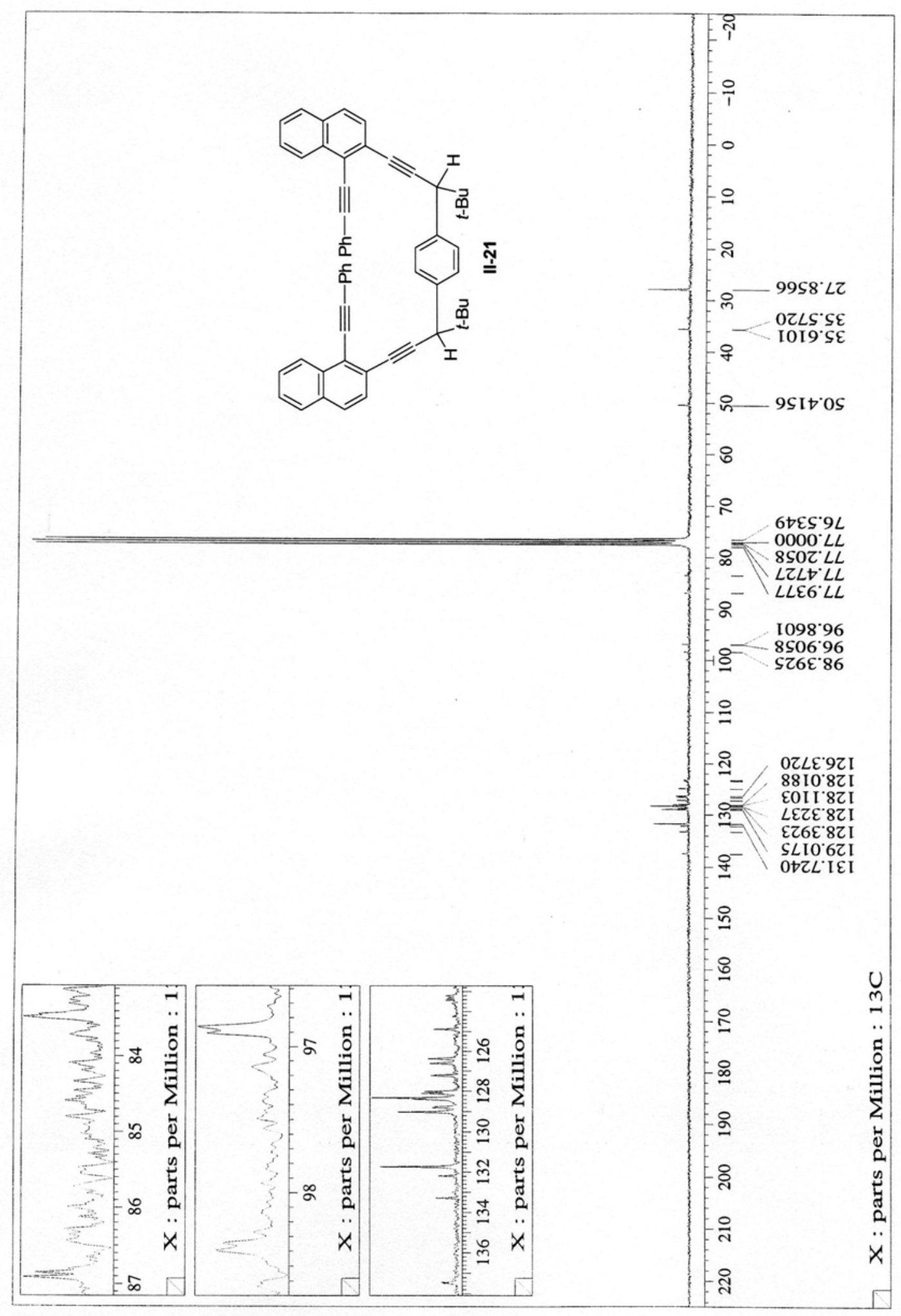




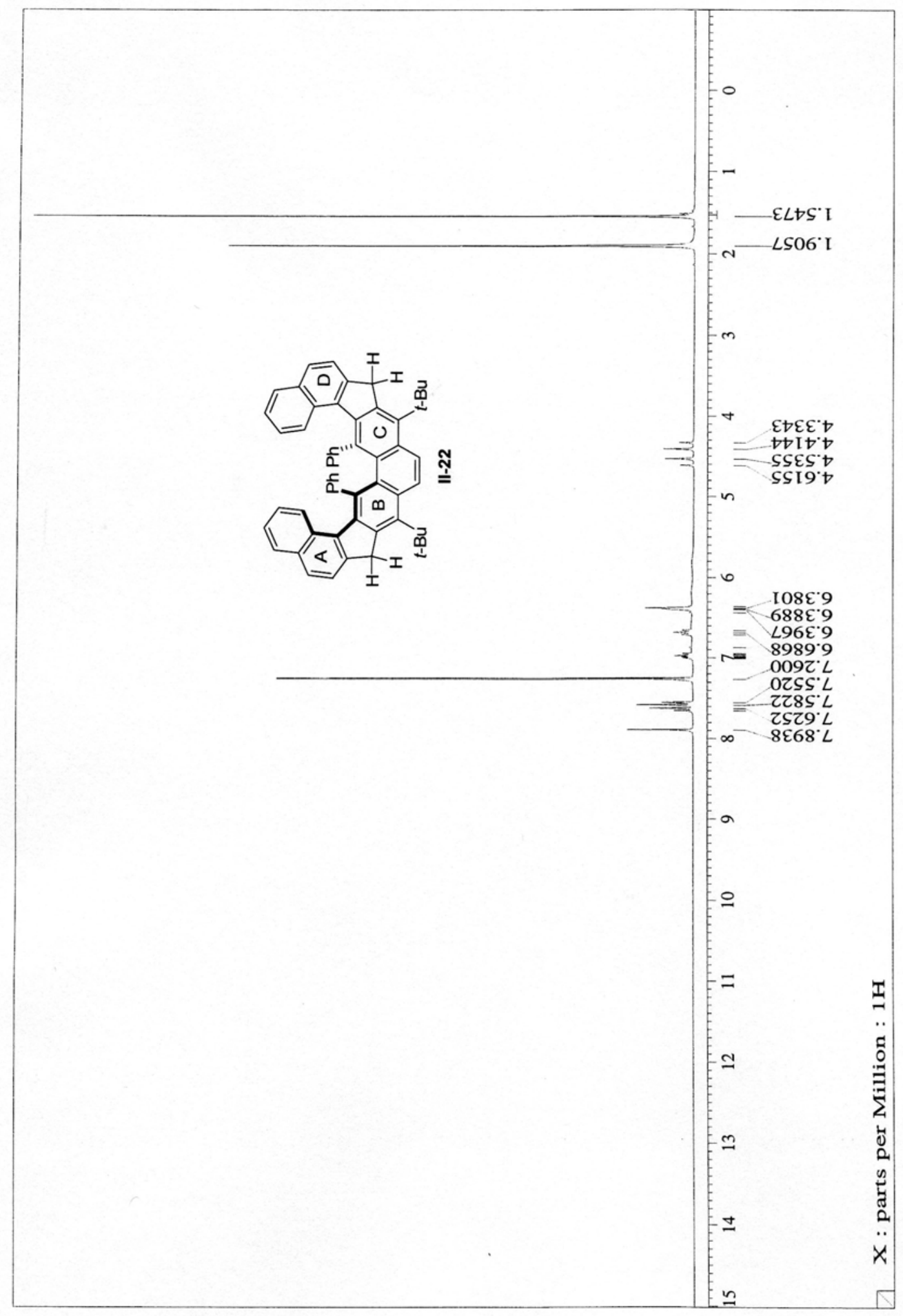




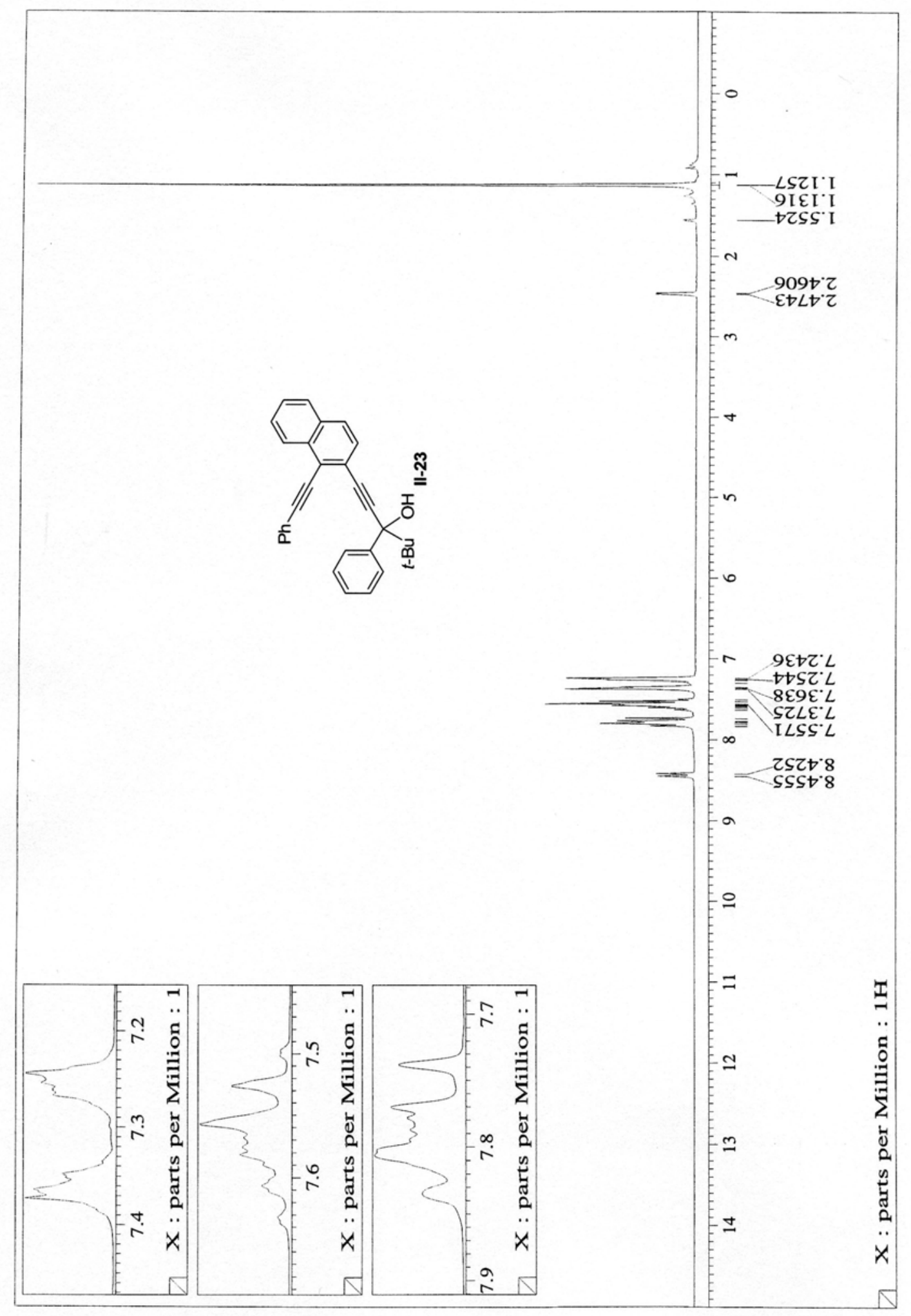




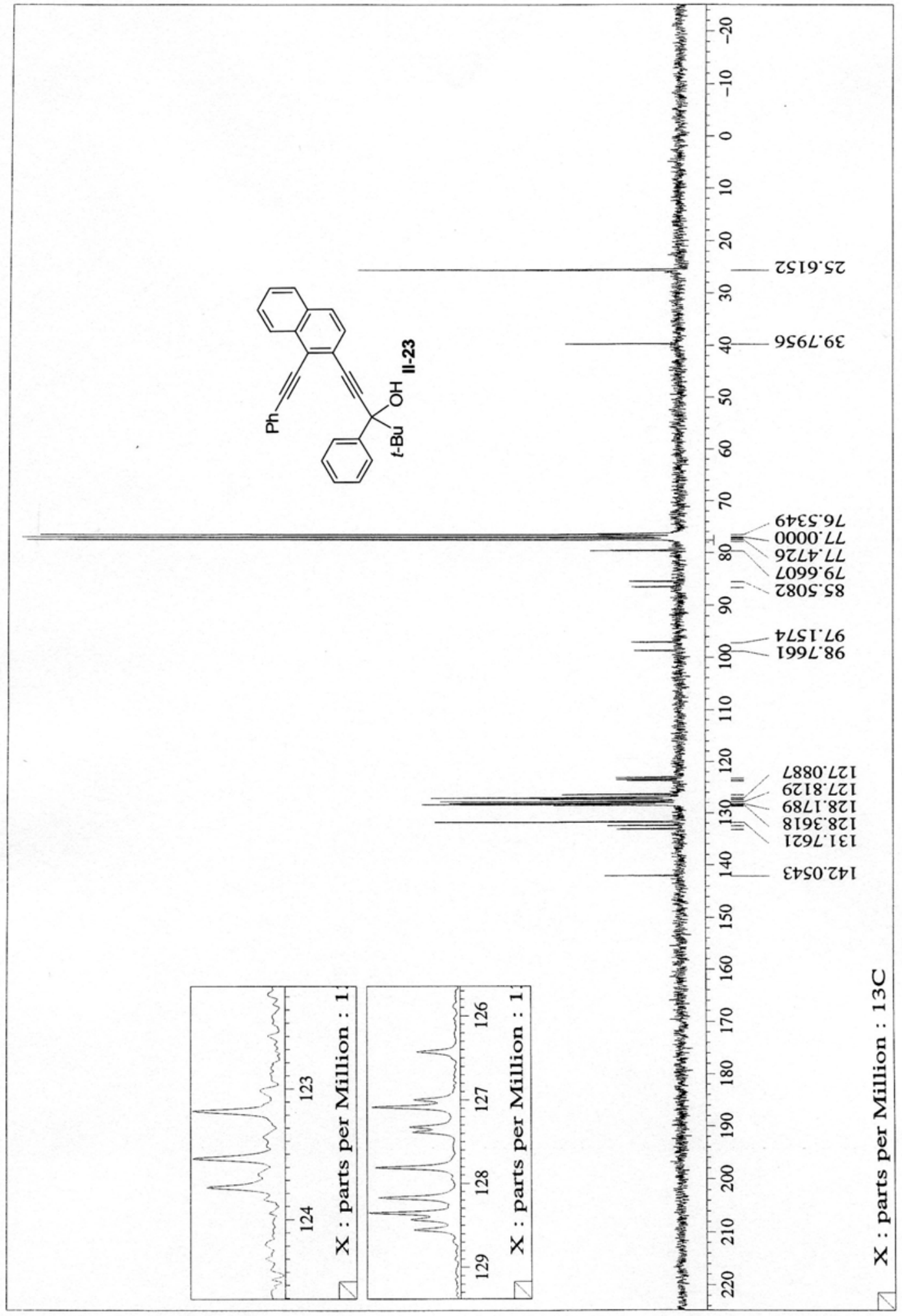




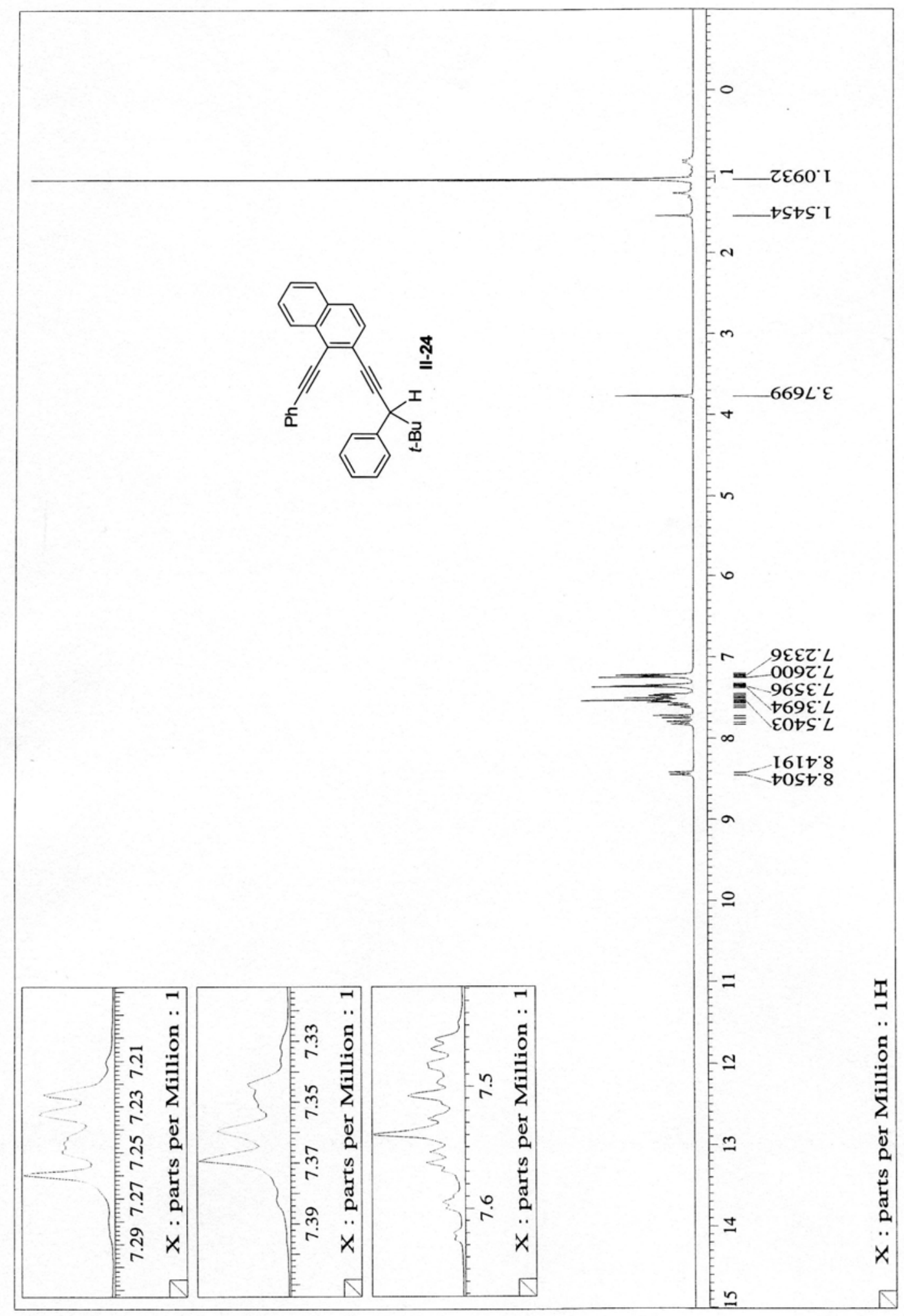




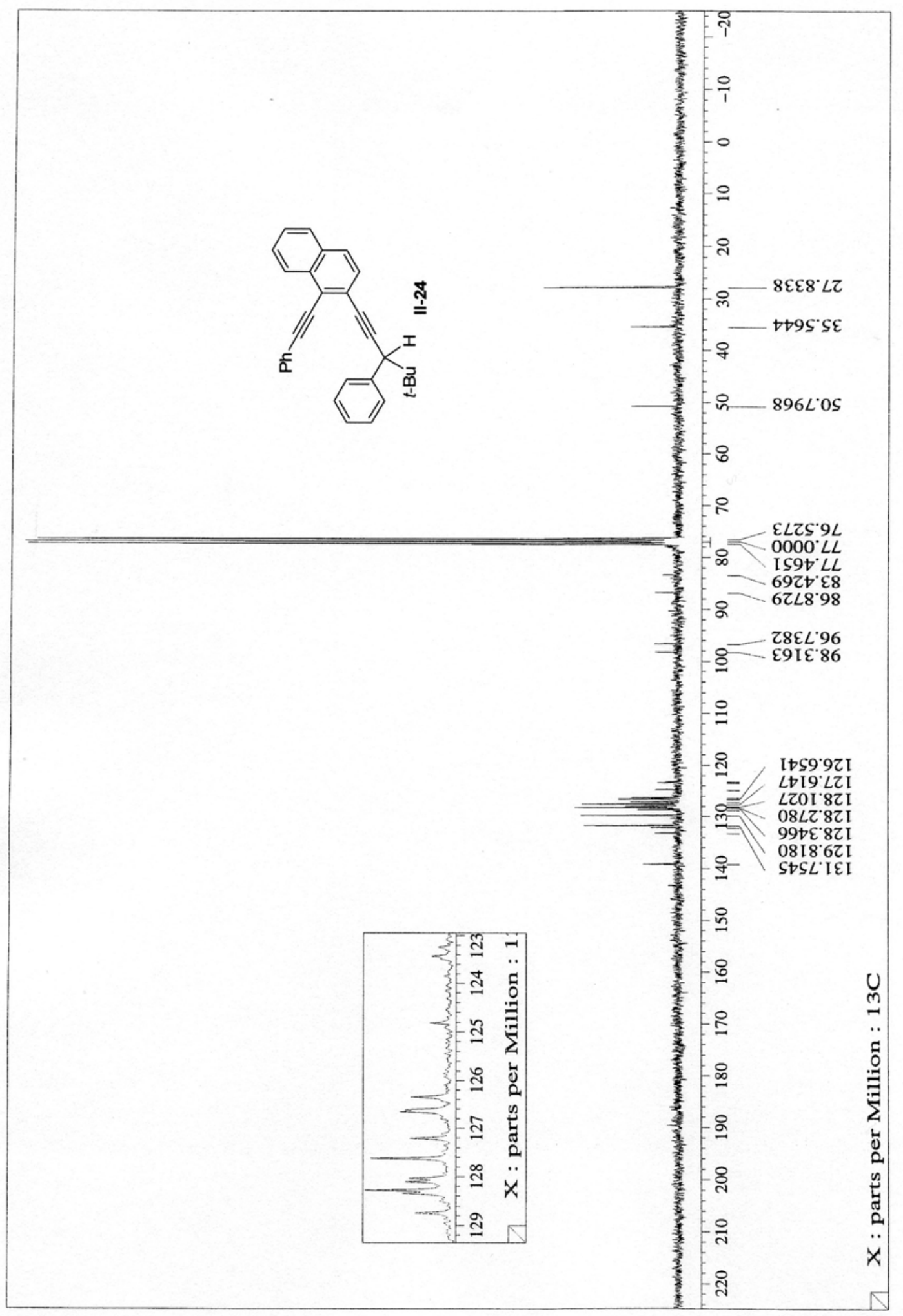




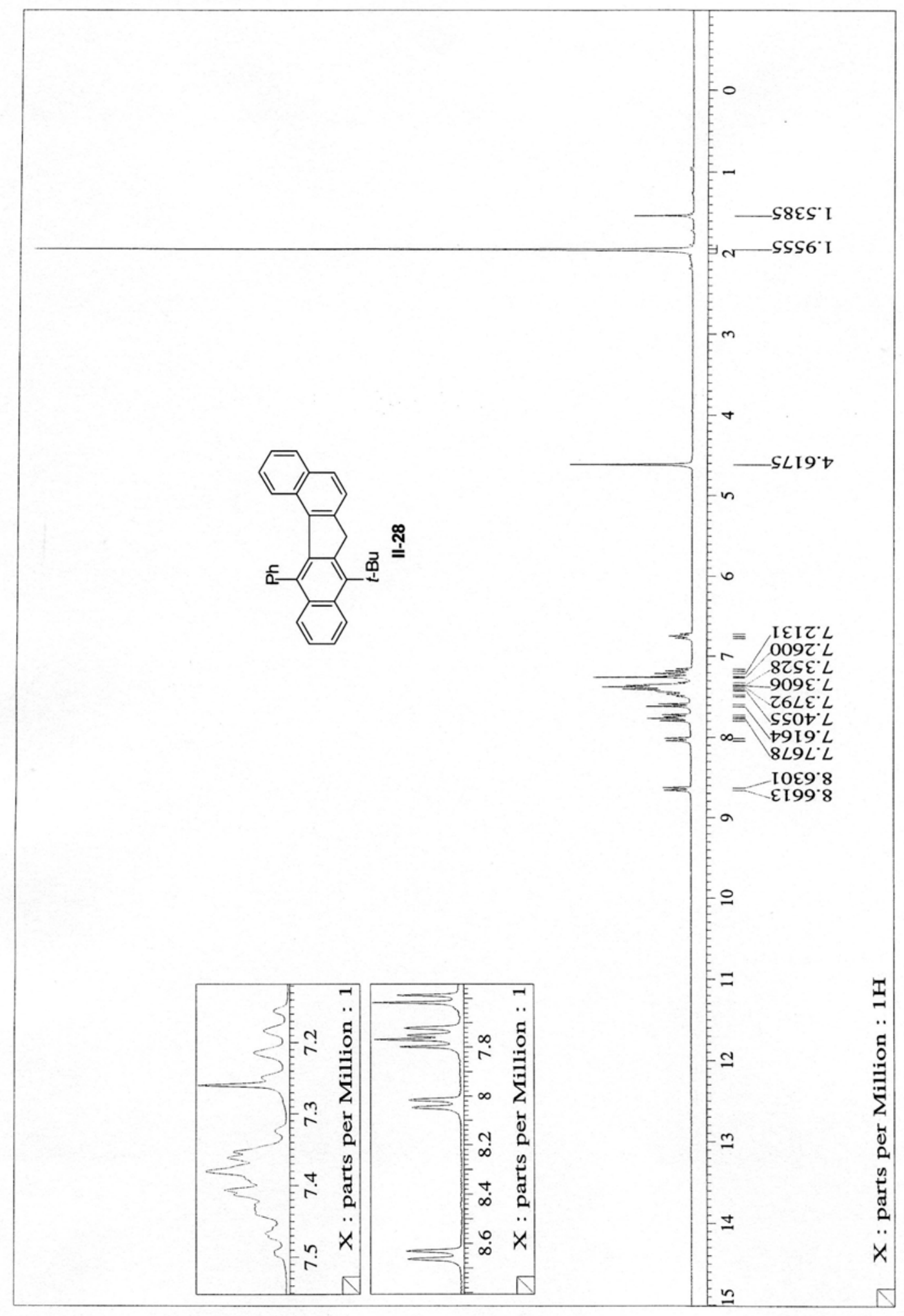




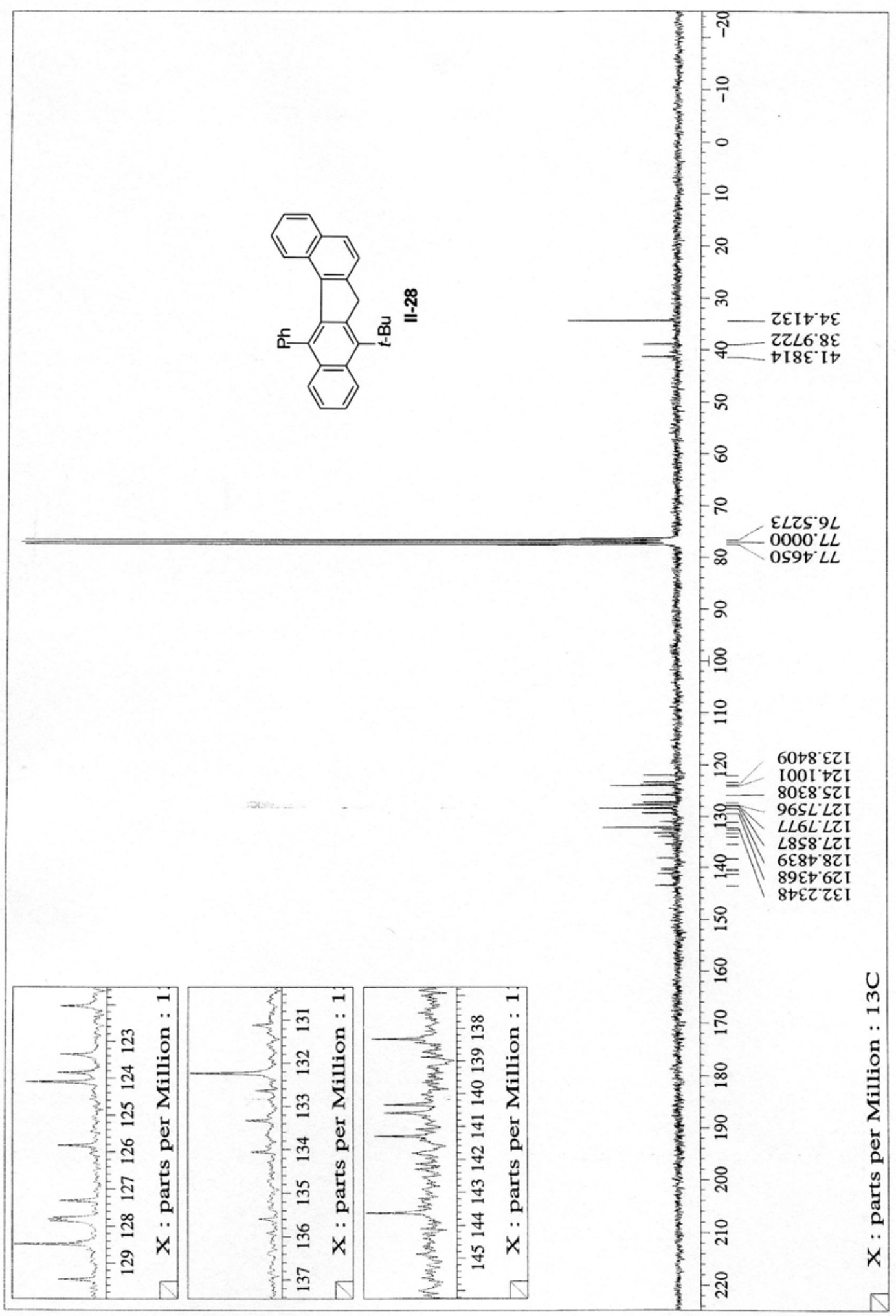




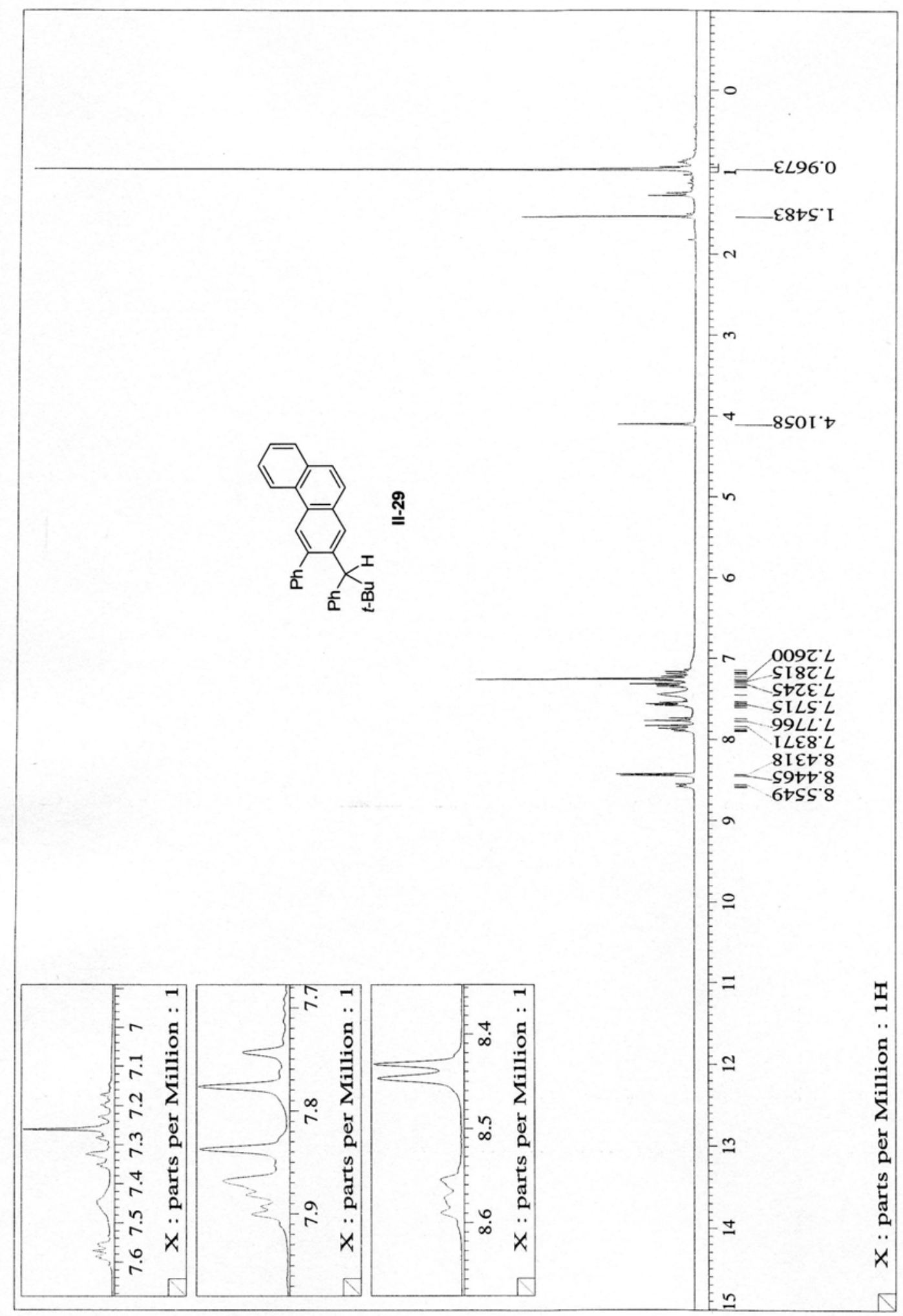




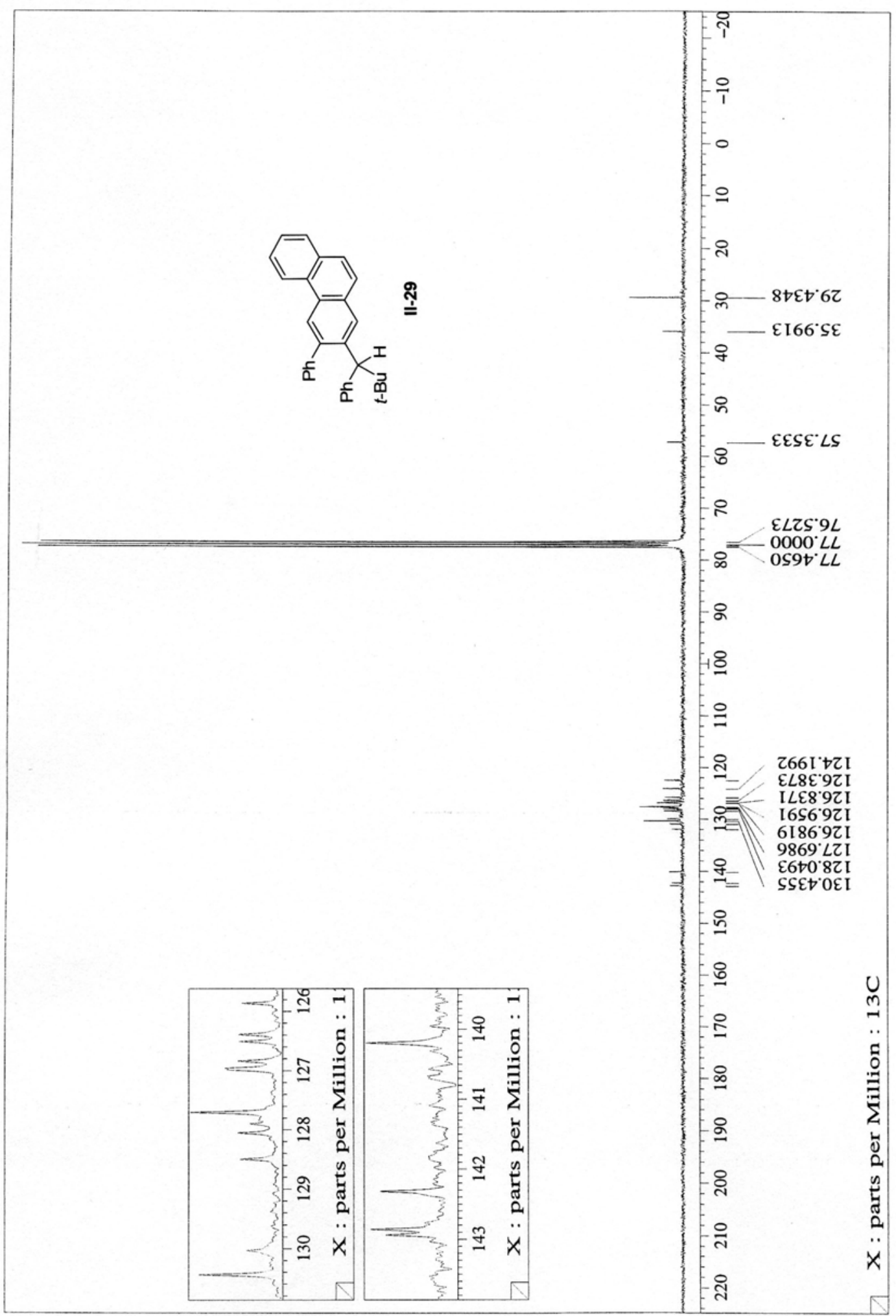




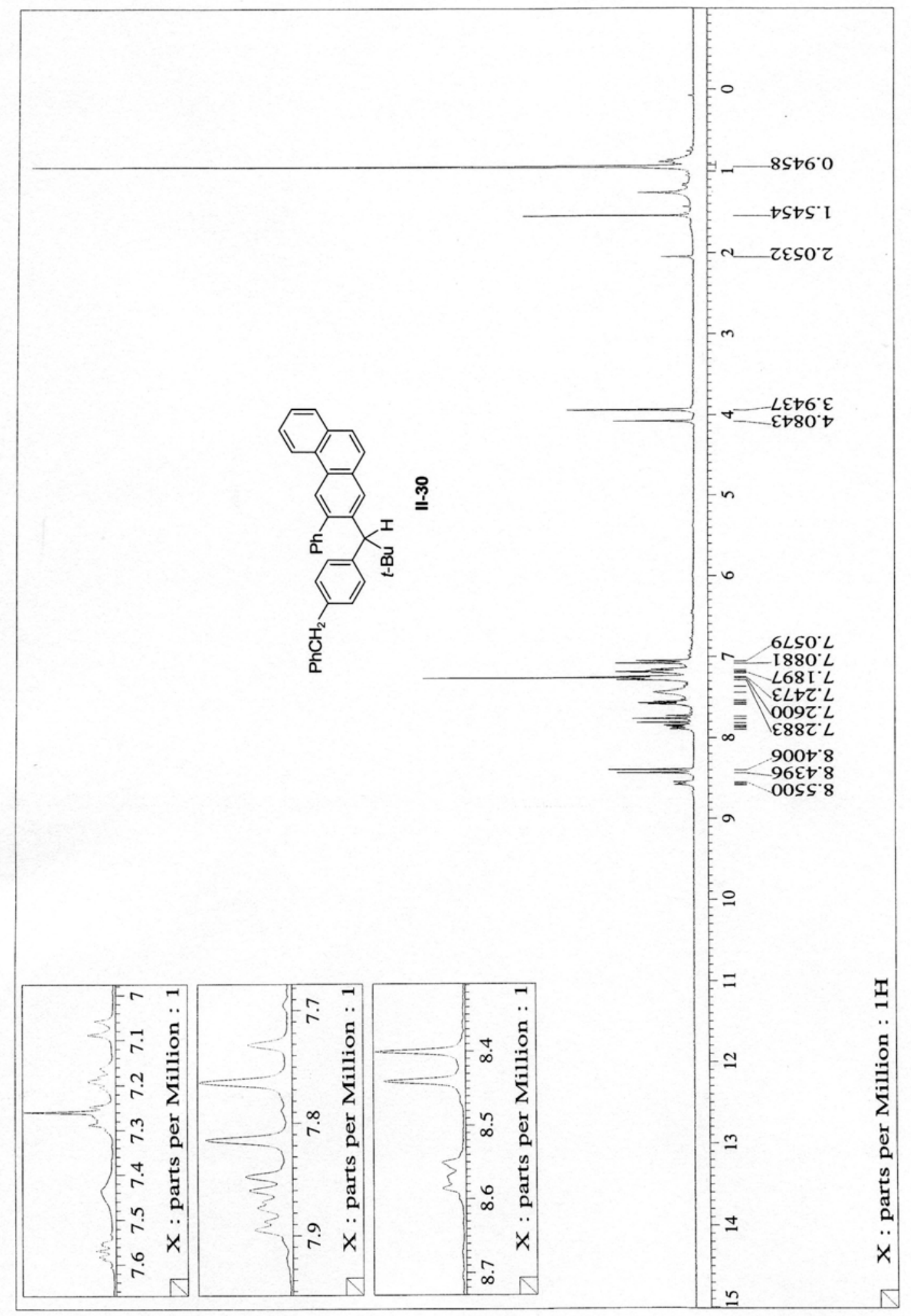




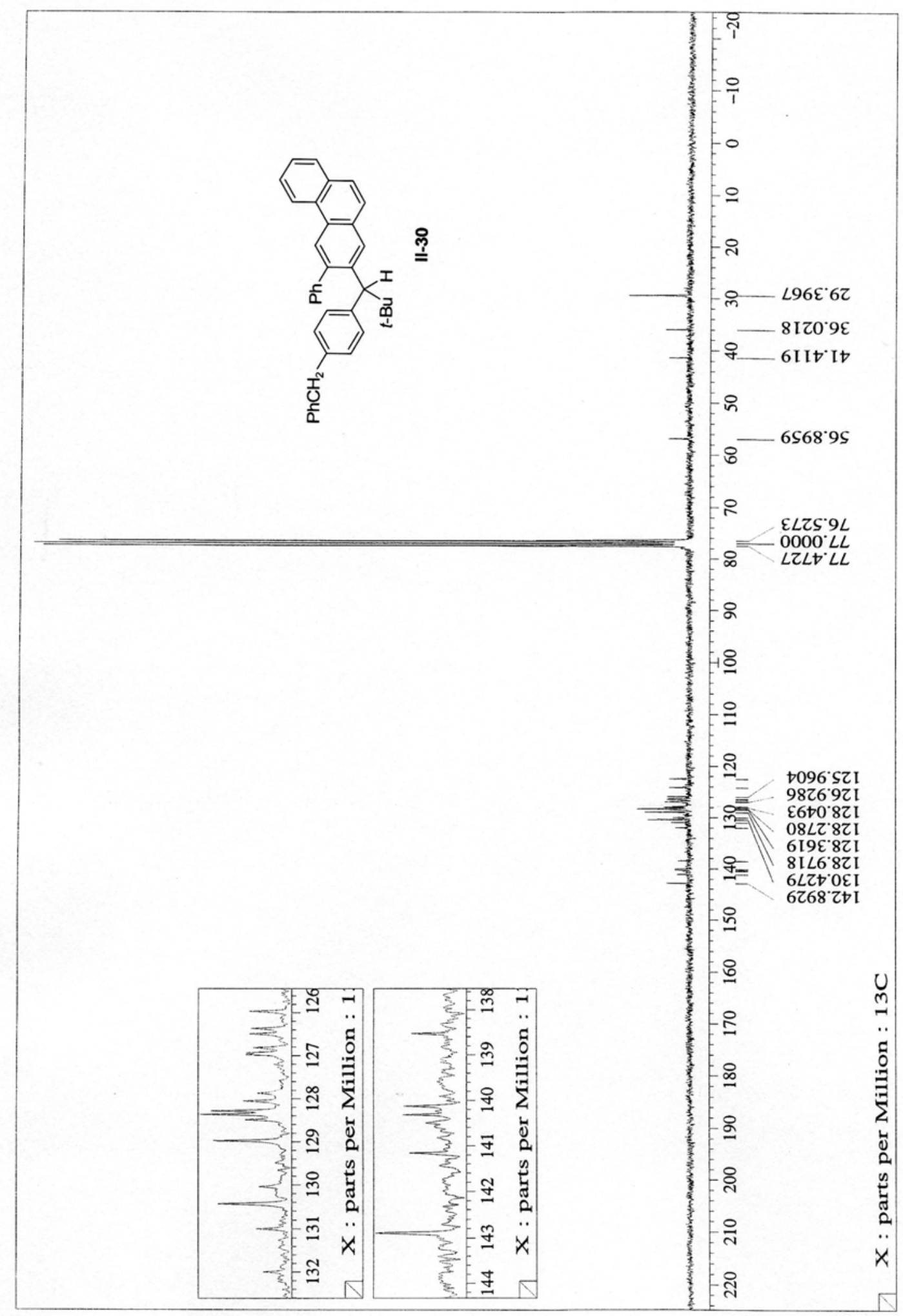




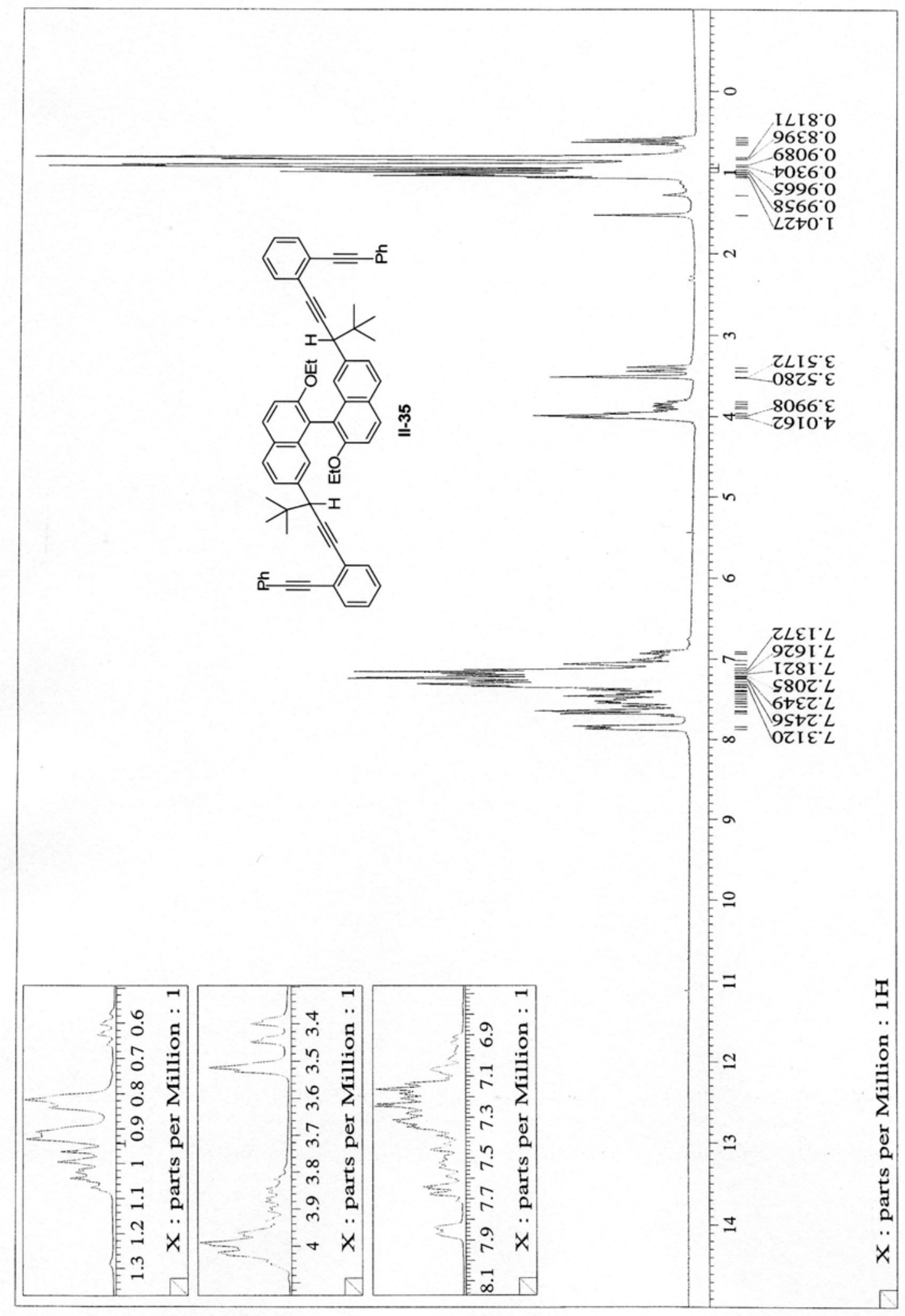




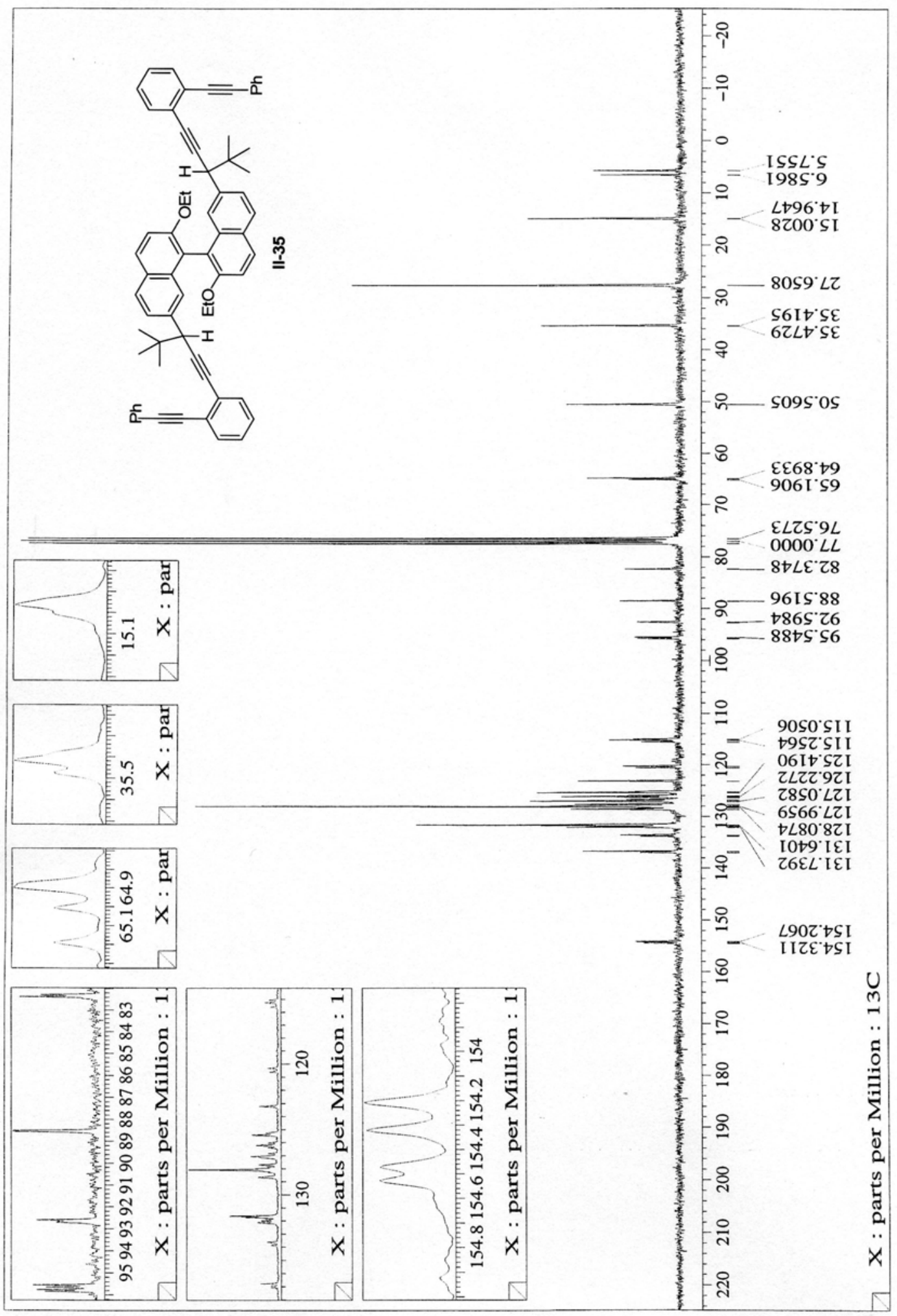




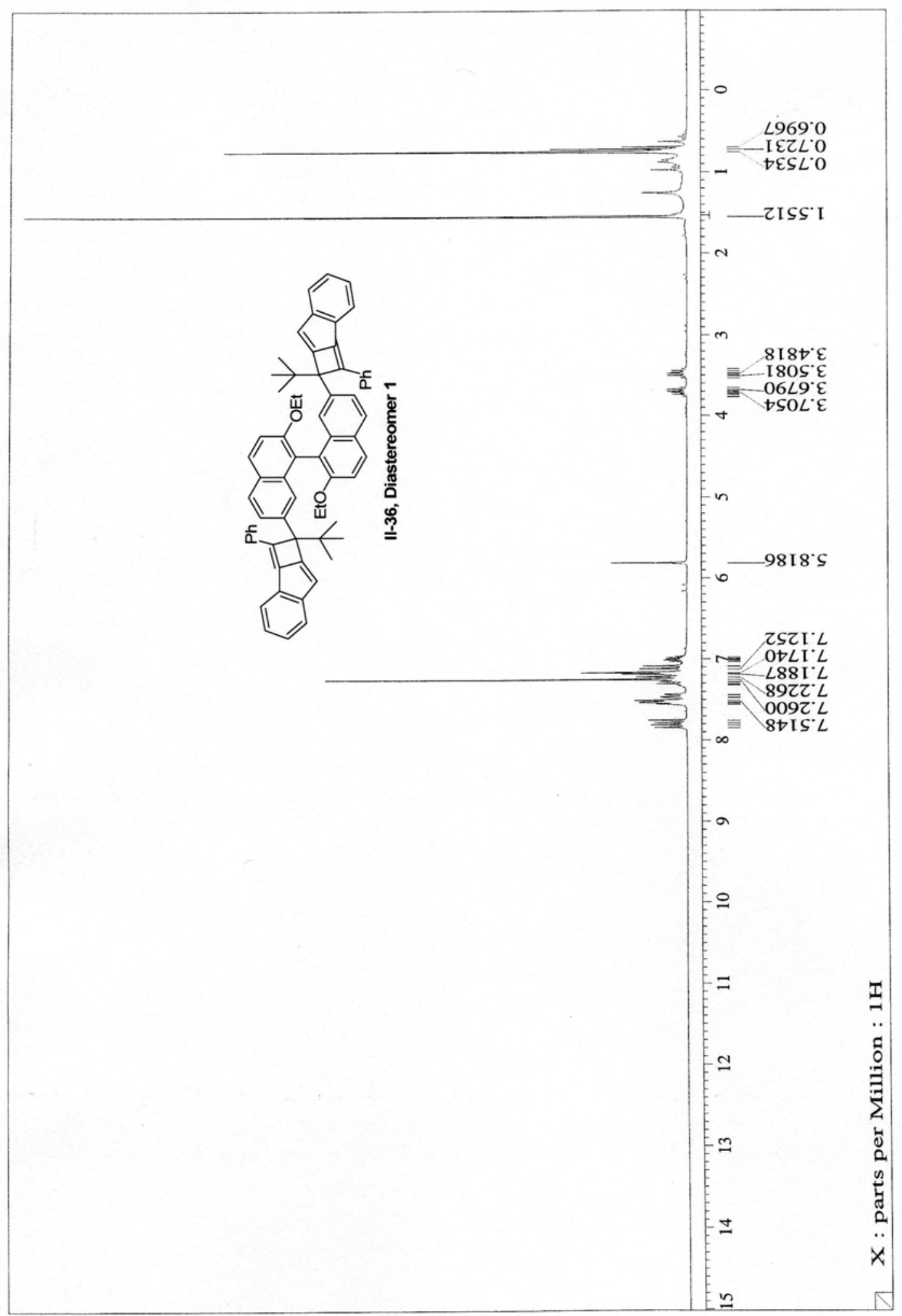




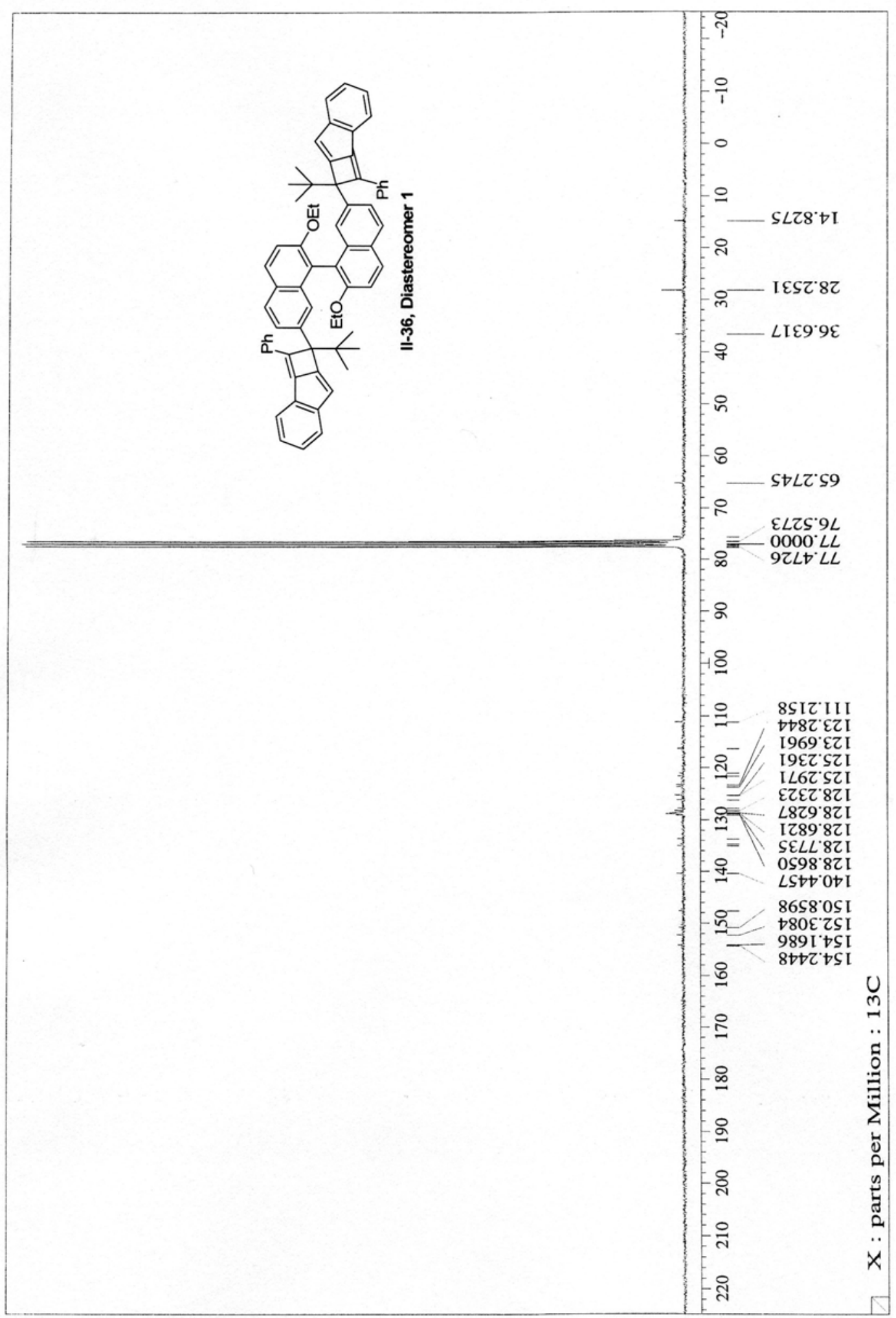




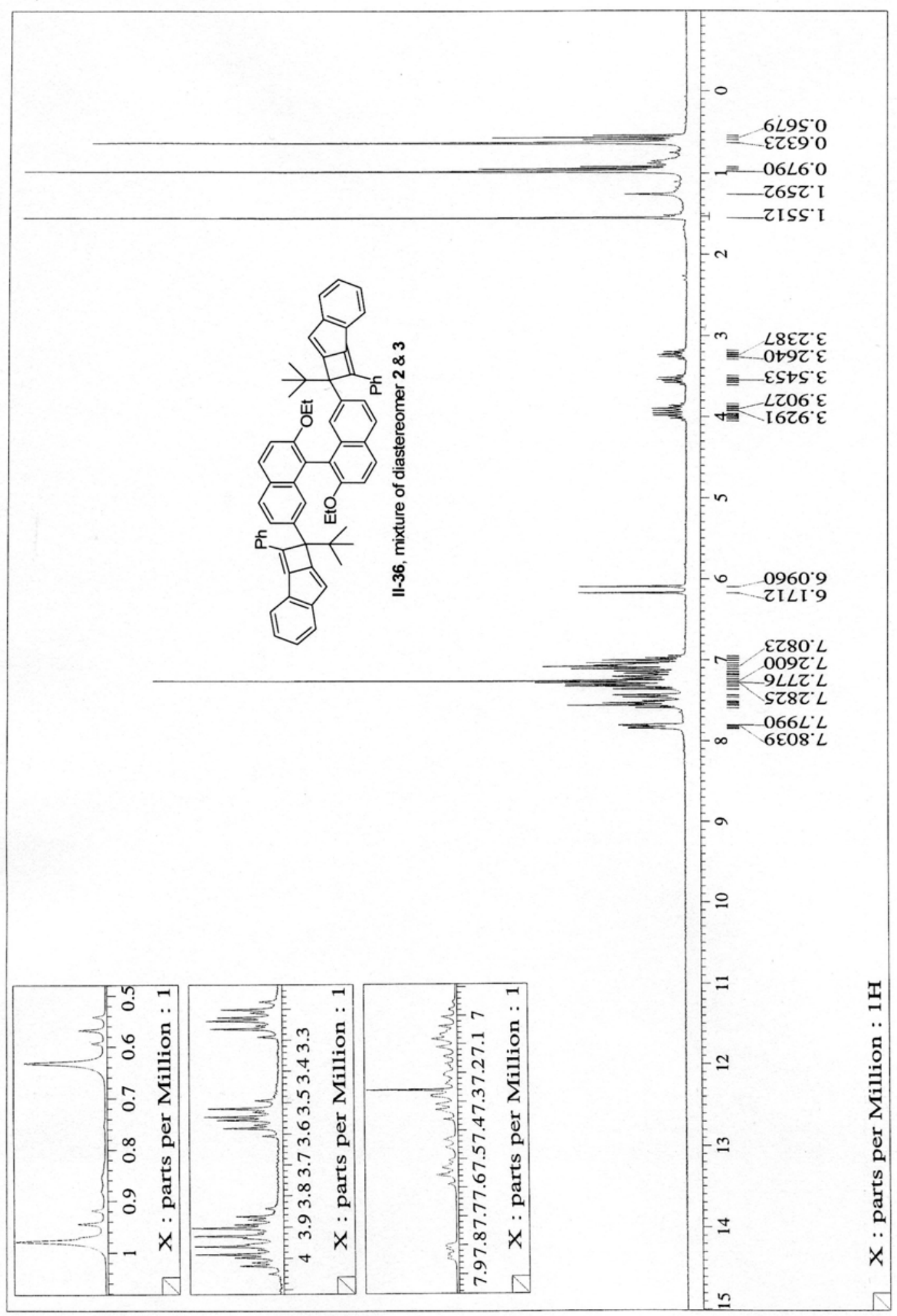




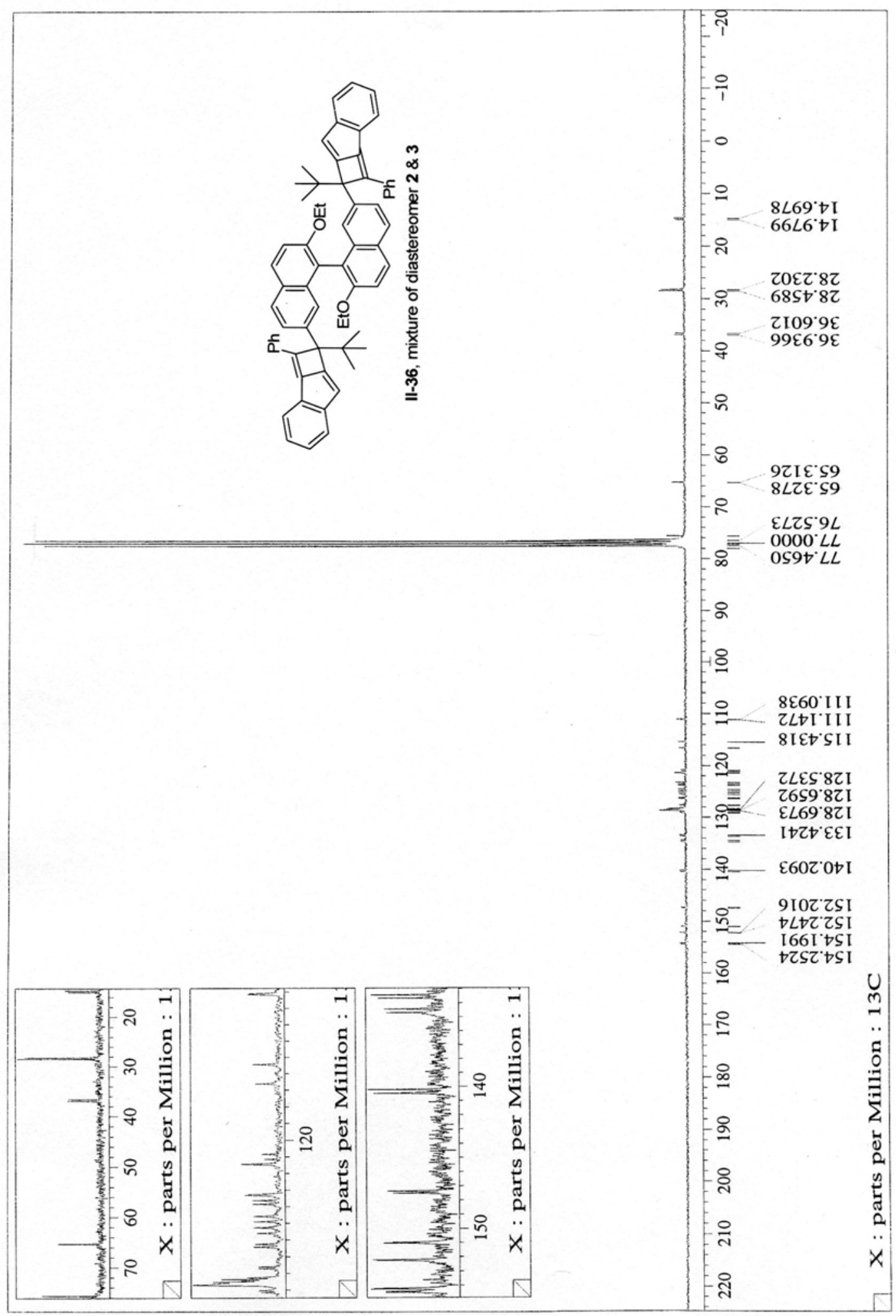




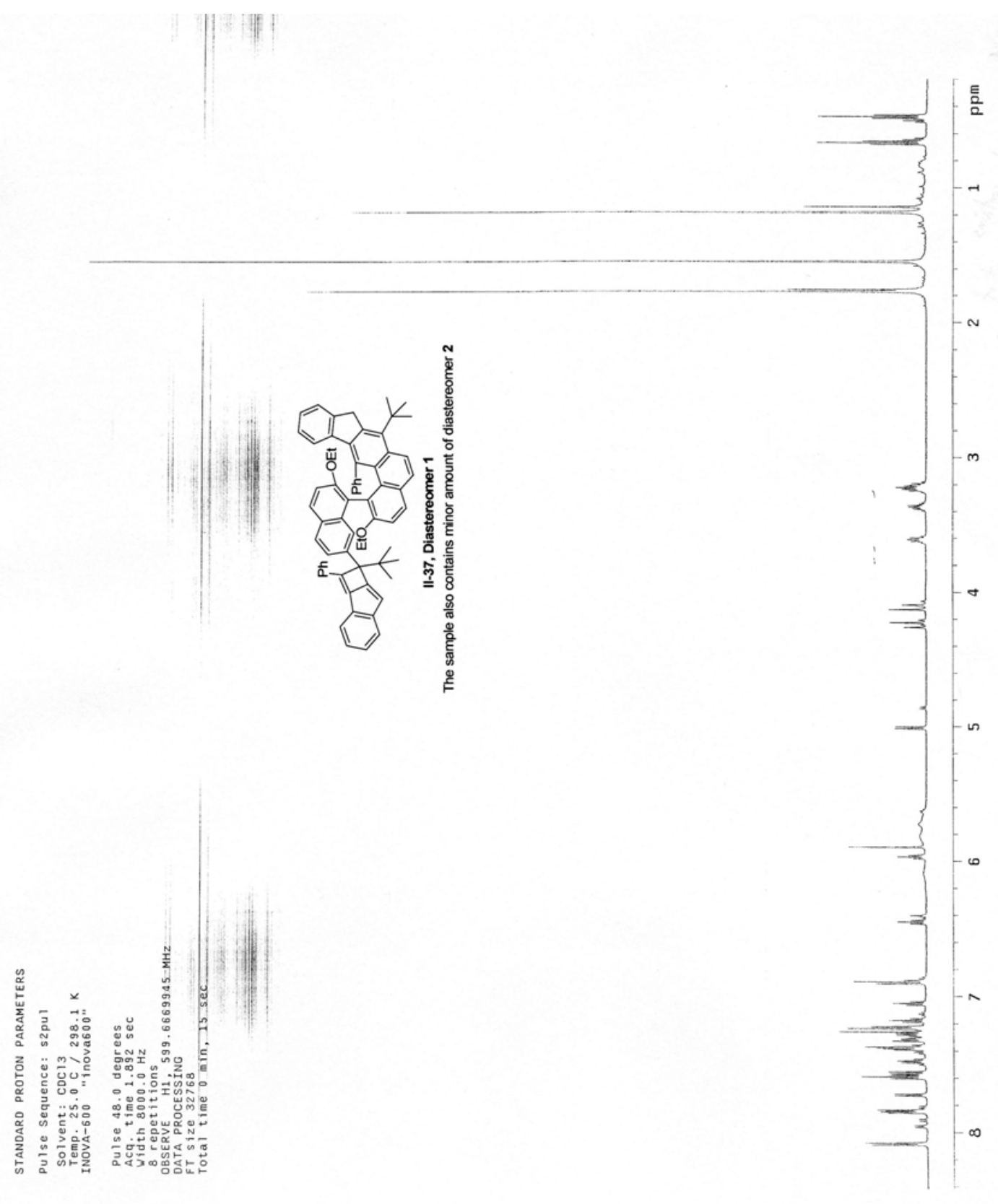




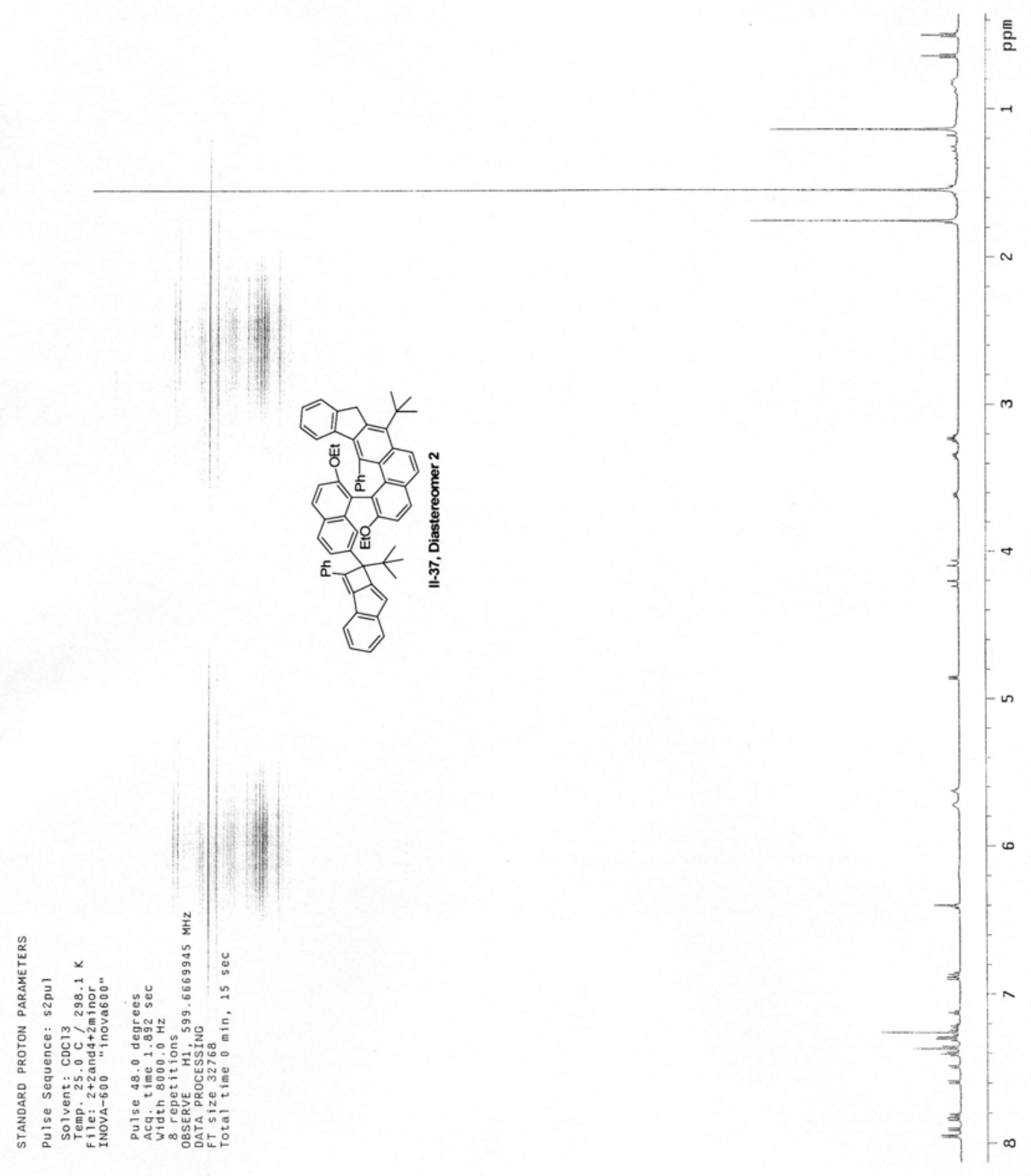




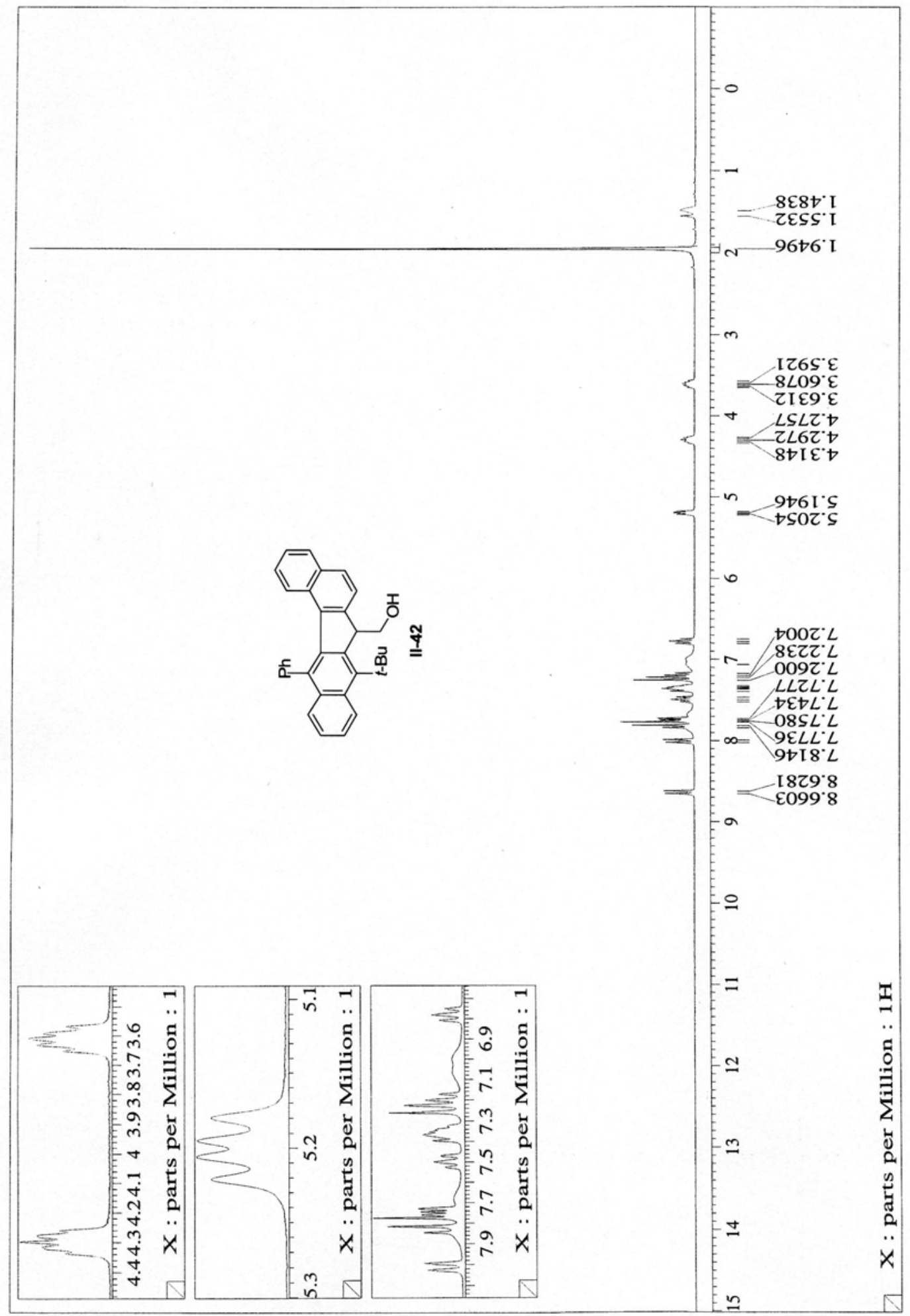




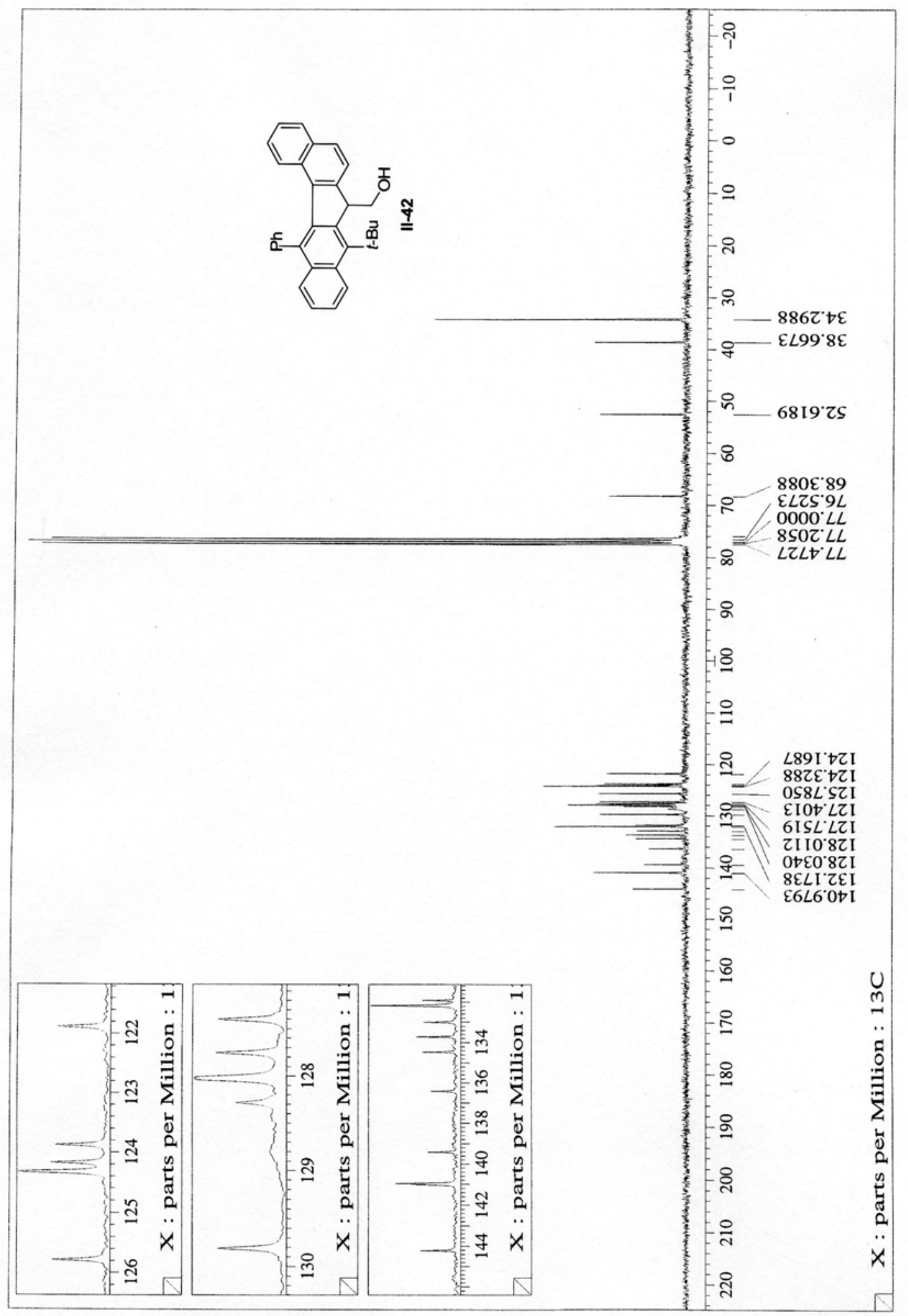




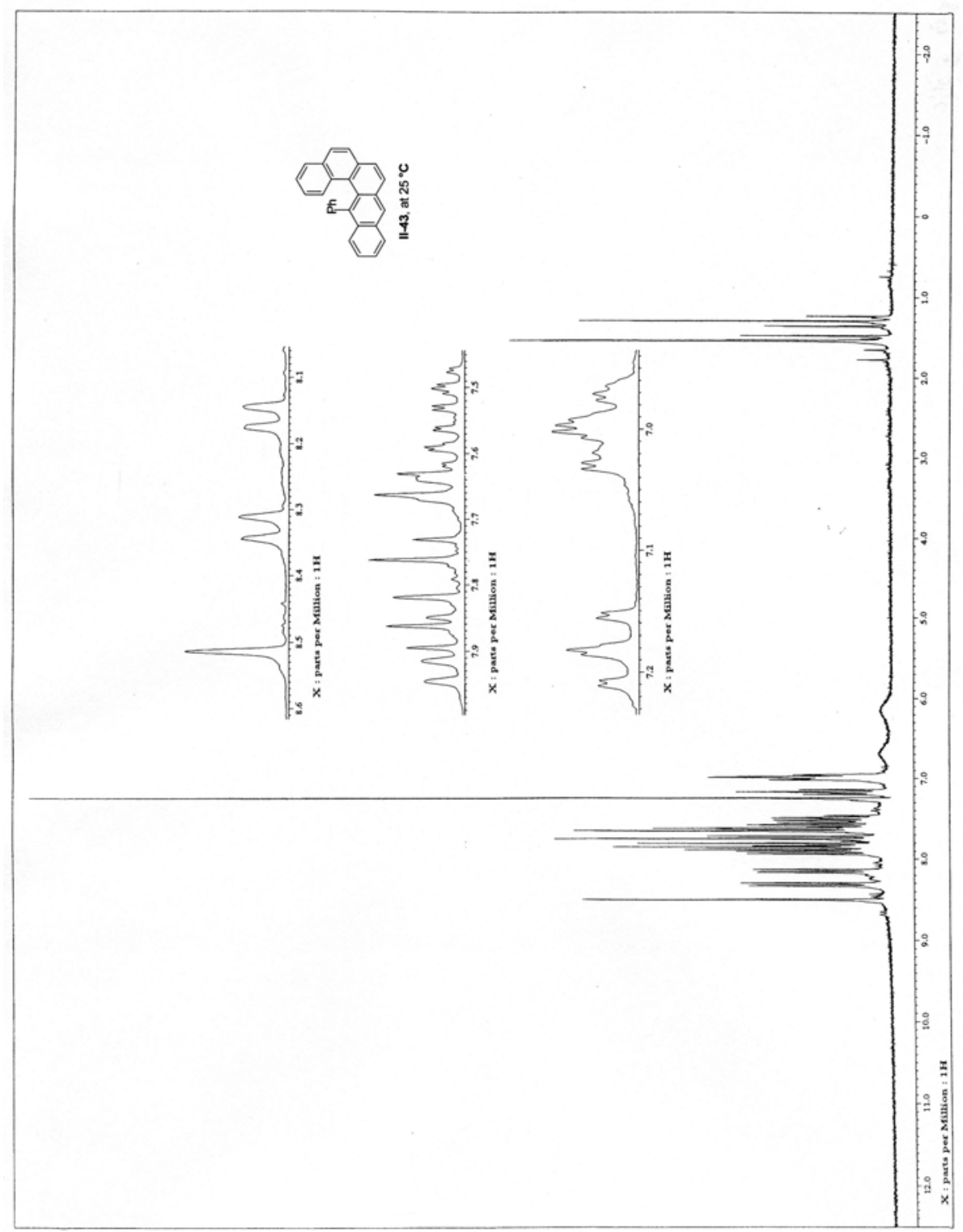




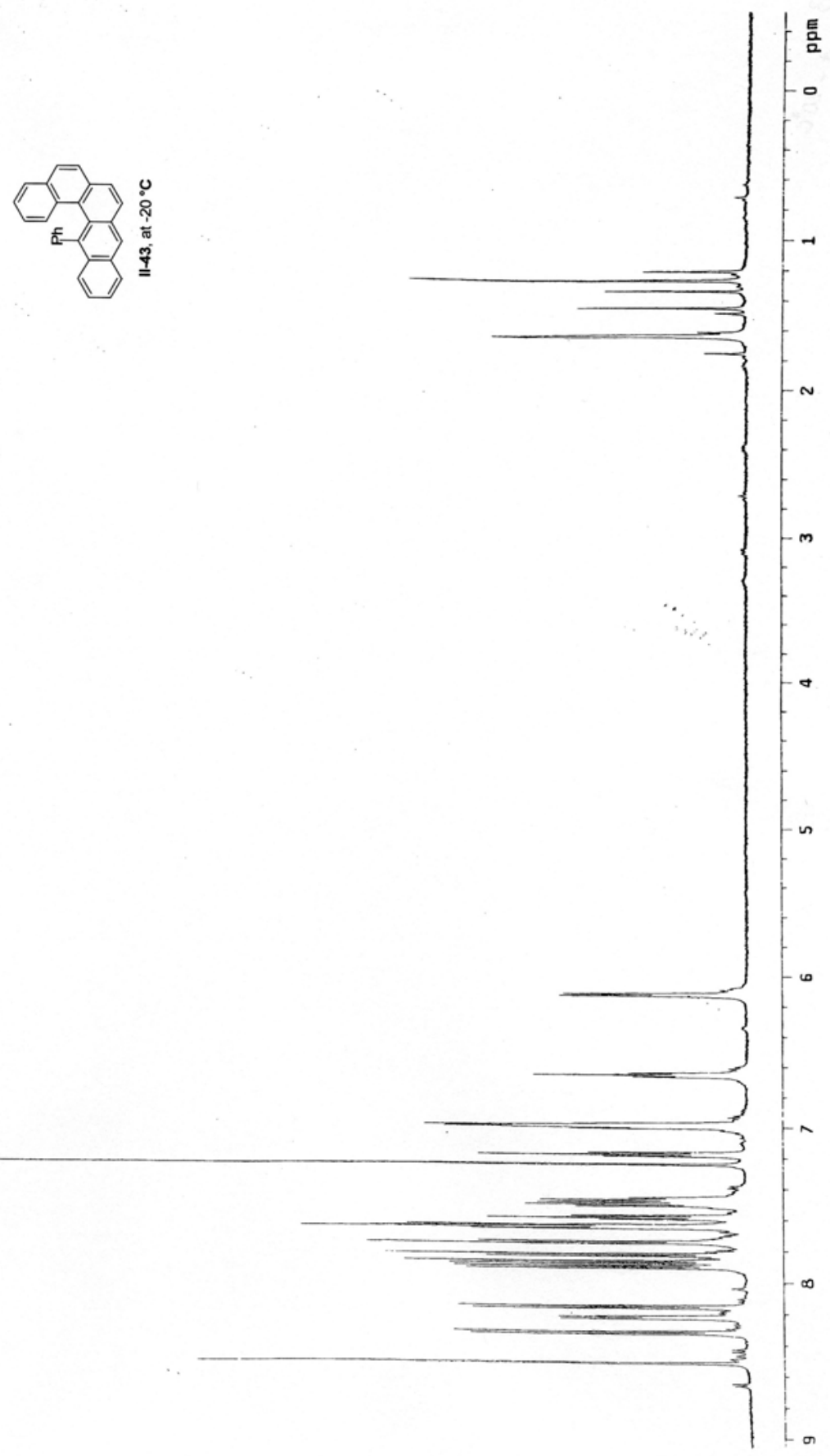




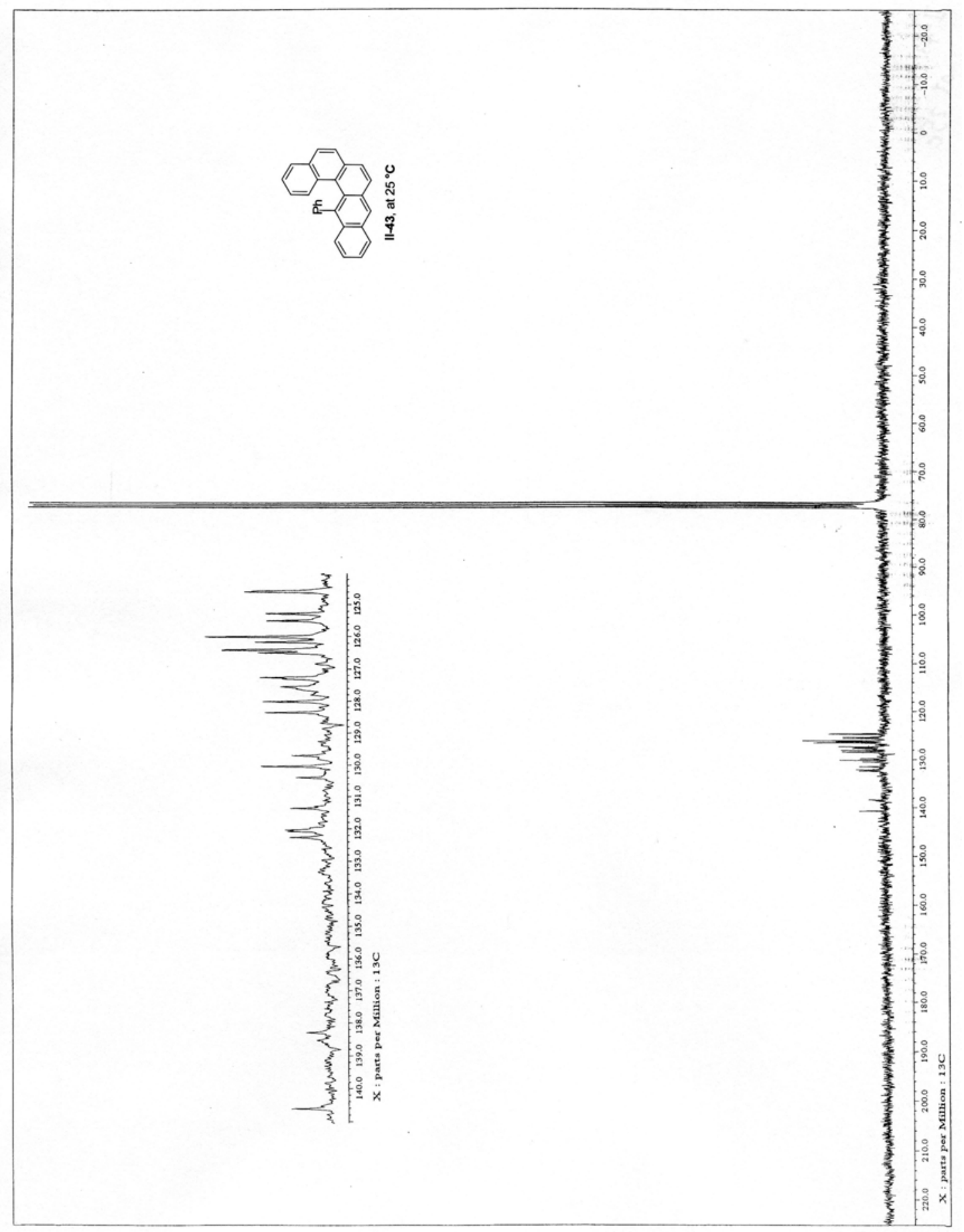




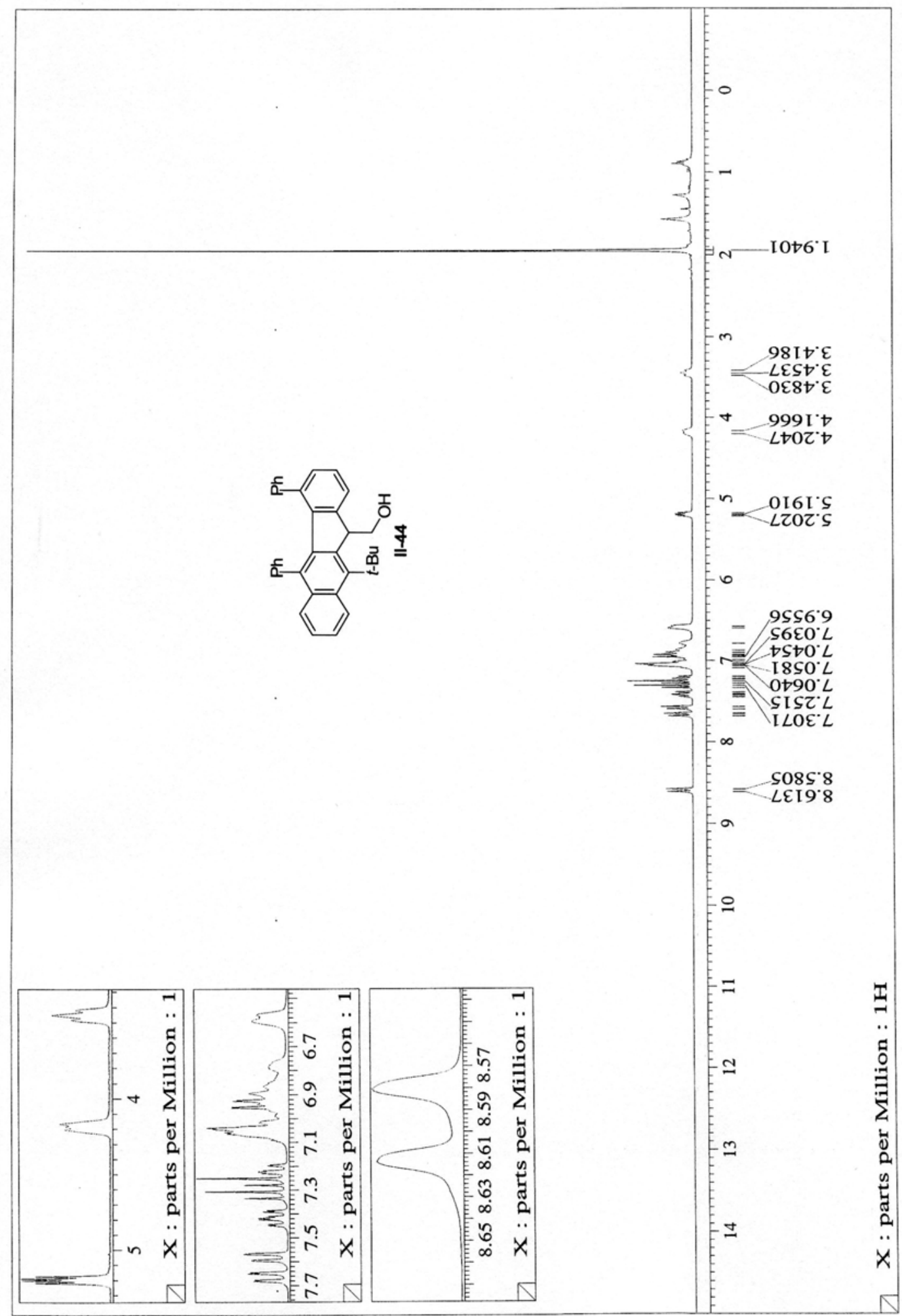




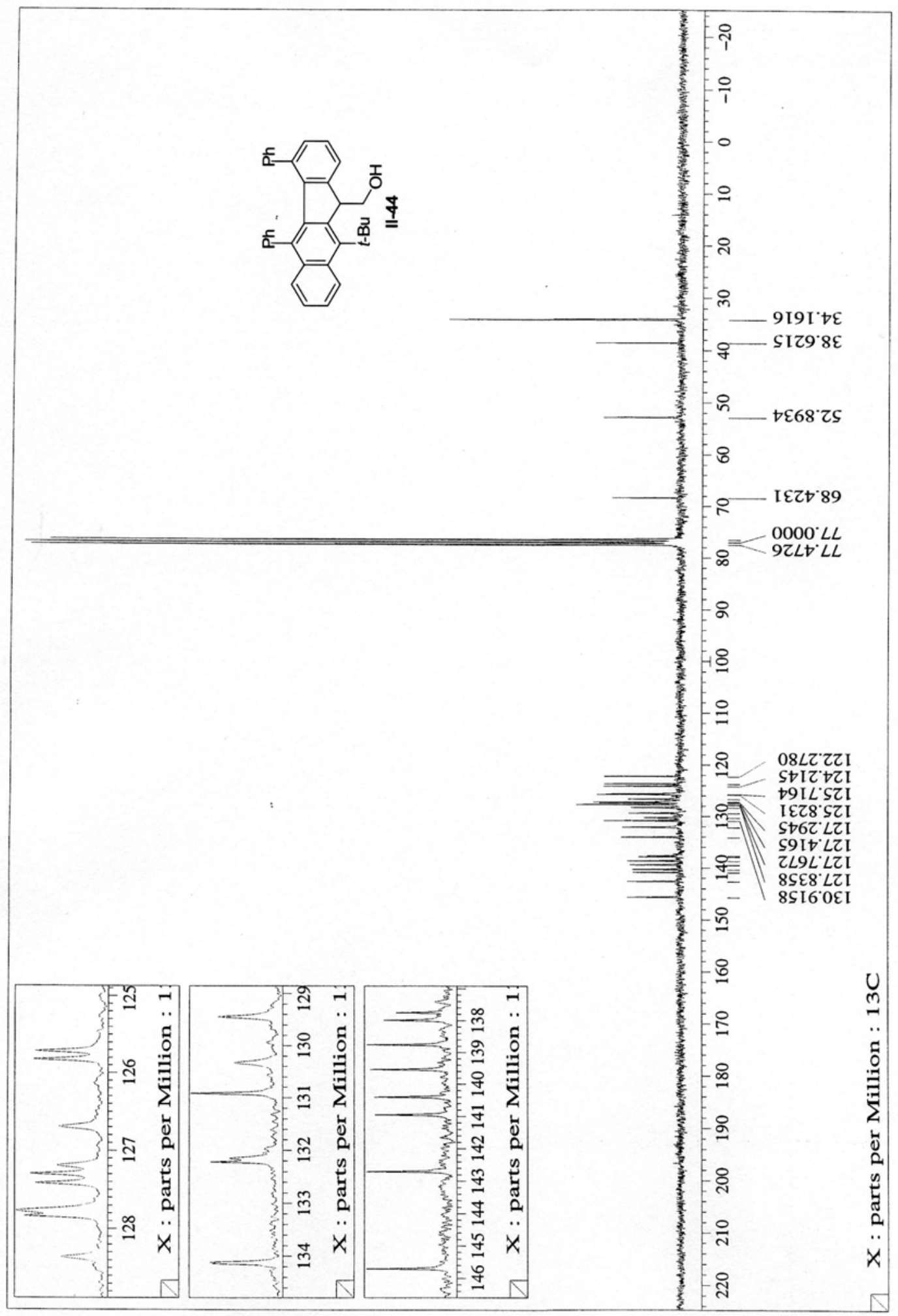




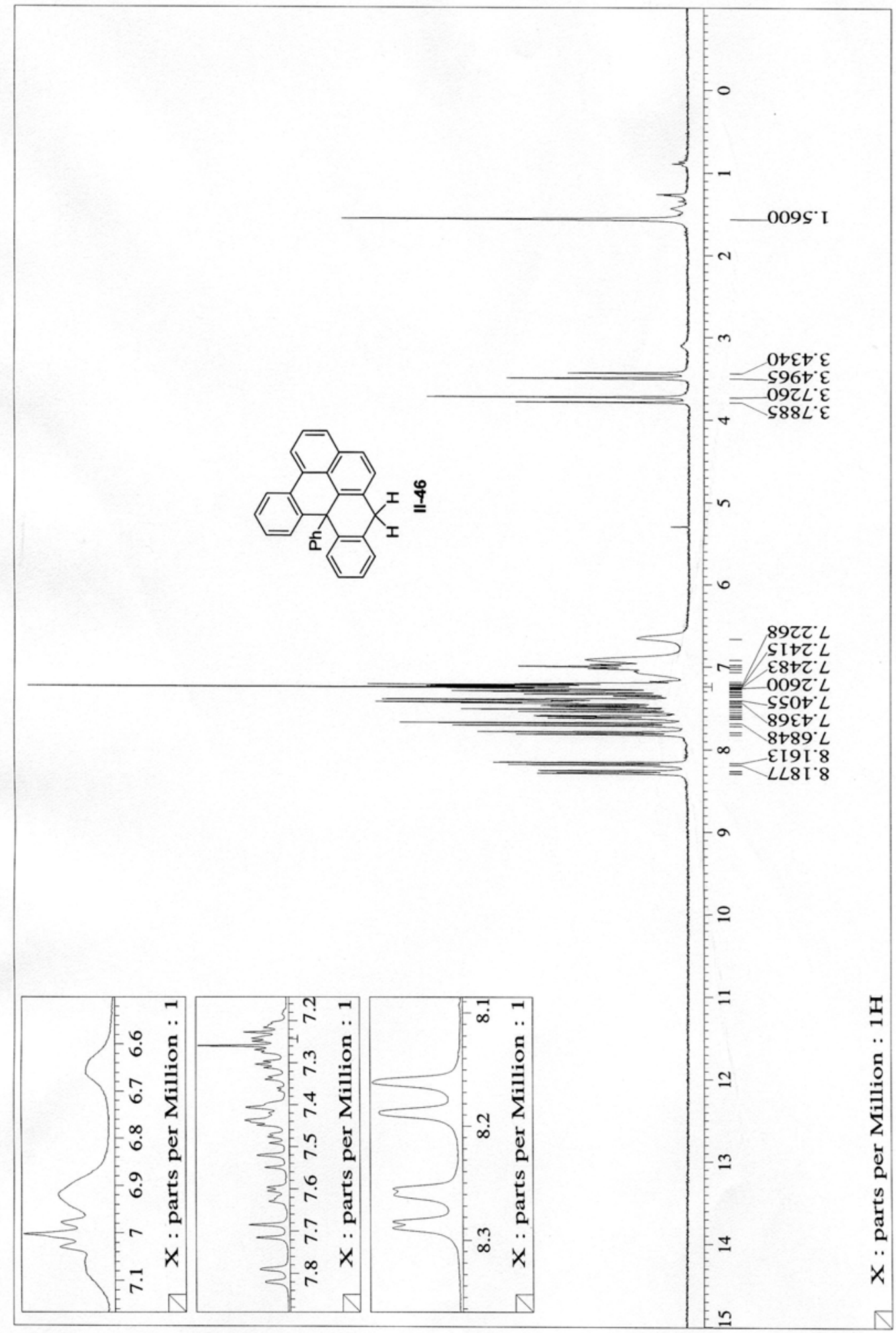




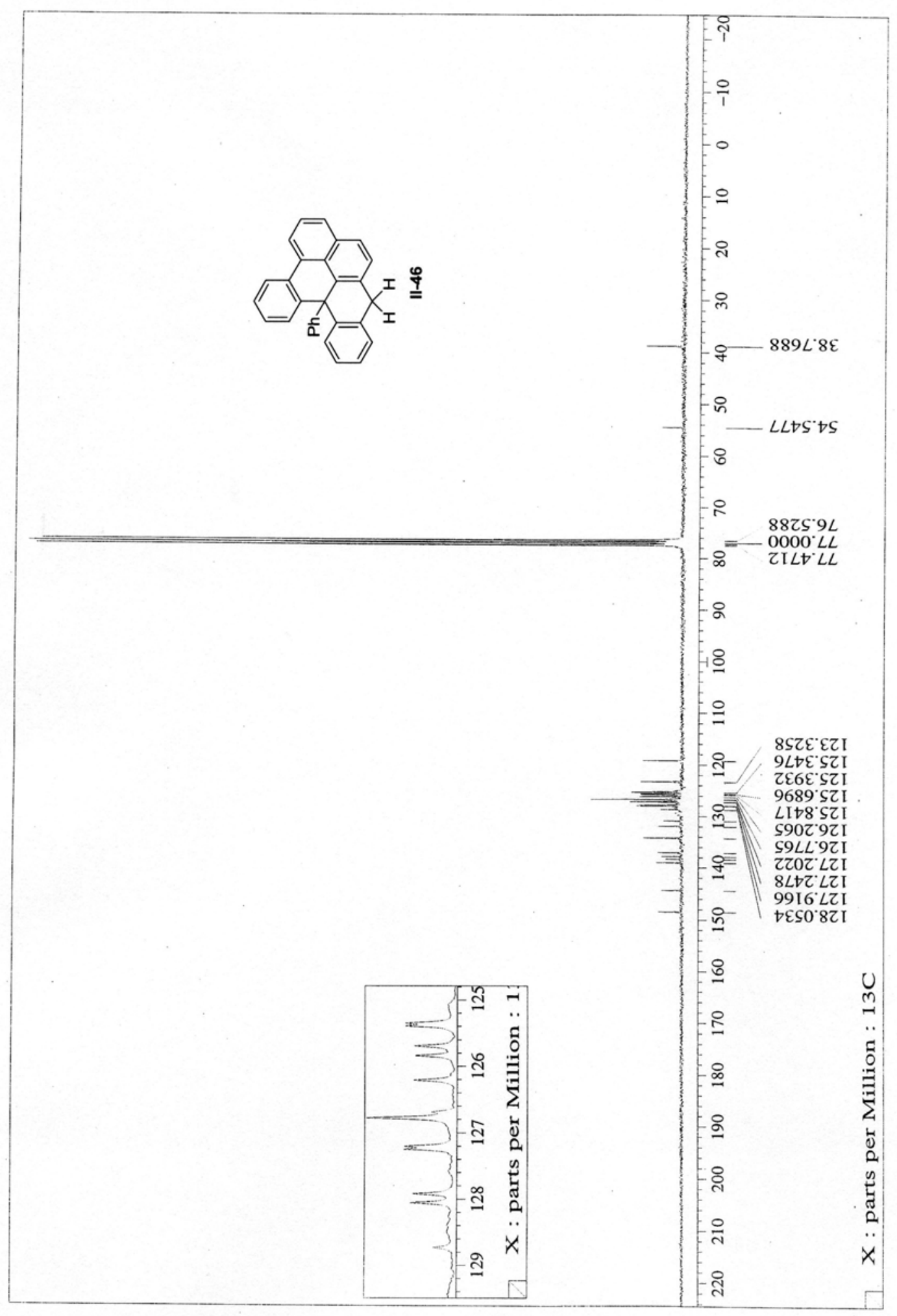




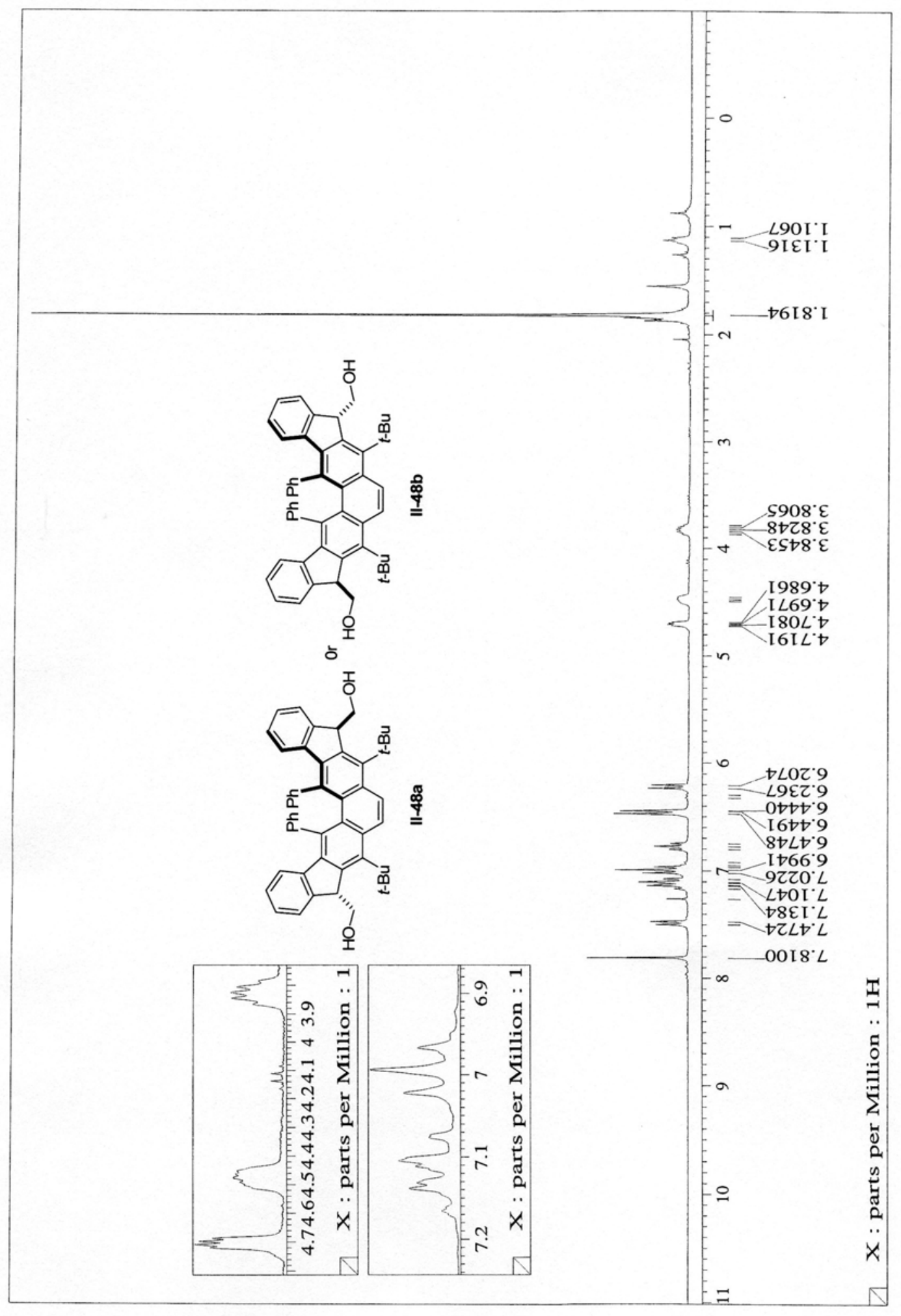




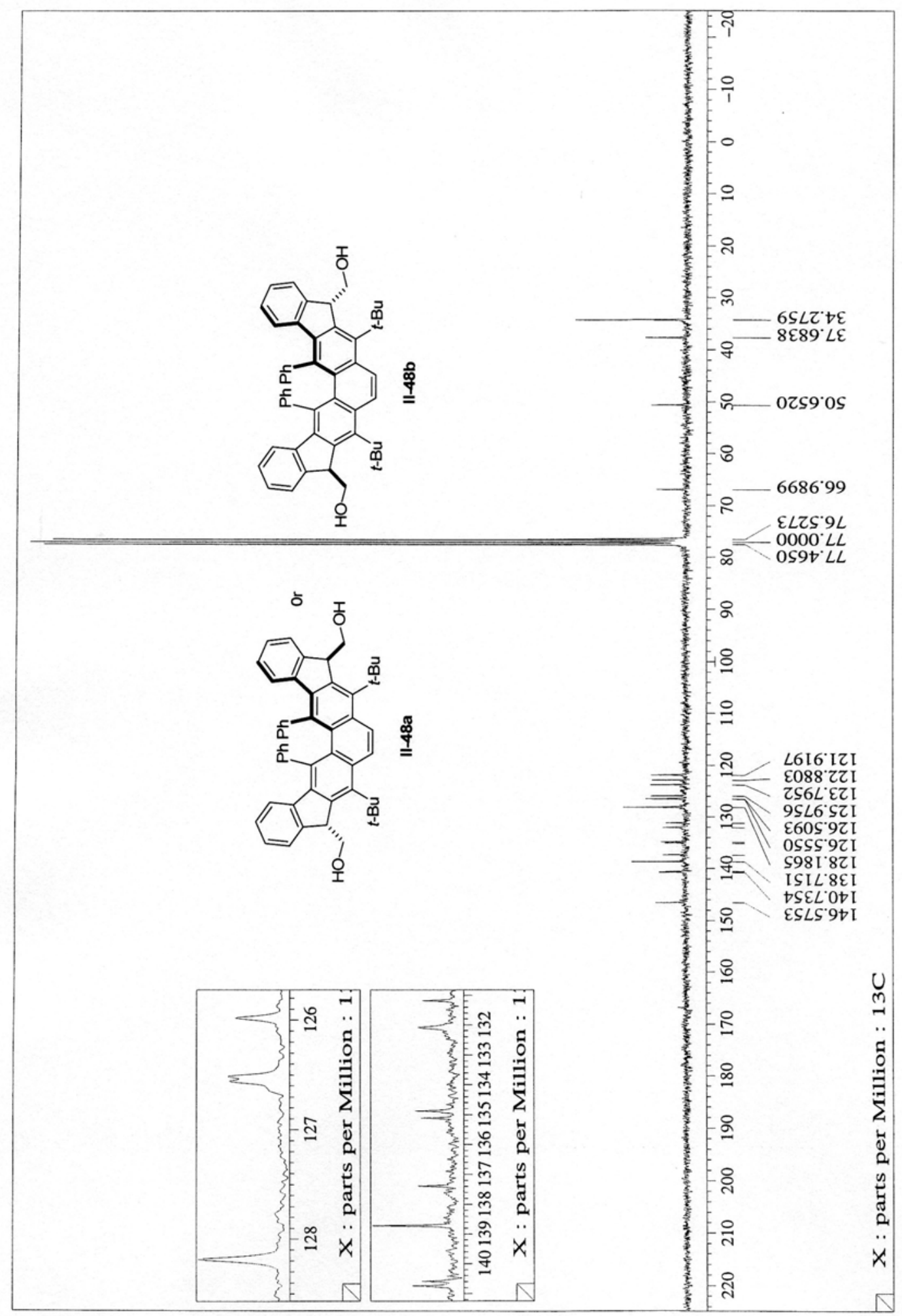




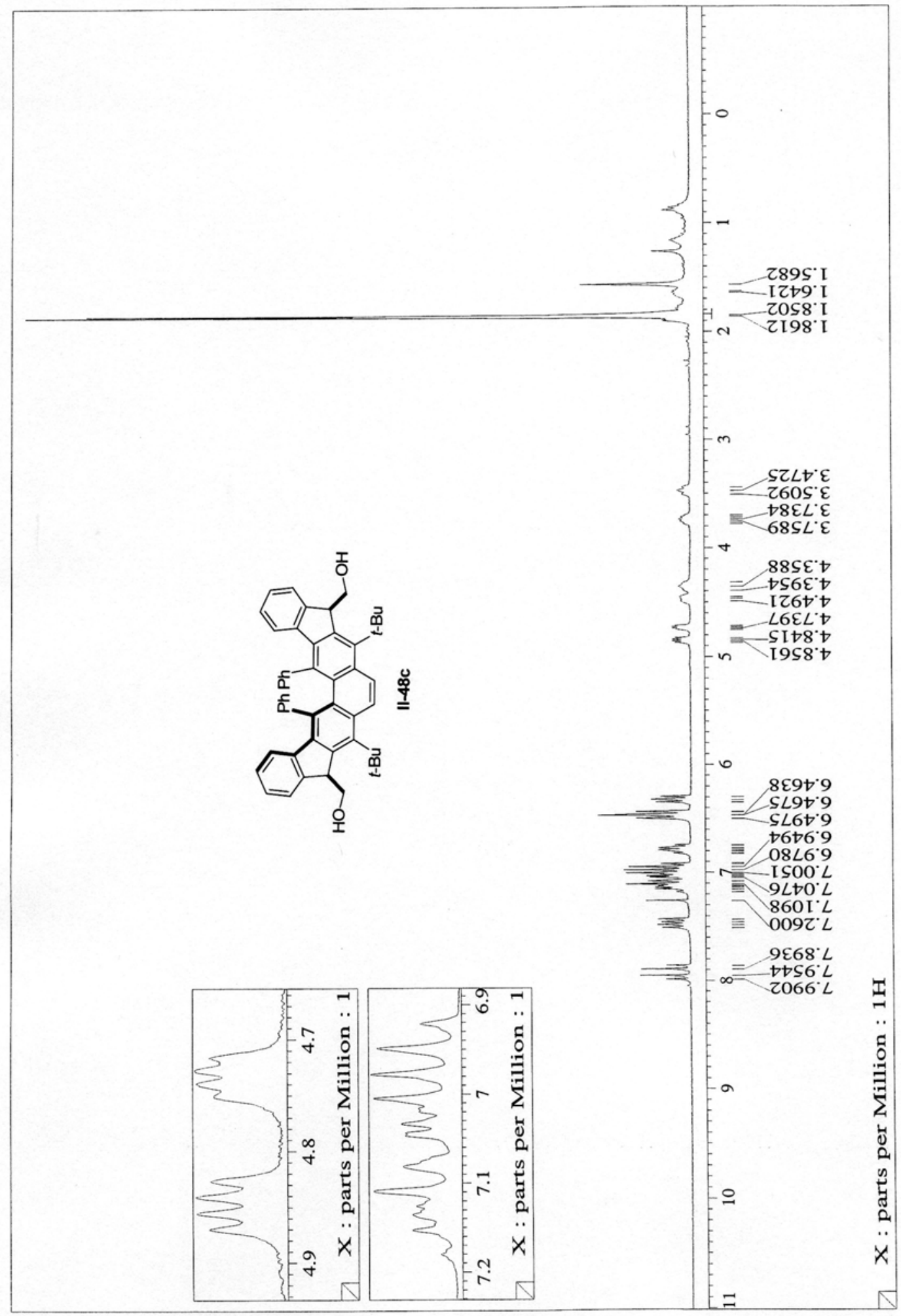




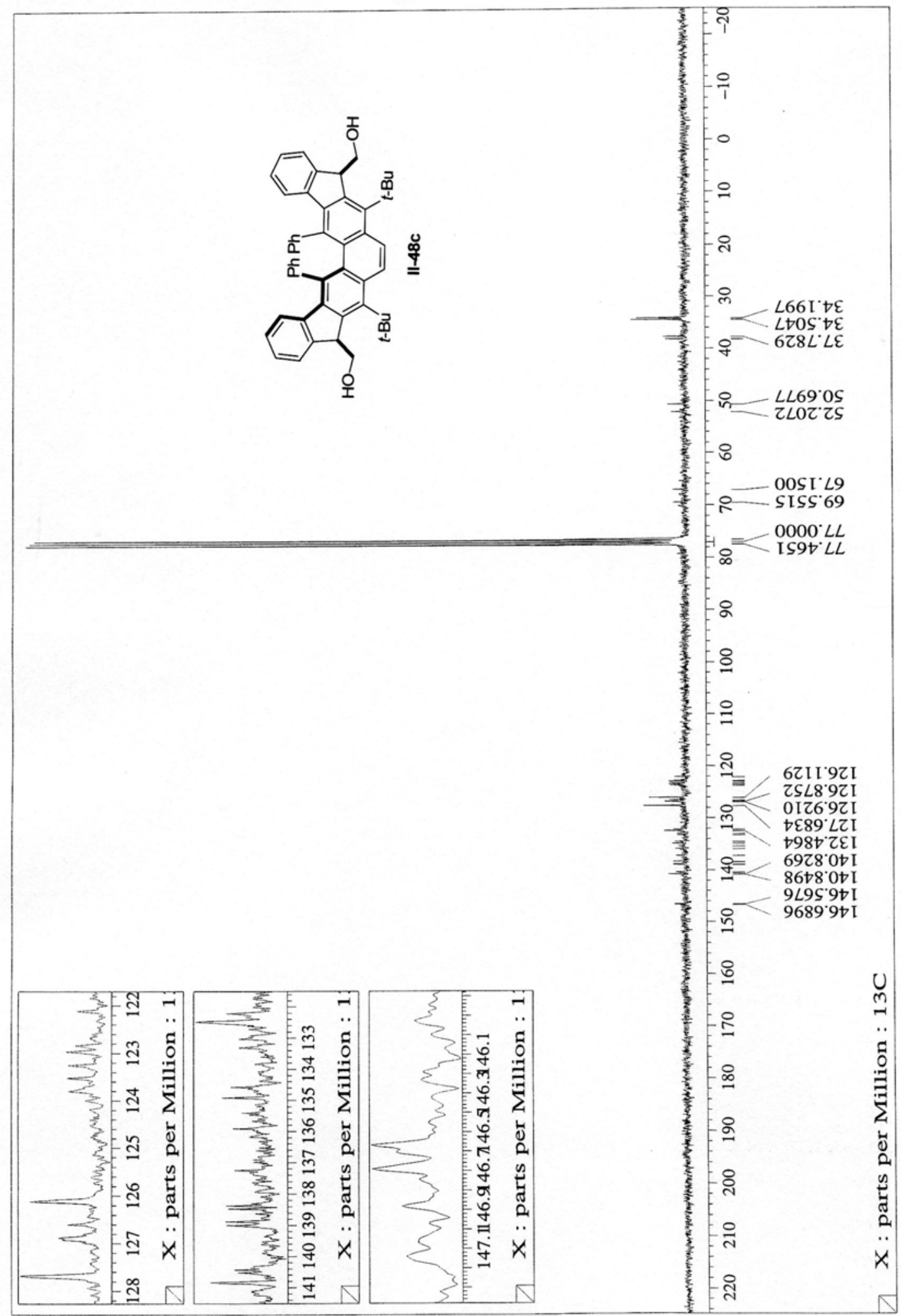




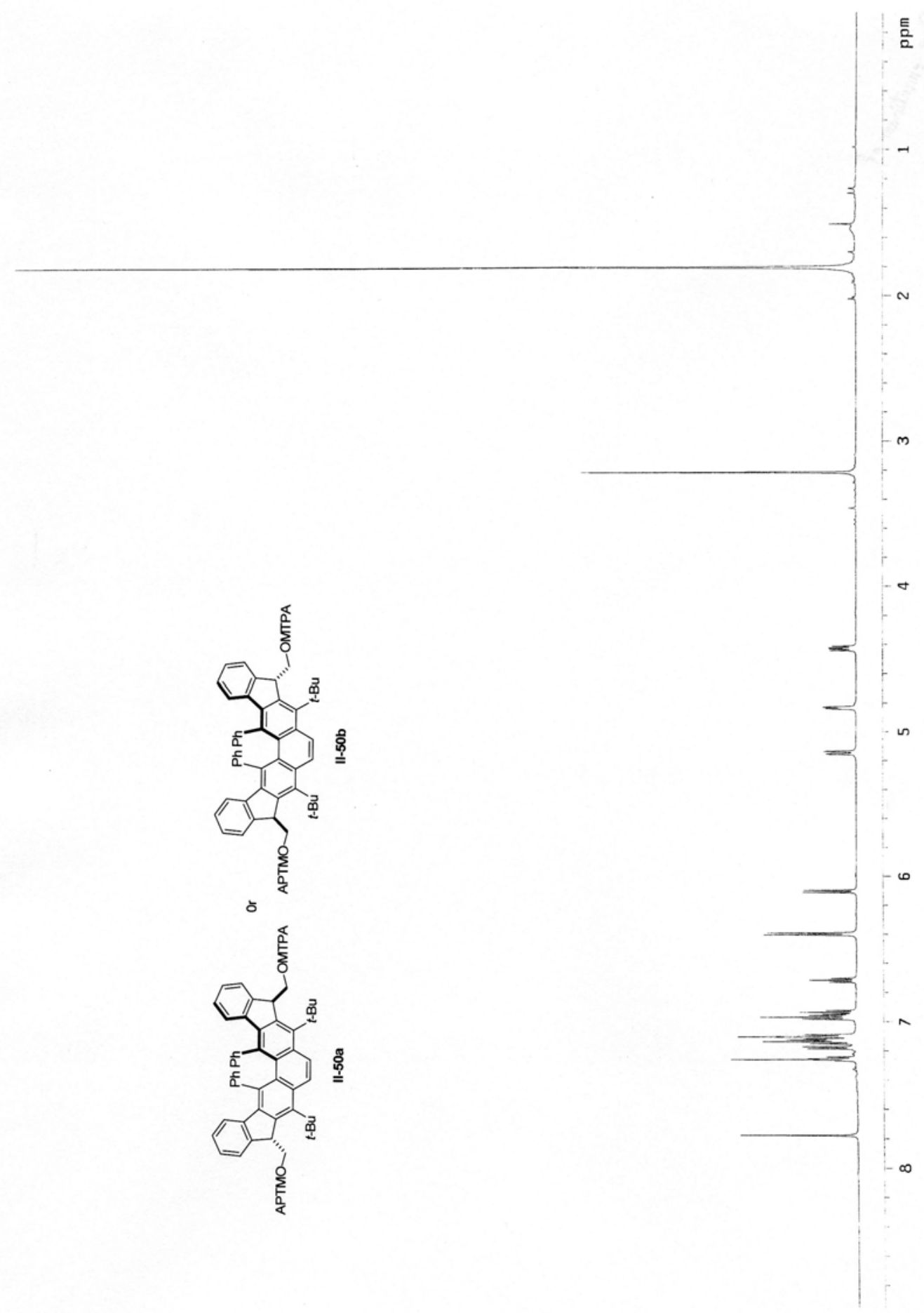




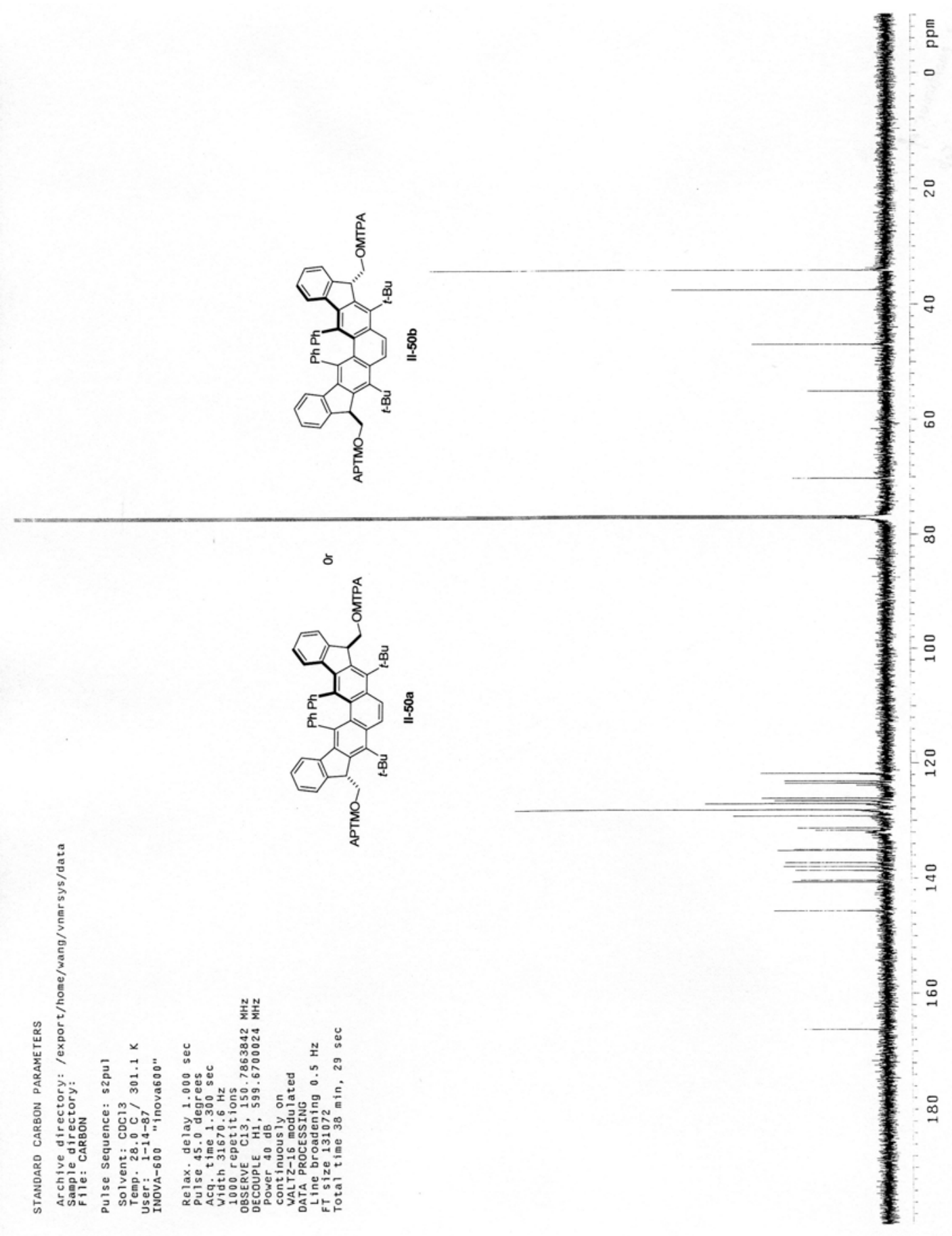




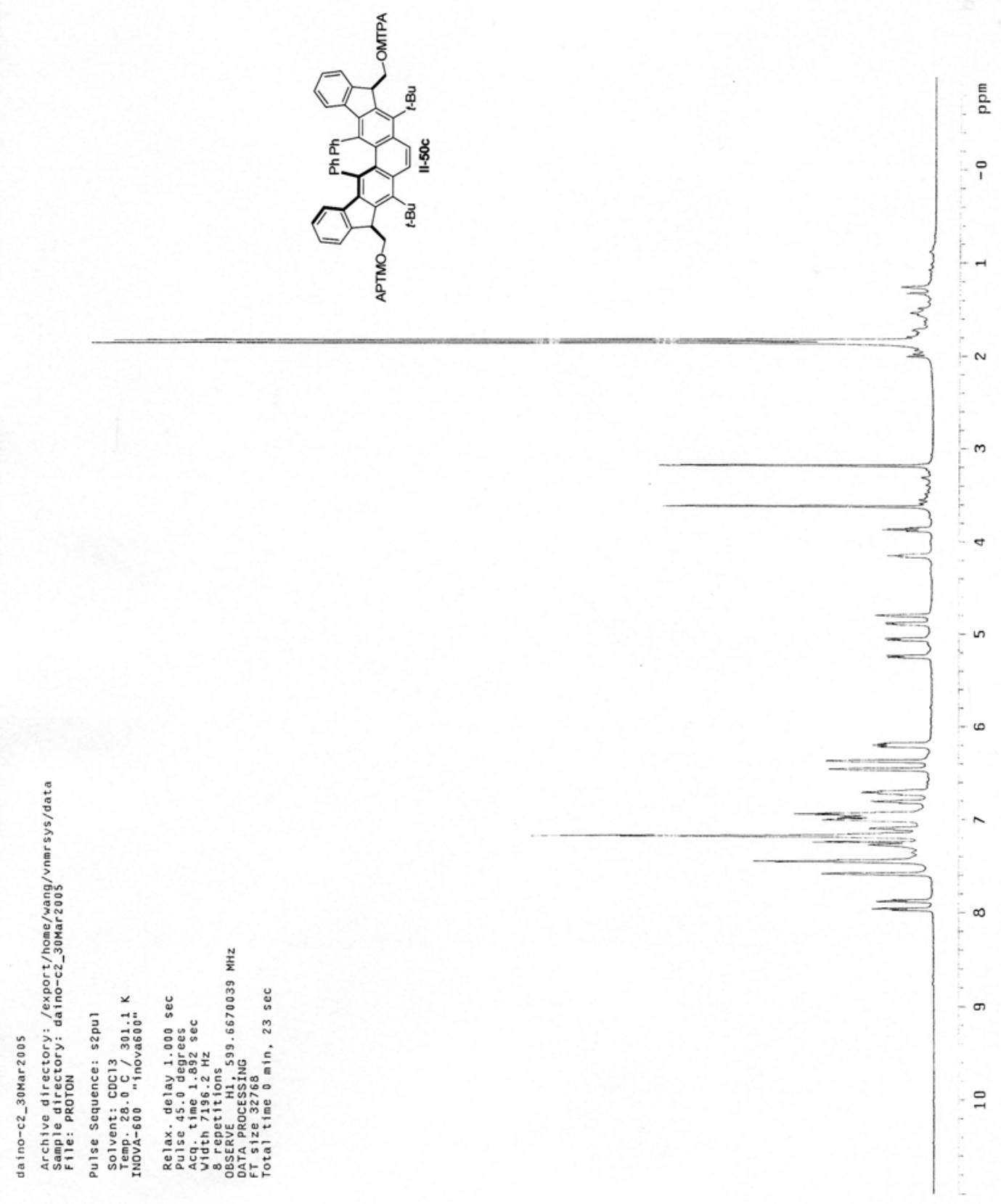




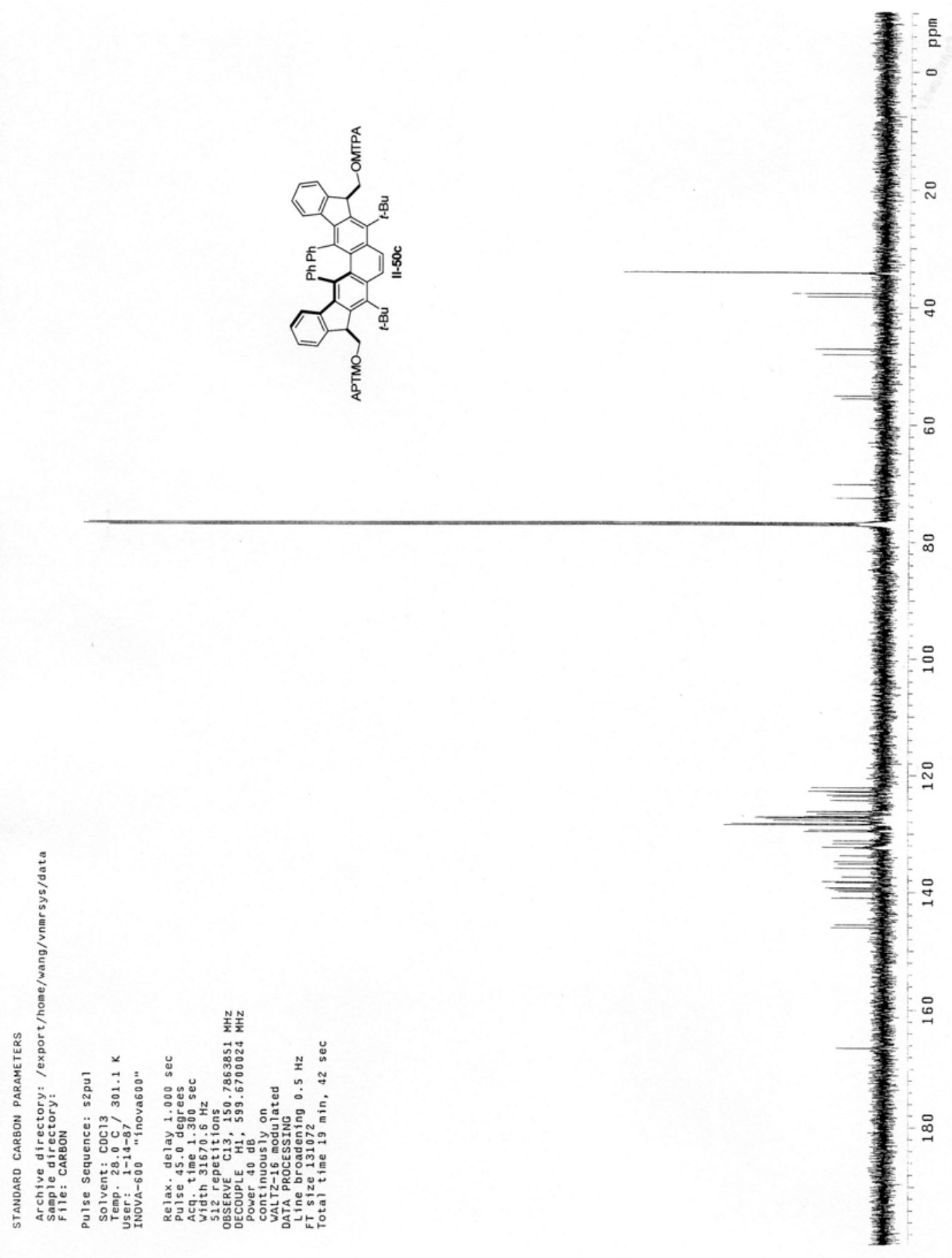




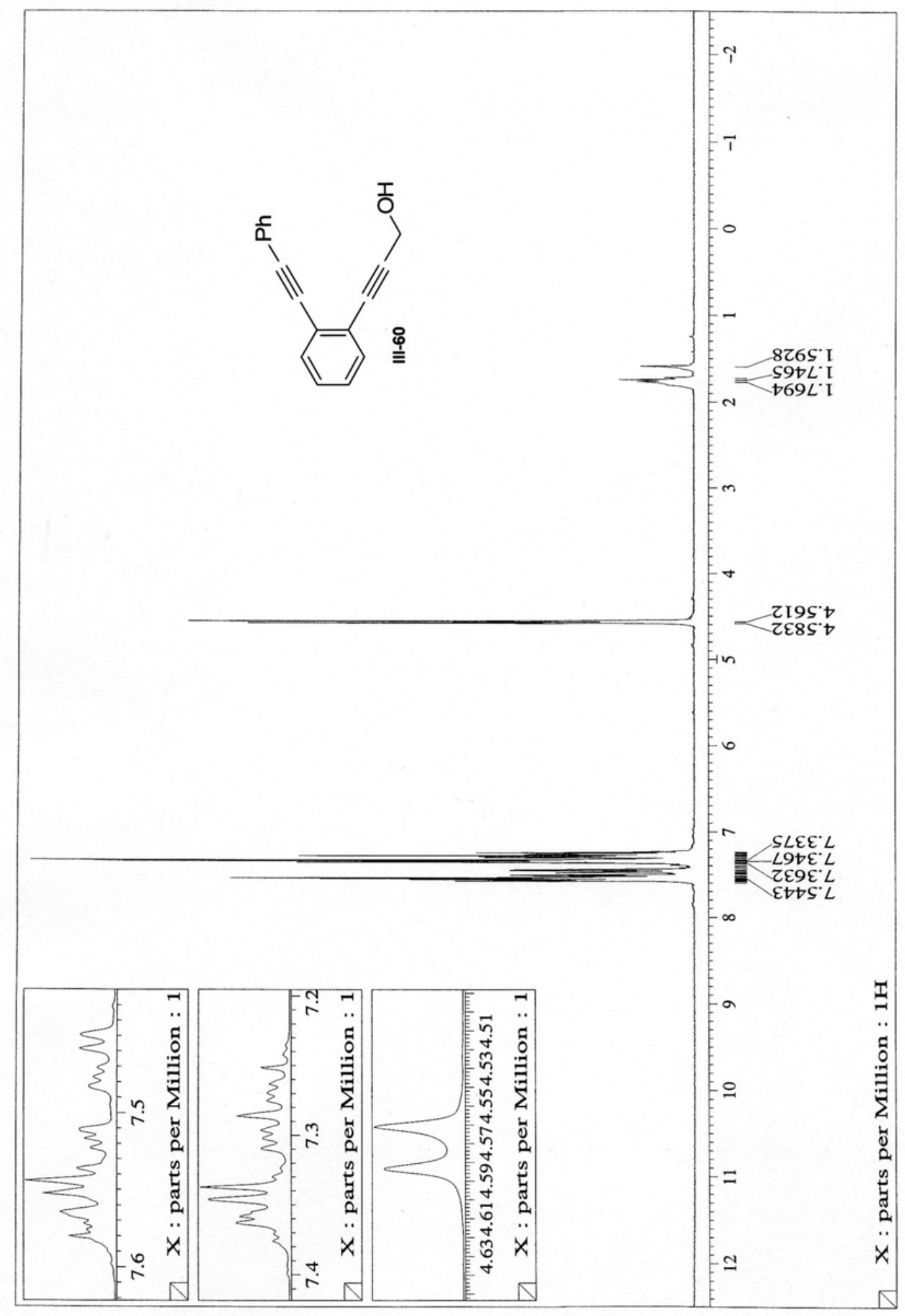




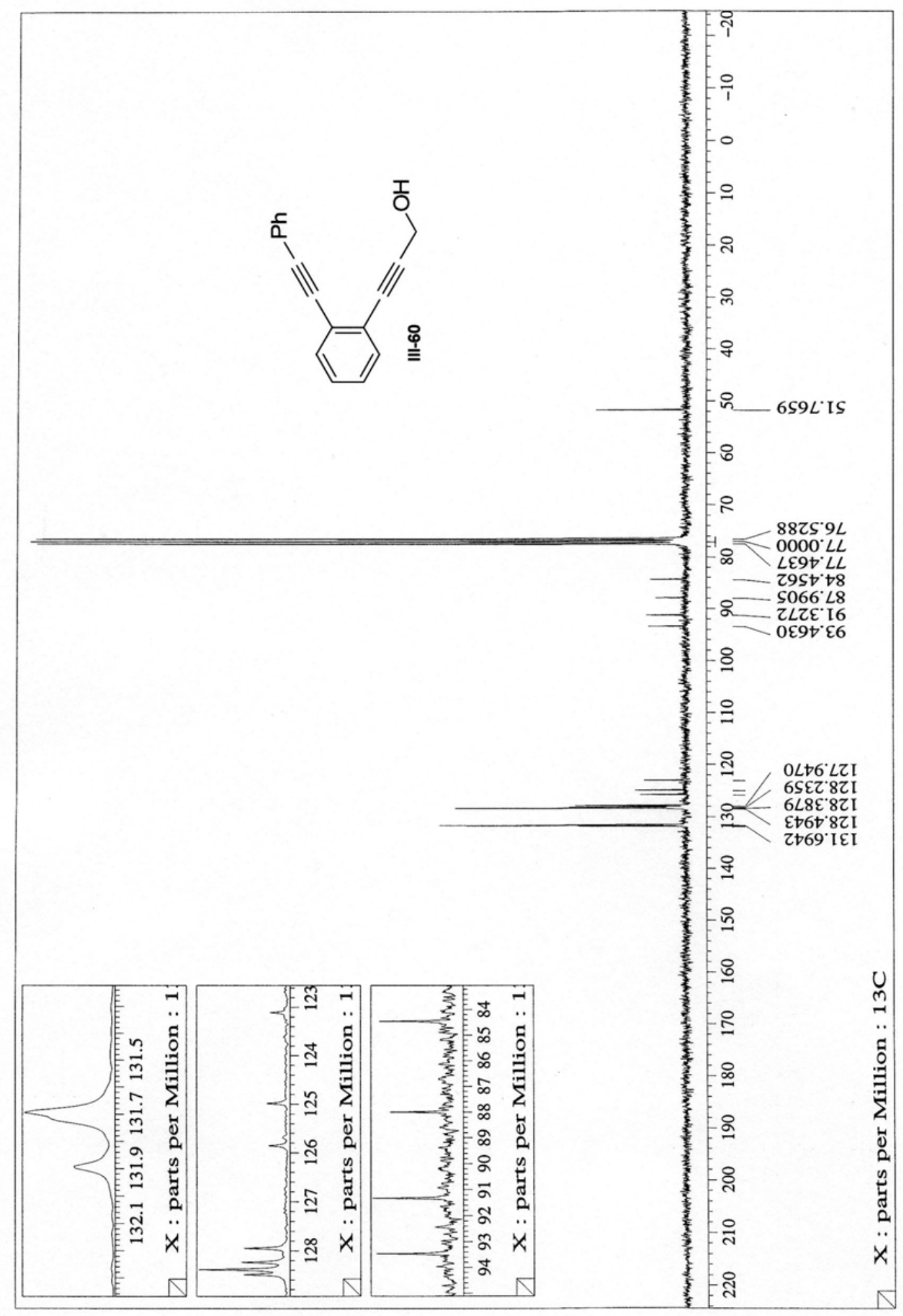




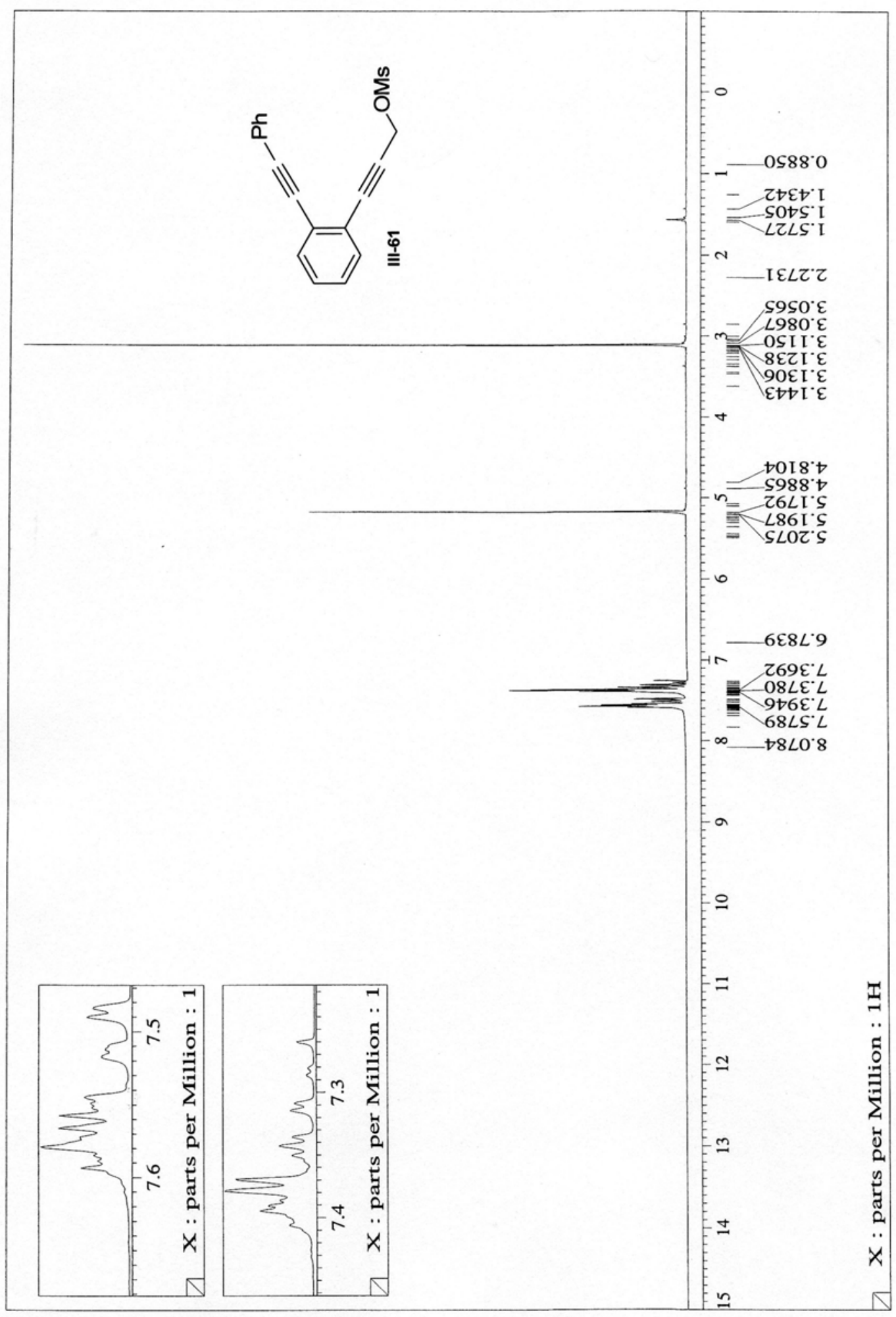




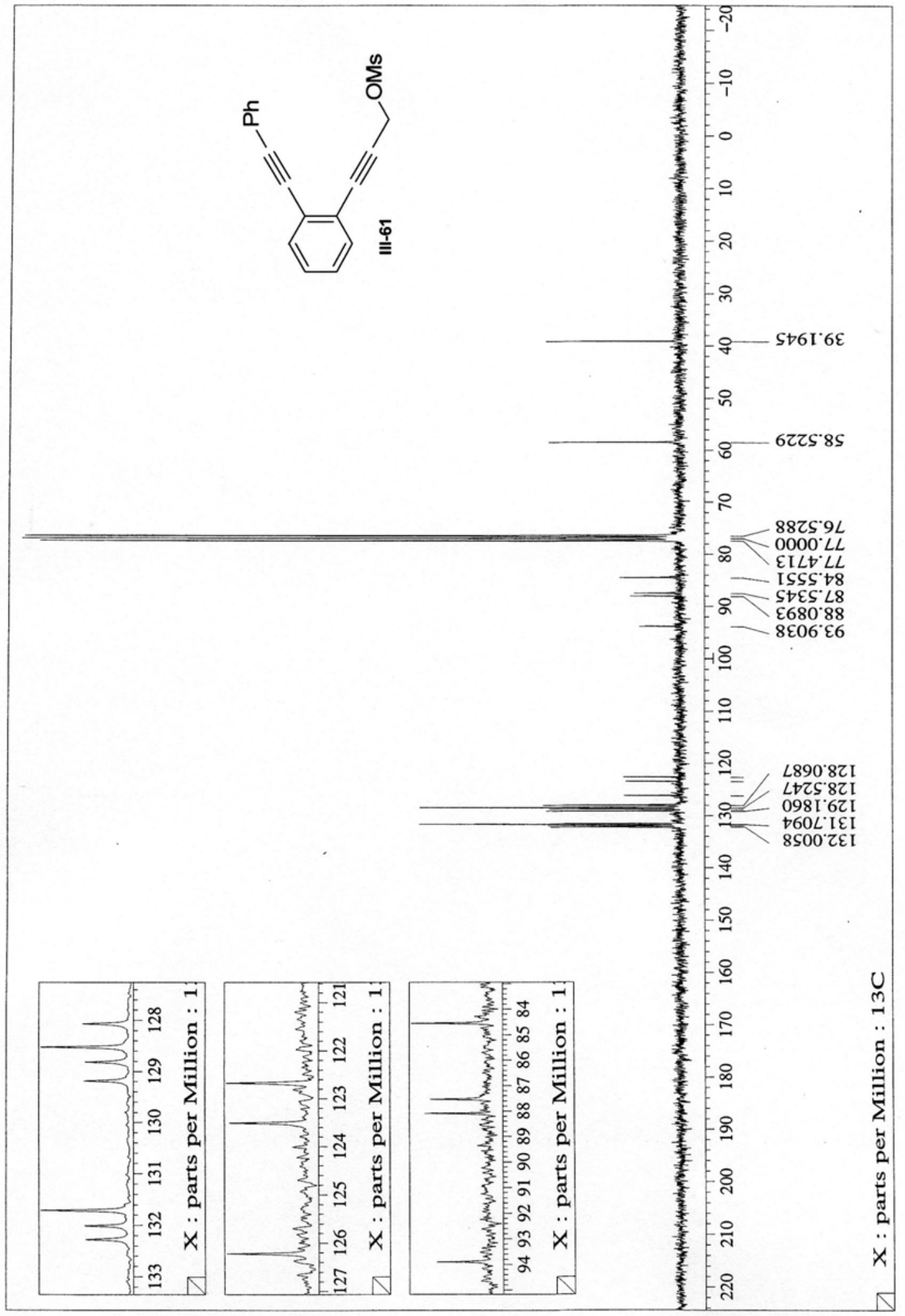




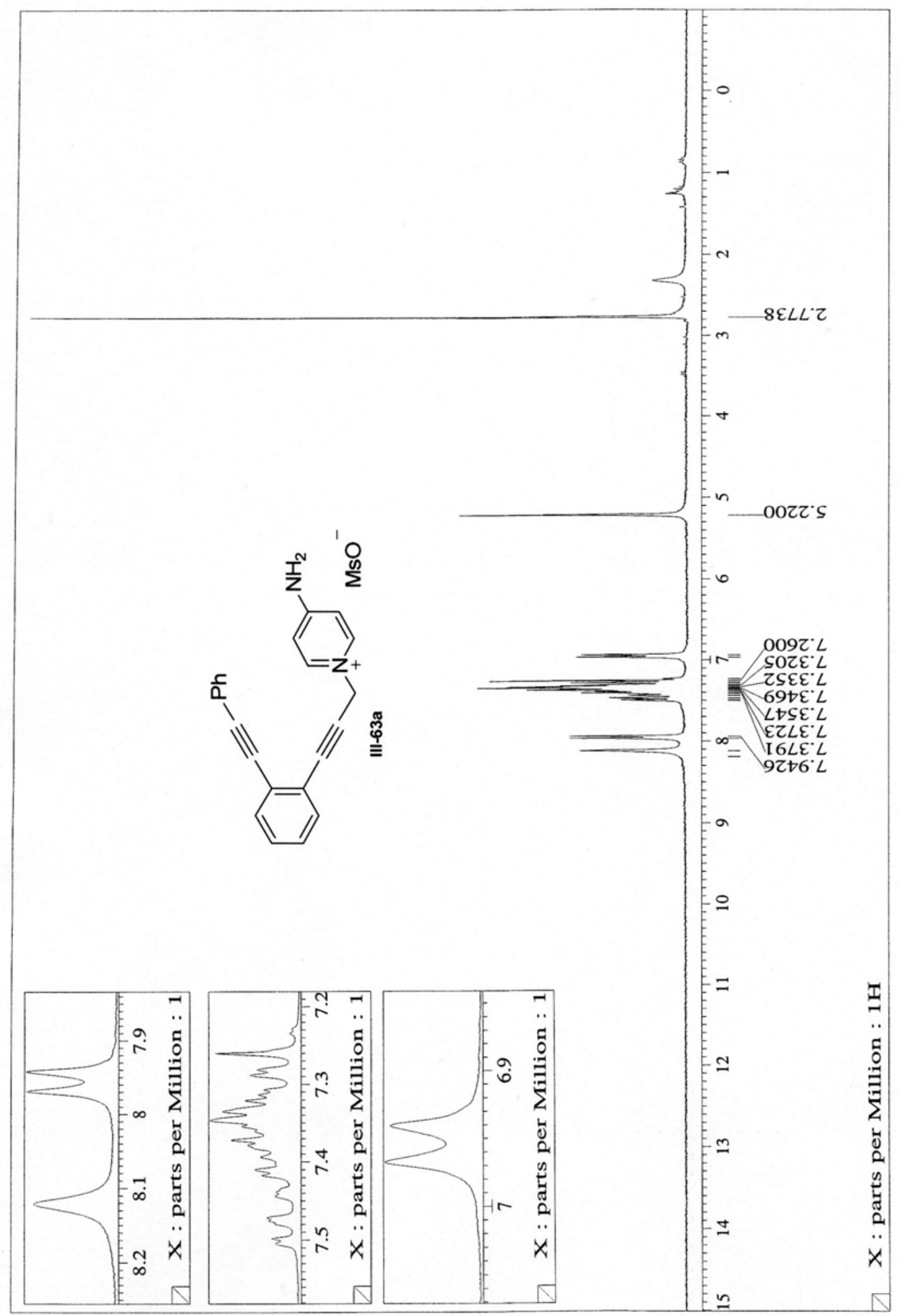




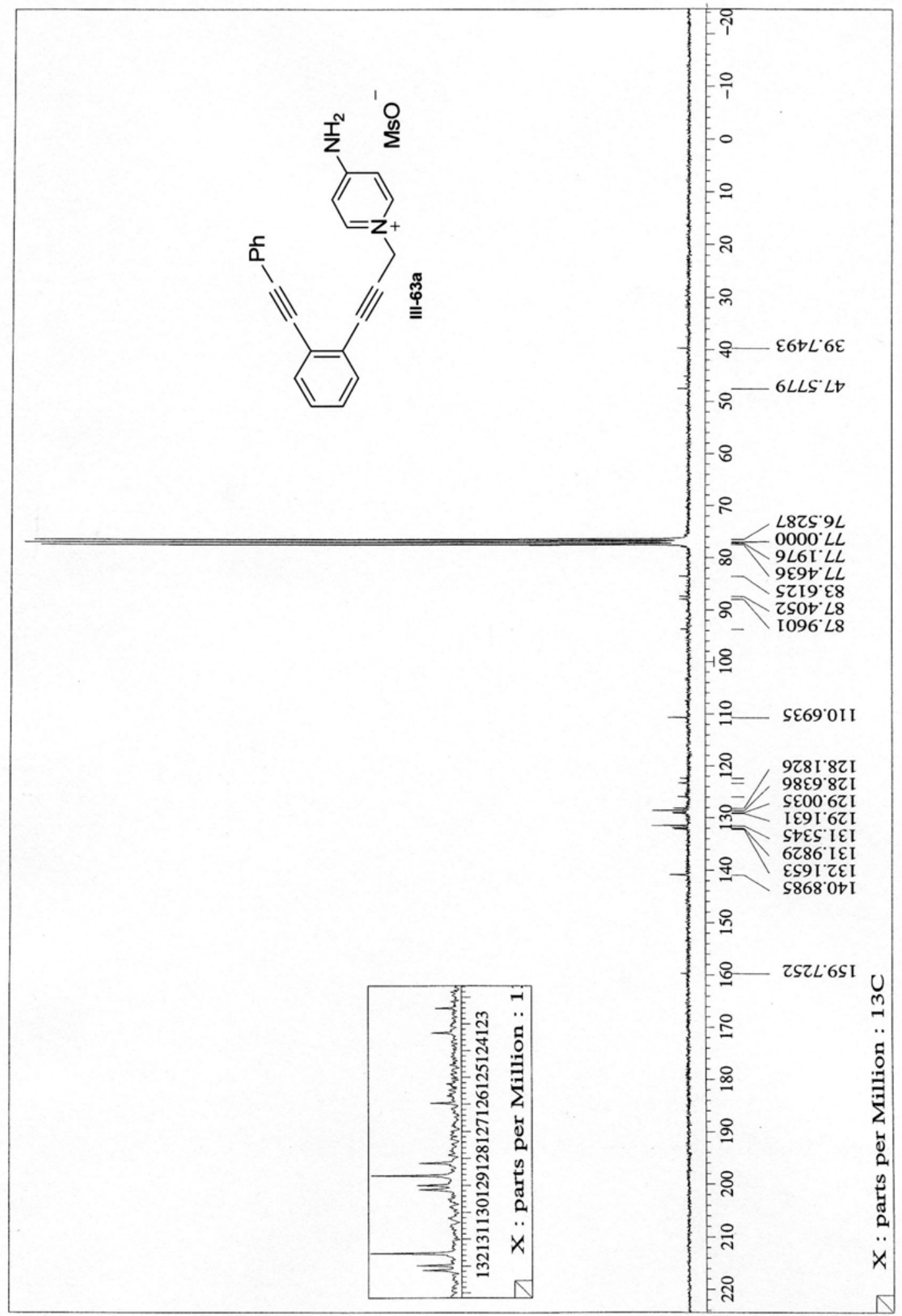




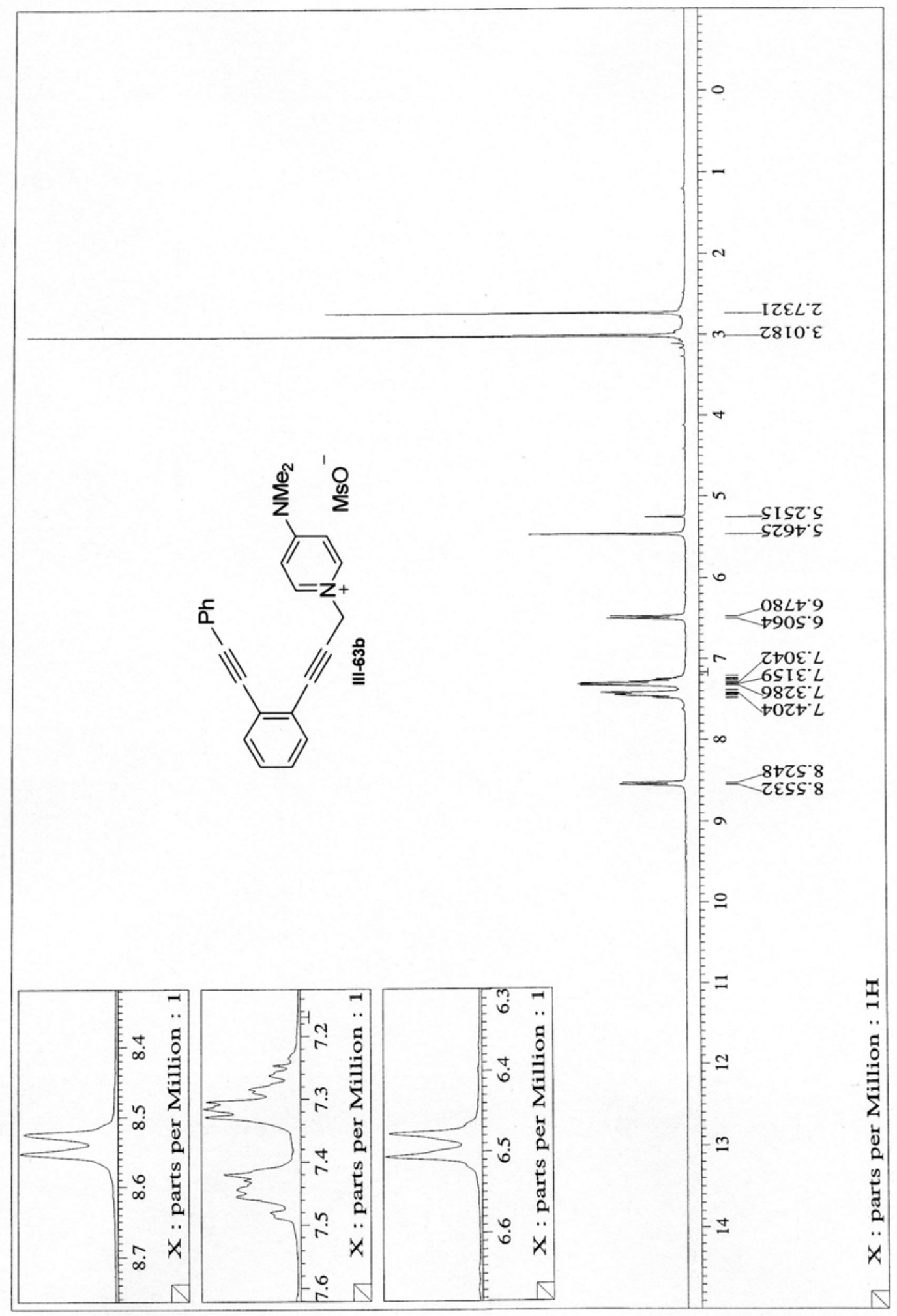




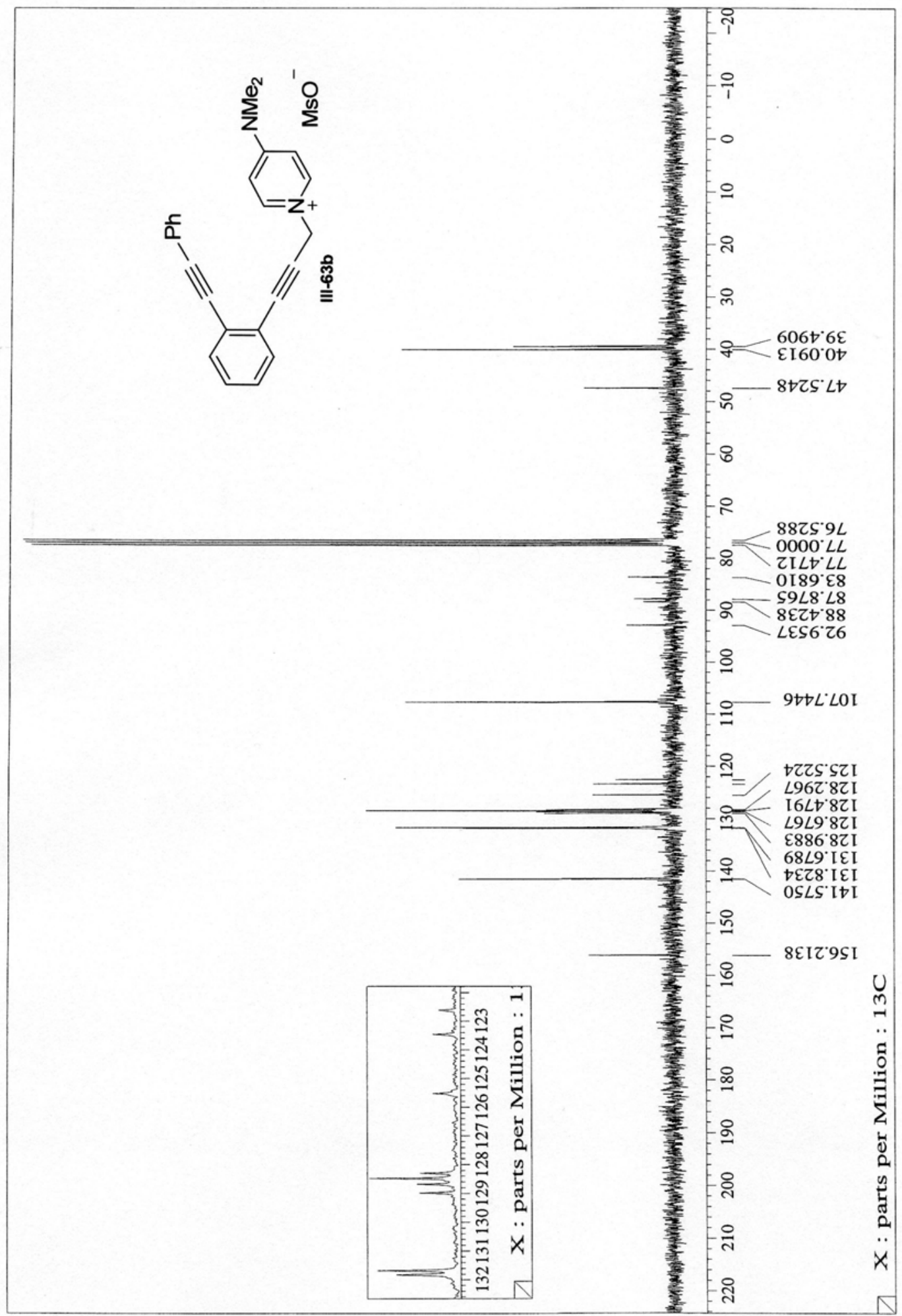




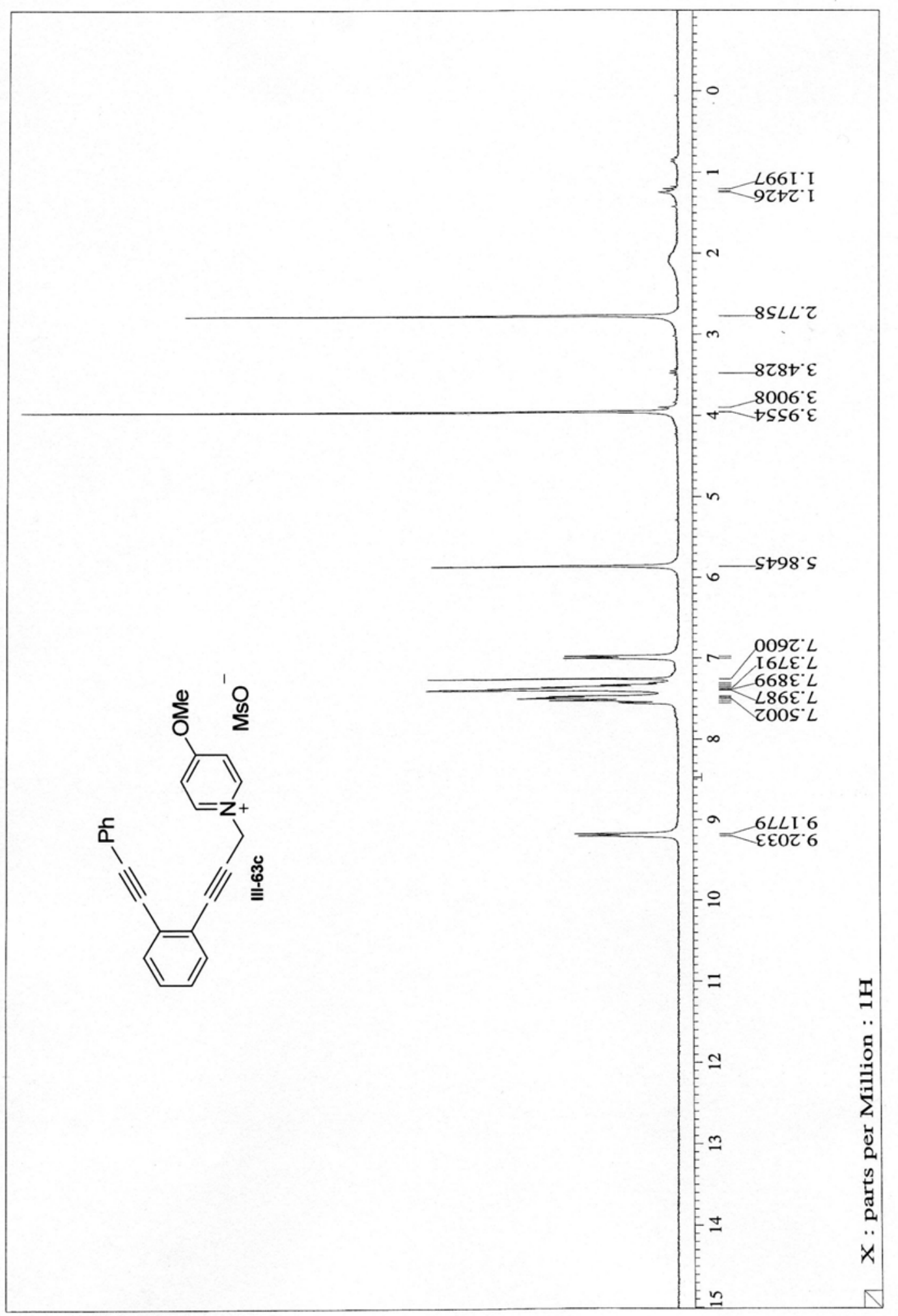




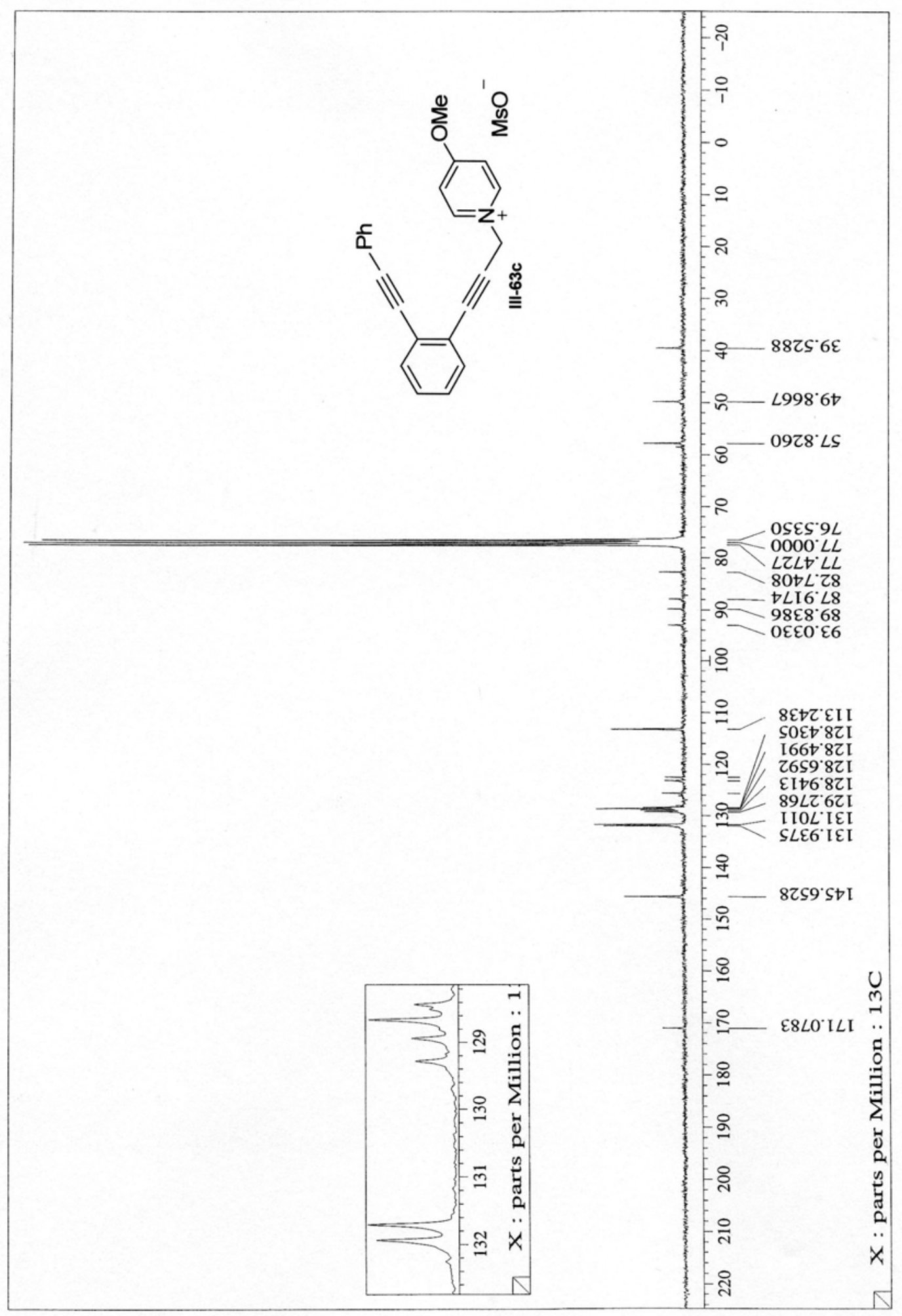




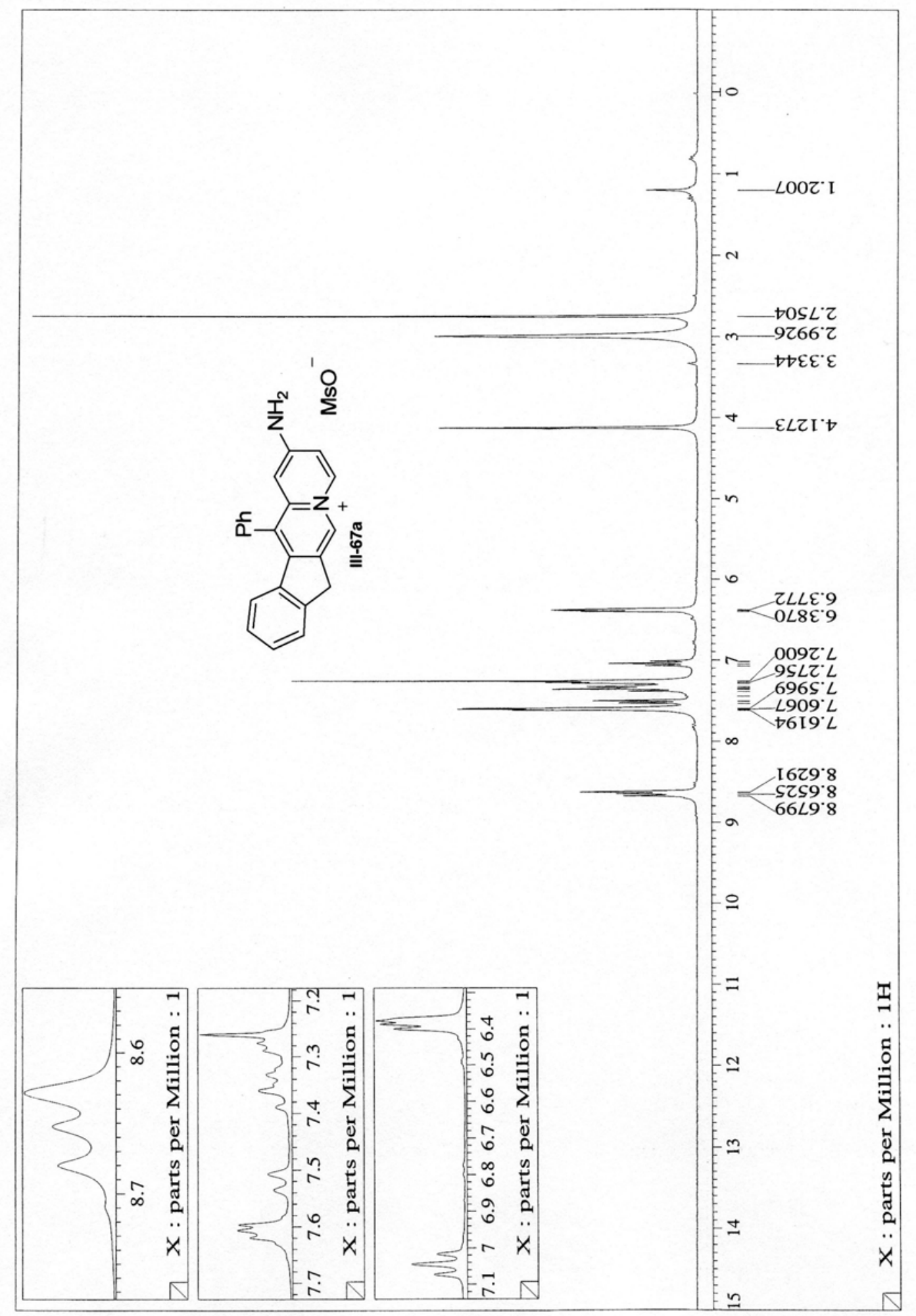




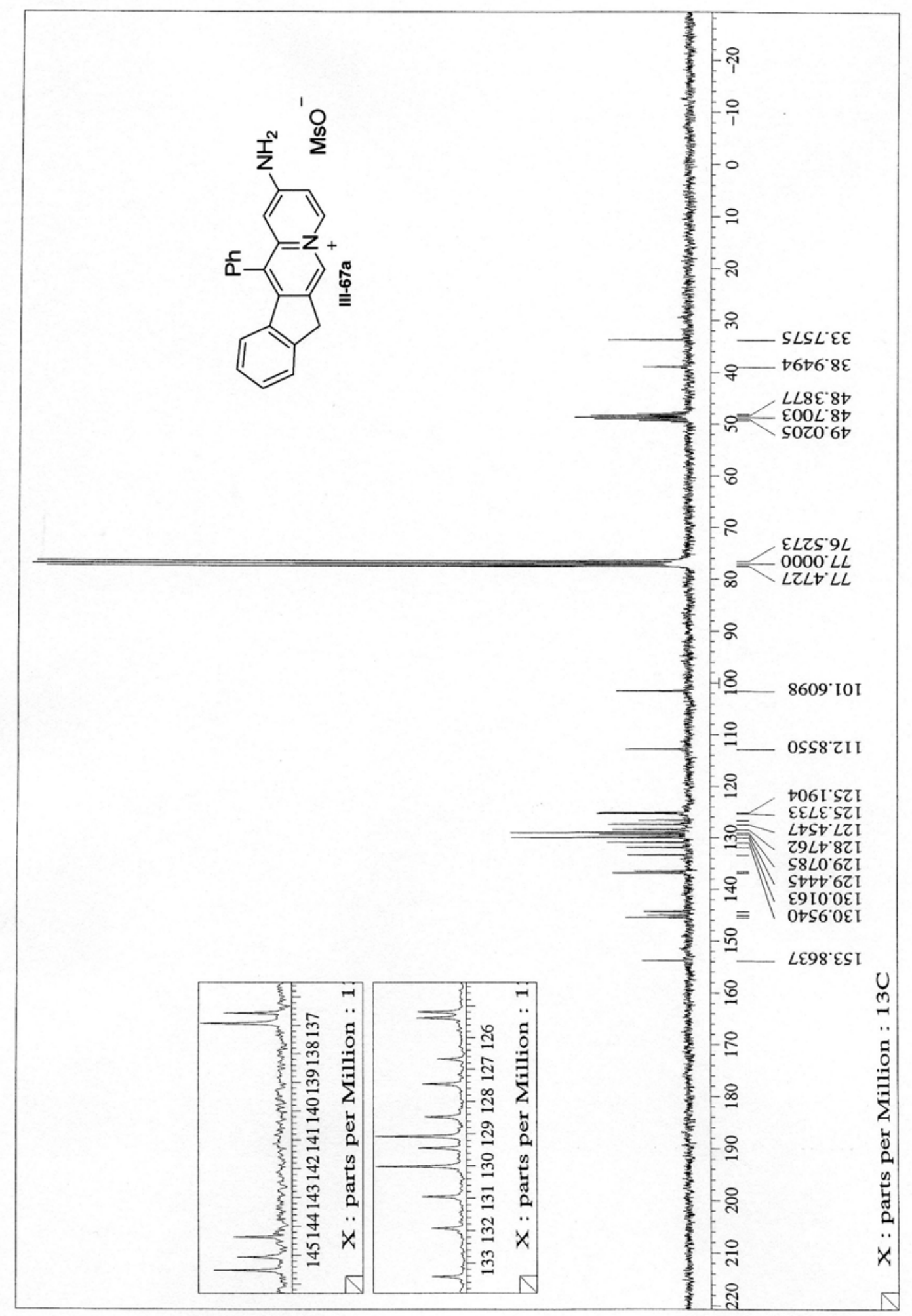




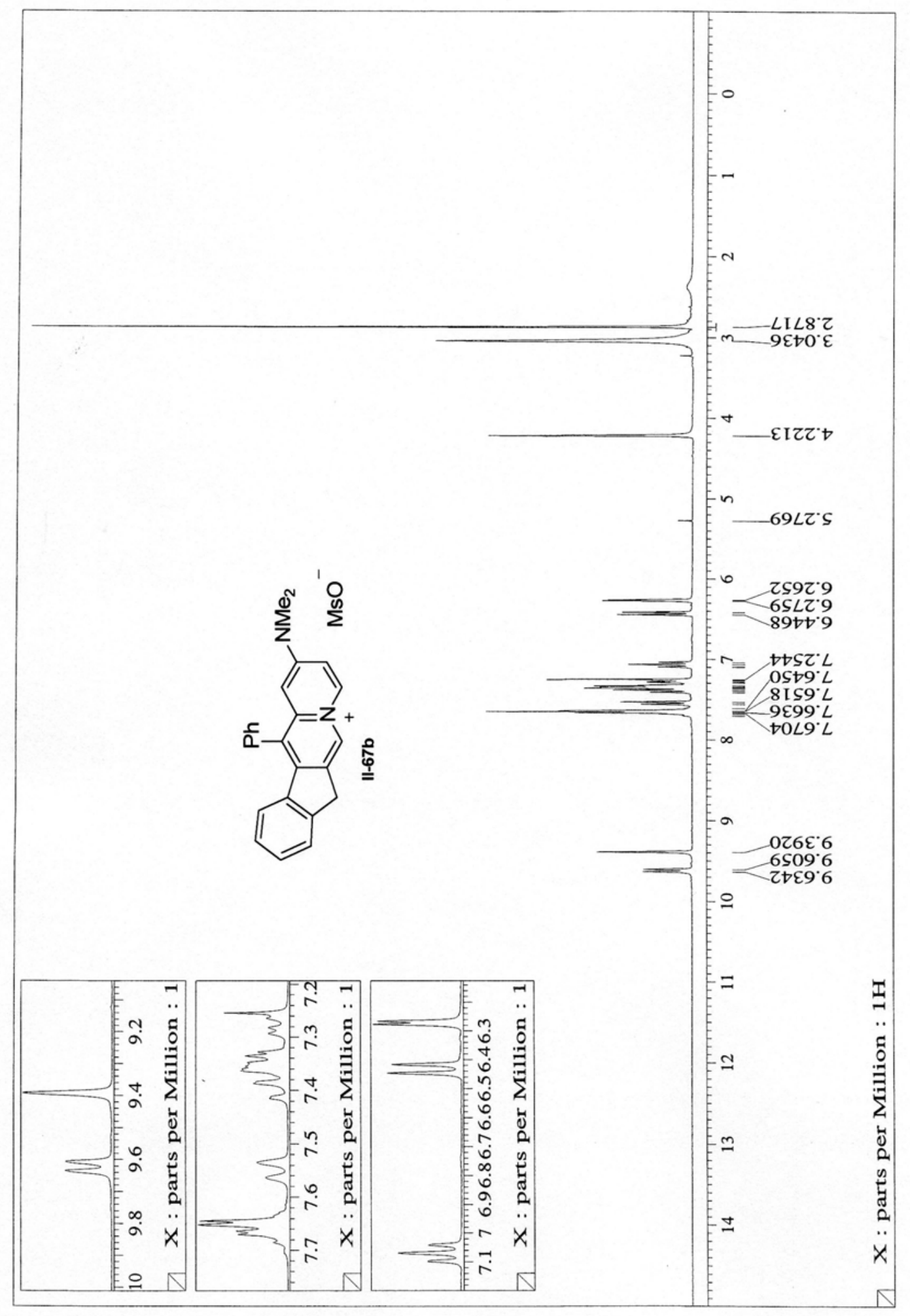




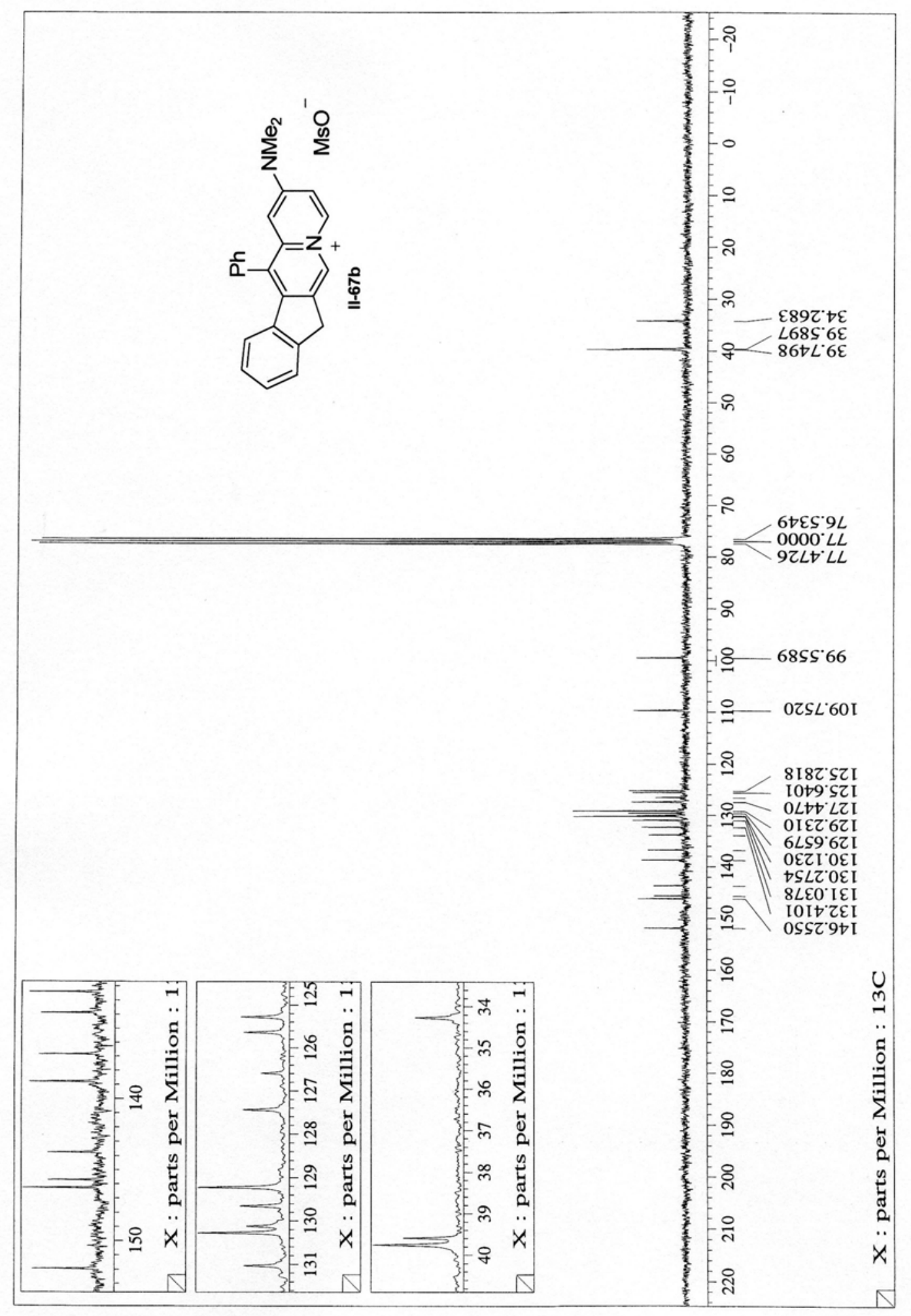




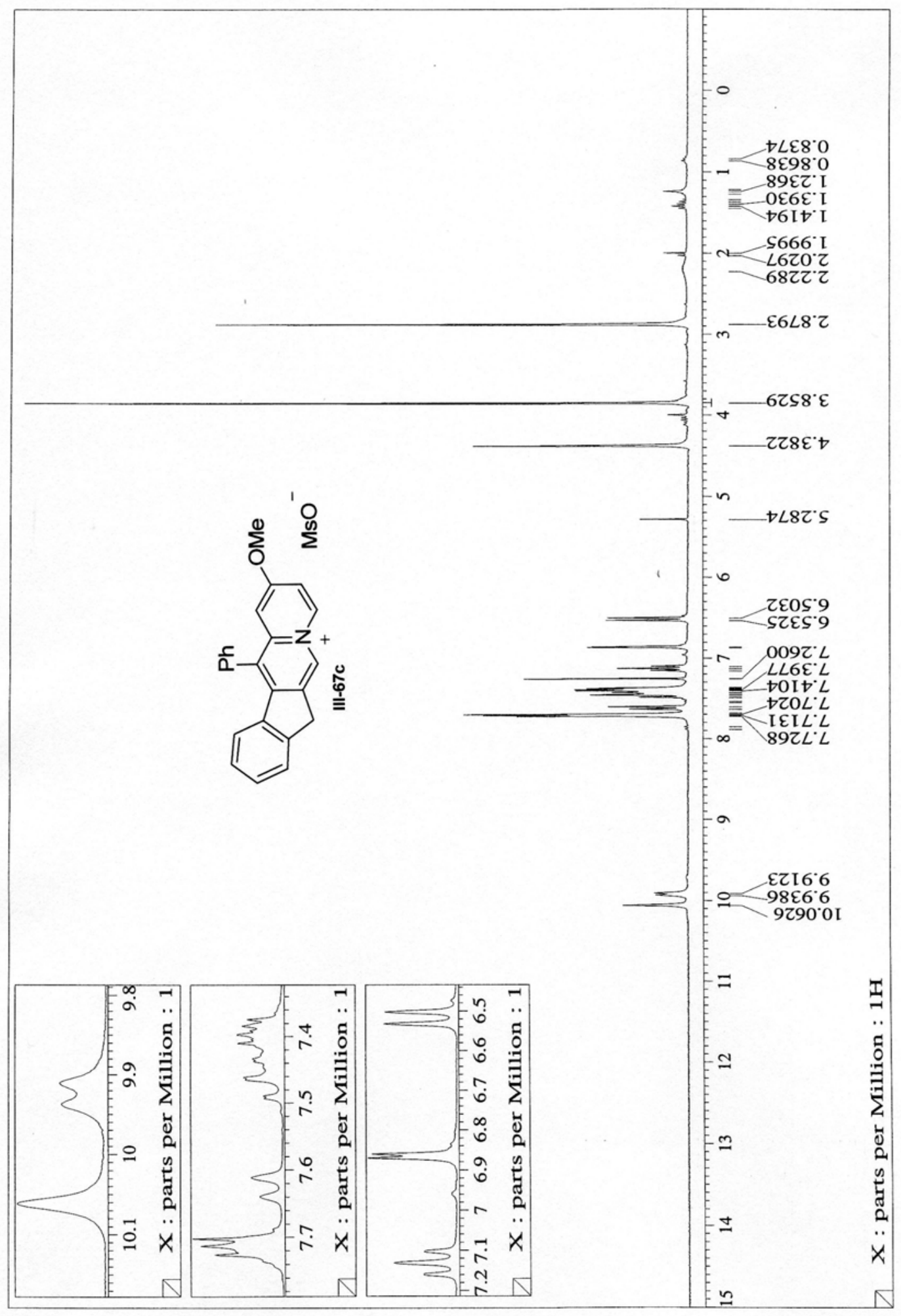




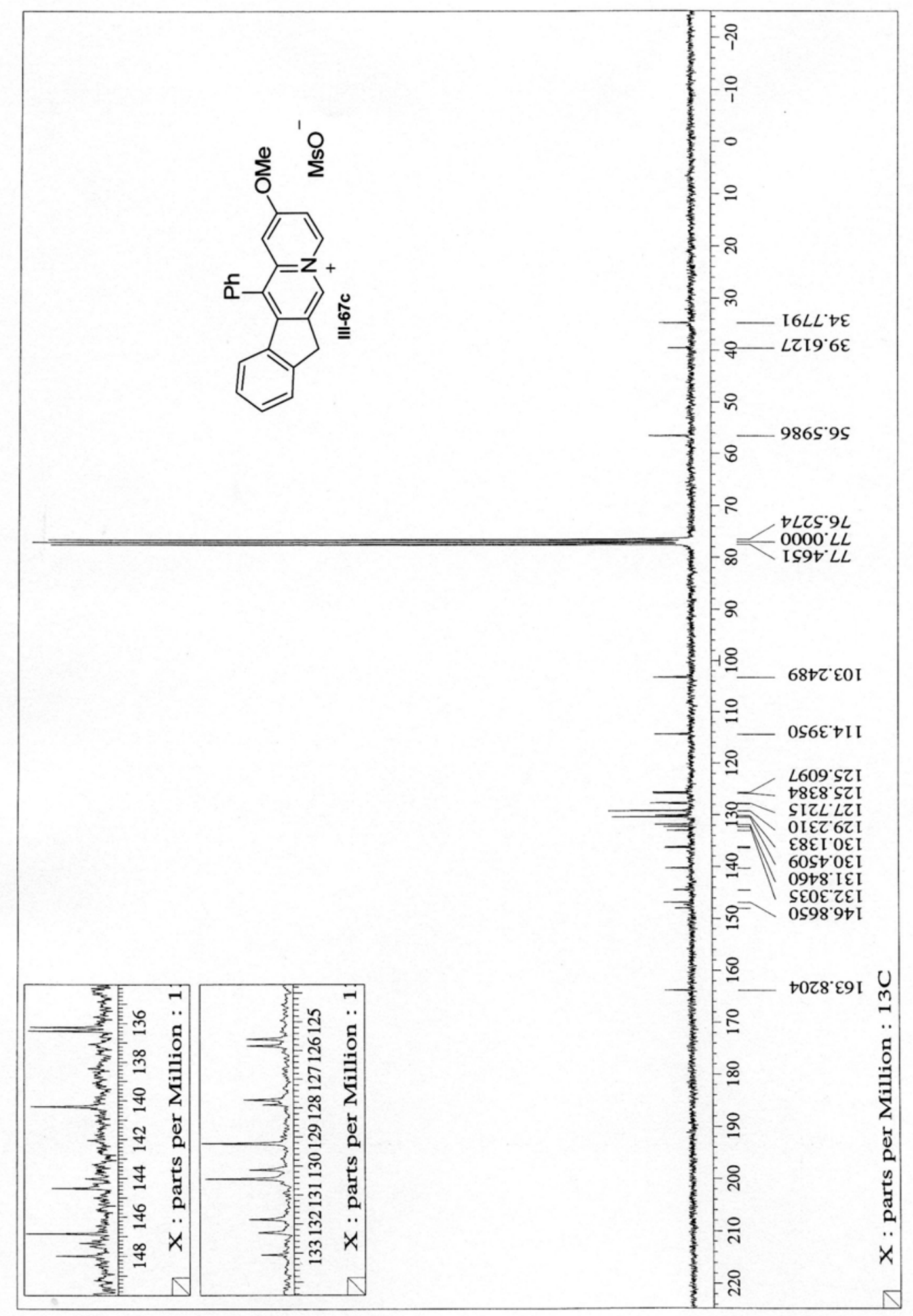




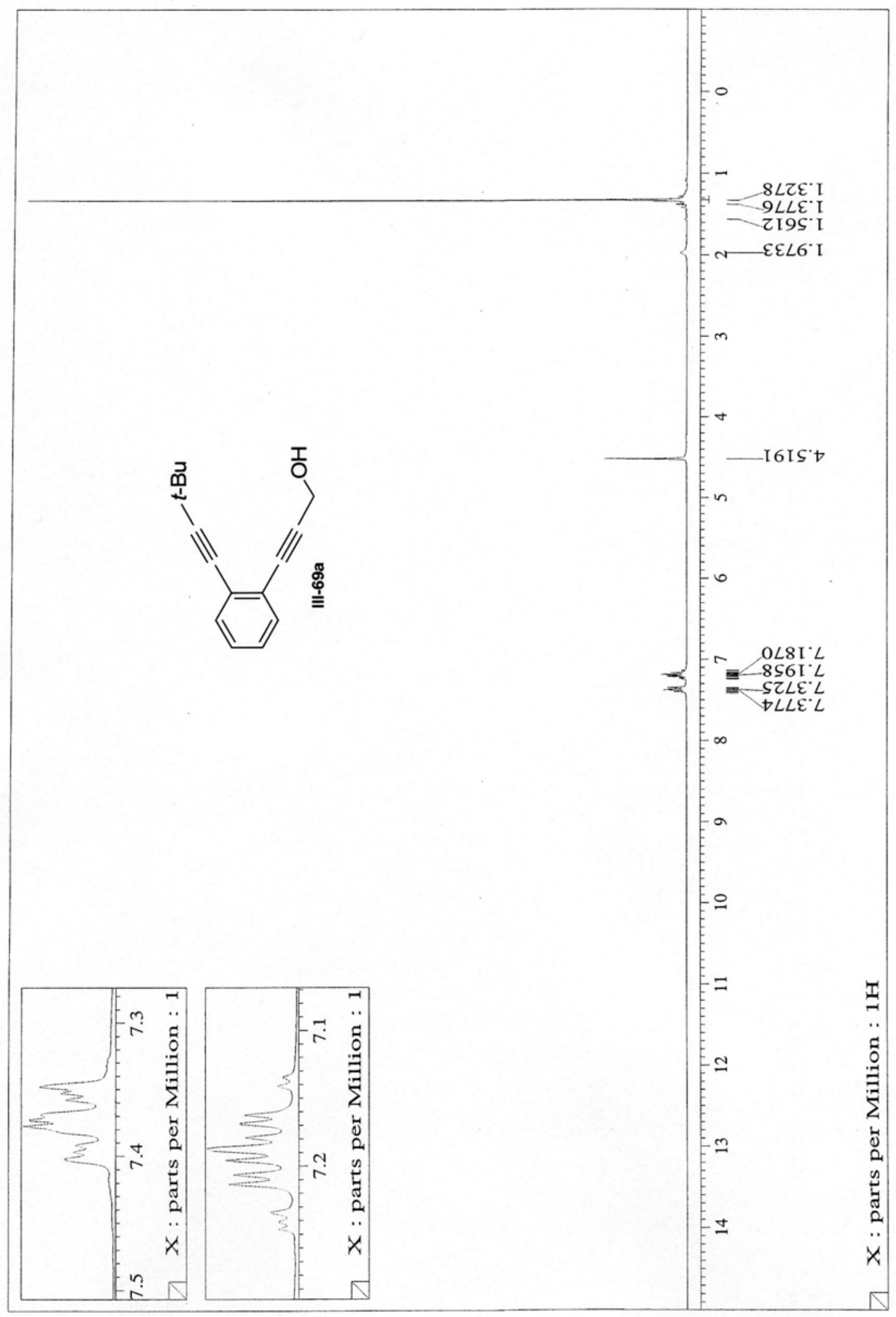




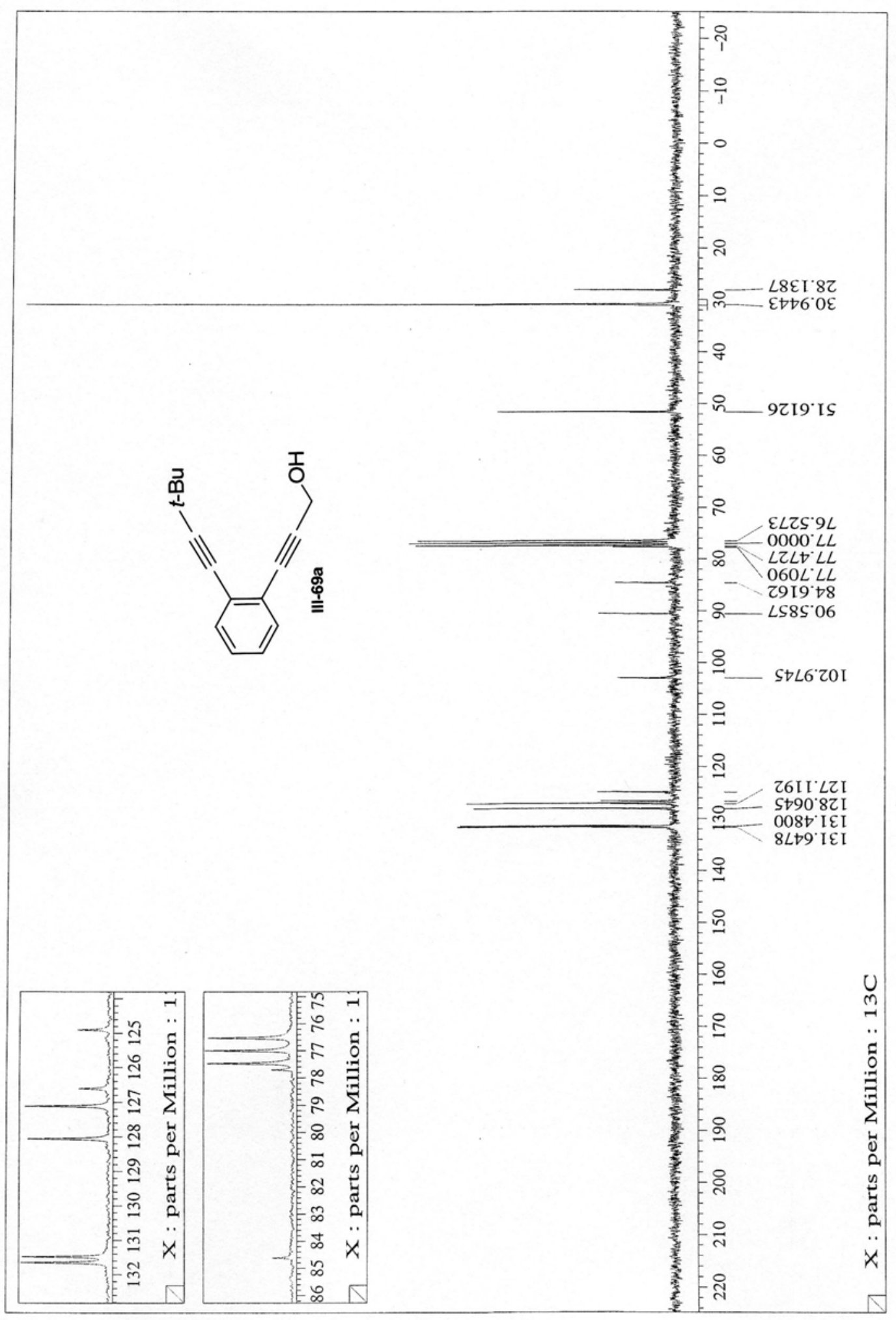




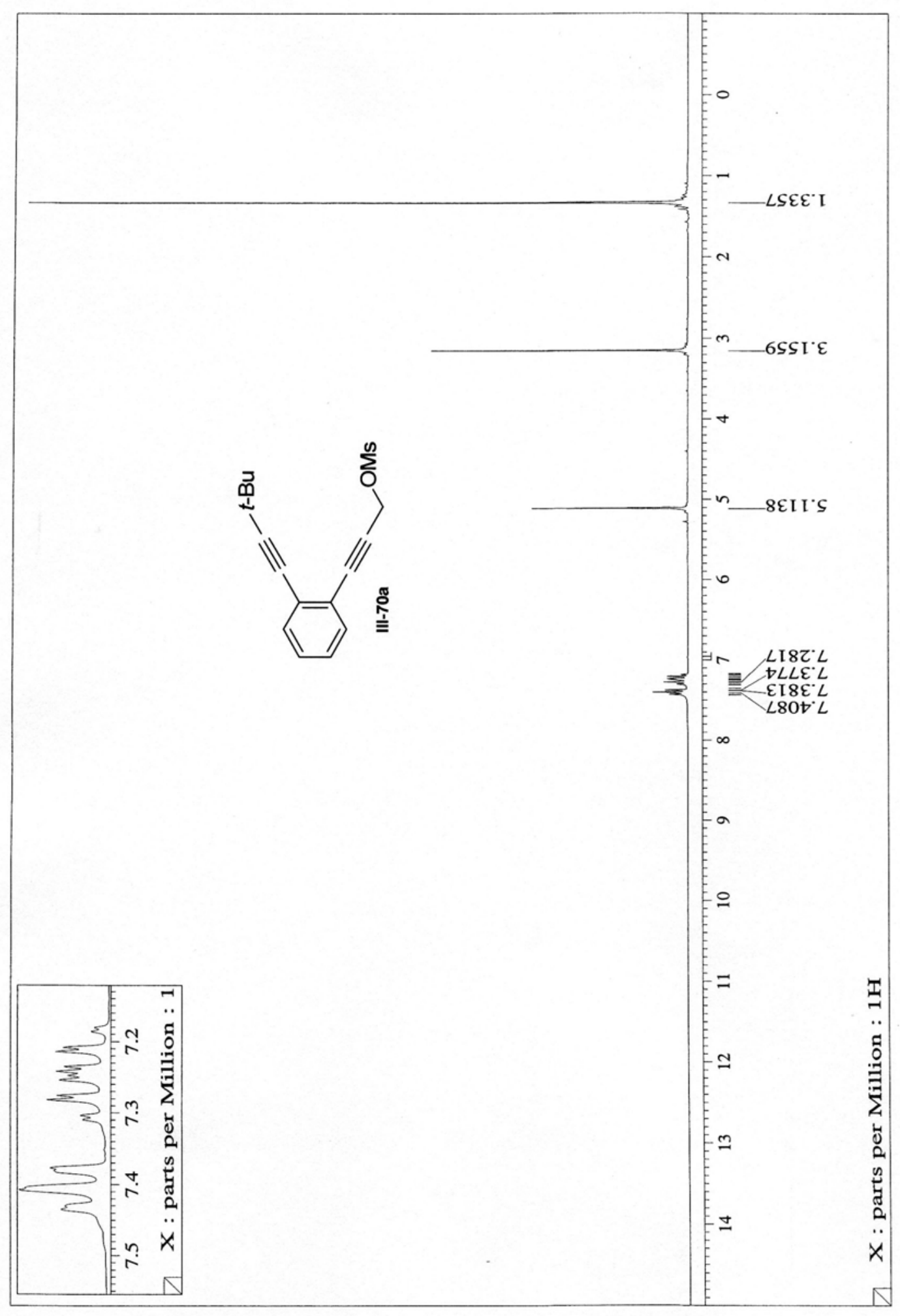




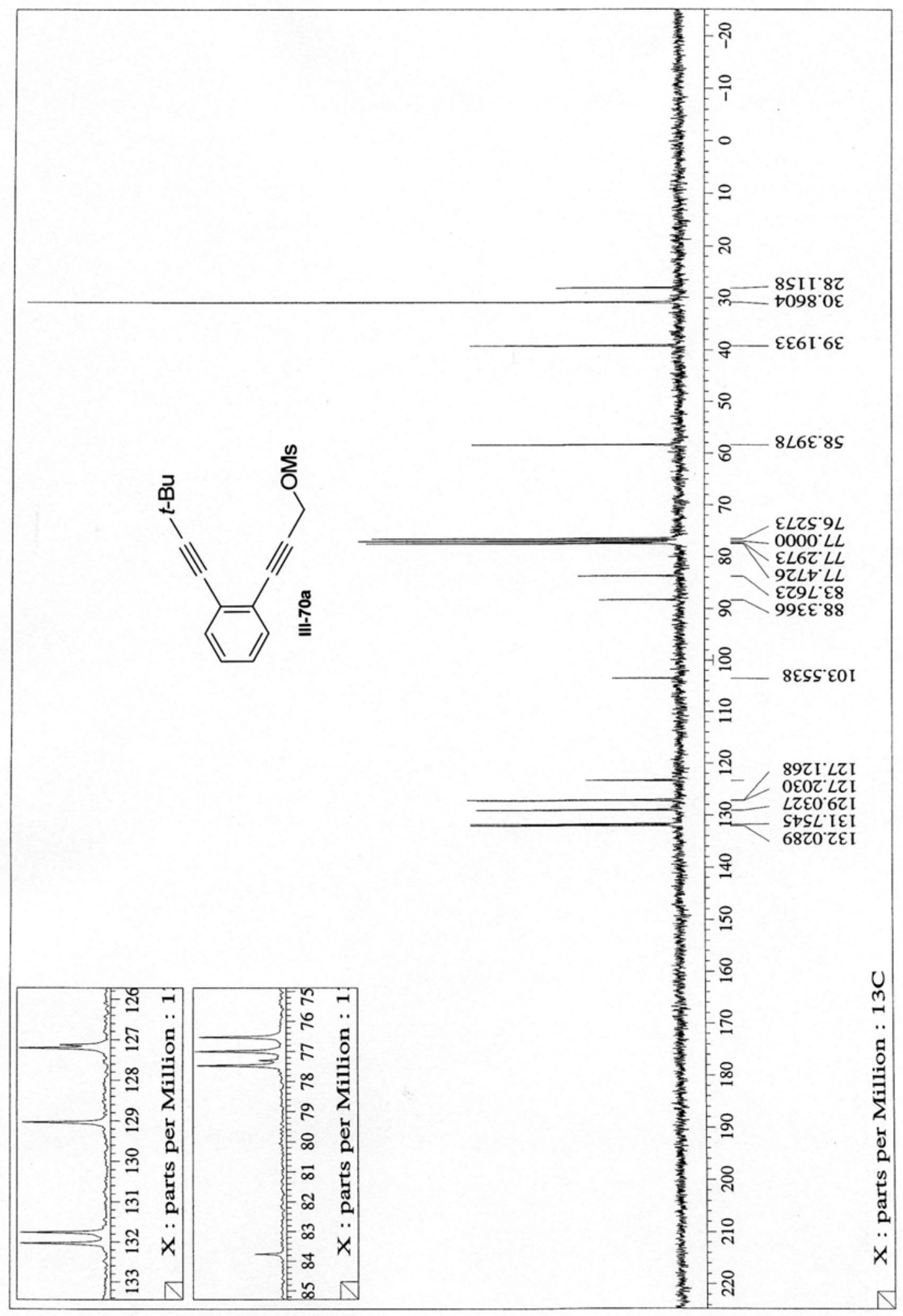




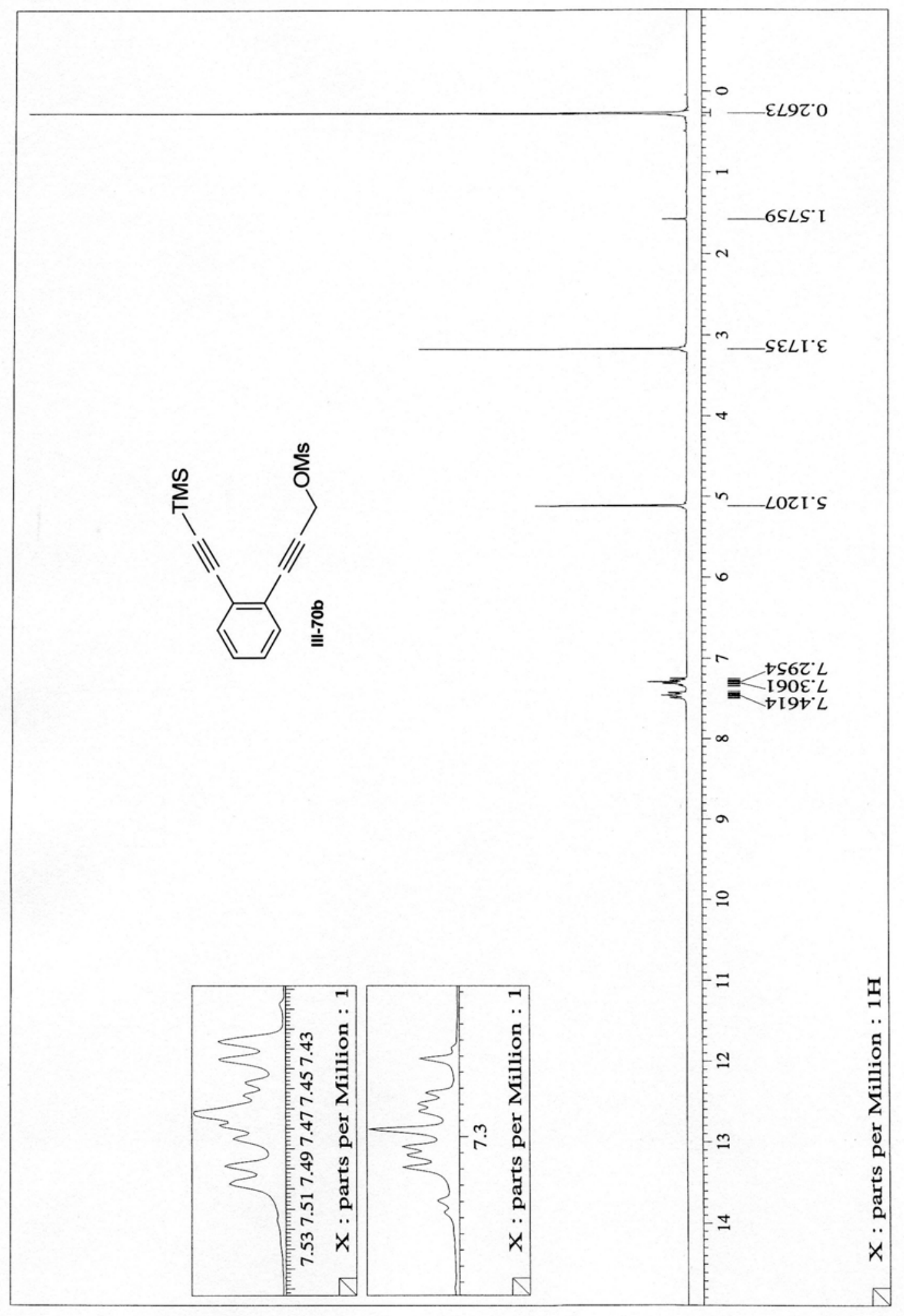




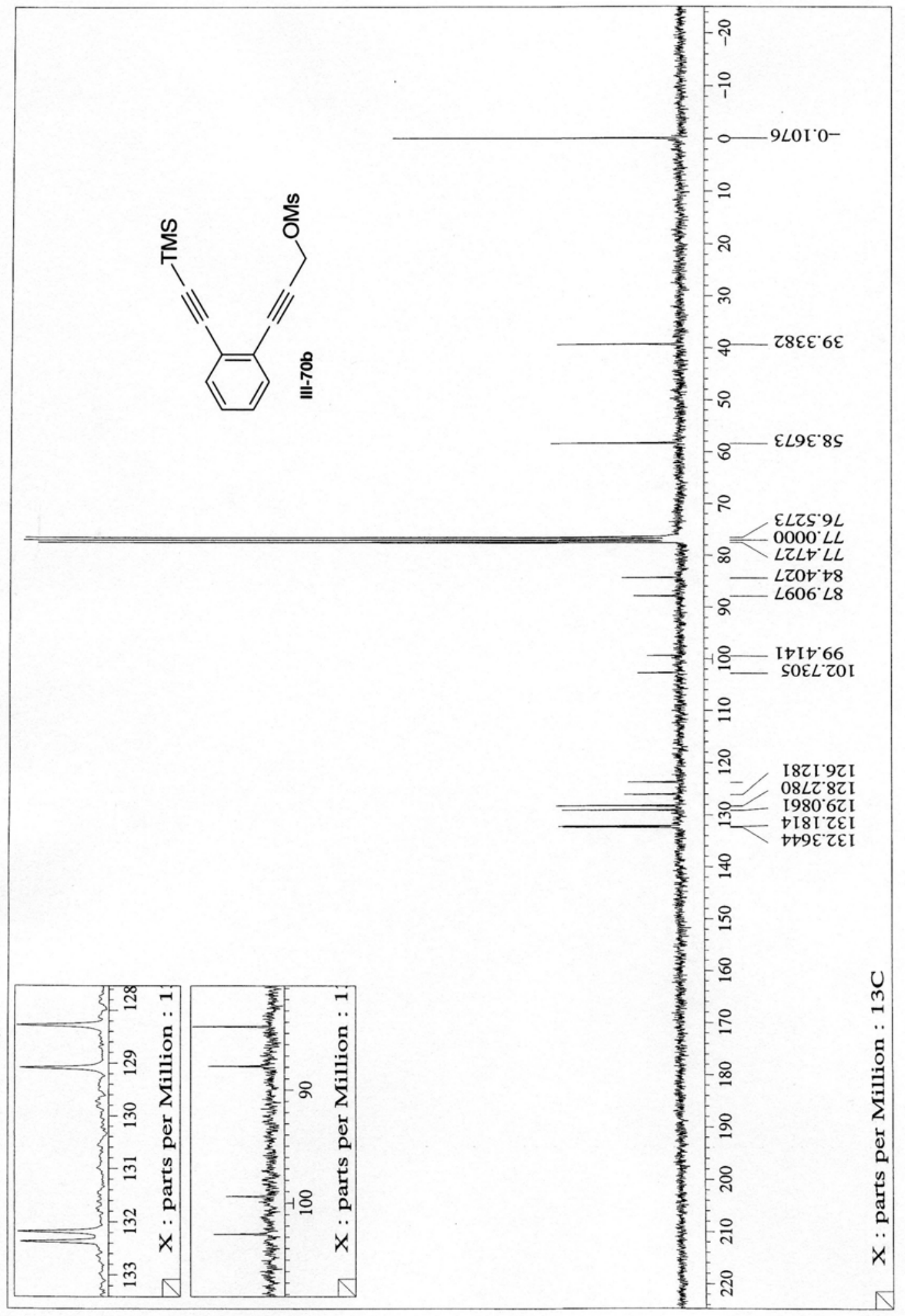




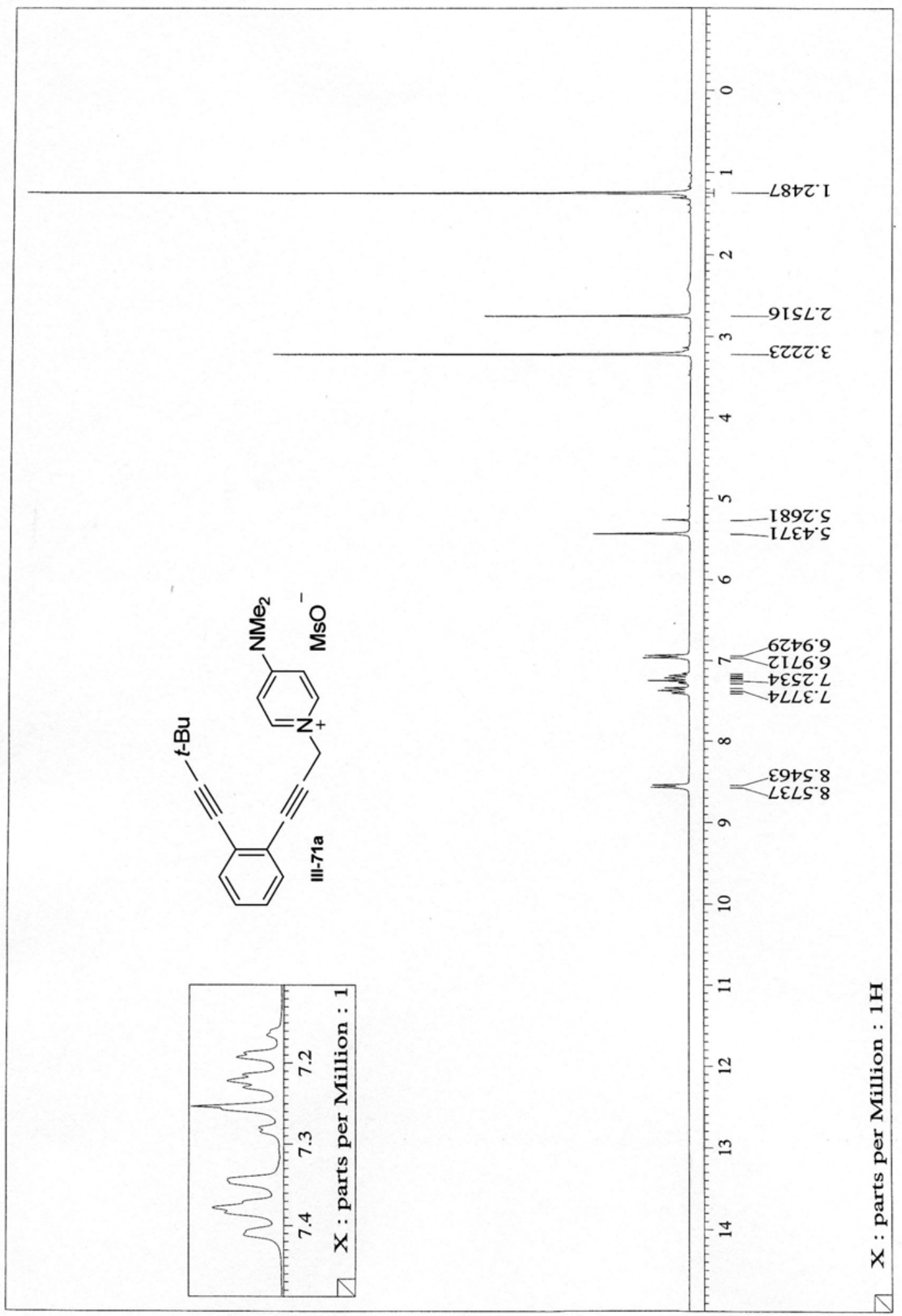




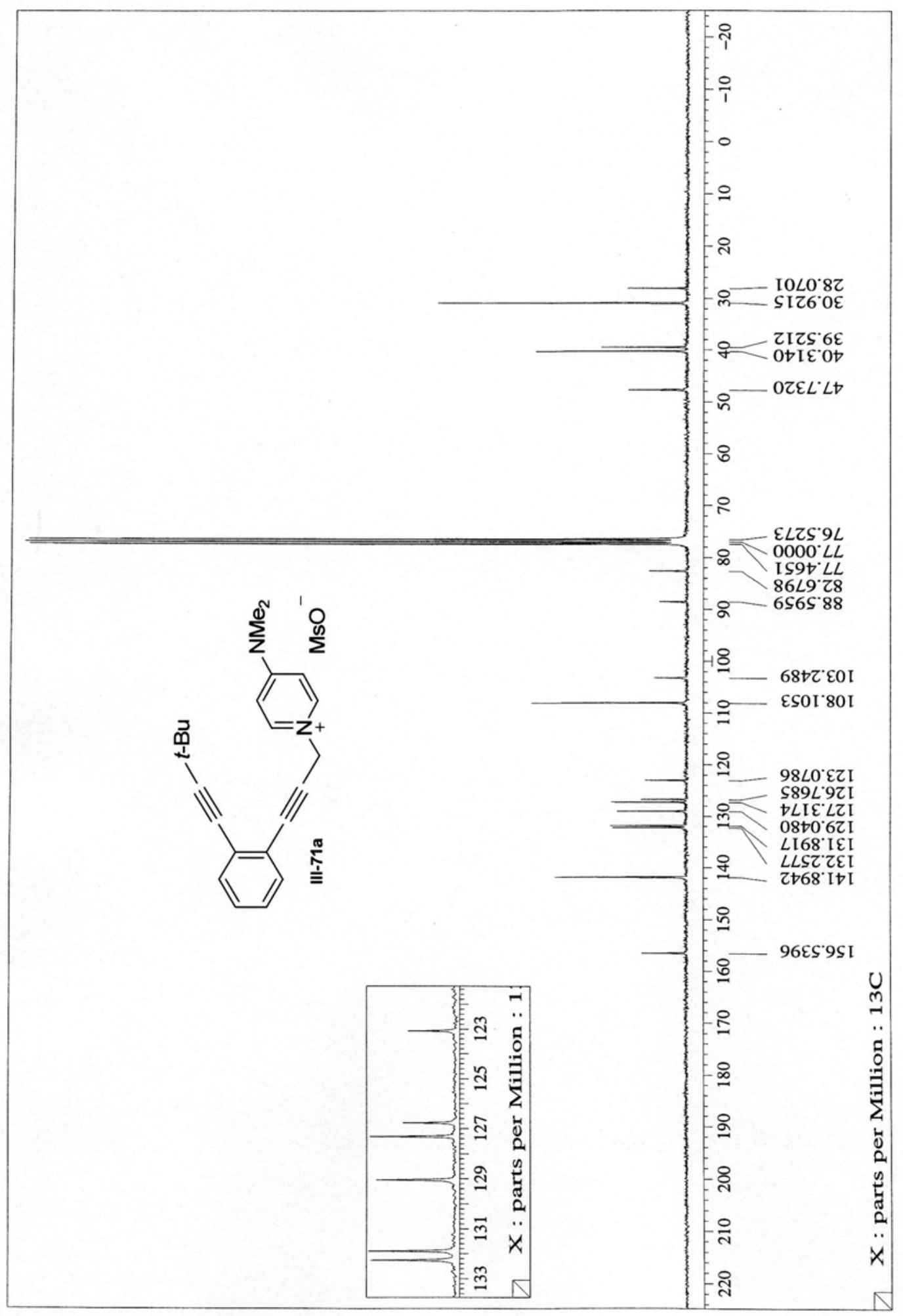




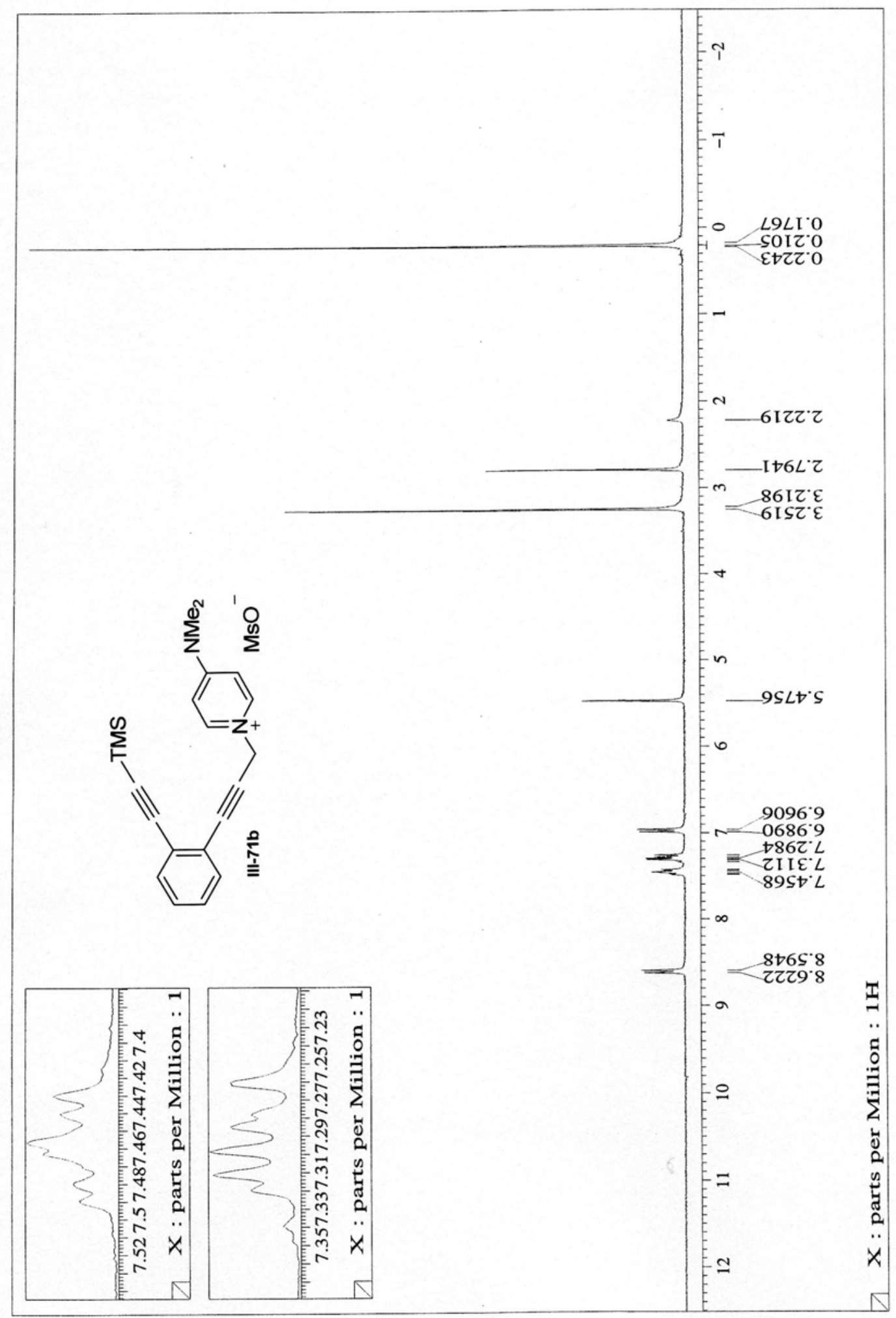




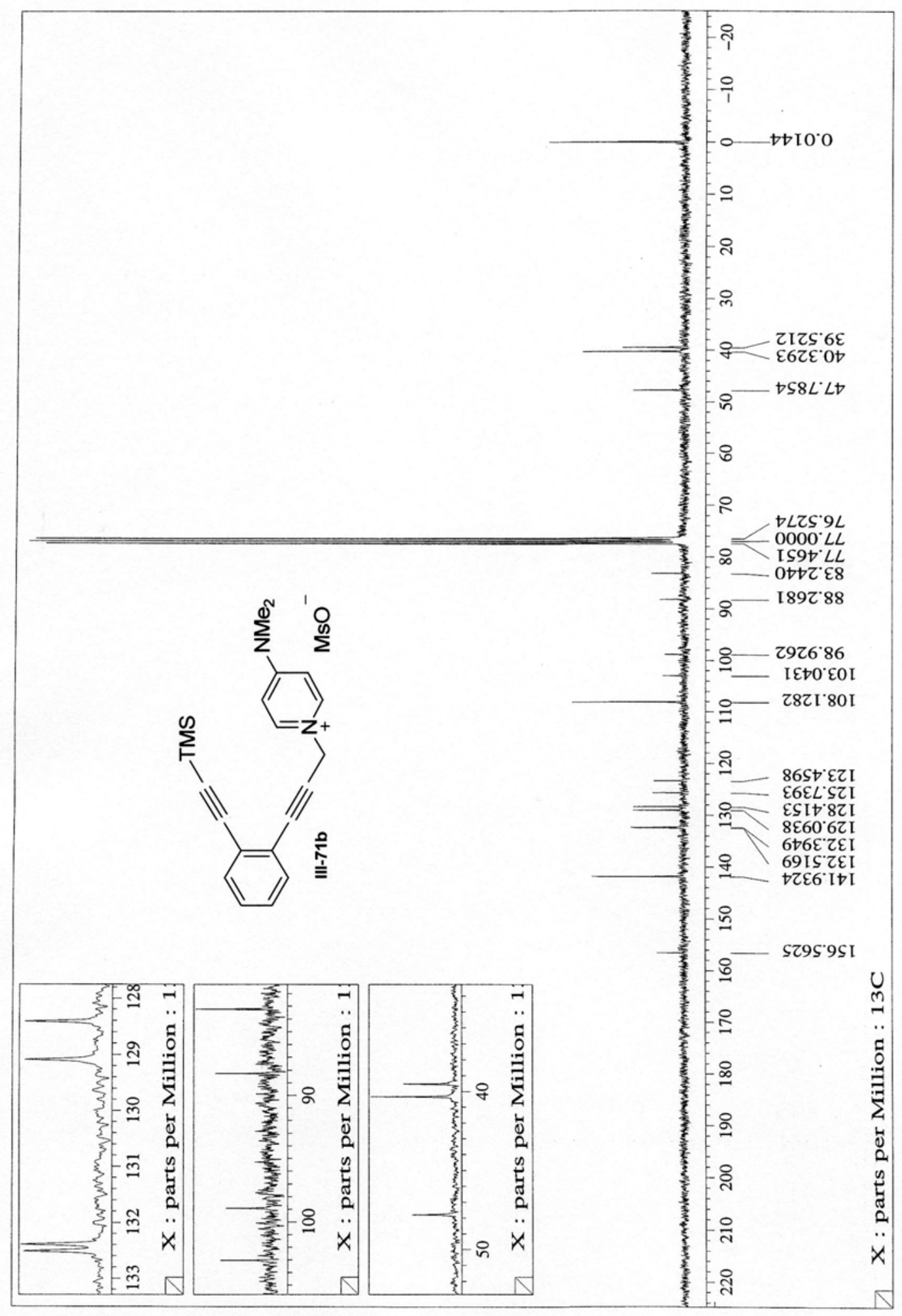




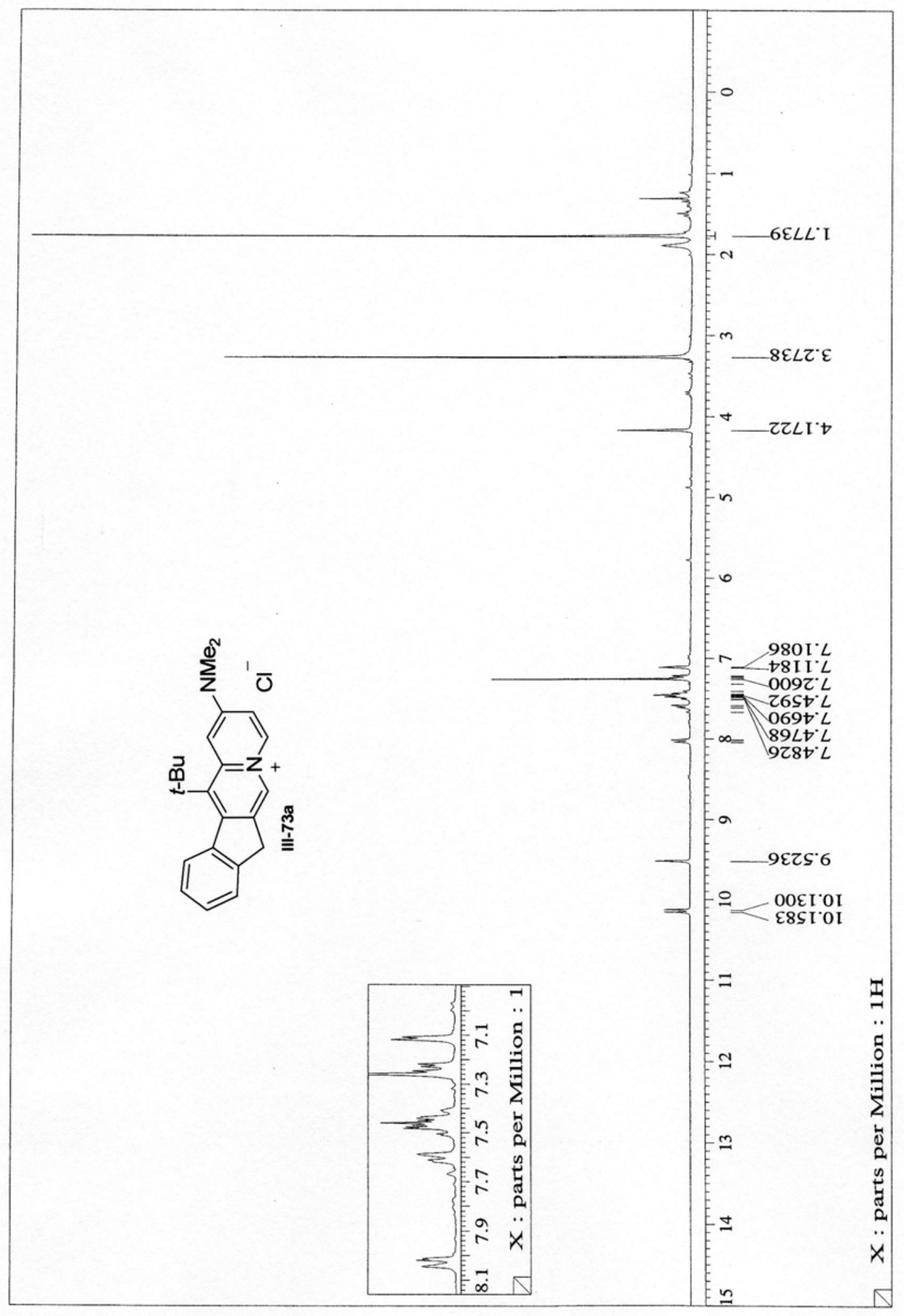




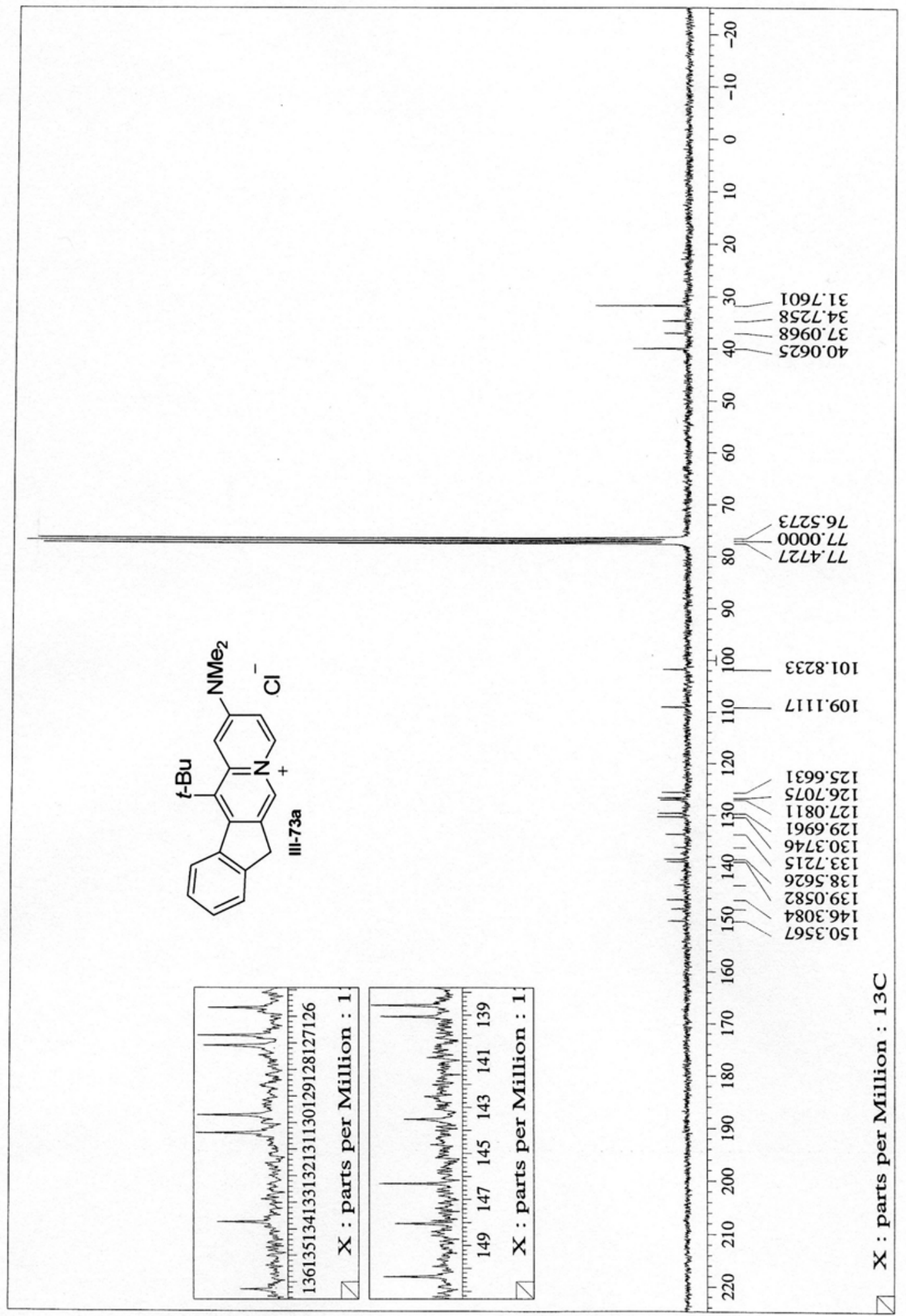




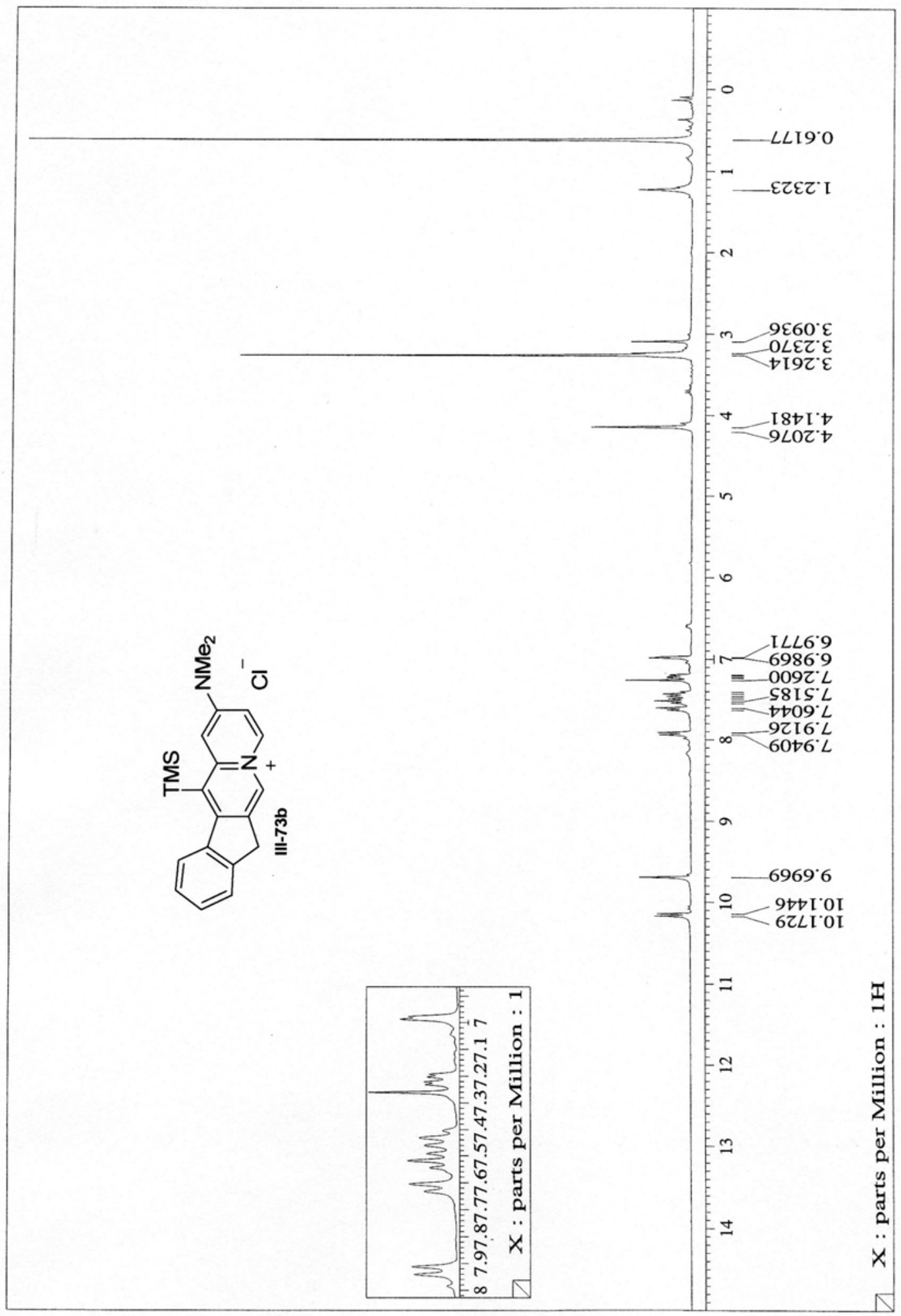




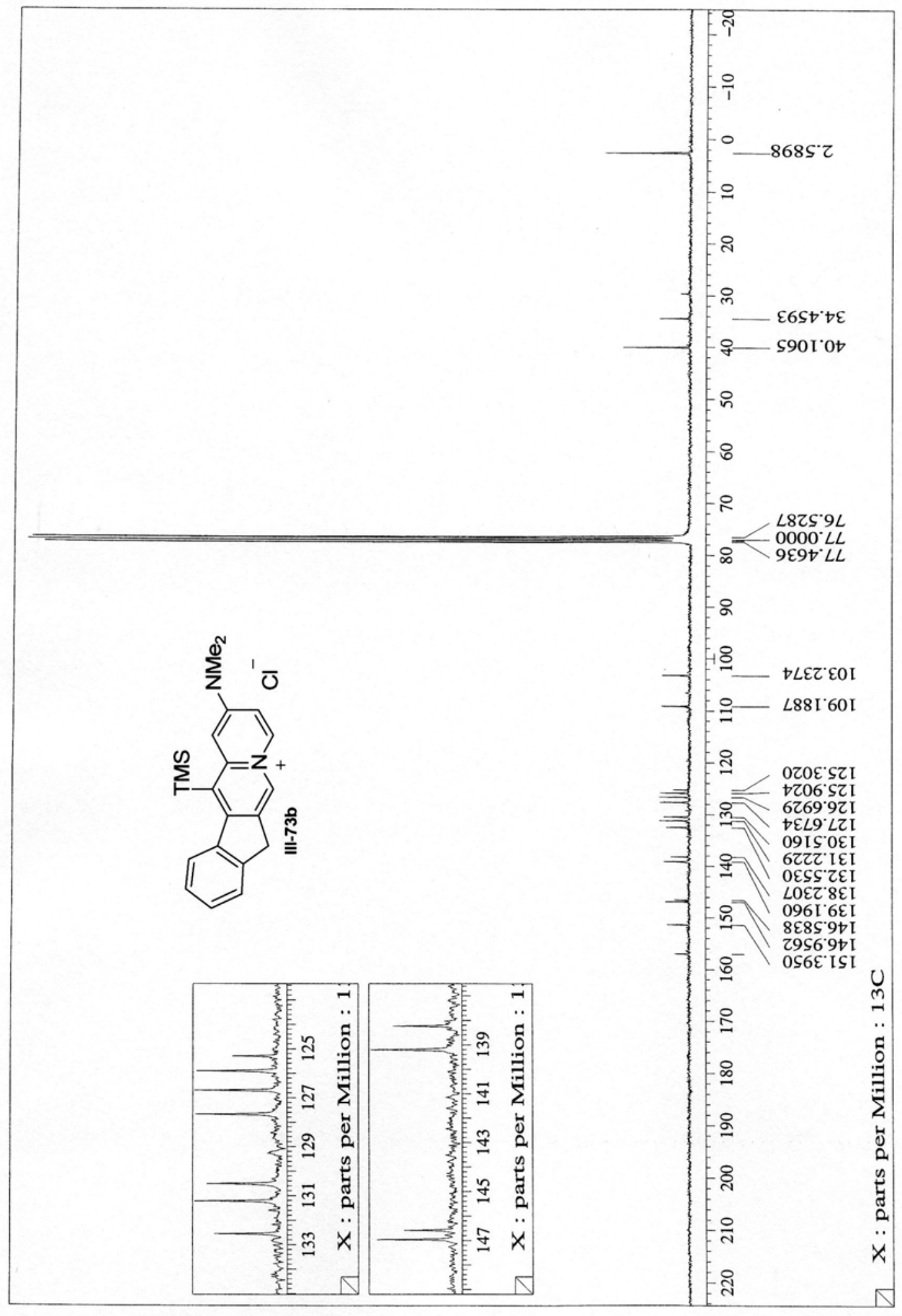




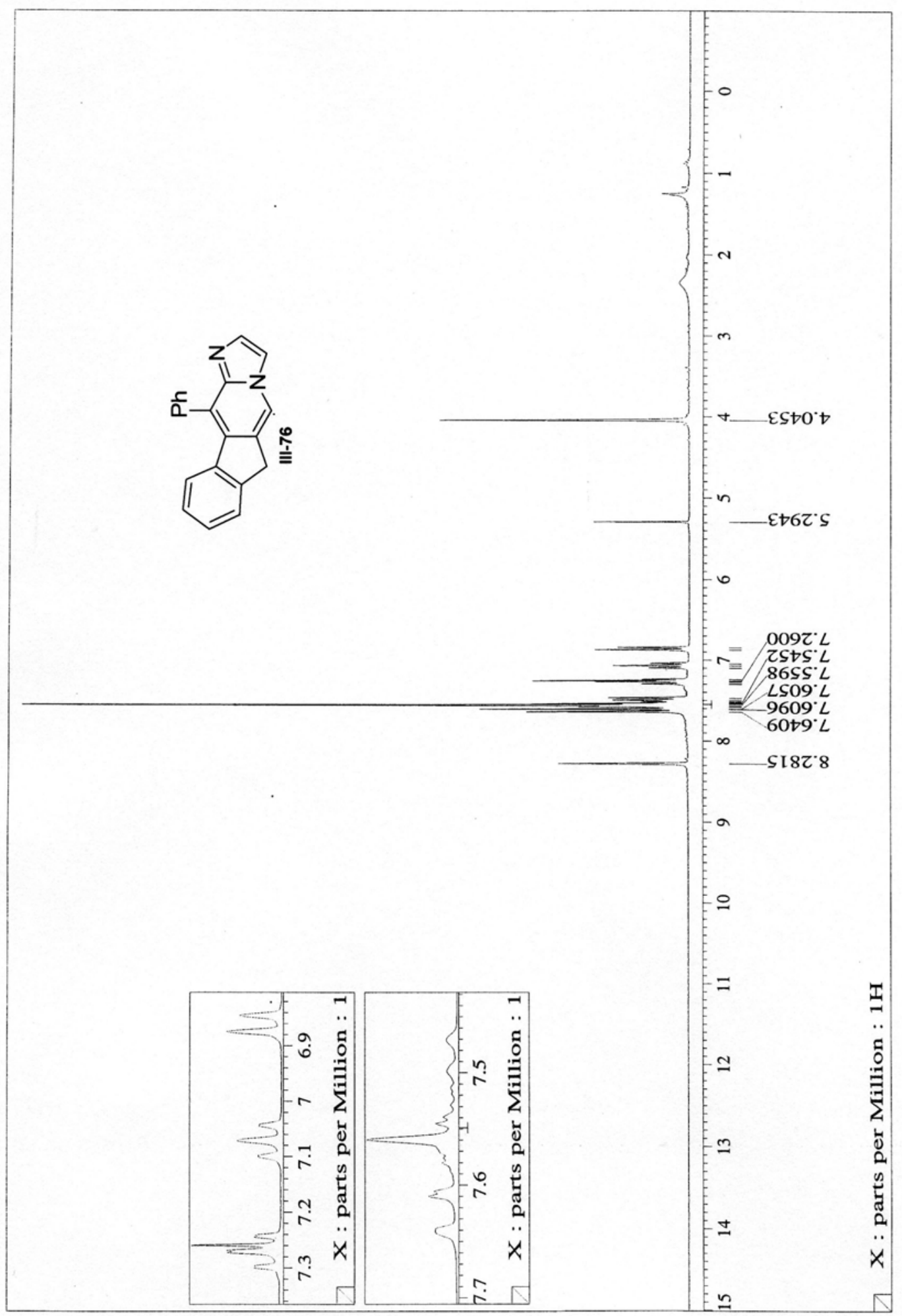




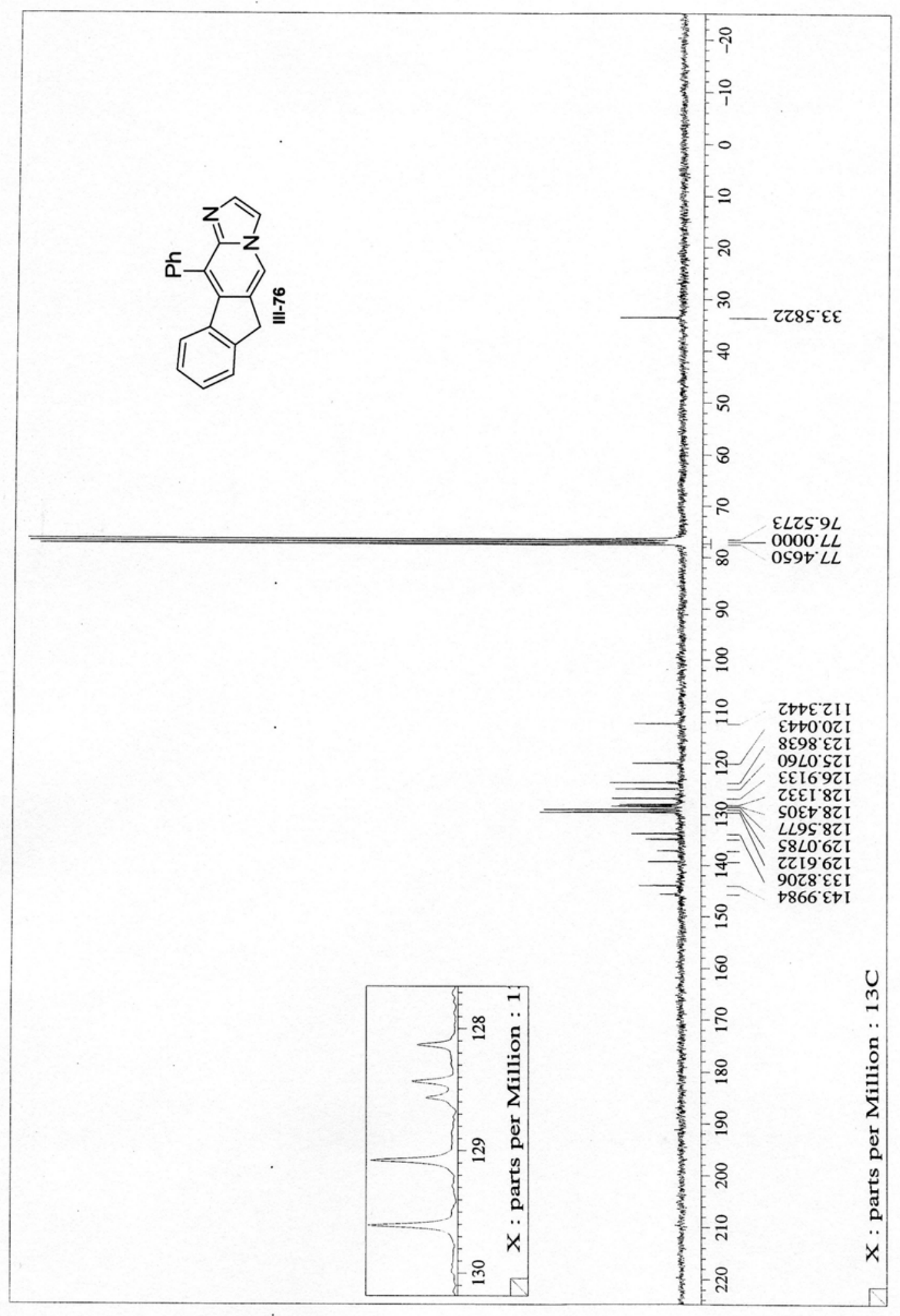




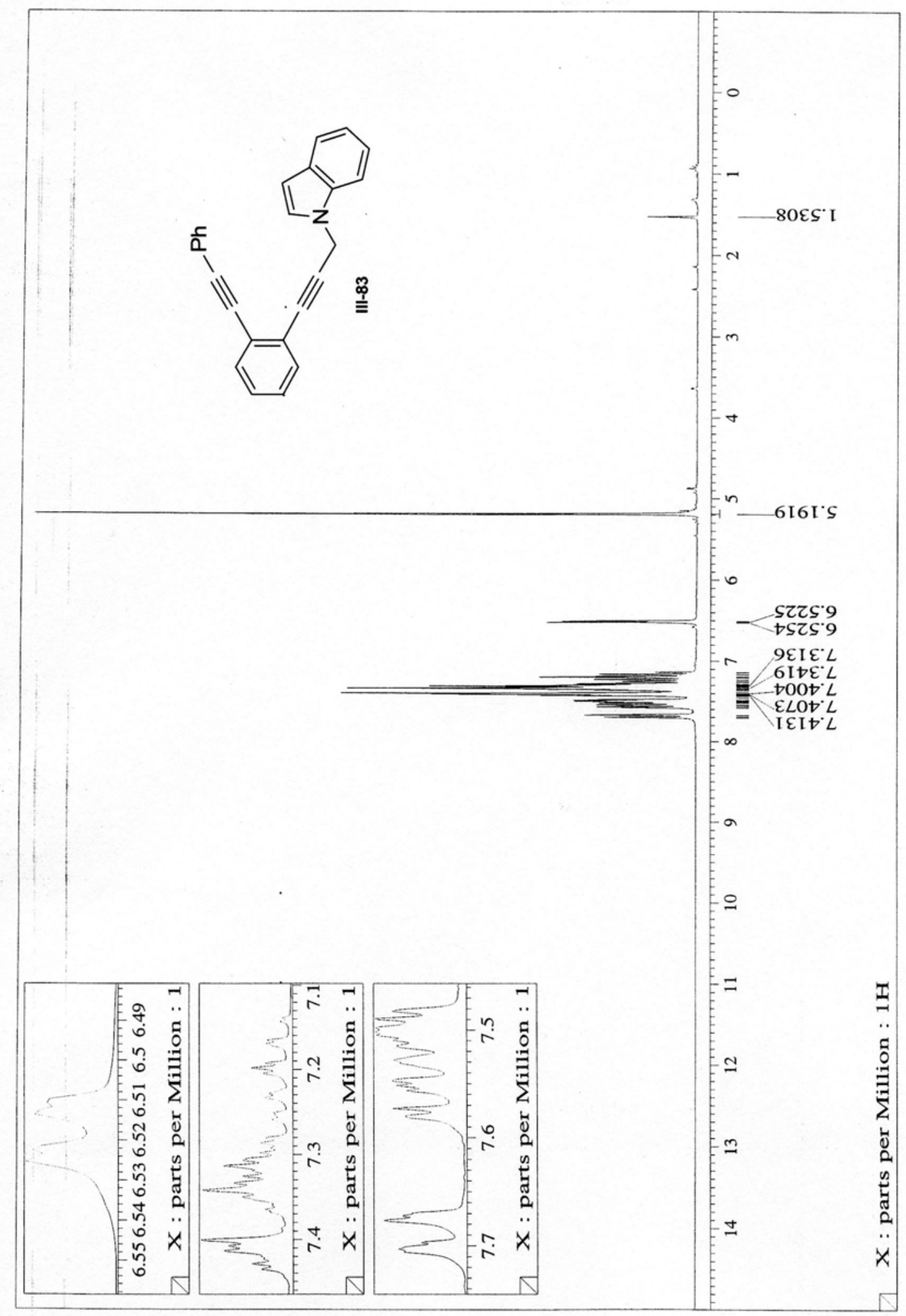




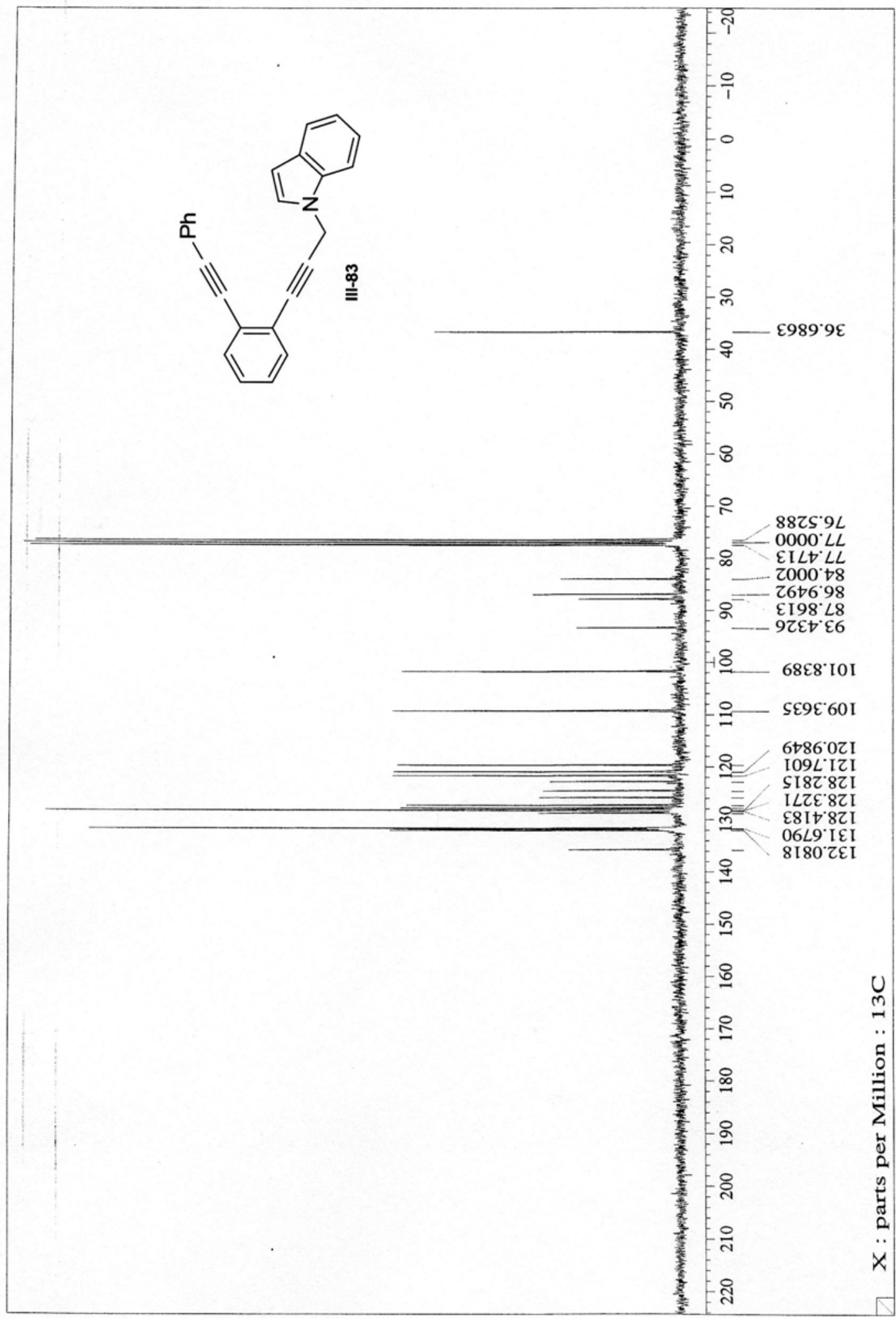




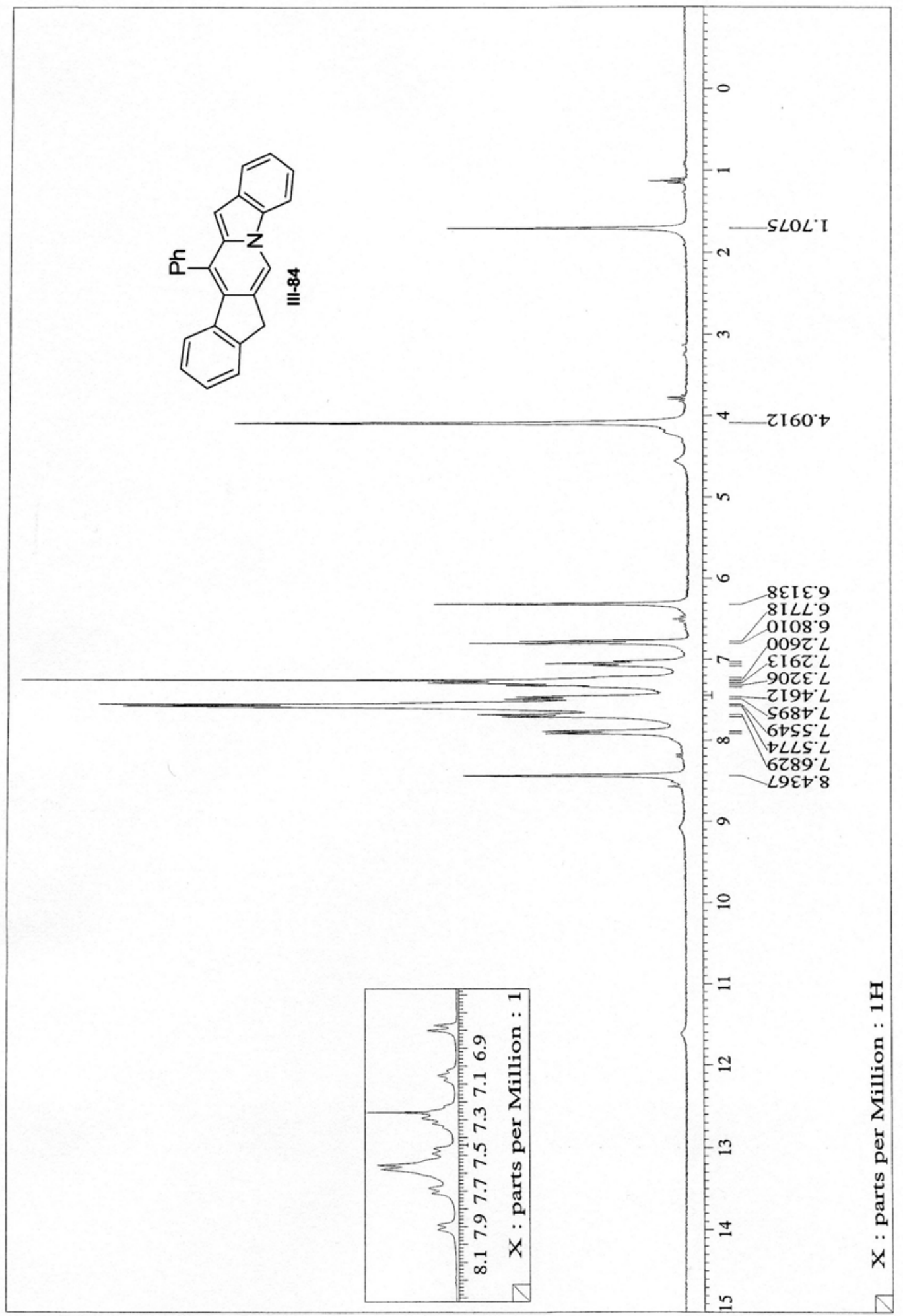




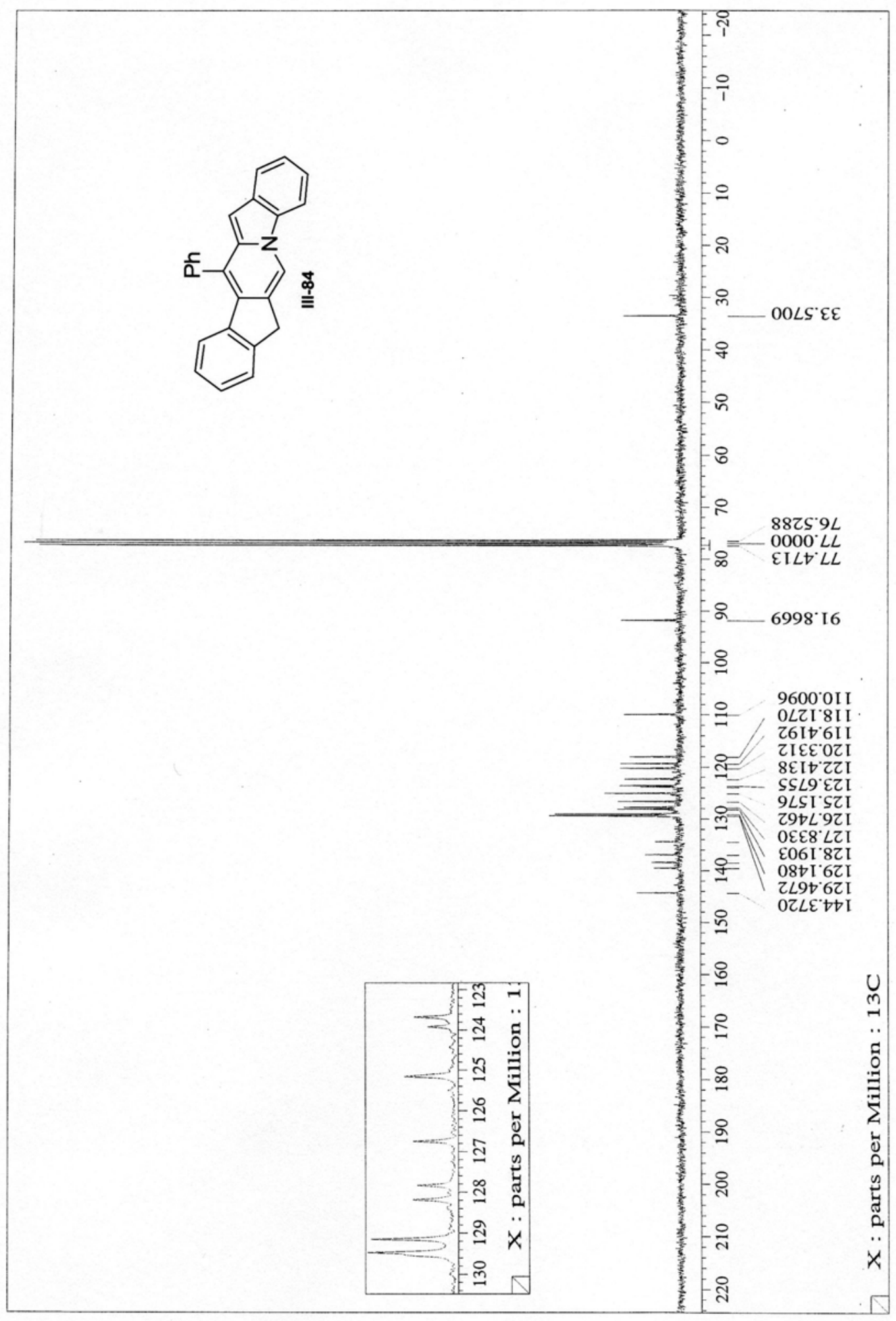




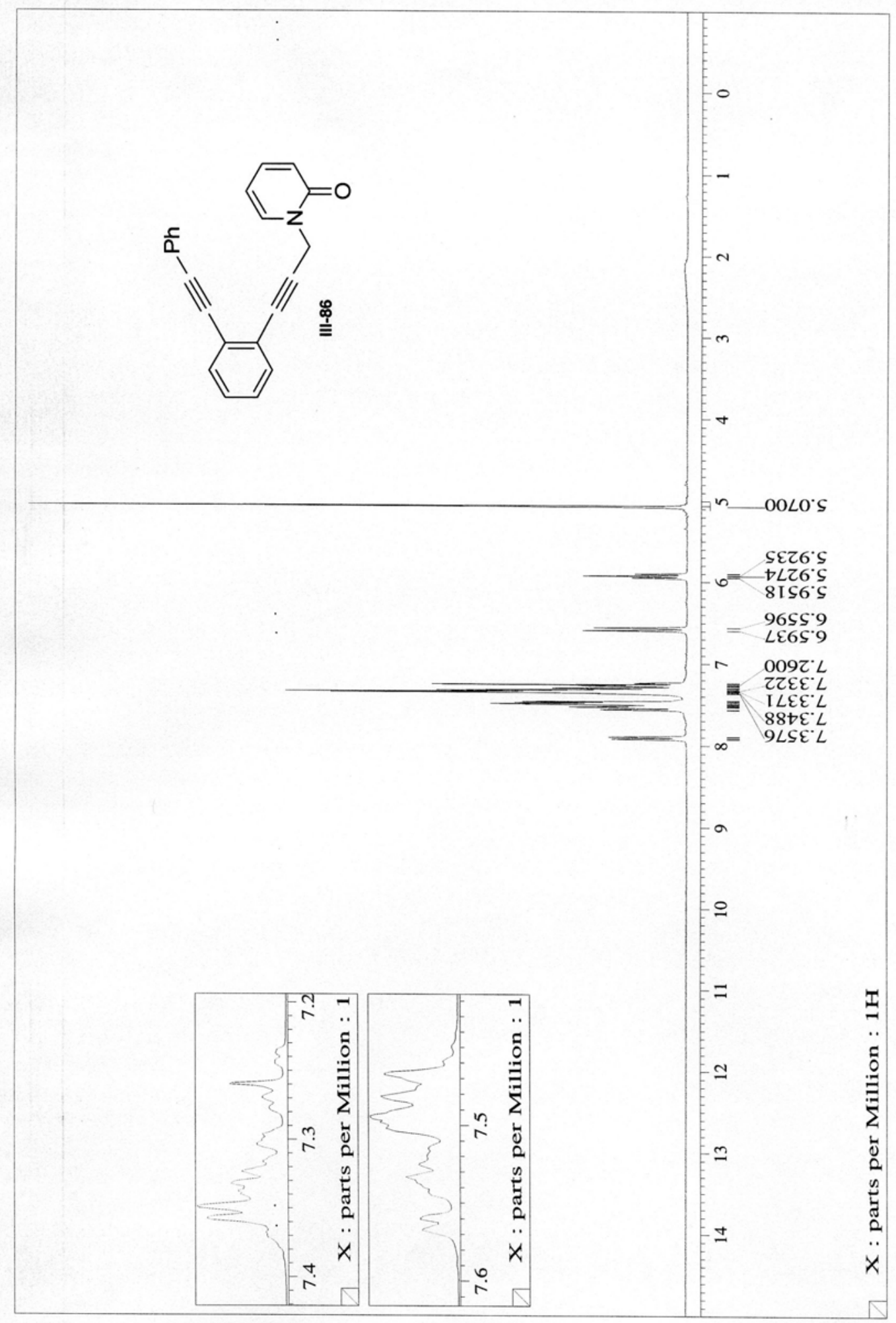




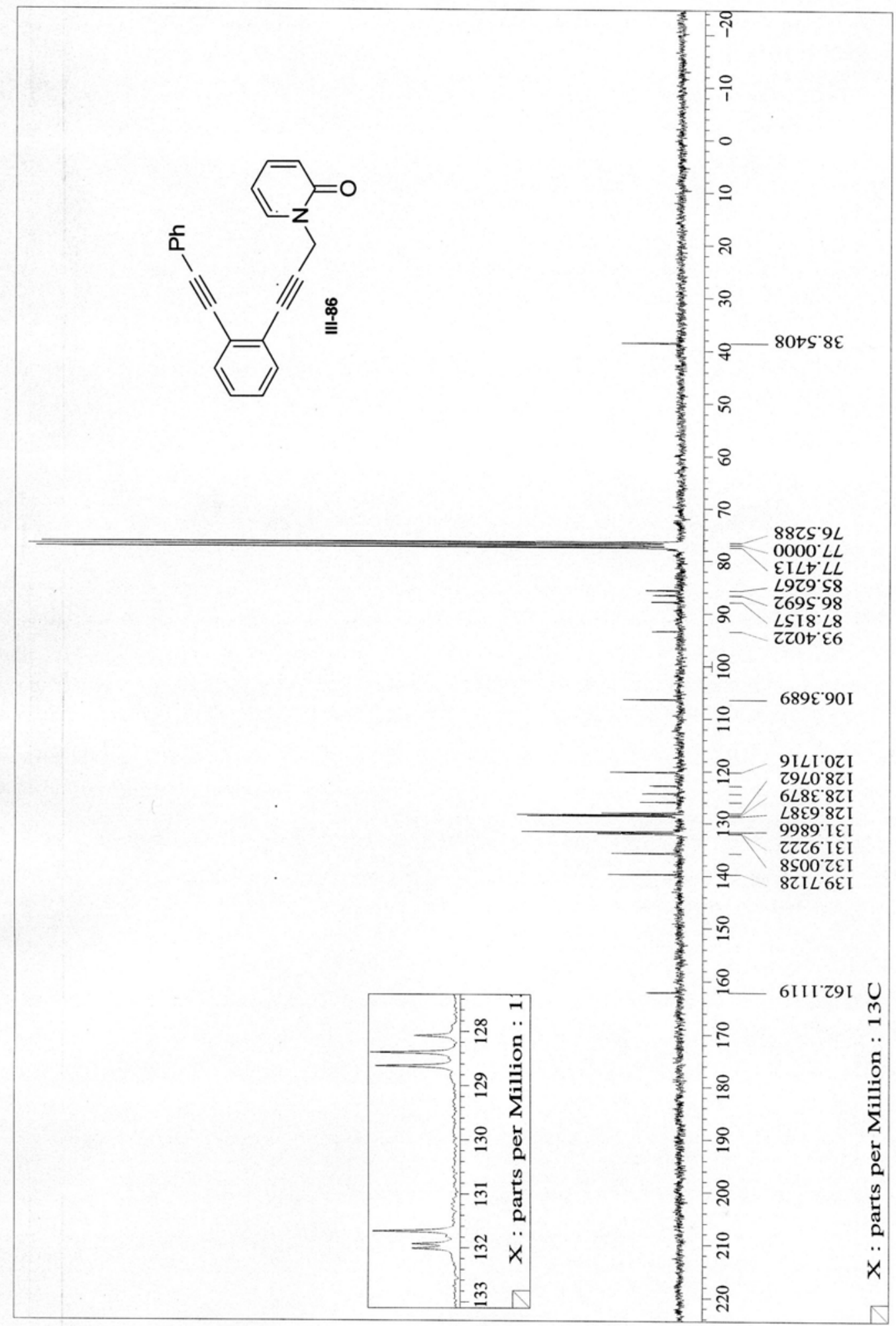




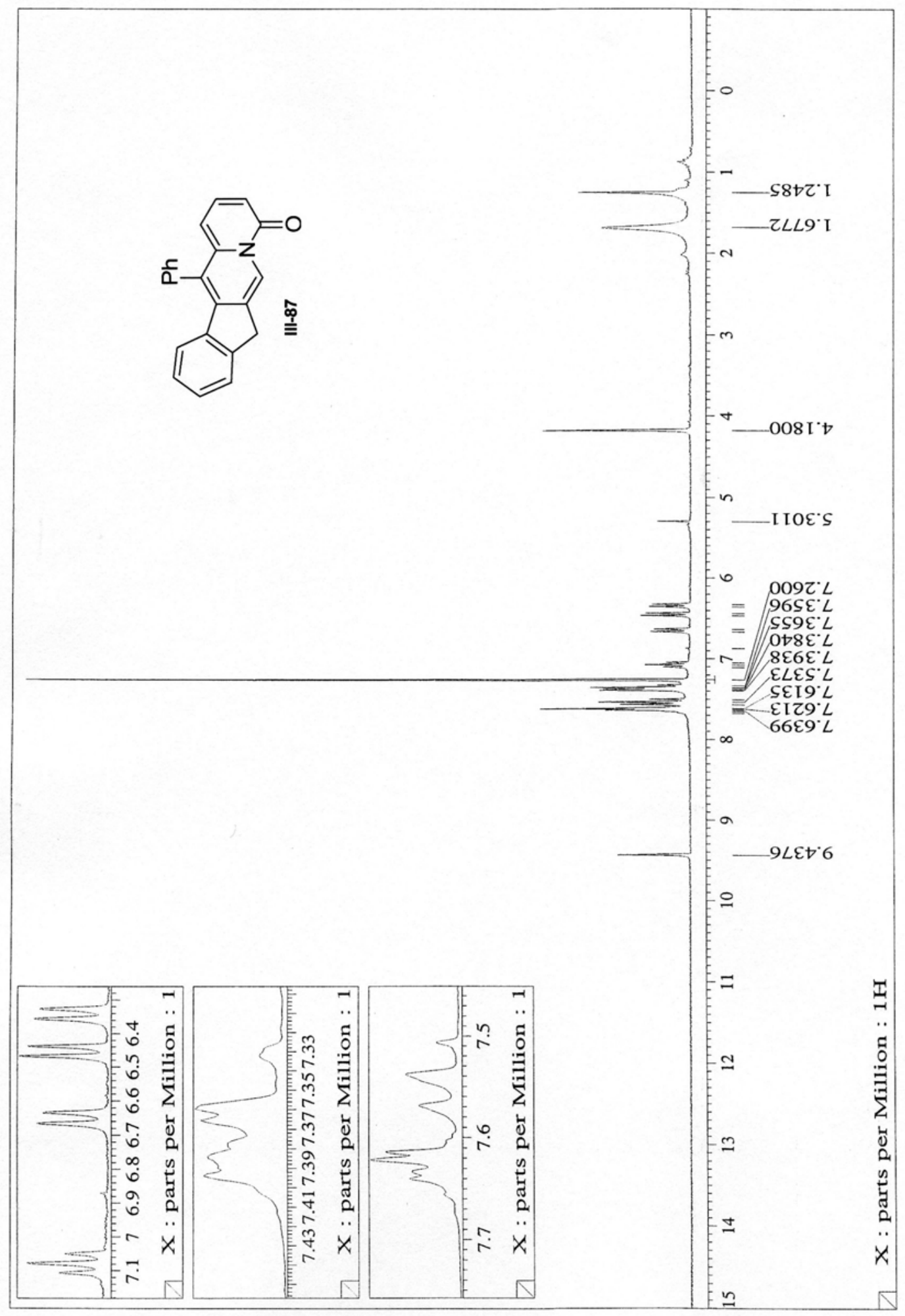




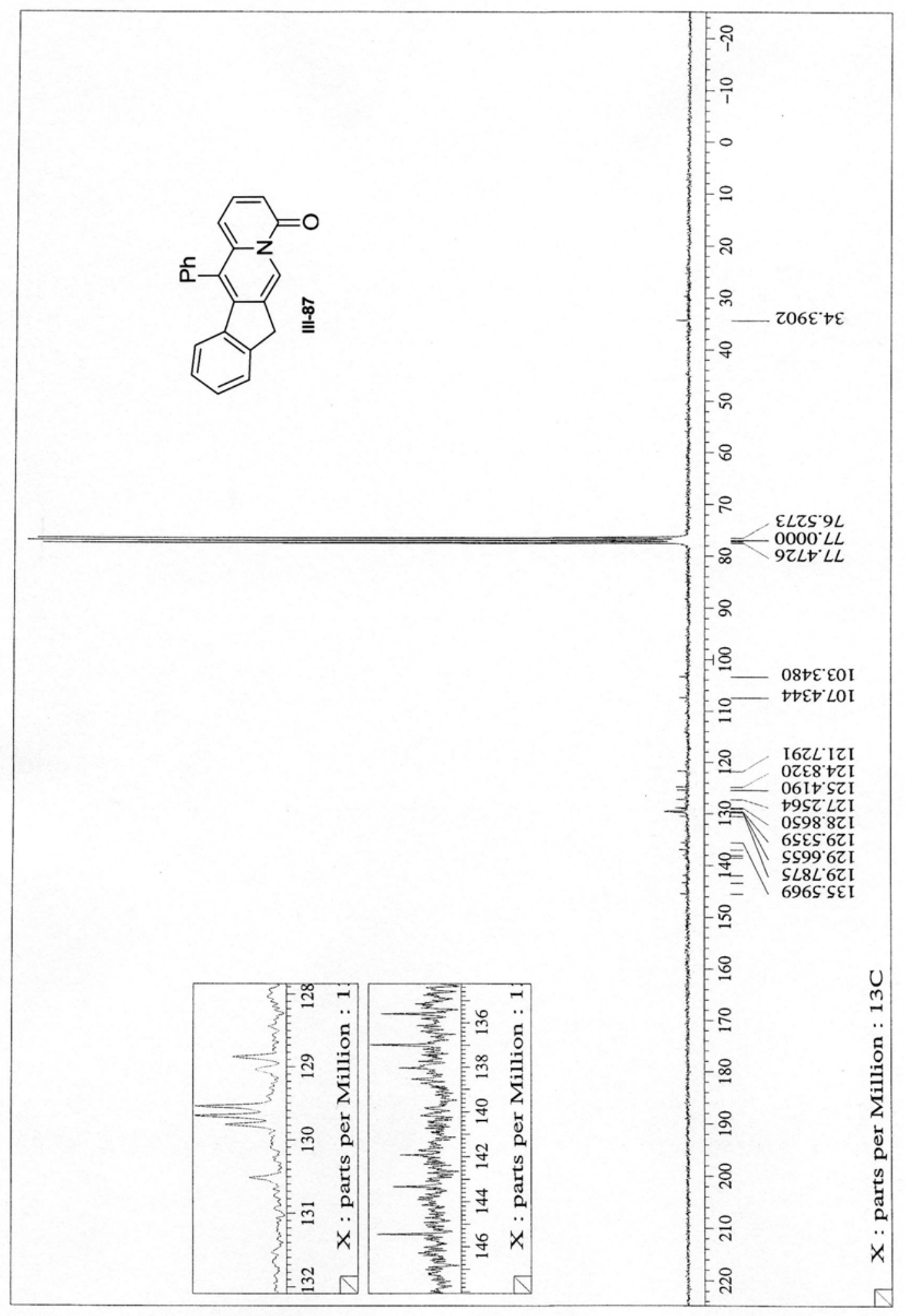




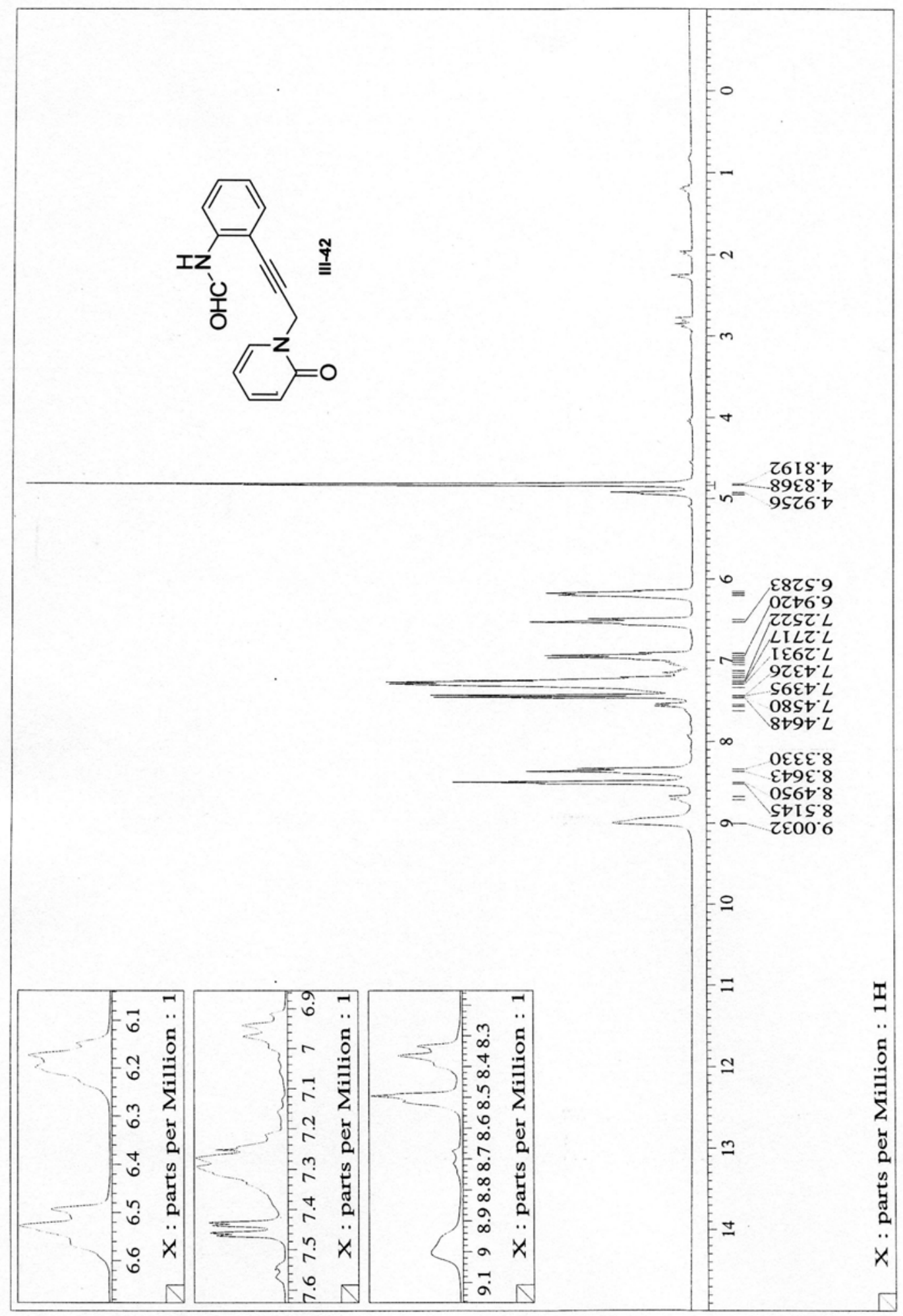




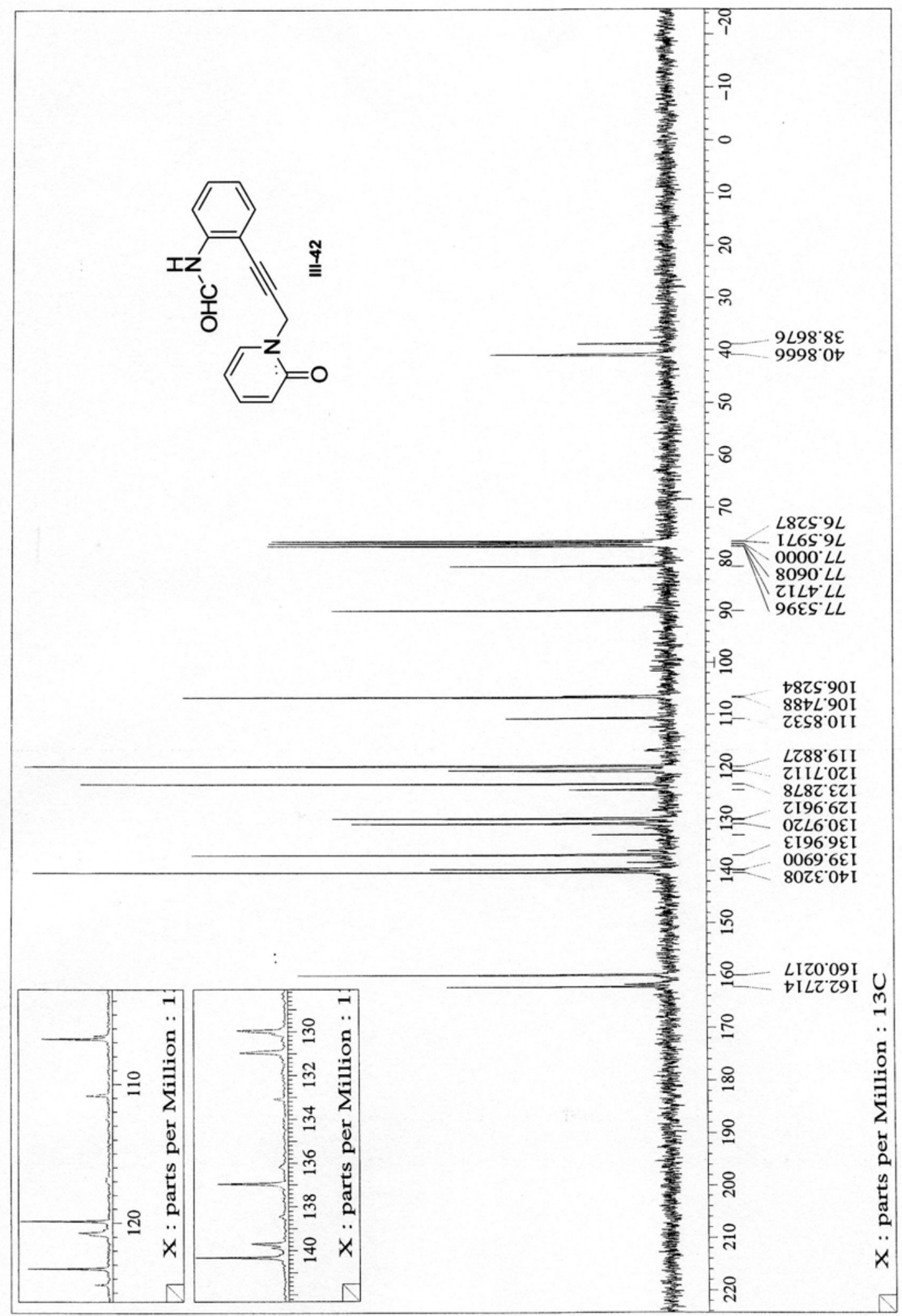




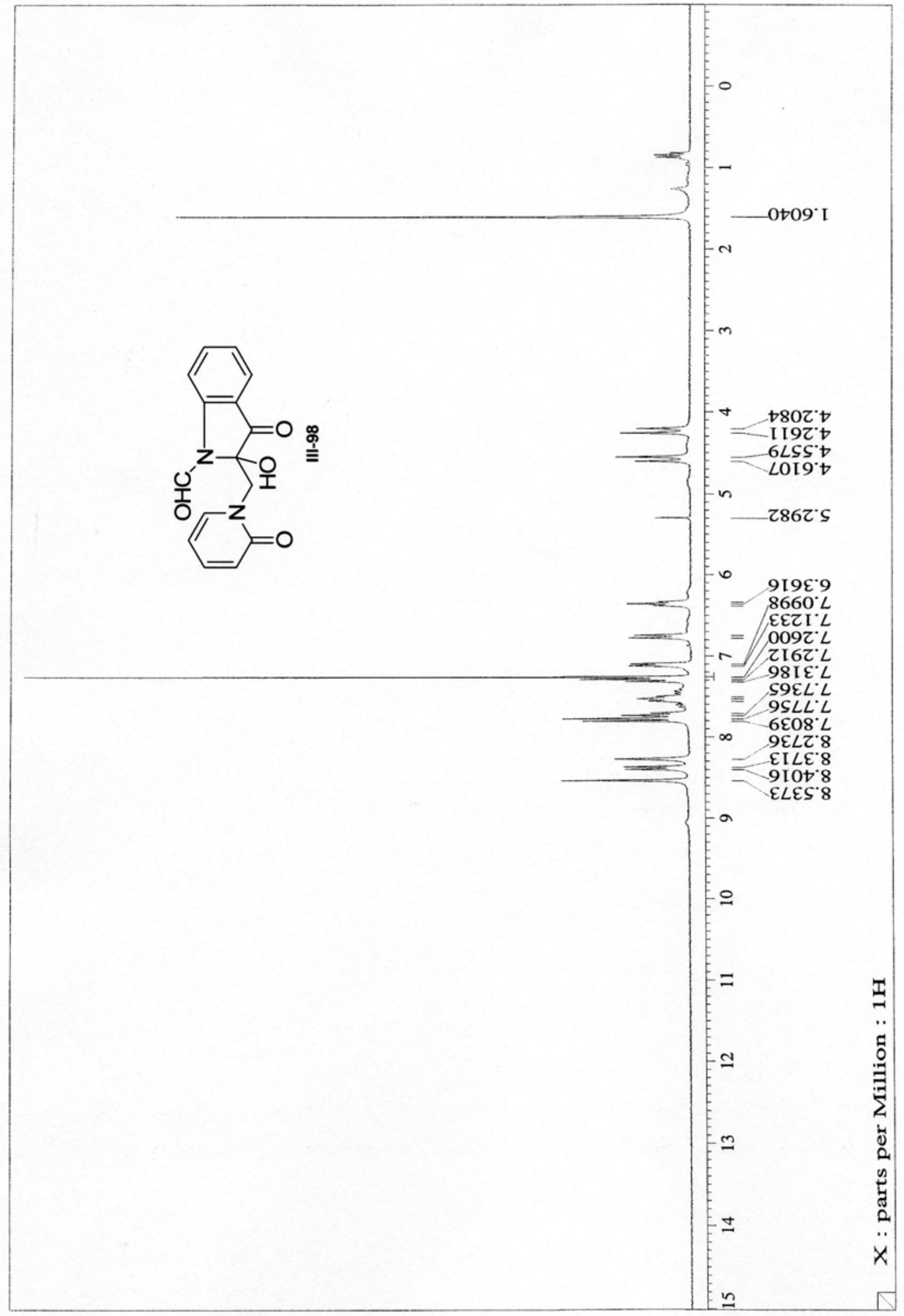




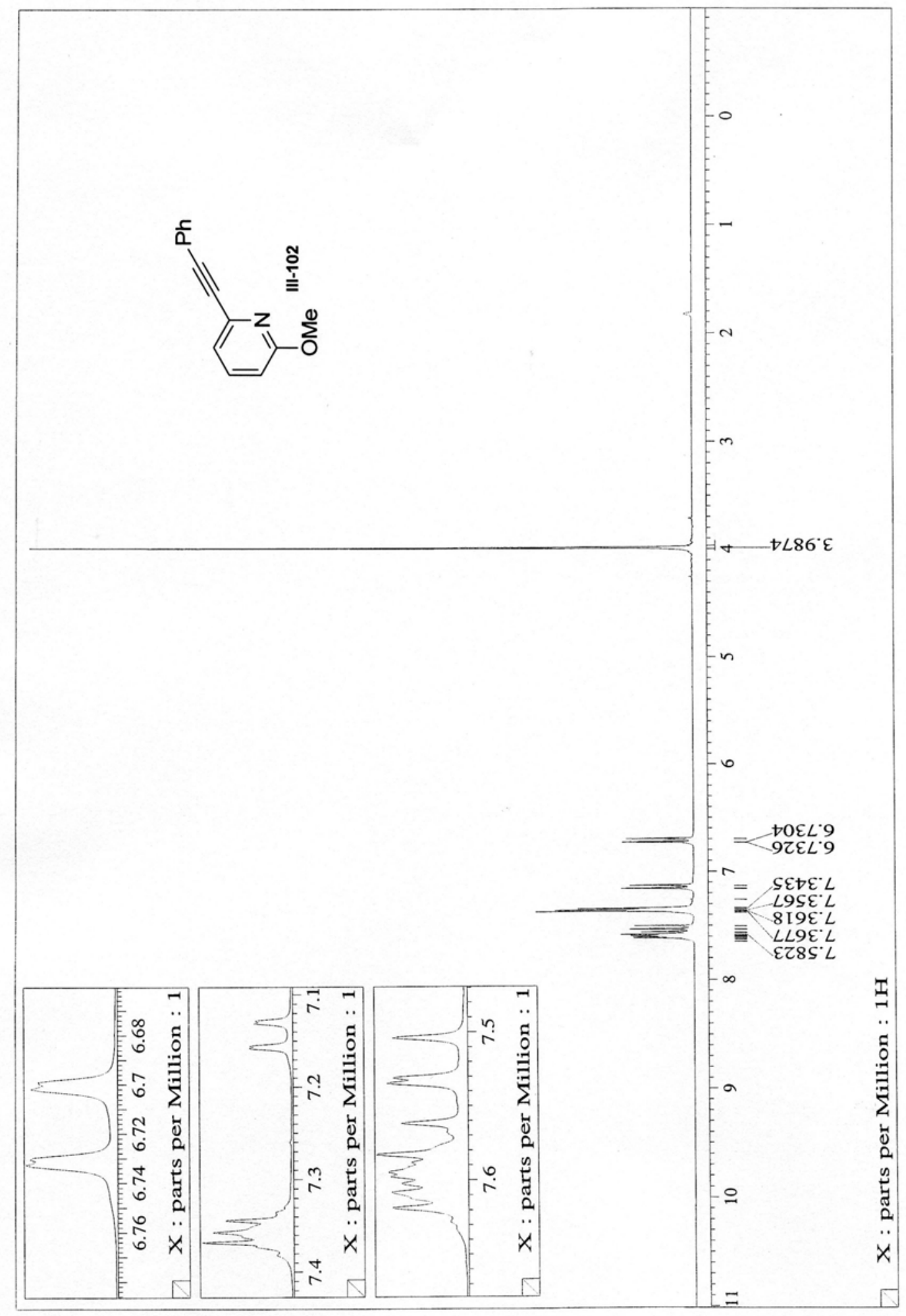




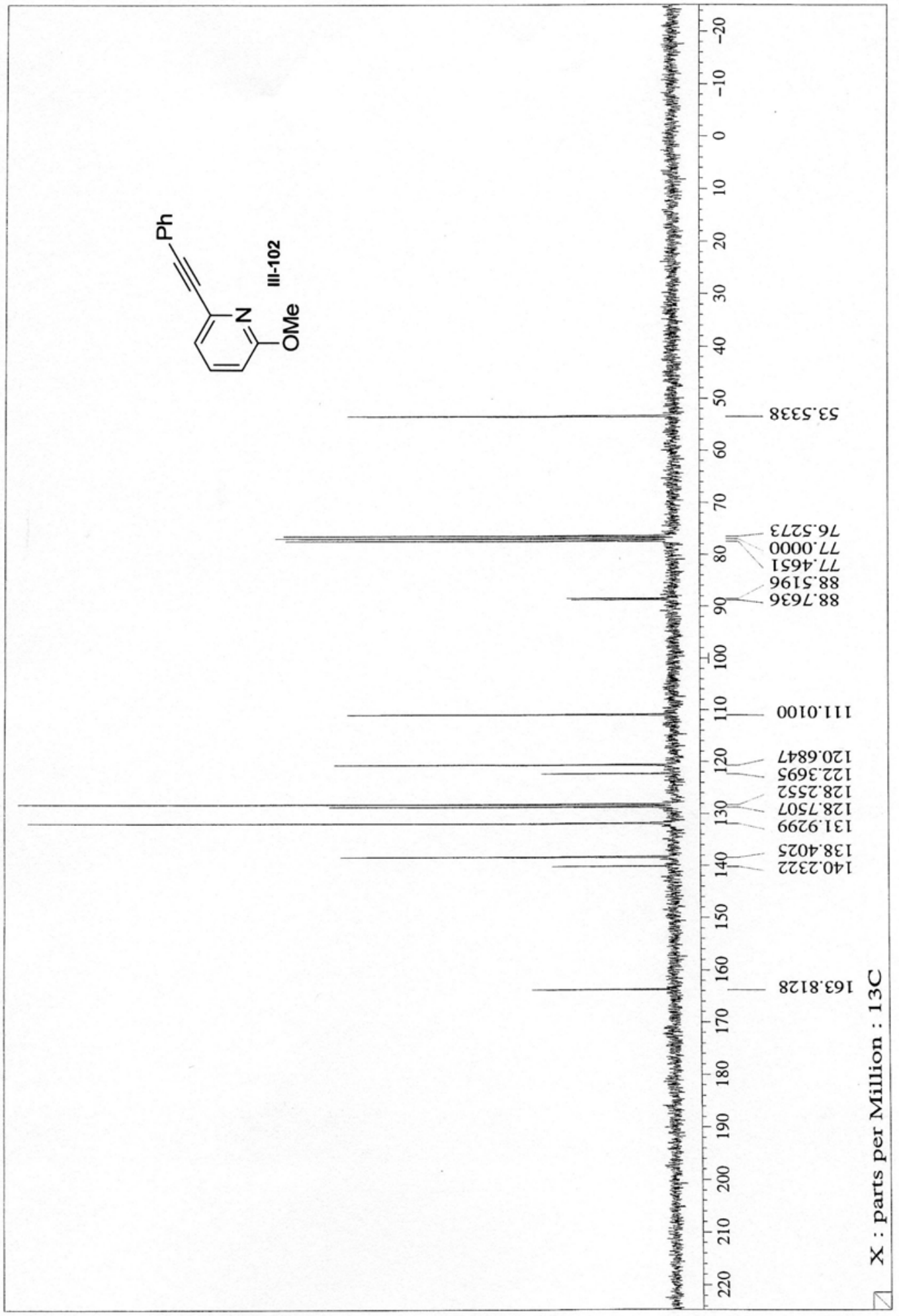




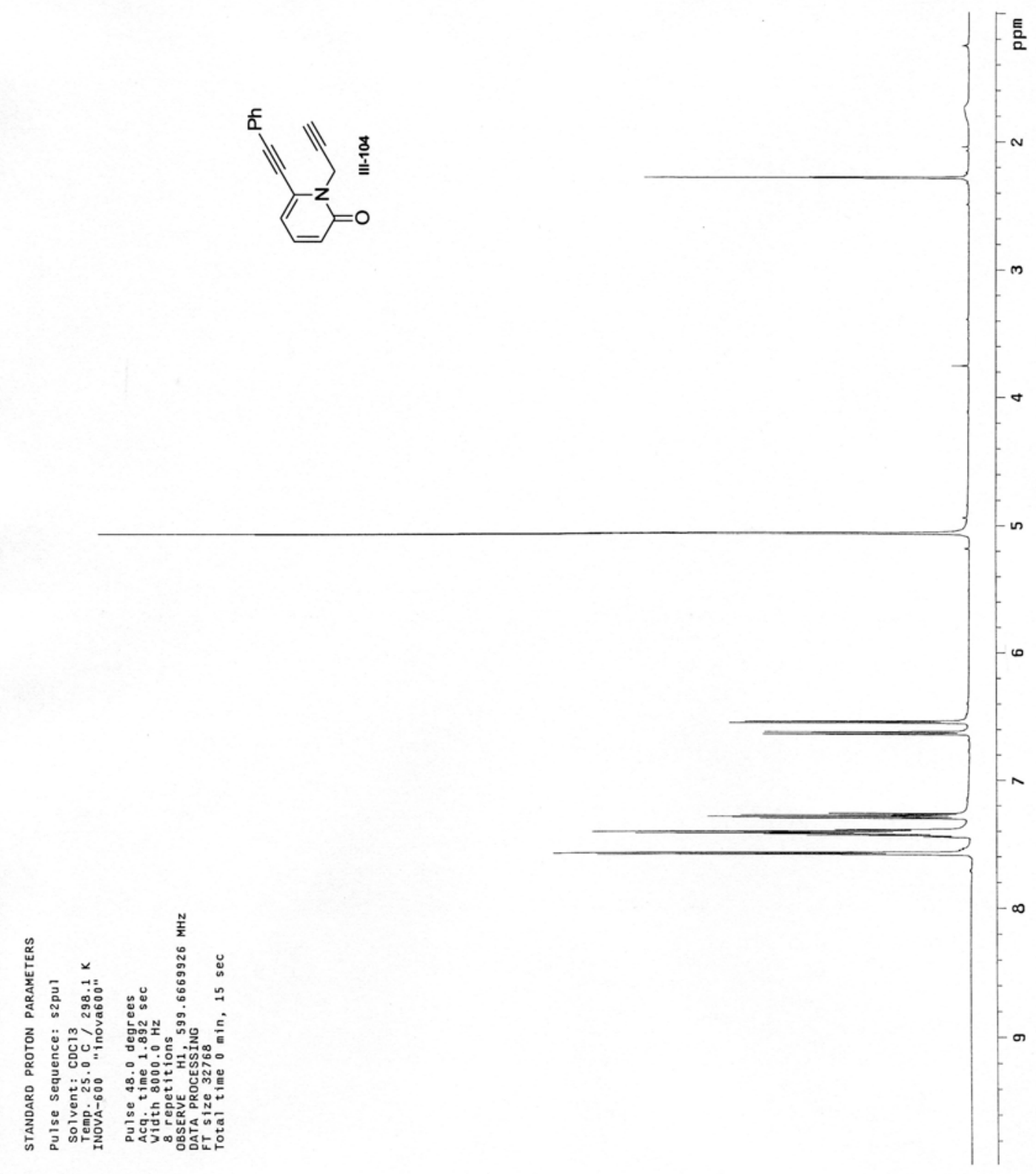




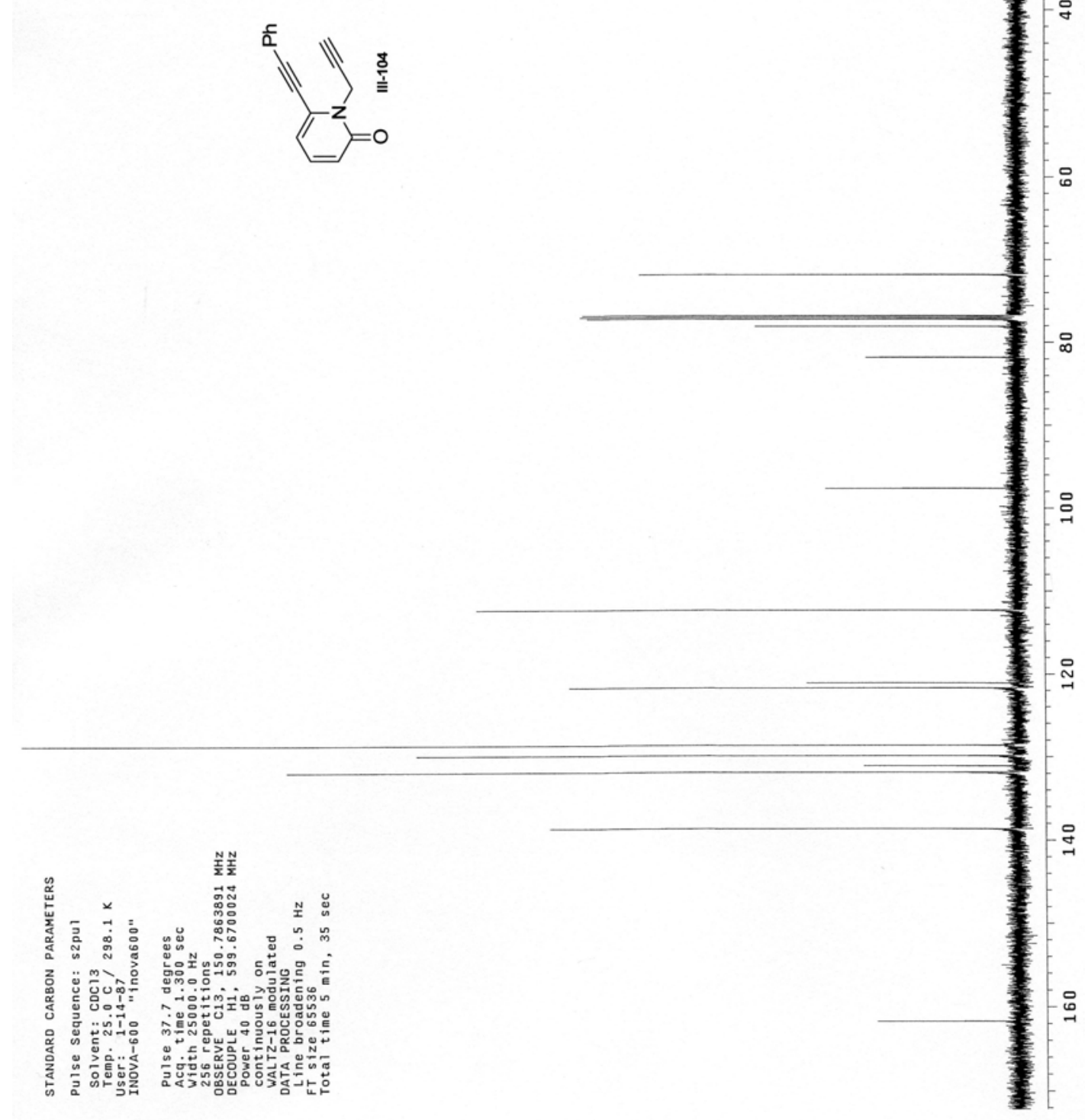



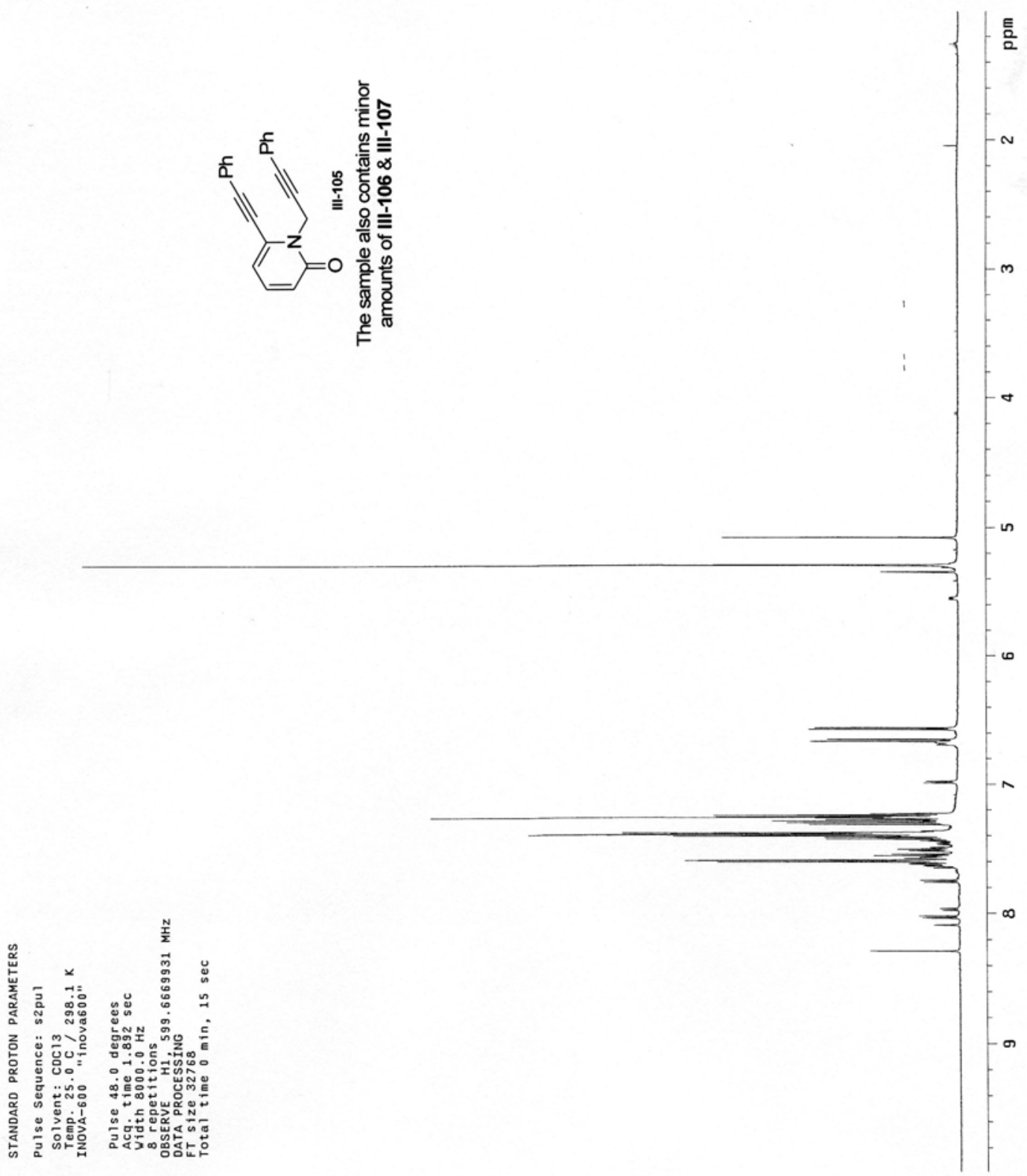


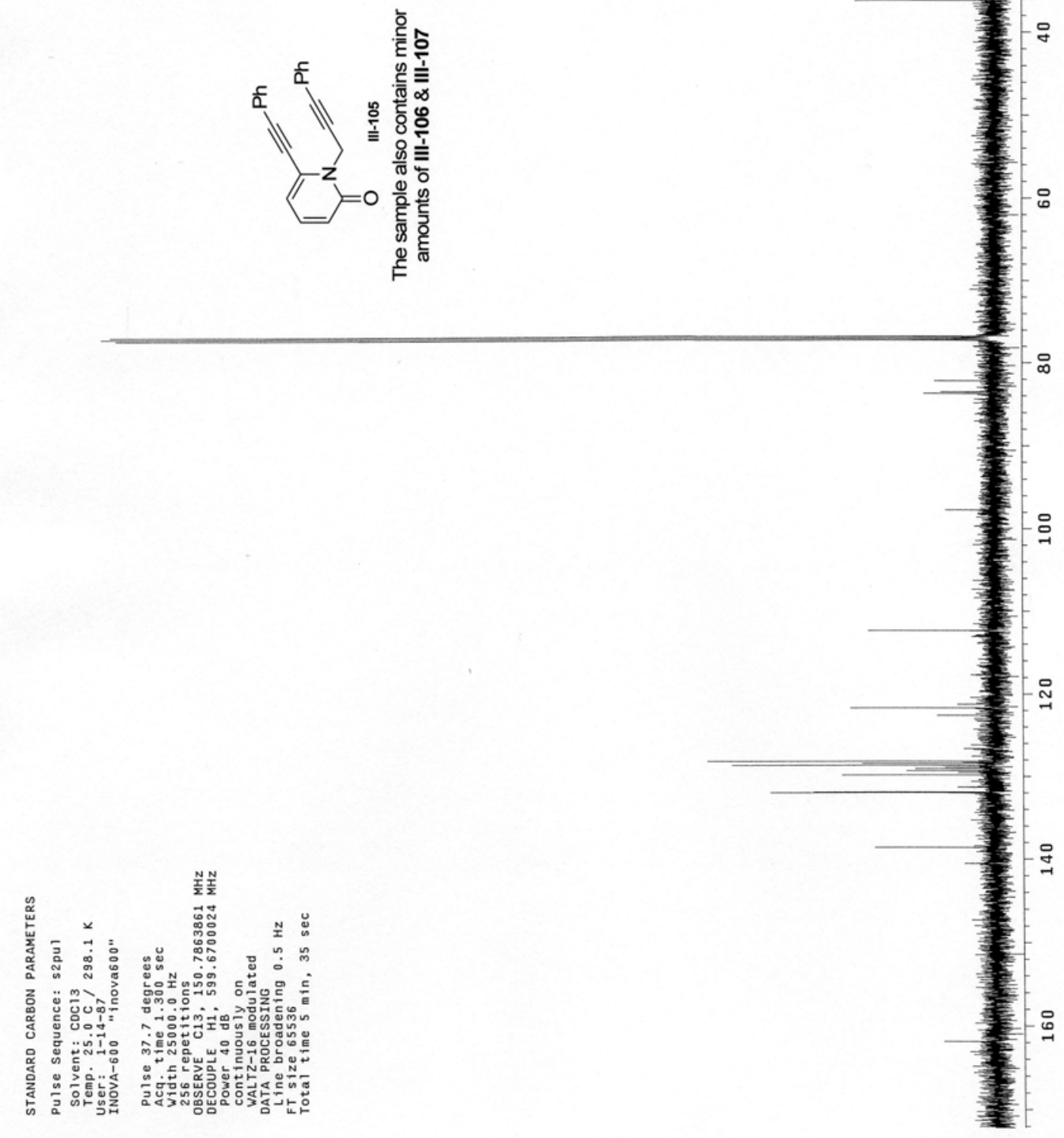




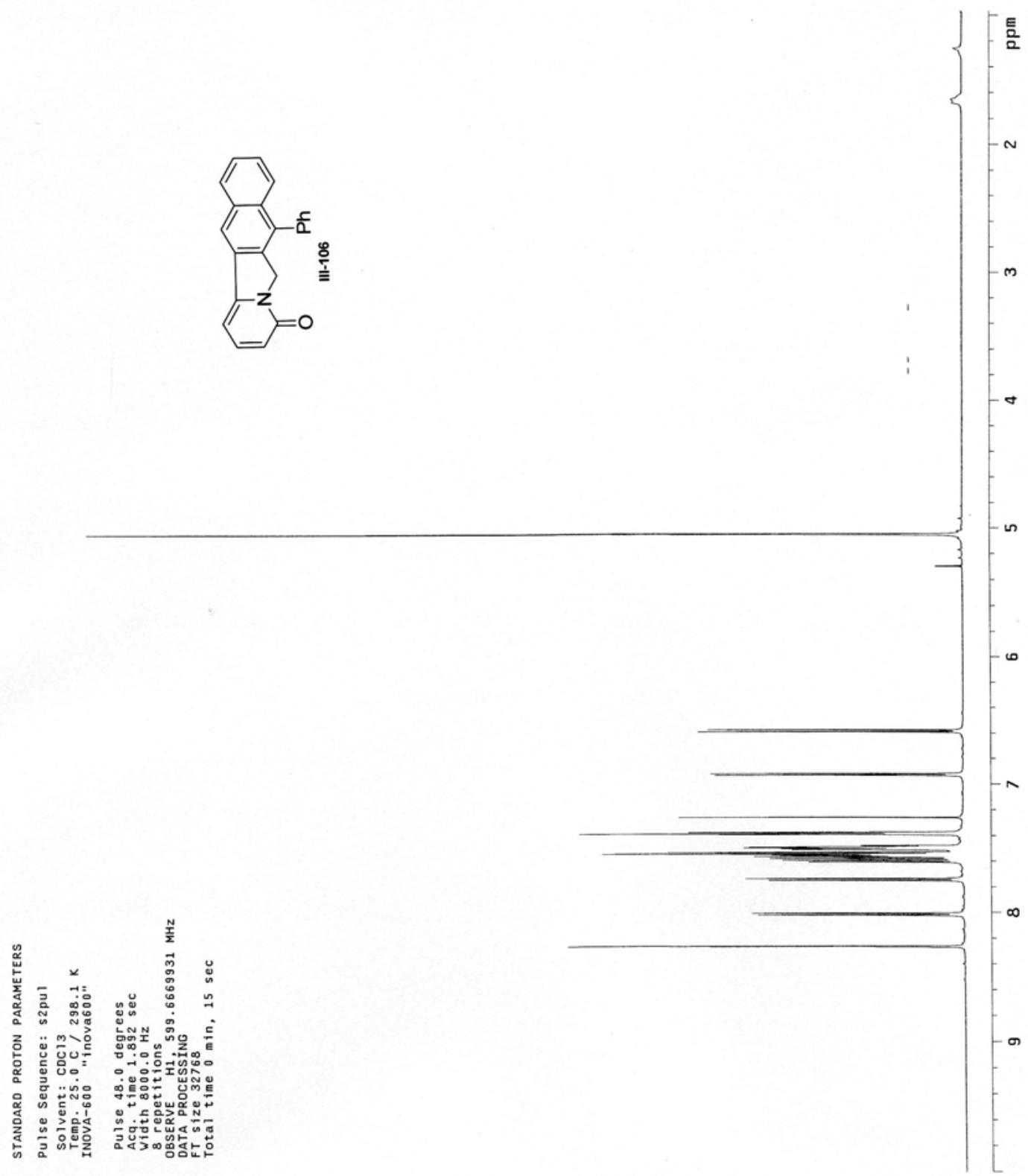



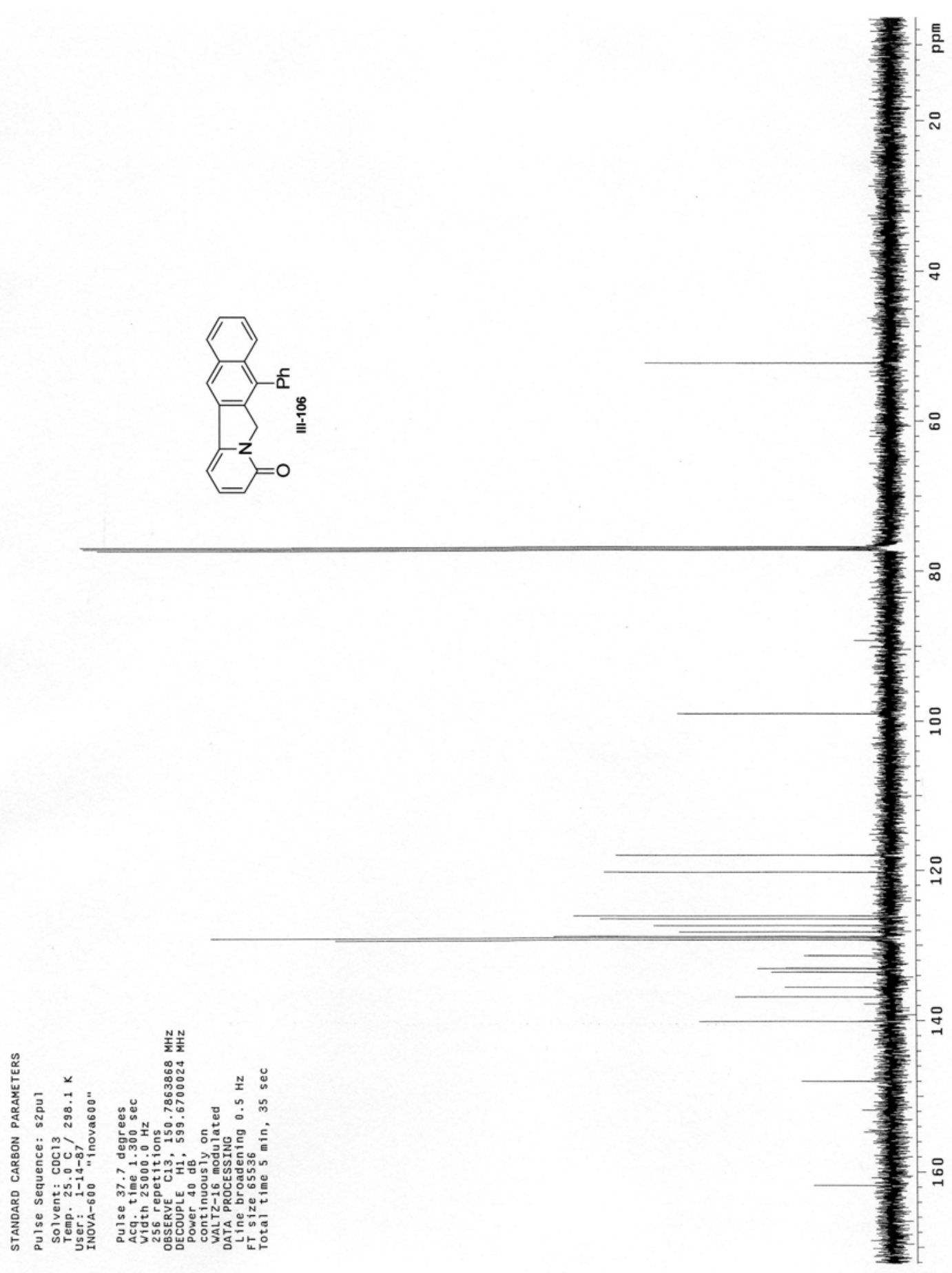


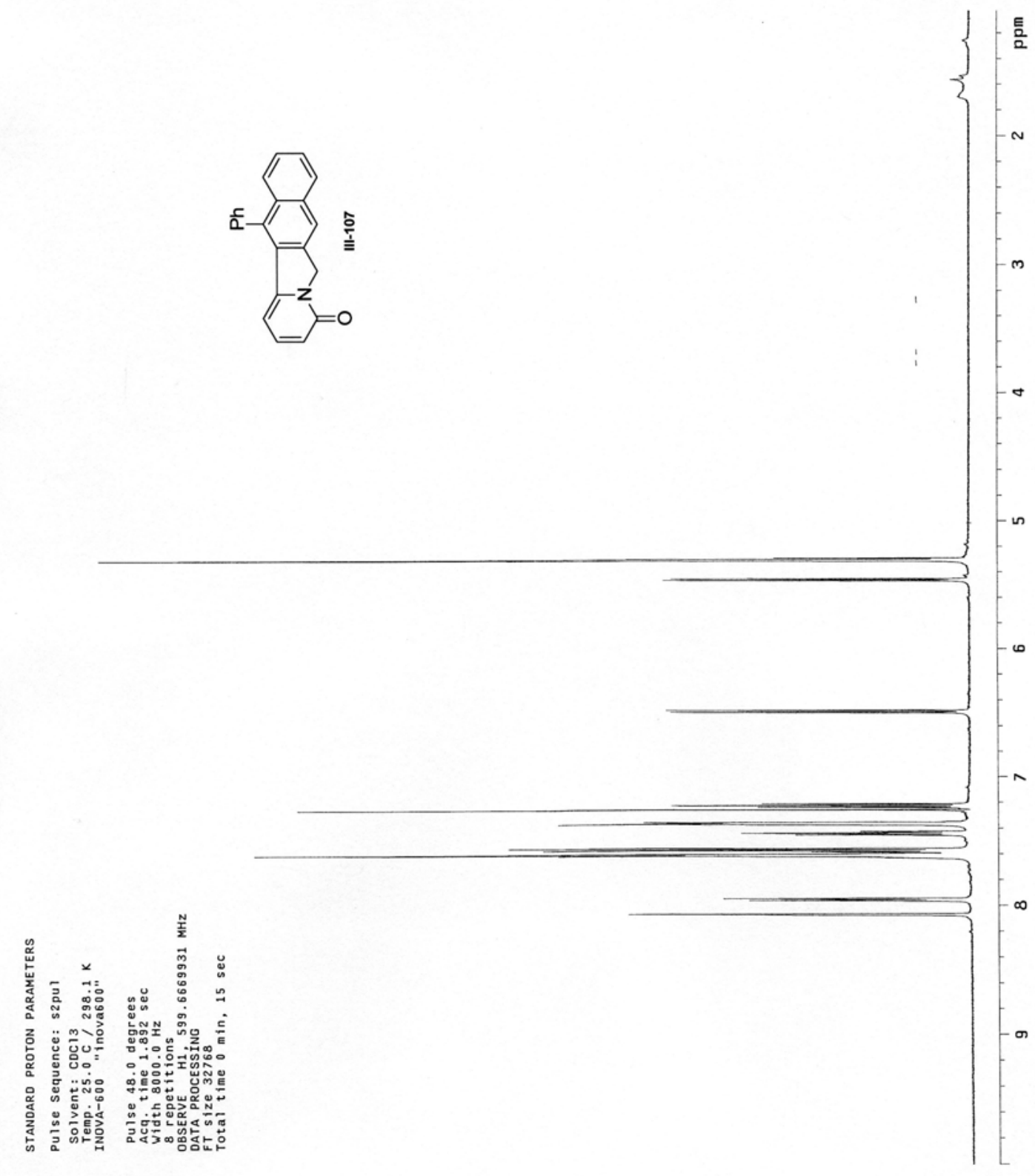




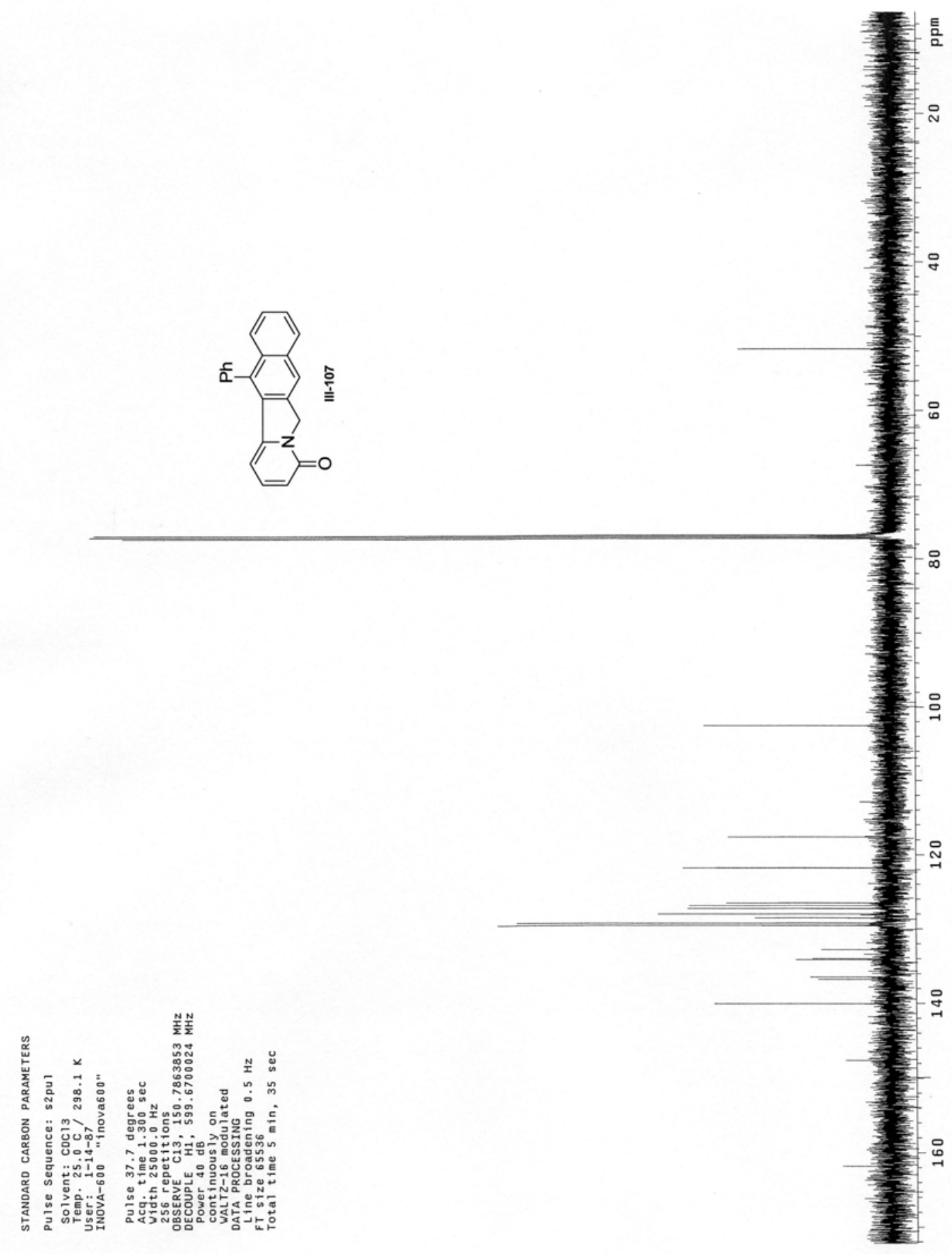




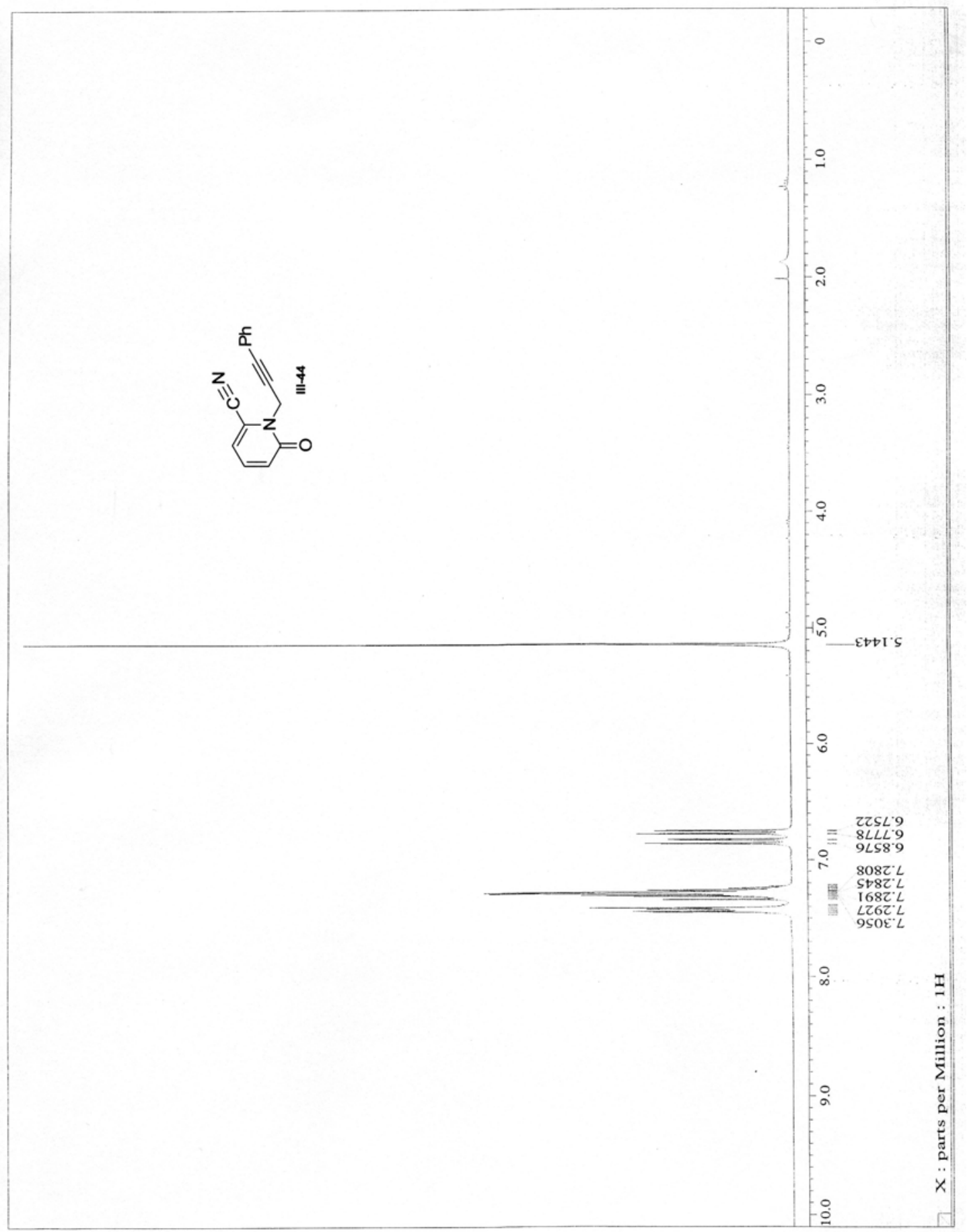




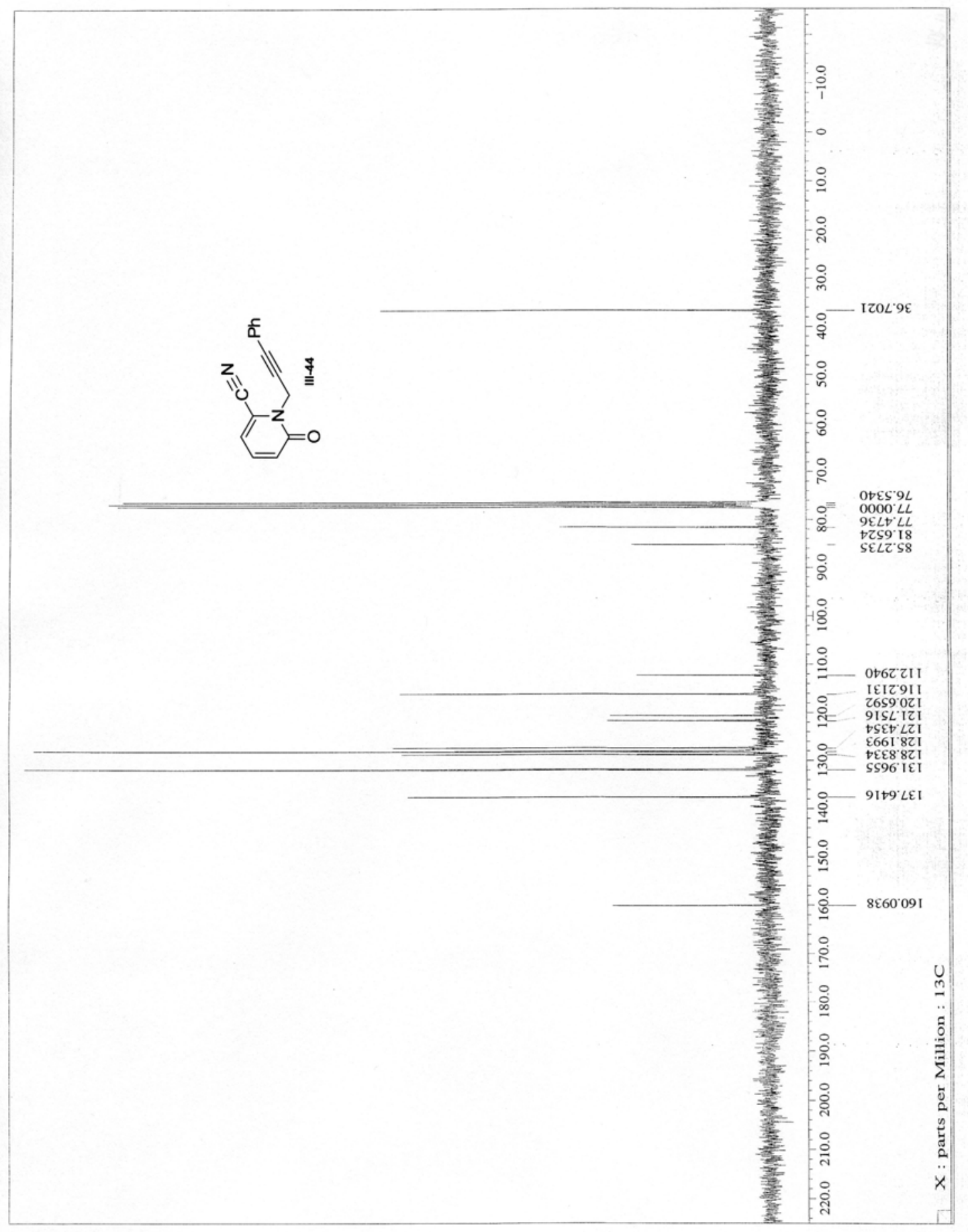




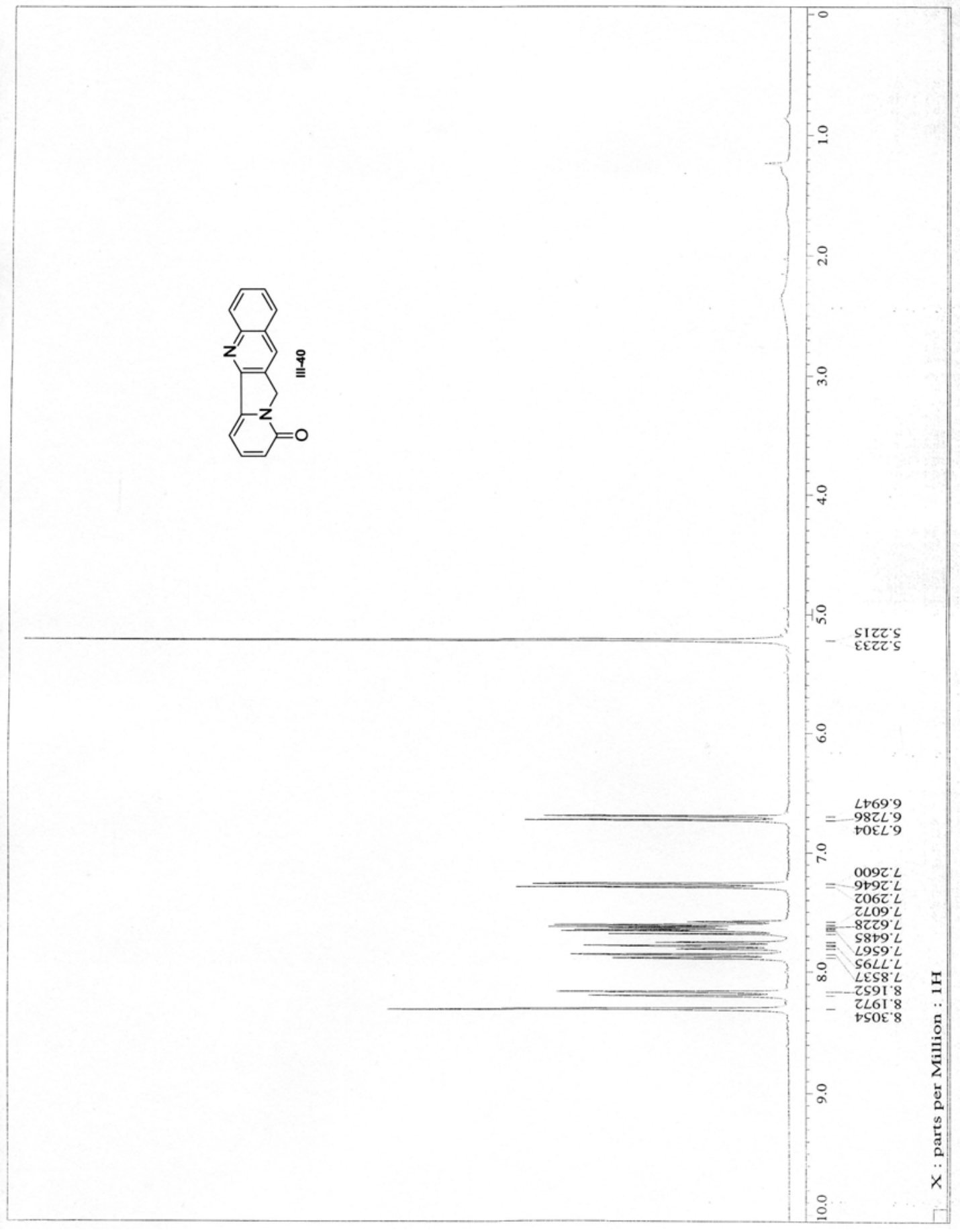




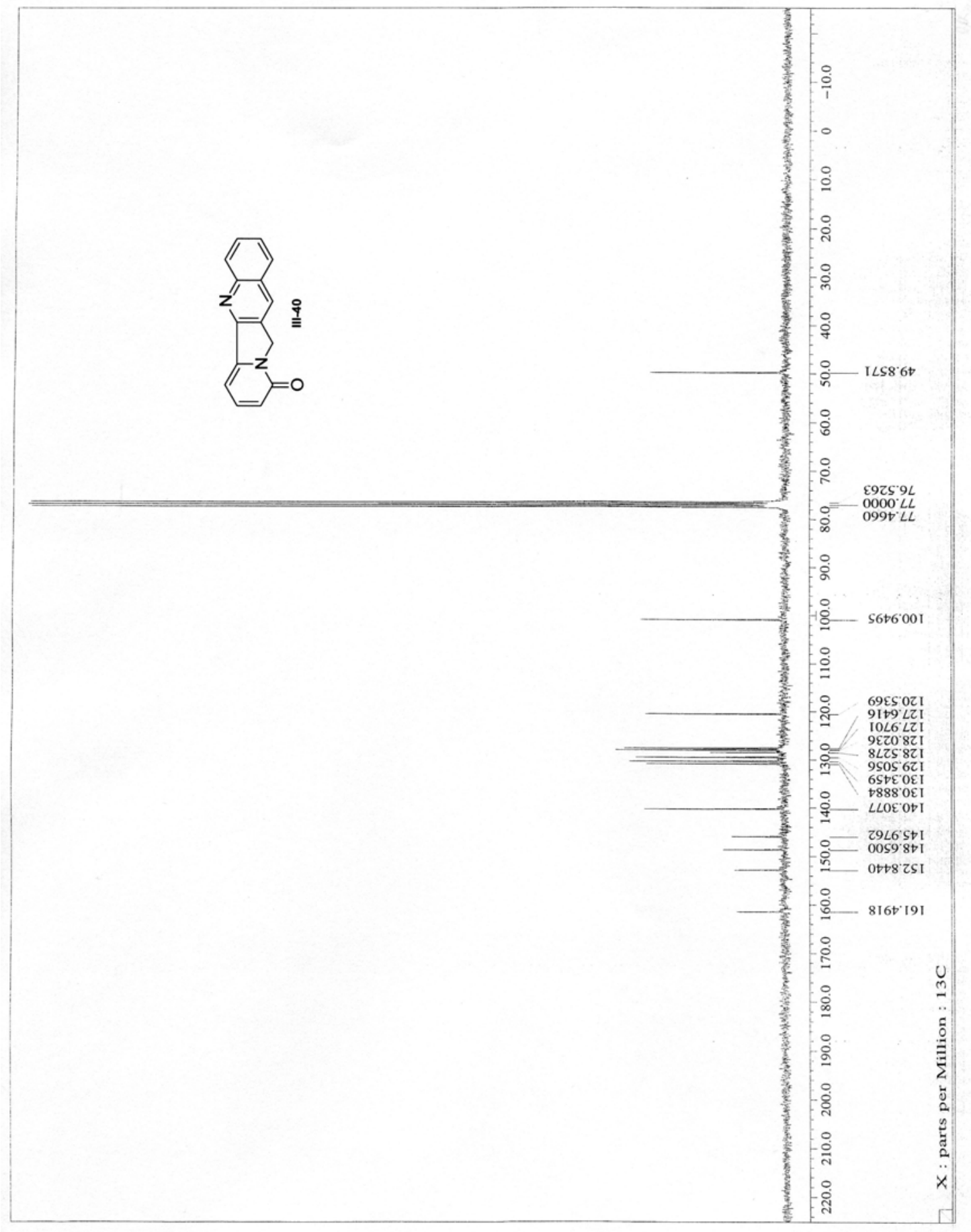




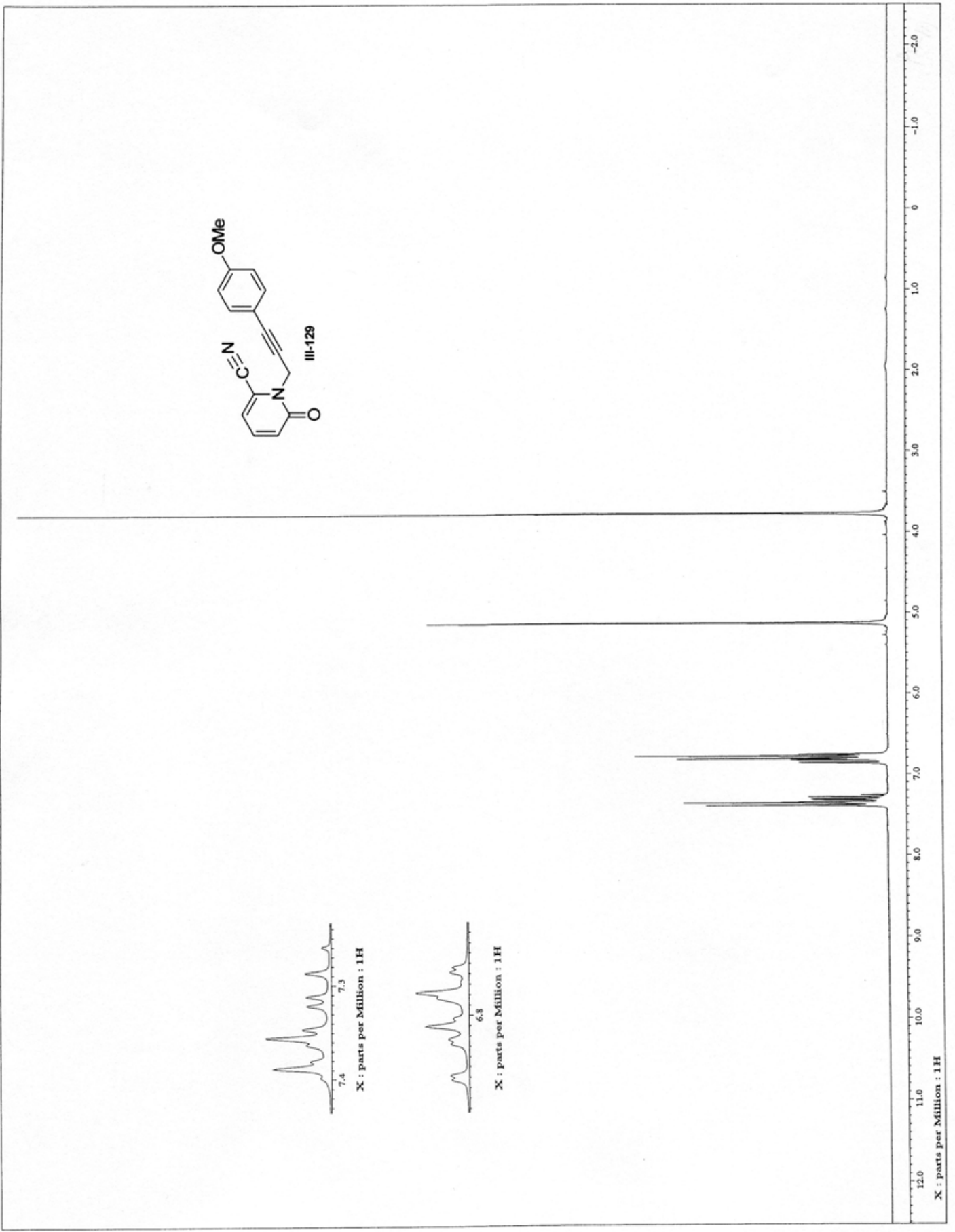




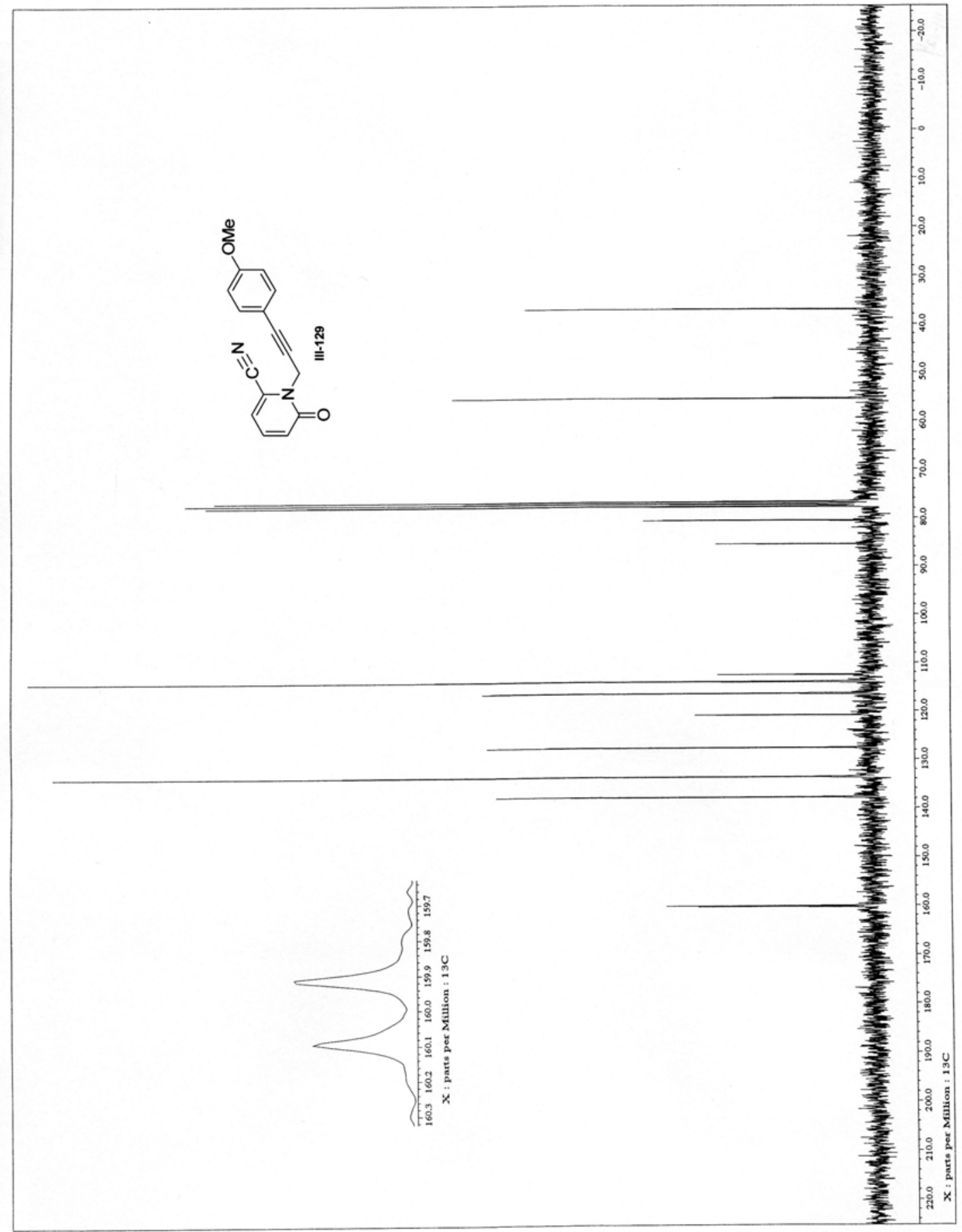




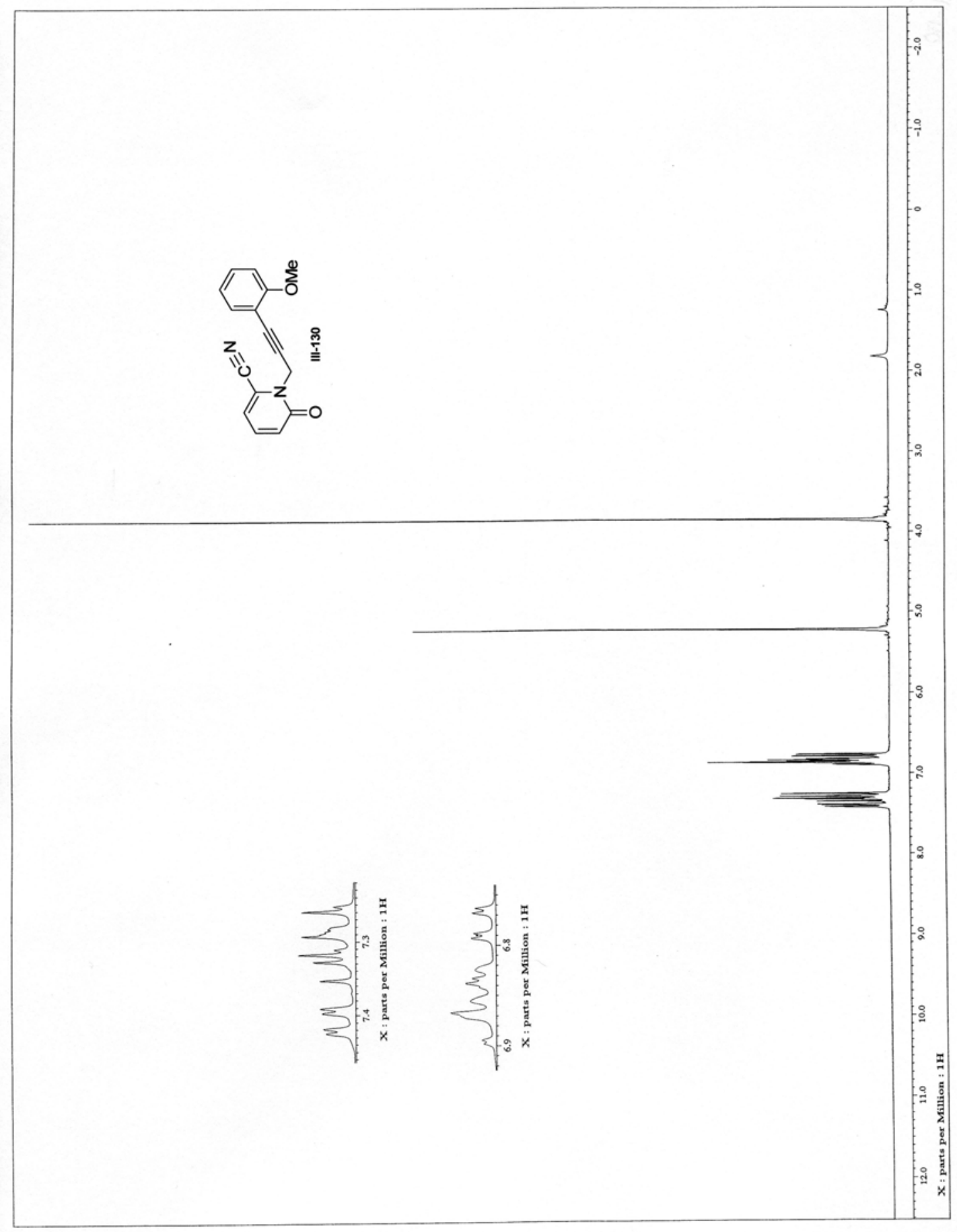




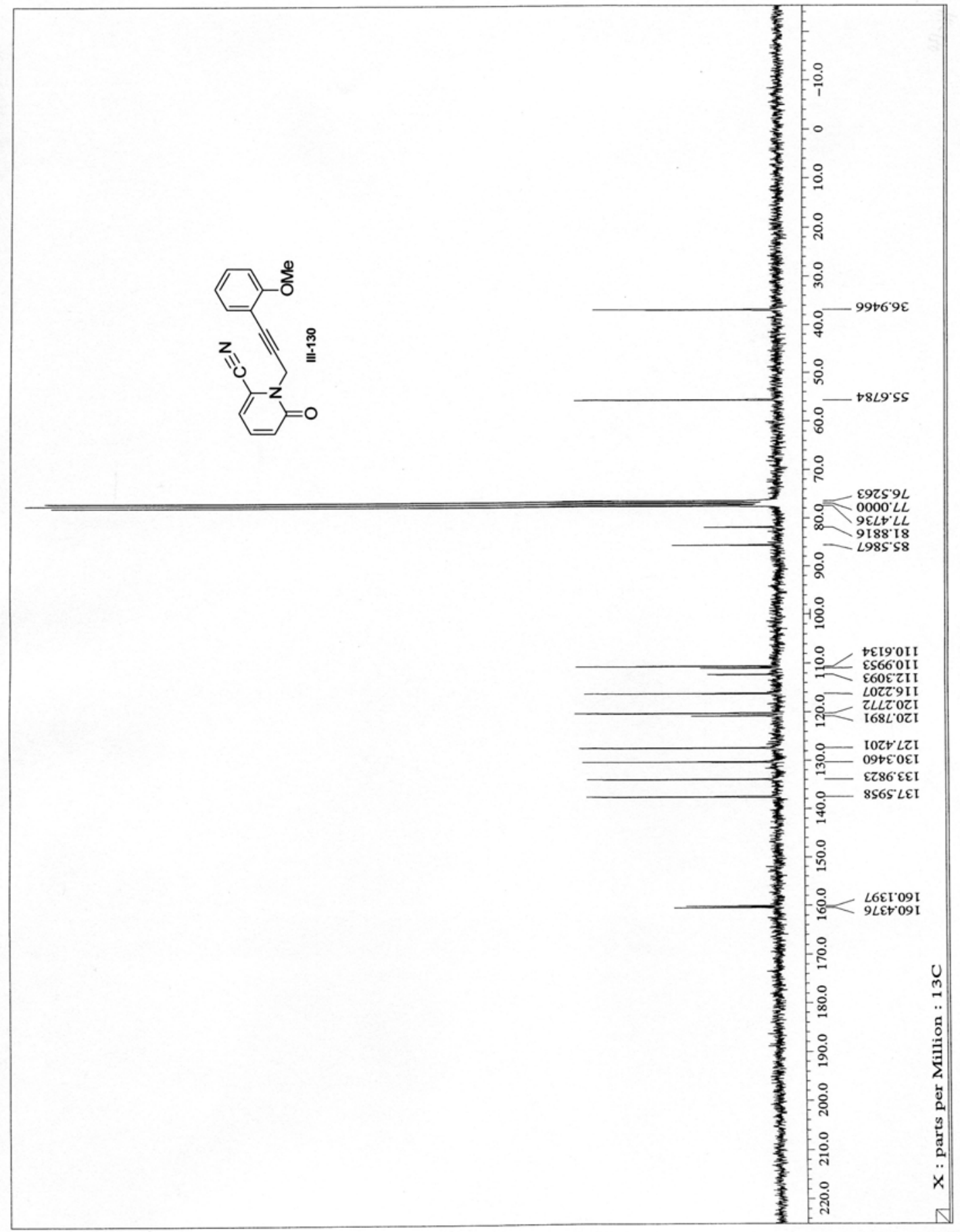




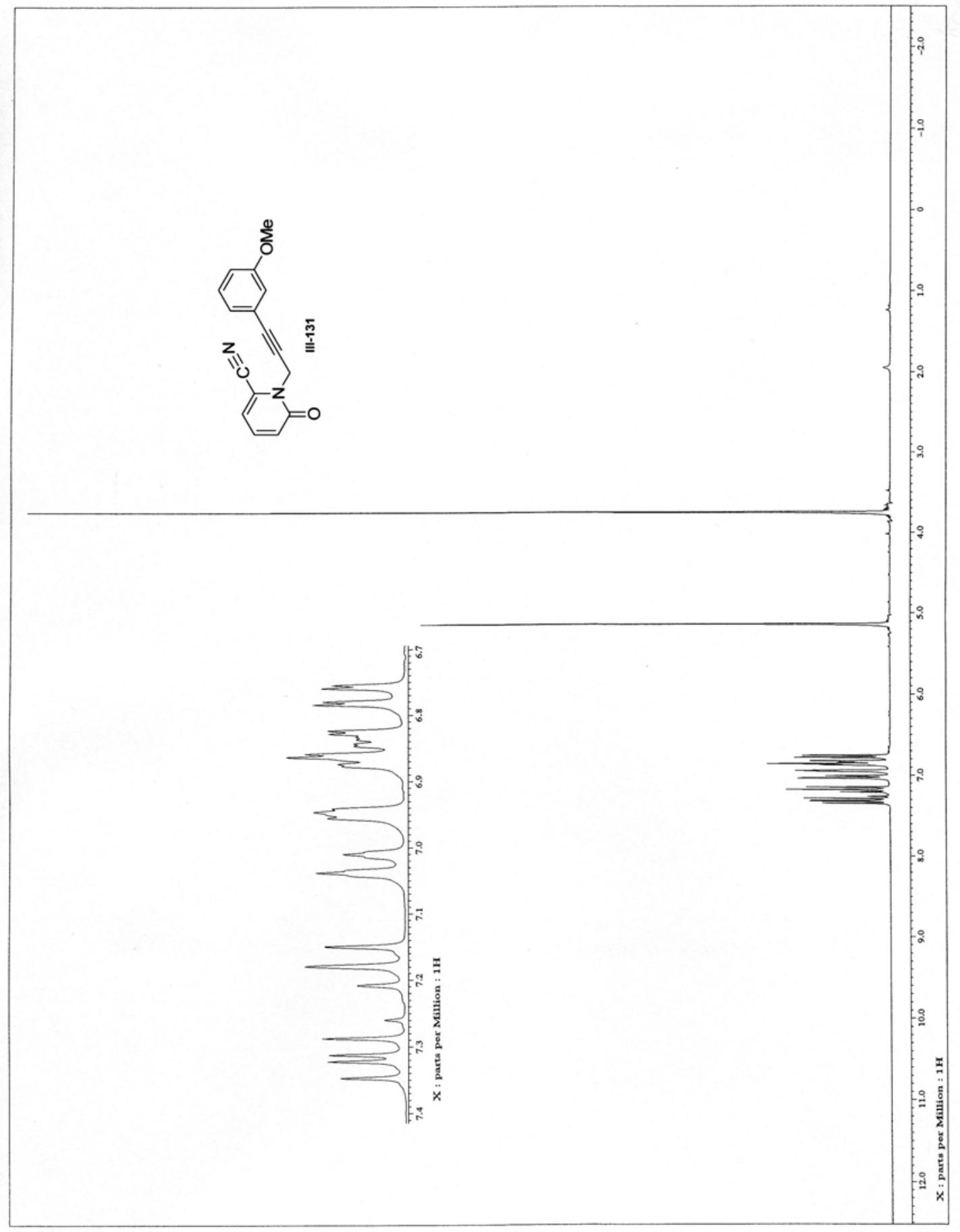




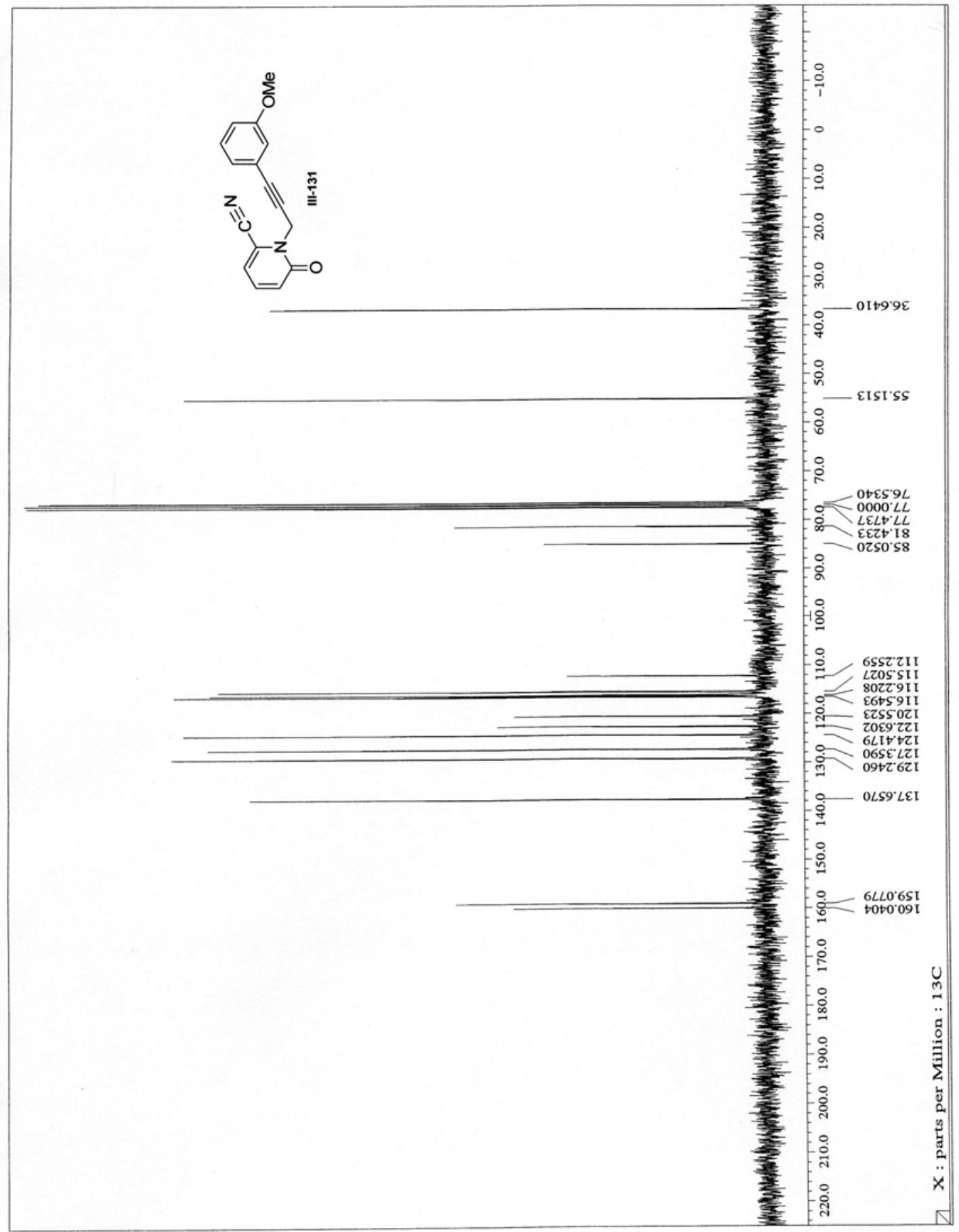




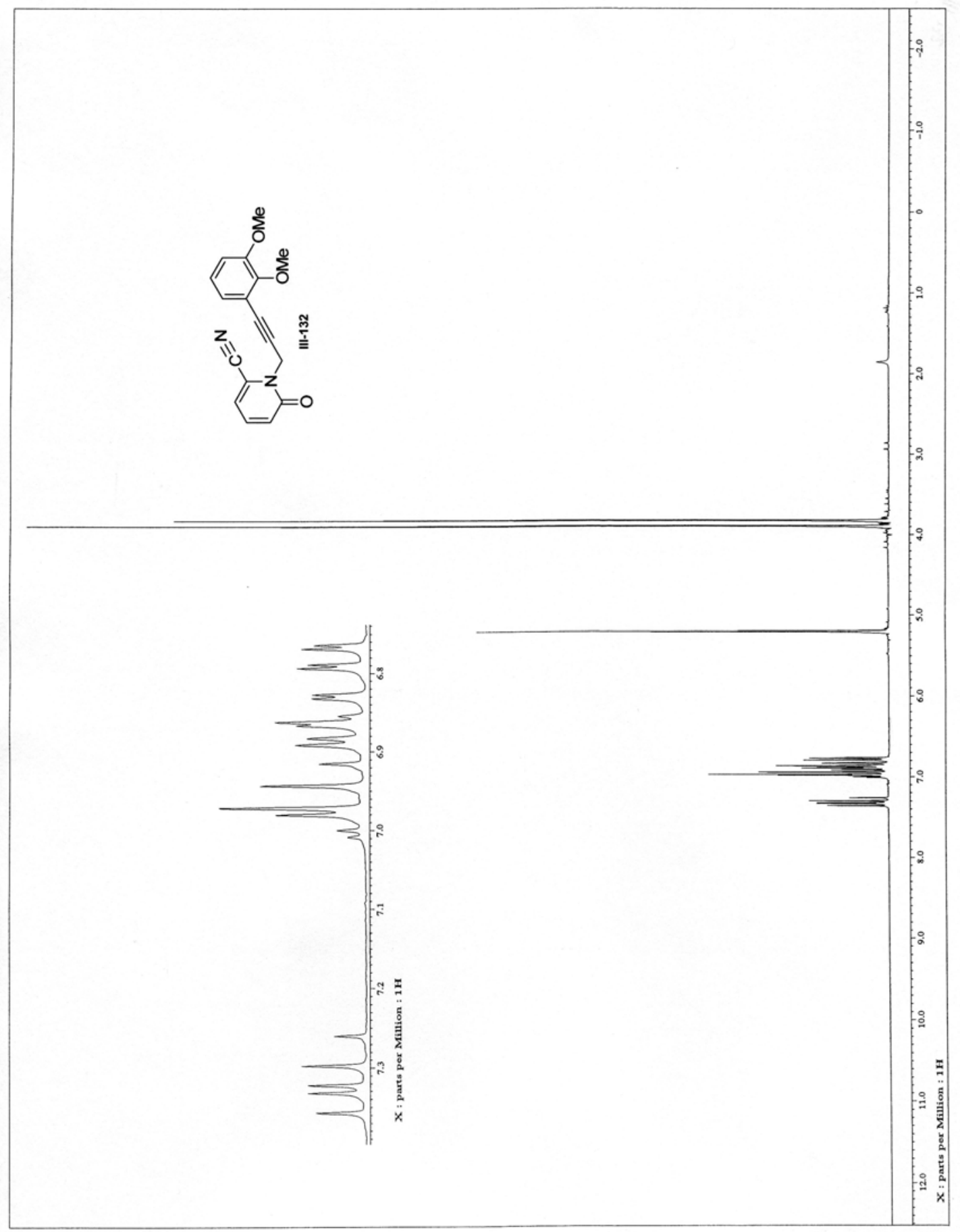




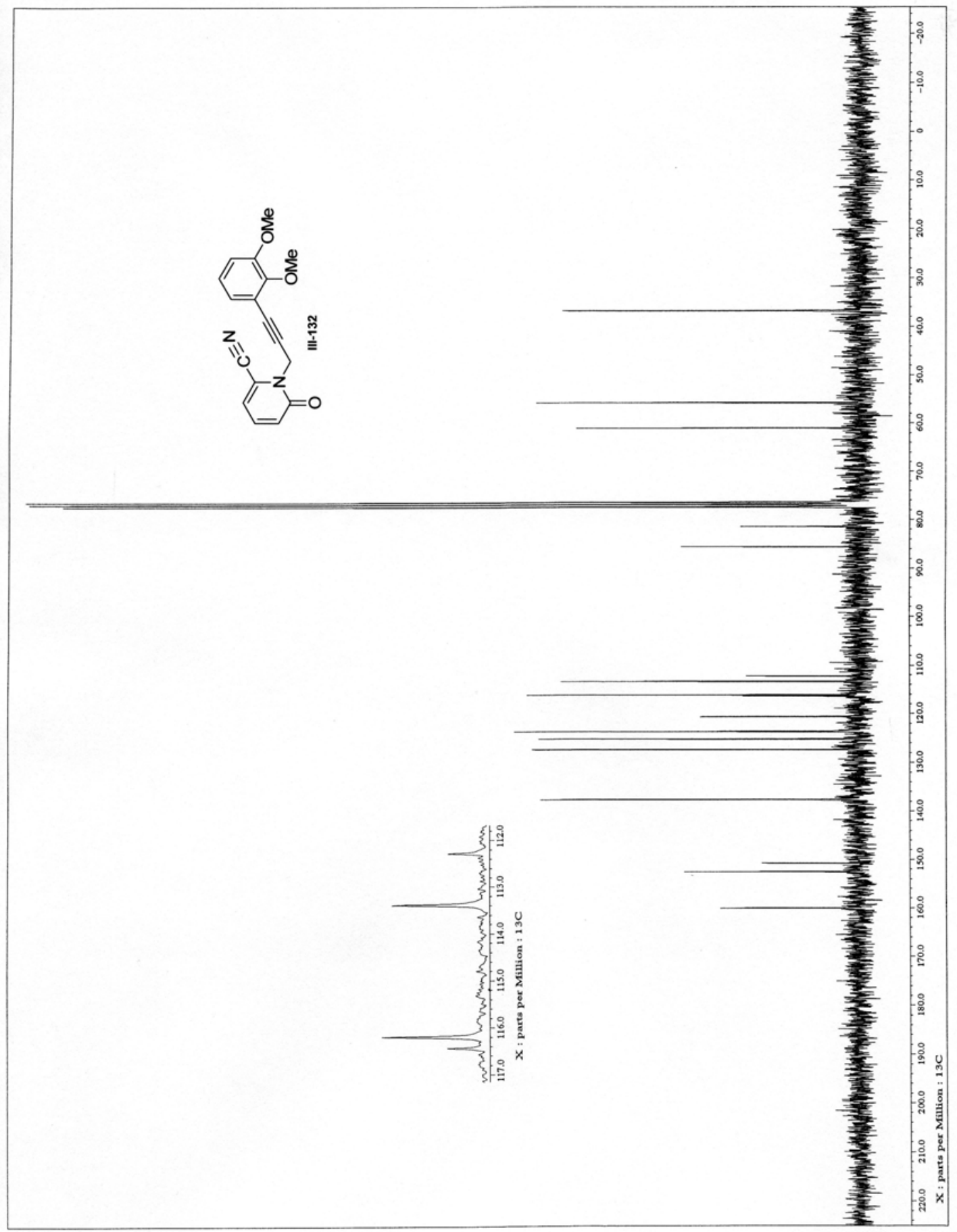




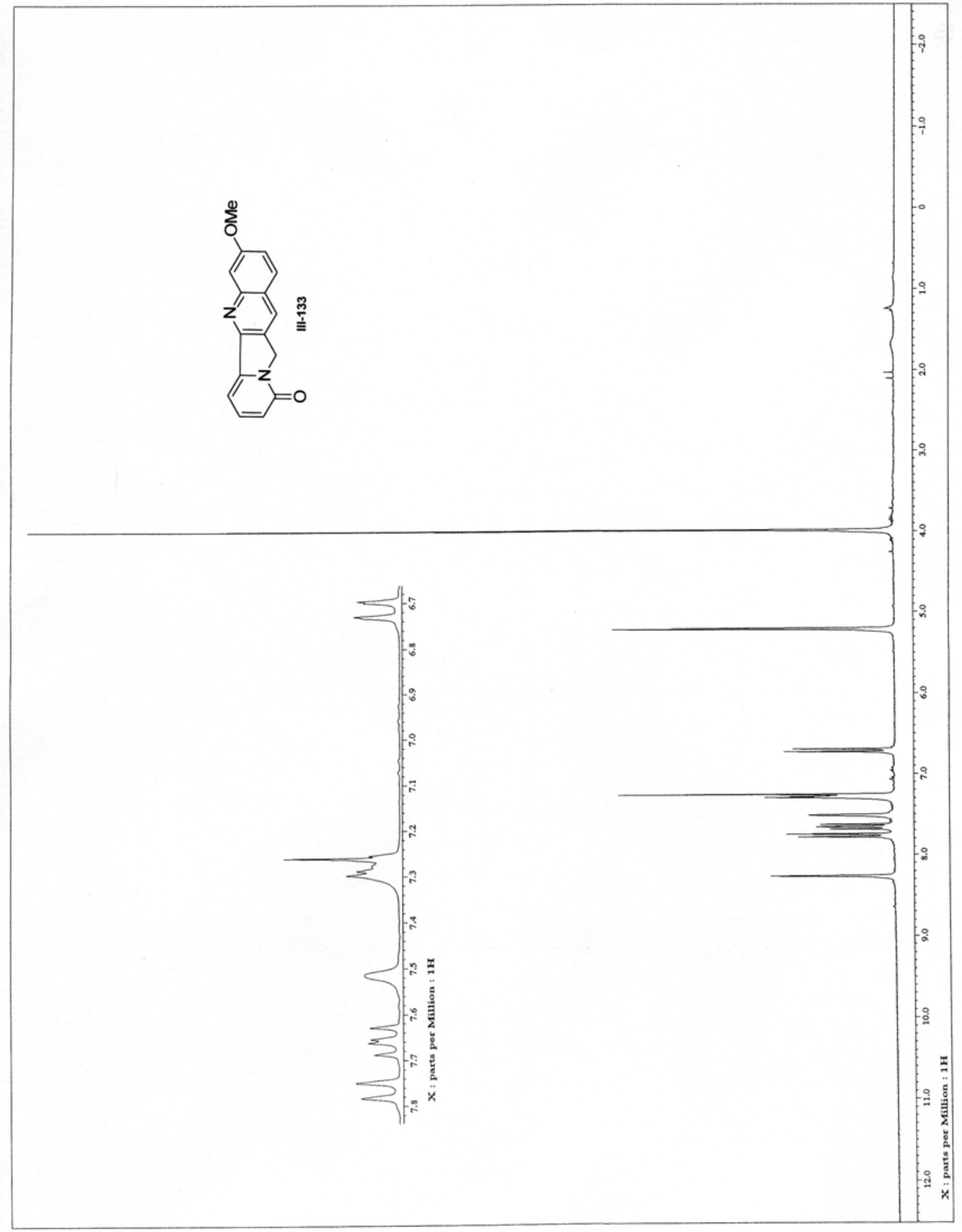




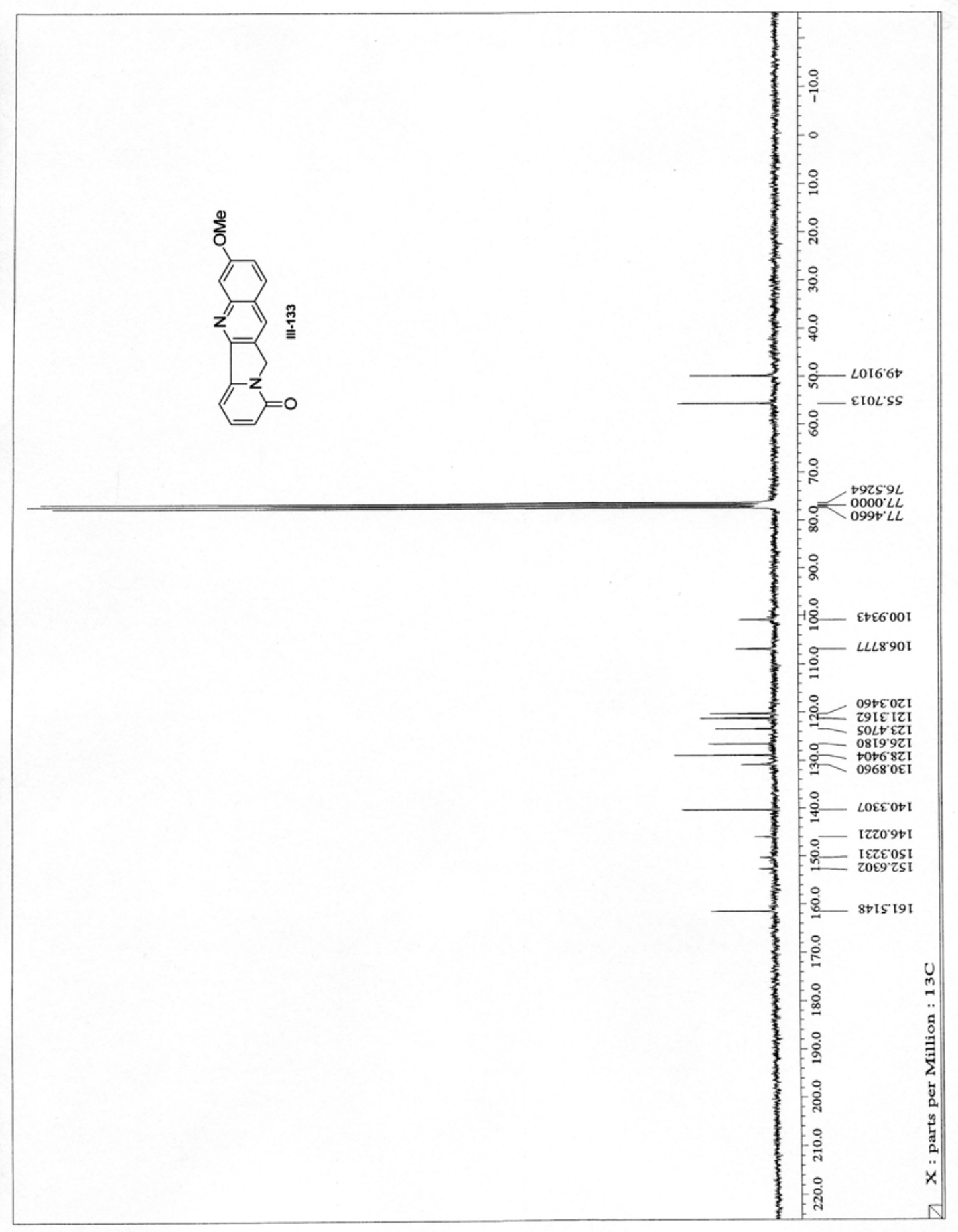




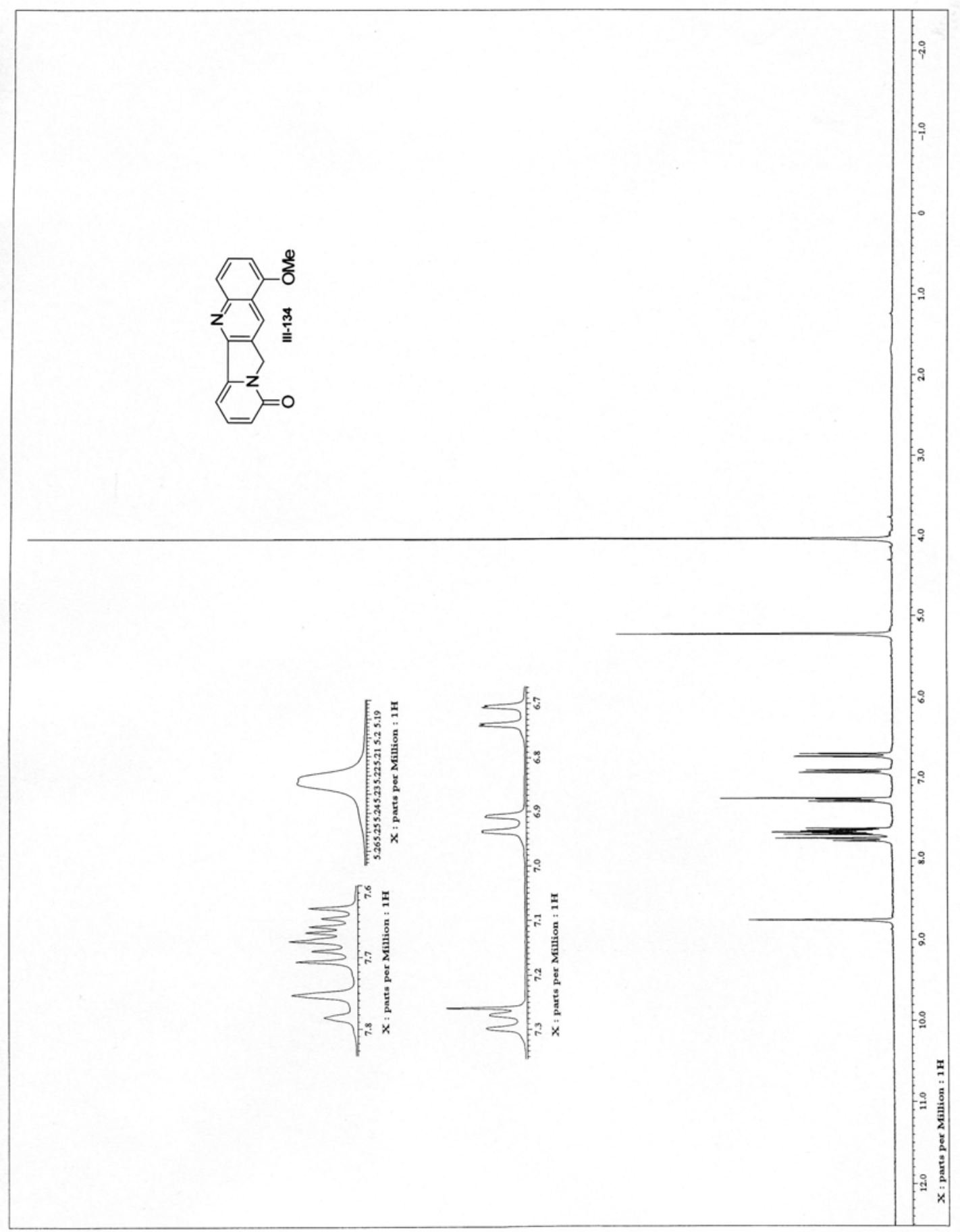




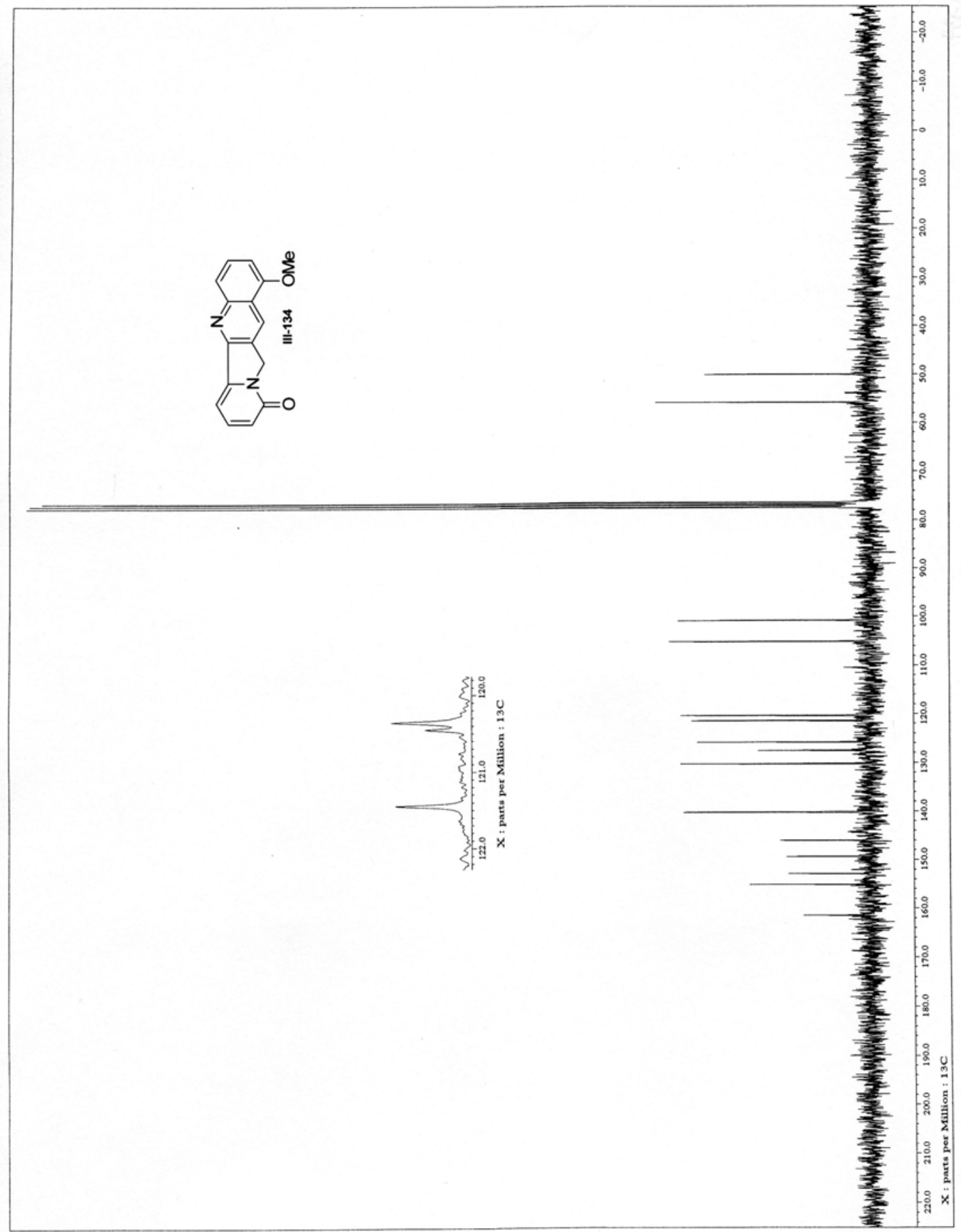




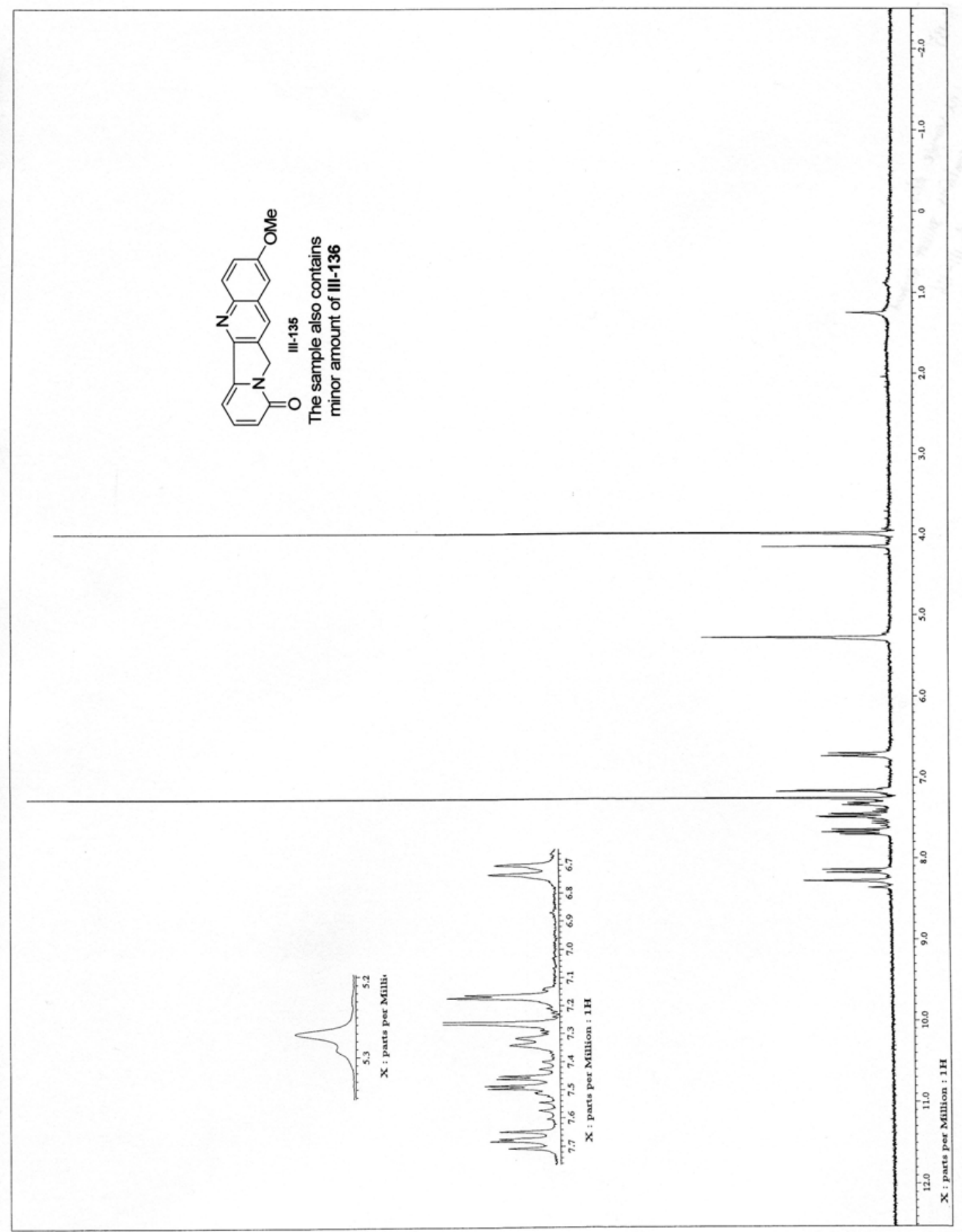




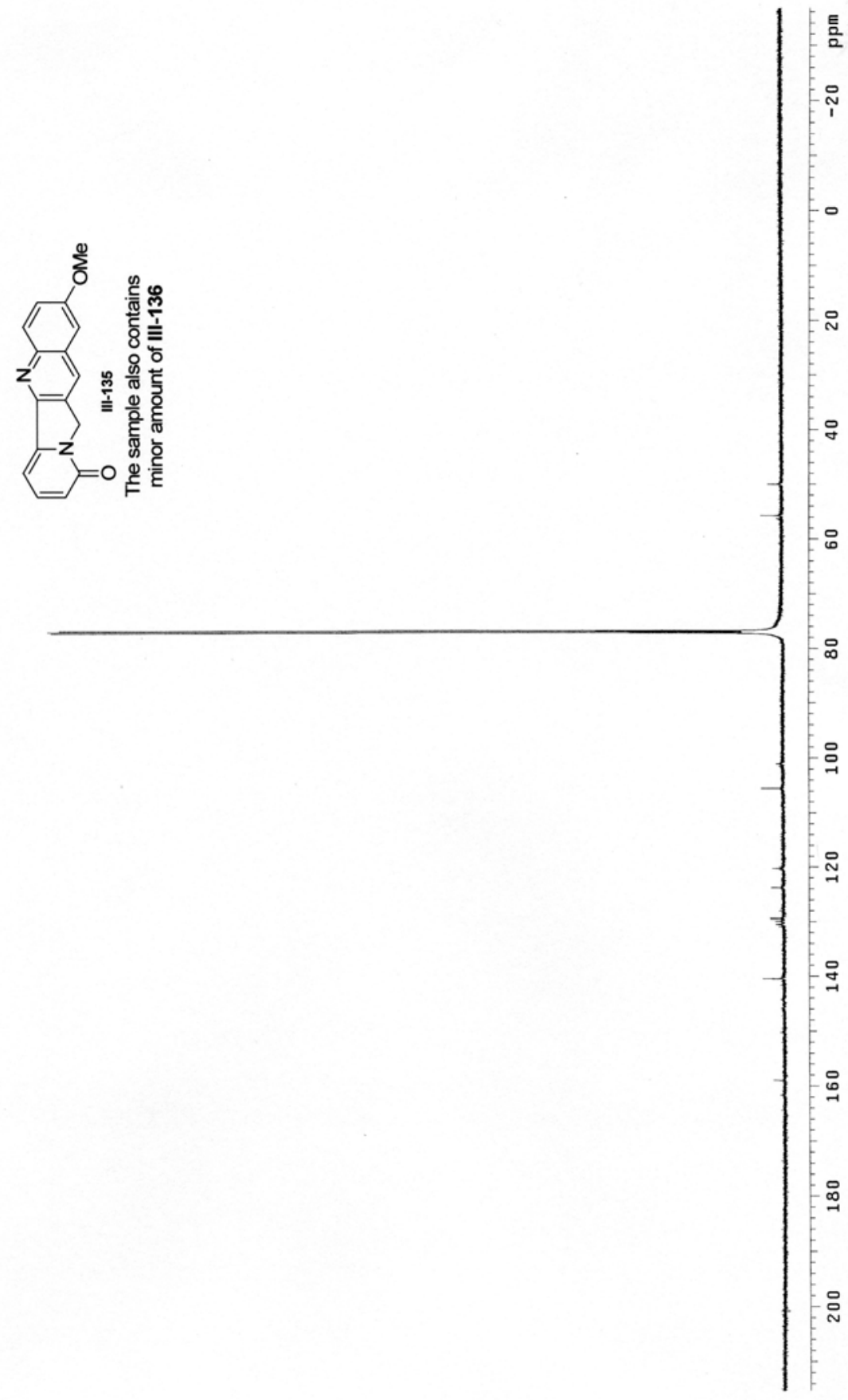




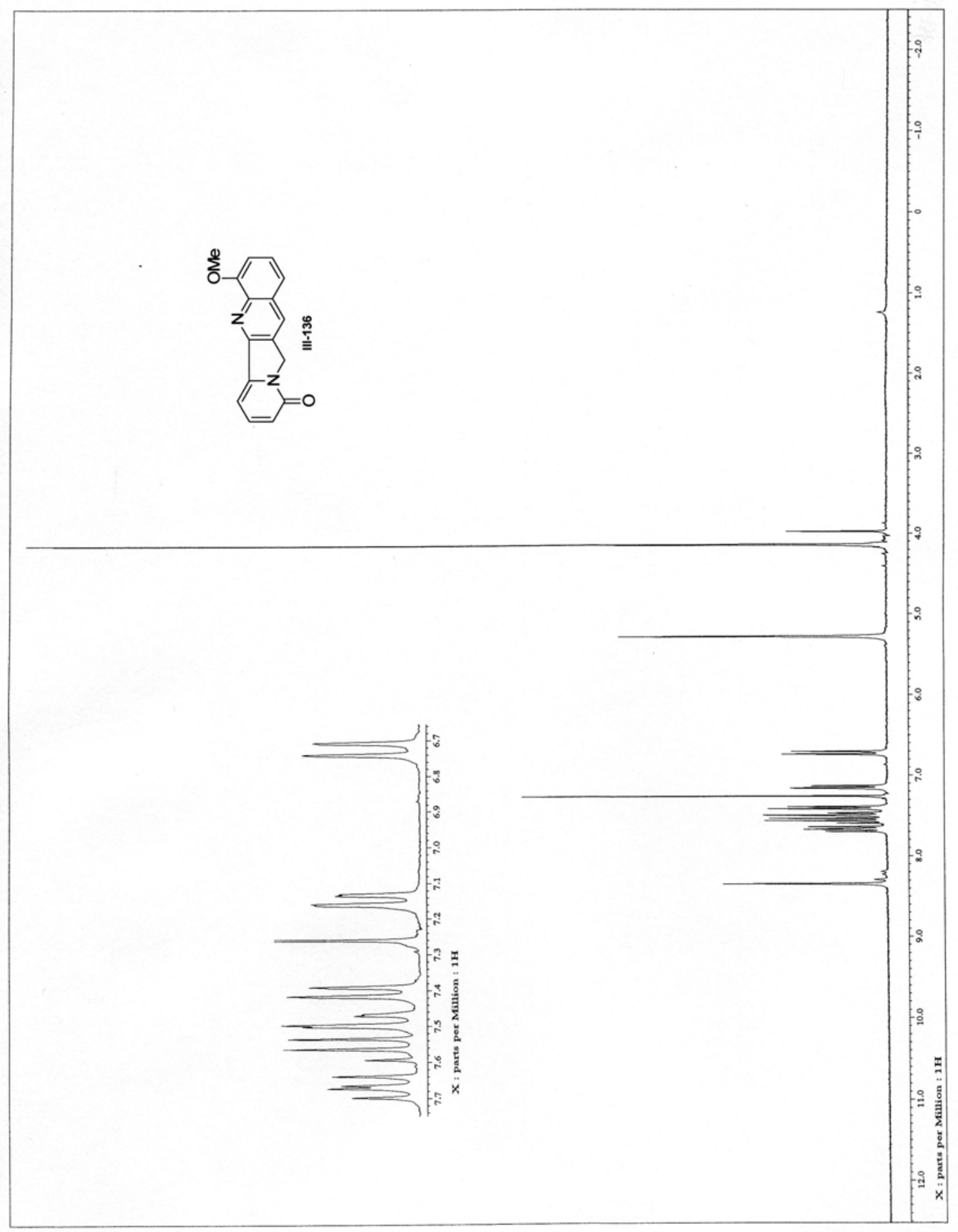




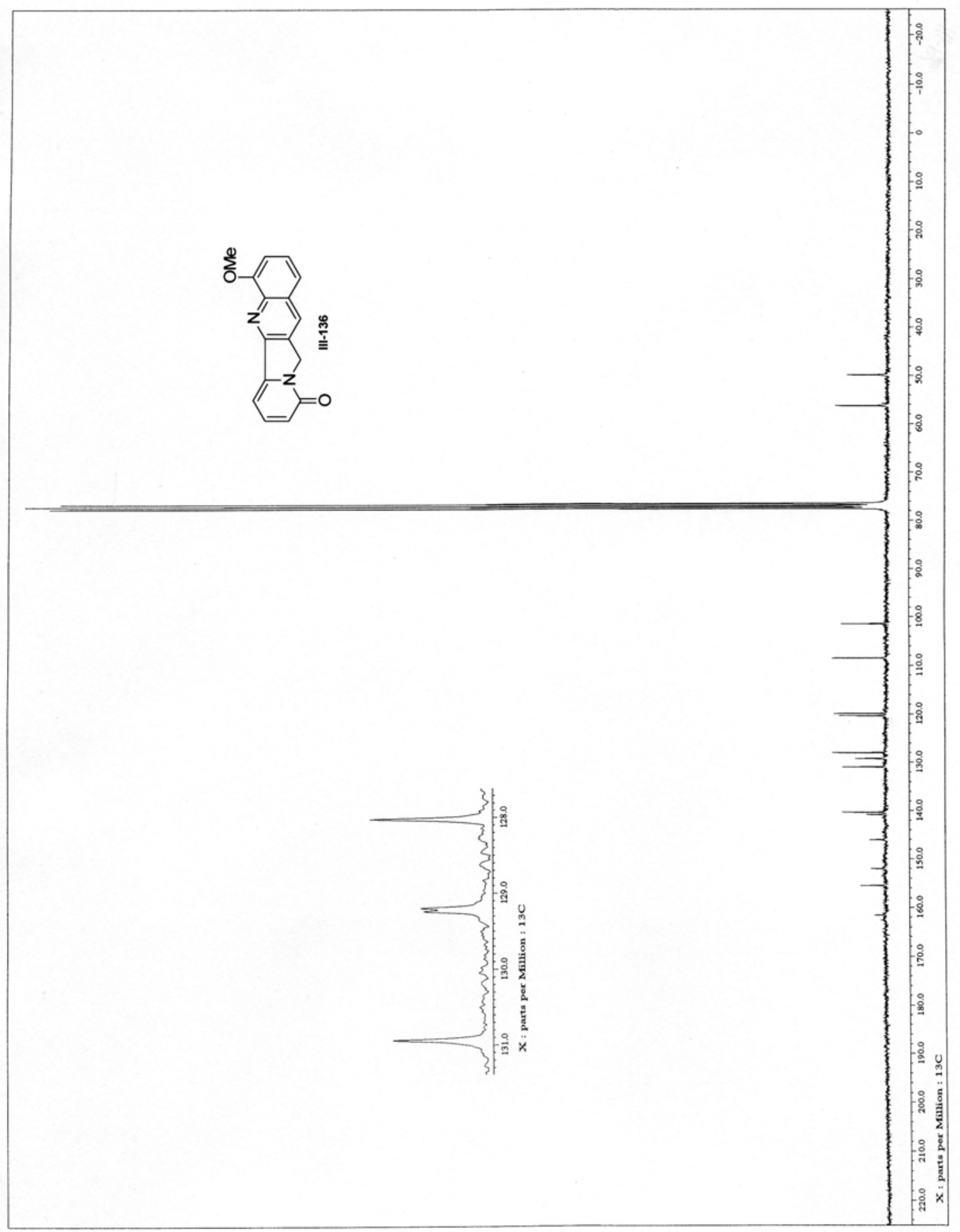




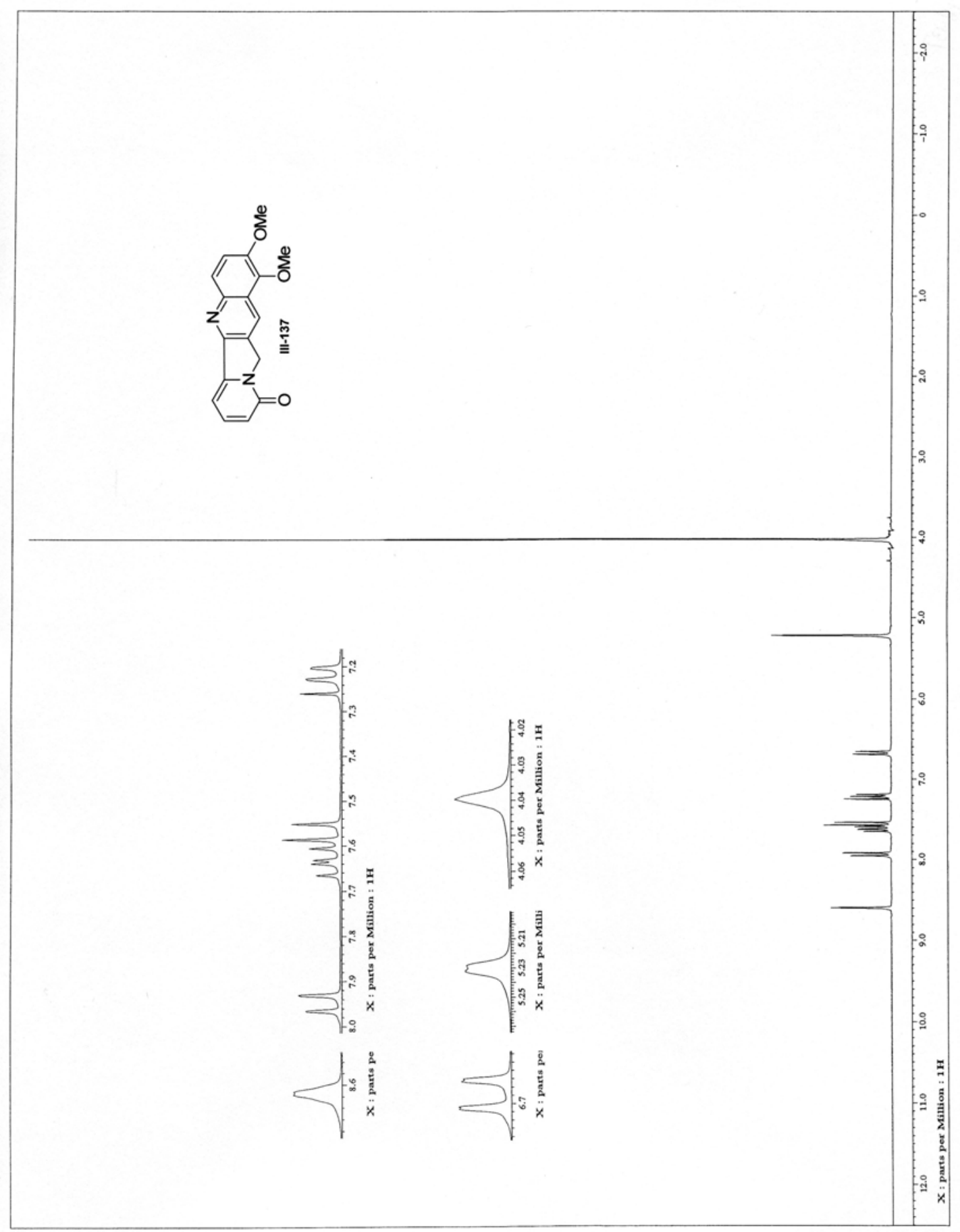




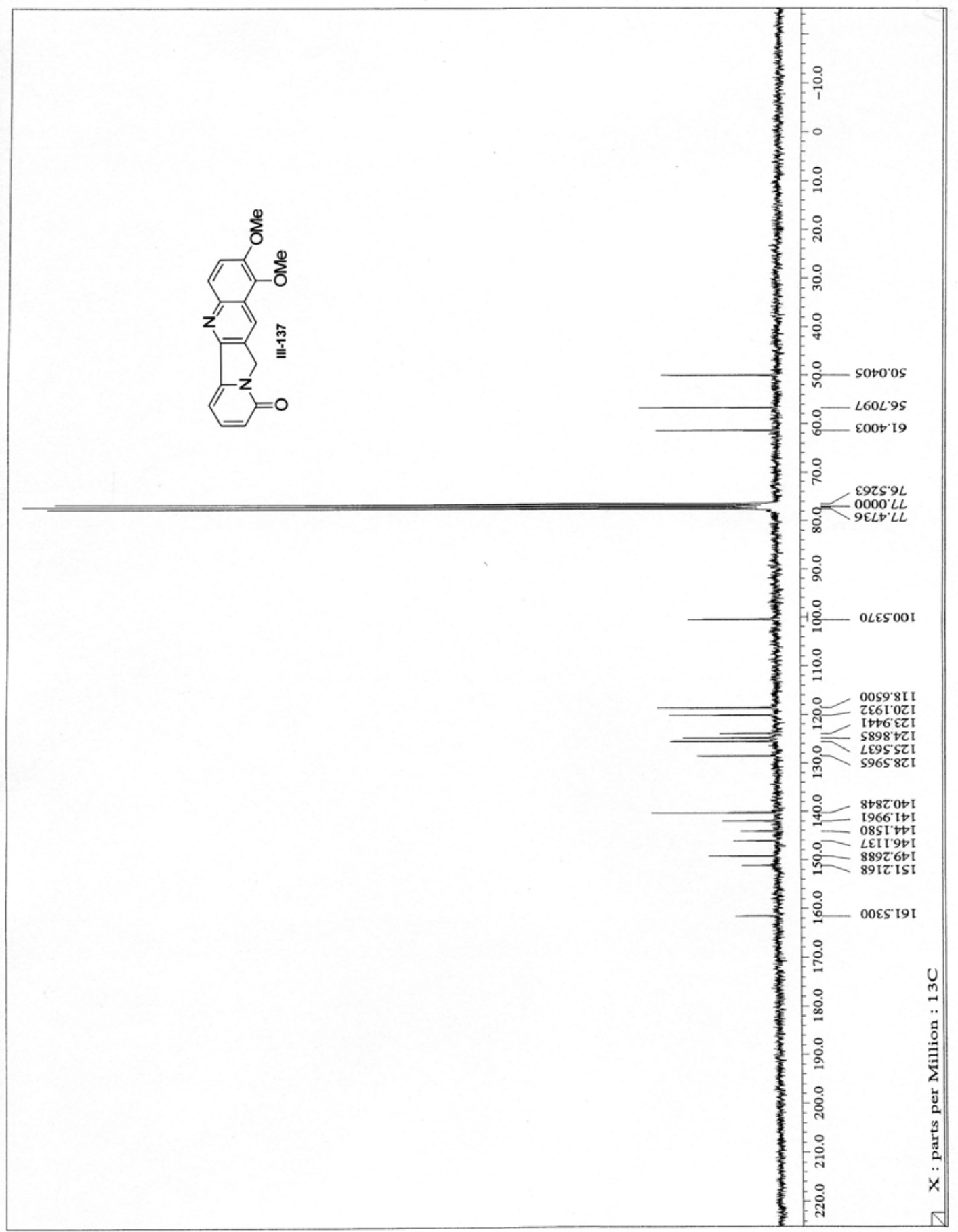




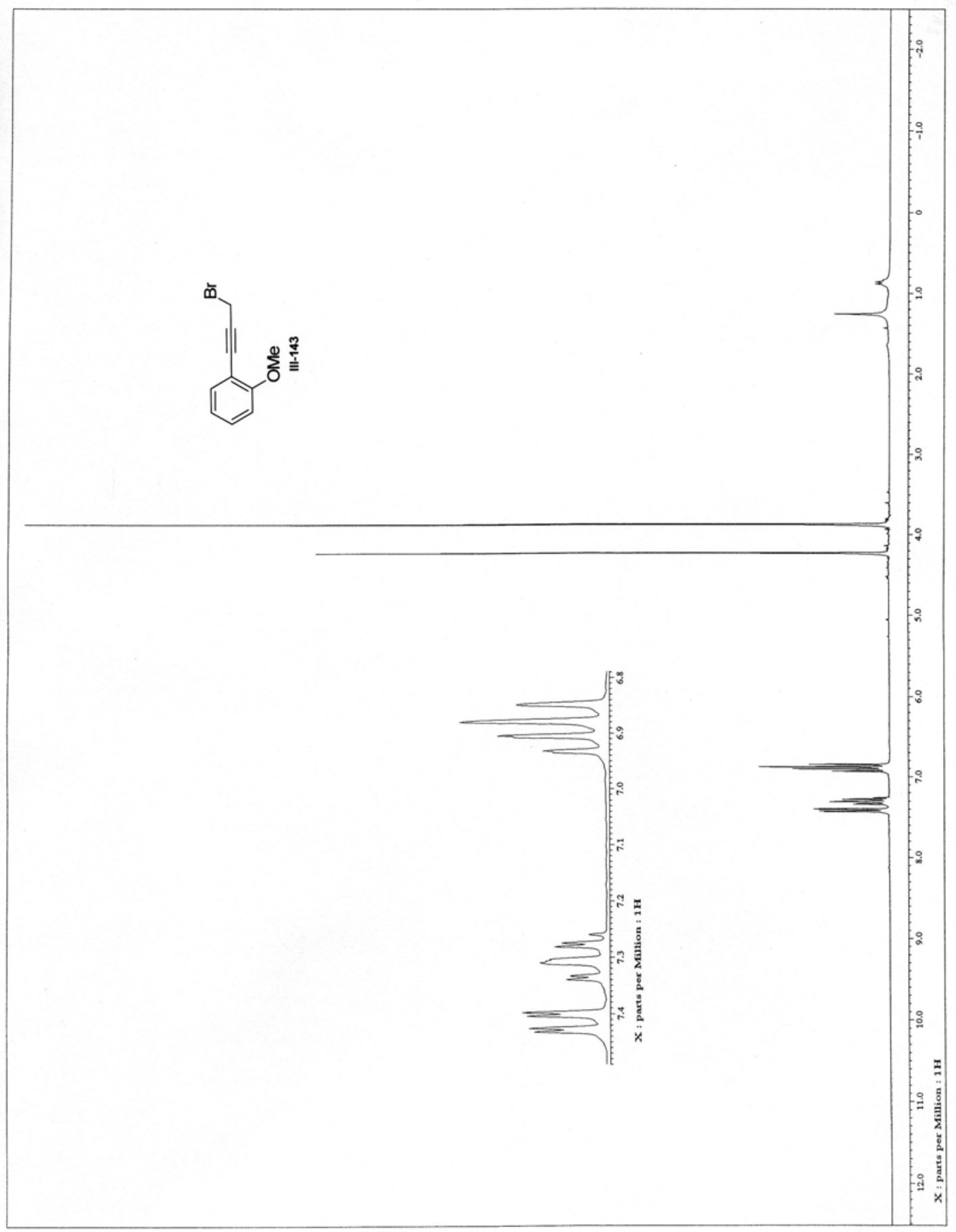




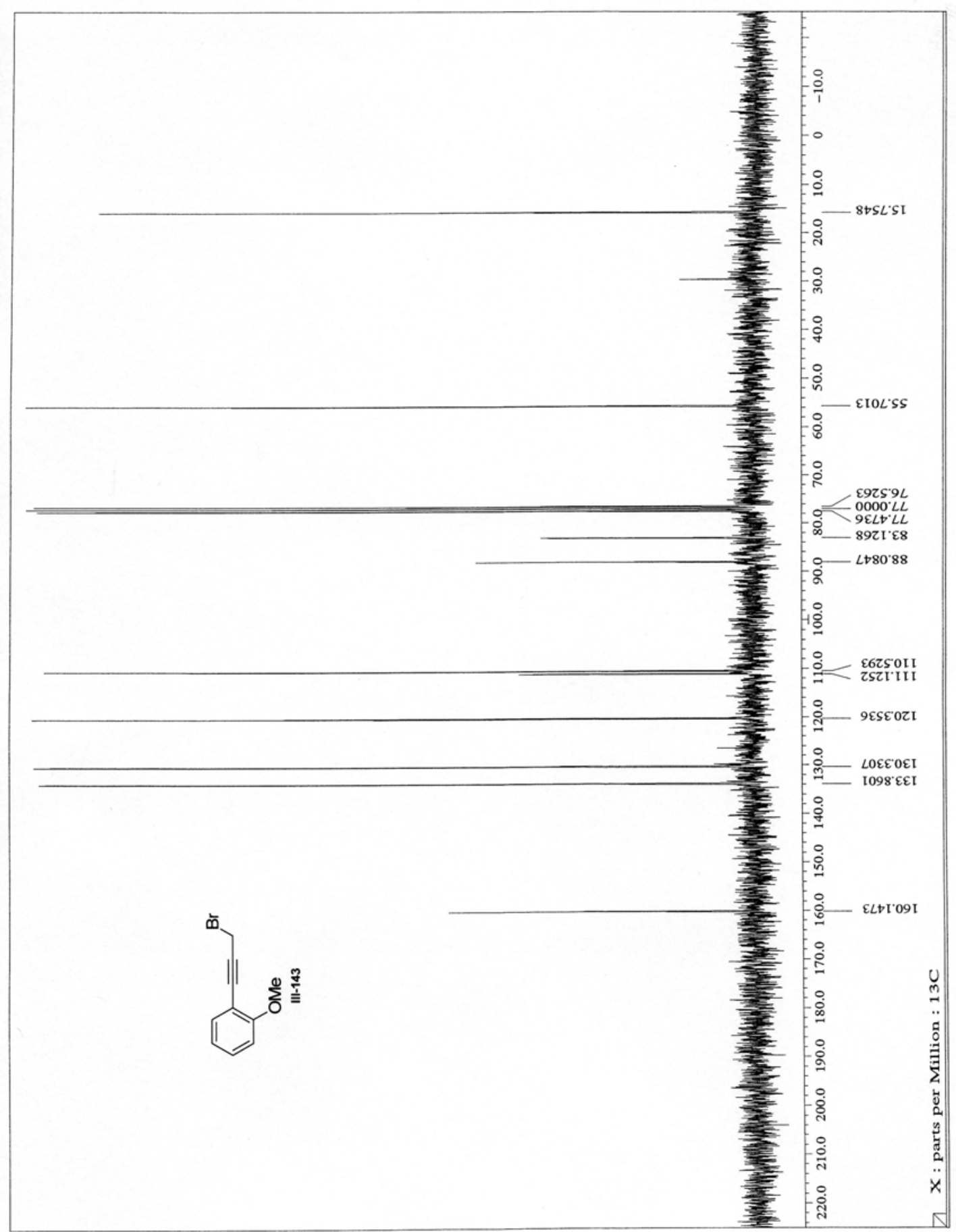




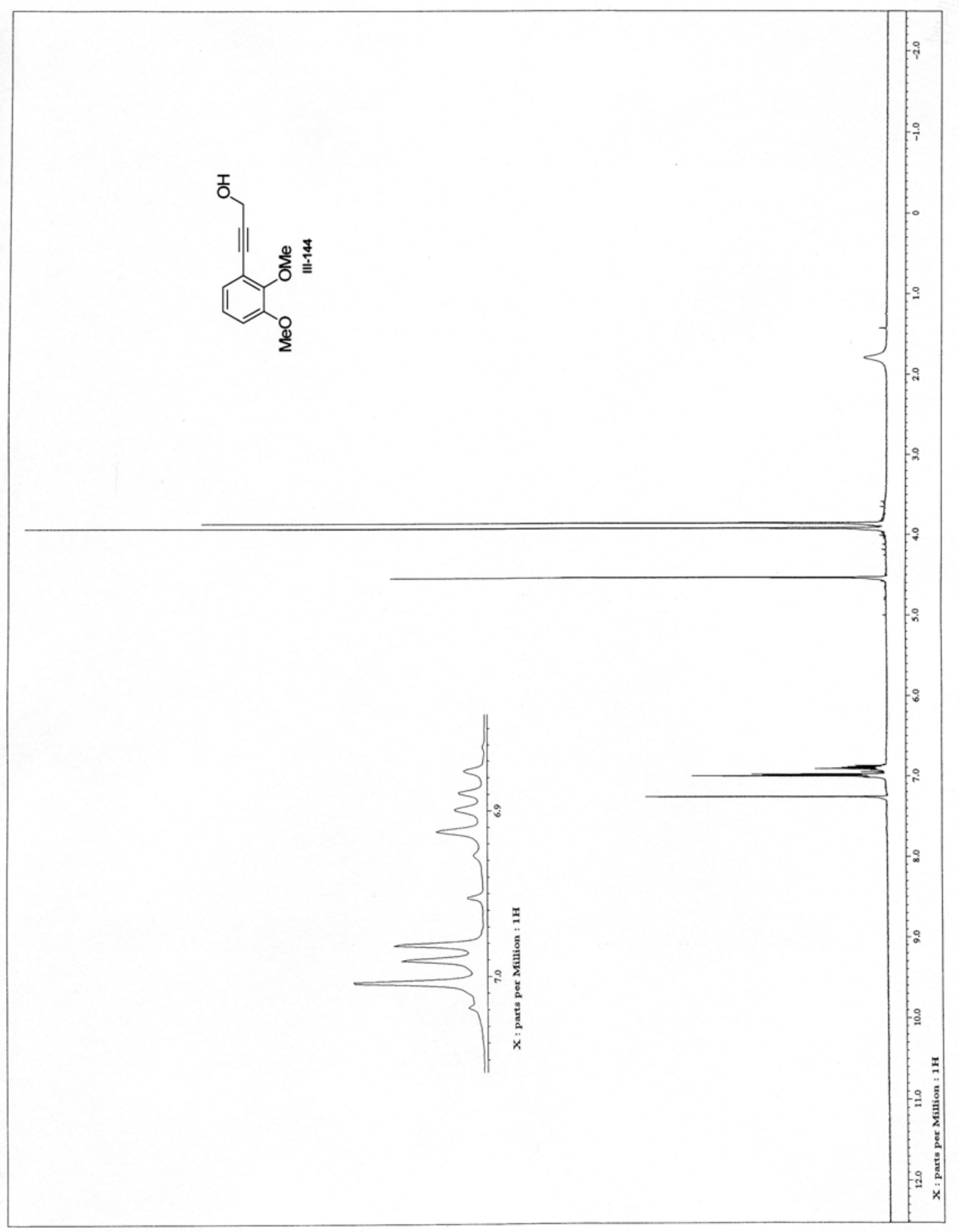




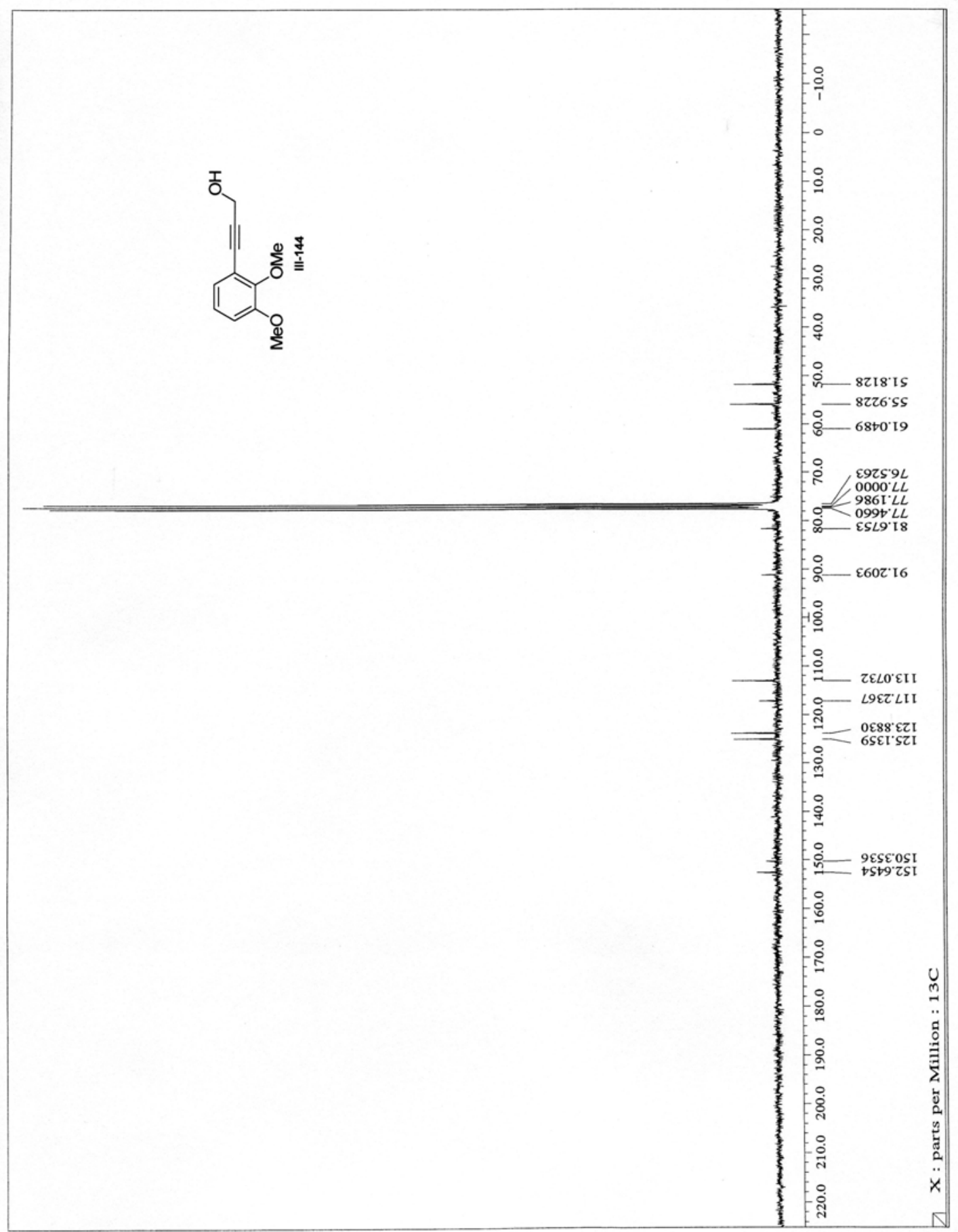




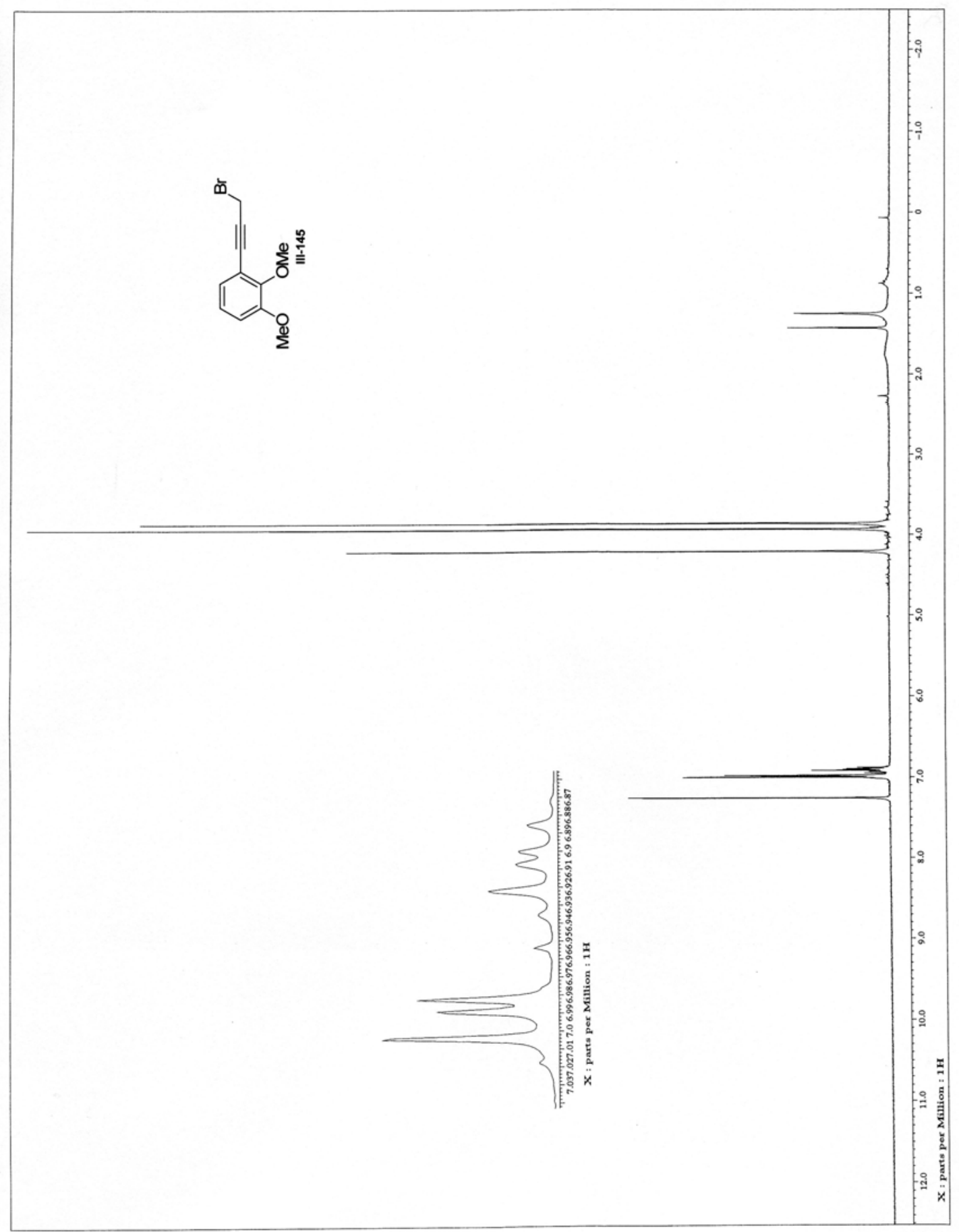




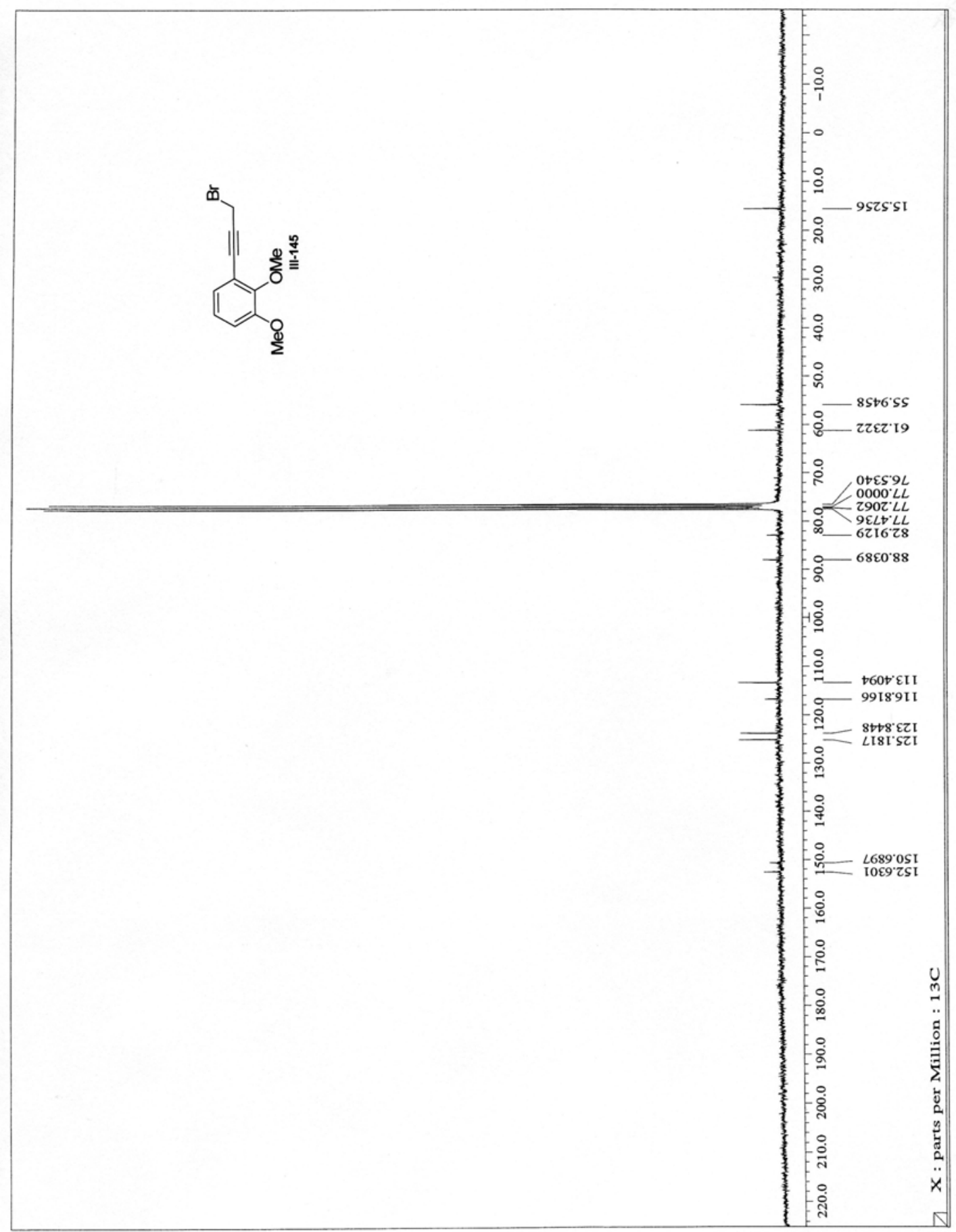




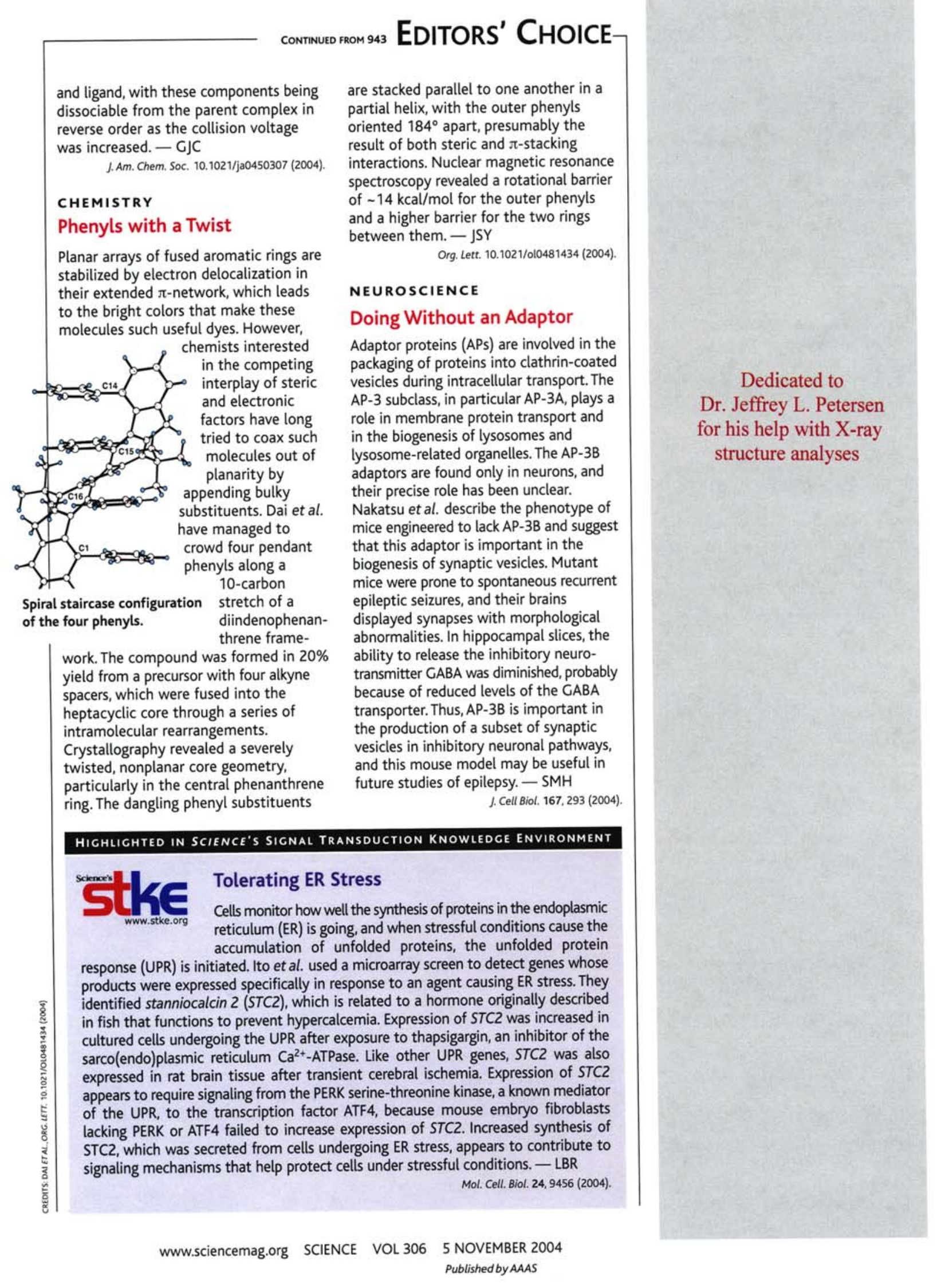




\section{Publications}

Ring expansion of $11 \mathrm{H}-$ benzo[b]fluorene-11-methanols and related compounds leading to 17,18-diphenyldibenzo[a,o]pentaphene and related polycyclic aromatic hydrocarbons with extended conjugation and novel architectures Yang, Y.; Dai, W.; Zhang, Y.; Petersen, J. L.; Wang, K. K. Tetrahedron in Press.

Synthesis of indeno-fused derivatives of quinolizinium salts, imidazo[1,2-a]pyridine, pyrido[1,2-a]indole, and 4H-quinolizin-4-one via benzannulated enyne-allenes Dai, W.; Petersen, J. L.; Wang, K. K. J. Org. Chem. 2005, 70, 6647-6652.

Synthesis and structure of a helical diindenophenanthrene with four congested phenyl substituents as a molecular spiral staircase Dai, W.; Petersen, J. L.; Wang, K. K. Org. Lett. 2004, 6, 4355-4357. The results of this study were also featured in the Editors' Choice section of the November 5, 2004 issue of Science.

\section{Presentations}

Synthesis of the parent and substituted tetracyclic $A B C D$ ring cores of camptothecin via allenic nitriles Wang, K. K.; Dai, W.; Petersen, J. L. Presented at $231^{\text {st }}$ ACS National Meeting, Atlanta, GA March 26-30, 2006. (Oral)

Synthesis and structure of a helical diindenophenanthrene with four congested phenyl substituents as a molecular spiral staircase Dai, W.; Petersen, J. L.; Wang, K. K. Presented at $228^{\text {th }}$ ACS National Meeting, Philadelphia, PA August 26-30, 2004. (Poster including Sci-Mix) 